VNIVERSiDAD

BSALAMANCA

DEPARTAMENTO DE BOTÁNICA

CENTRO HISPANO LVSO DE INVESTIGACIONES AGRARIAS (CIALE)

\title{
Estudio del contenido polínico en la atmósfera de la ciudad de Salamanca y su relación con los parámetros climatológicos y los cuadros clínicos de alergia
}


Diseño Portada: Cristina Alcalde Eon/ David Rodríguez de la Cruz Ilustración portada: polen de Quercus tomado de Solomon (1970) Ilustración lomo: polen de Poaceae tomado de Solomon (1970) 


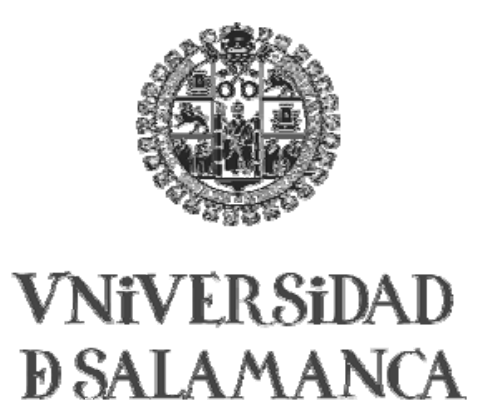

D. José Sánchez Sánchez, profesor Titular del Departamento de Botánica de la Universidad de Salamanca, y D. Félix Lorente Toledano, profesor Titular del Departamento de Obstetricia, Ginecología y Pediatría de la Universidad de Salamanca

INFORMAN:

En calidad de directores de la Memoria Doctoral cuyo título es: "Estudio del contenido polínico en la atmósfera de la ciudad de Salamanca y su relación con los parámetros climatológicos y los cuadros clínicos de alergia", realizada por el Licenciado en Biología D. David Rodríguez de la Cruz, consideran finalizado el trabajo y autorizan la presentación, a fin de que pueda ser juzgado por el Tribunal correspondiente.

Y para que así conste, firmamos el presente informe en Salamanca a 15 de mayo de 2008

D. José Sánchez Sánchez

D. Félix Lorente Toledano 

Debe conocer el lector que estas líneas, que son las primeras que acostumbra a leer, son las últimas (y quizás las más complicadas) que el autor de esta Memoria Doctoral escribe, pues le permite pensar en todo lo que este trabajo ha supuesto en su desarrollo personal y profesional y, con ello, agradecer a todas aquellas personas que han contribuido a su realización. También ha de saber que los "meseteños" se han forjado una fama de ser gente de pocas palabras. No seré menos (o al menos, lo intentaré, por el bien de conservar las tradiciones).

En primer lugar, a mis directores de Tesis, José Sánchez Sánchez y Félix Lorente Toledano, ya que ambos fueron los que me dieron la oportunidad de introducirme en el peculiar mundo de la investigación científica y además, por si esto no fuera ya suficiente, mantuvieron una disposición a solucionar los contratiempos que fueron surgiendo, todo ello acompañado de un excelente trato personal.

Justo al lado se encuentran mis compañeros del Departamento de Botánica, especialmente Fani, que comparte los sinsabores que aportan los granos de polen y cuyo afán por poner en valor todo lo que hacemos debe ser destacado junto a su mano tendida siempre que fue necesario, y Sergio, que me ha acompañado en todo este periplo con una gran amabilidad y en un buen número de experiencias que ahora recuerdo con especial cariño. No me olvido de todos los "setólogos" que han llenado numerosos momentos laborales con una sonrisa, como Abel y sus preciosas botas de agua, Felipe y sus temazos, y Patricia con sus interesantes temas de conversación. Y después, sólo por la distancia que nos separa en el Departamento, vienen los botánicos locos, personas singulares de entre las que destaco (por orden de aparición, perdóneme todo aquél al que haya olvidado) a Luis, que todavía no me ha "mangao el peluco", María, a vueltas con la molécula, Santis, futuro catedrático "filálogo", Mónica y sus golpes a los portas, Bea y Sara, luchando por y para sus Tesinas, Blanca, también peleando por la merienda-cena, ... No puedo dejar de recordar a dos zamoranos de renombre, de los que como el resto de compañeros, guardaré un gratísimo recuerdo: Álvaro, "tronjco" y "tocador" de la gaita alistana, y Lp, la gran conocedora del cine pakistaní y amante de las garrapatas. Tampoco me olvido de las más nuevas, Rosa y Silvia, que comienzan a aumentar sus dioptrías en el microscopio, ni del resto de profesores del Departamento, por su buena acogida, así como de Juan Carlos, indispensable en temas burocráticos, y de Javi, siempre atento tras una pila de pliegos. Muchas gracias a todos por todos estos años.

En otro párrafo, pero muy unido al anterior, escribiré unas palabras sobre Chencho y Jose, a los que también he conocido en el ámbito científico y con los que mantengo una relación que trasciende mucho más de todo ello. Les estoy muy agradecido por esas pequeñas cosas, o grandes, según la perspectiva con que se miren.

La familia. Es más que obvio incluirla, porque su apoyo en numerosos aspectos resulta indispensable para poder llevar a cabo un trabajo como el que se presenta, sobretodo mis padres y hermana, mis abuelos y abuela, mis tíos,... pues siempre han mostrado gran interés por todo lo que hacía y han tenido palabras de afecto ante el extravagante camino que he tomado durante estos años. 
Visto lo escrito, no estoy respetando las costumbres "meseteñas", pues aún queda destacar a todo el Servicio de Inmunoalergia del Hospital Clínico Universitario de Salamanca por su simpatía y ayuda, en especial a Carmen, por repartir conocimientos, Ignacio, por su excelente capacidad científica y un inmejorable trato personal, Eva y David, por compartir los sinsabores "pretésicos", Marien, Esther, Elena... Muchas gracias a todos.

No debo dejar de mencionar el apoyo económico, aportado por la Universidad de Salamanca y el Banco Santander Central Hispano gracias a una beca predoctoral, ni el apoyo material de la Concejalía de Medio Ambiente del Ayuntamiento de Salamanca y del Convenio firmado por la Consejería de Sanidad y la Universidad de León (con participación del Grupo de Palinología y Conservación Vegetal de la Universidad de Salamanca). En este mismo apartado, reseñar la Ayuda a la Movilidad del Personal Investigador concedida por la Universidad de Salamanca para realizar una estancia de investigación de dos meses en el Centre d'Ecologie Fonctionnelle et Evolutive de Montpellier (Francia).

Merci beaucoup aussi à toute l'équipe du département "Fonctionnement des Ecosystèmes" pour votre gentillesse, spécialement à Isabelle, Iñaki, Sylvain, Verónica, Tanya, Manu,...

Un poco más abajo, en la página y en la Facultad de Farmacia, pero no excavado bajo ninguna roca madre, se encuentra el área de Bromatología y su grupo de investigación hermano, fuente de cafés, merendolas, cenas y viajes viarios varios con la compañía de gente agradable y atenta como Joaquín, Kike, José Luis, Ivania, Romi, Anita, Susana, Montse, Raúl, José Miguel, Kathrin, Nacho, Mati,...

Agradecimiento a nivel nacional a todos los aerobiólogos repartidos por el país, por su gran ayuda y su disposición, como me han aportado Delia, Rosa, Carmen, Zulima, Ana, Javi, Silvia, Herminia, Diego, Carmen, Begoña, y, afortunadamente, un largo etcétera.

Cris, qué puedo decir, las pocas palabras que acostumbro a usar (y en este caso, que entran esta página), serían insuficientes para expresar mi agradecimiento y muchas más cosas. Como me queda espacio, una palabra, libélula, y punto.

Por último, y no por ello menos importantes, los amigos, que son más de los que merezco y responsables de vivencias imborrables. A TODOS os corresponde un trozo de este engendro: biólogos locos (Sergio, Marthuska, Bea, Raúlo, Rober, Amaia, Eva, Lucía, Viti, Oli, César,... y el resto), garridenses (Niveas, Javi, Julito, Manolón, Jeri, Villa, Salvio, Turu, Davicete, Miri, Pot, Tomás, Alber, Moni, Marina, Eva, Estela, Cristina, Tere, Laura), frikis-coenwoodmaníacosmodernetes-poperiles-punkis guays (Eli, David, Vega, Alberto, Marimar, Patri, Bratos -jerber, Olivencio, Rober, Edu-, Jors, Pablo, Paty, Chuchi,...), roleros (Miguel, Carlos, Gago,...),...

Disculpen todos aquellos a los que haya olvidado, pues se queda en eso, en un olvido, pues la realización de una Tesis Doctoral también tiene efectos secundarios. Lástima, no me queda más espacio y, además, aquí no quedaría muy bien. Termino ya. En resumen: GRACIAS. 




\section{ÍNDICE}

1. Introducción 1

1.1. La Aerobiología 1

1.1.1. Desarrollo histórico $\quad 1$

1.1.2. Interés y aplicaciones de la Aerobiología 3

1.1.3. Procesos aerobiológicos 4

1.1.4. Factores que afectan al contenido de polen y esporas en el aire 7

1.1.5. Métodos de muestreo en Aerobiología $\quad 10$

1.2. Morfología polínica 12

1.3. Reacción alérgica 17

$\begin{array}{lr}\text { 1.3.1 Alérgenos } & 18\end{array}$

$\begin{array}{lr}1.3 .2 \text { Anticuerpos } & 18\end{array}$

1.3.3. Polinosis 19

1.3.4. Pruebas de diagnóstico $\quad 21$

2. Área de estudio $\quad 23$

2.1. Localización geográfica $\quad 23$

2.2. Biogeografía $\quad 25$

2.3. Clima $\quad 25$

2.4. Paisaje vegetal $\quad 25$

2.4.1. Vegetación natural 26

2.4.2. Vegetación cultivada y repoblaciones $\quad 28$

2.4.3. Vegetación ornamental urbana 30

3. Justificación y objetivos 33

3.1. Justificación $\quad 33$

3.2. Objetivos $\quad 33$

4. Material y métodos 35

4.1. Metodología de muestreo en los estudios aerobiológicos 35

4.1.1. Toma de muestras

4.1.2. Preparación de las muestras 36

4.1.3. Análisis cuantitativo y cualitativo $\quad 37$

4.1.4. Presentación de los datos $\quad 41$

4.1.4.1. Presentación numérica $\quad 41$

4.1.4.2. Presentación gráfica 43

4.2. Metodología empleada en los estudios clínicos 45

4.2.1. Población estudiada $\quad 45$

4.2.2. Pruebas intraepidérmicas 46

4.2.3. Determinación de la cantidad total de IgE específica 46

4.2.4. Presentación de los datos 47

5. Resultados $\quad 49$

5.1. Variables climatológicas durante el período de estudio 49 
5.1.1. Temperatura $\quad 49$

5.1.2. Precipitación $\quad 50$

5.1.3. Humedad relativa $\quad 51$

5.1.4. Insolación $\quad 52$

5.1.5. Viento

5.2. Espectro polínico de la ciudad de Salamanca

5.2.1. Aspectos generales

5.2.2. Tipos de polen con representación superior al 1\% (al menos 5 años) 61

5.2.3. Tipos de polen con representación superior o igual al 1\% (al menos 1 año) 121

5.2.4. Tipos de polen con representación superior o igual al o,5\% (al menos 1 año) 189

5.2.5. Tipos de polen con representación superior o igual al o,1\% (al menos 3 años) 213

5.2.6. Otros tipos de polen $\quad 235$

5.2.7. Calendario polínico $\quad 238$

5.3. Comparativa entre dos captadores 241

5.4. Contenido de esporas de pteridófitos en la ciudad de Salamanca 251

5.5. Grado de sensibilización a diferentes alérgenos de polen 255

5.5.1. Perfil demográfico y sintomatología de los pacientes estudiados 255

5.5.2. Prevalencia de positivos obtenidos por los métodos utilizados $\quad 256$

5.5.3. Valores de IgE específica $\quad 257$

5.5.4. Concentraciones polínicas umbrales $\quad 257$

5.5.5. Relación entre el polen presente en la atmósfera y los resultados obtenidos $\quad 259$

\section{Discusión}

6.1. Espectro polínico y variación interanual 263

6.2. Variación estacional $\quad 269$

6.3. Contenido polínico y parámetros climatológicos 273

6.4. Valoración de los métodos utilizados para calcular el PPP 277

6.5. Variación intradiaria $\quad 279$

6.6. Diferencias cuantitativas y cualitativas entre los dos captadores $\quad 281$

6.7. Evolución anual, estacional y horaria de las esporas de pteridófitos 284

6.8. Análisis del estudio clínico sobre una muestra poblacional de Salamanca $\quad 286$

7. Conclusiones 291

8. Bibliografía $\quad 295$

Anexo: Láminas de polen y esporas 321 
Introducción 



\subsection{La Aerobiología}

\subsubsection{Desarrollo histórico}

Las primeras referencias acerca de la naturaleza de los granos de polen nos llevan a la obra de Herodoto (484-425 a.C.), que refleja parte de las observaciones de asirios y babilonios sobre las palmeras datileras y detalla la polinización de los pies femeninos gracias a la diseminación de partículas fecundantes presentes en los pies masculinos. Dentro de la ingente obra con carácter científico de Aristóteles (384-323 a.C.) se confirma no sólo que en el aire existen partículas que participan en la reproducción vegetal sino que estas mismas desencadenaban enfermedades.

Durante casi dieciocho siglos no encontramos reseñas históricas, salvo algunas que destacan la estacionalidad de los procesos de floración y las alergias en el siglo X, hasta que Monardi (1462-1536) estudia el papel de los estambres en la reproducción vegetal. La difusión del microscopio a mediados del siglo XVII dio lugar a un mayor estudio de las estructuras vegetales, en los que destacan los trabajos de Marcelo Malpighi (1628-1694) y Nehemiah Grew (1628-1711) donde se describen ciertos caracteres morfológicos de los granos de polen. Años más tarde, Rudolf Jacob Camerarius demuestra experimentalmente que el polen es indispensable para la formación de frutos, mientras que Koelreuter deduce la existencia de plantas que dispersaban su polen por el viento y otras a través de animales, denominándolas “anemófilas” y entomófilas”, respectivamente.

En la segunda mitad del siglo XIX, diversos autores como Brown, Purkinje y Fischer desarrollan conceptos sobre los que se fundamenta la taxonomía polínica, realizan las primeras descripciones de un buen número de granos de polen e introducen las primeras clasificaciones basándose en caracteres morfológicos.

En el siglo XX la Aerobiología experimenta un gran avance que le hace constituirse como una Ciencia con entidad propia sobre la base del desarrollo de Ciencias auxiliares. Miquel (1850-1922) diseña el primer prototipo de captador volumétrico y observa el efecto negativo que la lluvia ejerce sobre el contenido de partículas en la atmósfera junto a la existencia de ritmos circadianos en la emisión de polen. El término aerobiología acuñado por el alemán Meier, es definido por primera vez por Hyde (1952) como la Ciencia que se ocupa del estudio de los granos de polen, esporas de hongos y bacterias contenidas en la atmósfera. El propio Hyde precisa la Aeropalinología como una rama de la Aerobiología que trata exclusivamente del estudio de los granos de polen y esporas presentes en el aire. En ese mismo año, Hirst (1952) diseña un captador volumétrico que permite conocer las variaciones horarias y diarias de las partículas biológicas contenidas en el aire, mientras que el sueco 
Erdtman (1952, 1966, 1969) y el noruego Faegri $(1956,1975)$ publican diversos trabajos sobre morfología polínica y metodología aerobiológica.

En la década de los setenta, Gregory (1973) propone una nueva definición para el término aerobiología en la cual se afirma que se trata de una Ciencia que se encarga del estudio de toda partícula, viable o no viable, transportada por el viento, incluyendo así la interacción de los parámetros meteorológicos. Pathirane (1975) precisa esta definición describiendo a la Aerobiología como Ciencia que se ocupa del estudio de la liberación, retención, dispersión, transporte, deposición e incidencia atmosférica de granos de polen, esporas y otros microorganismos aerovagantes. En las últimas décadas, esta definición se ha ampliado para incluir a las partículas no bióticas presentes en la atmósfera (Lebowitz \& O’Rourke, 1991; Spieksma, 1992).

El conjunto de avances experimentados en el último tramo del siglo XX, ha conllevado un gran esfuerzo integrador en la discusión y la difusión de los resultados obtenidos por parte de los diferentes grupos de investigación en variados aspectos de la Aerobiología, que se ha visto reflejado en la formación de diversas agrupaciones y organizaciones y la celebración de numerosos Congresos, Simposios y Cursos basados en esta reciente Ciencia. Entre ellos, debemos destacar la fundación de la Asociación Internacional de Aerobiología (IAA) en 1974, que se reúne cada cuatro años en un foro en el que se exponen los trabajos aerobiológicos. De hecho, en el Tercer Congreso Internacional en Suiza (1986), se creó la European Aeroallergen Network (EAN) / European Pollen Information (EPI) que se encarga de difundir y divulgar la información aerobiológica de más de 400 estaciones de muestreo repartidas por 28 países europeos.

La aparición de la Aerobiología como Ciencia en España, tal y como ha ocurrido con un buen número de disciplinas científicas, tiene lugar en el siglo XX con un trabajo sobre el contenido atmosférico de conidios de hongos y su implicación en procesos alérgicos en Santander (Jiménez, 1932). En décadas siguientes comenzaron a aparecer trabajos, como el realizado por Pla Dalmau (1958), que relacionaban los parámetros meteorológicos con la presencia de granos de polen en la atmósfera y su incidencia en casos clínicos de alergia, pese a que el verdadero auge se experimentara en los años ochenta, con un notable incremento de las estaciones de muestreo. Así pues, y de forma análoga a lo ocurrido en Europa, se crea en 1992 la Red Española de Aerobiología (REA) para integrar a todos los puntos de monitorizaje activos en ese momento, coordinarlos y crear una base de datos común que permita la difusión de los datos. En la actualidad, la REA incluye a más de cincuenta estaciones de muestreo, que envían semanalmente los datos al centro coordinador de la Red, ubicado en la Universidad de Córdoba, siendo, por tanto, la red de información aerobiológica más importante de España e integrada en las redes europeas "EAN/EPI". En el año 2006, se establece definitivamente la Red Aerobiológica de Castilla y León (RACyL), a través de un 
Convenio entre la Consejería de Sanidad y la Universidad de León, en el que colabora el grupo de Palinología y Conservación Vegetal de la Universidad de Salamanca, y que engloba a las nueve capitales de provincia de la Comunidad autónoma junto a las poblaciones de Ponferrada, Miranda de Ebro y Arenas de San Pedro.

\subsubsection{Interés y aplicaciones de la Aerobiología}

Esta ciencia de reciente creación ha desempeñado un papel de gran importancia en disciplinas del ámbito biosanitario, debido a los procesos alérgicos desencadenados por partículas biológicas, aunque en el transcurso de los últimos años, la Aerobiología se ha vinculado a un amplio abanico de campos de investigación. Así pues, haremos un breve recorrido sobre los aspectos más relevantes de estas ciencias relacionadas.

Como acabamos de señalar, la aplicación más importante de la Aerobiología está relacionada con la alergia, y por ende, con la Medicina. A este hecho hemos de sumar la incidencia de las esporas fúngicas en ambientes interiores, especialmente en lugares de trabajo con sistemas de ventilación artificiales o con una escasa ventilación y exceso de humedad (Lai, 2002; Huttunen et al., 2008). De esta forma, resulta necesario conocer el contenido de partículas que son susceptibles de desencadenar fenómenos alérgicos en todas aquellas personas que padecen esta enfermedad, para todo el personal sanitario implicado en esta materia y para los propios pacientes.

En los diversos aspectos que engloba la Agricultura, la Aerobiología participa como ciencia auxiliar en estudios fenológicos, en previsión de cosechas y en trabajos asociados a la fitopatología, y en especial, el control de plagas fúngicas. En el ámbito de la fenología de diversos taxones vegetales existen trabajos muy abundantes que hacen referencia al inicio, duración y severidad de la estación polínica (Nilsson \& Persson, 1981; Andersen, 1991; Galán et al., 1995; Jato et al., 2006; entre otros). Los trabajos que tratan sobre la incidencia de enfermedades fúngicas sobre cultivos y las concentraciones de esporas atmosféricas son menos numerosos (Díaz et al., 1997, Burt et al., 1998; Isard \& Ariatti, 2006). La aplicación de diversas metodologías propias de la Aerobiología resulta fundamental en la predicción de cosechas y en la posible relación entre la producción de polen previa y la producción vegetal agrícola (Cour \& Van Campo, 1980; González-Minero et al., 1998; Cunha et al., 2003).

La actual preocupación de la sociedad por el Medio Ambiente no es ajena a los estudios aerobiológicos, puesto que existen trabajos acerca de la relación entre pólenes y esporas y otros contaminantes atmosféricos (Emberlin, 1997; Cariñanos et al., 1998; Chehregani et al., 2004; Schoene et al., 2004). El conocido fenómeno del cambio climático que, desde hace dos décadas (Gall et al., 1992), suscita un gran interés, puede complementarse con la Aerobiología, debido a los análisis concentraciones de polen en el aire 
y diferentes sedimentos y su aplicación en la reconstrucción de la vegetación presente en épocas pretéritas. El conocimiento aportado por diversos estudios aerobiológicos (Osborne et al. 2000; Rasmussen, 2002; García-Mozo et al., 2006; Emberlin et al., 2007) revela también que el llamado calentamiento global puede influenciar el ciclo de vida de especies vegetales, adelantando la floración de las mismas y su consiguiente registro polínico en la atmósfera. Este posible cambio sería más evidente en plantas anuales que en perennes y en especies con floración primaveral.

Las partículas de carácter biológico presentes en el aire, especialmente esporas fúngicas, pueden ocasionar daños en espacios culturales y patrimoniales de numerosas ciudades, si llegan a germinar en ellos y dando lugar al biodeterioro de obras y construcciones de gran relevancia cultural (Petushkova \& Kanddyba, 1999; Mandrioli et al., 2003; Aira et al., 2007).

Por último, debemos señalar a la botánica forense, y en concreto a la Palinología forense, como una de las disciplinas con mayor desarrollo en la investigación criminológica, relacionadas no sólo con la Aerobiología sino también con otros ámbitos de la Palinología. El estudio del polen y de otras partículas microscópicas ha demostrado ser un recurso esencial para la resolución de numerosos casos policiales (Bryant \& Jones, 2006), puesto que estas partículas se pueden transportar por el aire y quedar adheridas a tejidos vivos o textiles. En el caso de los granos de polen, la presencia de la exina, que les hace susceptible de ser identificados a pesar del transcurso del tiempo, junto las peculiaridades fenológicas y corológicas de las especies vegetales productoras de los mismos, hace que su estudio tenga mayor aplicación en casos más variados (Nesterina et al., 2008; Boi et al., 2008).

\subsubsection{Procesos aerobiológicos}

Todos aquellos sucesos que siguen las partículas biológicas desde que se forman en las estructuras reproductoras hasta que sedimentan o impactan en cualquier superficie a través de la atmósfera, reciben el nombre de procesos aerobiológicos (Fig. 1.1.). La atmósfera es el medio gaseoso e inestable que contiene un gran número de partículas en suspensión, ya sean de origen inorgánico, procedentes, en gran medida, de la actividad industrial y la combustión de los vehículos (Cariñanos et al., 1999), o de origen orgánico, que son resultado de algún proceso biológico en el que la atmósfera participa como medio de transporte. Tal y como señalan Isard \& Gage (2001), existe un gran número de organismos, sobretodo esporas de hongos, granos de polen, ácaros y pequeños insectos, que utilizan el medio aéreo para dispersarse ya que resulta menos costoso desde el punto de vista energético. 


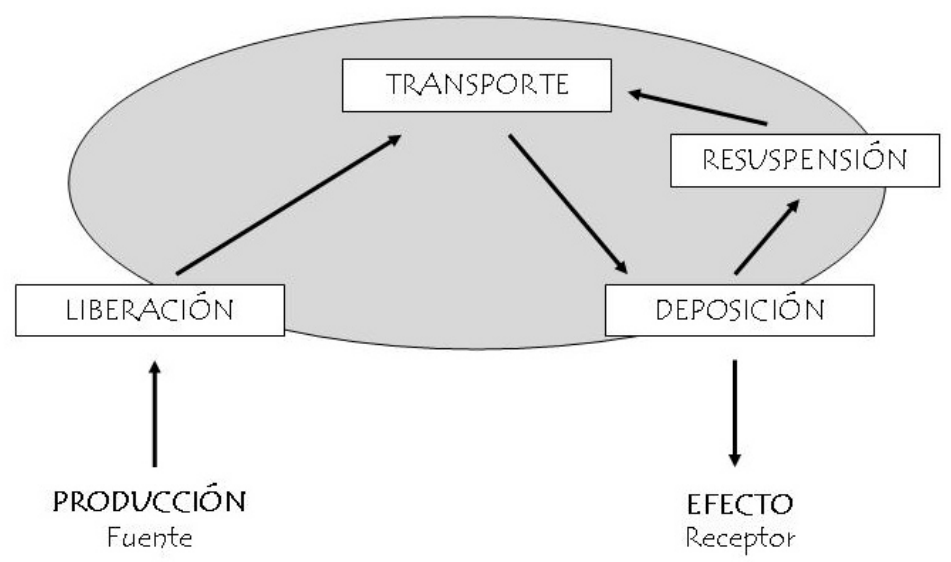

Fig. 1.1. Procesos aerobiológicos (adaptado de Spieksma, 1992).

La fuente productora o emisora es el primer eslabón implicado en la serie de factores que interviene en los procesos aerobiológicos, y a través del cual, una vez que los granos de polen y esporas de pteridófitos hayan sido formados en los sacos polínicos y microesporangios, respectivamente, son liberados al exterior y transportados hasta el estigma (en Angiospermas), el primordio seminal (en Gimnospermas) o un sustrato (Pteridófitos), donde acabarán germinando como consecuencia de su función reproductiva. En este punto, debemos señalar que, de acuerdo con Font Quer (1993), hablaríamos de polinación como la acción y efecto de soltar el polen de las anteras y de polinización cuando este alcance la estructura reproductora femenina. De este modo, en los estudios aeropalinológicos el grano de polen es "capturado" antes de llegar a los órganos sexuales femeninos, por lo que sería más correcto hablar de polinación y no de polinización cuando se analizan las concentraciones polínicas. No obstante, y debido a su uso tradicional, mantendremos el término polinización para referirnos al proceso de liberación y transporte del grano de polen, independientemente de si llega o no a las estructuras reproductoras femeninas.

La polinización puede llevarse a cabo a través de diferentes vectores, como puede ser el aire (polinización anemófila), el agua (hidrófila) o animales polinizadores (zoófila), destacando en este último caso la que realizan los insectos (entomófila). En algunos géneros se observa una coexistencia entre anemofilia y entomofilia que recibe el nombre de anfifilia o ambofilia, como en el caso del género Castanea Mill. (Hesse, 1978), y que puede ser debida a una adaptación local o regional ante una serie de cambios en las condiciones climatológicas o en los polinizadores (Culley et al., 2002). Las plantas anemófilas presentan ciertas adaptaciones para la polinización por el viento, como pueda ser una mayor producción de polen por individuo (Cruden, 2000), y dentro de las mismas se observan rasgos especiales en los granos de polen que producen, como el desarrollo de estructuras especiales 
(Schwendemann et al., 2007) o la reducción de su tamaño y/o el grosor de la exina (Niklas, 1985), que faciliten el transporte a través de la atmósfera (Fig. 1.2. A. y Fig. 1.2. B.).

A
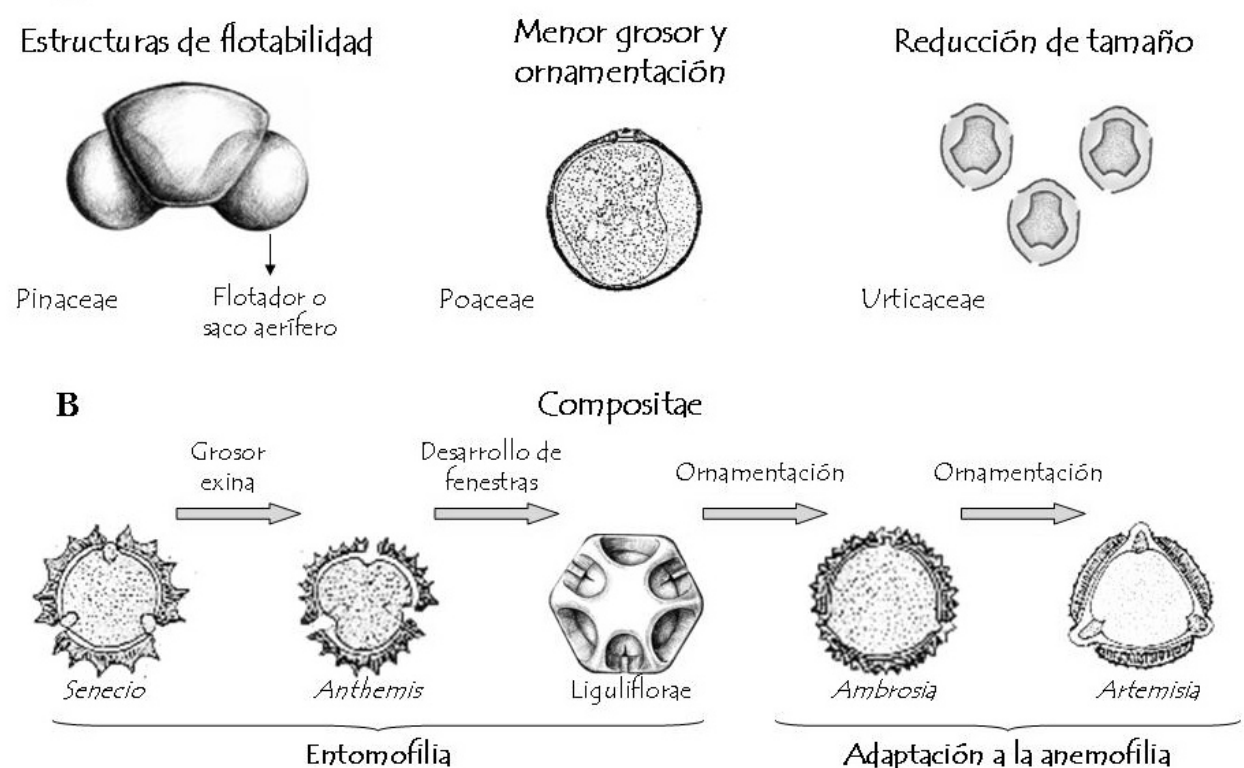

Fig. 1.2. A. Algunas adaptaciones de diferentes tipos de polen a la anemofilia. B. Adaptaciones a la anemofilia en una familia (Compositae) típicamente entomófila. (Ilustraciones tomadas de Solomon, 1970 y Davis, 2008).

Cuando las partículas son liberadas a la atmósfera, su evolución temporal y espacial va a estar condicionada, en gran medida, por los factores meteorológicos y por la presencia o ausencia de obstáculos orográficos tales como montañas, valles, océanos o incluso por edificaciones civiles. Una topografía acusada limitará su dispersión longitudinal, mientras que las corrientes atmosféricas propiciarán su desplazamiento en altura. Además, en función de la distancia que recorran estas partículas, se diferencian varios tipos de transporte, bien sea a escala local, donde las partículas se depositan en las proximidades de la fuente emisora, o a escala regional, en la que debido a las corrientes atmosféricas formadas por el calentamiento de la superficie terrestre las partículas pueden ascender a capas superiores y desplazarse a mayor distancia (Isard \& Gage, 2001). También puede hablarse de un transporte a larga escala (Rantio-Lehtimäki, 1994; Ranta et al., 2006) asociado a la circulación global atmosférica.

Tras este transporte a través de la atmósfera, la ausencia de turbulencias u otra serie de factores pueden dar lugar a la deposición de las partículas que, atendiendo a la causa que produce estos fenómenos, recibe diversas denominaciones. Así pues, se habla de "sedimentación" cuando es la gravedad la que favorece esta deposición, que afecta a partículas de mayor tamaño y/o peso. En partículas de tamaño y/o peso medio es frecuente que ocurran procesos de "impactación”, cuando chocan contra un obstáculo, mientras que en pequeñas partículas (inferiores a $3 \mu \mathrm{m}$ ), que son inhaladas y exhaladas con mayor facilidad, 
se suceden dinámicas de "difusión". En cualquier caso, estas partículas ya depositadas pueden volver a la circulación atmosférica gracias a fenómenos de "resuspensión", que explican, al menos en parte, la existencia de granos de polen en muestras aerobiológicas en fechas alejadas de su período de polinización (Mandrioli et al., 1980; Jarosz et al., 2004).

\subsubsection{Factores que afectan al contenido de polen y esporas en el aire}

\section{- Factores meteorológicos}

El análisis de cada parámetro meteorológico por separado y sus consiguientes efectos en las concentraciones de las partículas biológicas en la atmósfera sería erróneo, puesto que existe una interacción entre todos ellos. En función del taxon o del estado fenológico en el que se encuentre la planta, existen variaciones en la influencia de estos factores, al igual que en el grado de participación de cada uno de ellos.

Los parámetros meteorológicos, en términos generales, van a actuar a dos niveles. El primero de ellos se localiza en las etapas previas a la floración, donde el fotoperiodo o la duración del período frío influyen en el comienzo de la misma (Chuine et al., 1999), y las precipitaciones y temperaturas afectan a la intensidad de floración. El segundo puede dividirse en varias etapas conocidas como emisión, transporte, dispersión o deposición, y que se encuentran directamente influidas por la temperatura y la precipitación así como por la humedad relativa, la insolación o el viento, en un menor grado (Brichi et al., 1992).

La temperatura ejerce, en la mayoría de los casos, un efecto positivo sobre los niveles de polen en el aire, puesto que influye en todas las fenofases vegetales, adelantando o retrasando la formación de yemas florales, antesis, emisión y dispersión de los granos de polen (Leuschner \& Boehm, 1981; Spieksma \& Nikkels, 1998). En los últimos años, la temperatura acumulada se ha revelado como un factor desencadenante para el inicio de la floración en plantas leñosas (Wielgolaski, 1999; Chuine, 2000; García-Mozo et al., 2000), que, a su vez, depende del área geográfica y de las condiciones ambientales (Rodríguez-Rajo et al., 2003a; Orlandi et al., 2005; García-Mozo et al., 2008), pues condiciona el umbral de temperatura a partir del cual la planta comienza a acumular calor.

En este sentido, diversos estudios de variación horaria han puesto de manifiesto que las mayores concentraciones de polen atmosférico coinciden con el intervalo horario de temperaturas más elevadas (Käpylä, 1981; Galán et al., 1991; Alba et al., 2000; Ribeiro et al., 2008), debido también que cada especie presenta la necesidad de alcanzar un umbral determinado para que se produzca la dehiscencia de las anteras, y emisión de polen en las horas centrales del día.

La insolación es un parámetro directamente relacionado con la temperatura y el fotoperíodo. De hecho, la ampliación del fotoperíodo hace que se ponga fin a la dormición y 
se inicie la floración, debido a la activación en la síntesis de hormonas de crecimiento (giberelinas y citoquinas). Por tanto, el incremento de horas de sol favorece la presencia de polen en la atmósfera, gracias a la deshidratación y dehiscencia estaminal (Aira et al., 1998; Moreno Grau et al., 2000).

La precipitación condiciona la presencia de polen en la atmósfera dependiendo de su intensidad, del momento del día en el que acontezca o del estado fisiológico de la planta (Bartková-Ščevková, 2003). Durante la liberación y la dispersión de los granos de polen, la lluvia bloquea la liberación ejerciendo además una acción mecánica sobre las partículas y las precipita al suelo, en el fenómeno conocido como lavado atmosférico, más efectivo en primavera y verano (Belmonte \& Roure, 1985; Fornaciari et al., 1997; Peternel et al., 2006). Asimismo, se ha visto que las lluvias prolongadas y suaves son más efectivas en este efecto ppnegativo que las poco duraderas e intensas (Iglesias et al., 1993; Rodríguez et al., 2008).

La sequía, de vital importancia en el área mediterránea, tiene lugar cuando la precipitación es menor que la evapotranspiración potencial o demanda evaporativa de la atmósfera, provocando, en términos fisiológicos, un estrés hídrico para la vegetación como consecuencia del extenso y severo período de escasez de agua. Las especies vegetales requieren de un umbral previo de precipitación para iniciar su período de crecimiento y reproducción anual que, si se ve modificado, dará lugar a períodos fenológicos anómalos o confusos (Cariñanos et al., 2004).

La humedad relativa del aire favorece el desarrollo de la planta y la floración, aunque un incremento por encima de un umbral específico (Galán et al., 1989; Emberlin \& Norris-Hill, 1991) impide la dehiscencia de las anteras y el consiguiente descenso de las concentraciones polínicas. De este modo, cuando la humedad relativa disminuye las paredes de la antera se deshidratan y se rompen con mayor facilidad, favoreciendo la salida de los granos de polen. Dichos granos de polen, dado el fenómeno de la "harmomegatía", absorben agua si la humedad relativa es elevada, lo cual hace que se vuelvan más pesados y sedimenten (Emberlin, 1994). Así pues, la sequedad ambiental moderada favorece la dispersión polínica.

No debe obviarse que el viento resulta imprescindible en el transporte y dispersión de partículas biológicas desde la fuente de emisión hasta el lugar donde se depositan, pero para analizar de forma adecuada su influencia sobre dichas partículas hemos de tener en cuenta sus dos componentes principales, la velocidad y la dirección. La velocidad va a tener una incidencia negativa en las concentraciones de partículas tanto si es baja, pues ralentiza el balanceo de las anteras y la subsiguiente liberación del polen, como si es elevada, pues produce un efecto de dispersión (Bricchi et al., 1992; Damialis et al., 2005). La dirección juega un papel importante en la composición del espectro polínico cualitativo y cuantitativo que se observa en las muestras aerobiológicas, como han puesto de manifiesto diversos autores mostrando el efecto positivo de la dirección del viento en las concentraciones de 
aeropolen (Jato et al., 2000; Kasprzyk, 2008). Por último, cabe señalar dos aspectos relacionados con el viento, mencionados con anterioridad, como el fenómeno de "resuspensión” y el transporte a larga distancia, este último con gran profusión de trabajos en los últimos años (Cecchi et al., 2007; Stach et al., 2007).

\section{- Fenología}

La fenología es la disciplina que, tal y como señala Lieth (1974), versa sobre el estudio de los fenómenos biológicos que se desarrollan de forma periódica en el tiempo, sobre los factores bióticos y abióticos que los desencadenan, así como la interrelación de estos fenómenos en la misma o en diferentes especies. Los muestreos aerobiológicos permiten conocer el inicio de floración de diversos táxones, conllevando, por tanto, la existencia de una estrecha relación entre la fenología y la aerobiología, ya sea para conocer la emisión polínica de especies anemófilas y la configuración de mapas espacio-temporales de floración (Hidalgo et al., 2003; Alba et al., 2006), o en la predicción de cosechas (Cristofolini \& Gottardini, 2000; Fornaciari et al., 2002).

\section{- Flora y Vegetación}

El contenido de polen atmosférico de una determinada área va a depender de las formaciones vegetales cercanas, aunque todo ello esté sujeto a su vez a la contribución que puedan tener las diferentes especies presentes en dichas formaciones, como consecuencia de su producción polínica, tipo de polinización o eficacia en el transporte de los granos de polen. Asimismo, la vegetación está sujeta a constantes cambios que condicionan que la vegetación actual sea el resultado de diversos factores ecológicos y climáticos junto a la presión antrópica.

Las concentraciones polínicas en un determinado lugar pueden tener dos componentes: los granos de polen procedentes de la vegetación local y aquellos producidos en lugares alejados y transportados a esa zona mediante masas de aire (Faegri \& Iversen, 1989). Asimismo, a medida que se incrementa la distancia desde la fuente emisora, la cantidad de polen disminuye logarítmicamente (Käpylä, 1984). Por último, conforme a modelos de dispersión polínica (Prentice, 1985), el polen aspirado por un captador procede fundamentalmente de fuentes locales (hasta 200 metros), y en menor proporción, fuentes extralocales (de 200 metros a 2 kilómetros), regionales (de 2 a 200 kilómetros) y extraregionales (más de 200 kilómetros).

\section{-Producción polínica y dispersión}

Los análisis biológicos realizados para determinar la cantidad de granos que produce una especie pueden ser utilizados para estimar el número de granos de polen que van a 
dispersarse durante una estación por el aire, siempre que se conozca previamente la densidad de la vegetación por unidad de superficie (Tormo et al., 1996). Las especies anemófilas son las que van a presentar una mayor producción de polen para intentar compensar una menor eficiencia en la polinización (Faegri \& van der Pijl, 1979), pero adoptando diferentes estrategias según la especie, ya que si en Olea europaea L. hay una gran producción de polen por antera debido al escaso número de estambres por flor, en Quercus ilex subsp. ballota (Desf.) Samp., con menor cantidad de anteras, existe un mayor número de inflorescencias en cada individuo.

\subsection{Métodos de muestreo en Aerobiología}

A lo largo del desarrollo histórico de la Aerobiología se han utilizado diferentes metodologías e instrumentos de muestreo basados en principios físicos tales como la deposición gravitacional, la impactación, la succión y la filtración (Ogden et al., 1974) o los más recientes de precipitación e intrusión (Mandrioli et al., 1998). Cada uno ellos posee una serie de características específicas que debe tenerse en cuenta a la hora de elegir el método más adecuado para retener las partículas y el análisis que se pretenda realizar.

\section{- Métodos de deposición gravitacional o gravimétricos}

Consiste en la exposición de una superficie horizontal sobre la cual se depositan partículas por efecto de la gravedad, quedando retenidas por acción de una sustancia adhesiva. La eficacia de esta metodología varía en función del tamaño de las partículas, la velocidad y dirección del viento así como con las posibles turbulencias atmosféricas. Los captadores principales de este tipo son los desarrollados por Durham (1946), modificado por Pla Dalmau (1958), y Tauber (1967), aunque en todos ellos resulta imposible calcular el volumen de aire muestreado y, por tanto, no pueden expresarse los datos obtenidos por unidad de volumen (Lacey et al., 1996)

\section{- Métodos de impacto}

Este método se basa en el choque del aire contra una superficie que intercepta y retiene las partículas que transporta, aunque no debe obviarse que para que estas partículas sean transportadas la velocidad del viento ha de ser mayor que la fuerza gravitacional y que las propias partículas adquieren una inercia que puede conllevar resistencia a los cambios atmosféricos y a la futura impactación en un obstáculo. La eficacia de los principales captadores utilizados, Rotorod (Perkins, 1957) y Rotoslide (Ogden \& Raynor, 1967), depende de la velocidad del viento, de los caracteres morfológicos de la partícula y del tamaño del captador (Mandrioli et al., 1998). De igual manera, debemos destacar que la principal 
desventaja de este tipo de captadores reside en que no pueden actuar durante períodos prolongados de tiempo.

\section{- Métodos de succión}

Los muestreadores o captadores utilizados en este tipo de metodología son aquellos que mediante una bomba de vacío u otro sistema análogo absorben un volumen de aire conocido que contiene partículas biológicas. Entre los captadores de succión encontramos dos tipos principales, ambos ideados originalmente para captar esporas fúngicas. El primero de ellos, conocido como spore-trap (Hirst, 1952), está diseñado para que las partículas penetren a través de un orificio, mediante un flujo de aire conocido, y se depositen por impacto en la superficie de una cinta transparente cubierta de una sustancia adhesiva. En la actualidad existen dos modelos utilizados por sendas casas comerciales: "Burkard 7-days recording” (Burkard Manufacturing Co. Ltd.) y "Lanzoni VPSS 2000" (Lanzoni s.r.l), con las mismas ventajas (simplicidad y registro continuo) e inconvenientes (resultados variables en función de la velocidad del viento y el tamaño de las partículas).

El otro captador de succión, denominado "Impactador en cascada" y siendo el tipo Andersen (Davies, 1971) el más utilizado, se basa también en la entrada a través de un orificio de un flujo de aire conocido que atraviesa un conjunto de placas metálicas apiladas y perforadas, en las que se encuentran placas de Petri con agar. El tamaño de estas perforaciones se hace progresivamente menor hacia la base, por lo que las partículas de menor tamaño impactan en la parte inferior. A continuación, se incuban las placas de Petri para conocer el tipo de esporas presentes en cada nivel, análogo a los diferentes niveles y filtros existentes en el tracto respiratorio desde la nariz hasta los alvéolos pulmonares.

\section{- Métodos de filtración}

Encontramos dos tipos de métodos fundamentados en que el aire pase a través de una superficie porosa en la que las partículas, en función de su tamaño, queden retenidas o la atraviesen. Cour (1974), diseñó un captador en el que la superficie filtradora se compone de cinco gasas hidrófilas impregnadas con aceite de silicona, sostenidas por un bastidor metálico y acompañadas de una veleta y otro dispositivo horizontal inmóvil que recoge las partículas depositadas por sedimentación gravitacional. Además puede acoplarse un anemómetro que indique el recorrido de la columna de aire y una posterior transformación volumétrica de los datos. El principal inconveniente de este captador es que no permite conocer las variaciones diarias junto a que en el análisis del contenido de las gasas se efectúa el proceso acetolítico (Erdtman, 1960) y la consiguiente perdida de información, debido a su agresiva acción sobre las esporas fúngicas y ciertos tipos de granos de polen, especialmente anemófilos. 
Los filtros de superficie tipo membrana, más recientes y funcionalmente más apropiados para la observación al microscopio (Mandrioli et al., 1998), son incorporados por varios tipos de captadores con aplicación al estudio de polen, esporas y aeroplancton (Suárez \& Seoane, 1983, 1985).

\section{- Métodos de precipitación electrostática e intrusión líquida}

Tratamos de manera conjunta estas dos técnicas por su menor relevancia en estudios aerobiológicos. En el método de precipitación electrostática las pequeñas partículas atrapadas se cargan eléctricamente y son atraídas hacia un electrodo de carga opuesta, encontrándose una variante (precipitación térmica) por la cual el flujo de aire introducido se calienta y se desplaza hacia una superficie fría.

Las técnicas de intrusión líquida se desarrollan en un contenedor de agua al que se le introduce aire, que al ascender forma burbujas y hace que las partículas sean transferidas al medio líquido e incluidas en él. Es por ello, que las intrusiones en medio acuoso hayan sido recomendadas para el estudio de microalgas, ya que con ello se preserva la viabilidad de estos organismos microscópicos (Mandrioli et al., 1998)

\subsection{Morfología polínica}

El grano de polen o microspora de las fanerógamas tiene su origen en los sacos polínicos o microsporangios, gracias al proceso de división meiótica de las células madre del grano de polen y que da lugar a cuatro células hijas o granos de polen que se disponen habitualmente en forma de tétrada. En el interior de estos granos se desarrolla el gametófito masculino.

Una serie de envolturas inertes que protegen una o varias células vivas forman parte del grano de polen. La parte viva dará lugar a los núcleos espermáticos (o gametos en algunas gimnospermas) y al tubo polínico, mientras que las envolturas inertes se encargan de proteger a la mencionada parte viva en su desplazamiento. Esta serie de envolturas forman una pared denominada esporodermis o cubierta externa, configurada por de dos capas, exina e intina, diferenciadas ontogenética, química y morfológicamente.

La exina es la pared más externa del grano de polen, constituida por esporopoleninas, formadas por polimerización oxidativa de carotenos y ésteres de carotenos en proporciones variables. Es muy resistente a la oxidación, ataques de ácidos y bases fuertes, al igual que a temperaturas superiores a $300^{\circ} \mathrm{C}$. Para diferenciar esta pared en una serie de capas siguiendo criterios morfológicos, Erdtman (1969) divide a la cubierta del grano de polen en intina y exina, y subdivide a esta última en sexina y nexina (Fig.1.3). Atendiendo a criterios ontogénicos y químico-físicos (Faegri \& Iversen, 1975), la exina ha sido diferenciada 
en endexina y ectexina. La endexina (Fig. 1.3.) posee una estructura lisa y homogénea, excepto en la parte abertural donde pueden localizarse engrosamientos. La ectexina o capa más externa está formada a su vez por tres capas: téctum, infratéctum y capa basal. Sobre el téctum puede haber una serie de elementos esculturales o relieve que forman la ornamentación del polen (Fig 1.4.A.).

En la ectexina pueden encontrarse perforaciones, depresiones tectales o hendiduras más largas que anchas, dando lugar a granos de polen perforados, foveolados o fosulados, respectivamente. Si el téctum es liso, se habla de polen psilado, estriado cuando presenta estrías, rugulado si posee elementos con disposición irregular, reticulados y retipilados, cuando conforma retículos (Fig. 1.4.B.). En algunos granos de polen, denominados atectados, no se encuentra la capa tectal y los elementos esculturales, si los hubiere, se asentarían sobre el infratéctum, o bien es este último el que ocupa la función estructural del téctum.

La intina es la pared más interna del grano de polen y químicamente poco resistente, puesto que está formada por celulosa, polisacáridos, enzimas y proteínas. En muchas ocasiones, estos últimos compuestos son los responsables de las reacciones alérgicas y de la autoincompatibilidad entre los vegetales (Márquez et al., 1997).

\section{Faegri \& Iversen (1975) $\quad$ Erdtman (1969)}

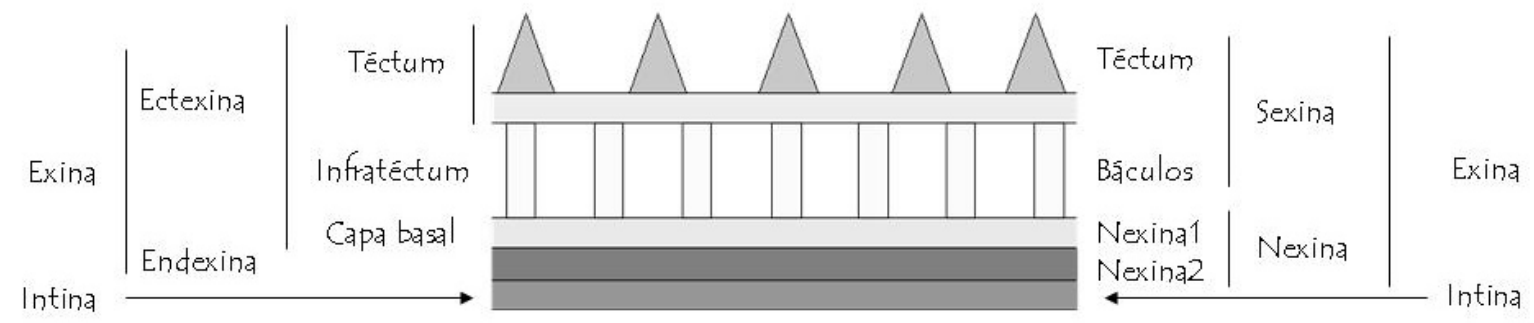

Fig. 1.3. Estructura de la cubierta del grano de polen atendiendo a criterios ontogénicos y físico-químicos (Faegri \& Iversen, 1975) y morfológicos (Erdtman, 1969). 
A

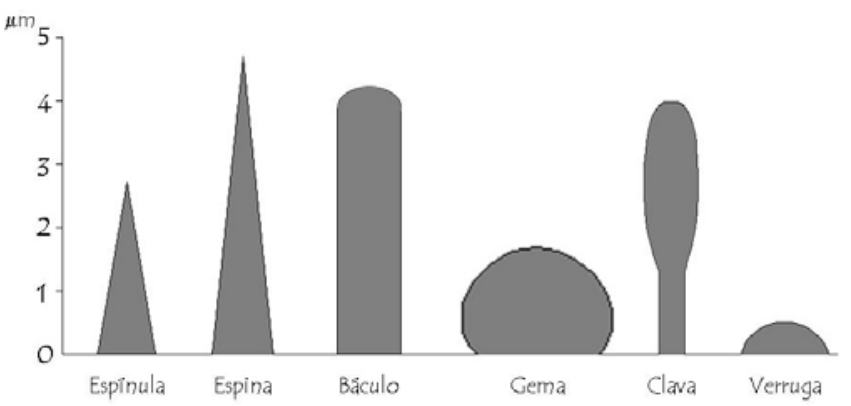

B

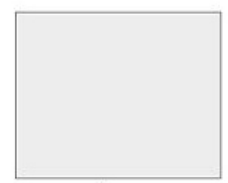

Psilado

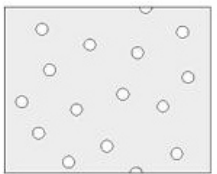

Perforado

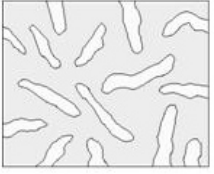

Fosulado

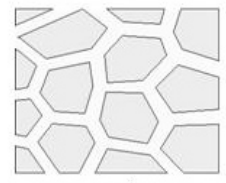

Reticulado

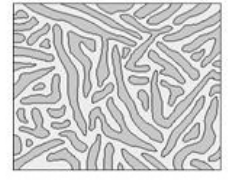

Rugulado

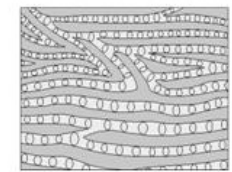

Estriado-reticulado

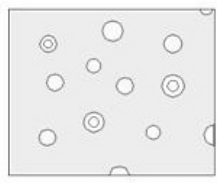

Foveolado

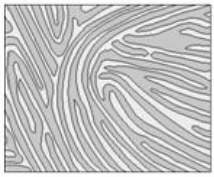

Estriado

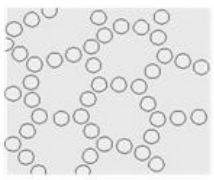

Retipilado

Fig. 1.4. A. Elementos esculturales en sección transversal. B. Vista superficial de los principales tipos de ornamentación. (adaptado de Sáenz, 2004).

El proceso de división meiótica, como señalamos anteriormente, da lugar a una tétrada con cuatro granos de polen, que generalmente se disgrega y hace que los granos se dispersen individualmente. Esta estructura tetraédrica hace posible que se diferencie en cada grano de polen, una zona proximal (la más cercana al centro de la tétrada), y una zona distal (la más alejada a esta), teniendo en cuenta que el grano de polen es un objeto tridimensional. A cada una de estas zonas se les denomina polo, y a la línea imaginaria que los une se le llama eje polar (P). De forma perpendicular a este eje, se halla el diámetro ecuatorial (E), siendo ambos fundamentales para definir la forma del grano de polen (Erdtman, 1969), gracias a la relación entre ambos $(\mathrm{P} / \mathrm{E})$. 


\begin{tabular}{cc}
\hline $\mathbf{P} / \mathbf{E}(\mu \mathbf{m})$ & Forma \\
\hline 2 & Perprolato \\
$2-1,33$ & Prolato \\
$1,33-1,14$ & Subprolato \\
1 & Esferoidal \\
$1-0,88$ & Oblato-esferoidal \\
$0,88-0,75$ & Suboblato \\
$0,75-0,50$ & Oblato \\
$<0,50$ & Peroblato \\
\hline
\end{tabular}

Asimismo, el tamaño del polen puede definirse por la longitud de su eje polar y su diámetro ecuatorial, por lo que atendiendo al eje de mayor longitud se diferencian los siguientes tipos (Erdtman, l.c.). No obstante, debemos reseñar que en lo referente a la polaridad existen granos de polen polares, diferenciándose en isopolares y heteropolares, en función de si los dos polos son o no iguales, y granos apolares, en los que su tamaño se define en función de su diámetro.

\begin{tabular}{cc}
\hline P/E $(\mu \mathbf{m})$ & Tamaño \\
\hline$>200$ & Gigante \\
$100-200$ & Muy grande \\
$50-100$ & Grande \\
$25-50$ & Mediano \\
$10-25$ & Pequeño \\
$<10$ & Muy pequeño \\
\hline
\end{tabular}

La simetría está determinada, en parte, por la distribución de las aberturas germinativas, pudiendo ser simétricos, si existe algún plano de simetría, o asimétricos, si no lo tienen.

Reciben el nombre de aberturas ciertas áreas superficiales donde la exina está sensiblemente adelgazada, y a través de las cuales sale el tubo polínico en el momento de la germinación. Además permiten el cambio de volumen de los granos de polen como respuesta a variaciones de humedad, en lo que se conoce como función harmomégata. Según su forma se denominan colpos si se trata de aberturas alargadas y paralelas al eje polar, poros si son circulares o levemente elípticos, colporado si están compuestas por colpo y poro, o sulcos, si son aberturas alargadas en la zona distal o proximal (Fig. 1.5.). Las aberturas pueden variar en función del número y de su posición. Así, según su número, los granos de polen pueden ser inaberturados, y variar desde monoaberturados hasta poliaberturados. Del mismo modo, según su posición, las aberturas pueden disponerse por toda la superficie (panto-), en la zona 
ecuatorial (zono-) o en los polos, ya sea en la zona distal (ana-), en la zona proximal (cata-) o en ambas (anacata). La combinación del número, la posición y los tipos de aberturas da lugar a una gran variedad de tipos polínicos.

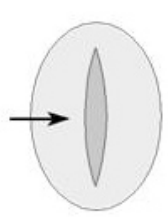

Colpo

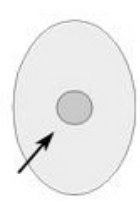

Poro

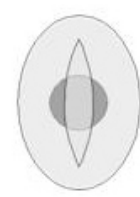

Colporo

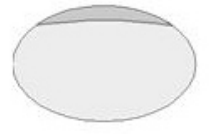

Sulco

Fig. 1.5. Tipos principales de aberturas.

En el caso de las esporas de pteridófitos, debemos señalar los aspectos más importantes con respecto a lo tratado para la morfología polínica. Las esporas pueden definirse como unidades reproductoras especializadas que en el caso de los pteridófitos se forman en número de cuatro tras una meiosis de las células madres de las esporas o esporocitos, configurándose inicialmente, como en el caso de los granos de polen, en una estructura tetraédrica. En el momento de la germinación estas esporas se abren gracias a la existencia de una única abertura o lesura, situada en la cara proximal, denominándose esporas monoletas. Las esporas con lesura trirradiada se conocen como esporas triletas. La esporodermis agrupa a un conjunto de capas que podríamos diferenciar en dos grupos, esclerina y endosporio. La esclerina (Fig. 1.6.) está formada por dos capas: el perisporio, que es la capa más externa, no siempre resistente a altas temperaturas y a ácidos y bases fuertes, y el exosporio, una capa gruesa, resistente y cutinizada que puede presentar hendiduras o relieves de diversa forma. La capa más interna, denominada endosporio, es de naturaleza celulósica, y es considerada como una estructura homóloga a la intina del polen de espermatófitos (Saénz, 1978), al igual que en el caso del exosporio y la exina.
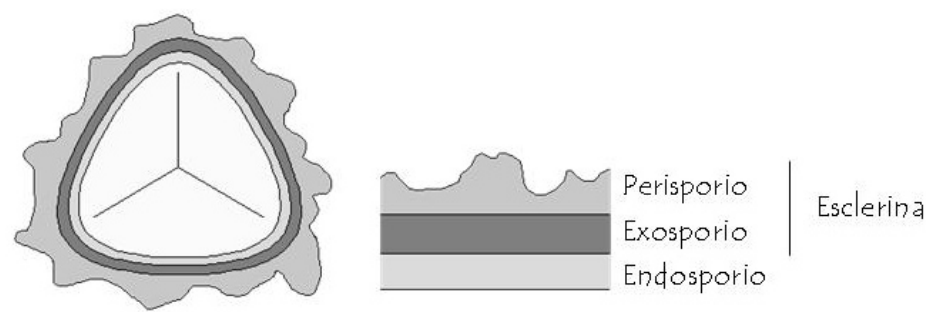

Fig. 1.6. Estructura de la esporodermis en pteridófitos (adaptado de Sáenz, 2004). 


\subsection{Reacción alérgica}

La alergia, neologismo derivado del griego állos - érgon (función diferente, en contraposición a la nomergia o función normal), se define como una disfunción del sistema inmunológico que desencadena una respuesta inapropiada o exagerada frente a sustancias que normalmente no producen tal reacción en la mayoría de los individuos, y que puede producirse por el contacto con una gran variedad de estímulos, tales como aeroalérgenos, medicamentos, u otros, que originan un estado de sensibilidad especial, aún ante cantidades mínimas. Los procesos alérgicos se manifiestan por medio de un conjunto de fenómenos de carácter respiratorio, digestivo o eruptivo, bien conocidos.

Las incidencia de las enfermedades alérgicas se ha visto incrementada en los últimos años, principalmente en los países desarrollados. Se estima que un $23 \%$ de la población padece alguna alergopatía y que muchas de ellas se producen por sensibilidad a los granos de polen (García, 1999), por lo que uno de los principales objetivos en el estudio de la alergia es la creación de métodos de mejora para el diagnóstico, tratamiento y prevención de esta enfermedad de hipersensibilidad. En este aspecto, desde sus comienzos como Ciencia, la Aerobiología ha tenido un vínculo a este campo de la Medicina, aportando información sobre el contenido que estos granos de polen tienen en la atmósfera y contribuir, en la medida de lo posible, a crear un mecanismo de prevención eficaz.

En la actualidad conocemos que una serie de factores (genéticos, ambientales, exposición temprana, inicio de la lactancia artificial, contaminación atmosférica, generalización del uso de vacunaciones preventivas y de antibióticos, entre otros) pueden influir en la etiología y en el incremento de la rinitis y el asma bronquial asociados a procesos alérgicos (Ownby, 1990; Cookson, 1999; D’Amato, 2000). De entre todos ellos, debemos destacar la probada existencia de una propensión genética al desarrollo de patologías alérgicas (Sibbald et al., 1980; Dávila et al., 2009), los efectos de los contaminantes atmosféricos, ya sean de naturaleza inorgánica - $\mathrm{NO}_{2}, \mathrm{SO}_{2}, \ldots$ - (Seaton et al., 1995), u orgánica, como los vapores procedentes de los motores diesel (Díaz-Sánchez et al., 1997), e incluso la importancia de la mejora en la higiene en las sociedades industrializadas junto al mayor uso de vacunas y antibióticos, reduciendo la incidencia de infecciones que estimulan el sistema inmunitario y la protección frente al desarrollo de las enfermedades alérgicas (Strachan, 1989). Todo ello, viene a confirmar la complejidad de estas enfermedades, pues como ha señalado Hersey (2004), seguirían un modelo tridimensional, con los genes, el ambiente y el momento de la exposición como factores principales, a la hora de abordar su estudio. De hecho, en los últimos años se ha demostrado que los efectos específicos que un genotipo poseía en la susceptibilidad a padecer asma o rinitis bronquial, se han visto modificados por las exposiciones ambientales (Werner et al., 2003). 


\subsubsection{Alérgenos}

Los alérgenos son sustancias extrañas que desencadenan una reacción alérgica en individuos susceptibles de desarrollar enfermedades alérgicas, tras un proceso conocido como sensibilización, por el cual el individuo se expone al alérgeno, bien por inhalación (aeroalérgenos), ingestión (alérgenos de alimentos) o inyección (alérgenos de picaduras de insectos). En general, la naturaleza bioquímica de los aeroalérgenos, nos remite un grupo heterogéneo de proteínas o glicoproteínas (10-6o kDa), cuya solubilidad en medios acuosos facilita su liberación desde las partículas inhaladas al llegar al sistema respiratorio (Chapman, 1998). Los alérgenos pueden clasificarse en función de los niveles de reacción inmunológica, y así un alérgeno mayoritario es aquel al que se encuentran sensibilizadas, como mínimo, el 50\% de los individuos sensibles a ese tipo de alérgeno, y alérgeno minoritario, al que están sensibilizadas menos del 50\% (De Weerd et al., 2002).

En los granos de polen, los alérgenos están localizados principalmente en la exina (Knox, 1984), aunque también se han localizado en otras zonas como en el citoplasma, los gránulos de almidón intracelulares, la intina (Fischer et al., 1996; Behrendt et al., 1997; Vrtala et al., 1999), o en las partículas de Ubisch u orbículos de algunas familias como Betulaceae o Poaceae, que son partículas más pequeñas que el grano de polen, procedentes de los restos de las anteras o del interior del grano de polen y fragmentadas por la hidratación, que pueden transportar alérgenos (Fountain, 2002; Vinckier et al., 2005). Con todo ello, el grano de polen es uno de los vehículos de transporte de aeroalérgenos más importante, que debe reunir ciertos requisitos para llevar a cabo un transporte eficaz, como proceder de una planta anemófila y ser liberado en grandes cantidades a la atmósfera y transportado a través del viento, tener un tamaño mediano-pequeño (15-35 $\mu \mathrm{m})$ y ser lo suficientemente ligero para poder ser desplazado a largas distancias, o liberar fácilmente los alérgenos al llegar a las mucosas.

\subsubsection{Anticuerpos}

Los anticuerpos son proteínas producidas por los vertebrados como defensa contra las infecciones o los agentes extraños, que se diferencian del resto de proteínas en la elevada variabilidad de formas que adoptan al ser generadas y en la posesión de un lugar de unión específico que reconoce a un antígeno. Estas proteínas también reciben el nombre de inmunoglobulinas, ya que se trata de globulinas (proteínas séricas) inmunitarias, reconociéndose en la mayoría de mamíferos superiores, cinco clases o isotipos (IgG, IgA, $\operatorname{IgM}$, IgD, e IgE), que difieren entre sí por su tamaño, carga y composición química, pese a compartir el mismo patrón estructural (Margni, 1996). Dicho patrón responde a cuatro 
cadenas polipeptídicas (dos cadenas pesadas y dos ligeras), iguales dos a dos y unidas por puentes disulfuro. A la región del antígeno reconocida por un anticuerpo se le denomina epítopo o determinante antigénico, y como quiera que un antígeno puede presentar un número variable de epítopos de estructura única o repetitiva ante ese antígeno, podrán formarse tantos anticuerpos como epítopos existan (Carreño \& Castillo, 2001). La IgE es la inmunoglobulina que desempeña un papel fundamental en los procesos alérgicos, como veremos a continuación, y está presente en cantidades mínimas en el suero, representando menos del o,001\% del total de inmunoglobulinas séricas. Además, dentro de la IgE sérica, el número de IgE específicas para un alérgeno no suele superar el 10\%, por lo que la cuantificación de las mismas precisa de técnicas muy sensibles.

\subsubsection{Polinosis}

La alergia producida por granos de polen recibe el nombre de polinosis, y no es más que una reacción de hipersensibilidad en la que la IgE tiene un papel primordial. El término hipersensibilidad hace referencia a aquellas reacciones del sistema inmunitario en las que las que la respuesta al antígeno ocasiona, además, daños a los tejidos propios, debido a respuestas incontroladas o excesivas frente a antígenos extraños (Kinet, 2002). Los antígenos contenidos en los granos de polen desencadenan una reacción de hipersensibilidad de tipo I, que comienza la primera vez que el alérgeno se pone en contacto con el sistema inmunológico de un individuo, con un pequeño número de células capaces de reconocerlas (Fig. 1.7.). Estas células, a través de mecanismos especiales, son capaces de unirse a unas células determinadas llamadas linfocitos $\mathrm{B}$, que se transforman en células plasmáticas que, a su vez, promueven la síntesis de moléculas de IgE específicas. Parte de estas moléculas pueden pasar al torrente sanguíneo, pero la mayor parte de ellas se unen a los receptores de alta afinidad de unas células denominadas mastocitos y basófilos, quedando así el individuo sensibilizado y preparado para reaccionar en el momento que se produzca un nuevo contacto con el alérgeno. Posteriormente, ante una segunda entrada del mismo alérgeno, éste se une a la IgE específica de la superficie de mastocitos y basófilos, desencadenándose entonces una serie de modificaciones bioquímicas intracelulares y que desembocan en una liberación de mediadores mastocitarios. Entre los mediadores químicos más comunes que participan activamente en la reacción alérgica, podemos distinguir los preformados o primarios, como la histamina, los proteoglicanos o las proteasas, o los secundarios o sintetizados de novo, como los leucotrienos, las prostaglandinas o las citocinas.

Estos mediadores actuarán en pocos minutos sobre las células diana provocando síntomas típicos en estos procesos y que, según el órgano en el que actúen, producirán una serie de manifestaciones clínicas. En la mucosa nasal, produce una inflamación conocida 
como rinitis que causa estornudos, picor, obstrucción, secreciones nasales y, en ocasiones, falta de olfato. En el ojo, puede producir una inflamación del conjuntivo, denominada conjuntivitis originando enrojecimiento, picor y lagrimeo. Asimismo, puede producirse una inflamación conjunta de ojos y nariz, que recibe el nombre de rinoconjuntivitis, sin olvidar la inflamación de las vías respiratorias, bien conocida como asma, que produce tos, disnea sibilancias en el pecho y secreciones (flemas).

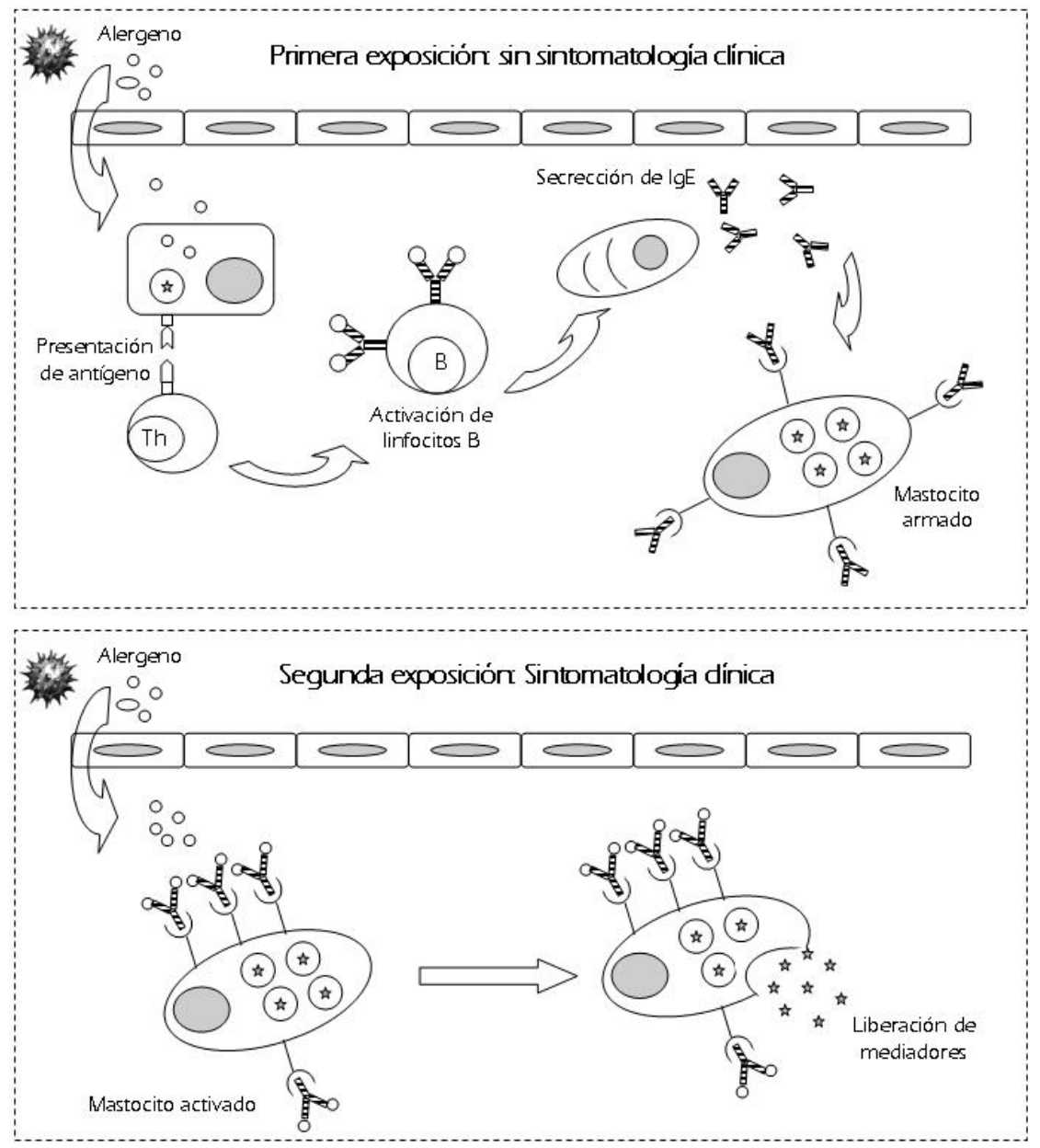

Fig. 1.7. Esquema de la reacción de hipersensibilidad de tipo I. Adaptado de Margni (1996).

La causa más común de polinosis en España, así como en el resto de Europa, se debe a la presencia en la atmósfera de polen de gramíneas no cultivadas, siendo dominante en el norte y el centro peninsular, pero quedando en un segundo lugar en la zona litoral mediterránea y en buena parte del sur, donde Parietaria judaica y Olea son la causa principal (Subiza et al., 2007). Otros tipos de polen también poseen importancia en varias zonas peninsulares como Cupressaceae o Platanus, pues alcanzan altos porcentajes de sensibilización y elevadas concentraciones atmosféricas, junto a otros como Betula, con incidencia en el norte, Plantago, Artemisia o Chenopodiaceae. 
El umbral de respuesta es variable de un paciente a otro, dependiendo de su grado de sensibilización, y además puede disminuir en un mismo paciente a medida que avanza la estación polínica, como se ha descrito en el efecto permisivo del antígeno o priming (Connell, 1969), por el cual la respuesta inflamatoria inducida por la reacción alérgica disminuye la cantidad de alérgeno necesaria para provocar los síntomas clínicos a medida que avanza la temporada polínica. En todo caso, se estiman como concentraciones atmosféricas altas de un tipo de polen, aquellas que son capaces de producir síntomas en gran parte de los pacientes clínicamente sensibles (50 granos $/ \mathrm{m}^{3}$ para el tipo Poaceae, 30 granos $/ \mathrm{m}^{3}$ para Urticaceae, 10-15 granos $/ \mathrm{m}^{3}$ para Chenopodiaceae,...), aunque puedan variar en función de la zona geográfica, como se ha visto para pacientes sensibilizados a diversos alérgenos del polen de Olea en la ciudad de Jaén, donde se necesitan 400 granos $/ \mathrm{m}^{3}$ para que dichos pacientes presenten síntomas clínicos (Florido et al., 1999).

\subsubsection{Pruebas de diagnóstico}

Comentaremos ahora las principales técnicas de diagnóstico en el campo de la alergología. Por un lado tenemos las técnicas in vivo, basadas en producir o inducir una reacción clínica puntual en el paciente supuestamente susceptible, destacándose las pruebas intraepidérmicas o prick-test, que consisten en introducir una pequeña cantidad de extracto alergénico en la piel del enfermo, evitando que sangre, gracias al uso de lancetas normalizadas de carácter desechable (Pepys, 1975). Otro tipo de pruebas, que de forma genérica, podemos considerar de provocación, se basan en producir la reacción en el órgano afectado, como las que tienen lugar en los bronquios con metacolina o alérgenos para estudiar la hiperreactividad bronquial inespecífica o específica, respectivamente, o la que puede realizarse en el fondo del saco conjuntival con unas gotas del extracto para observar la respuesta clínica usando el ojo no estimulado como control.

En las últimas décadas se vienen empleando con gran profusión técnicas in vitro, caracterizadas por la identificación del antígeno o del anticuerpo mediante una interacción simple (antígeno-anticuerpo), sin la participación de fenómenos asociados. De entre ellas podemos destacar, la cuantificación de IgE total en suero, cuya elevación sugiere la existencia de un problema alérgico (salvo la existencia de problemas hepáticos, parasitosis y/o inmunodeficiencias), o la determinación de IgE específica en sangre, mediante el uso de extractos alergénicos estandarizados y sus epítopos fijadores de IgE en fase sólida, conllevando que la capacidad de unión específica antígeno-anticuerpo de los IgE presentes en la fase líquida, sea muy elevada (Dolen, 2001), y posteriormente sea susceptible de ser medida por espectrofotometría. 

Área de estudio 



\subsection{Localización geográfica}

La provincia de Salamanca está situada en el centro oeste de la Península Ibérica y al suroeste de la Comunidad Autónoma de Castilla y León, de la que forma parte, con una altitud media de 830 metros sobre el nivel del mar (m.s.n.m.). Posee una extensión de $12.350 \mathrm{~km}^{2}$, que representa el $2,45 \%$ de la superficie nacional, y limita al norte con las provincias de Zamora y Valladolid, al sur con las provincias de Cáceres y Ávila, al este con la provincia de Ávila, y al oeste con Portugal. Los datos demográficos nos remiten, según el Instituto Nacional de Estadística (I. N. E., 2005), a una población de 352.414 habitantes, lo que supone una densidad de población de 28,5 habitantes por $\mathrm{km}^{2}$ en la provincia, mientras que en la capital y su alfoz se localizan alrededor de 200.00o habitantes.

Atendiendo a criterios geológicos y geográficos, siguiendo parcialmente a Llorente (1980), pueden diferenciarse cuatro zonas o "comarcas naturales" en la provincia (Fig. 2.1.; Tabla 2.1.), que pasamos a describir de forma breve. La primera de ellas, conocida como el llano de la Armuña y Peñaranda, localizada al noroeste, se originó como consecuencia de la colmatación durante el Cenozoico de las fracturas hercínicas formadas durante de la orogenia alpina, y dio lugar a llanuras terciarias de suelos sedimentarios con carbonatos (proceden de materiales como areniscas, arenas o arcillas) e incluso a pequeños afloramientos calizos. La morfología del terreno es llana, con un gradiente de altitud entre 700 y 900 m.s.n.m.

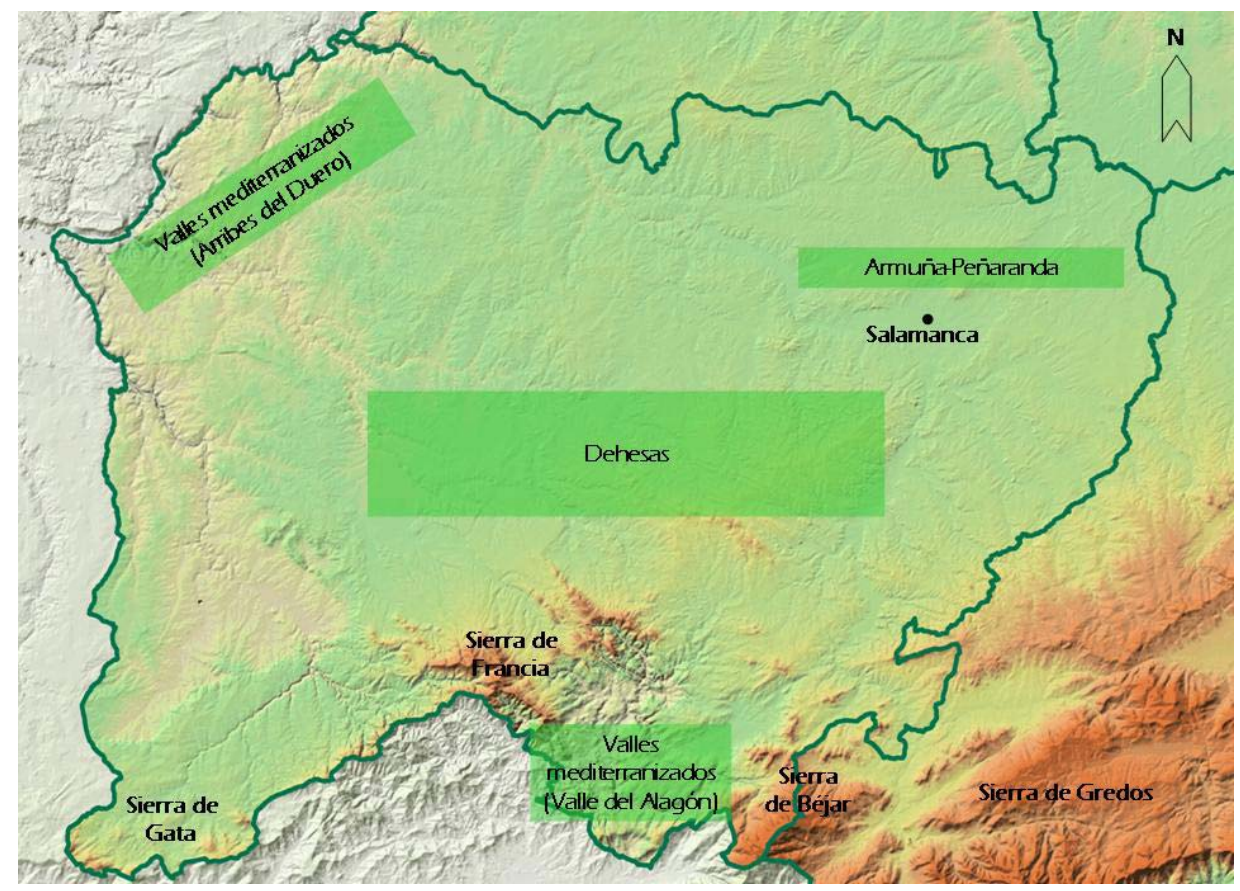

Fig 2.1. Orografía de la provincia de Salamanca y “comarcas naturales”. 
La zona de Dehesas se ubica en el centro-oeste de la provincia sobre llanuras modeladas de materiales paleozoicos con suelos de pizarras en zonas semiáridas y constituye, por tanto, una penillanura que comprende una mayor diferencia de altitud (entre 700 y 1100 m.s.n.m.) que la primera comarca mencionada.

La tercera comarca natural, las Sierras, se encuentra en el sur de la provincia y engloba, de oeste a este, a las sierras de Gata, de Francia y de Béjar, y sus piedemontes, exceptuando la cuenca alta del río Alagón, todos ellos pertenecientes al Sistema Central. Esta zona extensa y con peculiaridades locales presenta suelos de pizarras y áreas graníticas con altitudes medias superiores a los 1.000 m.s.n.m., sobre los que destacan los puntos más elevados de la provincia, como el Canchal de la Ceja (2.425 m.s.n.m.), el Hastiala (1.735 m.s.n.m. ), o el Jálama (1.493 m.s.n.m.).

La última de las zonas, los valles mediterraneizados, localizados al sur y al noroeste de la provincia, en lo que se conoce como cuenca alta del Alagón y las Arribes del Duero, respectivamente, presenta también suelos de granitos y pizarras con altimetrías inferiores a los 700 m.s.n.m., sobresaliendo el punto más bajo de la provincia, el muelle de Vega Terrón (120 m.s.n.m.).

La ciudad de Salamanca, por la que transcurre el río Tormes, el afluente meridional más importante del río Duero, está situada al noreste de la provincia $\left(40^{\circ} 58^{\prime} \mathrm{N} ; 5^{\circ} 40^{\prime} \mathrm{W}\right)$ a

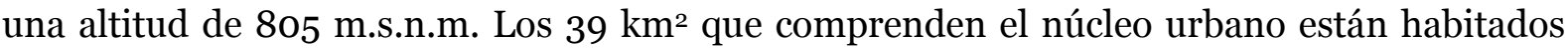
por 160.331 habitantes (4111 hab/ $\mathrm{km}^{2}$ ), relacionándose una población estimada de 217.069 habitantes entre los municipios del alfoz (I.N.E., 2005), y diversos componentes móviles (trabajadores no residentes, estudiantes, etc).

\begin{tabular}{|c|c|c|c|c|}
\hline Comarca natural & Roca & Suelos & Ombroclima & Vegetación \\
\hline Armuña-Peñaranda & $\begin{array}{c}\text { Areniscas, arenas, } \\
\text { gravas, } \\
\text { conglomerados } \\
\end{array}$ & $\begin{array}{l}\text { Sedimentos con } \\
\text { carbonatos }\end{array}$ & $\begin{array}{c}\text { Semiárido } \\
\text { Seco(300-600 } \\
\text { mm) } \\
\end{array}$ & $\begin{array}{c}\text { Cultivos } \\
\text { (Encinares basófilos) }\end{array}$ \\
\hline Dehesas & Pizarras, granitos & $\begin{array}{l}\text { Graníticos, } \\
\text { pizarras }\end{array}$ & $\begin{array}{c}\text { Seco } \\
\text { Subhúmedo } \\
(350-1000 \mathrm{~mm}) \\
\end{array}$ & $\begin{array}{l}\text { Encinares, } \\
\text { robledales }\end{array}$ \\
\hline Sierras & Pizarras, granitos & $\begin{array}{l}\text { Graníticos, } \\
\text { pizarras }\end{array}$ & $\begin{array}{l}\text { Subhúmedo } \\
\text { Húmedo (800- } \\
1500 \text { mm) }\end{array}$ & $\begin{array}{c}\text { Robledales, } \\
\text { encinares, pinares, } \\
\text { castañares } \\
\end{array}$ \\
\hline $\begin{array}{c}\text { Valles } \\
\text { mediterraneizados }\end{array}$ & Pizarras, granitos & $\begin{array}{l}\text { Graníticos, } \\
\text { pizarras }\end{array}$ & $\begin{array}{l}\text { Subhúmedo } \\
\text { (600-1000 mm) }\end{array}$ & $\begin{array}{c}\text { Complejos } \\
\text { mediterráneos } \\
\text { (alcornocales, } \\
\text { madroñales, } \\
\text { enebrales, } \\
\text { encinares) }\end{array}$ \\
\hline
\end{tabular}

Tabla 2.1. Relación entre comarcas naturales, roca, suelos, ombroclima y vegetación (Adaptado de Llorente, 1980 y Dorronsoro, 1992) 


\subsection{Biogeografía}

El territorio administrativo que comprende la provincia de Salamanca se incluye en su totalidad en el seno de la Región Mediterránea y la subregión Mediterránea Occidental (Rivas-Martínez et al., 2002). Esta delimitación provincial comprende, desde la perspectiva biogeográfica, áreas muy diversas en aspectos climáticos, geológicos, edafológicos y topográficos que permiten, junto con las diferentes formaciones vegetales y una amplia biodiversidad florística, delimitar dos provincias biogeográficas, cuyas divisiones están muy alejadas de las fronteras administrativas que conocemos.

Así, en lo biogeográfico, la provincia que ocupa un área mayor es la Mediterráneo Ibérica Occidental, cuyas señas de identidad más destacables son el dominio de sustratos silíceos y la presencia del termotipos mesomediterráneos (en la subprovincia LusoExtremadurense), supramediterráneos y oromediterráneos, y en zonas más elevadas se encuentra el piso bioclimático crioromediterráneo, de área muy reducida. La segunda provincia, la Mediterránea Ibérica Central, coincide con amplias zonas de la Armuña y el Campo de Peñaranda, que tienen como termotipo dominante el supramediterráneo.

\subsection{Clima}

El clima constituye, junto con la influencia secundaria del relieve, el factor natural más importante para la vegetación, según se refleja en la Tabla 2.1. En general, el clima del área de estudio es templado frío continental (Capel, 1981), que atendiendo a Rivas-Martínez y colaboradores (2004), podría definirse también como un bioclima mediterráneo pluviestacional-oceánico, junto a un bioclima temperado oceánico submediterráneo en ciertas áreas montañosas meridionales. Esto indica que existe una mayor influencia atlántica hacia el oeste y el sur de la provincia, y un grado de continentalidad más acusado hacia el norte y el este, que conlleva menor pluviosidad y temperatura.

\subsection{Paisaje vegetal}

La vegetación que potencialmente influye en el contenido polínico de la atmósfera de la ciudad de Salamanca se puede estructurar en tres grupos: la vegetación natural, representada en diferentes series potenciales de vegetación, la flora cultivada y la flora ornamental de la ciudad. 


\subsubsection{Vegetación natural}

Realizaremos unas consideraciones generales sobre la vegetación potencial presente dentro del territorio que, administrativamente, comprende la provincia de Salamanca, y que aparecen distribuidas gráficamente en la Figura 2.2. No obstante, no debe obviarse la influencia de la vegetación existente en provincias administrativas próximas, como los pinares existentes en la provincia de Ávila o Valladolid, e incluso de zonas más lejanas donde diferentes especies anemófilas pueden hacer llegar sus granos de polen hasta el captador, como puede ser el caso de los cultivos olivareros en regiones meridionales.

Para describir las principales series climatófilas de vegetación, esto es la vegetación en suelos o medios no excepcionales (como turberas, laderas abruptas...), presentes en la provincia de Salamanca (Rivas-Martínez, 1987) seguiremos las delimitaciones biogeográficas indicadas, tal y como muestra la Tabla 2.2.

En diversas zonas de la Sierra de Gata y en la fosa del Alagón, pertenecientes al Sector Toledano-Tagano (Subprovincia Luso-Extremadurense) existe un melojar con madroños (Arbutus unedo L.) y durillos (Viburnum tinus L.), de la serie Arbuto-Querceto pyrenaicae, en zonas menos expuestas al sol, como son las umbrías frescas y húmedas del piso mesomediterráneo. Este melojar lleva un cortejo florístico propio de matorrales esclerófilos y mediterráneos, como Asparagus acutifolius L., Asplenium onopteris L., Osyris alba L., Phyllirea angustifolia L., Pistacia terebinthus L. o Ruscus aculeatus L. En estas mismas áreas, pero a menor altitud y en zonas más soleadas, surgen alcornocales de Sanguisorbo agrimonioidis-Quercetum suberis, aunque, debido a la proximidad de ambas series, podemos encontrarnos zonas de contacto que desarrollan bosques mixtos de melojos y alcornoques. Además, sobre pizarras se desarrolla un encinar de Pyro bourgeanae-Querceto rotundifoliae, que lleva como especies acompañantes más significativas Olea europaea L. var. sylvestris y J asminum fruticans $\mathrm{L}$.

En la Subprovincia Carpetano-Leonesa, el Sector Bejarano Gredense desarrolla, en sus más altas cumbres crioromediterráneas, sobre crestas, espolones y rellanos rocosos de escasa cobertura nival, la serie Agrostio rupestris-Armerieto bigerrensis, caracterizada por la ausencia de Festuca indigesta Boiss., propia de otras zonas del Sistema Central, y por la presencia de Agrostis rupestris All., Armeria bigerrensis (Pau ex C. Vicioso \& Beltrán) Rivas Martínez o Jasione crispa subsp. centralis (Rivas Martínez) Rivas Martínez, coincidiendo en laderas situadas al Norte. 


\begin{tabular}{|c|c|c|c|}
\hline Provincia & Subprovincia & Sector & Serie climatófila \\
\hline $\begin{array}{l}\text { Mediterranea } \\
\text { Ibérica Central }\end{array}$ & Castellana & Castellano duriense & Junipero thuriferae-Querceto rotundifoliaes. \\
\hline \multirow{4}{*}{$\begin{array}{l}\text { Mediterránea } \\
\text { Ibérica } \\
\text { Occidental }\end{array}$} & \multirow{3}{*}{$\begin{array}{l}\text { Carpetano- } \\
\text { Leonesa }\end{array}$} & Bejarano Gredense & $\begin{array}{c}\text { Agrostio rupestris-Armerietum biguerrensis S. } \\
\text { Cytiso oromediterranei-Equinosparteto pulviniformis S. } \\
\text { Luzulo forsteri-Querceto pyrenaicaes. } \\
\text { Holco molli-Querceto pyrenaicaes. } \\
\text { (Junipero oxycedri-Querceto rotundifoliae S.) }\end{array}$ \\
\hline & & Salmantino & $\begin{array}{c}\text { Cytiso oromediterranei-Equinosparteto pulviniformis S. } \\
\text { Holco molli-Querceto pyrenaicaes. } \\
\text { Genisto falcatae-Querceto pyrenaicaes. } \\
\text { Genisto hystricis-Queceto rotundifoliaes. } \\
\text { (Junipero oxycedri-Querceto rotundifoliae S.) }\end{array}$ \\
\hline & & Lusitano-Duriense & $\begin{array}{l}\text { Genisto hystricis-Querceto rotundifoliaes. } \\
\text { Genisto falcatae-Quercetum pyrenaicaes. } \\
\text { Sanguisorbo agrimonioides-Querceto suberis S. }\end{array}$ \\
\hline & $\begin{array}{l}\text { Luso- } \\
\text { Extremadurense }\end{array}$ & Toledano-Tagano & $\begin{array}{c}\text { Arbuto-Querceto pyrenaicaes. } \\
\text { Pyro bourgeanae-Querceto rotundifoliaes. } \\
\text { Sanguisorbo agrimonioides-Querceto suberis S. }\end{array}$ \\
\hline
\end{tabular}

Tabla 2.2. Series climatófilas de vegetación principales en la provincia de Salamanca. (Adaptado de RivasMartínez, 1987 y Rivas-Martínez et al., 2002).

A menor altura, en el piso oromediterráneo, vegeta la serie del piorno serrano, Cytiso oromediterranei-Echinosparteto pulviniformis, que, al aclararse, puede dar lugar a la aparición de Festuca indigesta Boiss. o Jasione crispa subsp. sessiliflora Boiss. \& Reuter, entre otras. Mientras, en el supramediterráneo, domina la serie subhúmeda de roble melojo, Luzulo forsteri-Querceto pyrenaicae, caracterizada por la presencia de Cephalantera longifolia (L.) Fritsch., Luzula forsteri (Sm.) DC., Melittis melisophyllum L., Physospermum cornubiense (L.) DC. junto con algunos elementos neutrófilos, como pueden ser Lilium martagon L., Melica uniflora Retz. o Milium vernale Bieb., entre otros

La serie climácica Genisto hystricis-Querceto rotundifoliae se corresponde con un encinar abierto, y suele situarse entre la de los melojares Genisto falcatae-Querceto pyrenaicae. Ocupa grandes áreas de los sectores Salamantino y Lusitano-Duriense, habiendo sido, en la mayoría de los casos, objeto de una intensa explotación ganadera, que ha conducido a un adehesamiento, y ha dado lugar a uno de los paisajes más típicos de todo el occidente castellano-leonés. Dentro de la misma subprovincia corológica y del Sector Lusitano-Duriense, existe, en zonas escarpadas de los Arribes del Duero, la serie de alcornocales Sanguisorbo agrimonioidis-Quercetum suberis, pero a diferencia de los presentes en el valle del Alagón, está acompañada por enebrales de Juniperus oxycedrus L. En zonas algo menos accidentadas, se desarrolla la serie de encinares Genisto hystricisQuercetum rotundifoliae, al igual que pequeñas manchas de la serie del roble melojo Genisto falcatae-Quercetum pyrenaicae.

También destacaremos en la Subprovincia Carpetano-Leonesa, melojares pertenecientes a la asociación Holco molli-Querceto pyrenaicae, caracterizada por la 
presencia de Aquilegia vulgaris L. y Erythronium dens-canis L., entre otras, y por varias especies nemorales acidófilas comunes con otros melojares supramediterráneos, como Galium verum L., Genista falcata Brot., Holcus mollis L., Potentilla montana Brot., o Vincetoxicum nigrum (L.) Moench. Los encinares continentales de la serie Junipero oxycedri-Querceto rotundifoliae, localizados en el este provincial, son muy escasos, empezando a ser abundantes ya en Ávila coincidiendo con la aparición de un relieve más quebrado.

La Subprovincia Castellana (Provincia Mediterránea Ibérica Central) con un solo sector representado aquí, el Castellano Duriense, tiene una presencia importante al noreste de la ciudad de Salamanca, y se caracteriza por suelos básicos. Su potencialidad se correspondería con la serie Junipero thuriferae-Querceto rotundifoliae, que está representada por muy escasos encinares, como por ejemplo el de La Orbada, ya que el resto de los territorios de esta subprovincia se dedica a cultivos mesegueros y de leguminosas.

Finalizando con esta sucinta referencia a la vegetación de la provincia de Salamanca, indicaremos algunos aspectos de las comunidades riparias. Así, surgen formaciones, en ocasiones mixtas, de fresnos (Fraxinus angustifolia Vahl.), alisos (Alnus glutinosa Gaertn.), saúces (Salix fragilis L. y Salix atrocinerea Brot.), chopos (Populus nigra L. y Populus alba L.) y, en menor medida, olmos (Ulmus minor Mill.).

\subsubsection{Flora cultivada y repoblaciones}

Como se ha señalado con anterioridad, los cultivos herbáceos de cereales (trigo, cebada, centeno, maíz) y de leguminosas (lentejas, garbanzos, alubias) localizados hacia el noreste de la provincia, son los que mayor extensión alcanzan (Bellot et al., 1966). Asimismo, dentro de los cultivos de diferentes especies árboreas, es reseñable, a pesar de su su posible origen natural según estudios paleopalinológicos y moleculares (Fineschi et al., 2000), el castaño hacia el sur de la provincia (Castanea sativa Mill.), y el olivo (Olea europaea L.), en los valles mediterraneizados, sobre todo en la zona de Arribes del Duero. Haciendo una breve referencia a las diferentes repoblaciones, debemos destacar los pinares, fundamentalmente de pino resinero (Pinus pinaster Aiton.), pino silvestre (Pinus sylvestris L.), al sur y el oeste de la provincia, y de pino piñonero (Pinus pinea L.), hacia el norte y el este. No debemos olvidar la importancia, en ciertas zonas del sur de la provincia, de repoblaciones de eucalipto (Eucaliptus camaldulensis Dehnh., entre otros) y de chopos (Populus alba L. y Populus x canadiensis Moench., como principales especies) hacia el noreste. 


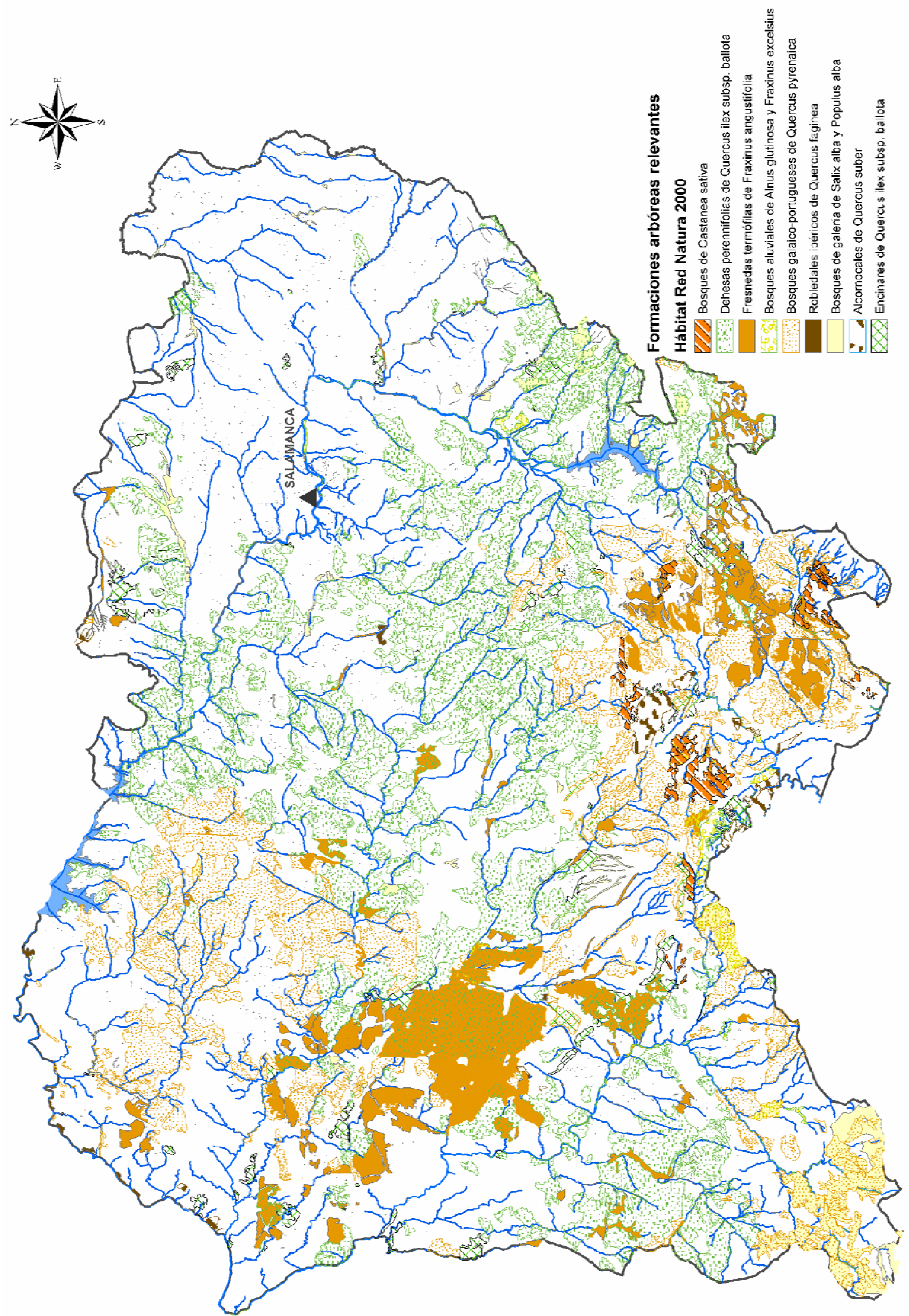

Fig. 2.2. Principales formaciones arbóreas naturales de la provincia de Salamanca. 


\subsubsection{Flora ornamental urbana}

La ciudad de Salamanca presenta una serie de espacios verdes presididos por pequeñas plazas en el centro de la ciudad, como la Plaza de los Bandos o la Plaza de la Libertad, y parques en las rondas del casco urbano, como el Parque de La Alamedilla, el Parque de los Jesuitas o el Parque de Wüzburg (Costa et al., 1985).

El elemento ornamental más abundante en el municipio corresponde al arbolado de alineación, presidido por el plátano de sombra (Platanus hispanica Mill. ex Münchh.) y el arce de hoja de fresno (Acer negundo L.), según datos del Servicio de Parques y Jardines del Excmo. Ayuntamiento de Salamanca, junto al chopo blanco (Populus alba L.) en zonas próximas al río Tormes, que bordea el sur de la ciudad (Tabla 2.3).

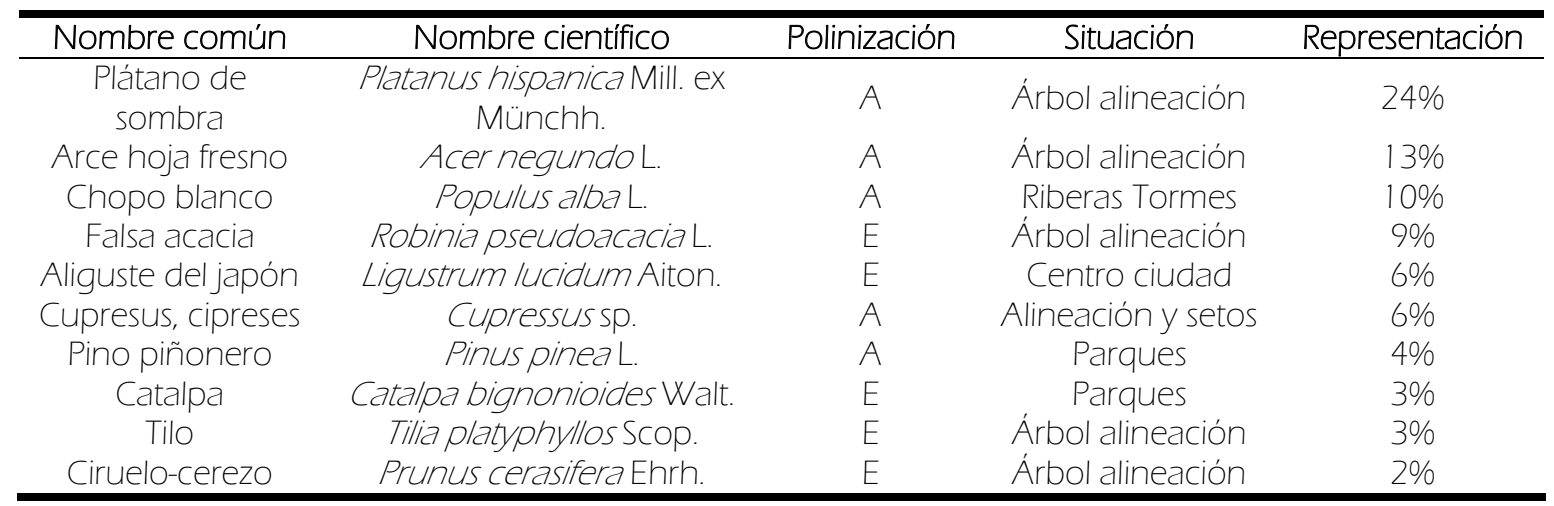

Tabla 2.3. Principales especies ornamentales de la ciudad de Salamanca, tipo de polinización (A anemófila; E entomófila), situación en el núcleo urbano y porcentajes de representación sobre el total. (Elaboración propia a partir de datos del Excmo. Ayto. de Salamanca, año 2003).

Resulta interesante poner de manifiesto el carácter anemófilo de los tres elementos arbóreos más abundantes dentro del núcleo urbano, puesto que el elemento arbóreo con carácter entomófilo más abundante corresponde a la falsa acacia (Robinia pseudoacacia L.), utilizado fundamentalmente como elemento de alineación en algunas calles y avenidas, seguido del aligustre del japón (Ligustrum lucidum Aiton.), de relativa abundancia en calles peatonales del centro de la ciudad y en nuevas zonas residenciales. Otros elementos arbóreos importantes, tanto en número como por su carácter anemófilo, en el entorno urbano vienen denominados por el Servicio de Parques y Jardines como Cupressus sp. En este género arbóreo se incluyen varias especies como Cupressus arizonica Greene., Cupressus lusitanica Mill., Cupressus macrocarpa Hartw., y sobre todo, Cupressus sempervirens L., citadas en la provincia de Salamanca (Romero \& Velasco, 1997). Reseñar también la presencia de pino piñonero (Pinus pinea L.), aunque gran número de ellos con escaso porte y edad que limitan enormemente su producción polínica, catalpas (Catalpa bignoniodes Walt.) y tilos (Tilia platyphyllos Scop.). En los últimos años se han instalado en diversas zonas del centro peatonal de la ciudad numerosos ejemplares de cerezo-ciruelo (Prunus cerasifera Ehrh.) y de 
castaño de indias (Aesculus hippocastanum L.), mientras que en rotondas y otros elementos viarios del entorno urbano se localizan olivos (Olea europaea L.) de cierto porte y avanzada edad. 

Justificación y objetivos 



\subsection{J ustificación}

El aumento de la contaminación del aire en las últimas décadas y el consiguiente incremento en el número de problemas ambientales y sanitarios, han desembocado en una mayor preocupación de la población y de los organismos públicos y privados hacia dichos problemas. Uno de los elementos presentes en el aire, el polen, es causa fundamental de problemas alérgicos (Leuschner et al., 2000), siendo de gran interés conocer, no sólo cuáles son los granos de polen alergógenos presentes en la atmósfera, sino también aquellos que, a pesar de su escasa representatividad, puedan ser causantes de sintomatologías alérgicas o de fenómenos de reactividad cruzada (Weber, 2003). Los principales tipos polínicos que presentan alérgenos responsables de procesos alérgicos se adscriben a especies anemófilas (D'Amato, 2001), puesto que su mecanismo de polinización favorece que alcancen elevados niveles en el aire en determinadas épocas. Además, y pese a que las esporas de pteridófitos sean elementos biológicos poco frecuentes y/o raros en la atmósfera (Kasprzyk, 2004), han aparecido estudios que reflejan la carcinogenicidad de esporas de Pteridium aquilinum (L.) Kuhn. (Freitas et al., 2001) y el posible riesgo para la salud pública debido a la inhalación o ingestión de las mismas (Wilson et al., 1998).

La realización de muestreos diarios a lo largo del período 2000-2007 ha permitido analizar el contenido de polen y esporas de pteridófitos en la ciudad de Salamanca durante los años referidos. Este análisis va a conllevar consigo una explicación de las tendencias de estas partículas biológicas, su posible aumento y modificación en la estacionalidad de algunas de ellas. Además, es interesante valorar la influencia de los parámetros meteorológicos sobre los niveles de partículas aerovagantes de origen biológico y evaluar las diferencias existentes en estos aspectos entre dos captadores situados en diferentes zonas de la ciudad de Salamanca, así como la incidencia en los cuadros clínicos de pacientes alérgicos a diferentes alérgenos contenidos en los diferentes tipos de polen.

\subsection{Objetivos}

Los objetivos que se plantean son los siguientes:

- $\quad$ Estudiar el comportamiento aerobiológico de los distintos tipos de polen presentes en la atmósfera de la ciudad de Salamanca, a lo largo de ocho años de estudio (2000-2007), evaluando su comportamiento interanual, estacional, diario y horario, este último en el trienio 2005-2007. 
- Analizar la evolución de las variables climatológicas durante la misma serie de años, para conocer su influencia sobre la intensidad y la estacionalidad de los diferentes tipos polínicos y los táxones que los producen.

- $\quad$ Establecer el inicio y la duración del período principal de polinización (PPP) de cada uno de los tipos de polen más importantes, mediante diversas propuestas para poder determinar la severidad del mismo y valorar la existencia de alteraciones o de estabilidad cíclica en el período de estudio.

- Comprobar el posible incremento de polen en la atmósfera de la ciudad de Salamanca durante los años de estudio, así como conocer a qué táxones es debido y evaluar las tendencias a largo plazo.

- Evaluar las posibles diferencias en el contenido polínico del último año de estudio entre el captador utilizado para conformar la serie de datos 2000-2007 y otro situado en un emplazamiento distinto en la misma ciudad.

- Estudiar el comportamiento aerobiológico de los tipos de esporas de pteridófitos localizados en la ciudad de Salamanca, a lo largo de diez años de estudio (1998-2007), dilucidando su comportamiento interanual, estacional, diario y horario, y la influencia las variables climatológicas en dicho comportamiento.

- Comprobar el porcentaje de sensibilización a diferentes alérgenos de polen en una muestra poblacional de Salamanca mediante la valoración de la cantidad de IgE específica frente a diversos alérgenos recombinantes en el suero del paciente y mediante los resultados de las pruebas intraepidérmicas. 
4

Material y métodos 



\subsection{Metodología de muestreo en los estudios aerobiológicos}

\subsubsection{Toma de muestras}

El periodo de muestreo de la atmósfera de la ciudad de Salamanca comprende el 1 de enero del año 2000 hasta el 7 de febrero de 2008, mediante el uso de un captador volumétrico tipo Hirst "Burkard spore trap 7-days recorder" (Fig. 4.1.A.) situado en la azotea del edificio que alberga el Patronato Municipal de la Vivienda del Excmo. Ayto. de Salamanca, enclavado en el centro histórico de la ciudad. Este captador se halla a 20 metros de altura y, debido a su peculiar emplazamiento, existen edificios colindantes que pueden ejercer un efecto pantalla o un efecto pasillo, y tergiversar de algún modo el registro de las concentraciones polínicas atmosféricas. Por este motivo, se utilizó un segundo captador tipo Hirst "Lanzoni VPPS 2000" (Fig. 4.1.B.), en la azotea de la Facultad de Farmacia de la Universidad de Salamanca (en el sur de la ciudad, próximo al río Tormes), a 25 metros de altura, y libre de edificaciones que pudieran ejercer este tipo de efectos desde el 1 de febrero del año 2007 al 7 de febrero de 2008, y así poder comparar los resultados obtenidos con ambos captadores. En el caso de las esporas de pteridófitos, el período de estudio fue más amplio (1998-2007), debido a sus bajas concentraciones en la atmósfera y su particular condición que le hace claramente diferente al análisis de los granos de polen, como veremos posteriormente.
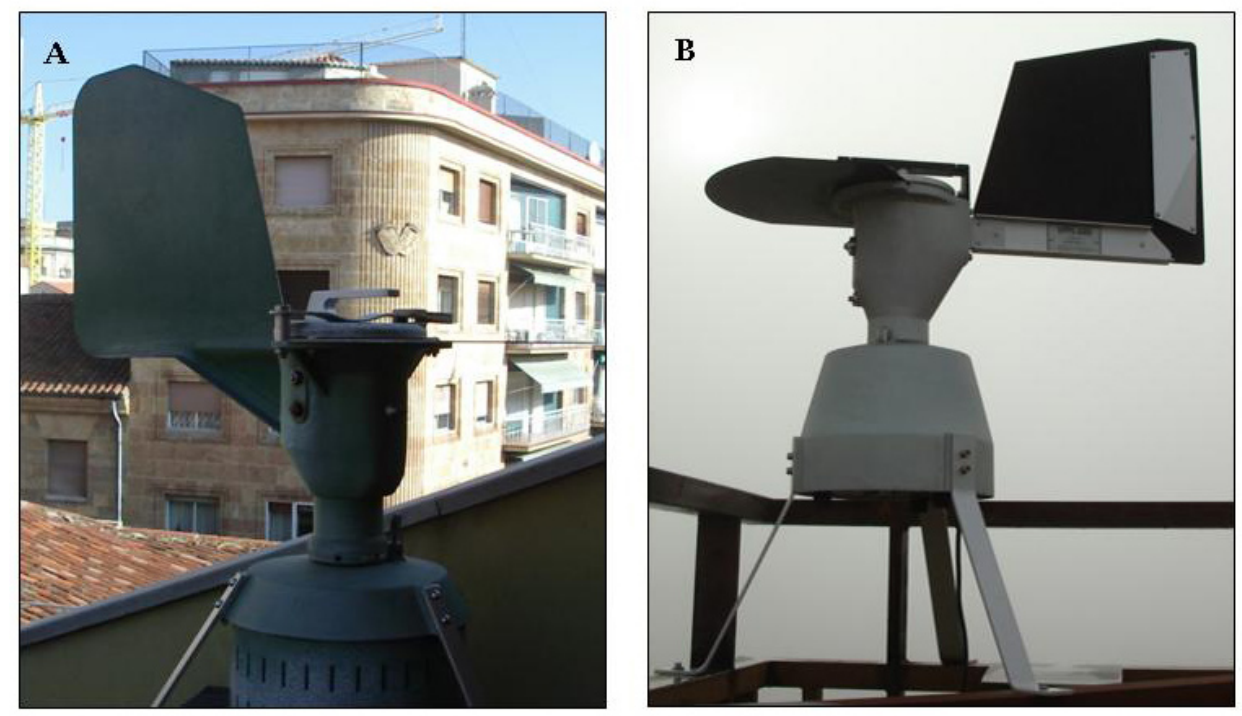

Fig. 4.1. Captadores volumétricos tipo Hirst. A. Burkard 7-days recorder. B. Lanzoni VPPS 2000.

El funcionamiento de ambos captadores es idéntico, respondiendo al prototipo que describió Hirst (1952), y por tanto, pasamos a hablar de sus componentes y características de manera conjunta. Así pues, en ambos casos, encontramos un cuerpo central, cabezal o 
unidad de impacto donde se sitúa una ranura de $2 \mathrm{~mm}$ de ancho y $14 \mathrm{~mm}$ de largo, que hemos mantenido limpia durante el período de estudio para evitar obstrucciones, y justo encima, una visera de protección semicircular. En el interior de este cabezal se dispone un tambor que mueve la cinta de muestreo debido a su conexión con un mecanismo de relojería que otorga una rotación de $2 \mathrm{~mm} /$ hora y completa su ciclo giratorio al cabo de 7 días. Este cuerpo central se abre por la parte superior y lleva acoplada una pieza donde está instalado el mecanismo de relojería y donde podremos incluir el tambor con la cinta transparente.

La cinta transparente de poliéster (Melinex) de $14 \mathrm{~mm}$ de ancho y $373 \mathrm{~mm}$ (en los productos comerciales en los que ya viene cortada) se coloca entre las marcas de inicio y fin de tambor impregnada con una capa fina y homogénea de una sustancia adhesiva, que en el caso del modelo Burkard se trató de vaselina filante y en el modelo Lanzoni de solución de silicona. Transcurridos siete días, la cinta con el registro de partículas aerovagantes es sustituida por una nueva cinta. Dicho registro de partículas se consigue a través un motor situado en la parte inferior del captador, compuesto por una bomba de vacío que aspira un volumen de 10 litros de aire por minuto y que está conectado a una fuente de alimentación eléctrica externa. Al igual que ocurría con la ranura de entrada, hemos mantenido en un estado correcto de limpieza el motor para evitar cualquier tipo de obstrucción y hemos comprobado con la ayuda de un caudalímetro que el volumen de aire succionado sea de 10 l/min.

\subsubsection{Preparación de las muestras}

La preparación de las muestras diarias, realizada tras el cambio del tambor, se elaboró de acorde a los siguientes pasos, siguiendo las normas establecidas (Domínguez et al., 1991; Galán et al., 2007) por la Red Española de Aerobiología (R.E.A.):

- La cinta transparente se fragmenta, con ayuda de una regla de metacrilato, en 6 trozos de $48 \mathrm{~mm}$, propios a seis días naturales, y otros dos de menor longitud, 18 y $30 \mathrm{~mm}$, correspondientes al día elegido para el cambio, en este caso, y siempre que fue posible, los lunes a las 9:0o horas, en el caso del captador Burkard. Para el captador Lanzoni VPSS 2000, el cambio se realizó el mismo día pero una hora más tarde, obteniendo dos fragmentos de 20 y $28 \mathrm{~mm}$.

- Cada uno de estos fragmentos se monta en un portaobjetos y sobre un medio de glicerogelatina con fucsina, previamente licuada, durante 10 minutos al baño maría a $80^{\circ}$ C. Esta glicerogelatina con fucsina se elabora a partir del tradicional protocolo que indica que se caliente en un vaso de precipitado la gelatina en escamas junto al agua destilada, y una vez fundida esta, se añada la glicerina hasta obtener una 
solución homogénea a la que se le adiciona fenol y por último varias gotas de fucsina básica. Los componentes de glicerogelatina y fucsina básica se indican a continuación:

\begin{tabular}{c|c} 
Glicerogelatina & Fucsina básica \\
\hline $50 \mathrm{ml}$. Glicerina pura & $0,1 \mathrm{~g}$ fucsina básica(escamas) \\
$42 \mathrm{ml}$ de agua destilada & $10 \mathrm{ml}$ alcohol etílico \\
$7 \mathrm{~g}$ de gelatina & $10 \mathrm{ml}$ agua destilada \\
$1 \mathrm{~g}$ de ácido fénico &
\end{tabular}

- Las preparaciones se etiquetan con la fecha correspondiente al muestreo en la parte izquierda del portaobjetos, desde donde se comenzará a realizar el conteo. Con una pipeta Pasteur se depositan en el portaobjetos unas cuantas gotas de glicerogelatina con fucsina, y luego, utilizando unas pinzas de punta fina se coloca el fragmento de cinta indicado. Después, se vuelven a añadir unas gotas en un cubreobjetos que se coloca sobre el fragmento de cinta con cuidado para que no se formen burbujas de aire y se extienda bien la sustancia colorante. Por último y una vez solidificada la glicerogelatina a temperatura ambiente, se introducen las preparaciones al frigorífico durante cinco o diez minutos a $4{ }^{\circ} \mathrm{C}$, y luego se sellan las muestras con esmalte transparente, que evitará contaminaciones y las preservará más tiempo.

\subsubsection{Análisis cuantitativo y cualitativo}

Las muestras diarias obtenidas se analizan al microscopio óptico Nikon Optiphot II, realizando cuatro barridos de izquierda a derecha con el objetivo 40x y ocular 10x, identificando los diferentes granos de polen y esporas de pteridófitos que aparecen, gracias a la palinoteca del Departamento de Botánica y a ilustraciones, claves y descripciones de polen y esporas (Erdtman, 1966; Valdés et al., 1987; Grant Smith, 2000; La Serna \& Domínguez, 2003; Trigo et al., 2008a). Asimismo, el reconocimiento de las especies vegetales más representativas al entorno del captador junto a sus caracteres ecológicos y fenológicos (Sánchez-Barbudo, 1991; Rico, 1992; entre otros), ha sido indispensable para valorar el grado de determinación a nivel polínico, esto es, si se adscribe a una especie, un género o una familia botánica y, además, ha sido de gran utilidad a la hora de explicar la presencia o ausencia de determinados tipos de polen en la atmósfera.

Para el análisis cuantitativo se utiliza un "Muestreo no probabilístico de Conveniencia”, que como hemos señalado antes, dispone realizar cuatro barridos horizontales que suponen entre el 12 y el 13\% de la superficie diaria muestreada, y que supera el 10\% que recomienda la European Aeroallergen Network (EAN). En todo caso, hemos adoptado el método descrito por la Red Española de Aerobiología (R.E.A.) que propone extrapolar el área total impactada multiplicando por un "factor de corrección" que permita 
expresar los datos en "número de granos de polen por metro cúbico de aire" (granos de polen $/ \mathrm{m}^{3}$ de aire) (Domínguez et al., 1991; Galán et al., 2007). La obtención del mencionado factor se obtiene tal y como se muestra en la Figura 4.2, y en nuestro caso es igual a o,64.

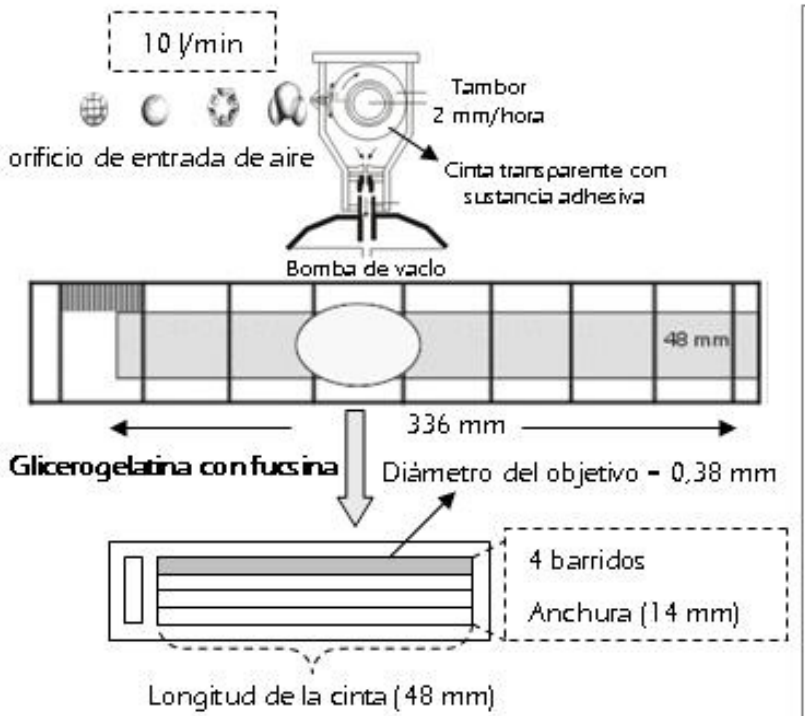

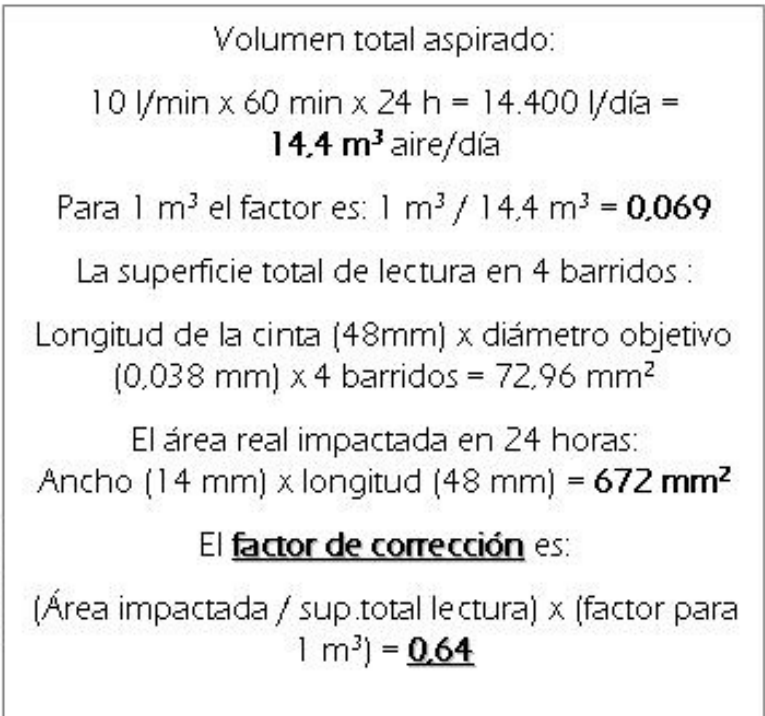

Fig. 4.2. Toma y análisis cuantitativo de las muestras. Obtención del factor de corrección.

Este método permite el estudio de las variaciones diarias, semanales, mensuales y anuales de los diferentes granos de polen y esporas de pteridófitos. La evaluación de las variaciones intradiarias se realizó desde el 1 de enero de 2005 hasta el 7 de febrero de 2008 en el captador situado en el centro histórico de la ciudad, y en todo el período analizado del captador localizado en el sur de la ciudad. Este análisis horario se realizado con la ayuda de una plantilla impresa sobre papel de acetato, que consta de 25 líneas transversales separadas entre sí por $2 \mathrm{~mm}$ de distancia, diferenciándose así las 24 horas del día, y permitiéndonos obtener el número de granos de polen por metro cúbico de aire cada hora. Los datos se anotan en unas hojas de recuento diseñadas para nuestro estudio (Fig. 4.3. y Fig. 4.4.). En la primera de ellas (Fig. 4.3.), diseñada para el recuento diario de pólenes y esporas de pteridófitos, los días correspondientes a una semana se muestran en horizontal, mientras que en vertical se disponen los diferentes tipos de polen y esporas de pteridófitos más comunes en la atmósfera de Salamanca (teniendo en cuenta la experiencia de años anteriores), dejando unos espacios en blanco para otros tipos. En la segunda (Fig. 4.4.), la disposición vertical es la misma, y en horizontal se disponen las veinticuatro horas correspondientes a un día. Asimismo, en ambas hojas de recuento se indica la estación de control a la que pertenece (sólo hubo una estación para todo el período estudiado salvo los últimos 372 días con dos estaciones), el número total de granos (por día, y también por semana o por horas, en cada una de las dos figuras), el factor de corrección empleado y la fecha de la muestra a analizar (semanas en la primera, días en la segunda). 


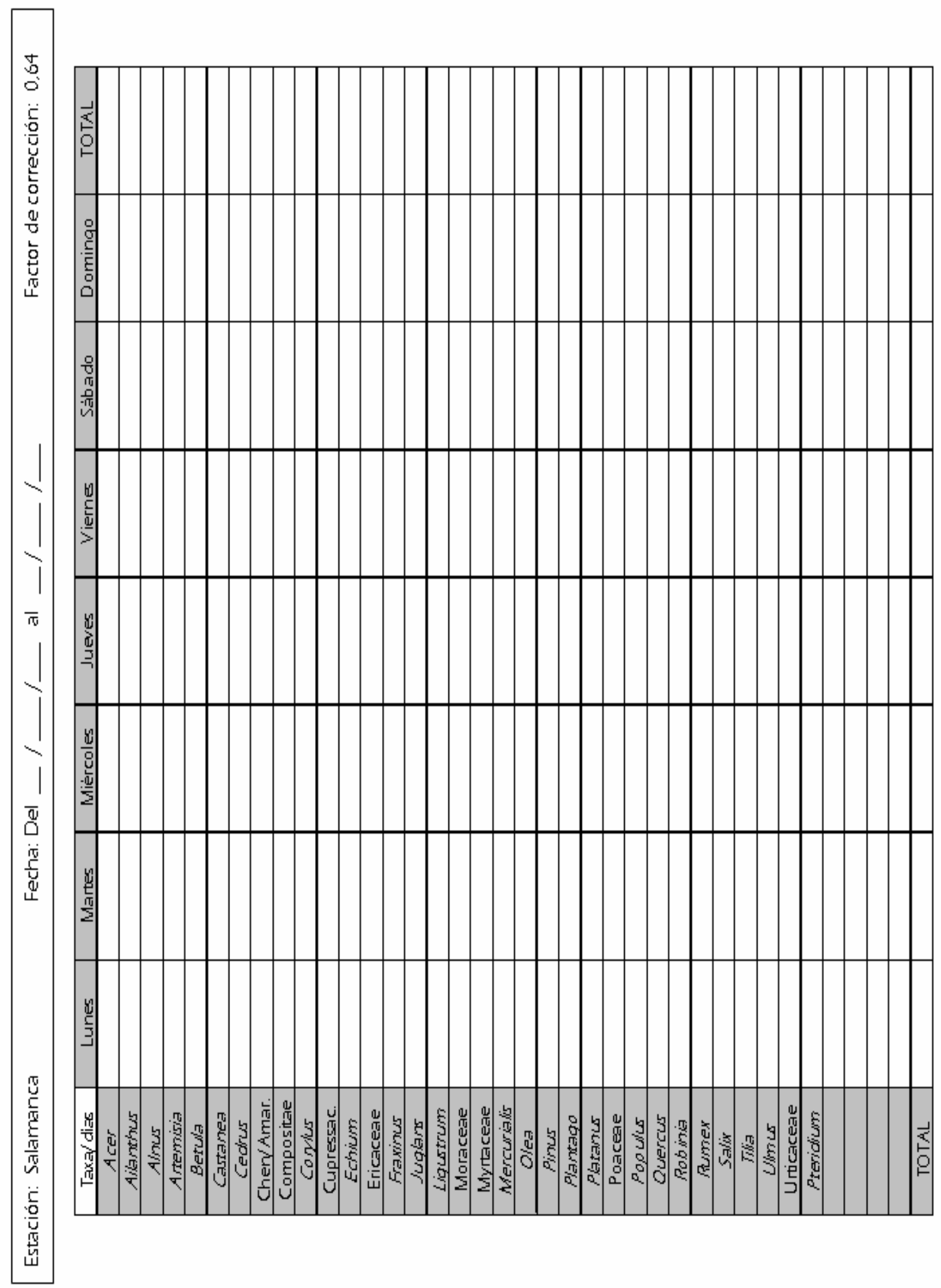

Fig. 4.3. Plantilla diaria/semanal utilizada en el período 2000-2004. 


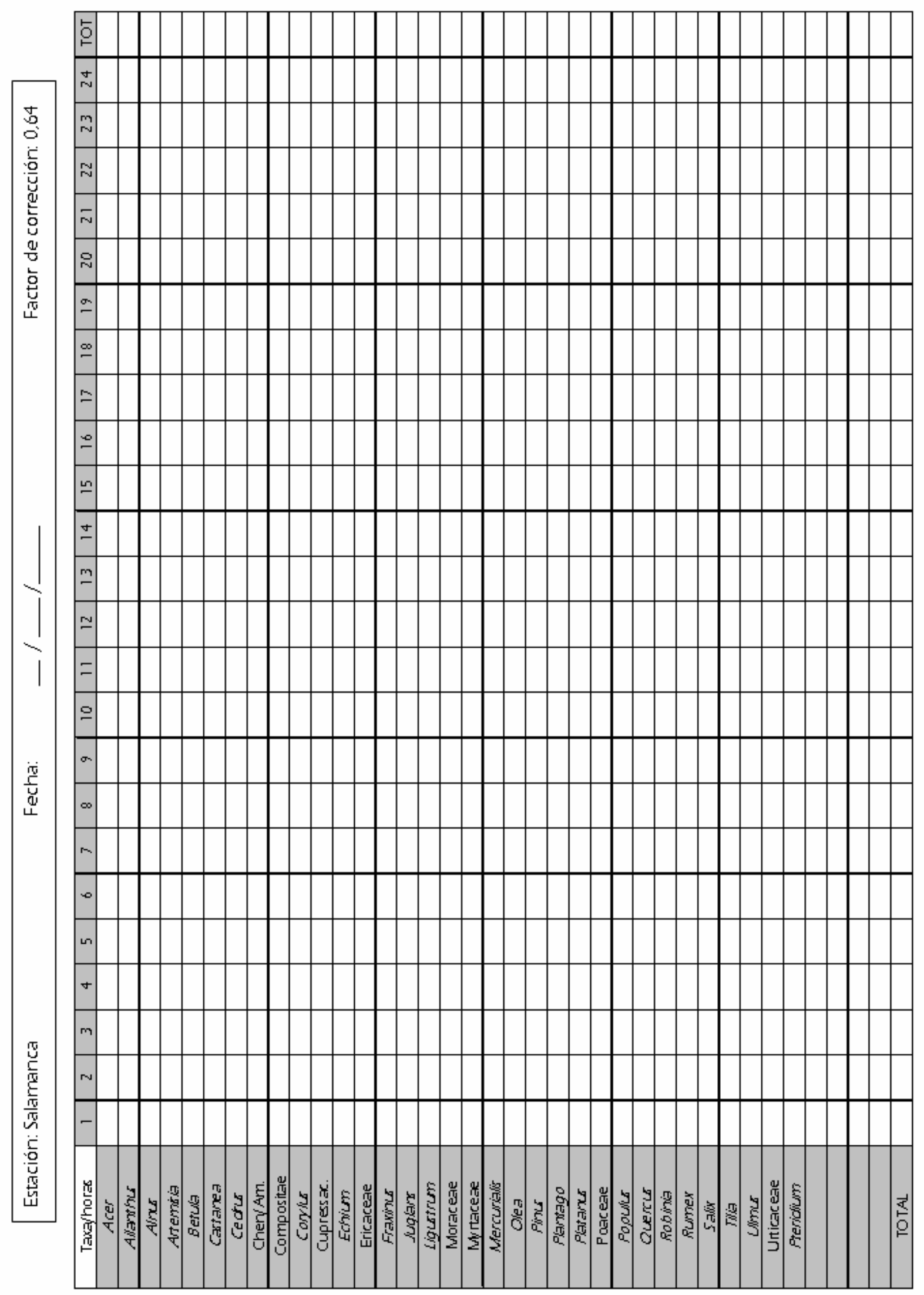

Fig. 4.4. Plantilla horaria/diaria utilizada en el período 2005-2007. 


\subsubsection{Presentación de los datos}

En el estudio de los diferentes tipos de polen identificados e incluidos en esta memoria de Tesis Doctoral, se han establecido cinco grupos atendiendo a la representatividad, expresado en el porcentaje sobre el total anual de cada uno de los años analizados, en el espectro polínico total. El primero de ellos se formalizó utilizando como umbral el 1\% de representatividad sobre el total anual en, como mínimo, cinco de los ocho años englobados en el período de estudio, incluyendo en el segundo grupo a aquellos tipos que superaron o igualaron este umbral en, al menos, un año y no alcanzando los cinco años. El resto de grupos ha englobado todos aquellos tipos con una representación superior o igual al $0,5 \%$ y al o,1\% (este último, al menos tres años), respectivamente, quedando un último grupo que incluyó a los tipos de polen con una representación inferior al o,1\%.

\subsubsection{Presentación numérica}

El estudio aerobiológico de los tipos polínicos que alcanzan o superan el $1 \%$ de representatividad en, al menos, cinco de los ocho años, incluye la dinámica de variación estacional e intradiaria, esta última sólo para las tres últimas anualidades estudiadas (20052007), y hace necesario determinar la estación polínica y acotar el período principal de polinización (PPP), tomando esta denominación más tradicional, a pesar de la reciente recomendación de utilizar el término estación polínica atmosférica (Jato et al., 2006). En este caso, hemos adoptado tres métodos diferentes, por su mayor difusión en los trabajos aerobiológicos, y que se basan en porcentajes sobre el total anual de cada uno de los tipos de polen a analizar. Así pues, el primero de ellos (Nilsson \& Persson, 1981) define el PPP como aquel período en el que se concentra el 90\% del total del polen acumulado para cada tipo de polen, estableciendo como día de comienzo del PPP el día en el que las concentraciones medias diarias acumuladas alcanzan el 5\% y como día final aquel en el que dichas concentraciones logran el 95\%. En el segundo (Andersen, 1991), el PPP es definido como el 95\% del total de polen anual, mientras que los días de inicio y fin de dicho PPP se establecen en los días en que las concentraciones acumuladas alcanzan el 2,5 y el 97,5, respectivamente. En el último de ellos (Galán et al., 1995), el PPP acumularía la serie de concentraciones al 98\%, dejando los días de inicio y fin correspondientes al 1\% y el 99\% de las medias diarias acumuladas para cada año y cada tipo analizado. Asimismo, en todas los métodos utilizados se definió el período prepico (PRE) como los días que transcurren desde que se inicia la estación polínica principal hasta que se alcanza el valor máximo diario. Con ello se pretende evaluar la incidencia que puedan tener los diversos métodos propuestos para definir el PPP en el posterior análisis estadístico con los parámetros meteorológicos. En el grupo que 
incluye a los tipos de polen con una representación superior o igual al $1 \%$ en un número de años entre uno y cuatro, el PPP y el PRE se definieron a través del método del 95\% del total de polen anual (Andersen, l.c.), teniendo en cuenta el menor número de granos de polen que presentaron los tipos incluidos en dicho grupo, y, por tanto, su menor importancia junto a la posición intermedia del método referido con respecto a los otros dos (90\% y 98\% del total de polen anual), salvo que el total anual fuese inferior a 10 pólenes, ya que este número bajo pudo tergiversar la duración de los mismos. En este mismo punto, dentro los tipos de polen con una representación superior o igual al 0,1\% durante, al menos, tres años, no existió delimitación del PPP y PRE.

Asimismo, cabe señalar que gracias a la media obtenida en cada uno de los días de los ocho años analizados, se definió el PPP y el PRE promedio para cada uno de los tres métodos utilizados, así como su duración.

El análisis estadístico de las concentraciones diarias de aquellos tipos de polen adscritos al primer y segundo grupos, durante todo el período estudiado, y en los PPP y PRE para cada uno de los años y los métodos empleados, con los parámetros meteorológicos más importantes se ha llevado cabo mediante el Test de correlación no paramétrico de Spearman, gracias al paquete informático SPSS, versión 12.o (SPSS Inc., Chincago, IL). Su elección se basa en que las concentraciones de partículas biológicas en la atmósfera no siguen una distribución normal., y la relación entra ambas variables se mide con el coeficiente de correlación de Spearman. Este coeficiente toma valores comprendidos entre -1 y 1, siendo la relación más fuerte cuanto más se aproxime a estos valores. El signo de esta relación nos indica si el aumento de una variable influye incrementando (signo positivo) o disminuyendo (signo negativo) los niveles de partículas biológicas, con diferentes grados de confianza o significación, que oscilan entre el 95\% y el 99\%, denotados con uno $\left(^{*}\right)$ o dos asteriscos $\left(^{* *}\right)$, respectivamente.

Los datos meteorológicos se han obtenido a través de la Agencia Estatal de Meterología (AEMET) en la estación meteorológica más cercana a la ciudad de Salamanca, y por consiguiente, a los lugares en donde fueron emplazados los captadores, la Base Aérea Matacán ( $40^{\circ} 56^{\prime} \mathrm{N} ; 5^{\circ} 29^{\prime} \mathrm{W} ; 790$ m.s.n.m.), situada a 10 kilómetros al este de la ciudad. Asimismo, y de forma puntual, también se tomaron datos de la estación meteorológica de Herguijuela de la Sierra $\left(40^{\circ} 26^{\prime} \mathrm{N} ; 6^{\circ} \mathrm{O} 4^{\prime} \mathrm{W} ; 648\right.$ m.s.n.m.), para evaluar la influencia de los parámetros meteorológicos en zonas próximas a poblaciones de Pteridium aquilinum (L.) Kuhn. Los parámetros meteorológicos utilizados en este estudio han sido: la temperatura media, máxima y mínima diarias (en ${ }^{\circ} \mathrm{C}$ ), la precipitación (en mm), la humedad relativa (en \%), la velocidad media del viento (en $\mathrm{km} / \mathrm{h}$ ), la frecuencia de calmas del viento (en \%), la insolación diaria (en horas) y la frecuencia de vientos del primer, segundo, tercer y 
cuarto cuadrante (IC, IIC, IIIC, IVC, en \%). En el caso de la estación de Herguijuela de la Sierra, sólo estuvieron disponibles, la temperatura media y precipitación total mensual.

Además para obtener un patrón de tendencias se ha realizado un Test de Regresión de tipo lineal que, con un error mínimo, permita conocer el comportamiento interanual de cada uno de los tipos de polen. Hablamos de regresión de una variable en una muestra de $n$ valores (x, y), cuando hay una línea que se ajusta a una nube de puntos, representada numéricamente por el índice de determinación $\mathrm{R}^{2}$ que no es más que el porcentaje de variabilidad que posee cada una de las variables analizadas. La bondad del modelo está delimitada por un valor de $\mathrm{R}^{2}$ próximo a 1 una la significación (Sig.) menor a 0,05.

Para las esporas de pteridófitos se han seguido los mismos criterios utilizados para los diversos tipos de polen, salvo en la determinación del período principal de esporas (PPE), puesto que se ha decidido utilizar el método propuesto por Andersen (l. c.), debido al escaso número de esporas presentes en la atmósfera de Salamanca. Este escaso número, y con objeto de conseguir un mejor y mayor conocimiento de dichas partículas de origen biológico, motivó que en este caso el período de estudio fuese ampliado dos años, de 1998 a 2007, aplicándose el mismo estadístico no paramétrico con los parámetros meteorológicos.

\subsubsection{Presentación gráfica}

El conocimiento de la evolución anual de todos los tipos de polen y esporas incluidos en este trabajo, para el conjunto de los años estudiados, resulta fundamental para evaluar la posible variación del número total de pólenes en la atmósfera de la ciudad de Salamanca, algo que se visualiza gracias a gráficas que incluyen en el eje de abscisas los años de estudio y en el de ordenadas las concentraciones totales de granos de polen o esporas.

La variación estacional se ha analizado mediante la elaboración de dos tipos de gráficas. En la primera de ellas, se configura la dinámica de las concentraciones totales mensuales promedio para el periodo estudiado, expresando en el eje de abscisas los meses del año y en el eje de ordenadas la concentraciones de pólenes o esporas. En la segunda, se incluye una representación gráfica de la media móvil de los cinco días anteriores para el promedio del período 2000-2007 (1998-2007 en el caso de las esporas de pteridófitos), que ayude a interpretar una tendencia general en la evolución polínica y de esporas de pteridófitos. Conviene destacar que, salvo en los tipos incluidos en el primer grupo, dicha media móvil representada en el eje de ordenadas se expresó como el porcentaje diario sobre el total promediado para los ocho años de estudio, debido a las bajas concentraciones obtenidas al realizar las medias móviles para los cinco días anteriores.

Como ya hemos señalado, se ha estudiado la evolución de las partículas biológicas ya mencionadas durante las 24 horas del día en el último trienio analizado. Por tanto, la 
variación intradiaria ha sido evaluada utilizando el porcentaje que representa la suma total anual promedio en cada una de las 24 horas sobre el total anual promedio en el conjunto del día, y dentro del período referido (2005-2007). Conviene reseñar que en los dos últimos grupos en los que hemos agrupado a los diferentes tipos de polen según su representatividad, aquellos que no alcanzaron el $0,5 \%$ en ninguna de las anualidades estudiados, no se realizó este análisis debido a su escaso número y las grandes oscilaciones que pudiera dar en la dinámica intrahoraria de las concentraciones polínicas y esporales. Este modelo ha sido utilizado a pesar de la existencia de otras propuestas (Galán et al., 1991; Sabariego et al., 1999; Aira et al., 2003), que configuran el patrón a través de las concentraciones obtenidas en el PPP y excluyendo los días del mismo en los que hubo registro de precipitaciones que pudieran modificar la distribución horaria de cada tipo de polen o espora. Uno de los motivos que nos han llevado a tomar las concentraciones horarias de todo el año han sido la escasa variación en el patrón intradiario que se observa al aplicar algunas de las metodologías propuestas por diversos autores (Fig. 4.5.) en diferentes tipos de polen seleccionados al azar, al igual que los años de estudio y la forma de acotar el PPP. Asimismo, conviene resaltar que a la hora de analizar cualquiera de las modelos y métodos referidos adquiere gran importancia delimitar en qué franja horaria del día resultan más abundantes los distintos pólenes y esporas, algo que también puede ser obtenido a través de la distribución horaria de un determinado tipo de polen o espora a lo largo de un año.

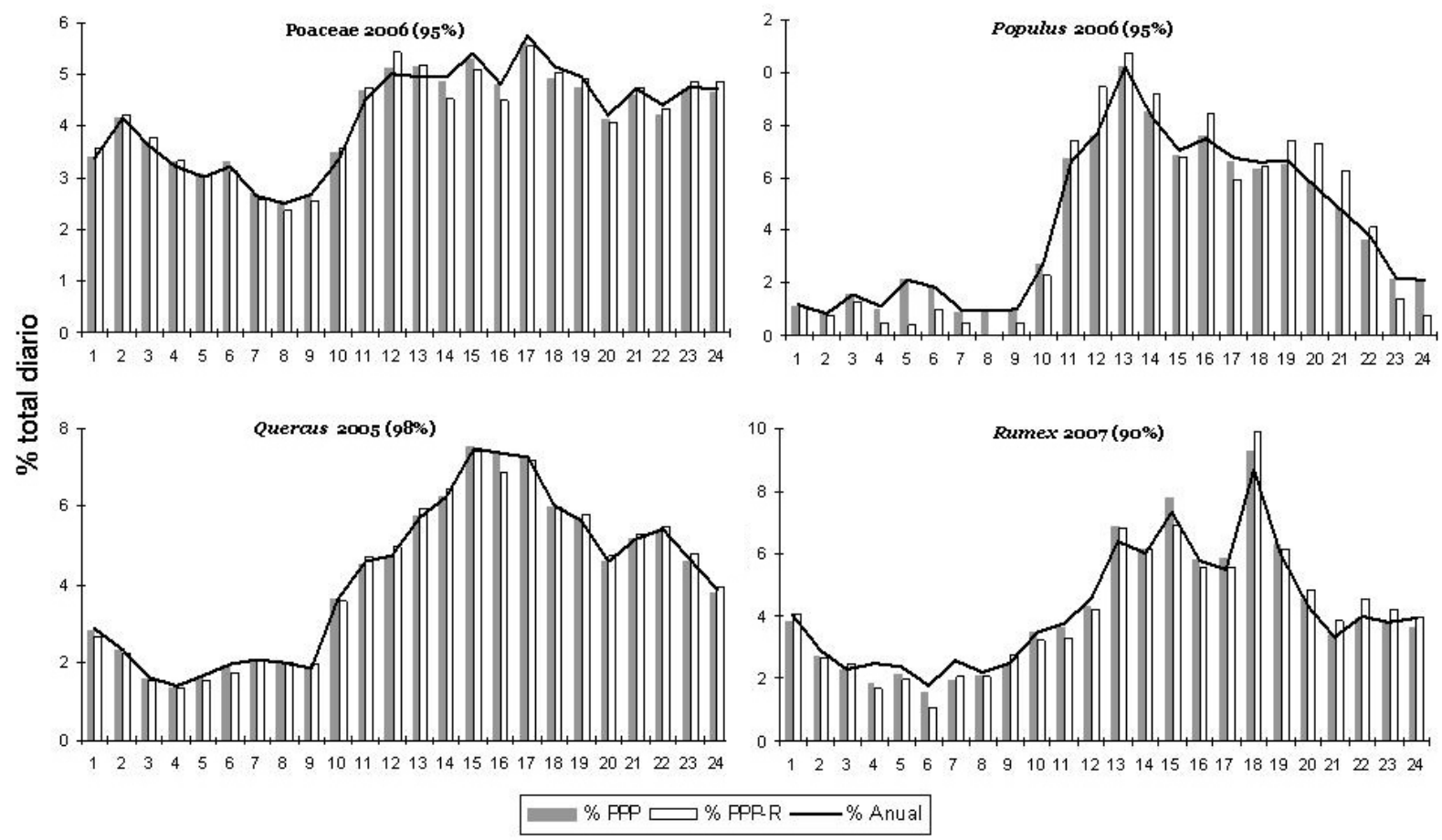

Fig. 4.5. Comparativa de diferentes modelos para evaluar la distribución horaria de varios tipos de polen, años y modelos de delimitación del período principal de polinización (PPP, entre paréntesis) escogidos al azar, durante el período principal de polinización (PPP), durante el período principal de polinización excluyendo los días en los que se registraron precipitaciones (PPP-R) y en todo el año analizado (Anual). 


\subsection{Metodología empleada en los estudios clínicos}

\subsubsection{Población estudiada}

Se ha considerado una muestra poblacional de 68 pacientes de ambos sexos, incluidos dentro del estudio EXPO, realizado a nivel nacional, y que acudieron a diversos centros del núcleo urbano de Salamanca (Hospital Clínico Universitario, Hospital de Los Montalvos y Clínica Alergoasma), tres meses antes del comienzo de la primavera de 2007 (noviembre, diciembre, enero), con edades comprendidas entre los 11 y los 63 años, siguiendo cuatro criterios de inclusión:

- pacientes que acuden de forma consecutiva a la consulta con historia clínica compatible con alergia al polen

- $\quad$ síntomas alérgicos estacionales en los 2 años previos

- 5 años de residencia en la misma zona

- $\quad$ sin haber recibido inmunoterapia

Los datos demográficos y clínicos de los pacientes fueron recogidos en unas hojas modelo, tal y como se muestra en la Tabla 4.1. Se incluyen sólo los meses anteriores al comienzo de la estación polínica, debido a anteriores estudios (Calvo, 1996) en la ciudad de Salamanca, que determinan que el $80 \%$ de los pacientes sensibilizados a diferentes alergenos de granos de polen presentan síntomas asociados en primavera y verano, así como que la bondad de los resultados en las pruebas intraepidérmicas sea independiente de la época del año en que las realicemos (Sin et al., 2001)..

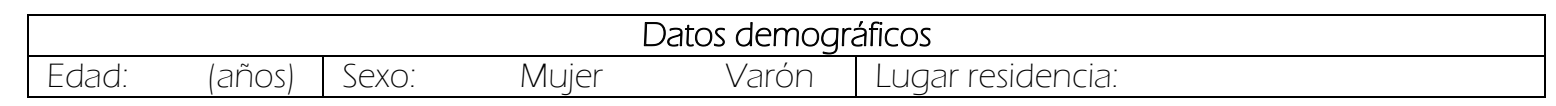

\begin{tabular}{|c|c|c|c|}
\hline \multicolumn{4}{|c|}{ Datos clínicos } \\
\hline \multicolumn{4}{|c|}{ Tiempo de evolución de la } \\
\hline \multirow{5}{*}{ Diagnóstico } & \multirow{2}{*}{ Asma } & $\begin{array}{l}\quad \text { Leve intermitente: } \\
\text { Sintomas diurnos } \\
\text { (2 días/semana) } \\
\text { Síntomas nocturnos } \\
\text { (2 veces/semana) }\end{array}$ & $\begin{array}{l}\quad \text { Leve persistente: } \\
\text { Sintomas diurnos }>2 \text { dias/sem. } \\
\text { no diario } \\
\text { Síntomas nocturnos }>2 \\
\text { veces/mes }\end{array}$ \\
\hline & & $\begin{array}{l}\text { Moderado persistente: } \\
\text { Síntomas diarios (afectan } \\
\text { actividad diaria y sueño) } \\
\text { Síntomas nocturnos }>1 \\
\text { vez/semana }\end{array}$ & $\begin{array}{l}\text { Grave persistente: } \\
\text { Síntomas continuos. Crisis } \\
\text { frecuentes. } \\
\text { Actividad habitual alterada. } \\
\text { Síntomas nocturnos frecuentes. }\end{array}$ \\
\hline & \multirow[b]{2}{*}{ Rinitis } & $\begin{array}{l}\text { Intermitente: } \\
\text { Sintomas }<4 \text { dias semana o } \\
\text { durante }<4 \text { semanas }\end{array}$ & $\begin{array}{l}\text { Persistente: } \\
\text { Sintomas }>4 \text { dias semana o } \\
\text { durante }>4 \text { semanas }\end{array}$ \\
\hline & & $\begin{array}{l}\quad \text { Leve (no presenta): } \\
\text { Trastornos del sueño } \\
\text { Trastorno actividad diaria } \\
\text { Absentismo escolar/laboral } \\
\text { Síntomas molestos }\end{array}$ & $\begin{array}{l}\text { Moderada-Severa } \\
\text { (uno o más de): } \\
\text { Trastornos del sueño } \\
\text { Trastorno actividad diaria } \\
\text { Absentismo escolar/laboral } \\
\text { Síntomas molestos }\end{array}$ \\
\hline & \multicolumn{3}{|c|}{ Conjuntivitis } \\
\hline
\end{tabular}

Tabla 4.1. Modelo de hoja de recogida de información 


\subsubsection{Pruebas intraepidérmicas}

Estas pruebas fueron realizadas por el personal médico de los centros médicos mencionados, siguiendo el método propuesto por el subcomité de pruebas cutáneas de la EAACI en 1993. De forma general, consisten en la colocación de una gota del extracto antigénico sobre la piel en el antebrazo y posteriormente realizar una pequeña punción, con una lanceta estandarizada con punta de $1 \mathrm{~mm}$. Al cabo de 15 -20 minutos se realiza una lectura de la reacción, a través de la valoración del tamaño de la pápula y gracias al uso de la histamina como control positivo y una solución salina como control negativo (Adkinson et al., 2003).

El panel de alergenos utilizados para este tipo de pruebas fue: Artemisia, Betula verrucosa, Cupressus arizonica, Melocotón, Mezcla de gramíneas (Dactylis, Festuca, Lolium, Phleum, Poa), Olea europaea, Parietaria judaica, Plantago lanceolata, Platanus acerifolia, Polcalcina (polen de palmera sin profilina), Profilina (palmera), y Salsola kali. Todos ellos han sido suministrados por Laboratorios ALK-Abelló, Madrid. En general, se consideró como prueba positiva a todas aquellas pápulas obtenidas con un diámetro igual o mayor a $3 \mathrm{~mm}$ con respecto al control negativo (Adinoff et al., 1990), recogiéndose, posteriormente, los datos obtenidos (expresados en número de positivos y mediana del tamaño de pápulas).

\subsubsection{Determinación de la cantidad total de IgE específica}

Para cuantificar la cantidad total de IgE específica para un alergeno, se tomaron muestras de suero de los mismos pacientes expuestos a las pruebas intraepidérmicas, que se analizaron mediante la técnica Advia Centaur (Bayer@), un inmunoensayo tipo sándwich de dos puntos que utiliza tecnología quimioluminométrica directa (Petersen et al., 2004). En este tipo de pruebas, precisamos de una muestra de suero de $30 \mu \mathrm{l}$, que debe haber coagulado adecuadamente antes de la centrifugación previa, en una cubeta, para que la IgE específica de este suero pueda unirse al anticuerpo anti-IgE de ratón presente en $450 \mu \mathrm{l}$ de fase sólida, puesto que está unido de forma covalente a las partículas paramagnéticas de dicha fase. Posteriormente, se realiza un lavado, por el cual se eliminan todos los componentes del suero no unidos a dicho anticuerpo anti-IgE de la fase sólida, como son la IgG o todas aquellas IgE no unidas al anticuerpo. Tras este lavado, se añaden $50 \mu$ de un alérgeno marcado con biotina, que se une a la IgE específica del suero, y por último, se adicionan $100 \mu \mathrm{l}$ de reactivo lumínico, que contiene éster de acridinio, dejando incubar la muestra durante 7,5 minutos a $37^{\circ} \mathrm{C}$ (Fig. 4.6.). Para activar la reacción de quimioluminiscencia, tras 3 lavados, se añaden $300 \mu \mathrm{l}$ de reactivo ácido y $300 \mu \mathrm{l}$ de reactivo base. 
A través de está última reacción de quimioluminscencia, se obtiene la cantidad de IgE específica, expresada en Unidades Internacionales (UI) por ml, presente en la muestra del paciente, gracias a la cantidad de unidades relativas de luz (URL) detectadas por el sistema, que requiere de una calibración de su curva patrón cada vez que se inicie un nuevo proceso.

Esta técnica, de mayor especificidad y sensibilidad similar a otras técnicas análogas como UniCAP $®$, posee ciertas ventajas con respecto a dichas técnicas análogas como son la pequeña cantidad de suero utilizada, una mejor y más rápida manipulación o la ausencia de interferencias en los resultados con IgG (Ricci et al., 2003).

El panel de $\operatorname{IgE}$ específicas frente a alérgenos recombinantes utilizados fue el siguiente: Artemisia (Art v 1), Betula (Bet v 1), Cupressus (Cup s 1), gramíneas (grupo 1 con Phl p 1, y grupo 5 con Phl p 5), Olea (Ole e 1 y Ole e 9), Parietaria (Par j 1), Plantago (Pla l 1), Salsola (Sal k 1), junto a los pan-alergenos (profilina con Mal d $4 \mathrm{~A}+\mathrm{B}$, polcalcina con Che a 3, y LTP de melocotón con Pru p 3).

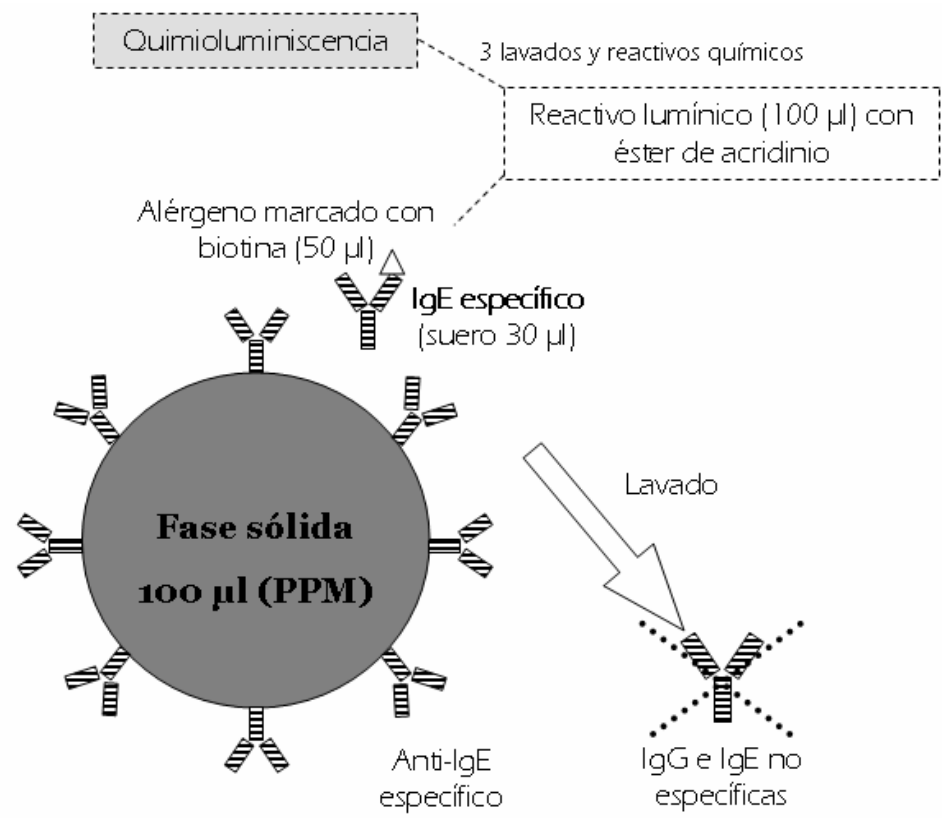

Fig. 4.6. Esquema de funcionamiento de la técnica Advia Centaur. PPM, partículas paramagnéticas (Adaptado de Petersen et al., 2004).

\subsubsection{Presentación de los datos}

Los resultados obtenidos tras realizar las pruebas intraepidérmicas fueron presentados de forma numérica exponiendo el número de pacientes que presentaron reacciones positivas a las mismas, junto al porcentaje sobre el total de pacientes estudiados y la mediana del tamaño de pápula. De igual forma, los resultados obtenidos al aplicar la técnica Advia Centaur, incluyeron el número de casos positivos, la prevalencia de los mismos 
sobre el total de pacientes y la mediana de los resultados de IgE específica (expresados en $\mathrm{UI} / \mathrm{ml}$ ). Se ha utilizado la mediana debido a la amplia distribución de los valores obtenidos de IgE en suero en individuos sanos (Kjellman et al., 1976), que en el caso de expresar los resultados a través de una media, tergiversarían los datos, sobretodo con un tamaño de muestra pequeño como el que ha sido incluido en este apartado.

De forma análoga se presentan también los resultados demográficos y clínicos resultantes del análisis efectuado por el personal médico de los centros clínicos salmantinos mencionados. La presentación de estos resultados incluye, además de la edad del paciente y el tiempo de evolución de la enfermedad (así como la media, la desviación típica, el mínimo y el máximo de los mismos), su división en tres grupos de edad (menores o iguales a 14 años, 15-17 años, y mayores o iguales a 18 años) y sexo, junto a la desviación típica. Los datos clínicos se dividieron en función del diagnóstico de los síntomas que tuvieron los pacientes (asma, rinitis/rinoconjuntivitis, o bien, rinitis/rinoconjuntivitis más asma), y la severidad del asma y la rinitis.

Por último, se ha llevado a cabo la presentación gráfica de algunos de los resultados obtenidos, como puedan ser las concentraciones de los tipos de polen con mayor incidencia alergénica y los valores umbrales de las mismas que pudieron desencadenar procesos alérgicos en todos aquellos pacientes sensibilizados, así como en la valoración de la relación entre el polen presente en la atmósfera y los resultados obtenidos en las técnicas in vivo e in vitro, gracias al uso de regresión lineal, acompañado del estadístico de correlación de Spearman. 
Resultados 



\subsection{Variables climatológicas durante el período de estudio}

Dentro de este apartado se presentan los valores obtenidos durante los ocho años de estudio para las variables climatológicas (temperatura, insolación, precipitación, humedad relativa y viento), que puede, condicionar, de forma positiva o negativa, los niveles de polen y esporas de la atmósfera de la ciudad de Salamanca e influir, no sólo en la variación estacional de los distintos tipos de polen y esporas de pteridófitos, sino también en las especies que los producen.

\subsubsection{Temperatura}

El promedio de la temperatura media anual durante el período de estudio ha sido de $12,1^{\circ} \mathrm{C}$ (Tabla 5.1.1), siendo el año 2003 cuando se alcanzan los valores más elevados $\left(12,9^{\circ} \mathrm{C}\right)$ y $2007\left(11,4^{\circ} \mathrm{C}\right)$ los menores, por lo que su valor difiere $1,5^{\circ} \mathrm{C}$ entre uno y otro año. Algo similar ocurre con la temperatura media máxima anual, cuyo valor ha oscilado entre $19,5^{\circ} \mathrm{C}$ en 2007 y $18,3^{\circ} \mathrm{C}$ en 2005 , y siendo en agosto de 2003 cuando presenta el valor mensual extremo $\left(32,1^{\circ} \mathrm{C}\right)$. En el caso de la temperatura mínima promedio varía entre $6,7^{\circ} \mathrm{C}(2006)$ y $4,2^{\circ} \mathrm{C}(2007)$, y registra su valor mensual más bajo en diciembre de $2001\left(-5,7^{\circ} \mathrm{C}\right)$.

\begin{tabular}{cccccc}
\hline Año & T med & T max & T min & $M$ & $\mathrm{M}$ \\
\hline 2000 & 11,9 & 18,6 & 5,1 & 36,4 & $-7,8$ \\
2001 & 12,1 & 18,8 & 5,4 & 36 & -12 \\
2002 & 12,5 & 19,0 & 6,0 & 35,2 & $-7,4$ \\
2003 & 12,9 & 19,3 & 6,3 & 38 & -9 \\
2004 & 11,9 & 18,6 & 5,3 & 37,5 & $-7,4$ \\
2005 & 11,6 & 18,3 & 5,4 & 37,4 & -9 \\
2006 & 12,5 & 18,8 & 6,7 & 35,6 & $-11,2$ \\
2007 & 11,4 & 19,5 & 4,2 & 39 & $-10,6$ \\
\hline Promedio & 12,1 & 18,9 & 5,5 & 36,9 & $-9,3$ \\
\hline
\end{tabular}

Tabla 5.1. Temperaturas medias anuales durante el período $2000-2007$ (en $\left.{ }^{\circ} \mathrm{C}\right)$. T med, temperatura media;

T max, temperatura máxima; T min, temperatura mínima; M, valor extremo de temperatura máxima; m, valor extremo de temperatura mínima.

Las tres variables (temperatura media, máxima y mínima) presentan un comportamiento muy similar durante los ocho años analizados si observamos sus valores anuales (Fig. 5.1.1.A.), observándose un descenso de la temperatura media en los años 2004, 2005 y 2007, algo más acusado para las temperaturas máximas, en una leve tendencia general al incremento interanual. En lo que respecta a la evolución de los valores medios semanales de las variables mencionadas se encuentra también un patrón de comportamiento paralelo por el cual se describe una curva ascendente desde la primavera temprana hasta la 
época estival, donde se registran los valores termométricos más elevados del año (Fig. 5.1.B.). A partir del mes de septiembre, las temperaturas vuelven a experimentar un descenso hasta situarse en su cotas más bajas, entre los meses de diciembre y febrero. Como ya señalamos en el capítulo del área de estudio, el clima mediterráneo continental que presenta la ciudad de Salamanca puede verse bien reflejado por las oscilaciones térmicas existentes entre el mes más frío enero con una temperatura media de $3,5^{\circ} \mathrm{C}$ para el período de estudio, y el mes más cálido, julio, con $21,2^{\circ} \mathrm{C}$.
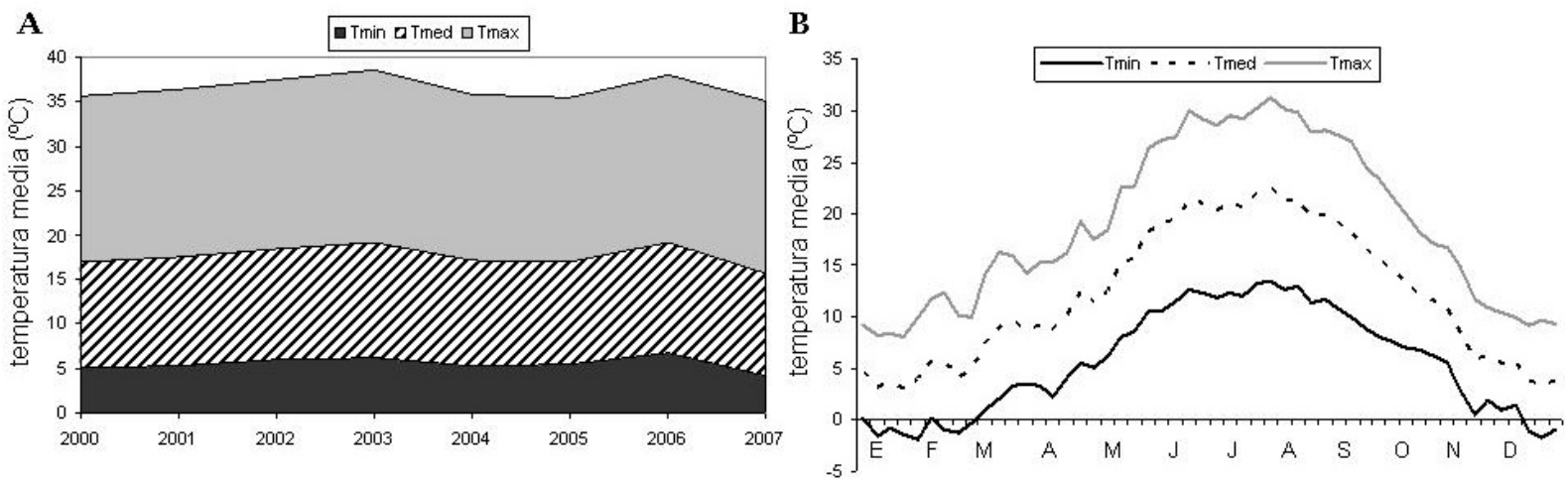

Fig. 5.1.1 A. Evolución de las temperaturas medias anuales durante el período 2000-2007. B. Temperaturas medias semanales promedio de los años analizados.

\subsubsection{Precipitación}

Los valores de precipitación durante los ocho años estudiados oscilaron entre los 272 mm del año 2004 y los $474 \mathrm{~mm}$ del año 2003, lo cual nos muestra una distribución algo irregular para las mismas, que tiene como promedio de los ocho años, $371 \mathrm{~mm}$ (Fig. 5.1.2.A.). La distribución semanal media de las precipitaciones (Fig. 5.1.2.B.) indica un patrón irregular de las precipitaciones a lo largo de un año promediado, puesto que los mayores valores se registran en los meses de otoño y primavera y los más bajos en los meses estivales. Este hecho se pone de manifiesto al comprobar los valores totales medios de cada mes, con $65 \mathrm{y}$ $39 \mathrm{~mm}$ en octubre y noviembre, y 37 y $41 \mathrm{~mm}$ en abril y mayo. Asimismo, en julio y agosto se presentan valores medios mensuales de 12 y $17 \mathrm{~mm}$, gracias a las características tormentas estivales. 

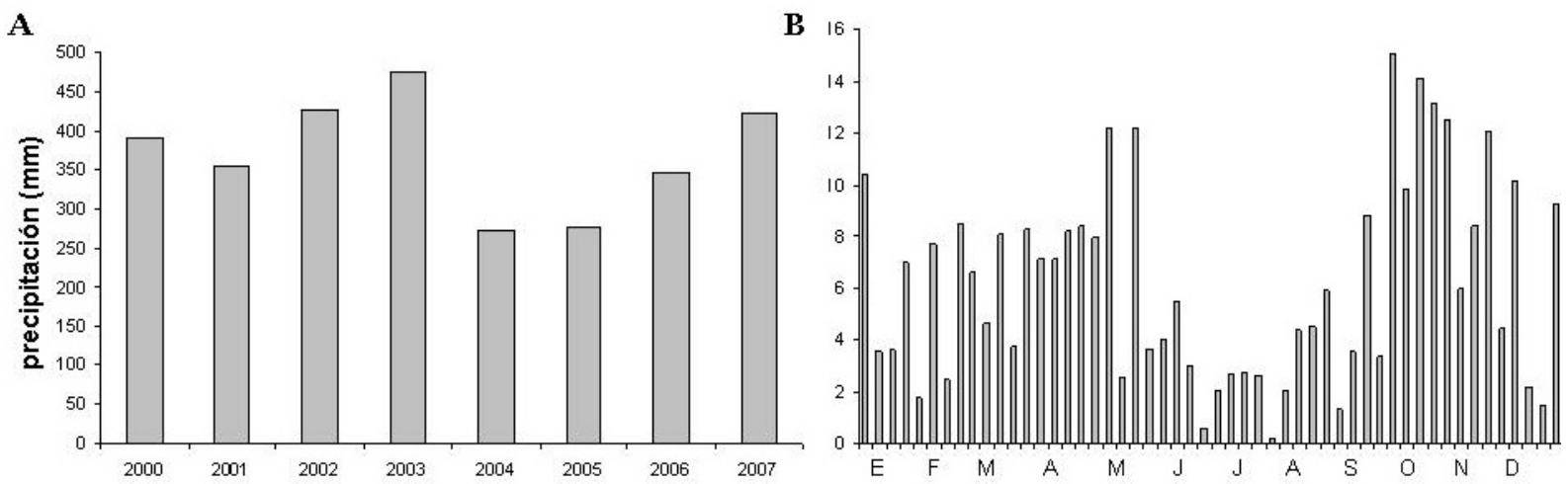

Fig. 5.1.2. A. Evolución del total anual de precipitaciones en los años estudiados. B. Precipitaciones totales semanales promedio durante el período 2000-2007.

Con los valores promedio de las temperaturas medias y de las precipitaciones para el período 2000-2007, se elabora un diagrama ombrotérmico de Bagnouls \& Gaussen (1954), para la ciudad de Salamanca y se compara con el diagrama obtenido para treinta años (1971-2000). En ambos puede detectarse un período de xericidad o sequía estival típico de los climas mediterráneos (Fig. 5.1.3.), con máximos equinocciales en lo referente a la pluviometría, aunque algo más elevados en los meses de otoño del período 2000-2007. En resumen, puede concluirse que no han existido cambios destacables en el ombro y termoclima general del núcleo urbano.

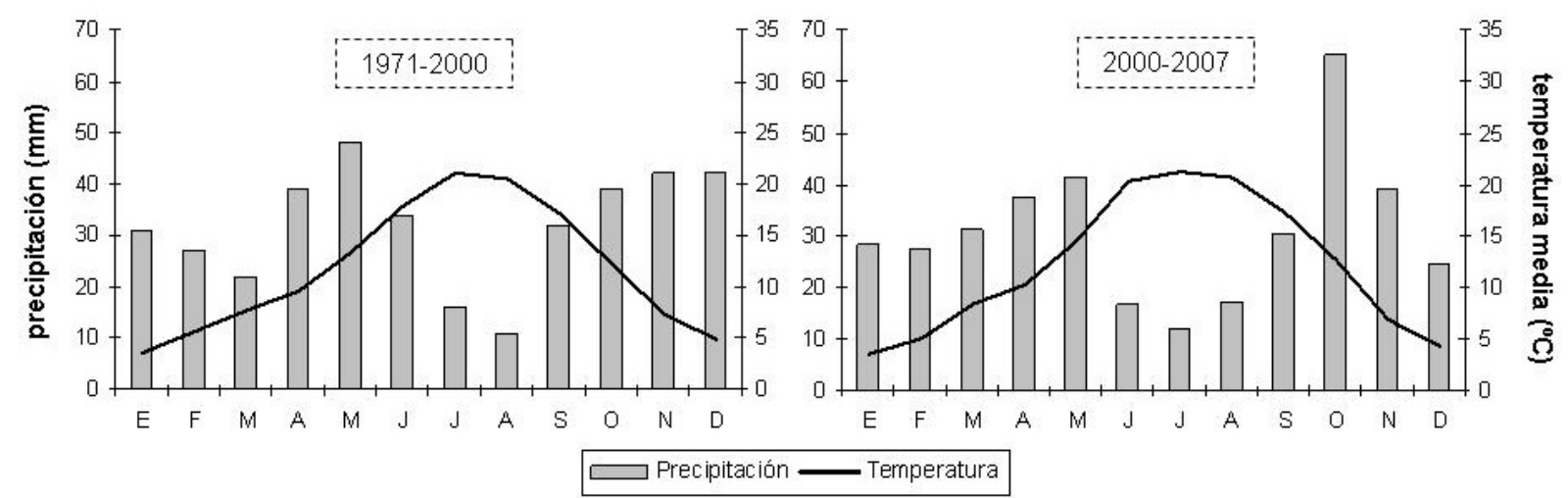

Fig. 5.1.3. Diagramas ombrotérmicos de Bagnouls \& Gaussen (1954), elaborados a partir de los datos promediados para los períodos 1971-2000 y 2000-2007.

\subsubsection{Humedad relativa}

En el transcurso de las anualidades analizadas la humedad relativa del aire ha presentado un valor medio de 66,2\%, con valores máximos de 70,6\% y 70,5\% en 2007 y 2003, respectivamente, y un mínimo en 2004 con 56,4\%, semejante a lo ocurrido con la cantidad total de precipitaciones (Fig. 5.1.4.A). La evolución semanal presenta un descenso gradual desde enero (Fig. 5.1.4.B), el mes con índices más elevados (83,7\%), hasta los meses 
estivales, siendo el mes de julio el que registra los valores mínimos anuales $(48,4 \%)$, y a partir del cual vuelven a recuperarse los valores máximos.

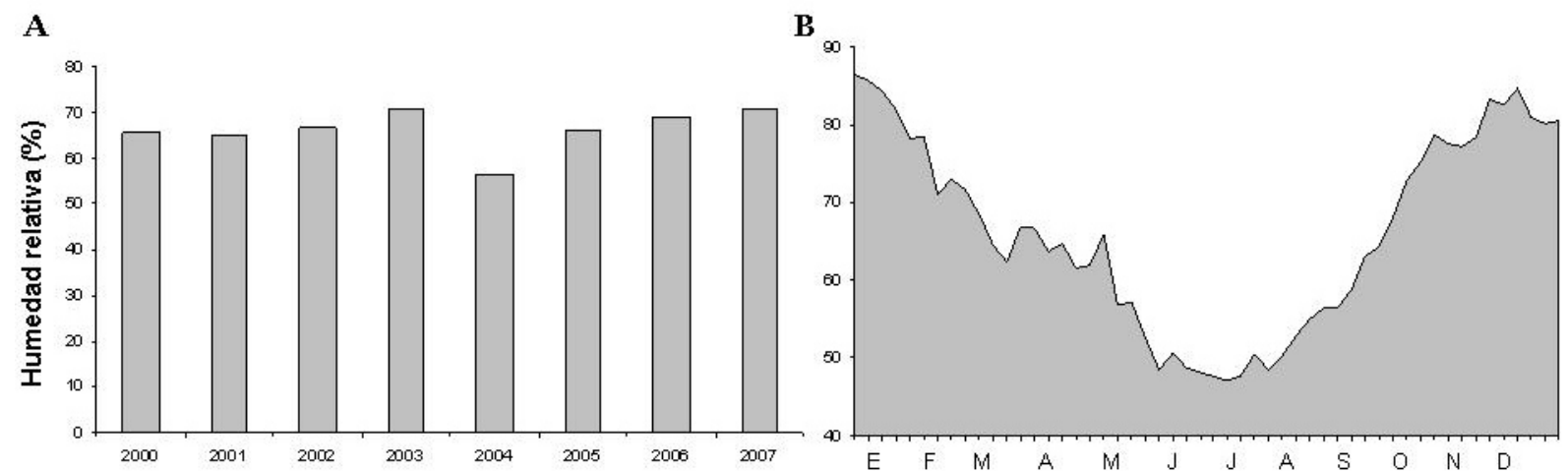

Fig. 5.1.4. A. Evolución del promedio anual de la humedad relativa en el período de estudio. B. Humedad relativa semanal promedio para los ocho años de estudio.

\subsubsection{Insolación}

Los valores anuales promedio para el período 2000-2007 indican que la insolación en la ciudad de Salamanca es media-alta, con 2688 horas de sol (6o,8\% de la insolación teórica), siendo el año 2007 (2974 horas, un 67,4\% de insolación teórica) el que presenta una mayor insolación y el año 2003 el de menor (2537 horas, un 57,3\% de insolación teórica). En la evolución semanal puede apreciarse que los meses de primavera y verano poseen una mayor insolación, con un total mensual promedio de 367 horas en julio, mientras que en los meses de otoño e invierno existe una reducción drástica, con un promedio de 113 horas en enero, debido a un aumento de la nubosidad y la disminución del fotoperíodo (Fig. 5.1.5.).
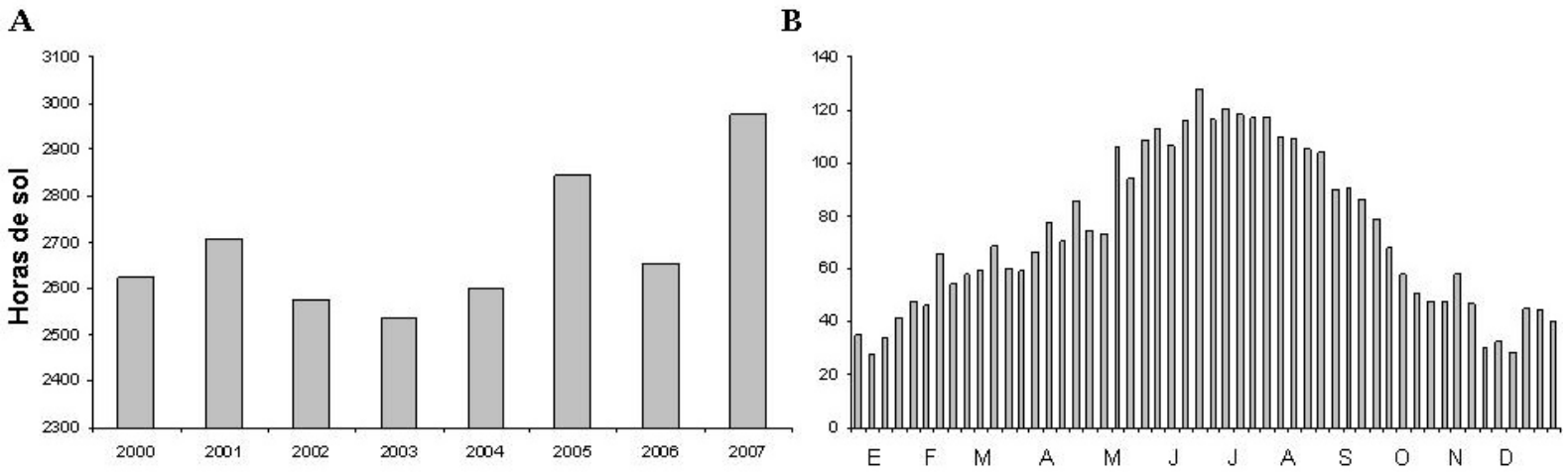

Fig. 5.1.5. A. Evolución del total anual de insolación en los años estudiados. B. Horas de sol totales semanales promedio durante el período 2000-2007. 


\subsubsection{Viento}

Dentro de este parámetro meteorológico debemos diferenciar dos componentes del mismo, como son la velocidad y la dirección. En el primero de ellos, el promedio para los ocho años estudiados es de $17 \mathrm{Km} / \mathrm{h}$, observándose un descenso a lo largo de este período (Fig. 5.1.6.A.), puesto que la velocidad media en el año 2002 (27 Km/h) es claramente superior a la registrada en $2007(10 \mathrm{~km} / \mathrm{h})$. La evolución semanal promedio de la velocidad del viento durante estos años (Fig. 5.1.6.B.) muestra unos valores más elevados durante finales del invierno y el inicio de la primavera $(23 \mathrm{Km} / \mathrm{h}$ en marzo y abril), y registros más bajos durante el final del verano (12 km/h en septiembre).
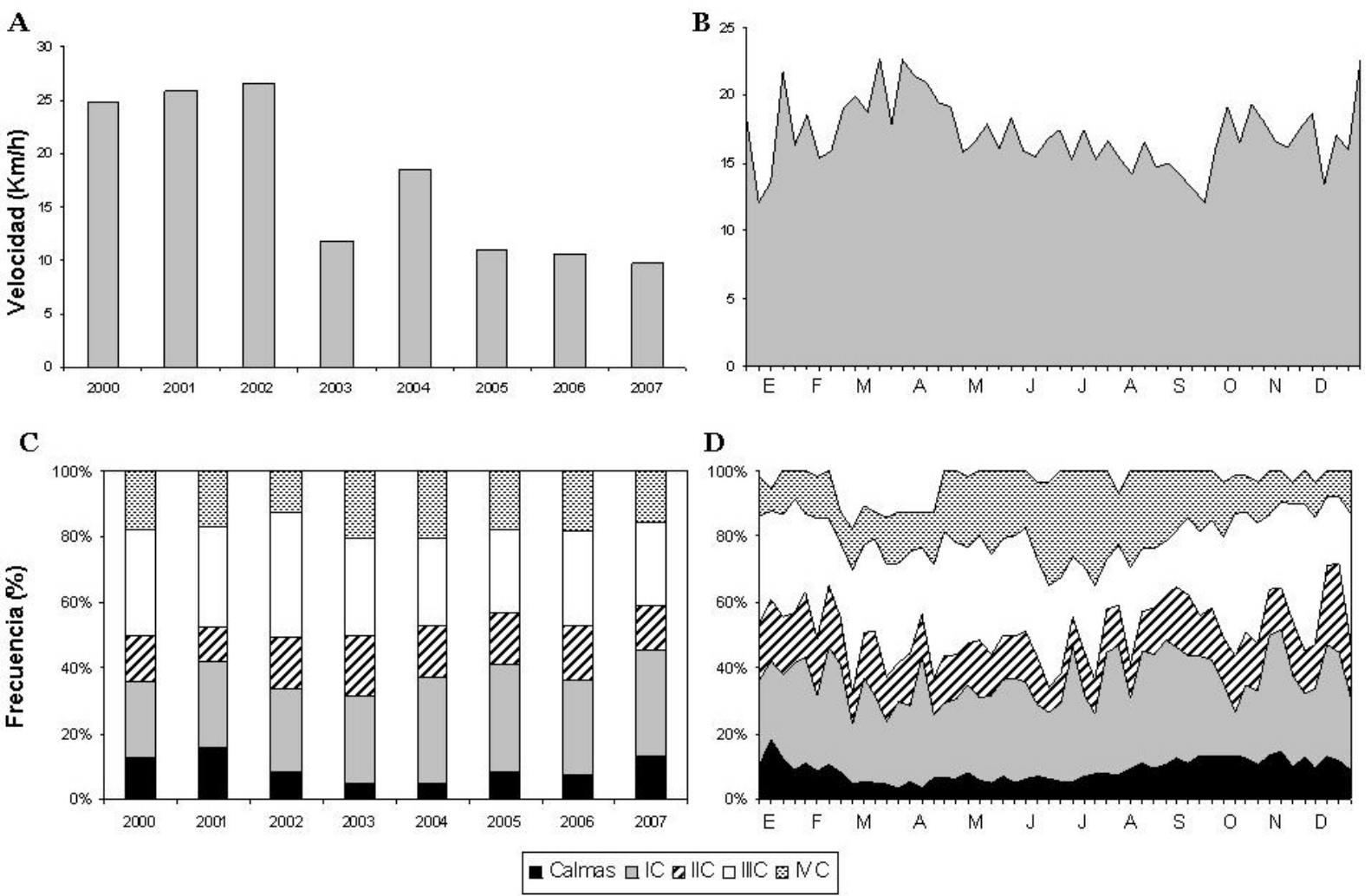

Fig. 5.1.6. A. Velocidad media anual del viento durante el período 2000-2007. B. Velocidad media semanal promedio para los ocho años de estudio. C. Frecuencia media anual del viento procedente de los cuatro cuadrantes y las calmas (IC: primer cuadrante, IIC: segundo cuadrante, IIIC: tercer cuadrante, IVC: cuarto cuadrante). D. Evolución semanal media de la frecuencia del viento procedente de cada uno de los cuatro cuadrantes y las calmas promediado para el período analizado.

El regimen de vientos ha sido muy similar durante este período (Fig. 5.1.6.C.) con predominio de los vientos procedentes del tercer cuadrante (29\% de frecuencia promedio para los ocho años), que oscila entre el 37\% de frecuencia media de 2002 y el 24\% de 2006, junto a los del primer cuadrante (28\% de frecuencia promedio), que varían entre el $33 \%$ de 2003 y 2004, y el 23\% de 2000. Los vientos procedentes del cuarto y segundo cuadrante 
presentaron una frecuencia promedio de $17 \%$ y 15\%, registros elevados en el año 2003 para ambos (20\% para los vientos del cuarto cuadrante y $18 \%$ para el segundo cuadrante) y valores más bajos en los años 2002 y 2001 para los vientos procedentes del cuarto y segundo cuadrante (12 y 10\%, respectivamente). La evolución semanal (Fig. 5.1.6.D.) nos indica mayores frecuencias promedio de los vientos procedentes del tercer cuadrante durante los meses de primavera (31\% en marzo, abril y mayo), correspondiéndose con las velocidades medias más altas. Asimismo, se observa una menor frecuencia durante los últimos meses de verano (21\% en agosto y septiembre), que coincide con una mayor frecuencia de los vientos del primer cuadrante (33\% en agosto y septiembre). Por último, las calmas (Fig. 5.1.6.C.) han presentado menores frecuencias durante el período estudiado, que oscilan entre el $15 \%$ de 2001 y el 4\% de 2004, y una evolución semanal que indica valores mayores promedio en los meses de otoño e inicios de invierno (13\% en octubre, noviembre y enero). 


\subsection{Espectro polínico de la ciudad de Salamanca}

\subsubsection{Aspectos generales}

El estudio de las muestras aerobiológicas obtenidas a lo largo de los ocho años incluidos en este trabajo ha dado lugar a la identificación de 72 tipos de polen diferentes, de los que 31 han podido adscribirse a un determinado tipo polínico en función de sus características morfológicas y de la presencia de especies productoras incluidas en cada tipo polínico en un área suficientemente grande y representativa de la vegetación circundante a la ciudad de Salamanca (Tabla 5.2.1.1.). Estos tipos polínicos pueden corresponderse a una sola especie, como el tipo polínico Aesculus hippocastanum que presenta la especie Aesculus hippocastanum L., a varias especies, como en el caso del tipo polínico Echium plantagineum L. que engloba a diversas especies del género Echium L., o incluso adscribirse a varias familias botánicas, como el tipo polínico J uniperus oyxcedrus al que se adscriben las familias Cupressaceae, Taxaceae, Taxodiaceae y Cefalotaxaceae. Conviene precisar que en los otros 42 pólenes diferentes identificados, utilizaremos la denominación tipos de polen y no tipos polínicos para evitar confusiones, pese a que no es objeto de este trabajo precisar la nomenclatura más adecuada y a que tendrán el mismo tratamiento en la exposición de los resultados. En este último caso, la valoración cualitativa de los diferentes pólenes identificados se ha realizado siguiendo las mismas premisas que para los tipos polínicos, obteniéndose un menor grado de determinación debido al menor grado de resolución que aportan las técnicas aerobiológicas en diversos aspectos morfológicos y ornamentales del grano de polen, al menos en comparación con los resultados aportados por otras técnicas como la acetolítica.

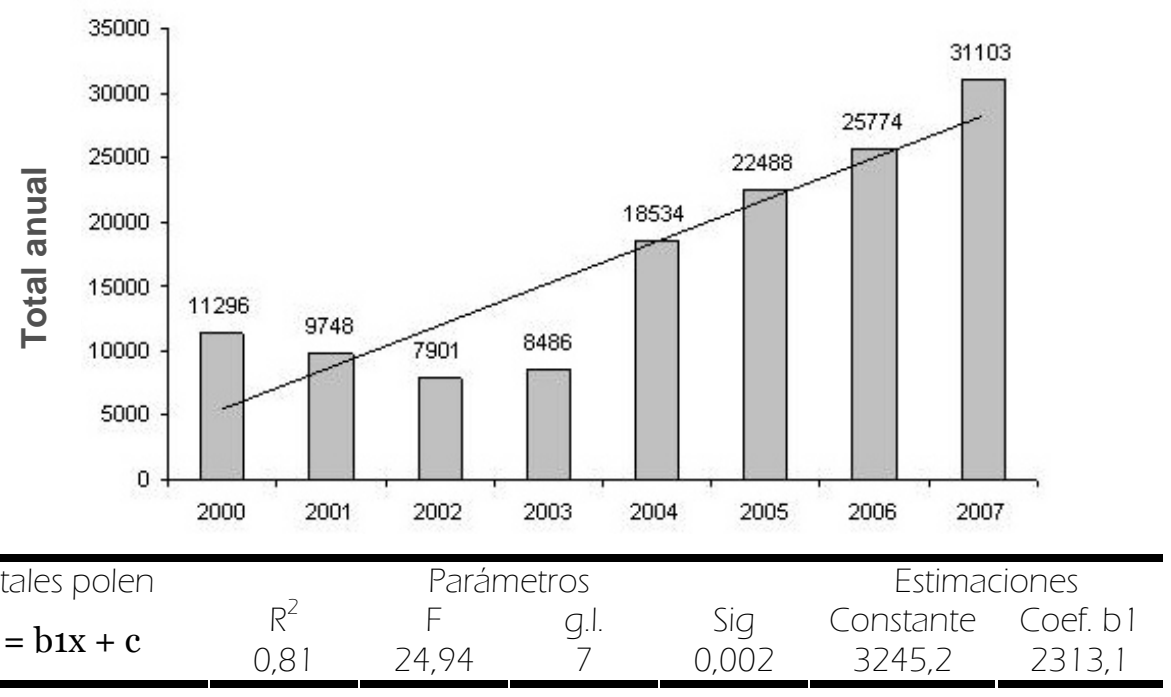

Fig. 5.2.1.1. Evolución anual del número total de granos de polen contabilizados y tendencias (análisis de regresión). 


\begin{tabular}{|c|c|c|c|}
\hline \multicolumn{3}{|c|}{ Pólenes identificados asignados a un tipo polínico } & \multirow{2}{*}{$\begin{array}{c}\text { Resto de pólenes } \\
\text { identificados } \\
\text { Denominación } \\
\end{array}$} \\
\hline Denominación & Tipo polínico & \multirow{10}{*}{$\begin{array}{c}\text { Referencias } \\
\text { Heath, 1984 } \\
\text { Candau, 1987g } \\
\text { Díez, 1987b } \\
\text { Díez \& Suárez, 1987 } \\
\text { Díez, 1987h. } \\
\text { Polo \& Díez, 1987 } \\
\text { Díez, 1987b } \\
\text { Díez, 1987e; } \\
\text { Bortenschlager, 1990 } \\
\text { Fernández, 1987a; Pardo } \\
\text { et al., 2000 }\end{array}$} & \\
\hline Aesculus & Aesculus hippocastanum & & Abies \\
\hline Ailanthus & Ailanthus altissima & & Acacia \\
\hline Alnus & Alnus glutinosa & & Acer \\
\hline Castanea & Castanea sativa & & Artemisia \\
\hline Celtis & Celtis australis & & Betula \\
\hline Convolvulus & Convolvulus arvensis & & Boraginaceae' \\
\hline Corylus & Corylus avellana & & \multirow{11}{*}{$\begin{array}{c}\text { Caryophyllaceae } \\
\text { Cedrus } \\
\text { Chenopodiaceae / } \\
\text { Amaranthaceae } \\
\text { Cistaceae } \\
\text { Citrus } \\
\text { Compositae } \\
\text { Cruciferae } \\
\text { Cyperaceae } \\
\text { Ericaceae } \\
\text { Euphorbiaceae } \\
\text { Forsythia }\end{array}$} \\
\hline Cupressaceae & Juniperus oxycedrus & & \\
\hline Cytisus & Cytisus scoparius & & \\
\hline Echium & Echium plantagineum & \multirow{21}{*}{$\begin{array}{c}\text { Díez, 1987c } \\
\text { Candau, 1987c } \\
\text { Díez, 1987a } \\
\text { Díez, 1987f } \\
\text { Polo, 1987 } \\
\text { Punt et al., 1991 } \\
\text { López \& Díez, 1987 } \\
\text { Candau, 1987a } \\
\text { Candau, 1987b } \\
\text { Candau, 1987c } \\
\text { Candau, 1987d } \\
\text { Candau, 1987e. } \\
\text { Denk \& Tekleva, 2006 } \\
\text { Fernández, 1987b } \\
\text { Díez, 1987g } \\
\text { Del Pino \& Díez, 1990 } \\
\text { Candau, 1987f } \\
\text { Díez, 1987d } \\
\text { Candau, 1987h } \\
\text { Christensen \& Blackmore, } \\
\text { 1988 } \\
\text { Díez, 1987h } \\
\text { Díez, 1987d } \\
\text { Fernández, 1987c }\end{array}$} & \\
\hline Fraxinus & Fraxinus angustifolia & & \\
\hline $\begin{array}{l}\text { Helianthus } \\
\text { Juglans }\end{array}$ & $\begin{array}{c}\text { Calendula arvensis } \\
\text { Juglans regia }\end{array}$ & & \\
\hline Juncaceae & Juncus acutus & & \\
\hline Ligustrum & Ligustrum vulgare & & \\
\hline Mercurialis & Mercurialis tomentosa & & \\
\hline Morus & Morus alba & & \\
\hline Myrtaceae & Myrtus communis & & \\
\hline Olea & Olea europaea & & Labiateae \\
\hline Papaver & Papaver rhoeas & & Lagerstroemia \\
\hline Plantago & Plantago coronopus & & Liguliflorae \\
\hline Platanus & Platanus x acerifolia & & Liliaceae \\
\hline Poaceae $^{3}$ & Festuca arundinacea & & Lotus \\
\hline $\begin{array}{l}\text { Populus } \\
\text { Robinia }\end{array}$ & $\begin{array}{c}\text { Populus alba } \\
\text { Robinia pseudoacacia }\end{array}$ & & $\begin{array}{l}\text { Malvaceae } \\
\text { Oxalis }\end{array}$ \\
\hline Rumex & Rumex conglomeratus & & Pinus \\
\hline Sambucus & Sambucus nigra & & Pittosporum \\
\hline Thymelaeaceae & Thymelaea villosa & & Quercus \\
\hline Tilia & Tilia platyphyllos & & Ranunculaceae \\
\hline UImus & Ulmus minor & & Rhamnaceae \\
\hline Viburnum & Viburnum tinus & & Rosaceae \\
\hline Vitis & Vitis vinifera & & $\begin{array}{c}\text { Rubiaceae } \\
\text { Salix } \\
\text { Scrophulariaceae } \\
\text { Solanacae } \\
\text { Sophora } \\
\text { Trifolium } \\
\text { Typha } \\
\text { Umbelliferae } \\
\text { Urticaceae }\end{array}$ \\
\hline
\end{tabular}

Tabla 5.2.1. Listado de táxones presentes en la atmósfera de la ciudad de Salamanca a través de los diferentes

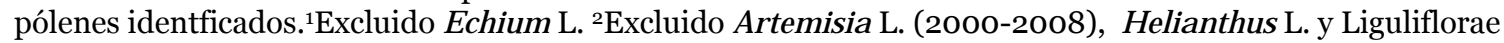
(2004-2007). 3Incluido Zea mays L. 4Excluido Mercurialis.

En el transcurso de los ocho años estudiados el total anual promedio de granos de polen contabilizados ha sido de 16916, siendo el año 2007,con 31103, el que presentó un mayor número y el año 2002, con un total de 7901 pólenes, el año con menor contenido polínico. Tal y como se muestra en la Fig. 5.2.1.1., el número total de granos de polen en este período se ha incrementado en los últimos años, suponiendo un aumento del $275 \%$ en el contenido polínico de la atmósfera. Este incremento también se observa en la tendencia que muestra la regresión lineal $\left(\mathrm{R}^{2}=0,81\right)$. 


\begin{tabular}{|c|c|c|c|c|c|c|c|c|}
\hline Taxa / Año & 2000 & 2001 & 2002 & 2003 & 2004 & 2005 & 2006 & 2007 \\
\hline Abies & & 1 & & & 3 & 2 & 1 & 1 \\
\hline Acacia & 1 & 1 & & 1 & 1 & & 1 & \\
\hline Acer & 322 & 202 & 43 & 79 & 116 & 169 & 105 & 96 \\
\hline Ailanthus & 190 & 110 & 97 & 33 & 19 & 65 & 45 & 14 \\
\hline Aesculus & & & & 22 & 27 & 84 & 67 & 39 \\
\hline Alnus & 122 & 74 & 150 & 79 & 120 & 255 & 241 & 189 \\
\hline Artemisia & 19 & 26 & 10 & 83 & 26 & 45 & 76 & 67 \\
\hline Betula & 15 & 38 & 33 & 8 & 100 & 148 & 137 & 150 \\
\hline Boraginaceae $^{1}$ & 1 & 5 & 2 & 3 & 3 & 8 & 4 & 3 \\
\hline Campanula & & 10 & 5 & 13 & 6 & 22 & 8 & 10 \\
\hline Castanea & 204 & 129 & 58 & 186 & 268 & 426 & 574 & 409 \\
\hline Caryophyllaceae & 1 & & 1 & & 2 & 4 & 1 & 5 \\
\hline Cedrus & 19 & 16 & 8 & 51 & 28 & 44 & 62 & 15 \\
\hline Celtis & 1 & 3 & 3 & 7 & 3 & 2 & 5 & \\
\hline Chenopodiaceae & 64 & 77 & 68 & 260 & 154 & 248 & 474 & 228 \\
\hline $\begin{array}{l}\text { Cistaceae } \\
\text { Citrus }\end{array}$ & 1 & 3 & & 7 & 6 & & & 4 \\
\hline Compositae $^{2}$ & 118 & 111 & 45 & 143 & 113 & 100 & 199 & 225 \\
\hline Convolvulus & & 1 & 1 & 3 & 1 & 1 & 4 & \\
\hline Corylus & 23 & 10 & 15 & 3 & 15 & 22 & 10 & 2 \\
\hline Cruciferae & & & & 15 & 29 & 15 & 77 & 49 \\
\hline Cupressaceae & 855 & 1180 & 1071 & 1071 & 1839 & 2327 & 2438 & 3635 \\
\hline Cyperaceae & 169 & 99 & 37 & 72 & 60 & 57 & 67 & 76 \\
\hline Cytisus & & 65 & 24 & 40 & 103 & 206 & 47 & 45 \\
\hline Echium & 124 & 19 & 15 & 113 & 67 & 36 & 268 & 248 \\
\hline Ericaceae & 46 & 58 & 61 & 47 & 170 & 152 & 188 & 195 \\
\hline Euphorbiaceae $^{4}$ & & & & & 2 & 7 & 6 & 28 \\
\hline Forsythia & & & & & & & & 1 \\
\hline Fraxinus & 92 & 72 & 182 & 84 & 198 & 241 & 260 & 378 \\
\hline Helianthus & & & & & 10 & 11 & 12 & 18 \\
\hline Juglans & 86 & 20 & 8 & 13 & 17 & 20 & 23 & 21 \\
\hline Juncaceae & 20 & 10 & 8 & 12 & 8 & 3 & 5 & 7 \\
\hline Labiatae & 10 & 2 & 3 & 6 & 31 & 15 & 13 & 40 \\
\hline Lagerstroemia & & & & & & 4 & 1 & 1 \\
\hline Liliaceae & & & & 6 & 4 & 7 & 11 & 4 \\
\hline Liguliflorae & & & & & 33 & 22 & 70 & 96 \\
\hline Ligustrum & 75 & 157 & 12 & 10 & 29 & 38 & 67 & 9 \\
\hline Lotus & & 4 & 14 & 28 & 3 & & & 6 \\
\hline Malvaceae & & & & & 1 & & & \\
\hline Mercurialis & 113 & 52 & 19 & 26 & 10 & 65 & 23 & 17 \\
\hline Morus & & 2 & & 24 & 15 & 33 & 21 & 12 \\
\hline Myrtaceae & 2 & 4 & 3 & 14 & 7 & 26 & 13 & 6 \\
\hline Olea & 272 & 660 & 482 & 401 & 763 & 1123 & 1954 & 678 \\
\hline Oxalis & & & & 1 & & 1 & & \\
\hline Papaver & & 1 & 9 & 106 & 18 & 80 & 15 & 4 \\
\hline Pinus & 380 & 334 & 322 & 211 & 1083 & 1347 & 822 & 687 \\
\hline Pittosporum & & & & & & 1 & & 2 \\
\hline Plantago & 583 & 314 & 218 & 392 & 565 & 638 & 868 & 1706 \\
\hline Platanus & 438 & 284 & 287 & 148 & 687 & 427 & 1530 & 1017 \\
\hline Poaceae & 2765 & 3046 & 1092 & 2314 & 4143 & 2602 & 5210 & 7832 \\
\hline Populus & 686 & 422 & 184 & 308 & 370 & 707 & 941 & 1087 \\
\hline Ouercus & 1982 & 826 & 2284 & 883 & 5768 & 8625 & 5949 & 9357 \\
\hline Ranunculaceae & & & & 1 & & & & \\
\hline Rhamnaceae & & & & & 1 & 5 & 1 & 1 \\
\hline Robinia & 78 & 175 & 136 & 54 & 31 & 83 & 25 & 23 \\
\hline Rosaceae & 18 & 143 & 113 & 48 & 20 & 70 & 55 & 5 \\
\hline Rubiaceae & & 7 & 1 & & 2 & & & 1 \\
\hline Rumex & 474 & 365 & 177 & 438 & 575 & 631 & 1036 & 1011 \\
\hline Salix & 100 & 70 & 52 & 26 & 72 & 100 & 179 & 118 \\
\hline Sambucus & 73 & 34 & 72 & 46 & 22 & 22 & 25 & 17 \\
\hline Scrophulariacae & & & & 17 & & 7 & 12 & 1 \\
\hline Solanaceae & & & & & 1 & 3 & 1 & \\
\hline Sophora & & & & & & 6 & 2 & 1 \\
\hline Thymelaeaceae & & & & 3 & 1 & 2 & 3 & 1 \\
\hline Tilia & 166 & 104 & 90 & 20 & 26 & 74 & 35 & 27 \\
\hline Trifolium & 20 & 82 & 49 & 35 & 10 & 11 & 40 & 9 \\
\hline Typha & 28 & 12 & 7 & 11 & 24 & 20 & 15 & 6 \\
\hline UImus & 113 & 61 & 31 & 51 & 81 & 47 & 51 & 84 \\
\hline Umbelliferae & & 8 & & 14 & 19 & 26 & 65 & 58 \\
\hline Urticaceae & 430 & 230 & 172 & 205 & 422 & 563 & 1197 & 1002 \\
\hline Viburnum & & & 20 & 6 & 1 & 12 & 4 & 6 \\
\hline Vitis & & 11 & 102 & 40 & 10 & 98 & 33 & 10 \\
\hline Otros & & & 3 & 148 & 215 & 262 & 164 & 115 \\
\hline TOTAL & 11296 & 9748 & 7901 & 8486 & 18534 & 22488 & 25774 & 31103 \\
\hline
\end{tabular}

Tabla 5.2.1.2. Totales anuales de los diferentes tipos de polen. Ver nota en Tabla 5.2.1.1. 


\begin{tabular}{|c|c|c|c|c|c|c|c|c|}
\hline Taxa / Año & 2000 & 2001 & 2002 & 2003 & 2004 & 2005 & 2006 & 2007 \\
\hline Abies & & - & & & - & - & - & - \\
\hline Acacia & - & - & & - & - & & - & - \\
\hline Acer & 2,8 & 2,1 & 0,5 & 0,9 & 0,6 & 0,8 & 0,4 & 0,3 \\
\hline Ailanthus & 1,7 & 1,1 & 1,2 & 0,4 & 0,1 & 0,3 & 0,2 & - \\
\hline Aesculus & & & & 0,3 & 0,1 & 0,4 & 0,3 & 0,1 \\
\hline Alnus & 1,1 & 0,8 & 1,9 & 0,9 & 0,6 & 1,1 & 0,9 & 0,6 \\
\hline Artemisia & 0,2 & 0,3 & 0,1 & 1,0 & 0,1 & 0,2 & 0,3 & 0,2 \\
\hline Betula & 0,1 & 0,4 & 0,4 & 0,1 & 0,5 & 0,7 & 0,5 & 0,5 \\
\hline Boraginaceae & - & 0,1 & - & - & - & - & - & - \\
\hline Campanula & & 0,1 & 0,1 & 0,2 & - & 0,1 & - & - \\
\hline Castanea & 1,8 & 1,3 & 0,7 & 2,2 & 1,4 & 1,9 & 2,2 & 1,3 \\
\hline Caryophyllaceae & - & & - & & - & - & - & - \\
\hline Cedrus & 0,2 & 0,2 & 0,1 & 0,6 & 0,2 & 0,2 & 0,2 & - \\
\hline Celtis & - & - & - & 0,1 & - & - & - & - \\
\hline Chenopodiaceae & 0,6 & 0,8 & 0,9 & 3,1 & 0,8 & 1,1 & 1,8 & 0,7 \\
\hline Cistaceae & - & - & & 0,1 & - & & & - \\
\hline Compositae $^{2}$ & 1,0 & 1,1 & 0,6 & 1,7 & 0,7 & 0,4 & 0,8 & 0,8 \\
\hline Convolvulus & & - & - & - & - & - & - & - \\
\hline Corylus & 0,2 & 0,1 & 0,2 & - & 0,1 & 0,1 & - & - \\
\hline Cruciferae & & & & 0,2 & 0,2 & 0,1 & 0,3 & 0,2 \\
\hline Cupressaceae & 7,6 & 12,1 & 13,6 & 12,6 & 9,9 & 10,3 & 9,5 & 11,7 \\
\hline Cyperaceae & 1,5 & 1,0 & 0,5 & 0,8 & 0,3 & 0,3 & 0,3 & 0,2 \\
\hline Cytisus & & 0,7 & 0,3 & 0,5 & 0,6 & 0,9 & 0,2 & 0,1 \\
\hline Echium & 1,1 & 0,2 & 0,2 & 1,3 & 0,4 & 0,2 & 1,0 & 0,8 \\
\hline Ericaceae & 0,4 & 0,6 & 0,8 & 0,6 & 0,9 & 0,7 & 0,7 & 0,6 \\
\hline Euphorbiaceae $^{4}$ & & & & & - & - & - & 0,1 \\
\hline Forsythia & & & & & & & & - \\
\hline Fraxinus & 0,8 & 0,7 & 2,3 & 1,0 & 1,1 & 1,1 & 1,0 & 1,2 \\
\hline Helianthus & & & & & 0,1 & - & - & 0,1 \\
\hline Juglans & 0,8 & 0,2 & 0,1 & 0,2 & 0,1 & 0,1 & 0,1 & 0,1 \\
\hline Juncaceae & 0,2 & 0,1 & 0,1 & 0,1 & - & - & - & - \\
\hline Labiatae & 0,1 & - & - & 0,1 & 0,2 & 0,1 & - & 0,1 \\
\hline Lagerstroemia & & & & & & - & - & - \\
\hline Liliaceae & & & & 0,1 & - & - & - & - \\
\hline Liguliflorae & & & & & 0,2 & 0,1 & 0,3 & 0,3 \\
\hline Ligustrum & 0,7 & 1,6 & 0,2 & 0,1 & 0,2 & 0,2 & 0,3 & - \\
\hline Lotus & & - & 0,2 & 0,3 & - & & & - \\
\hline Malvaceae & & & & & - & & & \\
\hline Mercurialis & 1,0 & 0,5 & 0,2 & 0,3 & 0,1 & 0,3 & 0,1 & 0,1 \\
\hline Morus & & - & & 0,3 & 0,1 & 0,1 & 0,1 & - \\
\hline Myrtaceae & - & - & - & 0,2 & - & 0,1 & - & - \\
\hline Olea & 2,4 & 6,8 & 6,1 & 4,7 & 4,1 & 5,0 & 7,6 & 2,2 \\
\hline Oxalis & & & & & & - & - & - \\
\hline Papaver & & - & 0,1 & 1,2 & 0,1 & 0,4 & 0,1 & - \\
\hline Pinus & 3,4 & 3,4 & 4,1 & 2,5 & 5,8 & 6,0 & 3,2 & 2,2 \\
\hline Pittosporum & & & & & & - & - & - \\
\hline Plantago & 5,2 & 3,2 & 2,8 & 4,6 & 3,0 & 2,8 & 3,4 & 5,5 \\
\hline Platanus & 3,9 & 2,9 & 3,6 & 1,7 & 3,7 & 1,9 & 5,9 & 3,3 \\
\hline Poaceae & 24,5 & 31,2 & 13,8 & 27,3 & 22,4 & 11,6 & 20,2 & 25,2 \\
\hline Populus & 6,1 & 4,3 & 2,3 & 3,6 & 2,0 & 3,1 & 3,7 & 3,5 \\
\hline Ouercus & 17,5 & 8,5 & 28,9 & 10,4 & 31,1 & 38,4 & 23,1 & 30,1 \\
\hline Ranunculaceae & & & & - & & & & \\
\hline Rhamnaceae & & & & & - & - & - & - \\
\hline Robinia & 0,7 & 1,8 & 1,7 & 0,6 & 0,2 & 0,4 & 0,1 & 0,1 \\
\hline Rosaceae & 0,2 & 1,5 & 1,4 & 0,6 & 0,1 & 0,3 & 0,2 & - \\
\hline Rubiaceae & & 0,1 & - & & - & & & - \\
\hline Rumex & 4,2 & 3,7 & 2,2 & 5,2 & 3,1 & 2,8 & 4,0 & 3,3 \\
\hline Salix & 0,9 & 0,7 & 0,7 & 0,3 & 0,4 & 0,4 & 0,7 & 0,4 \\
\hline Sambucus & 0,6 & 0,3 & 0,9 & 0,5 & 0,1 & 0,1 & 0,1 & 0,1 \\
\hline Scrophulariacae & & & & 0,2 & & - & - & - \\
\hline Solanaceae & & & & & - & - & - & - \\
\hline Sophora & & & & & & - & - & - \\
\hline Thymelaeaceae & & & & - & - & - & - & - \\
\hline Tilia & 1,5 & 1,1 & 1,1 & 0,2 & 0,1 & 0,3 & 0,1 & 0,1 \\
\hline Trifolium & 0,2 & 0,8 & 0,6 & 0,4 & 0,1 & - & 0,2 & - \\
\hline Typha & 0,2 & 0,1 & 0,1 & 0,1 & 0,1 & 0,1 & 0,1 & - \\
\hline Ulmus & 1,0 & 0,6 & 0,4 & 0,6 & 0,4 & 0,2 & 0,2 & 0,3 \\
\hline Umbelliferae & & 0,1 & & 0,2 & 0,1 & 0,1 & 0,3 & 0,2 \\
\hline Urticaceae & 3,8 & 2,4 & 2,2 & 2,4 & 2,3 & 2,5 & 4,6 & 3,2 \\
\hline Viburnum & & & 0,3 & 0,1 & - & 0,1 & - & - \\
\hline Vitis & & 0,1 & 1,3 & 0,5 & 0,1 & 0,4 & 0,1 & - \\
\hline Otros & & & - & 1,7 & 1,2 & 1,2 & 0,6 & 0,4 \\
\hline TOTAL & $100 \%$ & $100 \%$ & $100 \%$ & $100 \%$ & $100 \%$ & $100 \%$ & $100 \%$ & $100 \%$ \\
\hline
\end{tabular}

Tabla 5.2.1.3. Porcentajes de representación de los distintos tipos de polen. (- ) menores a 0,1\%. (Ver 5.2.1.1.) 
Los tipos de polen más representativos dentro del espectro polínico durante el período estudiado fueron Quercus y Poaceae, con un 23 y 22\%, respectivamente (Tabla 5.2.1.3). El resto de tipos han sido, en orden de importancia cuantitativa, Cupressaceae (11\%), Olea (5\%), Pinus (4\%), Populus (4\%), Platanus (3\%) y Castanea (2\%), dentro de los pólenes procedentes de especies leñosas, y Plantago (4\%), Rumex (4\%) y Urticaceae (3\%), dentro de los producidos por especies herbáceas. Además conviene destacar otro tipos con representación entre el o,5\% y el 1,2\% sobre el total, como Fraxinus (1,2\%), Acer (1\%), Alnus (1\%), Robinia (0,7\%), Ericaceae (0,7\%), Ailanthus (o,6\%), Tilia (o,6\%) y Salix (o,6\%), dentro de los procedentes de especies arbóreo-arbustivas, o Chenopodiaceae (1,2\%), Compositae (o,9\%), Echium (0,7\%) y Cyperaceae (o,6\%), dentro de las herbáceas. Los otros 48 tipos de polen, con representación inferior al o,5\%, aparecieron en la atmósfera de forma esporádica.

El total anual de los diversos pólenes considerados ha variado de unos años a otros (Tabla 5.2.1.1), presentando algunos de ellos fluctuaciones interanuales muy significativas, acordes con el aumento del contenido polínico ya referido a lo largo de los años estudiados. Asimismo, la evolución mensual de las concentraciones totales durante los ocho años analizados (Tabla 5.1.1.4) mostró también variaciones, pese a que existe una tendencia clara que indica que el mayor contenido polínico se localizó en los últimos meses de la primavera (mayo y junio) y las menores concentraciones en los meses de otoño. Dentro de esta dinámica general, el mes de mayo es el que presentó mayores niveles de polen, con un 35\% del total para el promedio de los años estudiados, y que osciló entre el 46 y el $47 \%$ de los años 2005 y 2006 y el 25\% de 2003. El mes de junio fue el segundo mes con mayores concentraciones de polen (27\% del total promediado), fluctuando entre el 37\% de los años 2001 y 2004, y el 13\% del año 2006. Los meses de marzo y abril, ambos con un 10\% sobre el total promedio, también presentaron una notable incidencia en el contenido polínico.

\begin{tabular}{|c|c|c|c|c|c|c|c|c|c|c|c|c|c|}
\hline & Ene & Feb & Mar & Abr & May & Jun & Jul & Ago & Sep & Oct & Nov & Dic & Total \\
\hline 2000 & 112 & 952 & 1479 & 695 & 3578 & 3826 & 380 & 144 & 58 & 33 & 12 & 27 & 11296 \\
2001 & 201 & 492 & 1004 & 794 & 2701 & 3639 & 637 & 88 & 99 & 42 & 35 & 15 & 9748 \\
2002 & 290 & 673 & 541 & 843 & 3366 & 1496 & 328 & 120 & 103 & 38 & 59 & 44 & 7901 \\
2003 & 104 & 358 & 925 & 673 & 2113 & 2673 & 652 & 315 & 229 & 116 & 52 & 276 & 8486 \\
2004 & 1014 & 682 & 862 & 1437 & 6134 & 6865 & 950 & 269 & 188 & 63 & 18 & 54 & 18534 \\
2005 & 100 & 1004 & 2367 & 2902 & 10464 & 4014 & 887 & 388 & 205 & 106 & 36 & 16 & 22488 \\
2006 & 78 & 1011 & 2888 & 3277 & 12284 & 3250 & 1244 & 620 & 251 & 199 & 443 & 229 & 25774 \\
2007 & 473 & 1850 & 3315 & 2606 & 9231 & 9204 & 3653 & 492 & 203 & 46 & 19 & 11 & 31103 \\
\hline Media & 296 & 878 & 1673 & 1653 & 6234 & 4371 & 1091 & 304 & 167 & 81 & 84 & 84 & 16916 \\
\hline
\end{tabular}

Tabla 5.2.1.4. Evolución mensual de las concentraciones totales (2000-2008).

A través de la media móvil de los cinco días anteriores para las concentraciones promedio para los ocho años (Fig. 5.2.1.2.) podemos inferir la dinámica de las concentraciones polínicas en este período, sobre la base de la existencia de granos de polen a 
lo largo de toda una anualidad promedidada. Así pues, los niveles de polen aumentaron a partir del mes de febrero hasta principios de junio, momento en el que las concentraciones de polen en la atmósfera disminuyen hasta llegar a sus niveles más bajos en los últimos meses del año. Este patrón general experimentó ligeros cambios en cada uno de los años estudiados, destacando los años 2002 y 2004, donde los niveles de polen comienzan a ascender desde los primeros días del mes de enero, o el año 2006, donde se observó un pequeño incremento a mediados del mes de noviembre.

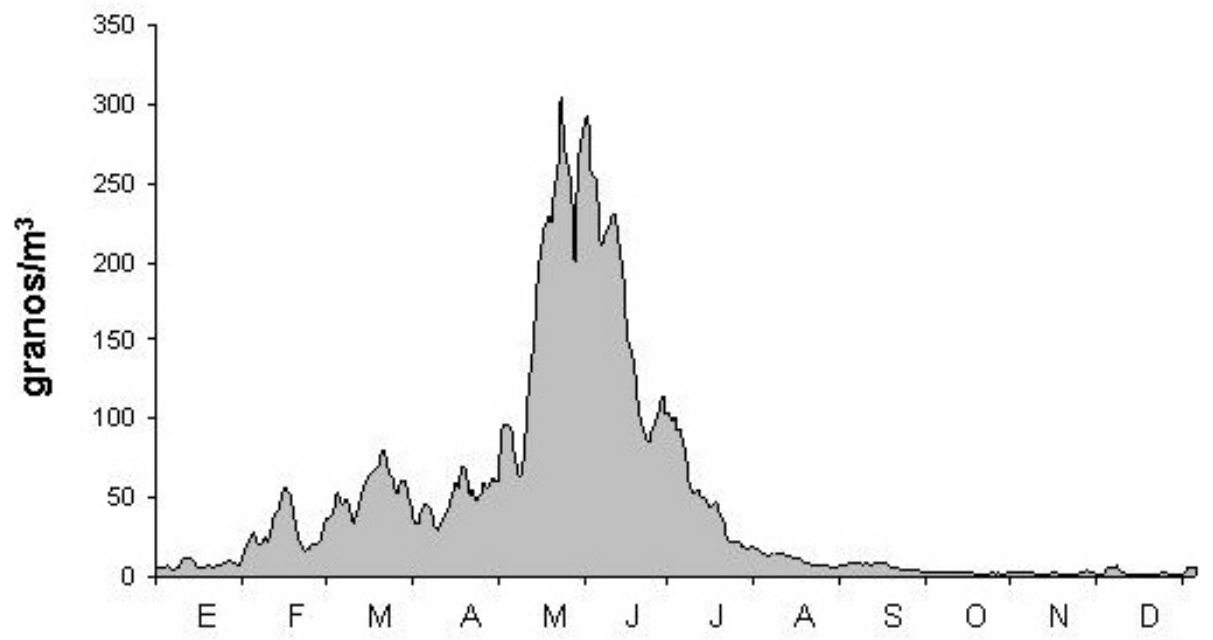

Fig. 5.2.1.2. Medias móviles de los cinco días anteriores para las concentraciones diarias promedio (2000-2007).

La evolución de las concentraciones polínicas a lo largo del año permite inferir cuándo se localizan las mayores concentraciones polínicas diarias, siendo el día 29 de mayo el día con los niveles de polen más elevado para el promedio de concentraciones diarias (399 granos $/ \mathrm{m}^{3}$ ). Estos valores fluctuaron desde los 1264 granos $/ \mathrm{m}^{3}$ el día 15 de mayo de 2005 a los 207 granos $/ \mathrm{m}^{3}$ del día 16 de junio, constituyendo además el intervalo temporal en el que se encontraron el resto de concentraciones más elevadas. 


\subsubsection{Tipos de polen con una representación superior o igual al 1\% (al menos 5 años)}

\subsubsection{Castanea}

\section{La variación interanual (Fig.} 5.2.2.1.) nos indica que durante los ocho años de estudio hubo un incremento en las concentraciones de este tipo polínico en la atmósfera de Salamanca, a pesar del descenso observado en los tres primeros años. Así pues, en un lustro (2002-2006) el total anual experimentó un aumento de los 58 a los 574 pólenes, suponiendo un incremento del $605 \%$, tal y como muestra también el análisis de tendencias a través de la regresión lineal $\left(\mathrm{R}^{2}=0,66\right)$. Estos valores supusieron entre un 2,2\% (2003 y2006) y un $0,7 \%$ (2002) del total de pólenes contabilizados (promedio: 1,6\%).

La variación estacional, analizada a partir del PPP y las tres metodologías referidas mostró una clara delimitación en los meses de junio y julio, independientemente de la duración de este PPP, variable en una decena de días según el modelo elegido para su cálculo (Tabla 5.2.2.1). En todo caso, la duración media se situó entre los 34 y los 46 días, comenzando entre principios $\mathrm{y}$ mediados de junio $\mathrm{y}$ finalizando a mediados o finales de julio. La única excepción a este patrón la constituye el año 2000 que a través del 98\% del contenido polínico total fijó el inicio del PPP a finales del mes de mayo (29 de mayo).

La evolución de las concentraciones a través de las concentraciones promedio para los cinco días anteriores durante el período 2000-2007 volvió a refrendar esta dinámica ya que
Tipo polínico: Castanea sativa

Especie(s): Castanea sativa Mill. (Fagaceae)

Distribución: Sur de Europa, norte de África y Asia menor. En la Península Ibérica, ocupa valles altos y templados de la cordillera Cantábrica, Pirineos Occidentales, el Sistema Central y, en menor medida, la cordillera Penibética. En la provincia de Salamanca, se distribuye por los valles del sur de las Sierras de Francia, fundamentalmente, de Gata y de Béjar, formando bosques que alcanzan grandes extensiones.

Época de floración: Inicio del período estival (junio y julio), en el centro y el norte peninsular, y a finales de la primavera (abril y mayo), en el sur.

Polinización: Anfifila, iniciándose con amentos de gran tamaño olorosos y sustancias adhesivas y acabando con un claro predominio de la anemofilia al secarse dichos amentos.

Morfología polínica (Lámina I): Polen trizonocolporado, isopolar y radiosimétrico, con una forma circular a subtriangular en vista polar y elíptica en vista ecuatorial (de subprolato a prolato), y un tamaño pequeño $(P=10-16 \mu \mathrm{m})$. Las ectoaberturas tipo colpo son terminales, mientras que las endoaberturas tipo poro se sitúan en el ecuador, con membrana abertural escábrida. La exina, de grosor fino (1-2 $\mu \mathrm{m})$, posee una superficie rugulada. 
los niveles de polen aumentan desde la primera semana del mes de junio hasta la última semana del mismo (Fig. 5.2.2.2.D.), presentando una concentración máxima de 18 granos $/ \mathrm{m}^{3}$ el día 27 de junio como media de los ocho años estudiados (Tabla 5.2.2.1.).

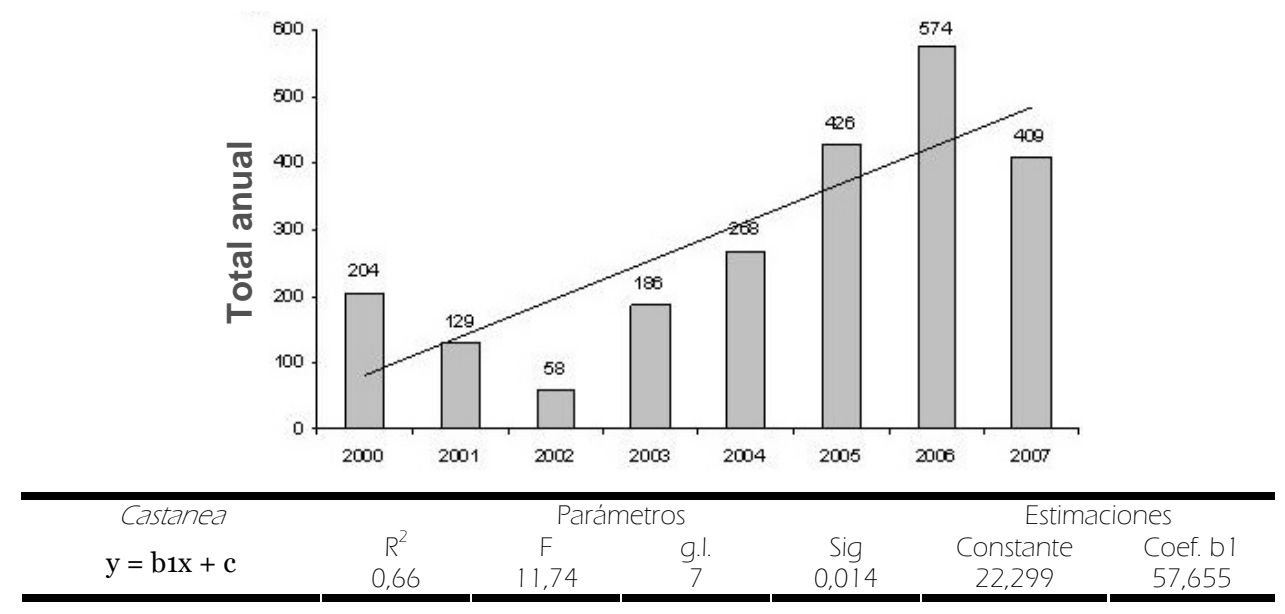

Fig. 5.2.2.1. Evolución anual del número total de pólenes de Castanea y tendencias (análisis de regresión).

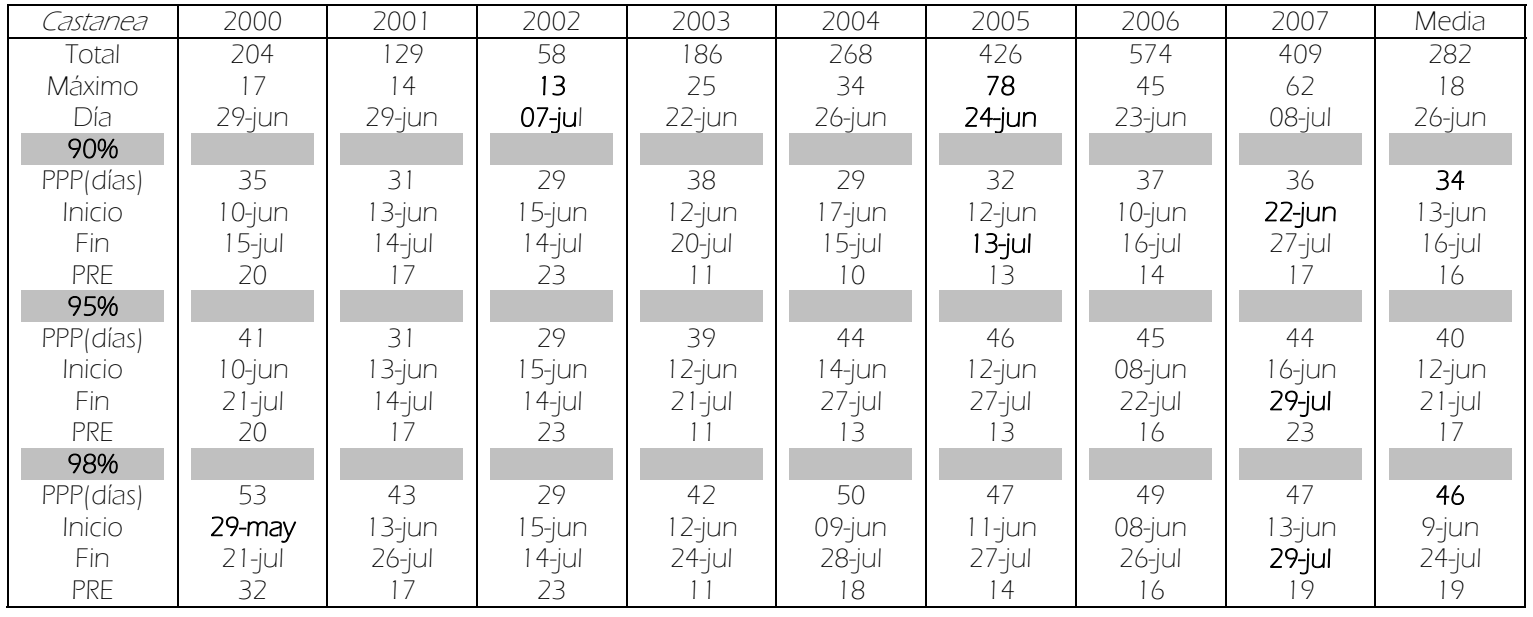

Tabla 5.2.2.1. Totales, concentraciones máximas diarias, períodos principales de polinización (PPP; fecha de inicio y fin) y días precedentes al valor máximo (PRE) durante los ocho años de estudio y el promedio de todos los parámetros para Castanea.

Las mayores concentraciones diarias para los años estudiados variaron tanto en número como en la fecha en la que se produjeron (Tabla 5.2.2.1.), oscilando entre los 78 granos $/ \mathrm{m}^{3}$ (24 junio de 2005) y los 13 granos $/ \mathrm{m}^{3}$ (7 julio de 2002). Posteriormente, las concentraciones de polen fueron disminuyendo hasta valores anecdóticos a finales del mes de julio, pudiendo encontrarse algunos granos de polen durante el mes de agosto (Fig. 5.2.2.2. A. B. C.).

En lo referente a la variación intradiaria (Fig. 5.2.2.3.), las mayores concentraciones se localizaron entre las 23 y las 8 horas, ya que suponen más del 50\% del total de pólenes contabilizados a lo largo de un día promedio para los años 2005, 2006 y 
2007. El resto de las horas mostraron porcentajes inferiores, que alcanzaron valores mínimos entre las 13 y las 18 horas.
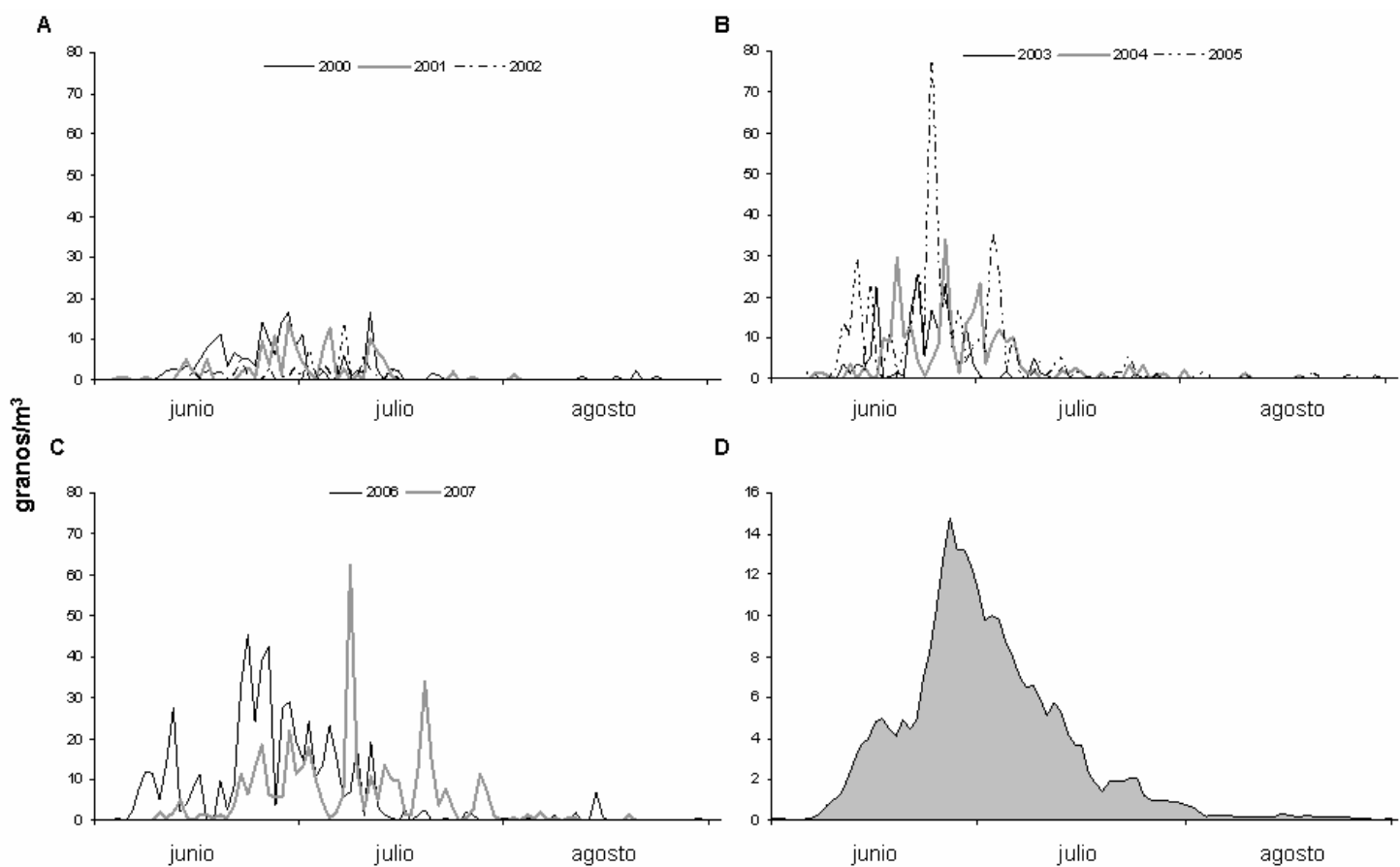

Fig. 5.2.2.2. Variación de las concentraciones medias diarias de Castanea durante el período 2000-2002 (A), 2003-2005 (B) y 2006-2007 (C). Medias móviles de los cinco días anteriores para las concentraciones diarias promedio de los ocho años estudiados (D).

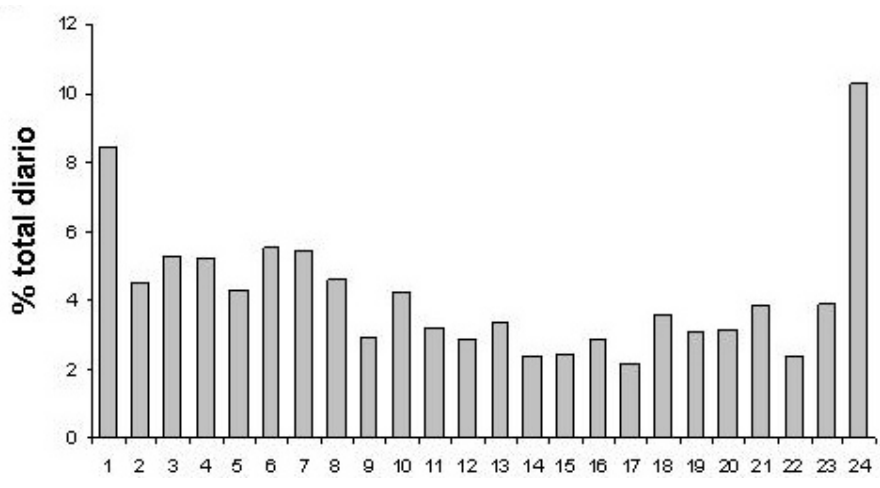

Fig. 5.2.2.3. Variación intradiaria del polen de Castanea.

El análisis de correlación (Tabla 5.2.2.2.) reflejó que las temperaturas medias, máximas y mínimas junto a la insolación influyeron positivamente en los niveles polínicos durante los ocho años analizados. Por el contrario, la precipitación y la humedad relativa ejercieron un efecto negativo sobre las concentraciones polínicas. En lo referente a los vientos, debe destacarse la correlación positiva con los vientos procedentes del IV cuadrante y negativa con los del II cuadrante. Si analizamos cada año y modelo estudiados por separado, se observa un patrón similar, aunque es reseñable la influencia negativa de vientos del I y II cuadrante y positiva de los vientos del III cuadrante durante el PPP y el PRE en el año 2007. Asimismo, durante el PRE de 2002 en cualquiera de las tres metodologías 
utilizadas la velocidad del viento influyó positivamente en los niveles de polen, mientras que lo hizo de manera negativa durante el PPP de 2006.

\begin{tabular}{|c|c|c|c|c|c|c|c|}
\hline \multicolumn{2}{|c|}{ Castanea } & Tmed & Tmax & Tmin & Insolación & Precipitación & Hrelativa \\
\hline 2000 & Anual & $0,425^{\star *}$ & $0,416^{* *}$ & $0,398 * *$ & $0,411^{\star *}$ & $-0,183^{\star \star}$ & $-0,439$ ** \\
\hline \multirow{2}{*}{$90 \%$} & PPP & $0,519 * *$ & $0,413 * *$ & $0,447 * *$ & $-0,091$ & $-0,303$ & $-0,126$ \\
\hline & PRE & $0,597 * *$ & 0,393 & 0,561 * & $-0,469 *$ & - & $-0,023$ \\
\hline \multirow{2}{*}{$95 \%$} & PPP & 0,194 & 0,131 & 0,181 & $-0,065$ & $-0,312^{\star}$ & $-0,132$ \\
\hline & PRE & $0,597 * *$ & 0,393 & $0,561^{*}$ & $-0,469 *$ & - & $-0,023$ \\
\hline \multirow{2}{*}{$98 \%$} & PPP & 0,252 & 0,226 & 0,218 & 0,090 & $-0,301$ * & $-0,258$ \\
\hline & PRE & $0,541 * *$ & $0,500^{* *}$ & $0,474^{* *}$ & 0,055 & $-0,312$ & $-0,377^{*}$ \\
\hline 2001 & Anual & $0,349 * \star$ & 0,332 ** & $0,351^{* *}$ & $0,331^{* *}$ & $-0,102$ & $-0,359$ ** \\
\hline \multirow{2}{*}{$90 \%$} & PPP & 0,033 & $-0,066$ & 0,254 & 0,122 & $-0,067$ & $-0,095$ \\
\hline & PRE & $-0,030$ & $-0,255$ & 0,372 & $-0,154$ & - & 0,068 \\
\hline \multirow{2}{*}{$95 \%$} & PPP & 0,033 & $-0,066$ & 0,254 & 0,122 & $-0,067$ & $-0,095$ \\
\hline & PRE & $-0,030$ & $-0,255$ & 0,372 & $-0,154$ & - & 0,068 \\
\hline \multirow{2}{*}{$98 \%$} & PPP & 0,115 & 0,019 & $0,306 *$ & 0,132 & $-0,103$ & $-0,179$ \\
\hline & PRE & $-0,030$ & $-0,255$ & 0,372 & $-0,154$ & - & 0,068 \\
\hline 2002 & Anual & $0,310 * *$ & $0,306 * *$ & $0,289 * *$ & $0,283^{* *}$ & $-0,119 * *$ & $-0,321$ ** \\
\hline \multirow{2}{*}{$90 \%$} & PPP & $0,593^{* *}$ & $0,594^{* *}$ & $0,578 * *$ & $0,515^{* *}$ & $-0,181$ & $-0,626^{* *}$ \\
\hline & PRE & 0,591 ** & $0,596 * *$ & $0,582 * *$ & $0,537 * *$ & $-0,255^{* *}$ & $-0,635 * *$ \\
\hline \multirow{2}{*}{$95 \%$} & PPP & $0,593 * *$ & $0,594 * *$ & $0,578 * *$ & $0,515 * *$ & $-0,181$ & $-0,626 * *$ \\
\hline & PRE & $0,591 * *$ & $0,596 * *$ & $0,582 * *$ & $0,537 * *$ & $-0,255^{* *}$ & $-0,635 * *$ \\
\hline \multirow{2}{*}{$98 \%$} & PPP & $0,593 * *$ & $0,594 * *$ & $0,578 * *$ & $0,515^{* *}$ & $-0,181$ & $-0,626 * *$ \\
\hline & PRE & $0,591 * *$ & $0,596 * *$ & $0,582 * *$ & $0,537 * *$ & $-0,255^{* *}$ & $-0,635 * *$ \\
\hline 2003 & Anual & $0,388^{*}$ & $0,369^{* *}$ & $0,381^{* *}$ & $0,307^{* *}$ & $-0,098$ & $-0,384^{* *}$ \\
\hline \multirow{2}{*}{$90 \%$} & PPP & $0,349 *$ & 0,244 & $0,474 * *$ & $-0,027$ & 0,155 & $-0,139$ \\
\hline & PRE & 0,283 & 0,128 & 0,259 & $-0,041$ & 0,224 & $-0,005$ \\
\hline \multirow{2}{*}{$95 \%$} & PPP & $0,359 *$ & 0,233 & $0,498 * *$ & $-0,043$ & 0,161 & $-0,154$ \\
\hline & PRE & 0,283 & 0,128 & 0,259 & $-0,041$ & 0,224 & $-0,005$ \\
\hline \multirow{2}{*}{$98 \%$} & PPP & $0,336 * *$ & 0,249 & $0,440 * *$ & $-0,056$ & $-0,171$ & $-0,185$ \\
\hline & PRE & 0,283 & 0,128 & 0,259 & $-0,041$ & 0,224 & $-0,005$ \\
\hline 2004 & Anual & 0,460 ** & $0,441^{* *}$ & $0,447 * *$ & $0,383^{* *}$ & $-0,114^{*}$ & $-0,346 * *$ \\
\hline \multirow{2}{*}{$90 \%$} & PPP & 0,302 & 0,304 & 0,238 & 0,106 & $-0,113$ & $-0,062$ \\
\hline & PRE & 0,190 & $-0,046$ & 0,175 & $-0,224$ & - & $-0,054$ \\
\hline \multirow{2}{*}{$95 \%$} & PPP & 0,070 & 0,123 & $-0,070$ & 0,130 & - & 0,051 \\
\hline & PRE & 0,190 & $-0,046$ & 0,175 & $-0,224$ & - & $-0,054$ \\
\hline \multirow{2}{*}{$98 \%$} & PPP & 0,027 & 0,127 & $-0,158$ & 0,119 & $-0,150$ & $-0,018$ \\
\hline & PRE & $-0,122$ & $-0,135$ & $-0,223$ & $-0,147$ & $-0,353$ & $-0,056$ \\
\hline 2005 & Anual & $0,514^{* *}$ & $0,487^{* *}$ & $0,504^{* *}$ & $0,437 * *$ & $-0,146^{* *}$ & $-0,471$ ** \\
\hline $90 \%$ & PPP & 0,041 & $-0,198$ & 0,259 & $-0,263$ & $-0,024$ & 0,137 \\
\hline $90 \%$ & PRE & $-0,124$ & $-0,302$ & 0,036 & $-0,064$ & $-0,135$ & 0,227 \\
\hline $050 \%$ & PPP & 0,087 & $-0,062$ & 0,091 & $-0,044$ & 0,048 & 0,051 \\
\hline $95 \%$ & PRE & $-0,124$ & $-0,302$ & 0,036 & $-0,064$ & $-0,135$ & 0,227 \\
\hline $080 \%$ & $\overline{P P P}$ & 0,065 & $-0,088$ & 0,071 & $-0,039$ & 0,043 & 0,039 \\
\hline $98 \%$ & PRE & $-0,108$ & $-0,251$ & 0,040 & $-0,060$ & $-0,143$ & 0,190 \\
\hline 2006 & Anual & $0,506 * *$ & $0,477^{* \star}$ & $0,511^{* *}$ & - & $-0,095$ & $-0,422^{* *}$ \\
\hline 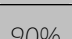 & PPP & $-0,058$ & $-0,099$ & $-0,235$ & - & $-0,366^{*}$ & $-0,411^{\star}$ \\
\hline $90 \%$ & PRE & $0,667 * *$ & $0,738 * *$ & 0,230 & - & $-0,327$ & $-0,666 * *$ \\
\hline $050 \%$ & PPP & $-0,187$ & $-0,166$ & $-0,234$ & - & $-0,251$ & $-0,274$ \\
\hline $95 \%$ & PRE & $0,664 * *$ & $0,716 * *$ & 0,225 & - & $-0,305^{\star}$ & $-0,612^{*}$ \\
\hline $080 \%$ & PPP & $-0,239$ & $-0,198$ & $-0,308^{*}$ & - & $-0,176$ & $-0,205$ \\
\hline $98 \%$ & PRE & $0,664 * *$ & 0,716 ** & 0,225 & - & $-0,305^{\star}$ & $-0,612^{*}$ \\
\hline 2007 & Anual & $0,494 * *$ & 0,476 ** & $0,442 * *$ & $0,417 * *$ & $-0,130^{*}$ & $-0,437^{* *}$ \\
\hline $90 \%$ & PPP & $-0,136$ & $-0,109$ & 0,072 & $-0,178$ & $-0,084$ & 0,047 \\
\hline $90 \%$ & PRE & $-0,266$ & $-0,317$ & 0,191 & $-0,436$ & - & 0,435 \\
\hline 950 & PPP & $-0,022$ & 0,021 & $-0,059$ & 0,013 & $-0,174$ & $-0,083$ \\
\hline $95 \%$ & PRE & 0,232 & 0,254 & 0,045 & 0,067 & $-0,350$ & $-0,205$ \\
\hline $980 \%$ & PPP & 0,024 & 0,077 & $-0,077$ & 0,150 & $-0,207$ & $-0,128$ \\
\hline $98 \%$ & PRE & 0,385 & $0,430 *$ & 0,074 & 0,238 & $-0,413^{*}$ & $-0,350$ \\
\hline Total & Anual & $0,434 * *$ & $0,416^{* \star}$ & $0,411^{* *}$ & $0,370 * *$ & $-0,126^{\star \star}$ & $-0,373^{\star *}$ \\
\hline
\end{tabular}

Tabla 5.2.2.2. Coeficientes de correlación de Spearman entre Castanea y las variables climatológicas. Tmed, Tmax, Tmin (temperatura media, máxima y mínima), Hrelativa (humedad relativa). Significación: $95 \%\left({ }^{*}\right)$, $99 \%(* *)$. (-) Ausencia de correlaciones. 


\begin{tabular}{|c|c|c|c|c|c|c|c|}
\hline \multicolumn{2}{|c|}{ Castanea } & Vemed & FrecCalm & V1Cuadr & V2Cuadr & V3Cuadr & V4Cuadr \\
\hline 2000 & Anual & 0,084 & $-0,072$ & 0,080 & $-0,060$ & $-0,069$ & 0,040 \\
\hline \multirow{2}{*}{$90 \%$} & PPP & $-0,149$ & 0,131 & $-0,133$ & $-0,062$ & 0,125 & 0,049 \\
\hline & PRE & $-0,432$ & $0,507^{*}$ & $-0,390$ & 0,156 & 0,306 & 0,239 \\
\hline \multirow{2}{*}{$95 \%$} & PPP & $-0,003$ & $-0,037$ & $-0,107$ & $-0,108$ & 0,082 & 0,005 \\
\hline & PRE & $-0,432$ & 0,507 * & $-0,390$ & 0,156 & 0,306 & 0,239 \\
\hline \multirow{2}{*}{$98 \%$} & PPP & 0,063 & $-0,076$ & $-0,058$ & $-0,160$ & 0,083 & $-0,077$ \\
\hline & PRE & $-0,022$ & 0,084 & $-0,181$ & $-0,017$ & 0,136 & $-0,043$ \\
\hline 2001 & Anual & 0,026 & $-0,84$ & $-0,118^{*}$ & $-0,090$ & 0,078 & $0,297^{* *}$ \\
\hline \multirow{2}{*}{$90 \%$} & PPP & 0,100 & $-0,167$ & $-0,246$ & $-0,084$ & 0,157 & 0,205 \\
\hline & PRE & 0,161 & $-0,210$ & $-0,394$ & $-0,168$ & 0,269 & $0,535^{*}$ \\
\hline \multirow{2}{*}{$95 \%$} & PPP & 0,100 & $-0,167$ & $-0,246$ & $-0,084$ & 0,157 & 0,205 \\
\hline & PRE & 0,161 & $-0,210$ & $-0,394$ & $-0,168$ & 0,269 & $0,535^{*}$ \\
\hline \multirow{2}{*}{$98 \%$} & PPP & 0,147 & $-0,172$ & $-0,141$ & $-0,011$ & 0,174 & 0,050 \\
\hline & PRE & 0,161 & $-0,210$ & $-0,394$ & $-0,168$ & 0,269 & $0,535^{*}$ \\
\hline 2002 & Anual & 0,042 & $-0,043$ & 0,017 & $-0,121^{*}$ & $-0,064$ & $0,117^{*}$ \\
\hline \multirow{2}{*}{$90 \%$} & PPP & 0,246 & $-0,266^{*}$ & 0,073 & $-0,306^{*}$ & $-0,101$ & $0,295^{*}$ \\
\hline & PRE & 0,270 * & $-0,234$ & 0,071 & $-0,263$ * & $-0,089$ & $0,277^{*}$ \\
\hline \multirow{2}{*}{$95 \%$} & PPP & 0,246 & $-0,266$ * & 0,073 & $-0,306$ * & $-0,101$ & $0,295^{*}$ \\
\hline & PRE & 0,270 * & $-0,234$ & 0,071 & $-0,263$ * & $-0,089$ & 0,277 * \\
\hline \multirow{2}{*}{$98 \%$} & PPP & 0,246 & $-0,266$ * & 0,073 & $-0,306$ * & $-0,101$ & $0,295^{*}$ \\
\hline & PRE & 0,270 * & $-0,234$ & 0,071 & $-0,263^{*}$ & $-0,089$ & $0,277^{*}$ \\
\hline 2003 & Anual & 0,015 & $-0,127^{*}$ & 0,001 & 0,092 & 0,055 & 0,079 \\
\hline \multirow{2}{*}{$90 \%$} & PPP & 0,149 & $-0,254$ & 0,135 & 0,191 & 0,116 & $-0,361$ * \\
\hline & PRE & $-0,138$ & 0,494 & $-0,434$ & 0,245 & 0,389 & 0,164 \\
\hline \multirow{2}{*}{$95 \%$} & PPP & 0,191 & $-0,289$ & 0,134 & 0,148 & 0,141 & $-0,371$ * \\
\hline & PRE & $-0,138$ & 0,494 & $-0,434$ & 0,245 & 0,389 & 0,164 \\
\hline \multirow{2}{*}{$98 \%$} & PPP & 0,156 & $-0,309 *$ & 0,197 & 0,205 & 0,122 & $-0,398 * *$ \\
\hline & PRE & $-0,138$ & 0,494 & $-0,434$ & 0,245 & 0,389 & 0,164 \\
\hline 2004 & Anual & $0,146^{*}$ & $-0,083$ & $-0,066$ & $-0,023$ & 0,010 & $0,234^{* *}$ \\
\hline \multirow{2}{*}{$90 \%$} & PPP & 0,305 & $0,394^{*}$ & $-0,285$ & 0,179 & 0,321 & 0,276 \\
\hline & PRE & 0,462 & 0,531 & $-0,319$ & 0,353 & 0,222 & 0,534 \\
\hline \multirow{2}{*}{$95 \%$} & PPP & 0,281 & 0,194 & $-0,184$ & 0,086 & 0,172 & 0,265 \\
\hline & PRE & 0,462 & 0,531 & $-0,319$ & 0,353 & 0,222 & 0,534 \\
\hline \multirow{2}{*}{$98 \%$} & PPP & 0,214 & 0,124 & $-0,164$ & 0,014 & 0,176 & 0,240 \\
\hline & PRE & 0,207 & 0,147 & $-0,434$ & 0,006 & 0,449 & 0,374 \\
\hline 2005 & Anual & 0,044 & $-0,115^{*}$ & 0,005 & $-0,102$ & 0,015 & $0,132^{*}$ \\
\hline $90 \%$ & PPP & $-0,043$ & 0,274 & $-0,49 * *$ & $-0,087$ & $0,500^{* *}$ & $0,462^{\star \star}$ \\
\hline $70 \%$ & PRE & 0,199 & 0,089 & $-0,612^{*}$ & $-0,481$ & $0,707^{* *}$ & 0,199 \\
\hline $95 \%$ & PPP & $-0,088$ & 0,093 & $-0,113$ & $-0,042$ & 0,093 & 0,218 \\
\hline $75 \%$ & PRE & 0,199 & 0,089 & $-0,612^{*}$ & $-0,481$ & $0,707^{* *}$ & 0,199 \\
\hline $98 \%$ & PPP & $-0,063$ & 0,091 & $-0,123$ & $-0,031$ & 0,126 & 0,210 \\
\hline $78 \%$ & PRE & 0,128 & 0,090 & $-0,602^{*}$ & $-0,487$ & $0,647^{*}$ & 0,232 \\
\hline 2006 & Anual & $-0,005$ & $-0,126 *$ & 0,039 & $-0,044$ & 0,009 & $0,221^{* *}$ \\
\hline $90 \%$ & PPP & $0,46^{* *}$ & $-0,081$ & $-0,44^{* *}$ & $-0,297$ & 0,303 & 0,295 \\
\hline $70 \%$ & PRE & 0,371 & $-0,224$ & $-0,100$ & 0,127 & 0,207 & $-0,196$ \\
\hline $95 \%$ & PPP & $0,500^{* *}$ & $-0,080$ & $-0,283$ & $-0,266$ & 0,107 & 0,237 \\
\hline $75 \%$ & PRE & 0,348 & $-0,229$ & $-0,124$ & 0,185 & 0,171 & $-0,221$ \\
\hline $080 \%$ & PPP & $0,530 * *$ & $-0,087$ & $-0,170$ & $-0,139$ & $-0,023$ & 0,180 \\
\hline $98 \%$ & PRE & 0,348 & $-0,229$ & $-0,124$ & 0,185 & 0,171 & $-0,221$ \\
\hline 2007 & Anual & 0,066 & 0,021 & $-0,20^{* *}$ & $-0,173^{* *}$ & $0,179^{* *}$ & $0,193^{* *}$ \\
\hline (ח & PPP & $0,333^{*}$ & $-0,115$ & $-0,389 *$ & $-0,396^{*}$ & 0,303 & 0,152 \\
\hline $70 \%$ & PRE & 0,401 & $-0,275$ & $-0,688 *$ & $-0,521$ * & 0,540 * & $0,622^{* *}$ \\
\hline $95 \%$ & PPP & 0,140 & $-0,041$ & $-0,162$ & $-0,371$ * & 0,104 & 0,194 \\
\hline $75 \%$ & PRE & $-0,124$ & $-0,061$ & $-0,090$ & $-0,406$ & $-0,040$ & $0,537^{* *}$ \\
\hline $980 \%$ & PPP & $-0,030$ & 0,061 & $-0,066$ & $-0,258$ & $-0,053$ & 0,257 \\
\hline $98 \%$ & PRE & $-0,269$ & 0,057 & 0,071 & $-0,195$ & $-0,274$ & $0,595^{* *}$ \\
\hline Total & Anual & $-0,002$ & $0,059^{* *}$ & $-0,022$ & $-0,075$ ** & 0,017 & $0,168^{* *}$ \\
\hline
\end{tabular}

Tabla 5.2.2.2. (Continuación). Coeficientes de correlación de Spearman entre Castanea y las variables climatológicas. Vemed (velocidad media), FrecCalmas (frecuencia de calmas), V1Cuad, V2Cuad, V3Cuad, V4Cuad (vientos procedentes del I, II, III y IV cuadrante). Significación: $95 \%(*)$, 99\%(**). (-) Ausencia de correlaciones. 


\subsubsection{Cupressaceae}

La variación interanual (Fig. 5.2.2.4.) de este tipo polínico en la atmósfera mostró un incremento en los niveles polínicos anuales durante el período 2000-2007. Este aumento, desde la perspectiva numérica, supuso el paso de los 855 granos de polen en el año 2000 a los 3635 de 2007, lo cual conlleva un aumento del 325\%. El valor del índice de determinación $\left(\mathrm{R}^{2}=0,85\right)$, también refrenda de manera estadística mediante regresión lineal esta tendencia. Los porcentajes de representación sobre el total de pólenes contabilizados en cada anualidad estudiada variaron del 13,6\% de 2002 al 7,6\% de 2000, con un porcentaje medio de 10,9\%.

La variación estacional, fue muy amplia (Tabla 5.2.2.3.), ya que abarcó la primera mitad del año con un PPP promedio que osciló entre 136 y 170 días, según el modelo utilizado, y localizado entre mediados y finales de enero hasta mediados de junio y principios de julio. Esta evidente variación en función del año analizado y del modelo usado, se presentó en las fechas de inicio, teniendo el 5 de enero de 2000 como fecha más temprana (método 98\%) y el 11 de febrero de 2006 como la más tardía (90\%), y en las fechas de finalización del

\section{Tipo polínico: Juniperus oxycedrus}

Especie(s): Varias pertenecientes a las familia Taxodiaceae, Cefalotaxaceae, Taxaceae y Cupressaceae, fundamentalmente de los géneros Juniperus L. y Cupressus L.

Distribución: Familias botánicas nativas de hemisferio Norte, diseminadas también por el hemisferio Sur. En la Península Ibérica destacan los matorrales xerófilos de varias especies de género Juniperus L., como los presentes en Arribes de Duero con Juniperus oxycedrus L. Diversas especies del género Cupressus L. están ampliamente cultivadas de forma ornamental en muchas ciudades, como en Salamanca.

Época de floración: Sucesiva a lo largo de año, fundamentalmente en invierno, y variable en función de las especies.

Polinización: Anemófila.

Morfología polínica (Lámina II): Polen inaberturado o monoanaporado, con una abertura tipo úlcera o leptoma en el polo distal difícil de apreciar al microscopio óptico, apolar y radiosimétrico, con una forma esferoidal, y un tamaño mediano (diámetro $=20-30 \mu \mathrm{m}$ ). La exina, delgada $(1,2-1,5 \mu \mathrm{m}), \quad$ y con un infratéctum sin columelas, se fractura con facilidad y posee una superficie psilada o suavemente granulada con orbículos distribuidos irregularmente. La intina es gruesa junto a un citoplasma con un típico aspecto estrellado.

PPP, con un intervalo entre el 16 de abril de 2005 (90\%) y el 20 de julio de 2006 (98\%).

La dinámica que presentaron las concentraciones polínicas de Cupressaceae (Fig. 5.2.2.5.D.) representada con las concentraciones promedio para los cinco días anteriores durante los años analizados, mostró un incremento de las concentraciones desde los meses de noviembre y diciembre hasta finales de marzo, presentando una concentración máxima de 77 granos $/ \mathrm{m}^{3}$ el día 4 de marzo como media del período 2000-2007 (Tabla 5.2.2.3.). 
Asimismo, se produjo una disminución en los niveles de polen en abril, manteniéndose en la atmósfera durante el resto del año, especialmente en los meses de mayo y junio. Las concentraciones diarias más elevadas dentro de los ocho años (Fig. 5.2.2.5. A. B. C.), localizadas a finales de febrero e inicios de marzo, variaron entre los 550 granos $/ \mathrm{m}^{3}$ (4 de marzo de 2007) y los 55 granos/m³ (29 de febrero de 2000).

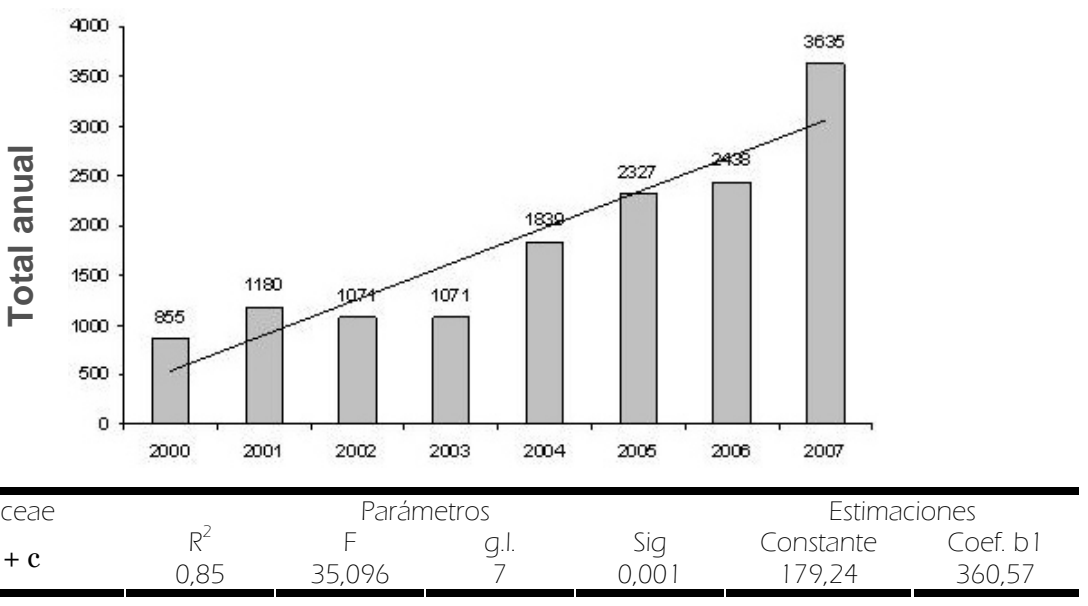

Fig. 5.2.2.4. Evolución anual del número total de pólenes de Cupressaceae y tendencias (análisis de regresión).

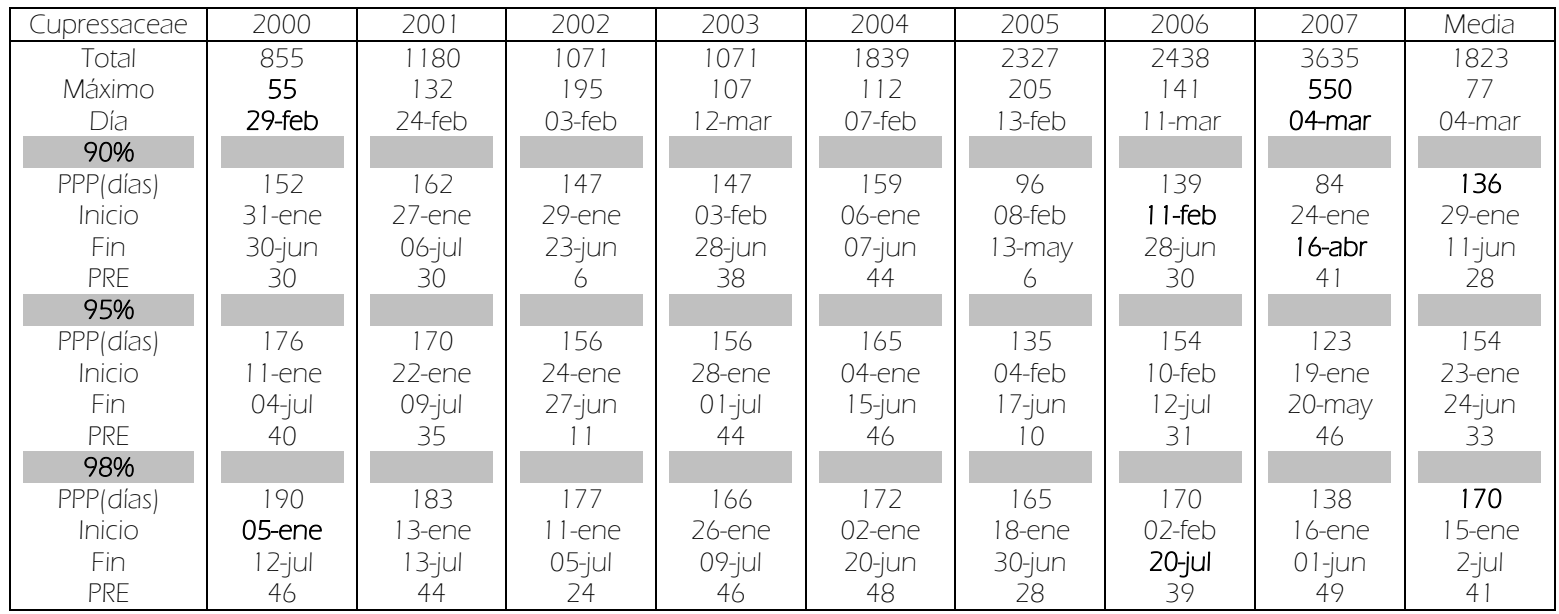

Tabla 5.2.2.3. Totales, concentraciones máximas diarias, períodos principales de polinización (PPP; fecha de inicio y fin) y días precedentes al valor máximo (PRE) durante los ocho años de estudio y el promedio de todos los parámetros para Cupressaceae.

La variación intradiaria (Fig. 5.2.2.6.) mostró un claro patrón a lo largo de un día promedio para los últimos tres años estudiados, por el que los niveles de polen aumentaron desde las primeras horas del día hasta las horas centrales del día, momento en el que comienzan a disminuir las concentraciones hasta las últimas horas del día. Así pues, el 60\% de las concentraciones polínicas distribuidas a lo largo de un día se concentran en las horas centrales del día, entre las 11 y las 20 horas. 

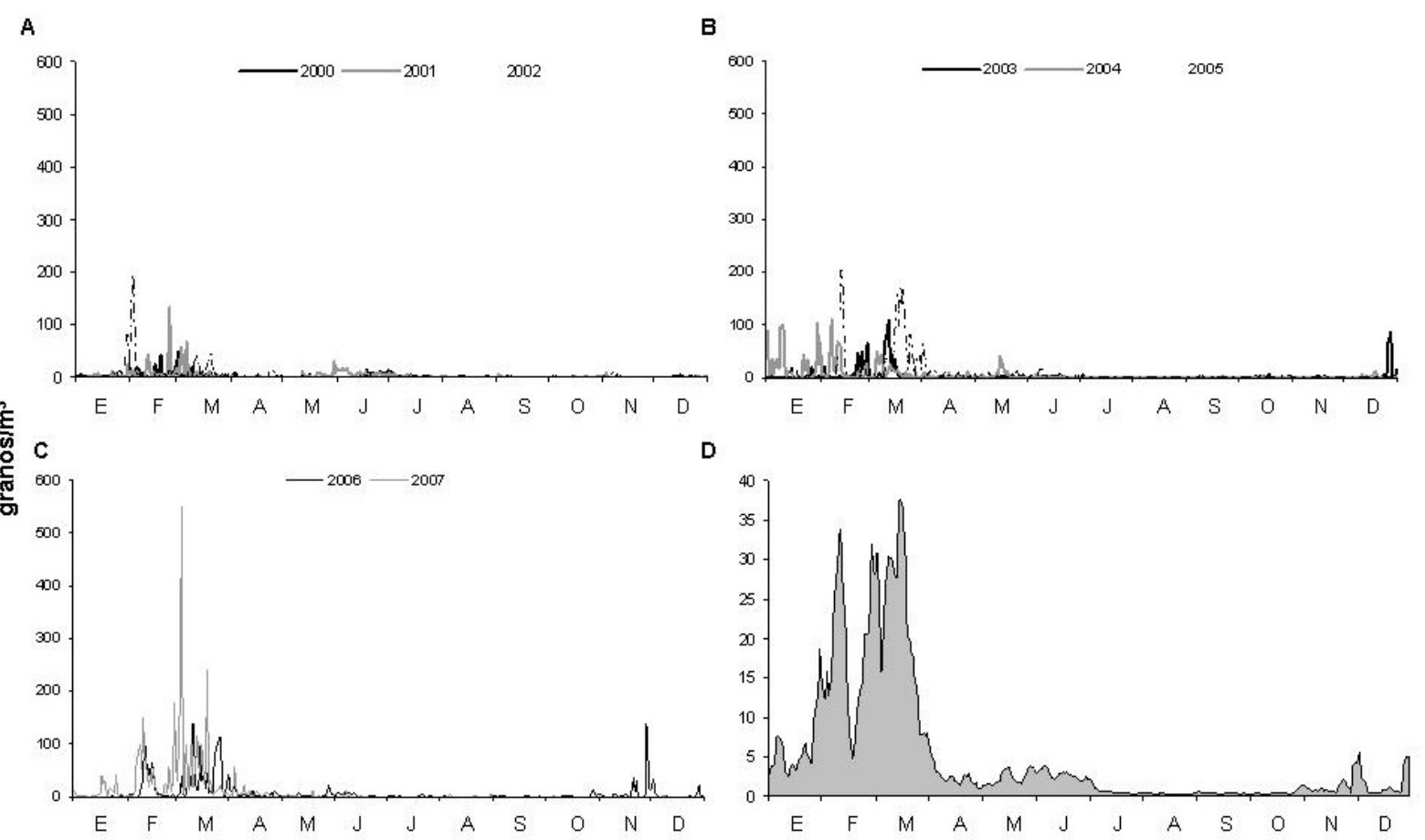

Fig. 5.2.2.5. Variación de las concentraciones medias diarias de Cupressaceae durante el período 2000-2002 (A), 2003-2005 (B) y 2006-2007 (C). Medias móviles de los cinco días anteriores para las concentraciones diarias promedio de los ocho años estudiados (D).

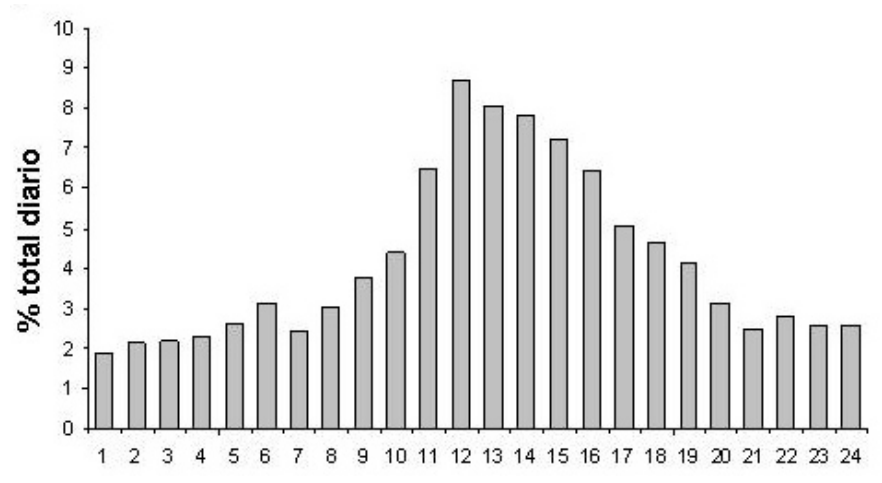

Fig. 5.2.6. Variación intradiaria del polen de Cupressaceae.

Las temperaturas medias, máximas y mínimas junto a la insolación influyeron de forma negativa en los niveles polínicos durante los ocho años analizados, tras el análisis de correlación (Tabla 5.2.2.4.) aunque con coeficientes bajos, y no mostrando correlaciones importantes con otras variables. No obstante, esta influencia negativa se tornó positiva y con coeficientes más elevados al aplicar este tipo de estadísticos de correlación no paramétricos en el PRE de las tres metodologías empleadas para la mayoría de los años analizados. Algo parecido aunque de signo contrario, ocurrió con la humedad relativa y los niveles de polen durante el PRE en un buen número de anualidades. Respecto a los vientos, la velocidad media tuvo una incidencia negativa en algunos años, períodos y metodologías, y positiva en otras anualidades, períodos y métodos, como los vientos procedentes del III cuadrante que influyeron positivamente en el contenido polínico durante algunos años y períodos 
determinados y negativa en otros. Además, salvo en el PRE del año 2001 (98\%), los vientos provenientes del I cuadrante incidieron negativamente en los niveles de polen durante, fundamentalmente, el PRE de la mayoría de los años estudiados.

\begin{tabular}{|c|c|c|c|c|c|c|c|}
\hline \multicolumn{2}{|c|}{ Cupressaceae } & Tmed & Tmax & Tmin & Insolación & Precipitación & Hrelativa \\
\hline 2000 & Anual & $-0,15^{* *}$ & $-0,042$ & $-0,24^{* *}$ & 0,043 & $-0,237^{* *}$ & $-0,122^{\star *}$ \\
\hline \multirow{2}{*}{$90 \%$} & PPP & $-0,158$ & 0,068 & $-0,29 * *$ & 0,092 & $-0,378^{* *}$ & $-0,216^{* *}$ \\
\hline & PRE & $-0,102$ & $-0,130$ & 0,064 & $-0,146$ & 0,190 & 0,040 \\
\hline \multirow{2}{*}{$95 \%$} & PPP & $-0,104$ & 0,084 & $-0,22 * \star$ & 0,123 & $-0,362^{\star \star}$ & $-0,217^{\star *}$ \\
\hline & PRE & $0,532^{* *}$ & $0,503^{* *}$ & 0,506 ** & 0,181 & 0,142 & $-0,438$ ** \\
\hline \multirow{2}{*}{$98 \%$} & PPP & $-0,100$ & 0,068 & $-0,21$ ** & 0,113 & $-0,358 * \star$ & $-0,191$ ** \\
\hline & PRE & $0,549 * *$ & $0,53 * *$ & $0,505^{\star *}$ & 0,223 & 0,095 & $-0,449 * \star$ \\
\hline 2001 & Anual & 0,150 ** & $0,112^{*}$ & $0,170^{* *}$ & 0,095 & 0,076 & $-0,088$ \\
\hline \multirow{2}{*}{$90 \%$} & PPP & $0,295 * *$ & $0,225^{* *}$ & $0,347 * *$ & 0,152 & $-0,023$ & $-0,116$ \\
\hline & PRE & 0,238 & 0,247 & 0,065 & 0,116 & $-0,414^{*}$ & $-0,004$ \\
\hline \multirow{2}{*}{$95 \%$} & PPP & $0,264^{* *}$ & $0,194^{\star}$ & 0,321 ** & 0,121 & 0,001 & $-0,091$ \\
\hline & PRE & $0,389 *$ & $0,394 *$ & 0,064 & 0,127 & $-0,297$ & 0,001 \\
\hline \multirow{2}{*}{$98 \%$} & PPP & 0,276 ** & 0,224 ** & $0,313^{* *}$ & 0,140 & $-0,021$ & $-0,130$ \\
\hline & PRE & $0,410 * *$ & $0,508 * *$ & $-0,002$ & 0,236 & $-0,274$ & $-0,179$ \\
\hline 2002 & Anual & $-0,28^{* *}$ & $-0,20^{* \star}$ & $-0,34^{* *}$ & $-0,054$ & $-0,097$ & $-0,087$ \\
\hline \multirow{2}{*}{$90 \%$} & PPP & $-0,27^{* *}$ & $-0,18 * *$ & $-0,33 * *$ & $-0,19 *$ & $-0,154$ & 0,102 \\
\hline & PRE & $-0,435$ & $-0,771$ & $0,829 *$ & $-0,029$ & - & 0,143 \\
\hline \multirow{2}{*}{$95 \%$} & PPP & $-0,26 * *$ & $-0,17^{* *}$ & $-0,31 * *$ & $-0,18^{*}$ & $-0,149$ & 0,099 \\
\hline & PRE & $-0,451$ & 0,055 & $-0,245$ & 0,055 & $-0,300$ & $-0,609$ * \\
\hline \multirow{2}{*}{$98 \%$} & PPP & $-0,17 * *$ & $-0,095$ & $-0,23 * *$ & $-0,119$ & $-0,148 *$ & 0,025 \\
\hline & PRE & 0,420 * & 0,540 ** & 0,163 & 0,255 & $-0,398$ & $-0,579 * *$ \\
\hline 2003 & Anual & $-0,20$ ** & $-0,17^{\star \star}$ & $-0,23^{* *}$ & $-0,12^{*}$ & $-0,023$ & 0,041 \\
\hline \multirow{2}{*}{$90 \%$} & PPP & $-0,131$ & $-0,108$ & $-0,100$ & $-0,2^{\star \star}$ & 0,122 & 0,089 \\
\hline & PRE & $0,498 * *$ & 0,391 * & $0,459 * *$ & $-0,010$ & 0,180 & $-0,347 *$ \\
\hline \multirow{2}{*}{$95 \%$} & PPP & $-0,153$ & $-0,130$ & $-0,128$ & $-0,2^{\star \star}$ & 0,092 & 0,116 \\
\hline & PRE & 0,466 ** & $0,386 * *$ & $0,422 * *$ & $-0,044$ & 0,119 & $-0,265$ \\
\hline \multirow{2}{*}{$98 \%$} & PPP & $-0,168^{*}$ & $-0,142$ & $-0,145$ & $-0,3 * *$ & 0,078 & 0,143 \\
\hline & PRE & 0,466 ** & $0,408 * *$ & 0,416 ** & $-0,018$ & 0,094 & $-0,229$ \\
\hline 2004 & Anual & $-0,23^{* *}$ & $-0,20^{* *}$ & $-0,28^{* \star}$ & $-0,096$ & $-0,028$ & 0,102 \\
\hline \multirow{2}{*}{$90 \%$} & PPP & $-0,058$ & $-0,018$ & $-0,085$ & $-0,126$ & $-0,057$ & $0,192^{\star}$ \\
\hline & PRE & 0,084 & 0,127 & 0,216 & $-0,4 * \star$ & 0,057 & 0,471 * * \\
\hline \multirow{2}{*}{$95 \%$} & PPP & $-0,112$ & $-0,069$ & $-0,141$ & $-0,16$ * & $-0,059$ & $0,220 * *$ \\
\hline & PRE & 0,087 & 0,142 & 0,187 & $-0,4^{* *}$ & 0,045 & 0,460 ** \\
\hline \multirow{2}{*}{$98 \%$} & PPP & $-0,136$ & $-0,092$ & $0,168^{*}$ & $0,17^{\star}$ & $-0,042$ & $0,235^{* *}$ \\
\hline & PRE & 0,100 & 0,150 & 0,178 & $-0,4 * *$ & 0,061 & $0,469 * *$ \\
\hline 2005 & Anual & $-0,044$ & $-0,020$ & $-0,083$ & 0,011 & 0,029 & $-0,091$ \\
\hline $80 \%$ & PPP & 0,122 & 0,166 & 0,067 & $-0,21^{*}$ & $-0,025$ & $-0,141$ \\
\hline $90 \%$ & PRE & 0,609 & $0,812^{*}$ & 0,029 & 0,087 & - & $-0,638$ \\
\hline $95 \%$ & PPP & $-0,018$ & 0,018 & $-0,059$ & $-0,143$ & $-0,045$ & $-0,036$ \\
\hline $75 \%$ & PRE & 0,434 & 0,610 & $-0,184$ & 0,317 & $-0,448$ & $-0,659$ * \\
\hline $98 \%$ & PPP & 0,065 & 0,097 & 0,008 & $-0,060$ & 0,033 & $-0,066$ \\
\hline $98 \%$ & PRE & $0,402 * *$ & $0,519 * *$ & 0,069 & 0,317 & $-0,039$ & 0,078 \\
\hline 2006 & Anual & $-0,12^{* \star}$ & $-0,083$ & $-0,17^{\star \star}$ & $0,3^{* *}$ & 0,026 & $-0,090$ \\
\hline $90 \%$ & PPP & $-0,188^{*}$ & $-0,153$ & $-0,187^{\star}$ & 0,248 & 0,032 & 0,082 \\
\hline $70 \%$ & PRE & 0,770 ** & $0,853^{* *}$ & 0,536 ** & 0,248 & $-0,085$ & $-0,429$ * \\
\hline 95\% & PPP & $-0,28^{* *}$ & $-0,25^{* *}$ & $-0,28$ ** & 0,222 & 0,062 & 0,150 \\
\hline $75 \%$ & PRE & $0,767 * *$ & 0,860 ** & $0,504^{* *}$ & 0,222 & $-0,110$ & $-0,442^{\star}$ \\
\hline $98 \%$ & PPP & $-0,27^{* *}$ & $-0,25^{\star \star}$ & $-0,28 * *$ & $-0,024$ & 0,054 & 0,125 \\
\hline $78 \%$ & PRE & $0,771^{* *}$ & 0,764 ** & $0,534 * *$ & $-0,024$ & - & $-0,467^{* *}$ \\
\hline 2007 & Anual & $-0,17^{* \star}$ & $-0,21^{* *}$ & $-0,16^{* \star}$ & $0,2^{* *}$ & $0,141^{* *}$ & $0,128^{*}$ \\
\hline $90 \%$ & PPP & $0,468^{* *}$ & $0,337^{* *}$ & $0,277^{*}$ & $0,23^{*}$ & $-0,011$ & $-0,232^{*}$ \\
\hline $70 \%$ & PRE & $0,707 * *$ & $0,642^{* *}$ & 0,601 ** & $0,33 *$ & 0,131 & $-0,306$ \\
\hline $95 \%$ & PPP & $-0,170$ & $-0,122$ & $-0,24^{* \star}$ & 0,016 & $-0,054$ & $-0,004$ \\
\hline $75 \%$ & PRE & $0,680 * *$ & 0,631 ** & $0,557 * *$ & 0,36 * & 0,129 & $-0,315^{\star}$ \\
\hline & PPP & $-0,28$ ** & $-0,22^{* *}$ & $-0,33^{* *}$ & 0,009 & $-0,103$ & 0,012 \\
\hline $98 \%$ & PRE & $0,67 * *$ & $0,63 * *$ & $0,53^{* *}$ & $0,34 *$ & 0,124 & $-0,319$ * \\
\hline Total & Anual & $-0,13^{* *}$ & $-0,10 * \star$ & $-0,15^{* *}$ & $-0,031$ & $-0,015$ & $-0,018$ \\
\hline
\end{tabular}

Tabla 5.2.2.4. Coeficientes de correlación de Spearman entre Cupressaceae y las variables climatológicas.

Tmed, Tmax, Tmin (temperatura media, máxima y mínima), Hrelativa (humedad relativa). Significación: $95 \%(*), 99 \%(* *)$. (-) Ausencia de correlaciones. 


\begin{tabular}{|c|c|c|c|c|c|c|c|}
\hline \multicolumn{2}{|c|}{ Cupressaceae } & Vemed & FrecCalm & VICuadr & V2Cuadr & V3Cuadr & V4Cuadr \\
\hline 2000 & Anual & $-0,15^{\star *}$ & $0,111^{*}$ & $0,184^{*}$ & $0,164^{*}$ & $-0,185^{* *}$ & $-0,059$ \\
\hline \multirow{2}{*}{$90 \%$} & PPP & $-0,22^{* *}$ & $0,33^{* *}$ & 0,131 & 0,124 & $-0,130$ & $-0,071$ \\
\hline & PRE & 0,100 & 0,068 & $-0,240$ & $-0,062$ & 0,174 & 0,155 \\
\hline \multirow{2}{*}{$95 \%$} & PPP & $-0,174^{*}$ & $0,278 * *$ & 0,116 & 0,101 & $-0,119$ & $-0,071$ \\
\hline & PRE & 0,138 & 0,151 & $-0,461$ ** & $-0,250$ & $0,404^{* *}$ & $0,368 * *$ \\
\hline \multirow{2}{*}{$98 \%$} & PPP & $-0,184 *$ & $0,271 * *$ & 0,114 & 0,104 & $-0,117$ & $-0,067$ \\
\hline & PRE & 0,120 & 0,132 & $-0,466$ ** & $-0,227$ & $0,427^{* *}$ & $0,367^{* *}$ \\
\hline 2001 & Anual & $0,124^{*}$ & $-0,157^{* *}$ & $-0,159$ ** & $-0,103$ & $0,175^{* *}$ & 0,073 \\
\hline \multirow{2}{*}{$90 \%$} & PPP & $-0,098$ & 0,048 & $-0,041$ & 0,073 & 0,030 & $-0,010$ \\
\hline & PRE & $-0,278$ & 0,177 & 0,323 & 0,072 & $-0,421$ * & $-0,014$ \\
\hline \multirow{2}{*}{$95 \%$} & PPP & $-0,043$ & 0,010 & $-0,045$ & 0,054 & 0,045 & $-0,019$ \\
\hline & PRE & $-0,150$ & 0,170 & 0,323 & 0,157 & $-0,336$ & $-0,018$ \\
\hline \multirow{2}{*}{$98 \%$} & PPP & $-0,045$ & 0,040 & 0,009 & 0,088 & $-0,002$ & $-0,029$ \\
\hline & PRE & $-0,082$ & 0,221 & $0,423^{* *}$ & 0,280 & $-0,396 * *$ & $-0,189$ \\
\hline 2002 & Anual & $-0,013$ & 0,089 & $-0,035$ & 0,035 & 0,049 & $-0,162^{\star \star}$ \\
\hline \multirow{2}{*}{$90 \%$} & PPP & $-0,066$ & 0,077 & $-0,038$ & $0,255^{\star *}$ & 0,010 & $-0,086$ \\
\hline & PRE & 0,886 * & $-0,886$ * & $-0,886$ * & $-0,771$ & $0,943^{* *}$ & 0,926 ** \\
\hline \multirow{2}{*}{$95 \%$} & PPP & $-0,065$ & 0,071 & $-0,037$ & $0,227^{* *}$ & 0,020 & $-0,087$ \\
\hline & PRE & 0,636 * & $-0,477$ & 0,097 & $-0,091$ & 0,136 & 0,474 \\
\hline \multirow{2}{*}{$98 \%$} & PPP & 0,029 & $-0,013$ & $-0,038$ & 0,132 & 0,093 & $-0,132$ \\
\hline & PRE & $0,569 * *$ & $-0,661^{* *}$ & $-0,076$ & $-0,189$ & 0,357 & $-0,188$ \\
\hline 2003 & Anual & $-0,007$ & 0,009 & $-0,035$ & $0,142^{\star \star}$ & 0,046 & $-0,116^{* *}$ \\
\hline \multirow{2}{*}{$90 \%$} & PPP & $-0,076$ & 0,102 & $-0,154$ & $0,310^{* *}$ & 0,127 & $-0,130$ \\
\hline & PRE & 0,174 & $-0,164$ & $-0,175$ & 0,248 & 0,252 & $-0,377$ ** \\
\hline \multirow{2}{*}{$95 \%$} & PPP & $-0,092$ & 0,126 & $-0,134$ & $0,295^{* *}$ & 0,117 & $-0,126$ \\
\hline & PRE & 0,111 & $-0,101$ & $-0,133$ & 0,221 & 0,237 & $-0,389$ ** \\
\hline \multirow{2}{*}{$98 \%$} & PPP & $-0,090$ & 0,107 & $-0,129$ & $0,274^{* *}$ & 0,102 & $-0,108$ \\
\hline & PRE & 0,101 & $-0,108$ & $-0,112$ & 0,230 & 0,220 & $-0,390$ ** \\
\hline 2004 & Anual & 0,020 & $-0,003$ & $-0,058$ & 0,003 & 0,097 & $-0,021$ \\
\hline \multirow{2}{*}{$90 \%$} & PPP & 0,056 & $0,204^{\star}$ & $-0,120$ & $0,188^{*}$ & $0,196^{*}$ & $-0,033$ \\
\hline & PRE & 0,089 & 0,007 & $-0,061$ & 0,039 & 0,101 & 0,020 \\
\hline \multirow{2}{*}{$95 \%$} & PPP & 0,068 & $0,207^{* *}$ & $-0,121$ & 0,186 * & $0,199 *$ & $-0,043$ \\
\hline & PRE & 0,146 & 0,039 & $-0,046$ & 0,051 & 0,067 & 0,041 \\
\hline \multirow{2}{*}{$98 \%$} & PPP & 0,070 & $0,229 * *$ & $-0,106$ & 0,196 * & 0,194 * & $-0,068$ \\
\hline & PRE & 0,199 & 0,021 & $-0,060$ & 0,039 & 0,090 & $-0,022$ \\
\hline 2005 & Anual & $0,167^{* *}$ & $-0,193$ ** & $-0,107^{*}$ & 0,067 & $0,141^{* \star}$ & 0,086 \\
\hline $90 \%$ & PPP & $-0,053$ & $-0,003$ & $-0,092$ & $0,249 *$ & 0,044 & $-0,029$ \\
\hline $70 \%$ & PRE & $-0,029$ & $-0,279$ & $-0,928$ ** & $-0,441$ & 0,471 & $0,956^{* *}$ \\
\hline $95 \%$ & PPP & $-0,009$ & 0,005 & $-0,049$ & $0,212^{*}$ & 0,030 & $-0,093$ \\
\hline $95 \%$ & PRE & $-0,257$ & $-0,342$ & $-0,689 *$ & $-0,280$ & 0,405 & $0,734^{*}$ \\
\hline $980 \%$ & PPP & $-0,010$ & 0,052 & $-0,137$ & 0,180 * & 0,096 & 0,006 \\
\hline $78 \%$ & PRE & $-0,45^{* *}$ & $0,591^{* *}$ & $-0,586^{* *}$ & $0,441^{*}$ & $0,463^{*}$ & $0,464^{*}$ \\
\hline 2006 & Anual & $-0,016$ & $-0,062$ & $-0,033$ & 0,030 & 0,044 & $-0,009$ \\
\hline $90 \%$ & PPP & $-0,022$ & $-0,151$ & 0,086 & 0,062 & $-0,052$ & $-0,329 * *$ \\
\hline $70 \%$ & PRE & $-0,139$ & 0,287 & 0,449 & 0,487 & $-0,682^{*}$ & 0,599 \\
\hline $95 \%$ & PPP & $-0,011$ & $-0,119$ & 0,029 & 0,010 & $-0,004$ & $-0,243^{* *}$ \\
\hline $75 \%$ & PRE & $-0,169$ & 0,317 & 0,443 & 0,491 & $-0,714$ ** & 0,580 * \\
\hline $98 \%$ & PPP & 0,009 & $-0,112$ & $-0,044$ & $-0,022$ & 0,034 & $-0,166$ \\
\hline $98 \%$ & PRE & $-0,065$ & $-0,110$ & $-0,379$ & $-0,049$ & 0,247 & $0,567^{* *}$ \\
\hline 2007 & Anual & $0,365^{* *}$ & $-0,453 * *$ & $-0,185^{* *}$ & $-0,023$ & $0,286 * *$ & 0,090 \\
\hline $90 \%$ & PPP & $0,485^{\star *}$ & $-0,323^{* *}$ & $-0,325^{* \star}$ & $-0,253^{*}$ & $0,302^{* *}$ & $-0,013$ \\
\hline $90 \%$ & PRE & 0,546 ** & $-0,382^{*}$ & $-0,575 * *$ & $-0,343^{*}$ & 0,636 ** & 0,025 \\
\hline $95 \%$ & PPP & $0,446 * *$ & $-0,401^{* *}$ & $-0,145$ & $-0,162$ & $0,183^{*}$ & $-0,088$ \\
\hline $95 \%$ & PRE & $0,552^{* *}$ & $-0,384^{* *}$ & $-0,569 * *$ & $-0,332^{*}$ & $0,616^{* *}$ & - \\
\hline & PPP & $0,410 * *$ & $-0,358 * *$ & $-0,108$ & $-0,116$ & 0,141 & $-0,094$ \\
\hline $98 \%$ & PRE & $0,551 * *$ & $-0,370 * *$ & $-0,553^{* *}$ & $-0,316^{*}$ & $0,592^{* *}$ & $-0,005$ \\
\hline Total & Anual & 0,014 & $-0,071$ ** & $-0,05 * \star$ & 0,034 & $0,074 * *$ & $-0,015$ \\
\hline
\end{tabular}

Tabla 5.2.2.4. (Continuación). Coeficientes de correlación de Spearman entre Cupressaceae y las variables climatológicas. Vemed (velocidad media), FrecCalmas (frecuencia de calmas), V1Cuad, V2Cuad, V3Cuad,

V4Cuad (vientos procedentes del I, II, III y IV cuadrante). Significación: $95 \%(*), 99 \%(* *)$. (-) Ausencia de correlaciones. 


\subsubsection{Fraxinus}

Los niveles del tipo polínico Fraxinus angustifolia en la atmósfera de Salamanca, experimentaron un ascenso durante el período analizado, ya que si en el año 2000 la concentración anual fue de 92, en el año 2007 alcanzó los 378. Esto supuso que la variación interanual (Fig. 5.2.2.7.) llevase consigo un aumento del $310 \%$ en las concentraciones anuales de este tipo polínico. El análisis de regresión de tipo lineal confirma esta tendencia a través del valor que tomó su índice de determinación $\left(\mathrm{R}^{2}=0,80\right)$. La representación media de los pólenes de Fraxinus a lo largo de los ocho años fue de 1,15\%, con un máximo de 2,3\% en 2002 y un mínimo de o,7\% en 2001.

La distribución de estos granos de polen a lo largo del año se localizó entre mediados-finales de enero y mediadosfinales de marzo, por lo que la variación estacional (Tabla 5.2.2.5.) tuvo un PPP promedio de 49 a 73 días, en función del modelo empleado para su cálculo. No obstante, el empleo de diferentes metodologías para delimitar el PPP marcó diferencias en las fechas de inicio $y$ finalización para los diferentes años incluidos, dejando el 6 de enero de los años 2003 y 2004 (98\% en 2003 y con todos los
Tipo polínico: Fraxinus angustifolia

Especie(s): Fraxinus angustifolia Vahl., y como ornamentales Fraxinus excelsior L. y Fraxinus ornus L. (Oleaceae).

Distribución: Género integrado por unas 60 especies repartidas por el hemisferio Norte. En la Península Ibérica, Fraxinus angustifolia Vahl. se encuentra ampliamente representado salvo en el Norte donde es más abundante Fraxinus excelsior L. En la provincia de Salamanca es común siguiendo cursos de ríos y arroyos así como en el piedemonte de las sierras del Sur.

Época de floración: Invierno y principios de primavera, aunque Fraxinus ornus L. florece en abril y mayo.

Polinización: Anemófila (Fraxinus ornus L. presenta entomofilia).

Morfología polínica (Lámina II): Polen trizonocolpado (a veces tetrazonocolpado), isopolar y radiosimétrico, con una forma circular a cuadrangular en vista polar y de circular a elíptica en vista ecuatorial (de oblatoesferoidal a subprolato), y un tamaño pequeñomediano $(P=15-35 \mu \mathrm{m})$. Las aberturas tipo colpo son estrechas y largas $(15 \mu \mathrm{m}$ de longitud). En algunos casos, existe un adelgazamiento de la exina (abertura colporoidada). La exina, de grosor fino (1,5-2 $\mu \mathrm{m})$, presenta una superficie reticulada, con lúmenes irregulares en tamaño y distribución. métodos en 2004) como fecha más temprana de inicio y el 9 de abril de 2007 como fecha de finalización más tardía. Debemos reseñar que en este último año 2007 como, en menor medida, en los años 2006, 2005 y 2002 se produjo un ligero retraso en el PPP, como pudo deducirse a partir de las metodologías usadas.

En todo caso, los niveles polínicos de este género en la atmósfera de la ciudad de Salamanca (Fig. 5.2.2.8.D.) aumentaron a partir de la primera semana del mes de enero 
hasta alcanzar los valores más elevados a mediados de febrero, como muestra el valor medio más elevado en los años analizados (12 granos/m³ , el 13 de febrero), gracias a la dinámica aportada por las concentraciones medias de los cincos días anteriores para el conjunto de anualidades. Asimismo, las mayores concentraciones diarias registradas dentro del período 2000-2007 oscilaron entre los 51 granos/m³ (16 de febrero de 2007) y los 5 granos $/ \mathrm{m}^{3}$ (16 de marzo de 2003). Los niveles de este tipo fueron disminuyendo hasta abril, con un ligero repunte en la mitad de marzo, presentándose en niveles bajos durante todo el mes de abril (Fig. 5.2.2.8. A. B. C.).

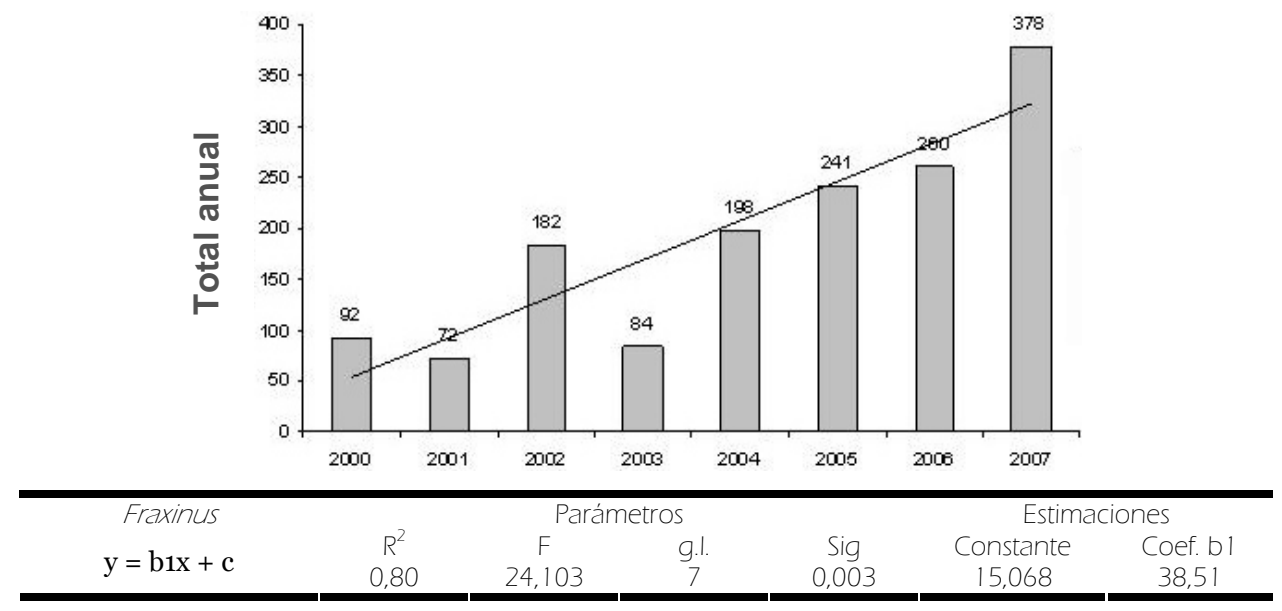

Fig. 5.2. 2.7. Evolución anual del número total de pólenes de Fraxinus y tendencias (análisis de regresión).

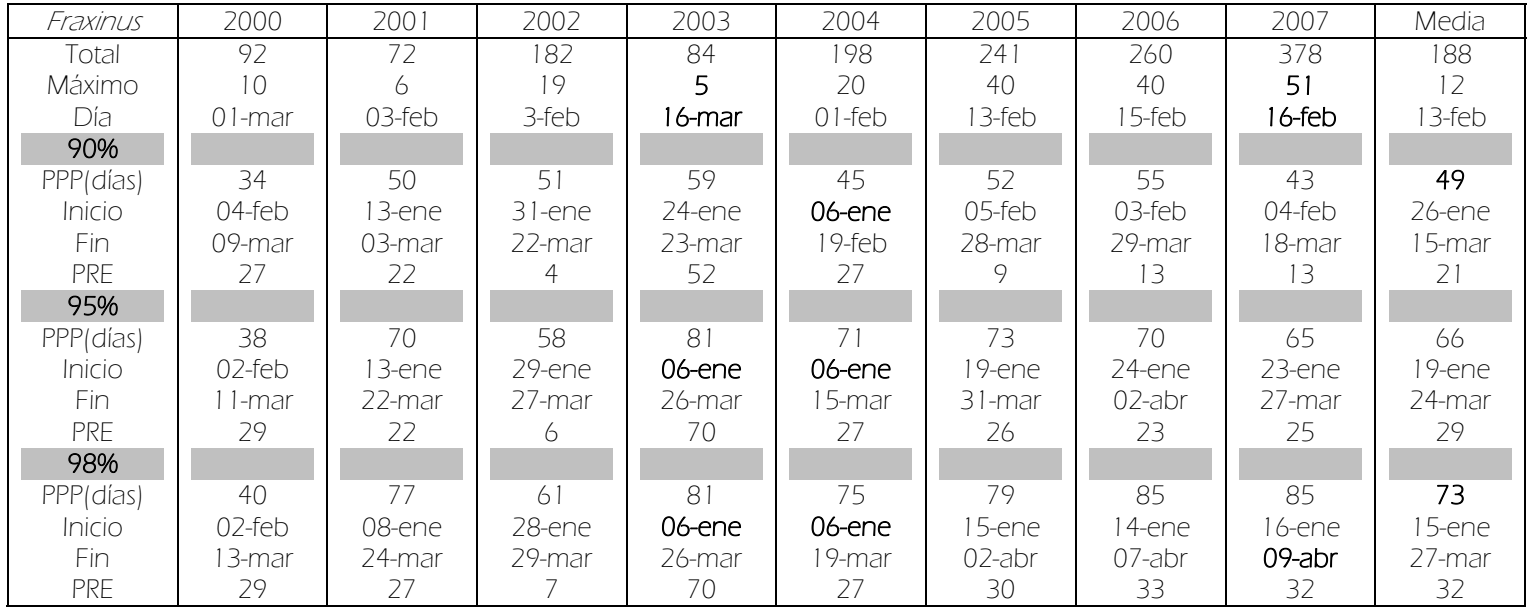

Tabla 5.2.2.5. Totales, concentraciones máximas diarias, períodos principales de polinización (PPP; fecha de inicio y fin) y días precedentes al valor máximo (PRE) durante los ocho años de estudio y el promedio de todos los parámetros para Fraxinus.

Los niveles de polen a lo largo del día se incrementaron a partir de las 9 horas hasta las 17 horas, mostrando porcentajes de representación variables hasta la medianoche, momento en el que las concentraciones horarias disminuyeron. Así pues la variación 
intradiaria (Fig. 5.2.2.9.) durante un día promedio para el trienio 2005-2007, presentó las mayores concentraciones horarias en la segunda mitad del día.

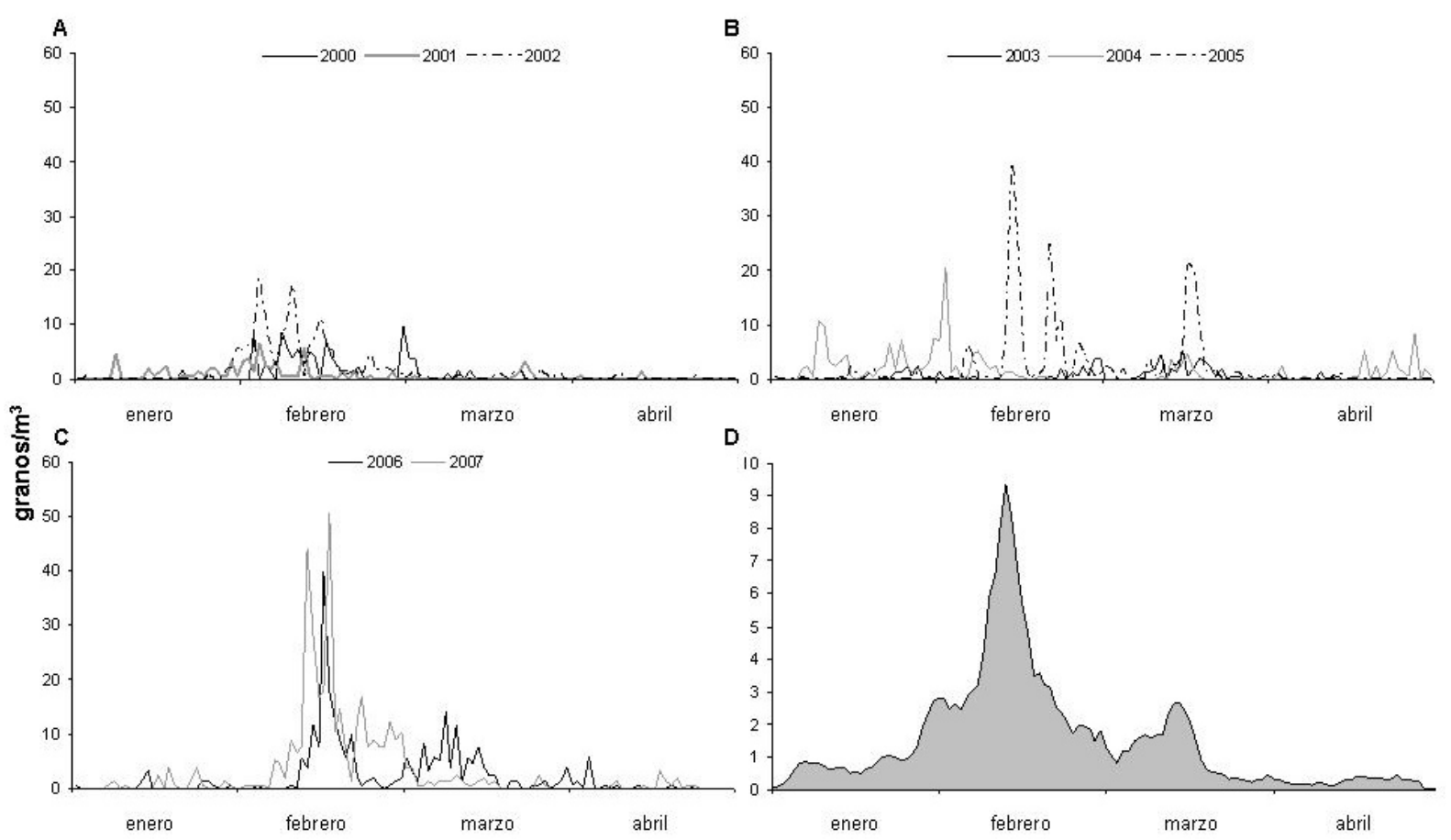

Fig. 5.2.2.8. Variación de las concentraciones medias diarias de Fraxinus durante el período 2000-2002 (A), 2003-2005 (B) y 2006-2007 (C). Medias móviles de los cinco días anteriores para las concentraciones diarias promedio de los ocho años estudiados (D).

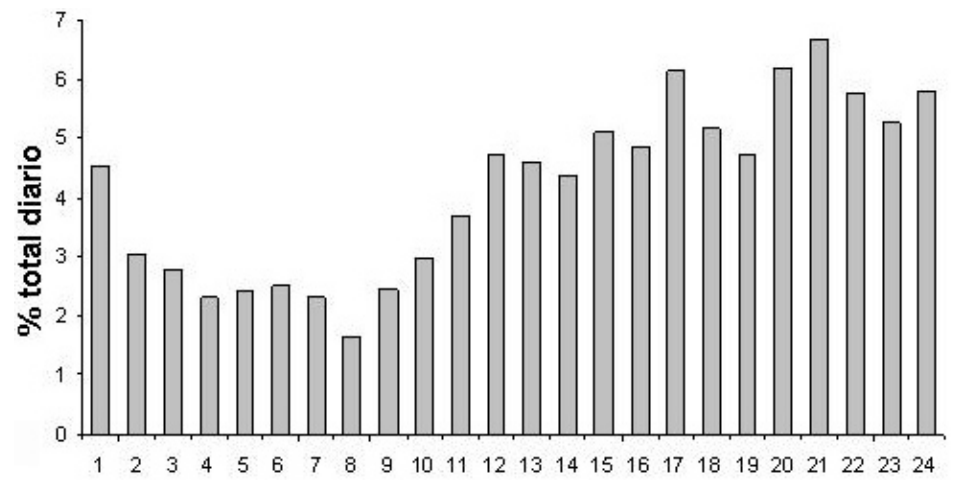

Fig. 5.2.2.9. Variación intradiaria del polen de Fraxinus.

El análisis de correlación (Tabla 5.2.2.6.) indicó que las temperaturas medias, máximas y mínimas junto a la insolación influyeron negativamente en los niveles polínicos durante los ocho años analizados, mientras que la humedad relativa tuvo un efecto positivo y el resto de parámetros mostraron valores bajos. En todo caso, los coeficientes de correlación de Spearman mostraron otro tipo de signo al analizar los años estudiados y métodos empleados para delimitar el PPP, como muestra las correlaciones significativas y de signo positivo con las temperaturas en el PPP y PRE del período 2003-2007, o negativas con la precipitación (PPP 2002 con las tres metodologías) o la humedad relativa (PPP y PRE 2003; PPP 2005 al 95 y 98\%; PPP 2006 98\%; PRE 2007 90\%). Asimismo, debe destacarse la 
correlación positiva con los vientos procedentes del III y IV cuadrante y la velocidad media en el PPP y PRE de diversos años (salvo en el 2003, con influencia negativa de los vientos del III cuadrante al 90\%) y negativa con vientos del I y II cuadrante, junto con las calmas.

\begin{tabular}{|c|c|c|c|c|c|c|c|}
\hline \multicolumn{2}{|c|}{ Fraxinus } & Tmed & Tmax & Tmin & Insolación & Precipitación & Hrelativa \\
\hline 2000 & Anual & $-0,20$ ** & $-0,098$ & $-0,27$ * & $-0,016$ & $-0,133^{\star \star}$ & 0,006 \\
\hline \multirow{2}{*}{$90 \%$} & PPP & $-0,307$ & $-0,54^{\star \star}$ & 0,110 & $-0,221$ & 0,213 & $0,371^{*}$ \\
\hline & PRE & $-0,077$ & $-0,49 * *$ & 0,321 & $-0,329$ & 0,207 & $0,403^{*}$ \\
\hline \multirow{2}{*}{$95 \%$} & PPP & $-0,243$ & $-0,49 * *$ & 0,141 & $-0,219$ & 0,196 & 0,351 * \\
\hline & PRE & 0,026 & $-0,44^{\star \star}$ & 0,364 & $-0,346$ & 0,186 & 0,352 \\
\hline \multirow{2}{*}{$98 \%$} & PPP & $-0,261$ & $-0,5 * \star$ & 0,131 & $-0,213$ & 0,196 & $0,352 *$ \\
\hline & PRE & 0,026 & $-0,44^{* *}$ & 0,364 & $-0,346$ & 0,186 & 0,352 \\
\hline 2001 & Anual & $-0,28^{* *}$ & $-0,33^{* *}$ & $-0,21^{* *}$ & $-0,23^{* *}$ & $0,168^{* *}$ & $0,339 * *$ \\
\hline \multirow{2}{*}{$90 \%$} & PPP & 0,278 & 0,132 & 0,234 & $-0,032$ & 0,053 & 0,133 \\
\hline & PRE & 0,230 & 0,280 & $-0,066$ & 0,343 & $-0,198$ & $-0,223$ \\
\hline \multirow{2}{*}{$95 \%$} & PPP & $-0,158$ & $-0,176$ & $-0,124$ & 0,048 & $-0,065$ & 0,197 \\
\hline & PRE & 0,230 & 0,280 & $-0,066$ & 0,343 & $-0,198$ & $-0,223$ \\
\hline \multirow{2}{*}{$98 \%$} & PPP & $-0,125$ & $-0,111$ & $-0,116$ & 0,111 & $-0,117$ & 0,111 \\
\hline & PRE & $-0,042$ & 0,109 & $-0,251$ & $0,403^{*}$ & $-0,314$ & $-0,237$ \\
\hline 2002 & Anual & $-0,35$ ** & $-0,27^{* \star}$ & $-0,40^{* *}$ & $-0,15$ ** & $-0,113^{*}$ & 0,057 \\
\hline \multirow{2}{*}{$90 \%$} & PPP & $-0,030$ & 0,157 & $-0,241$ & 0,044 & $-0,382^{\star *}$ & $-0,140$ \\
\hline & PRE & 0,800 & 0,200 & 0,400 & $-0,800$ & - & $-0,200$ \\
\hline \multirow{2}{*}{$95 \%$} & PPP & $-0,139$ & 0,017 & $-0,286$ * & $-0,130$ & $-0,320$ * & $-0,001$ \\
\hline & PRE & $-0,103$ & 0,058 & 0,174 & 0,058 & - & $-0,696$ \\
\hline \multirow{2}{*}{$98 \%$} & PPP & $-0,162$ & $-0,012$ & $-0,285^{\star}$ & $-0,151$ & $-0,332^{\star *}$ & 0,048 \\
\hline & PRE & $-0,377$ & $-0,018$ & 0,164 & 0,073 & - & $-0,800$ ** \\
\hline 2003 & Anual & $-0,32^{* *}$ & $-0,28^{* *}$ & $-0,34$ ** & $-0,16$ ** & 0,041 & $0,117^{\star}$ \\
\hline \multirow{2}{*}{$90 \%$} & PPP & $0,45^{\star *}$ & $0,50^{* *}$ & $0,271^{*}$ & $0,36^{* *}$ & $-0,001$ & $-0,471^{* *}$ \\
\hline & PRE & 0,39 ** & $0,43^{* *}$ & $0,33^{*}$ & $0,274^{*}$ & 0,032 & $-0,36 * *$ \\
\hline \multirow{2}{*}{$95 \%$} & PPP & $0,45 * *$ & 0,51 ** & $0,29 * *$ & $0,39 * *$ & $-0,052$ & $-0,465 * *$ \\
\hline & PRE & $0,39 * *$ & $0,45 * *$ & $0,33 * *$ & $0,36 * *$ & $-0,055$ & $-0,38 * *$ \\
\hline \multirow{2}{*}{$98 \%$} & PPP & $0,45^{* *}$ & 0,51 ** & $0,29 * *$ & $0,39 * *$ & $-0,052$ & $-0,465 * *$ \\
\hline & PRE & $0,39 * *$ & $0,45^{\star *}$ & $0,33^{* *}$ & 0,36 ** & $-0,055$ & $-0,38 * *$ \\
\hline 2004 & Anual & $-0,25^{\star \star}$ & $-0,22^{\star \star}$ & $-0,28 * \star$ & $-0,16$ ** & $-0,026$ & $0,144^{* *}$ \\
\hline \multirow{2}{*}{$90 \%$} & PPP & $0,321^{*}$ & 0,149 & $0,42^{\star \star}$ & $-0,41^{* *}$ & 0,164 & $0,413 * *$ \\
\hline & PRE & $0,46^{\star}$ & $0,48^{*}$ & $0,41^{*}$ & $-0,396$ * & 0,089 & 0,255 \\
\hline \multirow{2}{*}{$95 \%$} & PPP & $0,293^{*}$ & $0,284^{\star}$ & 0,222 & $-0,107$ & $-0,018$ & $0,312 * *$ \\
\hline & PRE & $0,46^{*}$ & $0,48 *$ & $0,41^{*}$ & $-0,396$ * & 0,089 & 0,255 \\
\hline \multirow{2}{*}{$98 \%$} & PPP & $0,32 * *$ & $0,30 * *$ & $0,256^{*}$ & $-0,096$ & $-0,028$ & $0,272^{*}$ \\
\hline & PRE & $0,46 *$ & $0,48 *$ & 0,41 * & $-0,396$ * & 0,089 & 0,255 \\
\hline 2005 & Anual & $-0,31^{* *}$ & $-0,27^{* *}$ & $-0,34^{* *}$ & $-0,15^{* *}$ & $-0,011$ & 0,088 \\
\hline ९०\% & PPP & 0,217 & 0,244 & 0,043 & 0,020 & $-0,140$ & $-0,220$ \\
\hline $70 \%$ & PRE & 0,184 & 0,254 & $-0,127$ & $-0,052$ & $-0,120$ & $-0,245$ \\
\hline $95 \%$ & PPP & 0,222 & $0,263^{*}$ & 0,026 & 0,122 & $-0,019$ & $-0,321$ ** \\
\hline $75 \%$ & PRE & 0,033 & 0,183 & $-0,148$ & $-0,111$ & 0,142 & $-0,065$ \\
\hline & PPP & 0,222 & $0,246^{*}$ & 0,035 & 0,126 & $-0,028$ & $-0,303$ ** \\
\hline $98 \%$ & PRE & 0,178 & 0,240 & $-0,025$ & $-0,137$ & 0,117 & $-0,016$ \\
\hline 2006 & Anual & $-0,39 * *$ & $-0,36^{* \star}$ & $-0,39 * *$ & $0,287^{*}$ & 0,021 & $0,150^{* *}$ \\
\hline $90 \%$ & PPP & 0,194 & 0,171 & 0,080 & $-0,127$ & $-0,059$ & $-0,157$ \\
\hline $90 \%$ & PRE & $0,73^{* *}$ & $0,585^{\star}$ & 0,486 & $-0,160$ & - & $-0,223$ \\
\hline $95 \%$ & PPP & $0,33^{* *}$ & $0,277^{*}$ & $0,254^{*}$ & 0,123 & 0,019 & $-0,230$ \\
\hline $75 \%$ & PRE & 0,54 ** & 0,377 & $0,58 * *$ & $-0,191$ & 0,087 & $-0,162$ \\
\hline $880 \%$ & PPP & $0,262^{*}$ & 0,31 ** & 0,154 & 0,153 & $-0,044$ & $-0,333 * *$ \\
\hline $78 \%$ & PRE & 0,263 & $0,369 *$ & 0,100 & 0,112 & $-0,021$ & $-0,232$ \\
\hline 2007 & Anual & $-0,26$ ** & $-0,31$ ** & $-0,25^{\star *}$ & $-0,24 * \star$ & $0,143^{* *}$ & $0,265^{\star *}$ \\
\hline $90 \%$ & PPP & 0,194 & $-0,083$ & 0,146 & $-0,247$ & 0,101 & 0,221 \\
\hline $70 \%$ & PRE & 0,363 & $0,603^{*}$ & $-0,325$ & $0,576^{*}$ & 0,091 & $-0,623^{*}$ \\
\hline $95 \%$ & PPP & $0,52^{* *}$ & 0,32 ** & $0,47 * *$ & $-0,171$ & 0,199 & $0,273^{*}$ \\
\hline $95 \%$ & PRE & $0,72^{* *}$ & $0,75^{\star *}$ & $0,464^{\star}$ & 0,222 & 0,313 & $-0,192$ \\
\hline & PPP & 0,50 ** & $0,266^{*}$ & 0,36 ** & $-0,018$ & 0,075 & 0,205 \\
\hline $98 \%$ & PRE & $0,63 * *$ & $0,61 * *$ & $0,369 *$ & 0,275 & 0,287 & $-0,327$ \\
\hline Total & Anual & $-0,3^{\star \star}$ & $-0,27^{* \star}$ & $-0,31^{\text {** }}$ & $-0,16^{* *}$ & 0,013 & $0,137^{* *}$ \\
\hline
\end{tabular}

Tabla 5.2.2.6. Coeficientes de correlación de Spearman entre Fraxinus y las variables climatológicas. Tmed, Tmax, Tmin (temperatura media, máxima y mínima), Hrelativa (humedad relativa). Significación: 95\%(*), $99 \%(* *)$. (-) Ausencia de correlaciones. 


\begin{tabular}{|c|c|c|c|c|c|c|c|}
\hline \multicolumn{2}{|c|}{ Fraxinus } & Vemed & FrecCalm & VICuadr & V2Cuadr & V3Cuadr & V4Cuadr \\
\hline 2000 & Anual & $-0,096$ & $0,121^{\star}$ & 0,046 & 0,025 & $-0,019$ & 0,056 \\
\hline \multirow{2}{*}{$90 \%$} & PPP & $0,341^{*}$ & $-0,173$ & 0,321 & $-0,441^{* \star}$ & $0,365^{\star}$ & 0,259 \\
\hline & PRE & 0,314 & $-0,235$ & $-0,299$ & $-0,493 * *$ & 0,343 & 0,221 \\
\hline \multirow{2}{*}{$95 \%$} & PPP & $0,358 *$ & $-0,211$ & $-0,388$ * & $-0,449$ ** & 0,430 ** & $0,326^{*}$ \\
\hline & PRE & 0,348 & $-0,268$ & $-0,393^{*}$ & $-0,517$ ** & $0,427^{\star}$ & 0,297 \\
\hline \multirow{2}{*}{$98 \%$} & PPP & $0,350 *$ & $-0,193$ & $-0,347^{*}$ & $-0,435^{* *}$ & $0,376 *$ & $0,319 *$ \\
\hline & PRE & 0,348 & $-0,268$ & $-0,393^{*}$ & $-0,517^{* *}$ & $0,427^{*}$ & 0,297 \\
\hline 2001 & Anual & $0,137^{\star \star}$ & $-0,098$ & $-0,198^{\star *}$ & $-0,077$ & $0,202^{\star \star}$ & $-0,134^{\star}$ \\
\hline \multirow{2}{*}{$90 \%$} & PPP & 0,089 & 0,060 & $-0,274$ & $-0,064$ & $0,300 *$ & 0,002 \\
\hline & PRE & $-0,157$ & 0,259 & 0,383 & 0,151 & $-0,133$ & $-0,126$ \\
\hline \multirow{2}{*}{$95 \%$} & PPP & $-0,058$ & 0,185 & $-0,018$ & 0,096 & $-0,032$ & 0,052 \\
\hline & PRE & $-0,157$ & 0,259 & 0,383 & 0,151 & $-0,133$ & $-0,126$ \\
\hline \multirow{2}{*}{$98 \%$} & PPP & $-0,016$ & 0,136 & $-0,062$ & 0,096 & $-0,007$ & 0,048 \\
\hline & PRE & $-0,160$ & 0,255 & 0,153 & 0,023 & $-0,055$ & 0,084 \\
\hline 2002 & Anual & $-0,022$ & 0,087 & 0,052 & $0,120^{*}$ & $-0,026$ & $-0,182^{* *}$ \\
\hline \multirow{2}{*}{$90 \%$} & PPP & $-0,102$ & 0,148 & $-0,029$ & 0,030 & $-0,015$ & 0,170 \\
\hline & PRE & 0,200 & $-0,200$ & $-0,200$ & 0,200 & 0,200 & - \\
\hline \multirow{2}{*}{$95 \%$} & PPP & $-0,058$ & 0,052 & $-0,096$ & 0,041 & 0,050 & 0,163 \\
\hline & PRE & 0,464 & $-0,464$ & $-0,464$ & $-0,319$ & 0,464 & 0,219 \\
\hline \multirow{2}{*}{$98 \%$} & PPP & $-0,078$ & 0,091 & $-0,095$ & 0,011 & 0,060 & 0,183 \\
\hline & PRE & 0,655 & $-0,655$ & $-0,655$ & $-0,291$ & 0,655 & 0,095 \\
\hline 2003 & Anual & $-0,007$ & 0,022 & $-0,045$ & $0,154^{* \star}$ & 0,042 & $-0,158^{* *}$ \\
\hline \multirow{2}{*}{$90 \%$} & PPP & 0,187 & $-0,137$ & $-0,065$ & 0,148 & 0,130 & $-0,335^{\star}$ \\
\hline & PRE & 0,152 & $-0,217$ & $-0,187$ & 0,130 & 0,192 & $-0,293^{*}$ \\
\hline \multirow{2}{*}{$95 \%$} & PPP & 0,054 & $-0,051$ & 0,022 & 0,181 & 0,034 & $-0,208$ \\
\hline & PRE & 0,039 & $-0,096$ & $-0,087$ & 0,166 & 0,082 & $-0,192$ \\
\hline \multirow{2}{*}{$98 \%$} & PPP & 0,054 & $-0,051$ & 0,022 & 0,181 & 0,034 & $-0,208$ \\
\hline & PRE & 0,039 & $-0,096$ & $-0,087$ & 0,166 & 0,082 & $-0,192$ \\
\hline 2004 & Anual & 0,021 & 0,073 & $-0,11^{\text {** }}$ & 0,036 & $0,119^{*}$ & $-0,039$ \\
\hline \multirow{2}{*}{$90 \%$} & PPP & 0,236 & $-0,313^{*}$ & $-0,306^{\star}$ & $-0,044$ & $0,338^{\star}$ & 0,104 \\
\hline & PRE & 0,265 & $-0,265$ & $-0,075$ & 0,141 & 0,206 & $-0,042$ \\
\hline \multirow{2}{*}{$95 \%$} & PPP & 0,018 & 0,125 & $-0,226$ & 0,177 & 0,224 & $-0,134$ \\
\hline & PRE & 0,265 & $-0,265$ & $-0,075$ & 0,141 & 0,206 & $-0,042$ \\
\hline \multirow{2}{*}{$98 \%$} & PPP & 0,027 & 0,128 & $-0,224$ & 0,183 & 0,227 & $-0,125$ \\
\hline & PRE & 0,265 & $-0,265$ & $-0,075$ & 0,141 & 0,206 & $-0,042$ \\
\hline 2005 & Anual & 0,044 & $-0,040$ & $-0,009$ & $0,122^{\star}$ & 0,051 & $-0,060$ \\
\hline $90 \%$ & PPP & $-0,162$ & 0,109 & $-0,38^{\star \star}$ & 0,193 & 0,137 & $0,435^{* *}$ \\
\hline $40 \%$ & PRE & $-0,031$ & $-0,247$ & $-0,85^{\star *}$ & $-0,590$ & 0,432 & $0,902^{* *}$ \\
\hline $95 \%$ & PPP & $-0,119$ & 0,127 & $-0,44^{* *}$ & 0,193 & 0,296 * & $0,32^{* *}$ \\
\hline & PRE & $-0,248$ & 0,192 & $-0,53 * *$ & 0,150 & $0,464^{*}$ & 0,501 * \\
\hline $98 \%$ & PPP & $-0,095$ & 0,100 & $-0,411$ ** & 0,187 & $0,317 * *$ & $0,282^{*}$ \\
\hline $78 \%$ & PRE & $-0,228$ & 0,231 & $-0,56 * *$ & 0,192 & $0,515^{\star *}$ & $0,457^{\star}$ \\
\hline 2006 & Anual & $0,155^{\star *}$ & $-0,053$ & $-0,132^{\star}$ & $-0,061$ & $0,123^{\star}$ & $-0,071$ \\
\hline ( & PPP & $0,489^{* *}$ & $-0,486^{*}$ & $-0,675^{* *}$ & $-0,358$ & $0,484^{\star}$ & 0,311 \\
\hline $90 \%$ & PRE & 0,245 & $-0,323$ & $-0,588 * *$ & 0,135 & 0,217 & $0,689 * *$ \\
\hline $95 \%$ & PPP & 0,486 ** & $-0,438 *$ & $-0,566 * *$ & $-0,431$ ** & $0,498 * *$ & 0,244 \\
\hline $95 \%$ & PRE & 0,171 & $-0,193$ & $-0,283$ & $-0,152$ & 0,186 & $0,505^{*}$ \\
\hline $880 \%$ & PPP & 0,419 ** & $-0,323^{*}$ & $-0,578$ ** & $-0,281$ & 0,494 ** & 0,234 \\
\hline $98 \%$ & PRE & $-0,004$ & $-0,078$ & $-0,358^{\star}$ & 0,032 & 0,243 & $0,464^{* *}$ \\
\hline 2007 & Anual & $0,288 * *$ & $-0,372^{* *}$ & $-0,225^{* *}$ & 0,019 & $0,285 * *$ & 0,012 \\
\hline $90 \%$ & PPP & $0,322^{*}$ & $-0,207$ & $-0,409$ ** & $-0,166$ & 0,456 ** & $-0,051$ \\
\hline $90 \%$ & PRE & 0,202 & $-0,141$ & 0,082 & 0,354 & $-0,014$ & $-0,338$ \\
\hline & PPP & 0,216 & $-0,153$ & $-0,578$ ** & $-0,060$ & 0,631 ** & $-0,120$ \\
\hline & PRE & 0,326 & $-0,197$ & $-0,681$ ** & $-0,016$ & $0,693 * *$ & $-0,020$ \\
\hline $98 \%$ & PPP & $0,276^{*}$ & $-0,221$ * & $-0,54$ ** & $-0,138$ & $0,585^{* *}$ & $-0,091$ \\
\hline $98 \%$ & PRE & $0,419 *$ & $-0,342$ & $-0,63 * *$ & $-0,212$ & $0,670 * *$ & 0,013 \\
\hline Total & Anual & 0,028 & $-0,059^{* \star}$ & $-0,07^{* \star}$ & $0,049 * *$ & $0,094^{* *}$ & $-0,069^{* *}$ \\
\hline
\end{tabular}

Tabla 5.2.2.6. (Continuación). Coeficientes de correlación de Spearman entre Fraxinus y las variables climatológicas. Vemed (velocidad media), FrecCalmas (frecuencia de calmas), V1Cuad, V2Cuad, V3Cuad,

V4Cuad (vientos procedentes del I, II, III y IV cuadrante). Significación: 95\%(*), 99\%(**). (-) Ausencia de correlaciones. 


\subsubsection{Olea}

La variación interanual (Fig. 5.2.2.10.) de este tipo polínico en la atmósfera registró un aumento en sus niveles anuales durante el período 20002007. Dicho incremento se vio reflejado en el total anual, pues en el año 2000 se contabilizaron 272 pólenes y en el año 2007, 678 (un 149\% más), si bien en el bienio 2005-2006 se anotaron mayores valores anuales (1123 y 1954 granos de polen, respectivamente). Todo ello condicionó que el índice de determinación $\left(\mathrm{R}^{2}=0,40\right)$, descriptivo de la regresión lineal, fuera más bajo que en otros casos pero indicando también una tendencia al incremento de las concentraciones de polen de Olea. Por otro lado, el porcentaje de representación sobre el total de pólenes contabilizados en cada anualidad estudiada osciló entre el 7,6\% de 2006 al 2,2\% de 2007, siendo 4,9\% el porcentaje medio.

La variación estacional, previo análisis a partir del PPP y los tres métodos utilizados (Tabla 5.2.2.7.) presentó una delimitación entre los meses de abril y junio, fundamentalmente mayo $\mathrm{y}$ junio. Desde cualquier metodología empleada, la duración media se situó entre los 42 y los 66 días, comenzando a mediados o finales de
Tipo polínico: Olea europaea.

Especie(s): Olea europaea L. (Oleaceae).

Distribución: Contorno de la región mediterránea de manera natural, aunque favorecida por el hombre como cultivo agrícola, empleándose también como elemento ornamental en núcleos urbanos. En la provincia de Salamanca abunda cultivada en bancales de Arribes de Duero y valles bajos y soleados de las sierras del Sur, con ejemplares dispersos por toda la provincia y utilizándose como ornamental en la ciudad de Salamanca.

Época de floración: De abril a junio, fundamentalmente.

Polinización: Anfifila, inicialmente entomófila, luego anemófila por su gran producción de polen y la facilidad en su transporte

Morfología polínica (Lámina III): Polen trizonocolporado, isopolar y radiosimétrico, con forma subcircular-lobulada en vista polar y subcircular-subelíptica en vista ecuatorial (de subprolato a suboblato), y un tamaño pequeñomediano $(P=22-28 \mu \mathrm{m})$. Las ectoaberturas tipo colpo son subterminales $y$ estrechas con membrana abertural granulada, mientras que las endoaberturas tipo poro son poco visibles. La exina, de grosor medio-grueso $(2-3 \mu \mathrm{m})$, presenta una superficie reticulada, con lúmenes irregulares en tamaño y distribución y muros estrechos.

abril, salvo en el año 2005, mediante el cálculo del PPP con el 98\% del total anual y que tuvo como fecha de inicio el 8 de abril. La finalización de este PPP se marcó de finales de junio al comienzo o a mediados de julio, teniendo como excepción el año 2000 que a través del 98\% del contenido polínico total tomó como fin del PPP la segunda semana del mes de junio (9 de junio). 
La evolución de los niveles de polen a través de las concentraciones promedio para los cinco días anteriores durante el período 2000-2007 indicó un aumento desde la primera semana de mayo hasta la última semana del mismo (Fig. 5.2.2.11.D.), presentando una concentración máxima de 55 granos/m³ el día 17 de mayo como media de los ocho años estudiados (Tabla 5.2.2.7.).

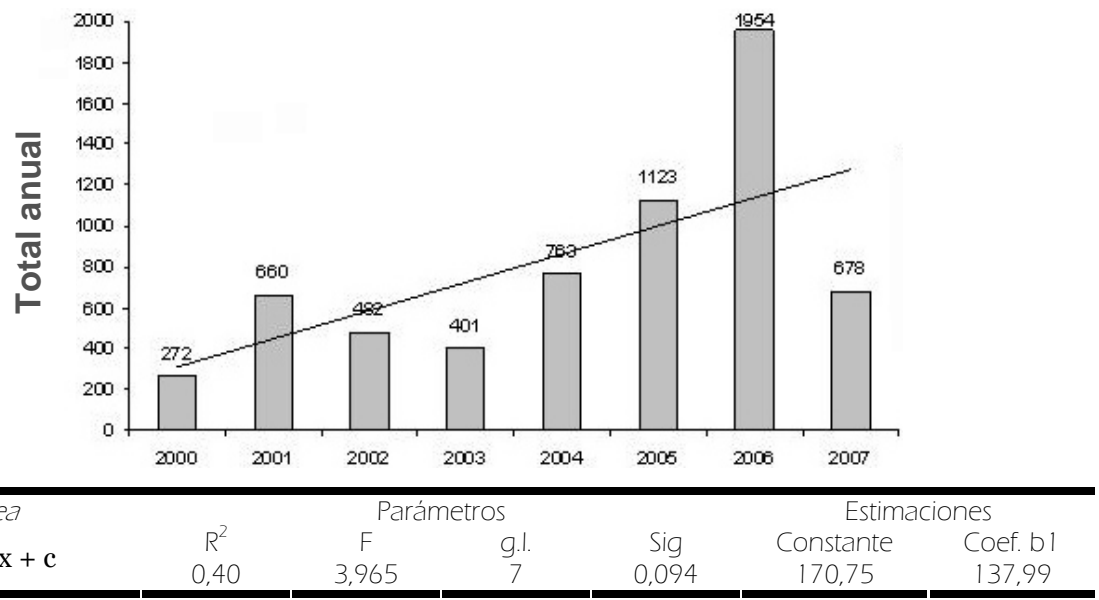

Fig. 5.2.2.10. Evolución anual del número total de pólenes de Olea y tendencias (análisis de regresión).

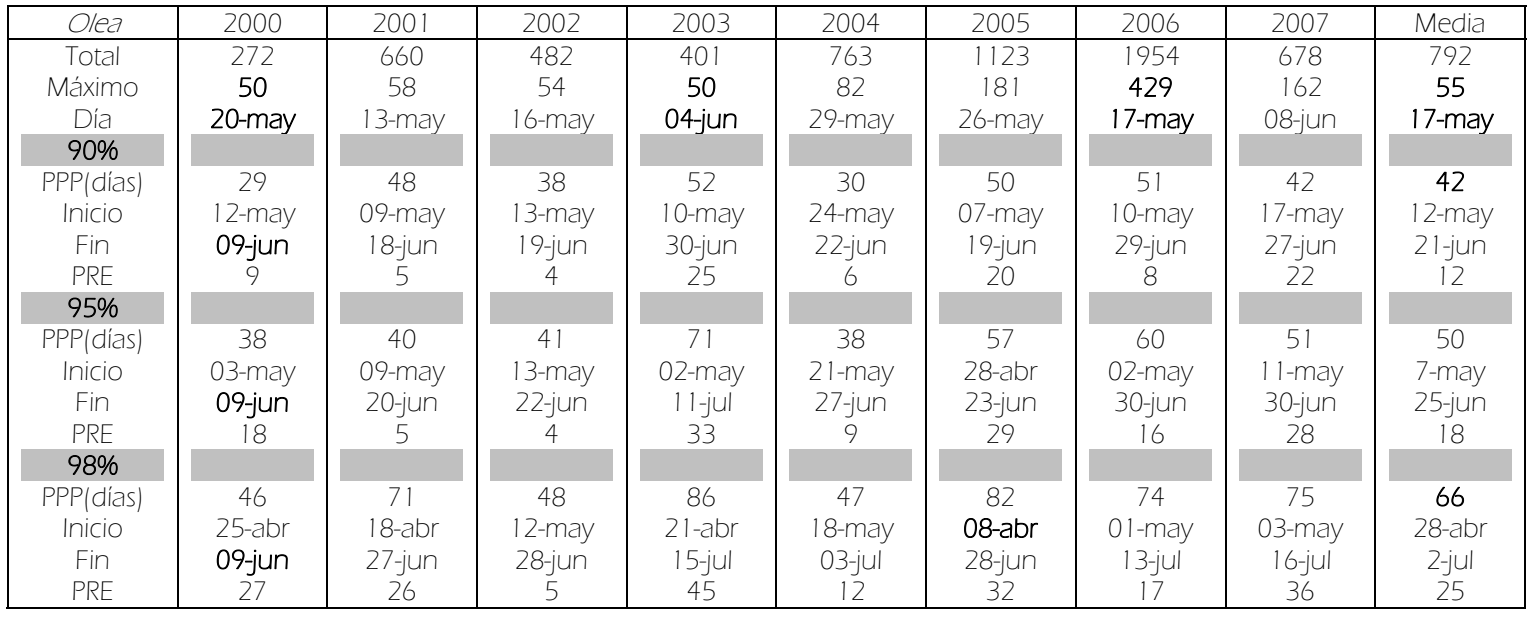

Tabla 5.2.2.7. Totales, concentraciones máximas diarias, períodos principales de polinización (PPP; fecha de inicio y fin) y días precedentes al valor máximo (PRE) durante los ocho años de estudio y el promedio de todos los parámetros para Olea.

Las mayores concentraciones diarias para los años estudiados variaron tanto en número como en la fecha en la que se produjeron (Tabla 5.2.2.7.; Fig. 5.2.2.11.A.B.C.), oscilando entre 429 granos $/ \mathrm{m}^{3}$ (17 mayo de 2006) y 50 granos $/ \mathrm{m}^{3}$ (20 mayo de 2000; 4 junio de 2003). Posteriormente, las concentraciones de polen fueron disminuyendo durante el mes de junio, con registros puntuales en el mes de julio. 


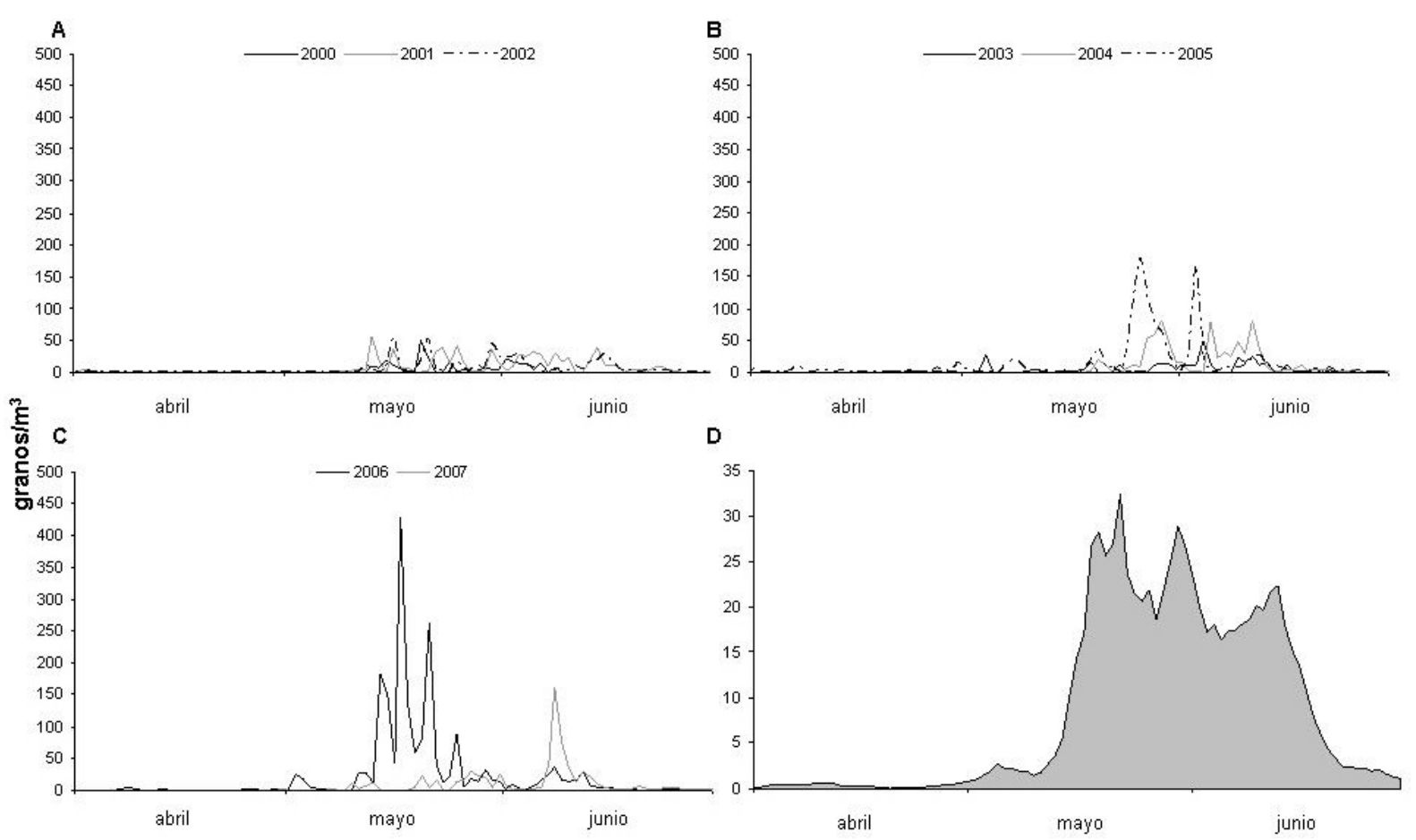

Fig. 5.2.2.11. Variación de las concentraciones medias diarias de Olea durante el período 2000-2002 (A), 20032005 (B) y 2006-2007 (C). Medias móviles de los cinco días anteriores para las concentraciones diarias promedio de los ocho años estudiados (D).

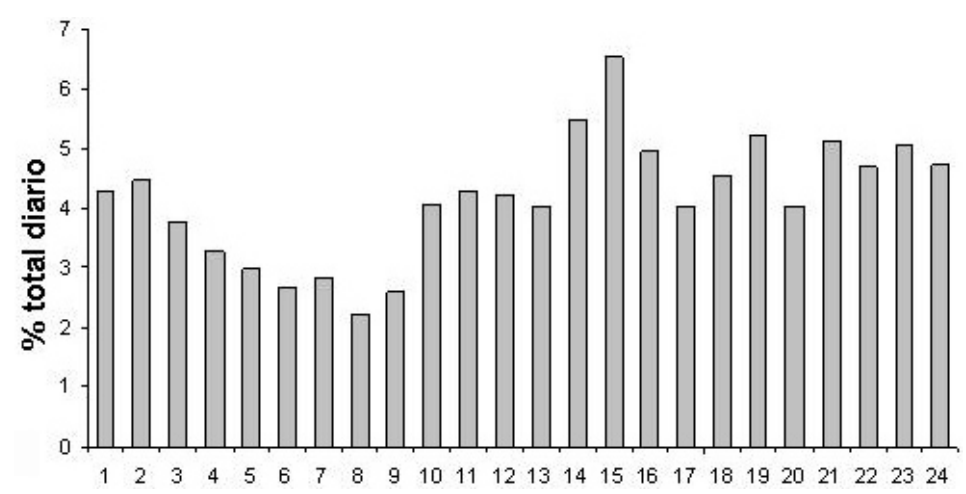

Fig. 5.2.2.12. Variación intradiaria del polen de Olea.

La variación intradiaria (Fig. 5.2.2.12.), presentada con un día promedio durante los años 2005, 2006 y 2007, registró las mayores concentraciones horarias a partir de las 14 horas, reflejando concentraciones elevadas hasta la medianoche.

Las temperaturas medias, máximas y mínimas junto a la insolación y los vientos procedentes del III y IV cuadrante ejercieron una influencia positiva en las concentraciones de polen de Olea durante los ocho años analizados, mientras que la humedad relativa lo hizo de forma negativa, después de efectuar el análisis de correlación (Tabla 5.2.2.8.). Asimismo, a través de los diferentes PPP obtenidos con los diversos métodos empleados, esta influencia se vio acrecentada con coeficientes más elevados al aplicar este tipo de estadísticos en el PRE y con independencia de si dicho PPP fue calculado al 90, 95 o 98\% del total anual. 
Hemos de destacar además que la frecuencia de las calmas ejerció un efecto negativo en los niveles de este tipo polínico durante los años 2005 y 2006.

\begin{tabular}{|c|c|c|c|c|c|c|c|}
\hline \multicolumn{2}{|c|}{ Olea } & Tmed & Tmax & Tmin & Insolación & Precipitación & Hrelativa \\
\hline 2000 & Anual & $0,218 * *$ & $0,191 * \star$ & 0,236 ** & $0,124^{*}$ & $-0,009$ & $-0,133^{*}$ \\
\hline \multirow{2}{*}{$90 \%$} & PPP & $0,424^{*}$ & $0,417^{*}$ & $0,395^{\star}$ & $-0,069$ & $0,432^{*}$ & $-0,131$ \\
\hline & PRE & 0,500 & $0,753^{*}$ & 0,267 & $-0,059$ & 0,274 & $-0,749 *$ \\
\hline \multirow{2}{*}{$95 \%$} & PPP & $0,680 * *$ & $0,654^{* *}$ & $0,497 * *$ & 0,274 & $-0,293$ & $-0,428 * *$ \\
\hline & PRE & $0,892^{* *}$ & $0,923^{* *}$ & 0,319 & $0,72^{\star *}$ & $-0,70$ ** & $-0,836$ ** \\
\hline \multirow{2}{*}{$98 \%$} & PPP & $0,753^{* *}$ & $0,732 * *$ & $0,605 * *$ & 0,371 * & $-0,276$ & $-0,478 * *$ \\
\hline & PRE & $0,815^{* *}$ & $0,843^{* *}$ & $0,503^{* *}$ & $0,66 * *$ & $-0,415^{*}$ & $-0,687 * *$ \\
\hline 2001 & Anual & $0,344^{* *}$ & $0,341^{* *}$ & $0,308^{* *}$ & $0,34^{* *}$ & $-0,079$ & $-0,369 * *$ \\
\hline \multirow{2}{*}{$90 \%$} & PPP & 0,249 & 0,122 & $0,370^{*}$ & 0,077 & $-0,027$ & $-0,123$ \\
\hline & PRE & 0,500 & 0,308 & 0,154 & 0,410 & $-0,287$ & $-0,975 * *$ \\
\hline \multirow{2}{*}{$95 \%$} & PPP & 0,168 & 0,068 & $0,366^{*}$ & 0,048 & $-0,009$ & $-0,078$ \\
\hline & PRE & 0,500 & 0,308 & 0,154 & 0,410 & $-0,287$ & $-0,975 * *$ \\
\hline \multirow{2}{*}{$98 \%$} & PPP & $0,585^{* *}$ & 0,520 ** & $0,618 * *$ & $0,33^{* *}$ & $-0,073$ & $-0,322$ ** \\
\hline & PRE & $0,444 * *$ & $0,470 * *$ & 0,358 & 0,038 & 0,068 & $-0,124$ \\
\hline 2002 & Anual & $0,399 * *$ & $0,341^{* *}$ & $0,304^{* *}$ & $0,34^{* *}$ & $-0,119^{*}$ & $-0,425$ ** \\
\hline \multirow{2}{*}{$90 \%$} & PPP & $0,492^{* *}$ & $0,485^{* *}$ & $0,448 * *$ & 0,079 & $-0,120$ & $-0,419 * *$ \\
\hline & PRE & 0,800 & 0,800 & 0,632 & $-0,400$ & - & $-0,600$ \\
\hline \multirow{2}{*}{$95 \%$} & PPP & $0,322 *$ & 0,299 & 0,321 * & $-0,073$ & $-0,069$ & $-0,317^{*}$ \\
\hline & PRE & 0,800 & 0,800 & 0,632 & $-0,400$ & - & $-0,600$ \\
\hline \multirow{2}{*}{$98 \%$} & PPP & 0,134 & 0,137 & 0,106 & $-0,161$ & $-0,003$ & $-0,251$ \\
\hline & PRE & 0,300 & 0,500 & 0,205 & $-0,400$ & - & $-0,600$ \\
\hline 2003 & Anual & 0,450 ** & $0,431^{\star *}$ & $0,412^{\star \star}$ & $0,39 * \star$ & $-0,103^{*}$ & $-0,474 * \star$ \\
\hline \multirow{2}{*}{$90 \%$} & PPP & 0,260 & 0,204 & $0,288^{\star}$ & $-0,4^{\star \star}$ & 0,138 & $-0,032$ \\
\hline & PRE & $0,657 * *$ & 0,218 & $0,789 * *$ & $-0,6 * *$ & 0,176 & 0,088 \\
\hline \multirow{2}{*}{$95 \%$} & PPP & $0,282^{*}$ & 0,223 & 0,380 ** & $-0,156$ & 0,021 & $-0,090$ \\
\hline & PRE & $0,687 * *$ & $0,378 *$ & 0,780 ** & $-0,167$ & $-0,109$ & $-0,164$ \\
\hline \multirow{2}{*}{$98 \%$} & PPP & $0,322 * *$ & 0,301 ** & $0,368^{* *}$ & $-0,019$ & $-0,011$ & $-0,155$ \\
\hline & PRE & 0,656 ** & 0,506 ** & 0,625 ** & 0,009 & $-0,080$ & $-0,232$ \\
\hline 2004 & Anual & $0,427^{* *}$ & $0,401^{* *}$ & $0,425^{\star *}$ & $0,35^{\star *}$ & $-0,022$ & $-0,336$ ** \\
\hline \multirow{2}{*}{$90 \%$} & PPP & 0,354 & 0,195 & $0,460^{\star}$ & $-0,339$ & 0,122 & 0,324 \\
\hline & PRE & 0,771 & 0,986 ** & 0,429 & $0,829 *$ & $-0,676$ & $-0,771$ \\
\hline \multirow{2}{*}{$95 \%$} & PPP & 0,204 & 0,138 & 0,252 & $-0,175$ & $-0,020$ & 0,130 \\
\hline & PRE & $0,882^{* *}$ & $0,848 * *$ & 0,479 & $0,85^{* *}$ & $-0,658$ & $-0,891^{\text {** }}$ \\
\hline \multirow{2}{*}{$98 \%$} & PPP & 0,030 & $-0,042$ & 0,136 & $-0,35^{\star}$ & 0,048 & 0,268 \\
\hline & PRE & $0,642^{*}$ & 0,350 & 0,509 & 0,284 & $-0,473$ & $-0,414$ \\
\hline 2005 & Anual & $0,387 * *$ & $0,365^{* *}$ & $0,347^{* *}$ & $0,31^{* *}$ & $-0,007$ & $-0,375$ ** \\
\hline ๑००\% & PPP & $0,339 *$ & 0,253 & $0,311^{*}$ & 0,116 & $-0,200$ & $-0,436 * *$ \\
\hline 90\% & PRE & 0,790 ** & $0,834^{* *}$ & 0,338 & 0,438 & $-0,45 * *$ & $-0,723 * *$ \\
\hline 950 & PPP & $0,271^{*}$ & 0,195 & 0,257 & 0,145 & $-0,096$ & $-0,393$ ** \\
\hline $95 \%$ & PRE & 0,656 ** & $0,629 * *$ & $0,410^{*}$ & 0,249 & $-0,244$ & $-0,553^{* *}$ \\
\hline 980\% & PPP & $0,402^{* *}$ & $0,395^{* *}$ & $0,353^{* *}$ & $0,220^{*}$ & $-0,122$ & $-0,488$ ** \\
\hline $98 \%$ & PRE & $0,574^{* *}$ & $0,576^{* *}$ & $0,423^{* *}$ & 0,288 * & $-0,228$ & $-0,515^{* *}$ \\
\hline 2006 & Anual & $0,373^{* *}$ & $0,373^{* \star}$ & $0,319 * *$ & - & $-0,047$ & $-0,486^{* *}$ \\
\hline $90 \%$ & PPP & $-0,168$ & $-0,201$ & $-0,295^{*}$ & - & $-0,122$ & $-0,351$ * \\
\hline $70 \%$ & PRE & 0,683 & 0,596 & 0,180 & - & $-0,166$ & $-0,180$ \\
\hline $95 \%$ & PPP & $-0,046$ & $-0,056$ & $-0,130$ & - & $-0,031$ & $-0,343 * *$ \\
\hline $75 \%$ & PRE & $0,762^{* *}$ & $0,749 * *$ & $0,597 *$ & - & 0,050 & $-0,311$ \\
\hline $98 \%$ & PPP & $-0,281^{*}$ & $-0,265^{*}$ & $-0,34$ ** & - & 0,028 & $-0,249$ * \\
\hline $78 \%$ & PRE & $0,758 * *$ & $0,722^{* *}$ & $0,645^{* *}$ & - & 0,093 & $-0,226$ \\
\hline 2007 & Anual & $0,347^{* *}$ & 0,296 ** & $0,360^{* *}$ & $0,24^{* \star}$ & 0,056 & $-0,214^{* *}$ \\
\hline $90 \%$ & PPP & $-0,020$ & $-0,088$ & 0,152 & $-0,139$ & 0,044 & 0,161 \\
\hline $70 \%$ & PRE & $-0,218$ & $-0,225$ & $-0,070$ & $-0,113$ & 0,105 & 0,238 \\
\hline $95 \%$ & PPP & $-0,011$ & $-0,094$ & 0,245 & $-0,210$ & 0,142 & 0,251 \\
\hline $75 \%$ & PRE & 0,111 & $-0,159$ & 0,140 & $-0,204$ & 0,226 & 0,308 \\
\hline & PPP & $-0,213$ & $-0,248^{*}$ & 0,015 & $-0,28 *$ & 0,224 & $0,360^{* *}$ \\
\hline $98 \%$ & PRE & $-0,024$ & $-0,100$ & 0,255 & $-0,255$ & 0,221 & 0,270 \\
\hline Total & Anual & $0,369 * *$ & $0,349 * *$ & $0,347 * *$ & $0,31^{* \star}$ & $-0,046 *$ & $-0,334 * *$ \\
\hline
\end{tabular}

Tabla 5.2.2.8. Coeficientes de correlación de Spearman entre Olea y las variables climatológicas. Tmed, Tmax, Tmin (temperatura media, máxima y mínima), Hrelativa (humedad relativa). Significación: 95\%(*), 99\%(**). () Ausencia de correlaciones. 


\begin{tabular}{|c|c|c|c|c|c|c|c|}
\hline \multicolumn{2}{|c|}{ Olea } & Vemed & FrecCalm & VICuadr & V2Cuadr & V3Cuadr & V4Cuadr \\
\hline 2000 & Anual & 0,032 & $-0,089$ & 0,009 & 0,062 & $-0,021$ & $0,108^{*}$ \\
\hline \multirow{2}{*}{$90 \%$} & PPP & $-0,059$ & 0,129 & 0,080 & 0,258 & $-0,119$ & 0,016 \\
\hline & PRE & $-0,017$ & $-0,192$ & 0,133 & 0,283 & 0,333 & - \\
\hline \multirow{2}{*}{$95 \%$} & PPP & 0,073 & $-0,102$ & 0,078 & 0,004 & $-0,208$ & 0,195 \\
\hline & PRE & $-0,210$ & $-0,110$ & 0,461 & 0,091 & $-0,516$ * & 0,123 \\
\hline \multirow{2}{*}{$98 \%$} & PPP & $-0,060$ & 0,064 & 0,102 & $-0,024$ & $-0,177$ & 0,208 \\
\hline & PRE & $-0,316$ & 0,147 & $0,398 *$ & 0,069 & $-0,319$ & 0,091 \\
\hline 2001 & Anual & 0,034 & $-0,063$ & $-0,087$ & $-0,103$ & 0,096 & $0,291^{* *}$ \\
\hline \multirow{2}{*}{$90 \%$} & PPP & 0,156 & $-0,213$ & $-0,365^{\star}$ & 0,040 & $0,437^{\star *}$ & 0,298 \\
\hline & PRE & 0,718 & $-0,462$ & 0,103 & $-0,103$ & 0,872 & $-0,616$ \\
\hline \multirow{2}{*}{$95 \%$} & PPP & 0,195 & $-0,236$ & $-0,383^{*}$ & $-0,005$ & $0,451 * *$ & 0,311 * \\
\hline & PRE & 0,718 & $-0,462$ & 0,103 & $-0,103$ & 0,872 & $-0,616$ \\
\hline \multirow{2}{*}{$98 \%$} & PPP & $-0,096$ & $-0,003$ & $-0,261$ * & 0,052 & $0,247^{*}$ & $0,244^{*}$ \\
\hline & PRE & $-0,291$ & 0,370 & $-0,120$ & $0,564^{* *}$ & 0,157 & $-0,150$ \\
\hline 2002 & Anual & 0,099 & $-0,025$ & $-0,143^{* \star}$ & $-0,171$ ** & $0,182^{\star *}$ & 0,053 \\
\hline \multirow{2}{*}{$90 \%$} & PPP & $-0,071$ & 0,156 & 0,186 & 0,281 & $-0,188$ & $-0,265$ \\
\hline & PRE & 0,400 & - & 0,600 & - & - & $-0,400$ \\
\hline \multirow{2}{*}{$95 \%$} & PPP & $-0,071$ & 0,063 & 0,164 & 0,239 & $-0,133$ & $-0,210$ \\
\hline & PRE & 0,400 & - & 0,600 & - & - & $-0,400$ \\
\hline \multirow{2}{*}{$98 \%$} & PPP & $-0,103$ & 0,207 & 0,007 & 0,242 & 0,049 & $-0,204$ \\
\hline & PRE & 0,400 & 0,200 & 0,300 & $-0,300$ & 0,100 & $-0,154$ \\
\hline 2003 & Anual & 0,048 & $-0,102$ & $-0,127^{\star}$ & $-0,088$ & $0,144^{* *}$ & $0,149^{* *}$ \\
\hline \multirow{2}{*}{$90 \%$} & PPP & $-0,059$ & 0,187 & $-0,39$ * & $0,318^{*}$ & $0,300 *$ & 0,190 \\
\hline & PRE & $-0,083$ & 0,371 & $-0,64 * *$ & $0,410^{*}$ & $0,687^{* *}$ & 0,294 \\
\hline \multirow{2}{*}{$95 \%$} & PPP & 0,059 & 0,010 & $-0,34 * *$ & $0,240 *$ & $0,302^{*}$ & 0,081 \\
\hline & PRE & $-0,007$ & 0,197 & $-0,57 * *$ & 0,305 & $0,643 * *$ & 0,284 \\
\hline \multirow{2}{*}{$98 \%$} & PPP & $-0,030$ & 0,059 & $-0,130$ & 0,142 & 0,143 & 0,093 \\
\hline & PRE & $-0,137$ & 0,262 & $-0,208$ & 0,130 & $0,313^{*}$ & 0,301 * \\
\hline 2004 & Anual & 0,099 & $-0,046$ & $-0,066$ & $-0,003$ & 0,038 & $0,178^{* \star}$ \\
\hline \multirow{2}{*}{$90 \%$} & PPP & $0,444^{\star}$ & $0,405^{*}$ & $-0,435^{\star}$ & 0,318 & $0,422^{\star}$ & 0,449 * \\
\hline & PRE & 0,029 & $-0,580$ & $-0,618$ & $-0,486$ & 0,371 & 0,429 \\
\hline \multirow{2}{*}{$95 \%$} & PPP & 0,315 & 0,323 * & $-0,296$ & 0,259 & $0,346^{*}$ & 0,286 \\
\hline & PRE & 0,580 & $-0,106$ & $-0,784^{*}$ & $-0,487$ & 0,689 * & 0,740 * \\
\hline \multirow{2}{*}{$98 \%$} & PPP & $0,305^{\star}$ & 0,200 & $-0,333^{*}$ & 0,191 & $0,446 * *$ & 0,213 \\
\hline & PRE & $0,611^{*}$ & $-0,115$ & $-0,727^{* *}$ & $-0,456$ & $0,737^{* *}$ & $0,666^{*}$ \\
\hline 2005 & Anual & $0,135^{\star}$ & $-0,199 * *$ & $-0,124^{*}$ & $-0,016$ & $0,190^{* *}$ & $0,174^{\star *}$ \\
\hline 9ח\% & PPP & 0,017 & 0,061 & $-0,114$ & $-0,014$ & 0,250 & $-0,064$ \\
\hline$\% \%$ & PRE & $-0,222$ & 0,127 & 0,117 & 0,292 & $-0,063$ & $-0,202$ \\
\hline 25\% & PPP & $-0,047$ & 0,088 & $-0,143$ & 0,023 & 0,253 & $-0,029$ \\
\hline $75 \%$ & PRE & $-0,152$ & 0,218 & $-0,127$ & 0,360 & 0,175 & $-0,064$ \\
\hline $980 \%$ & PPP & $-0,258 *$ & 0,194 & 0,109 & $0,252^{*}$ & 0,025 & $-0,157$ \\
\hline $78 \%$ & PRE & $-0,342^{*}$ & 0,374 ** & 0,117 & 0,497 ** & 0,013 & $-0,141$ \\
\hline 2006 & Anual & 0,035 & $-0,187^{* *}$ & $-0,017$ & $-0,002$ & 0,021 & $0,230^{* *}$ \\
\hline ๑०\% & PPP & $-0,175$ & $-0,154$ & $-0,216$ & 0,188 & $0,294^{\star}$ & $-0,204$ \\
\hline $70 \%$ & PRE & $-0,313$ & 0,587 & $-0,157$ & $-0,168$ & 0,623 & $-0,802^{*}$ \\
\hline $95 \%$ & PPP & $-0,056$ & $-0,201$ & $-0,148$ & 0,200 & 0,249 & $-0,268^{*}$ \\
\hline & PRE & 0,275 & 0,319 & $-0,146$ & 0,340 & $0,641 * *$ & $-0,668 * *$ \\
\hline $98 \%$ & PPP & $-0,041$ & $-0,192$ & $-0,155$ & 0,151 & 0,175 & $-0,149$ \\
\hline $98 \%$ & PRE & 0,162 & 0,230 & $-0,261$ & 0,285 & 0,634 ** & $-0,531^{*}$ \\
\hline 2007 & Anual & $0,147^{\star \star}$ & $-0,049$ & $-0,218^{\star \star}$ & $-0,096$ & 0,247 ** & 0,063 \\
\hline $90 \%$ & PPP & 0,091 & 0,047 & $-0,389 *$ & $-0,092$ & $0,512^{* *}$ & 0,059 \\
\hline & PRE & $-0,087$ & 0,115 & $-0,664^{* \star}$ & $-0,115$ & $0,673^{* *}$ & 0,300 \\
\hline $95 \%$ & PPP & 0,159 & $-0,062$ & $-0,347^{\star}$ & $-0,117$ & $0,486 * *$ & $-0,055$ \\
\hline $95 \%$ & PRE & 0,007 & $-0,009$ & $-0,455^{\star}$ & $-0,106$ & $0,512^{* *}$ & 0,100 \\
\hline $98 \%$ & PPP & $0,254^{*}$ & $-0,108$ & $-0,354 * *$ & $-0,028$ & $0,470 * *$ & $-0,218$ \\
\hline & PRE & 0,125 & $-0,216$ & $-0,384^{*}$ & $-0,113$ & $0,473^{* *}$ & $-0,019$ \\
\hline Total & Anual & 0,001 & $-0,096^{* *}$ & $-0,087^{* *}$ & $-0,036$ & $0,105^{\star \star}$ & $0,164^{\star *}$ \\
\hline
\end{tabular}

Tabla 5.2.2.8. (Continuación). Coeficientes de correlación de Spearman entre Olea y las variables climatológicas. Vemed (velocidad media), FrecCalmas (frecuencia de calmas), V1Cuad, V2Cuad, V3Cuad,

V4Cuad (vientos procedentes del I, II, III y IV cuadrante). Significación: 95\%(*), 99\%(**). (-) Ausencia de correlaciones. 


\subsubsection{Pinus}

El tipo de polen que incluye al género Pinus L. experimentó un incremento en sus niveles polínicos a través de los ocho años analizados, con una variación interanual (Fig. 5.2.2.13.) que pasó de un total de 380 en el año 2000 a los 687 del año 2007. A pesar de este incremento (un $81 \%$ más) los mayores valores anuales se registraron en 2004 y 2005, con 1083 y 1347 pólenes, respectivamente. Esta evolución en el número total de granos de polen dio lugar a un índice de determinación $\left(\mathrm{R}^{2}=0,37\right)$, propio de la regresión lineal que, pese a indicar también una tendencia al incremento de las concentraciones de polen de Pinus, tuviera un valor más bajo que con otros tipos. Los porcentajes de representación sobre el total de pólenes contabilizados en cada anualidad estudiada variaron del 6\% de 2005 al 2,2\% de 2007 , con un porcentaje medio de $3,8 \%$.

La distribución de estos granos de polen a lo largo del año se localizó entre mediados-finales de marzo hasta mediados de julio, por lo que la variación estacional (Tabla 5.2.2.9.) tuvo un PPP promedio muy amplio de 75 a 114 días, en función del modelo empleado para su cálculo. Sin embargo, el uso de estas
Tipo de polen: Pinus spp.

Especie(s): Pinus pinaster Aiton, Pinus pinea L. y Pinus sylvestris L. (Pinaceae), junto a otras especies cultivadas de uso forestal $y / 0$ ornamental.

Distribución: Este género engloba a un buen número de especies presentes en el hemisferio Norte, que en la Península Ibérica incluye a especies repartidas desde zonas próximas al mar (P. pinea L., P. halepensis Mill.) hasta regiones de alta montaña $(P$. pinaster Aiton, $P$. sylvestris L.). En la provincia de Salamanca, Pinus pinaster Aiton y Pinus sylvestris L. están ampliamente representadas en las sierras meridionales, mientras que Pinus pinea $\mathrm{L}$. se localiza en suelos arenosos del noreste provincial.

Época de floración: De febrero a junio.

Polinización: Anemófila.

Morfología polínica (Lámina III): Polen analeptomado con dos vesículas aeríferas laterales, heteropolar y bisimétrico, con forma elíptica en vista polar y plano-convexa en vista ecuatorial (de oblato a oblato-esferoidal), y un tamaño mediano-grande $(P=34-60 \mu \mathrm{m})$. $E$ leptoma está situado en el polo distal. La exina, de grosor medio-grueso $(2-4 \mu \mathrm{m})$, presenta una superficie granulado-verrugosa, que en las vesículas aeríferas asemeja un retículo de entramado alveolar al microscopio óptico (psilada-microperforada al MEB).

metodologías para delimitar el PPP marcó diferencias en las fechas de inicio y finalización para los diferentes años incluidos, dejando el 13 de abril del año 2005 (método 90\%) como fecha más tardía de inicio, el 17 de junio de 2000 (método 90\%) como fecha de finalización más temprana y el 23 de julio de 2005 (método 98\%) como fecha de fin más tardía. Los niveles polínicos de este género en la atmósfera de la ciudad de Salamanca (Fig. 5.2.2.14.D.) experimentaron un ascenso a partir de mediados de marzo hasta finales de abril, donde 
sufrieron un ligero descenso hasta finales de mayo, momento en el que hubo un repunte en las concentraciones polínicas, como indica el valor medio más elevado en los años analizados (24 granos/ $\mathrm{m}^{3}$ el 5 de junio), gracias a la dinámica aportada por las concentraciones medias de los cincos días anteriores para el conjunto de anualidades. En todo caso, las mayores concentraciones diarias registradas en los ocho años estudiados oscilaron en más de dos meses y con valores entre los 13 granos/m³ (27 de mayo de 2003) y los 132 granos/m³ (14 de abril de 2005). Asimismo, estos niveles disminuyeron a finales del mes de junio, mostrando concentraciones anecdóticas en julio (Fig. 5.2.2.14. A. B. C.).

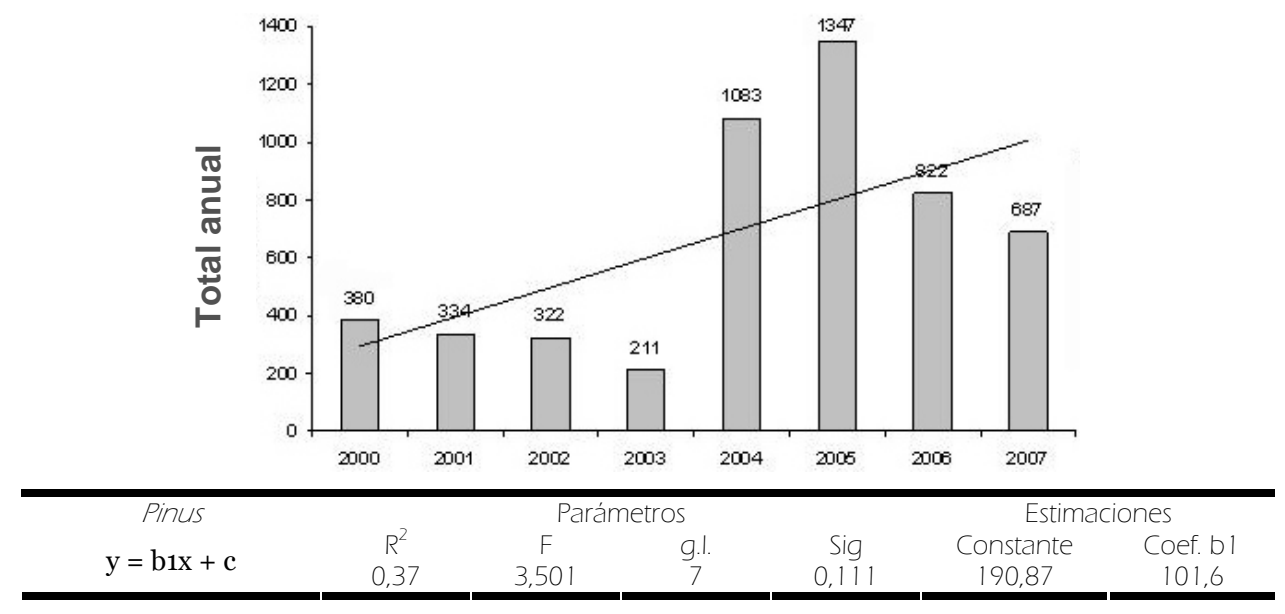

Fig. 5.2.13. Evolución anual del número total de pólenes de Pinus y tendencias (análisis de regresión).

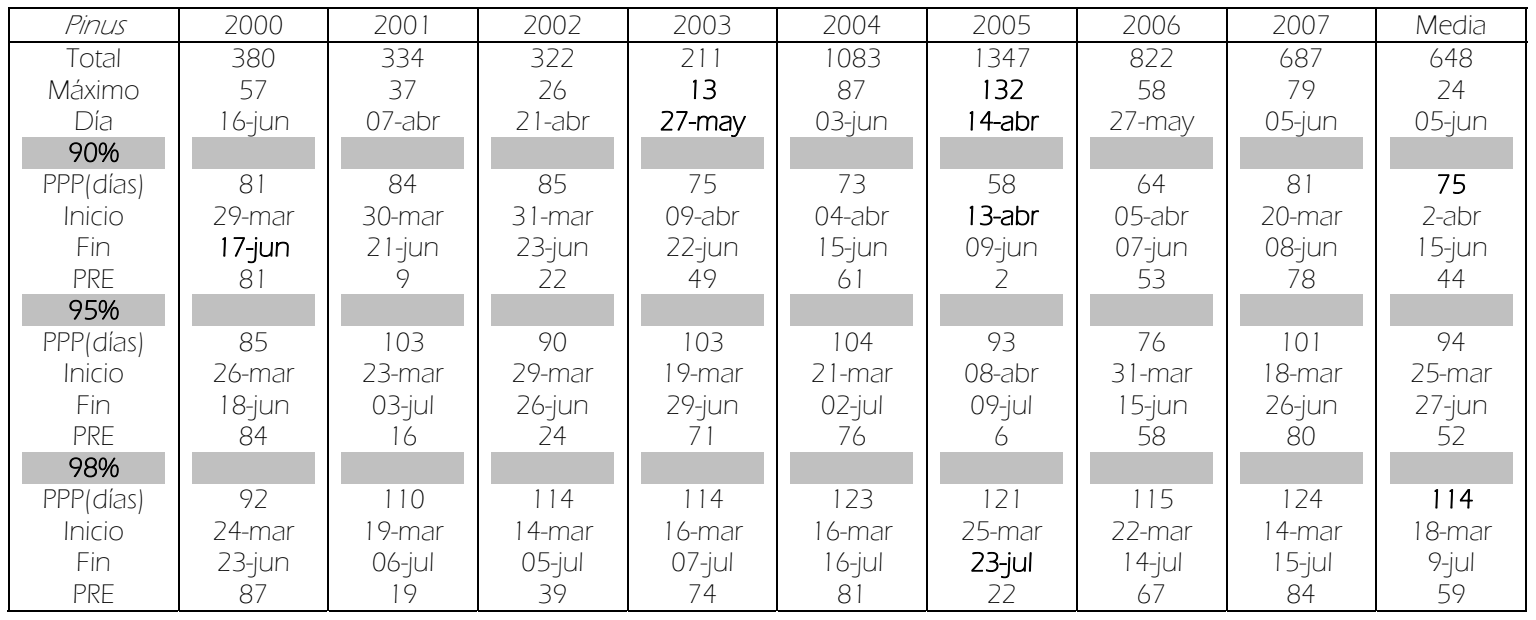

Tabla 5.2.2.9. Totales, concentraciones máximas diarias, períodos principales de polinización (PPP; fecha de inicio y fin) y días precedentes al valor máximo (PRE) durante los ocho años de estudio y el promedio de todos los parámetros para Pinus.

La variación intradiaria (Fig. 5.2.2.15.) a lo largo de un día promedio para los últimos tres años estudiados, mostró un patrón irregular en la distribución horaria, con mayores concentraciones de 23 a 3 horas y, en menor medida, de 14 a 19 horas, que supusieron casi la mitad de la concentración diaria promedio. 


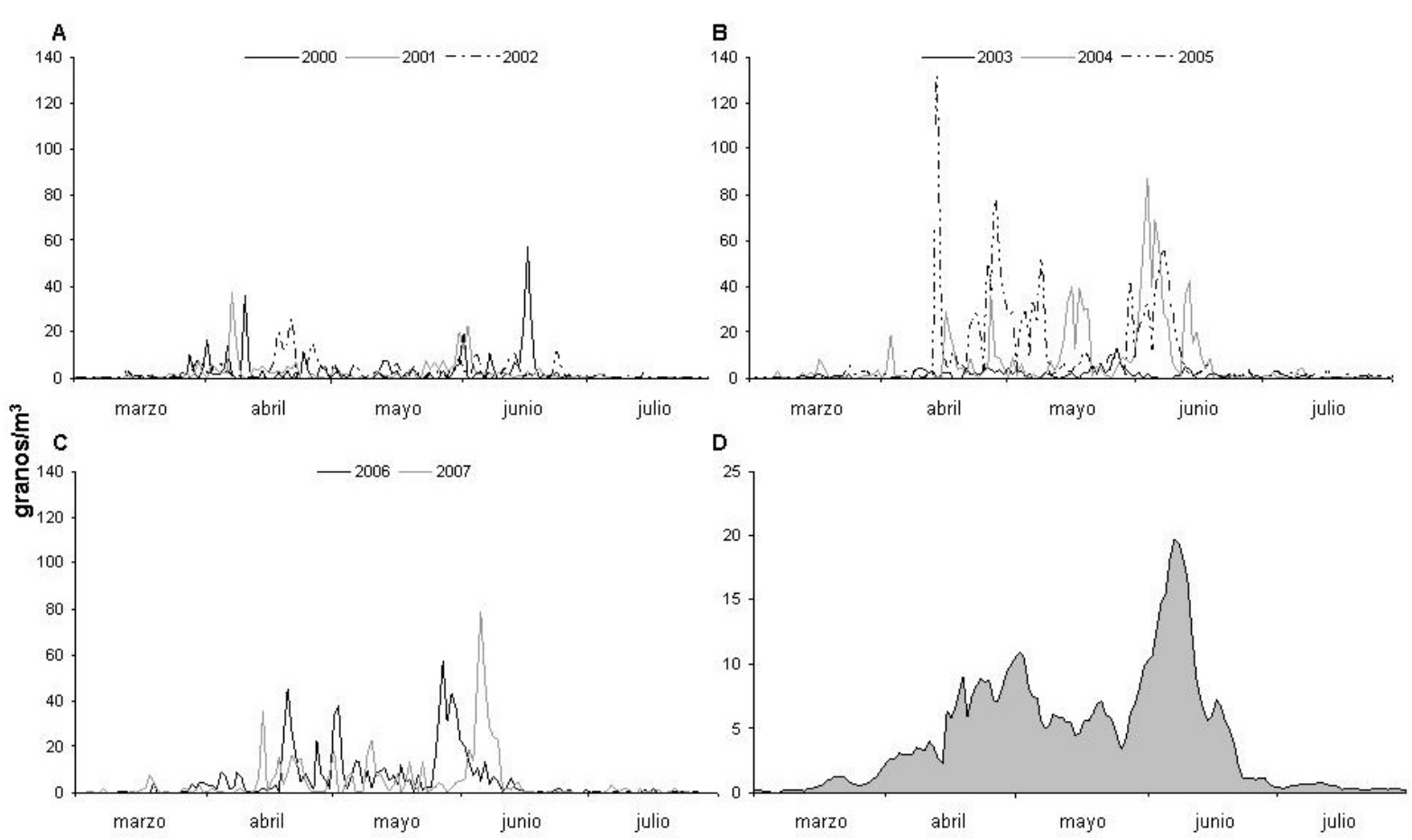

Fig. 5.2.2.14. Variación de las concentraciones medias diarias de Pinus durante el período 2000-2002 (A), 2003-2005 (B) y 2006-2007 (C). Medias móviles de los cinco días anteriores para las concentraciones diarias promedio de los ocho años estudiados (D).

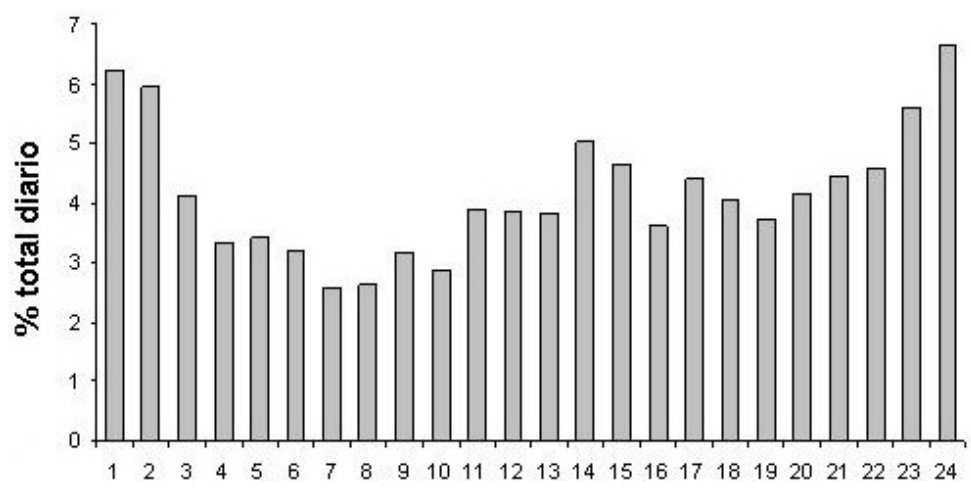

Fig. 5.2.2.15. Variación intradiaria del polen de Pinus.

El análisis de correlación (Tabla 5.2.2.10.) reflejó que las temperaturas medias, máximas y mínimas junto a la insolación influyeron positivamente en los niveles polínicos de Pinus durante los ocho años analizados. Por el contrario, la humedad relativa tuvo un efecto negativo sobre las concentraciones polínicas. Con respecto a los vientos, debe reseñarse la correlación positiva con los vientos procedentes del IV cuadrante y negativa con la frecuencia de las calmas. Si analizamos cada año y modelo estudiados por separado, se observa un patrón similar en muchas anualidades, con coeficientes de correlación más elevados, sobretodo en el PPP calculado a partir del 90\% de la concentraciones anuales de los últimos cuatro años analizados. Retomando el efecto de los vientos a lo largo de todos estos años, PPP y PRE, destacó la influencia positiva de los vientos procedentes del III cuadrante y negativa de los vientos del I cuadrante en el PRE del año 2002 con cualquier modelo empleado. En 
este mismo sentido, los vientos del III cuadrante ejercieron un efecto positivo durante los años 2005 y 2007, así como el efecto negativo de los vientos del I cuadrante en el año 2005 y la influencia negativa de la velocidad media del viento en el PRE de 2001 (método 90\%).

\begin{tabular}{|c|c|c|c|c|c|c|c|}
\hline \multicolumn{2}{|c|}{ Pinus } & Tmed & Tmax & Tmin & Insolación & Precipitación & Hrelativa \\
\hline 2000 & Anual & $0,121^{*}$ & $0,119^{*}$ & $0,113^{*}$ & $0,17^{* *}$ & $-0,016$ & $-0,244^{\star \star}$ \\
\hline \multirow{2}{*}{$90 \%$} & PPP & 0,163 & $0,251^{*}$ & 0,002 & $0,42^{\star *}$ & $-0,289^{* \star}$ & $-0,484^{\star *}$ \\
\hline & PRE & 0,130 & $0,225^{*}$ & $-0,043$ & $0,41 * *$ & $-0,284^{*}$ & $-0,484^{* *}$ \\
\hline \multirow{2}{*}{$95 \%$} & PPP & 0,122 & 0,208 & $-0,029$ & $0,42 * *$ & $-0,294^{* *}$ & $-0,479 * *$ \\
\hline & PRE & 0,087 & 0,178 & $-0,076$ & $0,41 * *$ & $-0,291 * *$ & $-0,486 * *$ \\
\hline \multirow{2}{*}{$98 \%$} & PPP & 0,099 & 0,180 & $-0,033$ & $0,38 * *$ & $-0,251^{*}$ & $-0,412^{* *}$ \\
\hline & PRE & 0,096 & 0,190 & $-0,064$ & $0,42^{* *}$ & $-0,274^{* *}$ & $-0,481 * *$ \\
\hline 2001 & Anual & $0,263^{* *}$ & $0,282^{* \star}$ & $0,202^{* \star}$ & $0,32^{\star \star}$ & $-0,077$ & $-0,375^{\star \star}$ \\
\hline \multirow{2}{*}{$90 \%$} & PPP & 0,086 & 0,100 & 0,074 & 0,190 & $-0,086$ & $-0,161$ \\
\hline & PRE & $-0,576$ & $-0,797$ * & $-0,136$ & 0,170 & 0,139 & $-0,145$ \\
\hline \multirow{2}{*}{$95 \%$} & PPP & 0,011 & 0,042 & $-0,024$ & 0,116 & $-0,070$ & $-0,066$ \\
\hline & PRE & 0,060 & 0,145 & 0,141 & 0,041 & $-0,234$ & $-0,227$ \\
\hline \multirow{2}{*}{$98 \%$} & PPP & 0,013 & 0,068 & $-0,051$ & 0,161 & $-0,116$ & $-0,118$ \\
\hline & PRE & $-0,126$ & 0,108 & $-0,138$ & 0,068 & $-0,145$ & $-0,290$ \\
\hline 2002 & Anual & $0,177^{\star *}$ & $0,206 * \star$ & $0,104^{*}$ & $0,27^{\star *}$ & $-0,051$ & $-0,395^{\star *}$ \\
\hline \multirow{2}{*}{$90 \%$} & PPP & 0,166 & $0,218^{*}$ & 0,033 & 0,122 & $-0,149$ & $-0,176$ \\
\hline & PRE & $0,601 * *$ & $0,617 * *$ & $0,468^{*}$ & $0,77 * *$ & $-0,319$ & $-0,577 * *$ \\
\hline \multirow{2}{*}{$95 \%$} & PPP & 0,123 & 0,180 & $-0,013$ & 0,080 & $-0,140$ & $-0,144$ \\
\hline & PRE & $0,630 * *$ & $0,648 * *$ & $0,474^{*}$ & $0,77 * *$ & $-0,347$ & $-0,594^{* *}$ \\
\hline \multirow{2}{*}{$98 \%$} & PPP & 0,129 & 0,135 & 0,089 & 0,071 & $-0,065$ & $-0,078$ \\
\hline & PRE & 0,134 & 0,074 & 0,304 & 0,316 & $-0,055$ & $-0,091$ \\
\hline 2003 & Anual & $0,346^{* *}$ & $0,366^{* *}$ & $0,240^{* *}$ & $0,36 * *$ & $-0,116^{*}$ & $-0,471 * *$ \\
\hline \multirow{2}{*}{$90 \%$} & PPP & $-0,215$ & $-0,114$ & $-0,32^{* *}$ & 0,032 & $-0,116$ & $-0,088$ \\
\hline & PRE & 0,059 & 0,183 & $-0,147$ & 0,233 & $-0,150$ & $-0,347$ * \\
\hline \multirow{2}{*}{$95 \%$} & PPP & 0,099 & 0,123 & $-0,063$ & 0,115 & $-0,126$ & $-0,194^{*}$ \\
\hline & PRE & $0,419 * *$ & $0,374 * *$ & 0,113 & $0,290^{*}$ & $-0,191$ & $-0,389 * *$ \\
\hline \multirow{2}{*}{$98 \%$} & $\overline{P P P}$ & 0,064 & 0,094 & $-0,071$ & 0,084 & $-0,102$ & $-0,174$ \\
\hline & PRE & $0,410 * *$ & $0,372^{* *}$ & 0,130 & $0,278^{*}$ & $-0,189$ & $-0,379 * *$ \\
\hline 2004 & Anual & $0,312^{* *}$ & $0,313^{* \star}$ & $0,267^{* *}$ & $0,31^{\star *}$ & $-0,035$ & $-0,355^{\star *}$ \\
\hline \multirow{2}{*}{$90 \%$} & PPP & $0,680^{* *}$ & $0,653^{* *}$ & $0,606^{* *}$ & $0,45^{* \star}$ & $-0,178$ & $-0,419^{* *}$ \\
\hline & PRE & $0,655^{* *}$ & $0,598 * *$ & $0,587 * *$ & $0,38 * *$ & $-0,165$ & $-0,375^{* *}$ \\
\hline \multirow{2}{*}{$95 \%$} & PPP & $0,382 * *$ & $0,372^{* *}$ & $0,339 * *$ & $0,202^{*}$ & $-0,076$ & $-0,179$ \\
\hline & PRE & $0,695 * *$ & $0,620 * *$ & $0,655^{* *}$ & $0,33 * *$ & $-0,164$ & $-0,295^{\star}$ \\
\hline \multirow{2}{*}{$98 \%$} & PPP & $0,224^{*}$ & $0,215^{*}$ & $0,199 *$ & 0,077 & $-0,014$ & $-0,068$ \\
\hline & PRE & $0,667 * *$ & $0,584^{* *}$ & $0,657 * *$ & $0,29 * *$ & $-0,144$ & $0,272^{*}$ \\
\hline 2005 & Anual & $0,456^{* *}$ & $0,438^{* \star}$ & $0,421^{* *}$ & $0,39 * *$ & $-0,020$ & $-0,436 * *$ \\
\hline ०००\% & PPP & $0,399 * *$ & $0,450^{* \star}$ & 0,175 & $0,41^{* *}$ & $-0,366^{* *}$ & $-0,451^{* *}$ \\
\hline $90 \%$ & PRE & - & - & - & - & - & - \\
\hline $95 \%$ & PPP & $-0,116$ & $-0,041$ & $-0,260^{*}$ & $-0,058$ & $-0,057$ & $-0,049$ \\
\hline $95 \%$ & PRE & 0,291 & $-0,036$ & 0,727 & $-0,746$ & - & 0,385 \\
\hline $880 \%$ & PPP & $-0,144$ & $-0,096$ & $-0,27 * *$ & $-0,049$ & $-0,080$ & $-0,023$ \\
\hline $98 \%$ & PRE & $-0,157$ & $-0,121$ & 0,012 & $-0,166$ & 0,130 & $-0,164$ \\
\hline 2006 & Anual & $0,272^{* *}$ & $0,281 * *$ & $0,190 * *$ & $0,280^{*}$ & $-0,092$ & $-0,502^{* *}$ \\
\hline ९००\% & PPP & 0,411 ** & $0,425^{\star \star}$ & 0,219 & - & $-0,213$ & $-0,227$ \\
\hline $90 \%$ & PRE & $0,394 * *$ & $0,384 * *$ & 0,193 & - & $-0,157$ & $-0,074$ \\
\hline $95 \%$ & PPP & $0,250^{*}$ & $0,283^{*}$ & 0,059 & - & $-0,266^{*}$ & $-0,222$ \\
\hline $95 \%$ & PRE & $0,402^{* *}$ & $0,383^{* *}$ & 0,214 & - & $-0,138$ & $-0,070$ \\
\hline ८8०\% & PPP & $-0,126$ & $-0,089$ & $-0,30$ ** & - & $-0,152$ & $-0,206^{*}$ \\
\hline $98 \%$ & PRE & $0,496 * *$ & $0,498 * *$ & 0,222 & - & $-0,216$ & $-0,247 *$ \\
\hline 2007 & Anual & $0,236^{* *}$ & $0,203^{* *}$ & $0,223^{* *}$ & $0,17^{\star \star}$ & 0,091 & $-0,224^{\star \star}$ \\
\hline ०००\% & PPP & $0,625^{\star *}$ & $0,577 \star \star$ & 0,491 ** & $0,37 * \star$ & $-0,278 * \star$ & $-0,381$ ** \\
\hline $90 \%$ & PRE & $0,584 * *$ & $0,530 * *$ & $0,450 * *$ & $0,34 * *$ & $-0,267 * *$ & $-0,336 * *$ \\
\hline $95 \%$ & PPP & $0,397 * *$ & $0,405^{* *}$ & $0,278 * *$ & 0,193 & $-0,189$ & $-0,288 * *$ \\
\hline $95 \%$ & PRE & $0,559 * *$ & 0,516 ** & $0,415^{* *}$ & $0,34 * *$ & $-0,277 * *$ & $-0,345^{* *}$ \\
\hline ८80\% & PPP & 0,116 & 0,124 & 0,114 & $-0,024$ & $-0,051$ & $-0,053$ \\
\hline $98 \%$ & PRE & $0,555^{* *}$ & $0,504^{* *}$ & $0,431 * *$ & $0,31 * *$ & $-0,244^{*}$ & $-0,312^{* *}$ \\
\hline Total & Anual & $0,284^{* *}$ & $0,283^{* *}$ & $0,232^{* *}$ & 0,30 ** & $-0,05^{* *}$ & $-0,375^{* *}$ \\
\hline
\end{tabular}

Tabla 5.2.2.10. Coeficientes de correlación de Spearman entre Pinus y las variables climatológicas. Tmed,

Tmax, Tmin (temperatura media, máxima y mínima), Hrelativa (humedad relativa). Significación: 95\%(*), $99 \%(* *) .(-)$ Ausencia de correlaciones. 


\begin{tabular}{|c|c|c|c|c|c|c|c|}
\hline \multicolumn{2}{|c|}{ Pinus } & Vemed & FrecCalm & VICuadr & V2Cuadr & V3Cuadr & V4Cuadr \\
\hline 2000 & Anual & $0,168^{* *}$ & $-0,215^{\star *}$ & 0,027 & 0,001 & 0,003 & $-0,016$ \\
\hline \multirow{2}{*}{$90 \%$} & PPP & $-0,020$ & 0,019 & 0,132 & 0,124 & $-0,168$ & $-0,126$ \\
\hline & PRE & $-0,027$ & 0,015 & 0,126 & 0,098 & $-0,154$ & $-0,95$ \\
\hline \multirow{2}{*}{$95 \%$} & PPP & $-0,033$ & 0,029 & 0,154 & 0,116 & $-0,182$ & $-0,111$ \\
\hline & PRE & $-0,040$ & 0,028 & 0,152 & 0,093 & $-0,172$ & $-0,082$ \\
\hline \multirow{2}{*}{$98 \%$} & PPP & $-0,027$ & 0,045 & 0,143 & 0,126 & $-0,158$ & $-0,120$ \\
\hline & PRE & $-0,042$ & 0,043 & 0,164 & 0,111 & $-0,171$ & $-0,101$ \\
\hline 2001 & Anual & 0,103 & $-0,144^{* *}$ & $-0,018$ & $-0,165^{* *}$ & 0,059 & $0,306^{* *}$ \\
\hline \multirow{2}{*}{$90 \%$} & PPP & $-0,110$ & $-0,022$ & 0,164 & $-0,081$ & $-0,174$ & 0,121 \\
\hline & PRE & $0,831^{* *}$ & $-0,664$ & $-0,554$ & $-0,485$ & 0,162 & $0,695^{\star}$ \\
\hline \multirow{2}{*}{$95 \%$} & PPP & $-0,115$ & $-0,003$ & 0,191 & $-0,109$ & $-0,202^{*}$ & 0,112 \\
\hline & PRE & 0,140 & 0,086 & $-0,121$ & $-0,177$ & $-0,230$ & 0,468 \\
\hline \multirow{2}{*}{$98 \%$} & PPP & $-0,171$ & 0,069 & $0,238 *$ & $-0,026$ & $-0,260 * *$ & 0,146 \\
\hline & PRE & $-0,156$ & 0,276 & $-0,020$ & 0,083 & $-0,422$ & $0,557^{*}$ \\
\hline 2002 & Anual & $-0,007$ & 0,092 & $-0,067$ & $-0,071$ & $0,112^{*}$ & $-0,080$ \\
\hline \multirow{2}{*}{$90 \%$} & PPP & $-0,237^{*}$ & $0,260^{*}$ & $-0,055$ & 0,105 & 0,006 & 0,079 \\
\hline & PRE & $-0,482^{*}$ & $0,584 * *$ & $-0,637$ ** & $-0,012$ & $0,562^{* *}$ & 0,554 ** \\
\hline \multirow{2}{*}{$95 \%$} & PPP & $-0,259$ * & 0,276 ** & $-0,051$ & 0,142 & 0,016 & 0,045 \\
\hline & PRE & $-0,524$ * & $0,580 * *$ & $-0,572^{* *}$ & 0,027 & $0,512^{*}$ & $0,555^{* *}$ \\
\hline \multirow{2}{*}{$98 \%$} & PPP & $-0,162$ & 0,152 & $-0,100$ & 0,036 & 0,161 & 0,102 \\
\hline & PRE & $-0,263$ & 0,148 & $-0,442 * \star$ & 0,071 & 0,419 ** & $0,428 * *$ \\
\hline 2003 & Anual & 0,066 & $-0,112^{*}$ & $0,104^{* *}$ & 0,052 & $-0,074$ & $-0,071$ \\
\hline \multirow{2}{*}{$90 \%$} & PPP & 0,145 & $-0,069$ & 0,032 & 0,131 & $-0,048$ & $-0,218$ \\
\hline & PRE & 0,228 & $-0,093$ & 0,005 & 0,106 & 0,016 & $-0,281$ \\
\hline \multirow{2}{*}{$95 \%$} & PPP & 0,084 & 0,006 & $-0,080$ & 0,105 & 0,036 & $-0,115$ \\
\hline & PRE & 0,218 & $-0,051$ & $-0,201$ & $-0,024$ & 0,179 & $-0,083$ \\
\hline \multirow{2}{*}{$98 \%$} & PPP & 0,117 & $-0,023$ & $-0,062$ & 0,138 & 0,036 & $-0,166$ \\
\hline & PRE & 0,215 & $-0,062$ & $-0,209$ & $-0,023$ & 0,176 & $-0,080$ \\
\hline 2004 & Anual & 0,019 & $-0,086$ & 0,010 & $-0,053$ & $-0,062$ & $0,138^{* *}$ \\
\hline \multirow{2}{*}{$90 \%$} & PPP & $-0,014$ & 0,037 & 0,036 & 0,085 & $-0,016$ & $-0,015$ \\
\hline & PRE & 0,095 & 0,046 & $-0,100$ & 0,073 & 0,060 & 0,080 \\
\hline \multirow{2}{*}{$95 \%$} & PPP & $-0,050$ & 0,109 & 0,035 & 0,166 & 0,019 & $-0,115$ \\
\hline & PRE & 0,154 & 0,179 & $-0,176$ & 0,147 & 0,141 & 0,103 \\
\hline \multirow{2}{*}{$98 \%$} & PPP & $-0,054$ & 0,130 & 0,011 & 0,146 & 0,045 & $-0,107$ \\
\hline & PRE & 0,132 & 0,136 & $-0,154$ & 0,131 & 0,120 & 0,081 \\
\hline 2005 & Anual & $0,260^{* *}$ & $-0,320^{* *}$ & $-0,097$ & $-0,173^{* *}$ & $0,152^{* \star}$ & $0,198^{\star \star}$ \\
\hline $90 \%$ & PPP & 0,095 & 0,018 & 0,258 & 0,037 & $-0,202$ & $-0,283^{*}$ \\
\hline $70 \%$ & PRE & - & - & - & - & - & - \\
\hline $95 \%$ & PPP & 0,067 & $-0,023$ & $-0,011$ & - & 0,037 & $-0,024$ \\
\hline $75 \%$ & PRE & 0,587 & 0,019 & 0,164 & $-0,927^{* *}$ & 0,385 & 0,688 \\
\hline $98 \%$ & PPP & 0,158 & $-0,033$ & $-0,010$ & $-0,062$ & 0,004 & 0,015 \\
\hline & PRE & 0,420 & $-0,129$ & $-0,233$ & $-0,404$ & 0,229 & 0,061 \\
\hline 2006 & Anual & 0,004 & $-0,182^{* *}$ & $0,123^{*}$ & 0,016 & $-0,078$ & 0,096 \\
\hline $90 \%$ & PPP & $-0,038$ & $-0,086$ & $0,336^{*}$ & 0,227 & $-0,282$ & $-0,434^{* *}$ \\
\hline & PRE & $-0,015$ & 0,059 & 0,189 & $0,439 * *$ & $-0,099$ & $-0,403^{*}$ \\
\hline $95 \%$ & PPP & 0,019 & 0,007 & $0,312^{*}$ & 0,039 & $-0,284^{*}$ & $-0,391$ ** \\
\hline & PRE & 0,003 & 0,059 & 0,189 & $0,439 * *$ & $-0,099$ & $-0,403^{*}$ \\
\hline $98 \%$ & PPP & $-0,043$ & $-0,116$ & $0,232^{*}$ & 0,156 & $-0,206$ & $-0,391$ ** \\
\hline & PRE & $-0,001$ & 0,059 & 0,189 & 0,439 ** & $-0,099$ & $-0,403^{*}$ \\
\hline 2007 & Anual & $0,121^{*}$ & $-0,085$ & $-0,115^{*}$ & 0,021 & $0,141^{* *}$ & 0,151 ** \\
\hline $90 \%$ & PPP & $-0,150$ & $0,273^{*}$ & $-0,060$ & 0,044 & 0,017 & $-0,273^{*}$ \\
\hline $70 \%$ & PRE & $-0,077$ & 0,230 * & $-0,083$ & 0,001 & 0,045 & $-0,268 *$ \\
\hline $95 \%$ & PPP & $-0,140$ & $0,211^{*}$ & 0,030 & 0,102 & $-0,022$ & $-0,205^{*}$ \\
\hline $95 \%$ & PRE & $-0,065$ & 0,214 & $-0,087$ & $-0,001$ & 0,049 & $-0,252^{*}$ \\
\hline $080 \%$ & PPP & $-0,089$ & 0,159 & 0,019 & 0,116 & $-0,040$ & $-0,182 *$ \\
\hline $98 \%$ & PRE & $-0,052$ & 0,209 & $-0,117$ & $-0,019$ & 0,059 & $-0,200$ \\
\hline Total & Anual & 0,024 & $-0,132^{* *}$ & 0,008 & $-0,041^{* *}$ & 0,021 & $0,103^{* \star}$ \\
\hline
\end{tabular}

Tabla 5.2.2.10. (Continuación). Coeficientes de correlación de Spearman entre Pinus y las variables climatológicas. Vemed (velocidad media), FrecCalmas (frecuencia de calmas), V1Cuad, V2Cuad, V3Cuad,

V4Cuad (vientos procedentes del I, II, III y IV cuadrante). Significación: 95\%(*), 99\%(**). (-) Ausencia de correlaciones. 


\subsubsection{Plantago}

La variación interanual (Fig. 5.2.2.16.) de este tipo polínico en la atmósfera de la ciudad de Salamanca indicó un incremento en los niveles polínicos anuales durante el período 2000-2007, reflejados en las concentraciones polínicas anuales: 583 pólenes del año 2000 y 1706 del año 2007. Esto supuso un aumento del $192 \%$ y, tras aplicar el análisis de tendencias mediante regresión lineal, un índice de determinación $\left(\mathrm{R}^{2}=0,56\right)$, que confirma esta dinámica. Por otro lado, el porcentaje de representación sobre el total de pólenes contabilizados en cada anualidad analizada osciló entre el 2,8\% de los años 2002 y 2005 al $5,5 \%$ de 2007 , siendo $3,8 \%$ el porcentaje medio.

La variación estacional de Plantago en la atmósfera de Salamanca, previa aplicación de los tres métodos utilizados (Tabla 5.2.2.11.) se localizó entre los meses de febrero y agosto, siendo mayo, junio y julio los meses con mayores concentraciones polínicas (Fig. 5.2.2.17.D.). A través de cualquiera de las metodologías empleadas para el cálculo del PPP, la duración media se situó entre 89 y 121 días, mostrándose muy variable ya que, generalmente, comenzó en el mes de abril, salvo en el año 2000 que comenzó a mediados y fines de febrero. La finalización de este PPP se localizó a finales de julio al comienzo o a mediados de agosto, teniendo como excepción el propio año 2000 que tomó como fin del PPP a finales del mes de junio e inicio de julio.

La dinámica que presentaron las concentraciones polínicas de Plantago (Fig. 5.2.2.17.D.) mostrada a través de las concentraciones promedio para los cinco días anteriores durante los años analizados, mostró un incremento de las concentraciones desde finales del mes de abril hasta mediados de junio, momento en el se produjo una disminución en los niveles de polen hasta el mes de agosto, con un pequeño repunte a mediados de julio. Las 
concentraciones diarias más elevadas dentro de los ocho años variaron de forma ostensible en valores numéricos y en la fecha en la que se produjeron (Tabla 5.2.2.11.; Fig. 5.2.2.17. A. B. C.)., como demuestran los 159 granos/m³ (13 de julio de 2007) y los 16 granos $/ \mathrm{m}^{3}$ (16 de mayo de 2002).

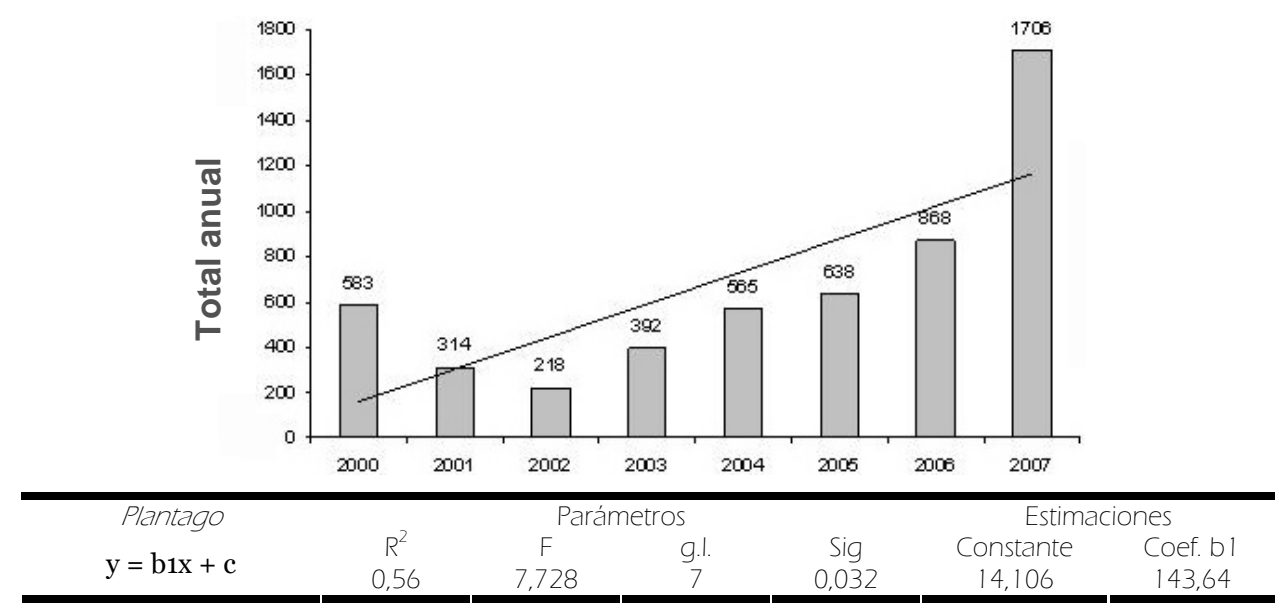

Fig. 5.2. 2.16. Evolución anual del número total de pólenes de Plantago y tendencias (análisis de regresión). B. Variación intradiaria del polen de Plantago.

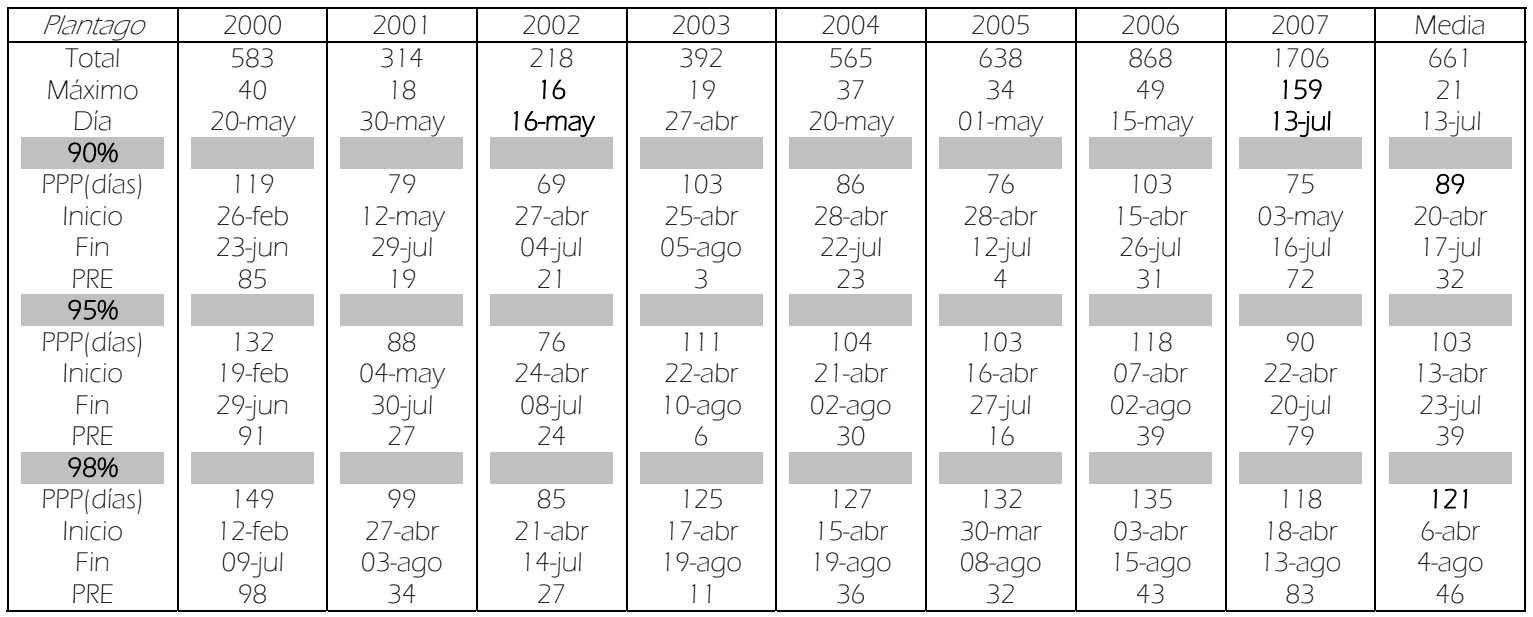

Tabla 5.2.2.11. Totales, concentraciones máximas diarias, períodos principales de polinización (PPP; fecha de inicio y fin) y días precedentes al valor máximo (PRE) durante los ocho años de estudio y el promedio de todos los parámetros para Plantago.

La variación intradiaria (Fig. 5.2.2.18.) mostró un claro patrón a lo largo de un día promedio para los últimos tres años estudiados, por el que los niveles de polen aumentaron desde las 8 horas del día hasta las 13 horas centrales del día, momento en el que comienzan a disminuir las concentraciones hasta las últimas horas del día. Así pues, las mayores concentraciones polínicas de Plantago se concentraron en las horas centrales del día. 


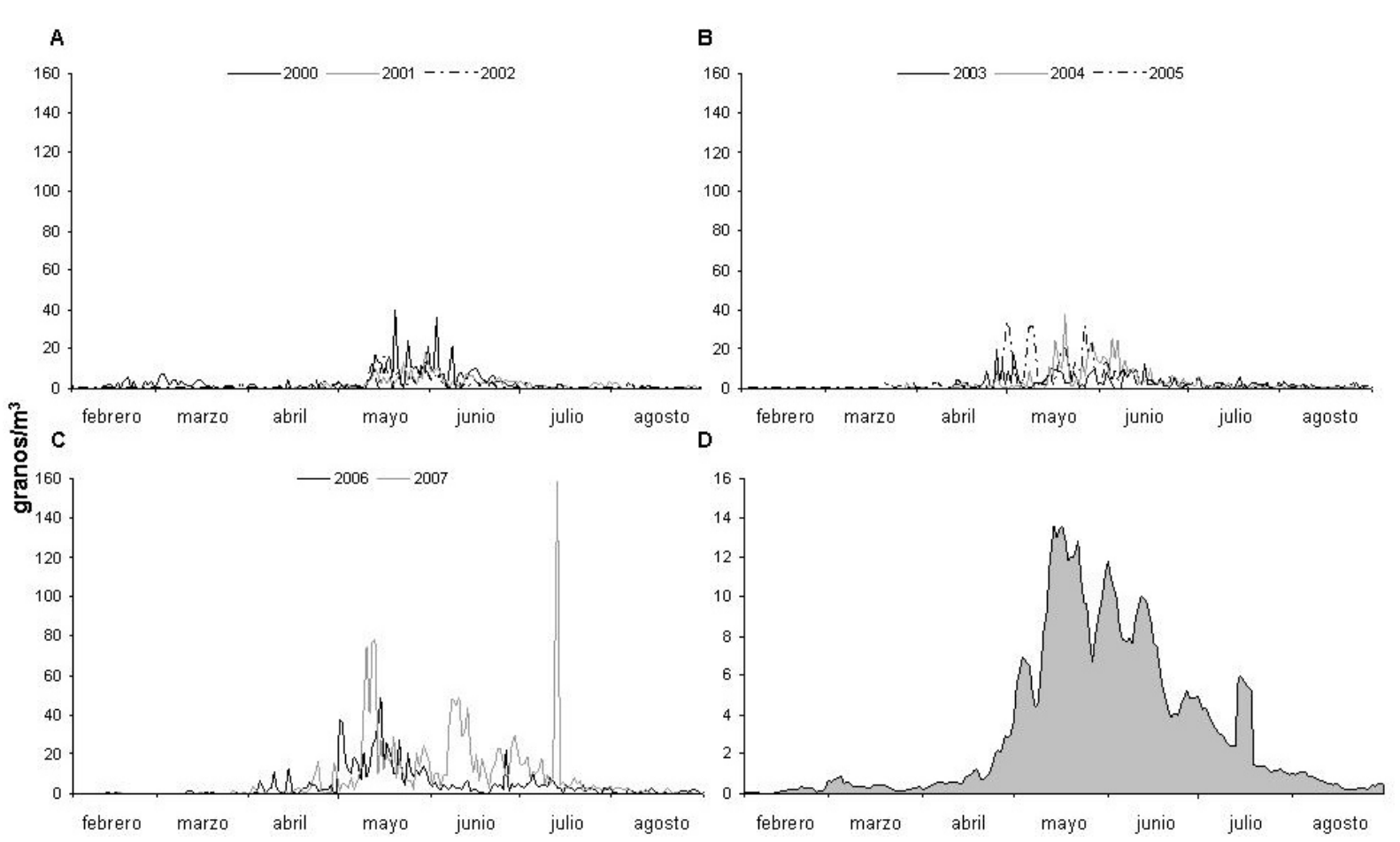

Fig. 5.2.2.17. Variación de las concentraciones medias diarias de Plantago durante el período 2000-2002 (A), 2003-2005 (B) y 2006-2007 (C). Medias móviles de los cinco días anteriores para las concentraciones diarias promedio de los ocho años estudiados (D).

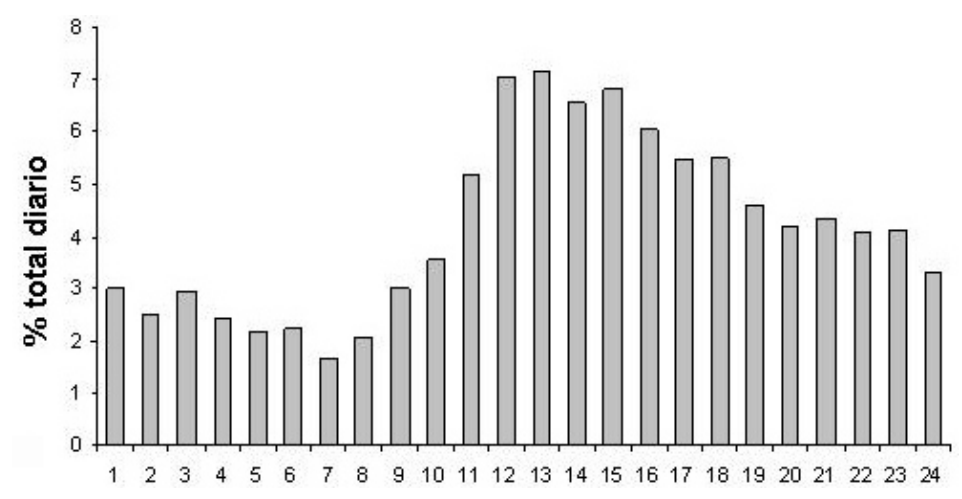

Fig. 5.2.2.18. Variación intradiaria del polen de Plantago.

Las temperaturas medias, máximas y mínimas junto a la insolación y los vientos procedentes del IV cuadrante tuvieron una influencia positiva en los niveles de este tipo polínico durante los ocho años analizados, así como el efecto negativo que ejercieron las precipitaciones y la humedad relativa, tras el análisis de correlación (Tabla 5.2.2.12.). No obstante, al aplicar este tipo de estadísticos de correlación no paramétricos en el PPP y el PRE de las tres metodologías empleadas para la mayoría de los años analizados, se obtuvieron correlaciones de distinto signo y significación que los resultados obtenidos en todo el período analizado. En este aspecto, podemos citar el efecto positivo que ejerció la frecuencia de las calmas en los PPP y PRE del año 2000 y en el año 2005, o el efecto negativo de la velocidad media del viento en el PPP y PRE del año 2000, o los vientos procedentes del primer cuadrante en el PPP y PRE del año 2006. 


\begin{tabular}{|c|c|c|c|c|c|c|c|}
\hline \multicolumn{2}{|c|}{ Plantago } & Tmed & Tmax & Tmin & Insolación & Precipitación & Hrelativa \\
\hline 2000 & Anual & $0,207^{* *}$ & $0,272^{* *}$ & 0,119 ** & $0,27^{* *}$ & $-0,153^{* *}$ & $-0,368^{* *}$ \\
\hline \multirow{2}{*}{$90 \%$} & PPP & $0,603^{* *}$ & 0,716 ** & $0,438 * *$ & $0,52^{\star *}$ & $-0,350 * *$ & $-0,437 * *$ \\
\hline & PRE & 0,301 ** & 0,592 ** & $-0,008$ & $0,46 * *$ & $-0,328 * *$ & $-0,412^{* *}$ \\
\hline \multirow{2}{*}{$95 \%$} & PPP & $0,568 * *$ & $0,692 * *$ & $0,413 * *$ & $0,49 * *$ & $-0,326 * *$ & $-0,442 * *$ \\
\hline & PRE & 0,274 ** & $0,588 * *$ & $-0,029$ & $0,44 * *$ & $-0,306 * *$ & $-0,410$ ** \\
\hline \multirow{2}{*}{$98 \%$} & PPP & $0,433^{* *}$ & $0,554 * *$ & $0,298 * *$ & $0,41 * *$ & $-0,285^{\star *}$ & $-0,357 * *$ \\
\hline & PRE & $0,237^{*}$ & $0,557 * *$ & $-0,050$ & $0,43 * *$ & $-0,308^{* *}$ & $-0,399 * *$ \\
\hline 2001 & Anual & $0,512^{* *}$ & $0,513^{* *}$ & $0,461^{* *}$ & $0,45^{\star \star}$ & $-0,115^{*}$ & $-0,499 * *$ \\
\hline \multirow{2}{*}{$90 \%$} & PPP & 0,233 & 0,218 & 0,170 & 0,161 & $-0,282^{*}$ & $-0,281$ * \\
\hline & PRE & 0,075 & $-0,042$ & 0,254 & $-0,420$ & - & 0,325 \\
\hline \multirow{2}{*}{$95 \%$} & PPP & 0,116 & 0,118 & 0,071 & 0,116 & $-0,240$ * & $-0,181$ \\
\hline & PRE & 0,289 & 0,322 & 0,377 & $-0,009$ & $-0,073$ & $-0,201$ \\
\hline \multirow{2}{*}{$98 \%$} & PPP & 0,266 ** & $0,269 * *$ & $0,234^{*}$ & $0,22^{\star *}$ & $-0,214^{*}$ & $-0,296$ ** \\
\hline & PRE & $0,709 * *$ & $0,655 * *$ & 0,734 ** & $0,45 * *$ & $-0,215$ & $-0,491$ ** \\
\hline 2002 & Anual & $0,349 * *$ & $0,361^{* *}$ & $0,283^{* *}$ & $0,39 * *$ & $-0,153^{* *}$ & $-0,463^{* *}$ \\
\hline \multirow{2}{*}{$90 \%$} & PPP & 0,099 & 0,111 & 0,043 & $-0,011$ & $-0,118$ & $-0,084$ \\
\hline & PRE & 0,560 ** & $0,635^{* *}$ & 0,295 & 0,259 & $-0,399$ & $-0,450$ * \\
\hline \multirow{2}{*}{$95 \%$} & PPP & 0,046 & 0,044 & 0,026 & $-0,072$ & $-0,085$ & $-0,021$ \\
\hline & PRE & $0,428 *$ & $0,471^{*}$ & 0,291 & 0,143 & $-0,329$ & $-0,280$ \\
\hline \multirow{2}{*}{$98 \%$} & PPP & 0,002 & 0,018 & $-0,026$ & $-0,052$ & $-0,119$ & $-0,057$ \\
\hline & PRE & 0,342 & 0,391 * & 0,218 & 0,090 & $-0,298$ & $-0,206$ \\
\hline 2003 & Anual & $0,570^{* *}$ & $0,554^{* *}$ & $0,507^{* *}$ & $0,48^{\star \star}$ & $-0,201^{* \star}$ & $-0,587^{* *}$ \\
\hline \multirow{2}{*}{$90 \%$} & PPP & $0,411^{*}$ & $0,342^{*}$ & $0,341^{*}$ & 0,012 & $-0,171$ & $-0,340^{*}$ \\
\hline & PRE & 0,500 & $1^{* \star}$ & $-0,500$ & $-0,500$ & - & $-0,500$ \\
\hline \multirow{2}{*}{$95 \%$} & PPP & 0,246 & 0,202 & 0,248 & $-0,064$ & $-0,071$ & $-0,191$ \\
\hline & PRE & $-0,086$ & 0,029 & $-0,600$ & $-0,371$ & 0,135 & 0,314 \\
\hline \multirow{2}{*}{$98 \%$} & PPP & $0,312^{*}$ & $0,300 *$ & $0,270^{*}$ & 0,021 & $-0,164$ & $-0,313^{*}$ \\
\hline & PRE & 0,494 & 0,406 & 0,054 & 0,016 & $-0,147$ & $-0,210$ \\
\hline 2004 & Anual & $0,579 * *$ & $0,565^{* *}$ & $0,553^{* *}$ & $0,48^{\star \star}$ & $-0,078$ & $-0,526^{* *}$ \\
\hline \multirow{2}{*}{$90 \%$} & PPP & $0,255^{\star}$ & $0,267^{\star}$ & $0,226^{*}$ & 0,161 & $-0,172$ & $-0,107$ \\
\hline & PRE & $0,464^{*}$ & $0,609 * *$ & 0,249 & $0,64 * *$ & $-0,544 * *$ & $-0,765^{* *}$ \\
\hline \multirow{2}{*}{$95 \%$} & PPP & 0,143 & 0,152 & 0,129 & 0,162 & $-0,077$ & $-0,041$ \\
\hline & PRE & $0,462^{* *}$ & $0,551 * *$ & 0,286 & $0,55^{* *}$ & $-0,313$ & $-0,567$ ** \\
\hline \multirow{2}{*}{$98 \%$} & PPP & 0,112 & 0,167 & 0,010 & $0,217^{*}$ & $-0,132$ & $-0,114$ \\
\hline & PRE & $0,466 * *$ & $0,540 * *$ & 0,298 & $0,50 * *$ & $-0,291$ & $-0,518^{* *}$ \\
\hline 2005 & Anual & $0,591^{* *}$ & $0,568^{* *}$ & $0,539 * *$ & $0,44 * \star$ & $-0,085$ & $-0,533^{* *}$ \\
\hline $90 \%$ & PPP & $-0,118$ & $-0,164$ & $-0,181$ & $-0,3^{* *}$ & $-0,056$ & 0,019 \\
\hline $70 \%$ & PRE & 0,200 & $-0,800$ & $1 * *$ & $-1 * \star$ & - & $-0,211$ \\
\hline $95 \%$ & PPP & $-0,007$ & $-0,021$ & $-0,095$ & $-0,103$ & $-0,132$ & $-0,076$ \\
\hline $75 \%$ & PRE & 0,827 ** & $0,847^{* *}$ & 0,442 & $0,539 *$ & $-0,727^{* *}$ & $-0,816$ ** \\
\hline $98 \%$ & PPP & $0,176^{*}$ & 0,150 & 0,083 & 0,028 & $-0,137$ & $-0,185^{*}$ \\
\hline $78 \%$ & PRE & $0,567^{* *}$ & 0,588 ** & $0,402^{*}$ & 0,276 & $-0,435^{*}$ & $-0,497$ ** \\
\hline 2006 & Anual & $0,580^{* *}$ & $0,585^{* *}$ & $0,485^{* *}$ & 0,035 & $-0,166^{* *}$ & $-0,698 * *$ \\
\hline $90 \%$ & PPP & $-0,114$ & $-0,126$ & $-0,185$ & - & $-0,208^{*}$ & $-0,253^{* *}$ \\
\hline $70 \%$ & PRE & 0,027 & $-0,010$ & $-0,075$ & - & $-0,249 *$ & $-0,271$ * \\
\hline $95 \%$ & PPP & $-0,069$ & $-0,076$ & $-0,145$ & - & $-0,116$ & $-0,281$ ** \\
\hline $75 \%$ & PRE & 0,142 & 0,093 & 0,031 & - & $-0,186$ & $-0,274^{* *}$ \\
\hline $98 \%$ & PPP & $-0,073$ & $-0,101$ & $-0,118$ & - & $-0,079$ & $-0,265^{* *}$ \\
\hline $78 \%$ & PRE & 0,183 & 0,132 & 0,057 & - & $-0,214^{*}$ & $-0,302^{* *}$ \\
\hline 2007 & Anual & $0,629^{* *}$ & $0,591^{* *}$ & $0,592^{* *}$ & $0,47^{* \star}$ & $-0,052$ & $-0,489$ ** \\
\hline $90 \%$ & PPP & 0,208 & 0,227 & 0,072 & 0,023 & $-0,121$ & $-0,124$ \\
\hline $70 \%$ & PRE & $0,278^{*}$ & $0,299 *$ & 0,144 & 0,026 & $-0,111$ & $-0,164$ \\
\hline $95 \%$ & PPP & $0,342^{* *}$ & $0,313^{* *}$ & 0,175 & 0,180 & $-0,269 *$ & $-0,211^{*}$ \\
\hline $75 \%$ & PRE & $0,409 * *$ & $0,414^{* *}$ & $0,229 *$ & 0,195 & $-0,292^{* *}$ & $-0,292 * *$ \\
\hline $980 \%$ & PPP & $-0,032$ & $-0,072$ & $-0,018$ & 0,052 & $-0,080$ & 0,078 \\
\hline $98 \%$ & PRE & $0,441^{* *}$ & $0,410^{* *}$ & 0,301 * & 0,208 & $-0,269 *$ & $-0,320$ ** \\
\hline Total & Anual & $0,505^{* *}$ & $0,503^{* *}$ & $0,440^{* *}$ & $0,44^{* *}$ & $-0,129 * *$ & $-0,486^{* *}$ \\
\hline
\end{tabular}

Tabla 5.2.2.12. Coeficientes de correlación de Spearman entre Plantago y las variables climatológicas. Tmed, Tmax, Tmin (temperatura media, máxima y mínima), Hrelativa (humedad relativa). Significación: 95\%(*), $99 \%(* *)$. (-) Ausencia de correlaciones. 


\begin{tabular}{|c|c|c|c|c|c|c|c|}
\hline \multicolumn{2}{|c|}{ Plantago } & Vemed & FrecCalm & VICuadr & V2Cuadr & V3Cuadr & V4Cuadr \\
\hline 2000 & Anual & $-0,010$ & $-0,049$ & $0,133^{\star}$ & 0,087 & $-0,116^{*}$ & 0,070 \\
\hline \multirow{2}{*}{$90 \%$} & PPP & $-0,32 * \star$ & $0,289 * *$ & 0,175 & 0,106 & $-0,244^{\star \star}$ & 0,172 \\
\hline & PRE & $-0,41 * *$ & $0,376 * *$ & $0,334 * *$ & 0,167 & $-0,309 * *$ & 0,028 \\
\hline \multirow{2}{*}{$95 \%$} & PPP & $-0,28 * *$ & 0,250 ** & 0,155 & 0,100 & $-0,224 * \star$ & 0,142 \\
\hline & PRE & $-0,40 * *$ & $0,375 * *$ & $0,298 * *$ & 0,170 & $-0,287 * \star$ & 0,016 \\
\hline \multirow{2}{*}{$98 \%$} & PPP & $-0,23^{* *}$ & $0,188^{*}$ & $0,169 *$ & 0,125 & $-0,245^{* *}$ & 0,077 \\
\hline & PRE & $-0,38 * *$ & $0,353^{* *}$ & $0,268 * *$ & 0,171 & $-0,273^{* *}$ & 0,035 \\
\hline 2001 & Anual & $-0,037$ & $-0,022$ & 0,007 & $-0,073$ & $-0,007$ & $0,337^{* *}$ \\
\hline \multirow{2}{*}{$90 \%$} & PPP & $-0,071$ & 0,050 & 0,007 & $-0,013$ & 0,127 & $-0,003$ \\
\hline & PRE & 0,259 & $-0,669$ * & $-0,117$ & $-0,209$ & $-0,298$ & 0,437 \\
\hline \multirow{2}{*}{$95 \%$} & PPP & $-0,011$ & 0,040 & $-0,026$ & $-0,041$ & 0,165 & $-0,019$ \\
\hline & PRE & $-0,136$ & 0,066 & $-0,180$ & 0,304 & 0,302 & 0,201 \\
\hline \multirow{2}{*}{$98 \%$} & PPP & $-0,037$ & 0,060 & $-0,082$ & $-0,021$ & 0,187 & $-0,036$ \\
\hline & PRE & $-0,199$ & 0,141 & $-0,291$ & 0,080 & 0,306 & 0,015 \\
\hline 2002 & Anual & 0,028 & 0,088 & $-0,071$ & $-0,164^{* *}$ & $0,136^{*}$ & 0,041 \\
\hline \multirow{2}{*}{$90 \%$} & PPP & $-0,125$ & 0,202 & $-0,160$ & 0,101 & $0,344^{* *}$ & $-0,198$ \\
\hline & PRE & $-0,041$ & 0,152 & $-0,320$ & 0,357 & 0,410 & $-0,308$ \\
\hline \multirow{2}{*}{$95 \%$} & PPP & $-0,050$ & 0,172 & $-0,198$ & 0,053 & $0,382^{* *}$ & $-0,252^{*}$ \\
\hline & PRE & 0,086 & 0,015 & $-0,344$ & 0,193 & $0,456^{*}$ & $-0,316$ \\
\hline \multirow{2}{*}{$98 \%$} & PPP & $-0,046$ & 0,214 & $-0,192$ & 0,097 & $0,382^{* *}$ & $-0,270^{*}$ \\
\hline & PRE & 0,070 & 0,016 & $-0,310$ & 0,121 & $0,419 *$ & $-0,196$ \\
\hline 2003 & Anual & 0,020 & $-0,059$ & $-0,038$ & $-0,064$ & 0,065 & $0,147^{* *}$ \\
\hline \multirow{2}{*}{$90 \%$} & PPP & $-0,064$ & 0,280 & $-0,333^{*}$ & 0,218 & 0,419 ** & 0,194 \\
\hline & PRE & $-1 * \star$ & 0,500 & - & 0,500 & 0,500 & $-1 * *$ \\
\hline \multirow{2}{*}{$95 \%$} & PPP & 0,020 & 0,240 & $-0,348 *$ & 0,091 & $0,469 * *$ & 0,188 \\
\hline & PRE & $-0,829$ * & 0,377 & $-0,152$ & 0,086 & 0,200 & $-0,771$ \\
\hline \multirow{2}{*}{$98 \%$} & PPP & $-0,064$ & 0,170 & $-0,171$ & 0,189 & $0,270^{*}$ & 0,051 \\
\hline & PRE & $-0,690$ * & 0,278 & $-0,055$ & 0,569 & $-0,103$ & $-0,400$ \\
\hline 2004 & Anual & $0,165^{* *}$ & $-0,057$ & $-0,092$ & - & 0,039 & $0,250^{* *}$ \\
\hline \multirow{2}{*}{$90 \%$} & PPP & 0,082 & $0,305^{\star *}$ & $-0,014$ & $0,345^{* *}$ & 0,091 & $-0,031$ \\
\hline & PRE & 0,108 & $0,477^{\star}$ & $-0,065$ & $0,546 * *$ & 0,182 & $-0,112$ \\
\hline \multirow{2}{*}{$95 \%$} & PPP & 0,049 & $0,218^{*}$ & $-0,046$ & $0,237^{\star}$ & 0,073 & $-0,020$ \\
\hline & PRE & 0,101 & 0,338 & $-0,118$ & $0,486 * *$ & 0,144 & $-0,125$ \\
\hline \multirow{2}{*}{$98 \%$} & PPP & 0,028 & $0,181^{*}$ & 0,093 & $0,246 * *$ & $-0,101$ & 0,001 \\
\hline & PRE & 0,076 & 0,323 & $-0,059$ & $0,418^{*}$ & 0,094 & $-0,102$ \\
\hline 2005 & Anual & 0,090 & $-0,146^{\star *}$ & $-0,128^{*}$ & $-0,047$ & $0,181^{\star}$ & $0,266^{* *}$ \\
\hline $90 \%$ & PPP & $-0,063$ & $0,265^{\star}$ & $-0,325^{\star *}$ & $0,247^{*}$ & $0,369 * \star$ & 0,154 \\
\hline $40 \%$ & PRE & $1^{* \star}$ & $-0,800$ & -1 ** & $-0,800$ & 0,800 & $-0,632$ \\
\hline $95 \%$ & PPP & $-0,190$ & $0,328 * *$ & 0,066 & $0,359 * *$ & 0,026 & $-0,021$ \\
\hline & PRE & $-0,65 * *$ & $0,739 * *$ & $0,657^{* *}$ & $0,789 * *$ & $-0,380$ & $-0,360$ \\
\hline $98 \%$ & PPP & $-0,129$ & 0,260 ** & $-0,070$ & $0,194 * *$ & 0,154 & 0,097 \\
\hline $78 \%$ & PRE & $-0,249$ & $0,468 * \star$ & $-0,132$ & 0,079 & 0,157 & 0,151 \\
\hline 2006 & Anual & 0,052 & $-0,140^{*}$ & 0,042 & 0,022 & $-0,035$ & $0,322^{\star \star}$ \\
\hline ९०\% & PPP & 0,087 & $-0,124$ & $-0,296^{* *}$ & - & 0,146 & 0,157 \\
\hline $70 \%$ & PRE & $-0,005$ & $-0,109$ & $-0,355^{\star *}$ & 0,075 & 0,260 * & 0,154 \\
\hline $95 \%$ & PPP & 0,074 & $-0,122$ & $-0,259 * *$ & $-0,004$ & 0,149 & 0,103 \\
\hline $95 \%$ & PRE & $-0,010$ & $-0,109$ & $-0,355^{* *}$ & 0,075 & $0,260 *$ & 0,154 \\
\hline $880 \%$ & PPP & 0,040 & $-0,001$ & $-0,345^{* *}$ & 0,073 & 0,259 ** & $0,202^{*}$ \\
\hline $98 \%$ & PRE & $-0,015$ & $-0,109$ & $-0,355^{\star *}$ & 0,075 & $0,260^{*}$ & 0,154 \\
\hline 2007 & Anual & 0,077 & 0,029 & $-0,186 * *$ & $-0,083$ & $0,186 * *$ & $0,180^{\star *}$ \\
\hline ๑ & PPP & 0,193 & 0,063 & $-0,379 * *$ & 0,011 & $0,423 * *$ & $-0,146$ \\
\hline $90 \%$ & PRE & 0,223 & 0,075 & $-0,404 * *$ & 0,030 & $0,485 * *$ & $-0,159$ \\
\hline & PPP & 0,193 & 0,029 & $-0,283^{* *}$ & $-0,053$ & $0,394 * *$ & $-0,235^{*}$ \\
\hline & PRE & 0,187 & 0,070 & $-0,334 * *$ & $-0,071$ & $0,444 * *$ & $-0,197$ \\
\hline $98 \%$ & PPP & 0,221 * & $-0,042$ & $-0,328 * *$ & $-0,070$ & 0,370 ** & $-0,132$ \\
\hline $98 \%$ & PRE & $0,232^{*}$ & - & $-0,337 * *$ & $-0,171$ & $0,450 * *$ & $-0,149$ \\
\hline Total & Anual & $-0,033$ & $-0,029$ & $-0,024$ & $-0,022$ & 0,035 & $0,212^{\star *}$ \\
\hline
\end{tabular}

Tabla 5.2.2.12. (Continuación). Coeficientes de correlación de Spearman entre Plantago y las variables climatológicas. Vemed (velocidad media), FrecCalmas (frecuencia de calmas), V1Cuad, V2Cuad, V3Cuad, V4Cuad (vientos procedentes del I, II, III y IV cuadrante). Significación: $95 \%\left({ }^{*}\right), 99 \%(* *)$. (-) Ausencia de correlaciones. 


\subsubsection{Platanus}

Los niveles del tipo polínico que incluye al plátano de sombra en la atmósfera de Salamanca, experimentaron un ascenso durante el período analizado, ya que si en el año 2000 la concentración anual fue de 438, en el año 2007 alcanzó 1017, pese a que el mayor total anual se registró en el año 2006 con 1530 granos de polen. Todo ello supuso que la variación interanual (Fig. 5.2.2.19.) llevase consigo un aumento del $132 \%$ en las concentraciones anuales de Platanus, un hecho confirmado a través del análisis de regresión de tipo lineal y el valor tomado por su índice de determinación $\left(\mathrm{R}^{2}=0,50\right)$. La representación media de los pólenes de este género a lo largo de los ocho años fue de 3,4\%, con un máximo de 5,9\% en 2006 y un mínimo de $1,7 \%$ en 2003.

La distribución de estos granos de polen en los años estudiados se localizó entre mediados-finales de marzo y las dos primeras semanas de mayo, por lo que la variación estacional (Tabla 5.2.2.13.) tuvo un PPP promedio de 27 a 45 días, en función del modelo empleado para su cálculo. No obstante, en el año 2000, y en menor medida en el año 2001, se observó que las fechas de inicio y finalización del PPP fueron más tempranas que en el resto de años estudiados, con el 1 de marzo (método 98\%) y el 14 de abril (método 90\%) como fechas más representativas. Del lado contrario, los días 14 de abril de 2007 (método 90\%) y 17 de mayo de 2003 (método 95\% y 98\%) fueron las fechas de delimitación del PPP más tardías.

Los niveles polínicos de Platanus en la atmósfera de la ciudad de Salamanca (Fig. 5.2.2.20.D.) comenzaron a aumentar a partir de mediados de marzo, experimentando un gran incremento durante la primera semana de abril y alcanzando las concentraciones más
Tipo polínico: Platanus $\mathrm{x}$ acerifolia.

Especie(s): Platanus hispanica Mill. ex Münchh. (Platanaceae).

Distribución: Este género incluye una decena de especies nativas de las zonas templadas de norte de América, sudeste de Europa, Himalaya e Indochina. En la Península Ibérica, y por ende, en la provincia de Salamanca, la especie Platanus hispanica Miller ex Münchh., originado por hibridación de Platanus orientalis L. y Platanus occidentalis L., es uno de los elementos de alineación y ornamentales más utilizados en los núcleos urbanos, pudiendo naturalizarse cerca de cursos de agua.

Época de floración: Marzo y abril.

Polinización: Anemófila.

Morfología polínica (Lámina III): polen trizonocolpado, isopolar y radiosimétrico, con forma de subtriangular a subcircular en vista polar y de subcircular a elíptica en vista ecuatorial (de oblato a esferoidal), y un tamaño pequeño $(\mathrm{P}=18-24 \mu \mathrm{m})$. Los colpos son subterminales, más anchos en la zona ecuatorial y con la membrana abertural granulada. La exina, de grosor medio $(2 \mu \mathrm{m})$, presenta una superficie reticulada con lúmenes pequeños e irregulares y muros psilados-equinulados al MEB. 
elevadas a mediados de este último mes, como muestra el valor medio más elevado en los años analizados (51 granos $/ \mathrm{m}^{3}$ el 16 de abril), mediante la dinámica aportada por las concentraciones medias de los cincos días anteriores para el conjunto de anualidades. En todo caso, las mayores concentraciones diarias registradas dentro del período 2000-2007 oscilaron entre los 297 granos/m³ (16 de abril de 2007) y los 49 granos/m³ (14 de abril de 2005). Posteriormente, estos niveles disminuyeron drásticamente en la última mitad abril, presentándose en niveles bajos durante la primera mitad de mayo (Fig. 5.2.2.20.A. B. C.).

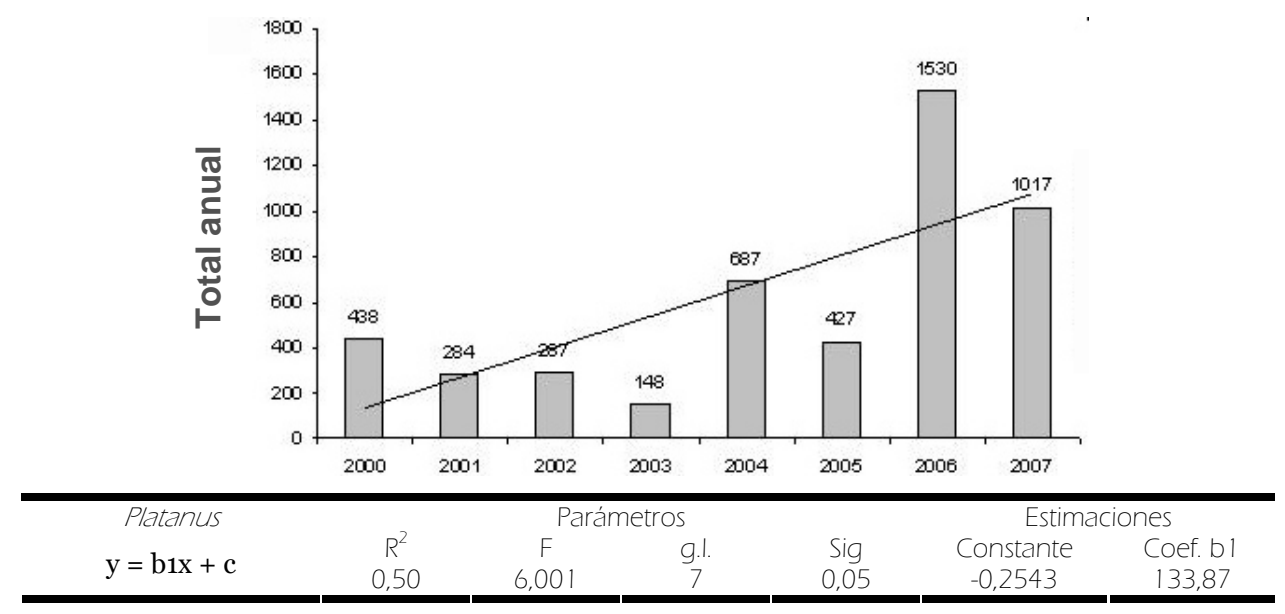

Fig. 5.2. 19. Evolución anual del número total de pólenes de Platanus y tendencias (análisis de regresión).

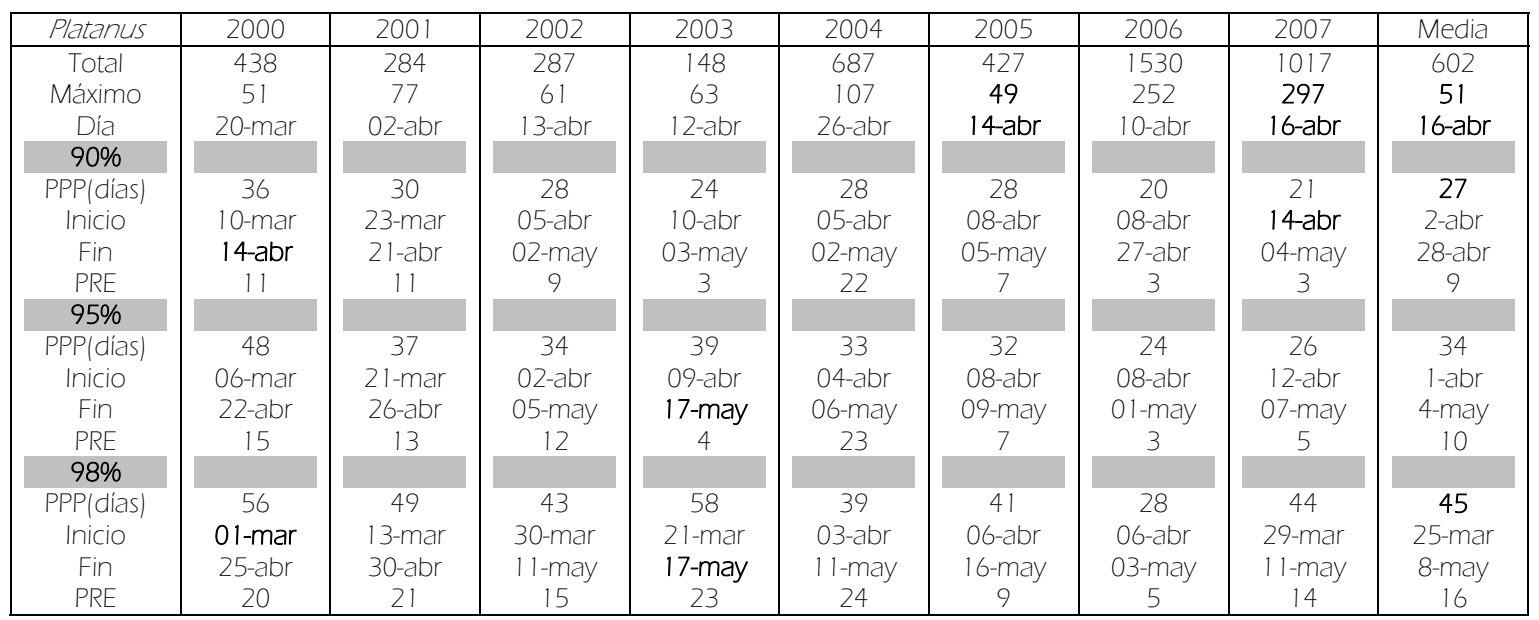

Tabla 5.2.2.13. Totales, concentraciones máximas diarias, períodos principales de polinización (PPP; fecha de inicio y fin) y días precedentes al valor máximo (PRE) durante los ocho años de estudio y el promedio de todos los parámetros para Platanus.

Las concentraciones de polen a lo largo del día se incrementaron a partir de las 9 horas hasta las 15 horas, mostrando los mayores porcentajes de representación desde esta hora hasta las 19 horas, momento en el que las concentraciones horarias disminuyeron. Por tanto, la variación intradiaria (Fig. 5.2.2.21.) durante un día promedio para el trienio 2005-2007, presentó los mayores niveles horarios en las primeras cinco horas de la tarde. 


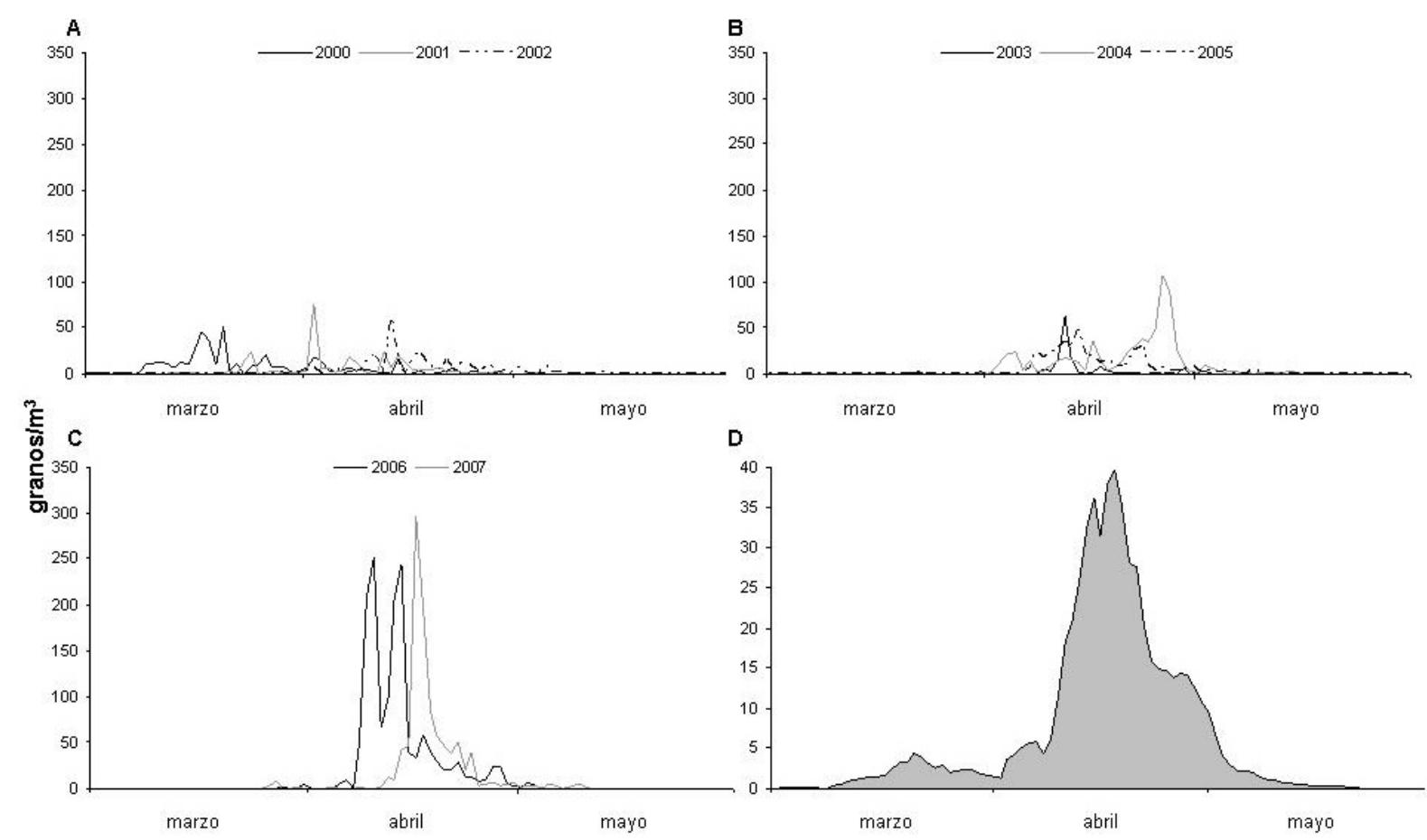

Fig. 5.2.2.20. Variación de las concentraciones medias diarias de Platanus durante el período 2000-2002 (A), 2003-2005 (B) y 2006-2007 (C). Medias móviles de los cinco días anteriores para las concentraciones diarias promedio de los ocho años estudiados (D).

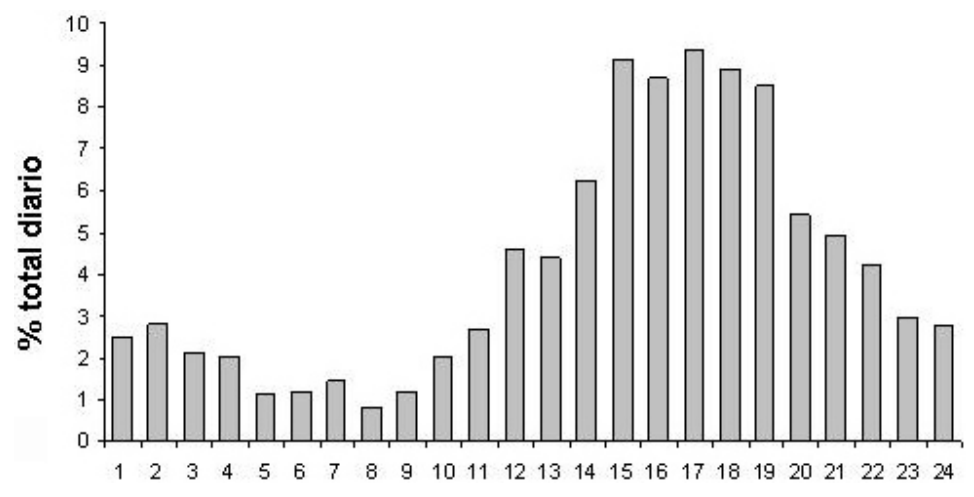

Fig. 5.2.21. Variación intradiaria del polen de Platanus.

El análisis de correlación (Tabla 5.2.2.14.) indicó que las temperaturas medias, máximas y mínimas junto a la insolación, precipitación, humedad relativa y vientos procedentes del II cuadrante así como la frecuencia de las calmas influyeron negativamente en los niveles polínicos durante los ocho años analizados, mientras que la velocidad media del viento y los vientos del III cuadrante tuvieron un efecto positivo, aunque todos ellos con coeficientes de correlación muy bajos. $\mathrm{Al}$ analizar los años estudiados y métodos empleados para delimitar el PPP, se obtuvieron coeficientes más elevados y de distinto signo a lo registrado para el período de estudio completo, como las correlaciones significativas y de signo positivo con las temperaturas y la insolación en el PPP y PRE del año 2004 y del año 2007 (método 98\%), y con la frecuencia de las calmas (PPP y PRE del año 2004 con las tres metodologías). Por último, debe destacarse los distintos signos y valores numéricos de los 
índices de correlación durante los distintos años y sus PPP y PRE para la frecuencia de los vientos procedentes de los diferentes cuadrantes.

\begin{tabular}{|c|c|c|c|c|c|c|c|}
\hline \multicolumn{2}{|c|}{ Platanus } & Tmed & Tmax & Tmin & Insolación & Precipitación & Hrelativa \\
\hline 2000 & Anual & $-0,23 * *$ & $-0,18 * \star$ & $-0,28 * \star$ & $-0,1^{* *}$ & 0,073 & $-0,070$ \\
\hline \multirow{2}{*}{$90 \%$} & PPP & 0,061 & $0,396^{\star}$ & $-0,416^{*}$ & 0,186 & $-0,246$ & $-0,354^{\star}$ \\
\hline & PRE & -0.425 & $-0,307$ & $-0,690^{*}$ & 0,037 & - & $-0,002$ \\
\hline \multirow{2}{*}{$95 \%$} & PPP & $-0,112$ & 0,251 & $-0,43 * *$ & 0,260 & $-0,319$ * & $-0,386$ ** \\
\hline & PRE & $-0,558 *$ & $-0,409$ & $-0,71 * *$ & 0,124 & - & 0,014 \\
\hline \multirow{2}{*}{$98 \%$} & PPP & $-0,086$ & 0,156 & $-0,293^{*}$ & 0,125 & $-0,193$ & $-0,279 *$ \\
\hline & PRE & $-0,118$ & $-0,111$ & $-0,266$ & $-0,016$ & - & $-0,190$ \\
\hline 2001 & Anual & $-0,129 *$ & $-0,121^{*}$ & $-0,14^{\star \star}$ & $-0,010$ & 0,020 & $-0,020$ \\
\hline \multirow{2}{*}{$90 \%$} & PPP & $-0,088$ & 0,059 & $-0,176$ & 0,196 & 0,022 & $-0,378^{*}$ \\
\hline & PRE & 0,426 & 0,571 & 0,154 & 0,101 & $-0,048$ & $-0,390$ \\
\hline \multirow{2}{*}{$95 \%$} & PPP & $-0,125$ & 0,082 & $-0,221$ & 0,140 & $-0,013$ & $-0,350 *$ \\
\hline & PRE & 0,301 & 0,451 & 0,058 & 0,081 & $-0,013$ & $-0,327$ \\
\hline \multirow{2}{*}{$98 \%$} & PPP & 0,009 & 0,197 & $-0,149$ & 0,199 & $-0,038$ & $-0,293 *$ \\
\hline & PRE & 0,308 & 0,347 & 0,183 & 0,085 & 0,041 & $-0,264$ \\
\hline 2002 & Anual & $-0,050$ & 0,002 & $-0,14^{* *}$ & $0,117^{*}$ & $-0,027$ & $-0,211^{* *}$ \\
\hline \multirow{2}{*}{$90 \%$} & PPP & $-0,027$ & $-0,002$ & $-0,015$ & $-0,011$ & $-0,121$ & $-0,010$ \\
\hline & PRE & - & $-0,033$ & 0,134 & 0,113 & $-0,153$ & $-0,190$ \\
\hline \multirow{2}{*}{$95 \%$} & PPP & 0,152 & 0,119 & 0,201 & $-0,050$ & $-0,052$ & 0,018 \\
\hline & PRE & 0,177 & 0,191 & 0,116 & $-0,138$ & 0,020 & 0,046 \\
\hline \multirow{2}{*}{$98 \%$} & PPP & 0,187 & 0,223 & 0,033 & 0,180 & $-0,167$ & $-0,167$ \\
\hline & PRE & 0,013 & 0,005 & 0,085 & $-0,252$ & 0,089 & 0,134 \\
\hline 2003 & Anual & $-0,042$ & $-0,048$ & $-0,073$ & $-0,075$ & 0,103 & $-0,071$ \\
\hline \multirow{2}{*}{$90 \%$} & PPP & $-0,076$ & 0,061 & $-0,096$ & $-0,252$ & 0,270 & $-0,013$ \\
\hline & PRE & $1 * *$ & $-0,500$ & $1 * *$ & $-1 * \star$ & $-1 * *$ & $1 * *$ \\
\hline \multirow{2}{*}{$95 \%$} & PPP & $-0,333^{*}$ & $-0,215$ & $-0,208$ & $-0,253$ & 0,233 & 0,051 \\
\hline & PRE & 0,400 & $-0,600$ & 0,800 & $-0,800$ & $-0,632$ & 0,800 \\
\hline \multirow{2}{*}{$98 \%$} & PPP & 0,007 & $-0,015$ & $-0,069$ & $-0,156$ & 0,134 & $-0,070$ \\
\hline & PRE & $-0,114$ & 0,095 & $-0,205$ & $-0,016$ & 0,013 & $-0,222$ \\
\hline 2004 & Anual & $-0,065$ & $-0,046$ & $-0,117^{*}$ & 0,055 & $-0,007$ & $-0,148 * \star$ \\
\hline \multirow{2}{*}{$90 \%$} & PPP & 0,550 ** & $0,614^{\star \star}$ & 0,215 & 0,361 & $-0,050$ & $-0,280$ \\
\hline & PRE & $0,484^{*}$ & $0,530 *$ & 0,204 & 0,419 & 0,121 & $-0,200$ \\
\hline \multirow{2}{*}{$95 \%$} & PPP & $0,549 * *$ & $0,620 * *$ & 0,133 & 0,441 * & $-0,246$ & $-0,316$ \\
\hline & PRE & $0,495 * *$ & $0,542 * *$ & 0,206 & $0,415^{*}$ & 0,129 & $-0,182$ \\
\hline \multirow{2}{*}{$98 \%$} & PPP & $0,459 * *$ & $0,578 * *$ & 0,002 & $0,41^{* *}$ & $-0,393^{*}$ & $-0,366^{*}$ \\
\hline & PRE & $0,508 * *$ & $0,557 * *$ & 0,202 & 0,430 * & $-0,051$ & $-0,234$ \\
\hline 2005 & Anual & 0,011 & 0,016 & $-0,010$ & 0,081 & $-0,012$ & $-0,042$ \\
\hline 0 & PPP & $-0,60 * \star$ & $-0,55^{\star \star}$ & $-0,49 * \star$ & $-0,39 *$ & 0,106 & $0,457^{\star}$ \\
\hline $90 \%$ & PRE & 0,643 & $0,821^{*}$ & 0,571 & $-0,250$ & - & 0,414 \\
\hline $95 \%$ & PPP & $-0,66 * *$ & $-0,66 * *$ & $-0,47^{* *}$ & $-0,41^{*}$ & 0,177 & $0,564^{* *}$ \\
\hline $95 \%$ & PRE & 0,643 & $0,821^{*}$ & 0,571 & $-0,250$ & - & 0,414 \\
\hline $980 \%$ & PPP & $-0,57 * *$ & $-0,47 * \star$ & $-0,56 * *$ & $-0,015$ & $-0,186$ & 0,097 \\
\hline $78 \%$ & PRE & $-0,233$ & $-0,084$ & $-0,259$ & 0,283 & $-0,411$ & $-0,077$ \\
\hline 2006 & Anual & $-0,028$ & $-0,003$ & $-0,074$ & - & 0,038 & $-0,148 * *$ \\
\hline ๑०\% & PPP & $-0,548 *$ & $-0,365$ & $-0,61$ ** & - & 0,346 & $-0,070$ \\
\hline $90 \%$ & PRE & $-0,500$ & $-0,500$ & 0,500 & - & 0,500 & $-0,500$ \\
\hline $95 \%$ & PPP & $-0,470$ * & $-0,455^{*}$ & $-0,189$ & - & $0,428 *$ & 0,158 \\
\hline $95 \%$ & PRE & $-0,500$ & $-0,500$ & 0,500 & - & 0,500 & $-0,500$ \\
\hline $98 \%$ & PPP & $-0,476^{*}$ & $-0,404^{*}$ & $-0,356$ & - & 0,191 & 0,076 \\
\hline $98 \%$ & PRE & $-0,300$ & $-0,100$ & $-0,700$ & - & 0,100 & $-0,800$ \\
\hline 2007 & Anual & 0,035 & 0,027 & 0,012 & 0,005 & $0,138 * *$ & $-0,016$ \\
\hline $90 \%$ & PPP & $0,548^{*}$ & $0,69^{* *}$ & $-0,315$ & $0,58^{* *}$ & $-0,570^{* *}$ & $-0,560$ ** \\
\hline $90 \%$ & PRE & $1 * *$ & $1 * \star$ & 0,500 & 0,500 & - & $-1 * \star$ \\
\hline 0501 & PPP & 0,427 * & $0,577 * *$ & $-0,155$ & 0,311 & $-0,394^{*}$ & $-0,322$ \\
\hline $95 \%$ & PRE & 0,600 & $1 * *$ & $-0,300$ & 0,800 & $-0,354$ & $-0,900 *$ \\
\hline $880 \%$ & PPP & $0,632 * *$ & $0,587 * *$ & $0,510 * *$ & $0,43 * *$ & $-0,279$ & $-0,280$ \\
\hline $98 \%$ & PRE & $0,741 * *$ & $0,719 * *$ & $0,604^{* *}$ & $0,64^{* *}$ & $-0,371$ & $-0,357$ \\
\hline Total & Anual & $-0,07^{* *}$ & $-0,05^{\star *}$ & $-0,10^{\star \star}$ & 0,029 & $-0,039 * *$ & $-0,104^{\star *}$ \\
\hline
\end{tabular}

Tabla 5.2.2.14. Coeficientes de correlación de Spearman entre Platanus y las variables climatológicas. Tmed,

Tmax, Tmin (temperatura media, máxima y mínima), Hrelativa (humedad relativa). Significación: 95\%(*), $99 \%(* *)$. (-) Ausencia de correlaciones. 


\begin{tabular}{|c|c|c|c|c|c|c|c|}
\hline \multicolumn{2}{|c|}{ Platanus } & Vemed & FrecCalm & VICuadr & V2Cuadr & V3Cuadr & V4Cuadr \\
\hline 2000 & Anual & $0,162^{\star \star}$ & $-0,162^{\star \star}$ & $-0,001$ & $-0,015$ & 0,043 & $-0,059$ \\
\hline \multirow{2}{*}{$90 \%$} & PPP & $-0,111$ & 0,214 & $0,465 * \star$ & 0,154 & $-0,393^{* *}$ & $-0,274$ \\
\hline & PRE & - & $-0,222$ & 0,087 & 0,060 & $-0,262$ & 0,109 \\
\hline \multirow{2}{*}{$95 \%$} & PPP & $-0,124$ & 0,160 & 0,418 ** & 0,130 & $-0,393 * *$ & $-0,110$ \\
\hline & PRE & 0,438 & $-0,422$ & 0,405 & $-0,350$ & $-0,275$ & $-0,133$ \\
\hline \multirow{2}{*}{$98 \%$} & PPP & $-0,058$ & 0,125 & 0,301 * & 0,102 & $-0,302^{*}$ & $-0,074$ \\
\hline & PRE & 0,387 & $-0,280$ & 0,346 & $-0,368$ & $-0,204$ & $-0,240$ \\
\hline 2001 & Anual & $0,222^{\star \star}$ & $-0,159^{\star \star}$ & $-0,164$ ** & $-0,226^{* *}$ & $0,178^{\star \star}$ & 0,040 \\
\hline \multirow{2}{*}{$90 \%$} & PPP & 0,180 & $-0,036$ & 0,166 & 0,174 & $-0,061$ & $-0,211$ \\
\hline & PRE & 0,005 & 0,217 & 0,316 & 0,400 & 0,099 & $-0,349$ \\
\hline \multirow{2}{*}{$95 \%$} & PPP & 0,010 & 0,038 & 0,272 & 0,233 & $-0,208$ & $-0,138$ \\
\hline & PRE & $-0,017$ & 0,203 & 0,314 & 0,393 & 0,024 & $-0,241$ \\
\hline \multirow{2}{*}{$98 \%$} & PPP & 0,006 & 0,070 & 0,230 & 0,105 & $-0,194$ & $-0,133$ \\
\hline & PRE & 0,131 & 0,063 & $-0,047$ & 0,075 & 0,016 & $-0,079$ \\
\hline 2002 & Anual & $-0,043$ & $0,109 *$ & $0,109 *$ & 0,020 & $-0,059$ & $-0,134^{*}$ \\
\hline \multirow{2}{*}{$90 \%$} & PPP & $-0,266$ & $-0,008$ & $0,382^{*}$ & $-0,072$ & $-0,264$ & $-0,225$ \\
\hline & PRE & $-0,075$ & 0,017 & 0,644 & $-0,444$ & $-0,563$ & $-0,773^{*}$ \\
\hline \multirow{2}{*}{$95 \%$} & PPP & $-0,270$ & 0,120 & $0,374^{*}$ & 0,053 & $-0,302$ & $-0,317$ \\
\hline & PRE & $-0,208$ & 0,133 & $0,654^{*}$ & $-0,088$ & $-0,474$ & $-0,656^{*}$ \\
\hline \multirow{2}{*}{$98 \%$} & PPP & $-0,211$ & 0,103 & 0,206 & 0,078 & $-0,155$ & $-0,262$ \\
\hline & PRE & $-0,013$ & 0,021 & 0,462 & $-0,203$ & $-0,333$ & $-0,497$ \\
\hline 2003 & Anual & $0,135^{\star *}$ & 0,002 & $-0,161^{\text {** }}$ & 0,072 & $0,172^{* \star}$ & $-0,089$ \\
\hline \multirow{2}{*}{$90 \%$} & PPP & $-0,012$ & 0,188 & $-0,075$ & $-0,038$ & 0,030 & 0,041 \\
\hline & PRE & 0,500 & $-0,500$ & $-0,500$ & 0,500 & 0,500 & $-1 * *$ \\
\hline \multirow{2}{*}{$95 \%$} & PPP & 0,189 & 0,191 & $-0,313$ & 0,193 & 0,309 & $-0,167$ \\
\hline & PRE & 0,316 & $-0,600$ & $-0,600$ & 0,211 & 0,600 & $-0,800$ \\
\hline \multirow{2}{*}{$98 \%$} & PPP & 0,162 & 0,256 & $-0,408$ ** & 0,121 & $0,392^{\star *}$ & $-0,061$ \\
\hline & PRE & 0,277 & 0,300 & $-0,492^{*}$ & $-0,134$ & $0,529 *$ & $-0,072$ \\
\hline 2004 & Anual & $-0,49$ & $-0,144^{* *}$ & 0,046 & $-0,136^{* *}$ & $-0,058$ & $-0,030$ \\
\hline \multirow{2}{*}{$90 \%$} & PPP & $-0,082$ & $0,448^{*}$ & 0,055 & 0,289 & 0,038 & 0,231 \\
\hline & PRE & 0,093 & 0,414 & $-0,153$ & 0,271 & 0,199 & $0,445^{\star}$ \\
\hline \multirow{2}{*}{$95 \%$} & PPP & $-0,149$ & $0,454 * *$ & 0,155 & $0,372^{*}$ & $-0,078$ & 0,068 \\
\hline & PRE & 0,100 & $0,416^{*}$ & $-0,163$ & 0,270 & 0,211 & $0,449 *$ \\
\hline \multirow{2}{*}{$98 \%$} & PPP & $-0,152$ & $0,457 * *$ & 0,182 & $0,472^{* *}$ & $-0,094$ & $-0,033$ \\
\hline & PRE & 0,075 & $0,432^{*}$ & $-0,077$ & 0,330 & 0,095 & $0,474^{*}$ \\
\hline 2005 & Anual & $0,264^{\star *}$ & $-0,209^{* *}$ & $-0,134^{*}$ & $-0,127^{\star}$ & $0,115^{\star}$ & 0,086 \\
\hline $90 \%$ & PPP & 0,353 & $-0,264$ & $-0,057$ & $-0,071$ & $-0,202$ & $-0,051$ \\
\hline $90 \%$ & PRE & 0,288 & $-0,408$ & $-0,571$ & $-0,071$ & 0,505 & 0,306 \\
\hline $95 \%$ & PPP & 0,411 * & $-0,269$ & $-0,190$ & $-0,165$ & $-0,069$ & 0,032 \\
\hline & PRE & 0,288 & $-0,408$ & $-0,571$ & $-0,071$ & 0,505 & 0,306 \\
\hline $98 \%$ & PPP & $0,437^{* *}$ & $-0,238$ & $-0,089$ & $-0,218$ & $-0,097$ & $-0,001$ \\
\hline $78 \%$ & PRE & 0,630 & $-0,492$ & 0,017 & $-0,500$ & 0,151 & $-0,025$ \\
\hline 2006 & Anual & $0,132^{\star}$ & $-0,029$ & $0,141^{*}$ & 0,017 & $-0,078$ & $-0,054$ \\
\hline $90 \%$ & PPP & 0,295 & $-0,580$ & 0,116 & $0,868^{*}$ & $-0,377$ & $-0,868^{*}$ \\
\hline & PRE & $-1 * *$ & - & - & - & - & - \\
\hline $95 \%$ & PPP & 0,350 & $-0,377$ & 0,134 & 0,338 & $-0,250$ & $-0,786 * *$ \\
\hline & PRE & $-1 * *$ & - & - & - & - & - \\
\hline $98 \%$ & PPP & 0,199 & $-0,204$ & 0,312 & 0,107 & $-0,385$ & $-0,790$ ** \\
\hline $98 \%$ & PRE & $-0,200$ & - & - & - & - & - \\
\hline 2007 & Anual & 0,003 & 0,041 & $-0,061$ & $0,137^{* *}$ & 0,059 & $0,105^{\star}$ \\
\hline $90 \%$ & PPP & $-0,044$ & 0,280 & $0,556^{* *}$ & $0,437^{*}$ & $-0,494^{*}$ & $-0,824^{* *}$ \\
\hline $70 \%$ & PRE & 0,866 & $1 * \star$ & 0,500 & 0,500 & $-1 * \star$ & $-1 * \star$ \\
\hline $95 \%$ & PPP & 0,001 & 0,153 & 0,334 & $0,412^{*}$ & $-0,219$ & $-0,585^{* *}$ \\
\hline & PRE & 0,667 & 0,400 & 0,900 * & 0,600 & $-0,700$ & $-0,400$ \\
\hline $98 \%$ & PPP & $-0,186$ & 0,471 ** & 0,025 & 0,050 & $-0,099$ & $-0,170$ \\
\hline $78 \%$ & PRE & $-0,233$ & $0,566^{\star}$ & 0,119 & $-0,385$ & $-0,045$ & 0,141 \\
\hline Total & Anual & $0,087^{* *}$ & $-0,065^{* *}$ & $-0,033$ & $-0,046^{*}$ & $0,047^{\star}$ & $-0,017$ \\
\hline
\end{tabular}

Tabla 5.2.2.14. (Continuación). Coeficientes de correlación de Spearman entre Platanus y las variables climatológicas. Vemed (velocidad media), FrecCalmas (frecuencia de calmas), V1Cuad, V2Cuad, V3Cuad, V4Cuad (vientos procedentes del I, II, III y IV cuadrante). Significación: $95 \%\left(^{*}\right), 99 \%(* *)$. (-) Ausencia de correlaciones. 


\subsubsection{Poaceae (= Graminae)}

La variación interanual (Fig. 5.2.2.22.) del polen de esta familia en la atmósfera mostró un incremento en los niveles polínicos totales anuales durante el período 2000-2007, como muestra el paso de los 2765 pólenes en el año 2000 a los 7832 , lo cual conllevó un aumento del 165\%. El valor del índice de determinación $\left(\mathrm{R}^{2}=\mathrm{O}\right.$, $54)$, refrenda de manera estadística, a través regresión lineal, esta tendencia. Los porcentajes de representación sobre el total de pólenes contabilizados en cada anualidad estudiada variaron del 31,2\% de 2002 al 11,6\% de 2005, con un porcentaje medio de $22 \%$.

La variación estacional, fue muy amplia (Tabla 5.2.2.15.), con un PPP promedio que osciló entre 100 y 188 días, según el modelo utilizado, y localizado entre los meses de febrero y marzo hasta el mes de agosto. Esta variación se hace más acusada en función del año analizado y del modelo usado, como indican las diversas fechas de inicio, que tuvieron el 31 de enero de 2004 y 2007 como fecha más temprana (método 98\%) y el 5 de mayo de 2003 como la más tardía (método 90\%), y las fechas de finalización del PPP, con un intervalo entre
Tipo polínico: Festuca arundinacea.

Especie(s): Esta familia incluye a más de 9000 especies, entre las que destacan aquellas con importancia económica como los cereales (Triticum vulgare L., Hordeum vulgare L., Secale cereale L., etc) o las que forman parte de pasto (Poa L. o Festuca L., entre otros).

Distribución: Familia cosmopolita con gran importancia en la biosfera puesto que se encuentran prácticamente en todo tipo de hábitat y determinan el carácter del paisaje en estepas, sabanas y praderas, como ocurre en la Península Ibérica y en la provincia de Salamanca, donde resultan fundamentales en la conformación de encinares adehesados y otras formaciones boscosas, así como en praderas.

Época de floración: Muy amplia, por la floración sucesiva de las diferentes especies, abarcando la práctica totalidad del año, salvo los últimos tres meses del año.

Polinización: Anemófila.

Morfología polínica (Lámina III): Polen monoanaporado, heteropolar y radiosimétrico, con forma circular a subcircular (esferoidal), y un tamaño de pequeño a mediano $(P=16-40$ $\mu \mathrm{m})$. El único poro está rodeado por un anillo, cubierto por un opérculo y tiene un tamaño de 2 a $4 \mu \mathrm{m}$ de diámetro. La exina, de grosor fino (1-1,5 $\mu \mathrm{m})$, presenta una superficie granulada. el 4 de julio de 2000 y 2001 (método 90\%) y el 20 de septiembre de 2003 (método 98\%).

La dinámica que presentaron los niveles polínicos de Poaceae (Fig. 5.2.2.23.D.) representada en las concentraciones promedio para los cinco días anteriores durante los años analizados registró una mayor presencia en los meses de febrero, marzo con respecto a enero y presentó un notable aumento a finales de abril, manteniéndose en niveles altos hasta julio, presentando una concentración máxima de 86 granos/m³ el día 8 de junio como media del período 2000-2007 (Tabla 5.2.2.15.). Posteriormente, durante el mes de julio estos niveles 
experimentaron una disminución, permaneciendo en la atmósfera durante el resto del año, aunque con concentraciones anecdóticas en los últimos tres meses del año. Las concentraciones diarias más elevadas dentro de estos ocho años (Tabla 5.2.2.15; Fig. 5.2.2.23. A. B. C.), localizadas en los meses de mayo y junio, variaron entre los 355 granos $/ \mathrm{m}^{3}$ (30 de junio de 2007) y los 74 granos $/ \mathrm{m}^{3}$ (16 de mayo de 2002).

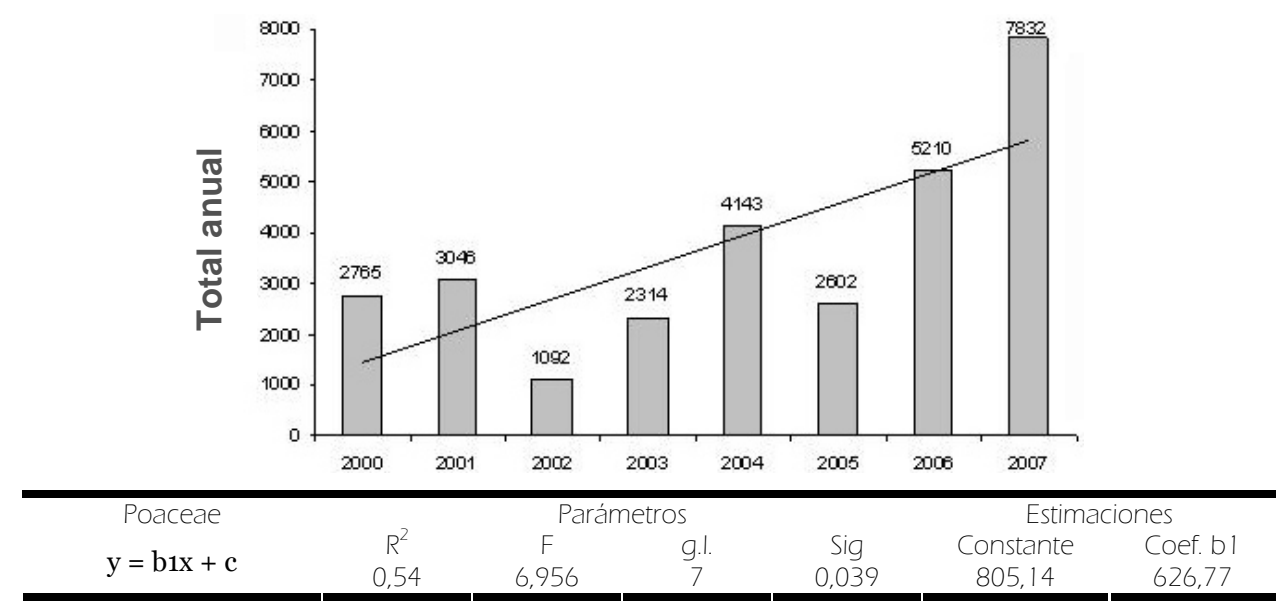

Fig. 5.2.2.2. Evolución anual del número total de pólenes de Poaceae y tendencias (análisis de regresión).

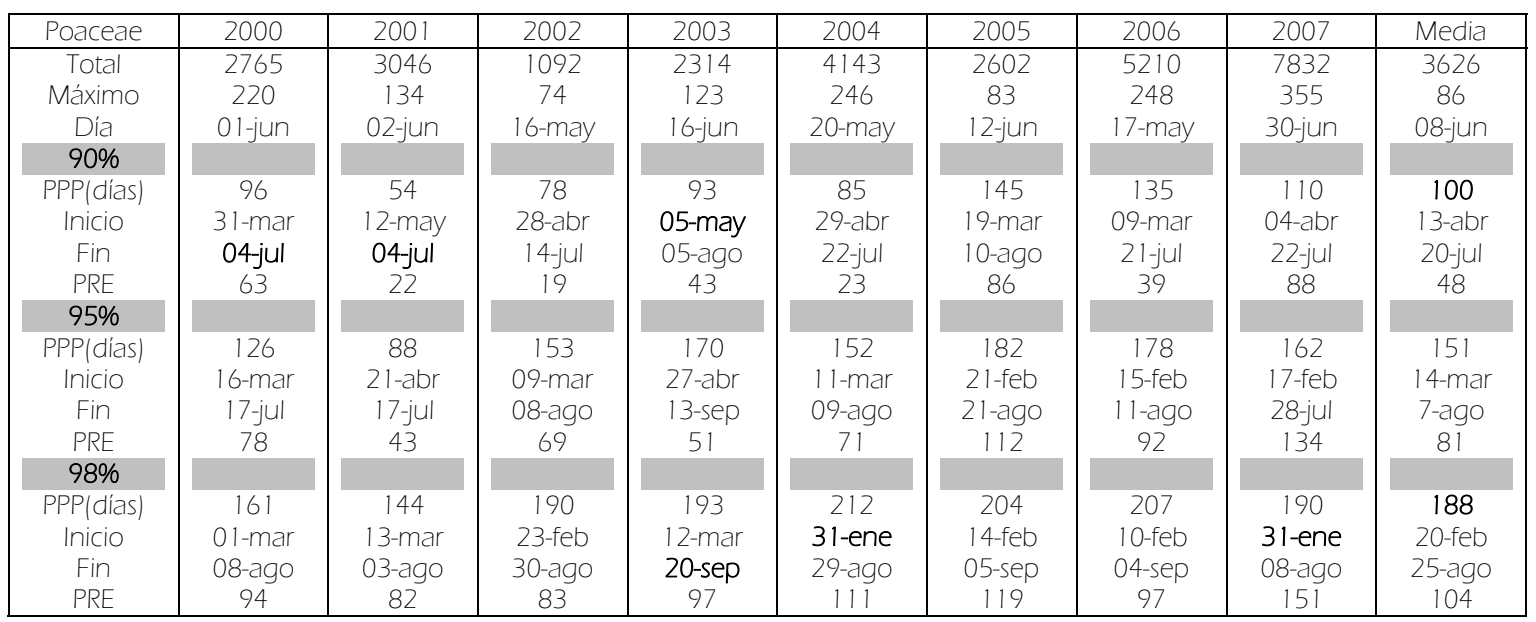

Tabla 5.2.2.15. Totales, concentraciones máximas diarias, períodos principales de polinización (PPP; fecha de inicio y fin) y días precedentes al valor máximo (PRE) durante los ocho años de estudio y el promedio de todos los parámetros para Poaceae.

La variación intradiaria (Fig. 5.2.2.24.) no mostró un claro patrón a lo largo de un día promedio para los últimos tres años estudiados, ya que la distribución fue, más o menos, regular durante las diferentes horas que componen un día. En todo caso, podemos señalar un ligero descenso entre las últimas horas de la noche y primeras horas de la mañana (4-9 horas) y un pequeño incremento en las últimas cuatro horas del día (21-24 horas). 


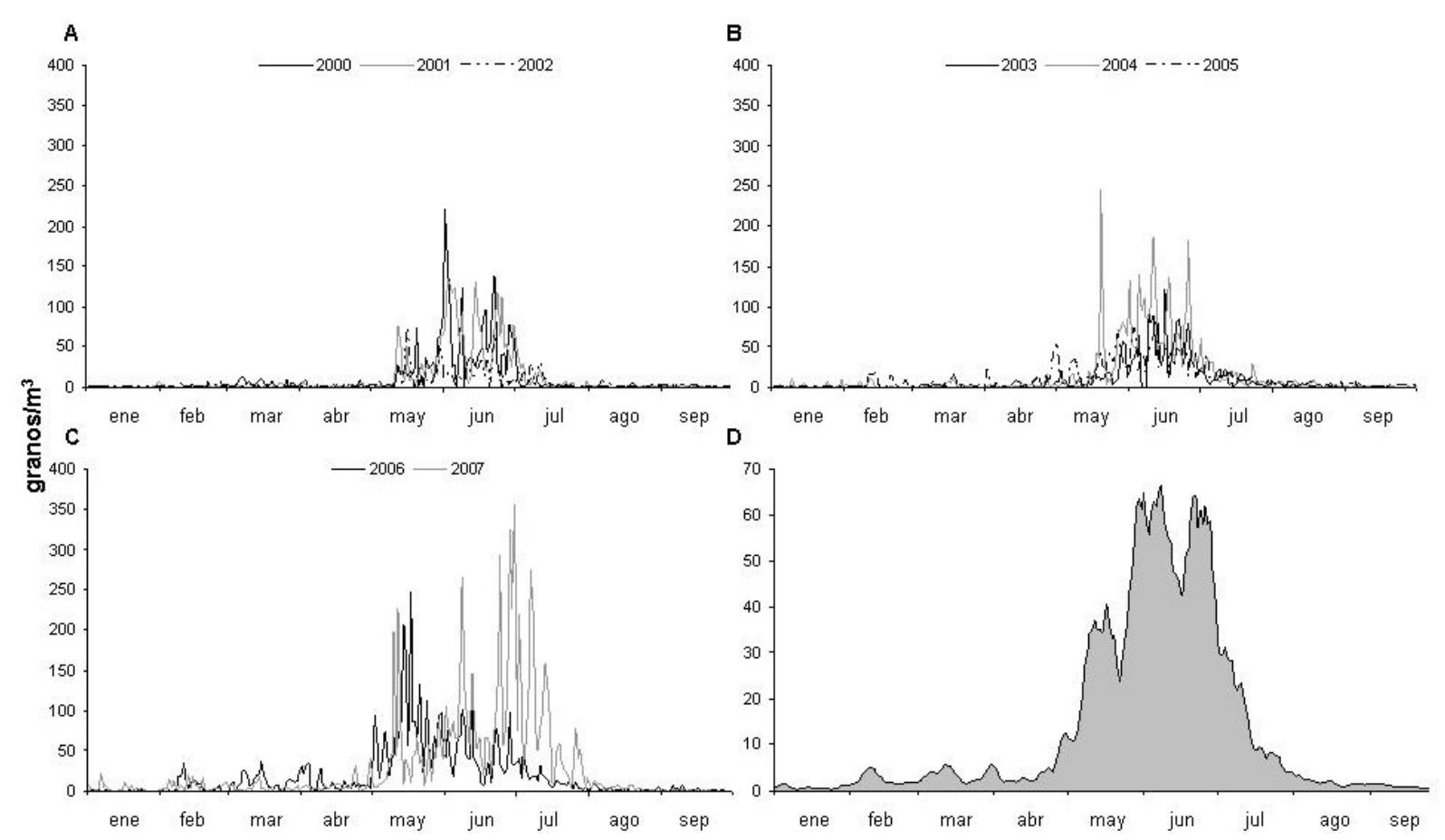

Fig. 5.2.2.23. Variación de las concentraciones medias diarias de Poaceae durante el período 2000-2002 (A), 2003-2005 (B) y 2006-2007 (C). Medias móviles de los cinco días anteriores para las concentraciones diarias promedio de los ocho años estudiados (D).

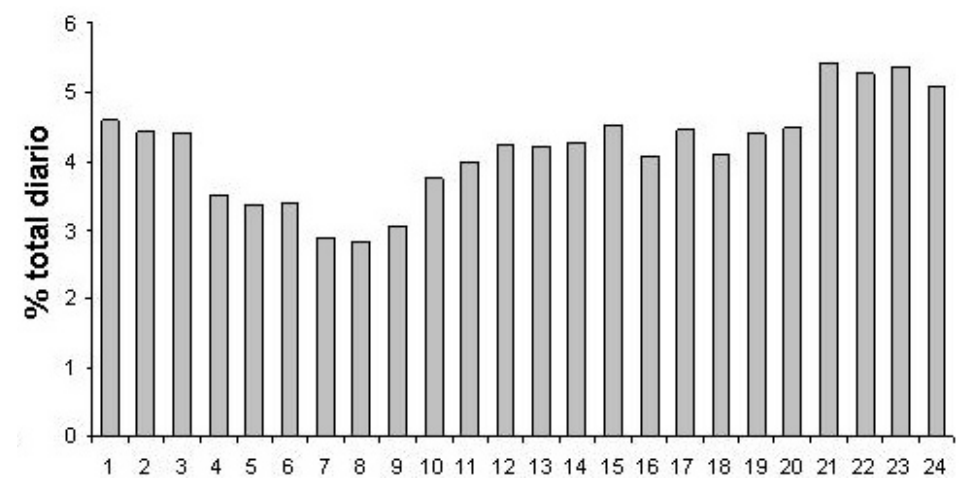

Fig. 5.2.2.24. Variación intradiaria del polen de Poaceae.

Las temperaturas medias, máximas y mínimas junto a la insolación y los vientos procedentes del IV cuadrante (también del III cuadrante, pero con bajos valores del índice de correlación) ejercieron una influencia positiva en las concentraciones polínicas de la familia Poaceae durante los ocho años analizados, mientras que las precipitaciones, la humedad relativa y, en menor medida, la velocidad media del viento y la frecuencia de las calmas lo hicieron de forma negativa, tras el análisis de correlación (Tabla 5.2.2.16.). Con respecto a los vientos, a través de los diferentes años y PPP obtenidos con los diversos métodos empleados, debemos comentar que en el año 2007, los vientos procedentes del I y II cuadrante tuvieron un efecto negativo en los niveles de polen de gramíneas, mientras que los vientos del III y IV ejercieron un efecto positivo, junto al año 2000 donde los vientos del I cuadrante ejercieron una influencia positiva y los vientos del III cuadrante tuvieron un efecto 
negativo. Otro de los componentes del viento, la frecuencia de las calmas tuvo un efecto positivo durante el año 2000, a través del PPP y PRE calculados a partir del 90\% y 95\% de los totales anuales, o en el año 2007, a partir del PPP y el PRE obtenidos con la metodología del $95 \%$ y el $98 \%$.

\begin{tabular}{|c|c|c|c|c|c|c|c|}
\hline \multicolumn{2}{|c|}{ Poaceae } & Tmed & Tmax & Tmin & Insolación & Precipitación & Hrelativa \\
\hline 2000 & Anual & $0,417^{* *}$ & 0,456 ** & 0,334 ** & $0,42^{\star \star}$ & $-0,197^{\star \star}$ & $-0,525^{* *}$ \\
\hline \multirow{2}{*}{$90 \%$} & PPP & 0,791 ** & $0,792 * *$ & 0,651 ** & $0,59 * \star$ & $-0,434^{\star \star}$ & $-0,663^{* *}$ \\
\hline & PRE & $0,638 * *$ & 0,630 ** & $0,519 * *$ & $0,42^{\star *}$ & $-0,271^{*}$ & $-0,398 * *$ \\
\hline \multirow{2}{*}{$95 \%$} & PPP & $0,676 * *$ & $0,690 * *$ & $0,577 * *$ & $0,53 * *$ & $-0,413 * *$ & $-0,564 * *$ \\
\hline & PRE & 0,507 ** & $0,587^{* *}$ & $0,377^{* *}$ & $0,45^{\star *}$ & $-0,312^{\star *}$ & $-0,387 * *$ \\
\hline \multirow{2}{*}{$98 \%$} & PPP & 0,401 ** & $0,444 * *$ & 0,310 ** & $0,29 * *$ & $-0,329 * \star$ & $-0,418 * *$ \\
\hline & PRE & $0,472^{* *}$ & $0,627^{* *}$ & $0,234^{\star}$ & $0,42^{\star *}$ & $-0,363^{* *}$ & $-0,408$ ** \\
\hline 2001 & Anual & $0,514^{* *}$ & $0,523 * *$ & $0,447 * *$ & $0,50 * *$ & $-0,130^{*}$ & $-0,545 * *$ \\
\hline \multirow{2}{*}{$90 \%$} & PPP & $0,390^{* *}$ & 0,268 & $0,454^{* *}$ & 0,291 * & $-0,137$ & $-0,357^{* *}$ \\
\hline & PRE & 0,348 & 0,321 & 0,408 & 0,074 & $-0,001$ & $-0,428 *$ \\
\hline \multirow{2}{*}{$95 \%$} & PPP & $0,679 * *$ & $0,655^{* *}$ & $0,638 * *$ & $0,52 * *$ & $-0,287^{* \star}$ & $-0,618$ ** \\
\hline & PRE & 0,779 ** & 0,736 ** & $0,773^{* *}$ & $0,45^{* *}$ & $-0,208$ & $-0,548 * *$ \\
\hline \multirow{2}{*}{$98 \%$} & PPP & 0,626 ** & 0,636 ** & $0,549 * *$ & $0,49 * *$ & $-0,169 *$ & $-0,603 * *$ \\
\hline & PRE & $0,570 * *$ & $0,564 * *$ & 0,506 ** & $0,36 * *$ & $-0,093$ & $-0,468 * *$ \\
\hline 2002 & Anual & $0,327^{* *}$ & $0,337^{\star *}$ & $0,273^{* *}$ & $0,35^{\star \star}$ & $-0,177^{\star \star}$ & $-0,368^{* *}$ \\
\hline \multirow{2}{*}{$90 \%$} & PPP & $0,549 * *$ & $0,575^{\star *}$ & $0,466 * *$ & $0,29 * \star$ & $-0,356^{* *}$ & $-0,503 * *$ \\
\hline & PRE & 0,459 * & $0,492^{*}$ & 0,288 & 0,174 & $-0,495^{*}$ & $-0,361$ \\
\hline \multirow{2}{*}{$95 \%$} & PPP & $0,376 * *$ & $0,348 * *$ & $0,395 * *$ & $0,28 * *$ & $-0,251 * \star$ & $-0,346 * *$ \\
\hline & PRE & $0,359 * *$ & $0,311^{* *}$ & $0,348 * *$ & 0,27 ** & $-0,333^{* *}$ & $-0,275^{\star}$ \\
\hline \multirow{2}{*}{$98 \%$} & PPP & 0,258 ** & $0,245^{* *}$ & $0,263^{* *}$ & $0,25^{* *}$ & $-0,239 * *$ & $-0,339 * *$ \\
\hline & PRE & $0,274^{*}$ & $0,278^{*}$ & $0,233^{*}$ & 0,250 * & $-0,327^{* *}$ & $-0,250^{*}$ \\
\hline 2003 & Anual & $0,632^{* *}$ & $0,628^{* *}$ & $0,543^{* *}$ & $0,56^{* *}$ & $-0,296^{* *}$ & $-0,642^{* *}$ \\
\hline \multirow{2}{*}{$90 \%$} & PPP & 0,194 & 0,170 & $0,222^{*}$ & 0,008 & $-0,010$ & $-0,210^{*}$ \\
\hline & PRE & $0,581^{* *}$ & $0,489 * *$ & $0,586 * *$ & $-0,167$ & $-0,065$ & $-0,272$ \\
\hline \multirow{2}{*}{$95 \%$} & PPP & 0,089 & 0,104 & $-0,024$ & 0,30 ** & $-0,220^{\star *}$ & $-0,431$ ** \\
\hline & PRE & $0,605^{* *}$ & $0,552^{* *}$ & $0,550 * *$ & $-0,039$ & $-0,086$ & $-0,332^{*}$ \\
\hline \multirow{2}{*}{$98 \%$} & PPP & $0,474^{* *}$ & 0,450 ** & $0,379 * *$ & 0,44 ** & $-0,246 * *$ & $-0,550$ ** \\
\hline & PRE & $0,737 * *$ & $0,666 * *$ & $0,568 * *$ & $0,34 * *$ & $-0,171$ & $-0,437 * *$ \\
\hline 2004 & Anual & $0,630^{* *}$ & $0,620^{* *}$ & $0,584^{* *}$ & $0,53^{* *}$ & $-0,115^{\star}$ & $-0,554^{* *}$ \\
\hline \multirow{2}{*}{$90 \%$} & PPP & $0,558^{* *}$ & 0,561 ** & $0,490 * *$ & $0,36^{* \star}$ & $-0,293^{* *}$ & $-0,244^{* *}$ \\
\hline & PRE & 0,308 & 0,560 ** & 0,009 & 0,74 ** & $-0,537^{* *}$ & $-0,754$ ** \\
\hline \multirow{2}{*}{$95 \%$} & PPP & $0,640 * *$ & $0,641 * *$ & $0,588 * *$ & 0,51 ** & $-0,159 *$ & $-0,344 * *$ \\
\hline & PRE & $0,485^{* *}$ & $0,479 * *$ & 0,404 ** & 0,31 ** & $-0,066$ & $-0,233$ \\
\hline \multirow{2}{*}{$98 \%$} & PPP & 0,631 ** & $0,624 * *$ & 0,605 ** & 0,51 ** & $-0,127$ & $-0,369 * *$ \\
\hline & PRE & $0,467^{* *}$ & $0,478 * *$ & $0,381^{* *}$ & $0,31^{* *}$ & $-0,079$ & $-0,285^{* *}$ \\
\hline 2005 & Anual & $0,678^{* *}$ & $0,691^{* *}$ & $0,579 * *$ & $0,63^{\star \star}$ & $-0,196^{\star \star}$ & $-0,747$ ** \\
\hline $90 \%$ & PPP & $0,556^{* *}$ & $0,518^{* *}$ & $0,459 * *$ & $0,45^{\star *}$ & $-0,314^{\star \star}$ & $-0,538 * *$ \\
\hline $90 \%$ & PRE & $0,799 * *$ & $0,783^{* *}$ & $0,623^{* *}$ & $0,58 * *$ & $-0,397 * *$ & $-0,748 * *$ \\
\hline $95 \%$ & PPP & $0,592^{* *}$ & $0,563^{* *}$ & 0,523 ** & $0,47^{* *}$ & $-0,243^{* *}$ & $-0,571$ ** \\
\hline $95 \%$ & PRE & 0,788 ** & 0,776 ** & $0,665^{* *}$ & $0,52 * \star$ & $-0,278 * *$ & $-0,682 * *$ \\
\hline $98 \%$ & PPP & $0,538^{* *}$ & $0,506 * *$ & $0,474 * *$ & 0,46 ** & $-0,202 * *$ & $-0,533^{* *}$ \\
\hline $98 \%$ & PRE & $0,776^{* *}$ & $0,762^{* *}$ & $0,661^{* *}$ & $0,48 * *$ & $-0,241^{* *}$ & $-0,661$ ** \\
\hline 2006 & Anual & $0,431^{* *}$ & $0,444 * *$ & $0,355^{* *}$ & 0,206 & $-0,169 * *$ & $-0,644 * *$ \\
\hline $90 \%$ & PPP & $0,469 * *$ & $0,477^{* \star}$ & $0,282^{* *}$ & - & $-0,348^{\star \star}$ & $-0,626 * *$ \\
\hline $70 \%$ & PRE & $0,613^{* *}$ & $0,664^{* *}$ & 0,239 * & - & $-0,339 * *$ & $-0,457$ ** \\
\hline $95 \%$ & PPP & $0,341^{* *}$ & $0,345^{* *}$ & $0,249 * *$ & $-0,072$ & $-0,231^{* *}$ & $-0,546$ ** \\
\hline $75 \%$ & PRE & $0,653^{* *}$ & $0,703^{* *}$ & $0,408 * *$ & $-0,072$ & $-0,296$ ** & $-0,521$ ** \\
\hline ๑8०\% & PPP & $0,183^{* *}$ & $0,155^{* *}$ & $0,144 * *$ & 0,005 & $-0,163^{*}$ & $-0,396$ ** \\
\hline $98 \%$ & PRE & $0,606^{* *}$ & $0,672^{* *}$ & $0,370 * *$ & 0,005 & $-0,301^{* *}$ & $-0,499$ ** \\
\hline 2007 & Anual & $0,541^{* *}$ & $0,480^{* \star}$ & $0,489 * *$ & $0,40^{\star \star}$ & $-0,010$ & $-0,417^{* *}$ \\
\hline & PPP & $0,743^{* *}$ & $0,687^{* *}$ & $0,542 * *$ & $0,57^{\star *}$ & $-0,420 * \star$ & $-0,577 * *$ \\
\hline $70 \%$ & PRE & $0,756^{* *}$ & $0,672^{* *}$ & $0,534 * *$ & $0,55^{* *}$ & $-0,388 * *$ & $-0,582^{* *}$ \\
\hline & PPP & $0,767^{* *}$ & $0,727^{* *}$ & $0,650 * *$ & $0,57^{* *}$ & $-0,360 * *$ & $-0,530$ ** \\
\hline $75 \%$ & PRE & 0,808 ** & 0,749 ** & $0,661^{* *}$ & $0,54 * *$ & $-0,306^{* *}$ & $-0,484$ ** \\
\hline & PPP & $0,702 * *$ & $0,680 * *$ & $0,611 * *$ & $0,53 * *$ & $-0,281 * *$ & $-0,507 * *$ \\
\hline $98 \%$ & PRE & $0,769 * *$ & $0,735^{* *}$ & $0,645^{* *}$ & $0,49 * *$ & $-0,236$ ** & $-0,482^{* *}$ \\
\hline Total & Anual & $0,507^{* *}$ & $0,513^{* *}$ & 0,438 ** & $0,47^{\star *}$ & $-0,16^{* \star}$ & $-0,511$ ** \\
\hline
\end{tabular}

Tabla 5.2.2.16. Coeficientes de correlación de Spearman entre Poaceae y las variables climatológicas. Tmed, Tmax, Tmin (temperatura media, máxima y mínima), Hrelativa (humedad relativa). Significación: 95\%(*), $99 \%(* *)$. (-) Ausencia de correlaciones. 


\begin{tabular}{|c|c|c|c|c|c|c|c|}
\hline \multicolumn{2}{|c|}{ Poaceae } & Vemed & FrecCalm & VICuadr & V2Cuadr & V3Cuadr & V4Cuadr \\
\hline 2000 & Anual & $-0,010$ & $-0,048$ & $0,208^{* \star}$ & 0,065 & $-0,168^{* \star}$ & 0,079 \\
\hline \multirow{2}{*}{$90 \%$} & PPP & $-0,31$ ** & $0,329 * *$ & $0,241^{\star}$ & 0,170 & $-0,305^{* *}$ & 0,147 \\
\hline & PRE & $-0,36$ ** & $0,283^{*}$ & 0,188 & 0,126 & $-0,321^{*}$ & 0,237 \\
\hline \multirow{2}{*}{$95 \%$} & PPP & $-0,25^{* *}$ & $0,259 * *$ & 0,191 * & 0,141 & $-0,228 *$ & 0,083 \\
\hline & PRE & $-0,32 * *$ & $0,260 *$ & $0,232^{*}$ & 0,103 & $-0,302 * *$ & 0,134 \\
\hline \multirow{2}{*}{$98 \%$} & PPP & $-0,131$ & 0,135 & 0,150 & $0,157^{\star}$ & $-0,154$ & 0,020 \\
\hline & PRE & $-0,33$ ** & 0,296 ** & 0,261 * & 0,119 & $-0,321^{* *}$ & 0,092 \\
\hline 2001 & Anual & 0,014 & $-0,075$ & $-0,037$ & $-0,124^{\star}$ & 0,012 & $0,357^{* *}$ \\
\hline \multirow{2}{*}{$90 \%$} & PPP & 0,161 & $-0,071$ & $-0,304^{*}$ & $-0,002$ & $0,334^{*}$ & 0,238 \\
\hline & PRE & 0,033 & 0,147 & $-0,042$ & 0,289 & 0,088 & 0,072 \\
\hline \multirow{2}{*}{$95 \%$} & PPP & $-0,092$ & 0,073 & $-0,101$ & 0,082 & 0,114 & 0,103 \\
\hline & PRE & $-0,238$ & 0,215 & $-0,018$ & 0,107 & 0,002 & 0,016 \\
\hline \multirow{2}{*}{$98 \%$} & PPP & $-0,25 * *$ & $0,196 *$ & 0,020 & $0,178 *$ & $-0,026$ & $0,203^{*}$ \\
\hline & PRE & $-0,29$ ** & 0,299 ** & 0,090 & 0,280 & $-0,076$ & 0,165 \\
\hline 2002 & Anual & $-0,008$ & 0,024 & $-0,054$ & $-0,109 *$ & 0,084 & 0,095 \\
\hline \multirow{2}{*}{$90 \%$} & PPP & $-0,35 * \star$ & $0,248^{*}$ & $-0,031$ & $0,284^{\star}$ & 0,047 & $-0,073$ \\
\hline & PRE & $-0,205$ & 0,155 & $-0,354$ & 0,391 & $0,495^{\star}$ & $-0,165$ \\
\hline \multirow{2}{*}{$95 \%$} & PPP & 0,023 & 0,093 & $-0,252^{* *}$ & $-0,171^{*}$ & 0,246 ** & $0,178^{*}$ \\
\hline & PRE & $-0,123$ & 0,231 & $-0,181$ & $-0,002$ & 0,220 & 0,162 \\
\hline \multirow{2}{*}{$98 \%$} & PPP & 0,023 & 0,080 & $-0,256^{* *}$ & $-0,171^{*}$ & $0,258 * *$ & 0,116 \\
\hline & PRE & $-0,146$ & $0,246^{*}$ & $-0,241^{*}$ & $-0,049$ & $0,282 * *$ & $0,238^{*}$ \\
\hline 2003 & Anual & $-0,080$ & $-0,010$ & 0,037 & $-0,048$ & $-0,006$ & $0,214^{* *}$ \\
\hline \multirow{2}{*}{$90 \%$} & PPP & 0,042 & $-0,092$ & $-0,070$ & 0,155 & $0,221^{*}$ & $-0,135$ \\
\hline & PRE & $-0,047$ & 0,098 & $-0,285$ & $0,380^{*}$ & 0,290 & 0,044 \\
\hline \multirow{2}{*}{$95 \%$} & PPP & 0,041 & $-0,063$ & $-0,086$ & 0,062 & $0,214^{*}$ & $-0,077$ \\
\hline & PRE & $-0,167$ & 0,109 & $-0,062$ & 0,326 * & 0,052 & 0,143 \\
\hline \multirow{2}{*}{$98 \%$} & PPP & $-0,040$ & $-0,020$ & $-0,109$ & $-0,113$ & $0,180^{*}$ & $0,151^{*}$ \\
\hline & PRE & $-0,115$ & 0,018 & $-0,131$ & $-0,054$ & 0,166 & $0,212^{*}$ \\
\hline 2004 & Anual & $0,210^{* *}$ & $-0,019$ & $-0,158^{* *}$ & $-0,055$ & $0,137^{* *}$ & $0,302^{* *}$ \\
\hline \multirow{2}{*}{$90 \%$} & PPP & 0,151 & $0,264^{*}$ & $-0,039$ & $0,319 * *$ & 0,123 & 0,089 \\
\hline & PRE & 0,272 & 0,467 * & $-0,160$ & $0,617^{* *}$ & 0,201 & $-0,020$ \\
\hline \multirow{2}{*}{$95 \%$} & PPP & 0,226 ** & $0,170 *$ & $-0,108$ & $0,250 * *$ & 0,069 & $0,269 * *$ \\
\hline & PRE & $0,333^{* *}$ & $0,307 * *$ & $-0,315^{* *}$ & $0,299 *$ & $0,315^{* *}$ & 0,228 \\
\hline \multirow{2}{*}{$98 \%$} & PPP & $0,152^{*}$ & 0,057 & $-0,127$ & 0,080 & 0,082 & 0,222 ** \\
\hline & PRE & 0,115 & 0,175 & $-0,185$ & 0,135 & $0,195^{\star}$ & 0,064 \\
\hline 2005 & Anual & 0,052 & $-0,167^{\star \star}$ & $-0,092$ & $-0,067$ & $0,147^{\star \star}$ & $0,324^{\star *}$ \\
\hline $90 \%$ & PPP & $-0,24 * *$ & $0,217^{* *}$ & 0,097 & 0,127 & $-0,077$ & $0,188^{*}$ \\
\hline $90 \%$ & PRE & $-0,31$ ** & $0,297 * *$ & 0,152 & 0,131 & $-0,124$ & 0,193 \\
\hline $95 \%$ & PPP & $-0,143$ & 0,077 & $-0,075$ & 0,088 & 0,055 & $0,271 * *$ \\
\hline & PRE & $-0,166$ & 0,104 & $-0,057$ & 0,092 & 0,016 & $0,287^{* *}$ \\
\hline $98 \%$ & PPP & $-0,112$ & 0,039 & $-0,092$ & 0,056 & 0,088 & $0,238 * *$ \\
\hline $78 \%$ & PRE & $-0,174$ & 0,115 & $-0,118$ & 0,061 & 0,070 & $0,306 * *$ \\
\hline 2006 & Anual & 0,024 & $-0,228^{* \star}$ & $-0,012$ & $-0,019$ & 0,068 & $0,294^{\star \star}$ \\
\hline ( & PPP & $-0,085$ & $-0,142$ & $-0,352^{* *}$ & - & $0,324^{* *}$ & 0,136 \\
\hline $70 \%$ & PRE & $-0,141$ & 0,067 & $0,712^{* *}$ & 0,243 & 0,834 ** & 0,431 * \\
\hline $95 \%$ & PPP & $-0,079$ & 0,018 & $-0,189$ * & $0,189 *$ & $0,194^{\star}$ & 0,179 \\
\hline $75 \%$ & PRE & $-0,136$ & 0,273 & $-0,256$ & $0,385^{*}$ & 0,289 & $0,558 * *$ \\
\hline 980\% & PPP & $-0,037$ & $-0,132$ & $-0,151$ & 0,099 & $0,198 *$ & 0,135 \\
\hline $70 \%$ & PRE & $-0,150$ & 0,249 & $-0,324$ ** & $0,335 *$ & $0,364 *$ & $0,533^{* *}$ \\
\hline 2007 & Anual & $0,247^{* *}$ & $-0,205^{\star *}$ & $-0,311^{* *}$ & $-0,108^{*}$ & $0,379 * *$ & $0,269^{* *}$ \\
\hline $90 \%$ & PPP & 0,045 & 0,089 & $-0,244^{*}$ & $-0,265^{* *}$ & $0,326 * *$ & $-0,017$ \\
\hline & PRE & 0,072 & 0,104 & $-0,276^{* *}$ & $-0,281^{\text {** }}$ & 0,346 ** & $-0,101$ \\
\hline & PPP & $-0,022$ & $0,226 * *$ & $-0,251$ ** & $-0,191$ * & $0,289 * *$ & $-0,117$ \\
\hline & PRE & $-0,011$ & $0,253^{* *}$ & $-0,281^{* *}$ & $-0,172$ & $0,307^{* *}$ & $-0,220^{*}$ \\
\hline $98 \%$ & PPP & $-0,160$ * & $0,365^{* *}$ & $-0,142$ & $-0,077$ & 0,130 & 0,020 \\
\hline $78 \%$ & PRE & $-0,136$ & $0,351^{* *}$ & $-0,127$ & $-0,057$ & 0,116 & $-0,076$ \\
\hline Total & Anual & $-0,07$ ** & $-0,083^{* *}$ & $-0,026$ & $-0,034$ & $0,055^{\star *}$ & $0,252^{\star *}$ \\
\hline
\end{tabular}

Tabla 5.2.2.16. (Continuación). Coeficientes de correlación de Spearman entre Poaceae y las variables climatológicas. Vemed (velocidad media), FrecCalmas (frecuencia de calmas), V1Cuad, V2Cuad, V3Cuad, V4Cuad (vientos procedentes del I, II, III y IV cuadrante). Significación: $95 \%(*), 99 \%\left(^{* *}\right)$. (-) Ausencia de correlaciones. 


\subsubsection{Populus}

Los niveles del tipo polínico Populus alba en la atmósfera de Salamanca, se incrementaron durante el período analizado, ya que si en el año 2000 la concentración anual fue de 686, en el año 2007 alcanzó los 1087. Esto supuso que la variación interanual (Fig. 5.2.2.25.) llevó consigo un aumento del $58 \%$ en las concentraciones anuales de este tipo polínico. El análisis de regresión de tipo lineal confirma esta tendencia a través del valor que tomó su índice de determinación $\left(\mathrm{R}^{2}=0,41\right)$, aunque su valor fuese más bajo que el que presentaron otros tipos. La representación media de los pólenes de Populus a lo largo de los ocho años fue de $3,5 \%$, con un máximo de $6,1 \%$ en 2000 y un mínimo de 2\% en 2004.

La distribución de los granos de polen de este género a lo largo del años estudiados se localizó entre mediadosfinales de febrero y finales de marzo e incios de abril, por lo que la variación estacional (Tabla 5.2.2.17.) tuvo un PPP promedio de 31 a 50 días, en función del modelo empleado para su cálculo. No obstante, el empleo de diferentes metodologías para el cálculo del PPP marcó diferencias en las fechas de inicio y
Tipo polínico: Populus alba

Especie(s): Populus alba L., Populus $x$ canadiensis Moench, Populus nigra L. y Populus tremula L. (Salicaceae).

Distribución: Las numerosas especies del género Populus L. se encuentran fundamentalmente en regiones templadas de hemisferio Norte. En la Península Ibérica, se encuentran asociadas a cauces fluviales $y$ cultivadas para uso forestal y/o ornamental, incluso naturalizadas. En la provincia de Salamanca es común siguiendo cursos de ríos, formando parte de repoblaciones y del arbolado de parques y calles de núcleos urbanos, y en el caso de Populus tremula L. disperso de forma puntual en las sierras meridionales y en Arribes de Duero.

Época de floración: Situada entre febrero y abril, dependiendo de las especies.

Polinización: Anemófila.

Morfología polínica (Lámina III): Polen inaperturado, apolar y radiosimétrico, con una forma circular (esferoidal), y un tamaño pequeño-mediano $(\mathrm{P}=22-31 \mu \mathrm{m})$. La exina posee un de grosor fino-medio $(1,5-3 \mu \mathrm{m})$ y presenta una superficie de perforada a finamente reticulada, con lúmenes que no alcanzan $1 \mu \mathrm{m}$ de diámetro y muros más anchos e irregulares sobre los que aparecen espínulas muy pequeñas.

finalización para los diferentes años incluidos, dejando el 25 de enero del año 2001 como fecha más temprana de inicio y el 17 de abril de 2007 como fecha de finalización más tardía (ambas obtenidas a través de la metodología del 98\%). Estos datos, unidos al hecho de presentar la fecha de finalización del PPP más temprana (17 marzo, 90\%), confirmaron que en el año 2000 los niveles de polen del género Populus se adelantaron unas semanas con respecto al patrón registrado en el resto de anualidades estudiadas (Fig. 5.2.2.26. A.). 
En todo caso, las concentraciones polínicas de este tipo en la atmósfera (Fig 5.2.2.26.D.) aumentaron a partir de finales de febrero hasta alcanzar los valores más elevados a finales de marzo, como muestra la dinámica aportada por las concentraciones medias de los cincos días anteriores para el conjunto de anualidades. Ello conllevó que las mayores concentraciones diarias registradas oscilaran entre los 22 granos $/ \mathrm{m}^{3}$ y los 271 granos $/ \mathrm{m}^{3}$ (26 de marzo de 2002 y 2006, respectivamente). Asimismo, a principios de abril estos niveles disminuyeron hasta desparecer a final del mencionado mes (Fig. 5.2.2.26. A. B. C.).

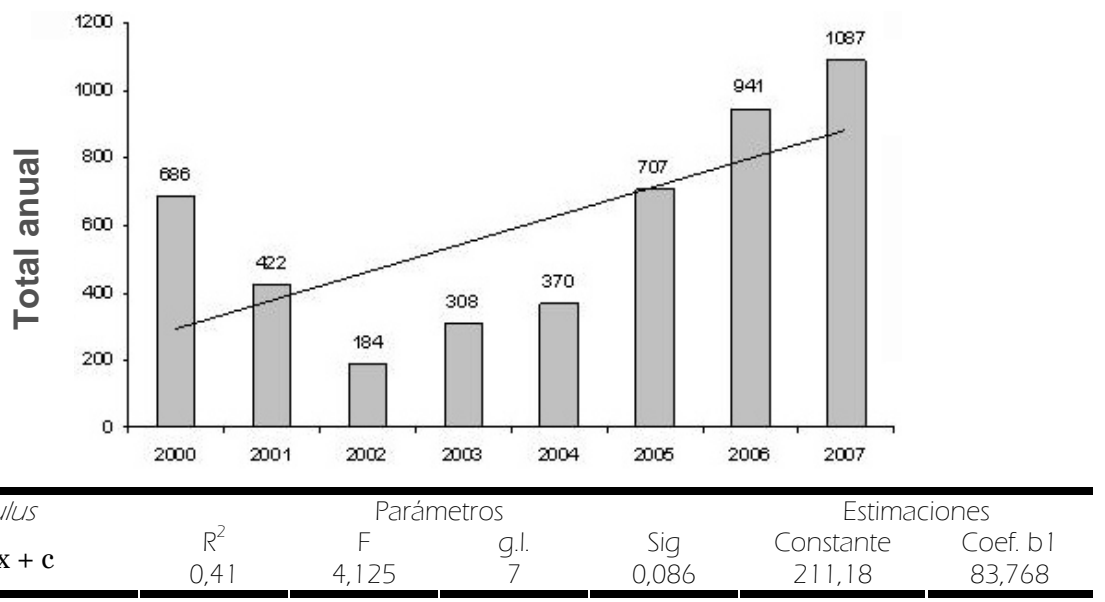

Fig. 5.2.2.25. Evolución anual del número total de pólenes de Populus y tendencias (análisis de regresión).

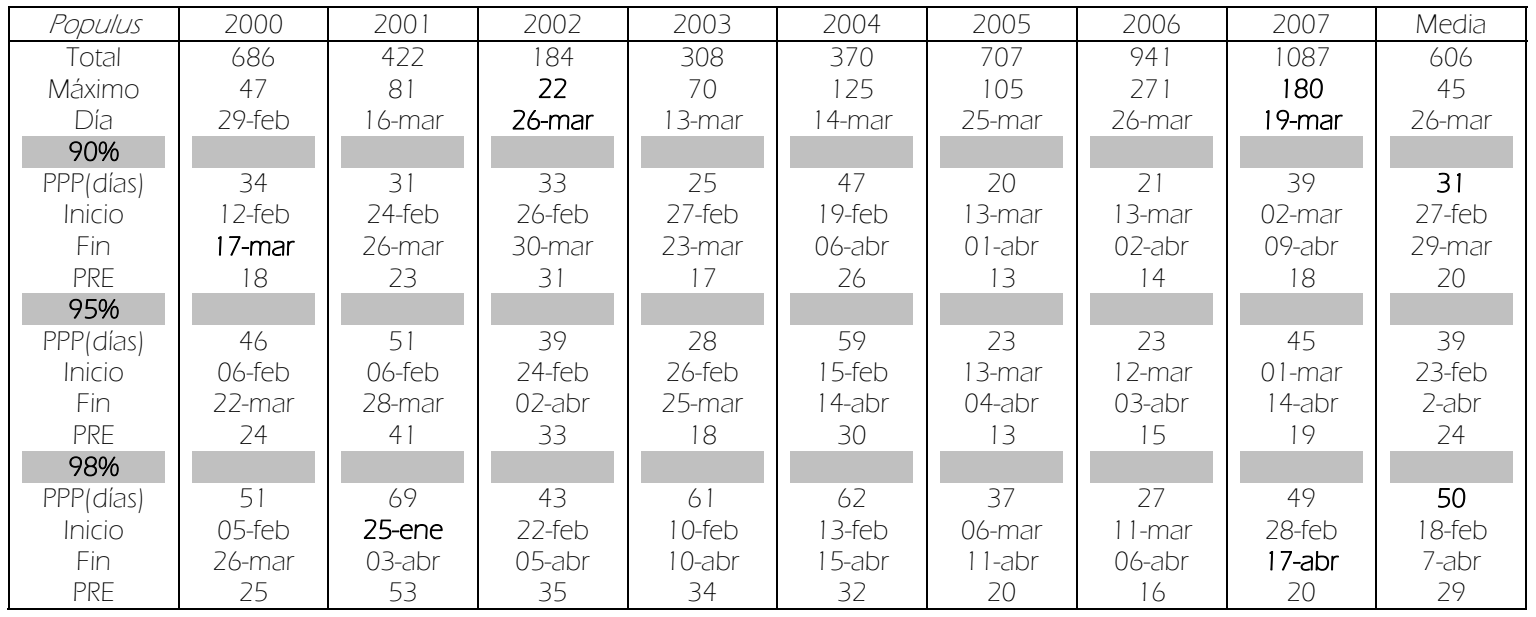

Tabla 5.2.2.17. Totales, concentraciones máximas diarias, períodos principales de polinización (PPP; fecha de inicio y fin) y días precedentes al valor máximo (PRE) durante los ocho años de estudio y el promedio de todos los parámetros para Populus.

La variación intradiaria (Fig. 5.2.2.27.) mostró un claro patrón a lo largo de un día promedio para los últimos tres años estudiados, por el que los niveles de polen aumentaron desde las 9 horas del día a las 14 horas, momento en el que comienzan a disminuir las concentraciones hasta las últimas horas del día. Así pues, las mayores concentraciones polínicas de Populus se concentraron en las horas centrales del día. 


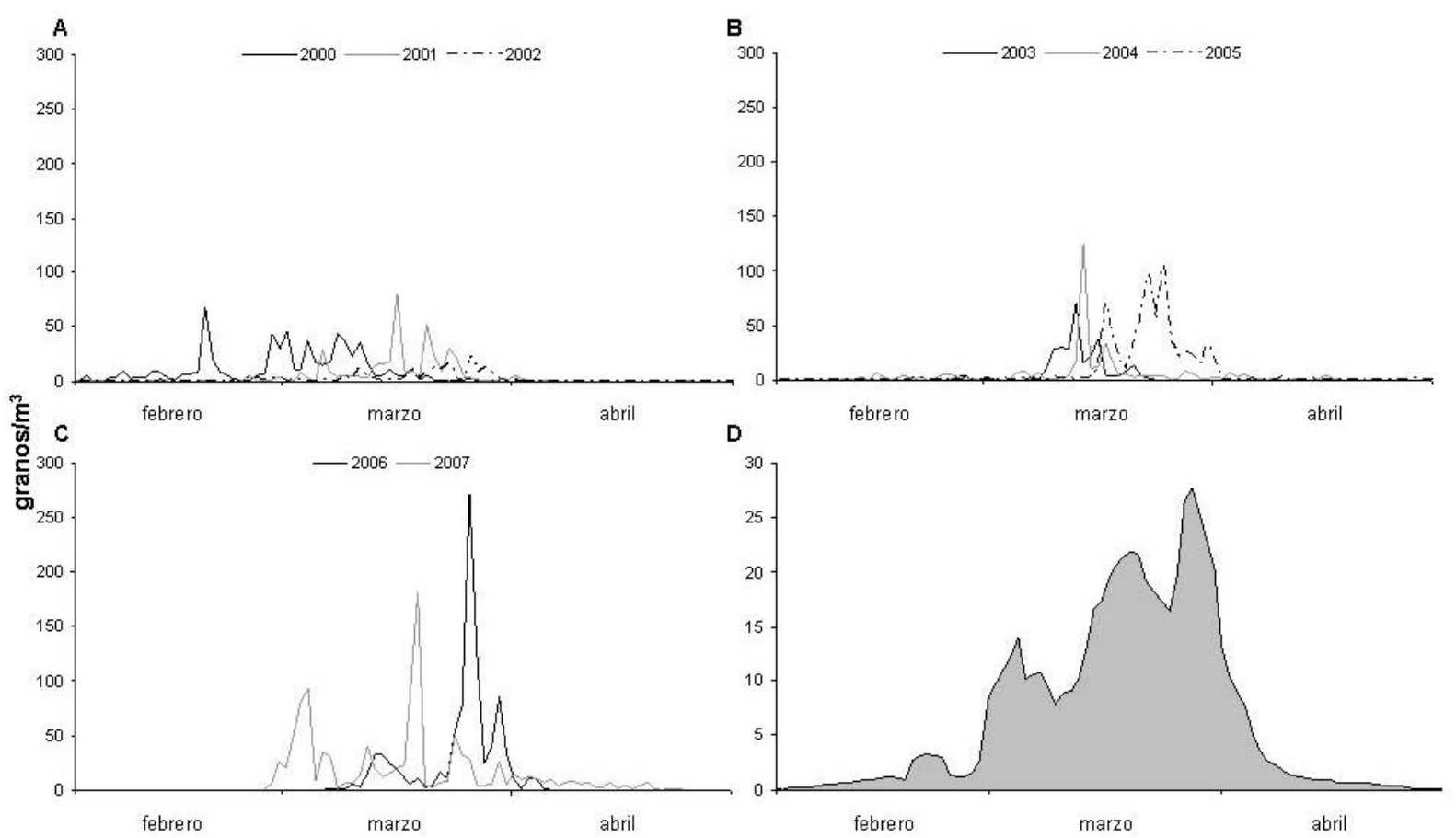

Fig. 5.2.2.26. Variación de las concentraciones medias diarias de Populus durante el período 2000-2002 (A), 2003-2005 (B) y 2006-2007 (C). Medias móviles de los cinco días anteriores para las concentraciones diarias promedio de los ocho años estudiados (D).

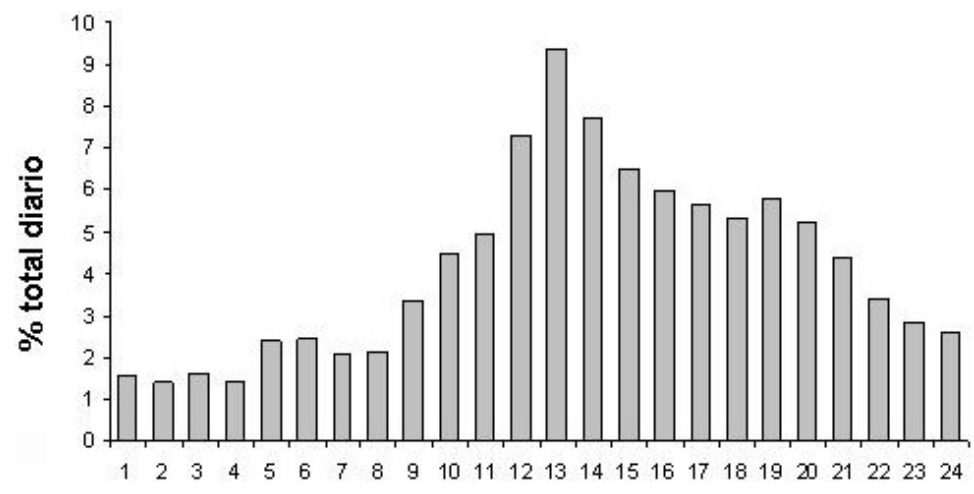

Fig. 5.2.2.27. Variación intradiaria del polen de Populus.

El análisis de correlación (Tabla 5.2.2.18.) indicó que las temperaturas medias, máximas y mínimas junto a la insolación y, en menor grado, la frecuencia de las calmas y los vientos procedentes del IV cuadrante, influyeron negativamente en los niveles polínicos durante los ocho años analizados, mientras que la precipitación tuvo un efecto positivo y el resto de parámetros mostraron valores bajos. En todo caso, los coeficientes de correlación de Spearman mostraron otro tipo de signo al analizar los años estudiados y métodos empleados para delimitar el PPP, como muestra las correlaciones significativas y de signo positivo con las temperaturas en el PPP y PRE de los años 2001-2004 y 2006, o negativas con la precipitación en el año 2000 o la humedad relativa en el PPP y PRE del año 2003 y en los años 2000 y 2001. Asimismo, debe destacarse la correlación positiva con los vientos procedentes del III cuadrante en los años 2001 y 2005 (con efecto negativo en el año 2000), 
de los vientos del II cuadrante en los años 2003 y 2007 y de los procedentes del I cuadrante en el año 2000 (ambos con efecto negativo en el año 2001), junto a la influencia positiva de la velocidad media del viento en los años 2001 y 2007.

\begin{tabular}{|c|c|c|c|c|c|c|c|}
\hline \multicolumn{2}{|c|}{ Populus } & Tmed & Tmax & Tmin & Insolación & Precipitación & Hrelativa \\
\hline 2000 & Anual & $-0,25$ ** & $-0,102$ & $-0,39 * *$ & $-0,025$ & $-0,170^{\star \star}$ & $-0,126^{*}$ \\
\hline \multirow{2}{*}{$90 \%$} & PPP & 0,253 & 0,262 & 0,156 & $-0,101$ & $-0,026$ & $-0,242$ \\
\hline & PRE & $-0,017$ & 0,033 & 0,029 & $-0,045$ & 0,141 & 0,065 \\
\hline \multirow{2}{*}{$95 \%$} & PPP & 0,257 & $0,408 * *$ & $-0,001$ & 0,145 & $-0,248$ & $-0,380 * *$ \\
\hline & PRE & $-0,006$ & 0,082 & 0,006 & 0,044 & 0,121 & $-0,050$ \\
\hline \multirow{2}{*}{$98 \%$} & PPP & 0,261 & $0,500 * *$ & $-0,117$ & 0,223 & $-0,305^{*}$ & $-0,405 * *$ \\
\hline & PRE & 0,021 & 0,065 & 0,029 & 0,061 & 0,128 & $-0,021$ \\
\hline 2001 & Anual & $-0,19 * \star$ & $-0,26 * \star$ & $-0,109$ * & $-0,3^{* *}$ & $0,232^{\star \star}$ & $0,284^{\star \star}$ \\
\hline \multirow{2}{*}{$90 \%$} & PPP & $0,460 * *$ & $0,559 * *$ & $0,373^{*}$ & 0,275 & $-0,151$ & $-0,226$ \\
\hline & PRE & 0,324 & $0,482^{\star}$ & 0,215 & 0,252 & $-0,011$ & $-0,073$ \\
\hline \multirow{2}{*}{$95 \%$} & PPP & $0,639 * *$ & $0,469 * *$ & $0,604 * *$ & $-0,027$ & 0,181 & $-0,122$ \\
\hline & PRE & 0,519 ** & $0,384^{\star}$ & $0,467^{* *}$ & $-0,080$ & 0,270 & $-0,086$ \\
\hline \multirow{2}{*}{$98 \%$} & PPP & $0,583^{* *}$ & $0,428 * *$ & $0,549 * *$ & 0,007 & 0,196 & $-0,159$ \\
\hline & PRE & $0,472^{* *}$ & 0,351 * & $0,399 * *$ & $-0,029$ & 0,240 & $-0,157$ \\
\hline 2002 & Anual & $-0,21$ ** & $-0,15^{\star \star}$ & $-0,28$ ** & $-0,070$ & 0,056 & $-0,049$ \\
\hline \multirow{2}{*}{$90 \%$} & PPP & $0,538^{* *}$ & $0,495^{\star *}$ & 0,293 & 0,196 & $-0,082$ & $-0,330$ \\
\hline & PRE & $0,544 * *$ & $0,468 *$ & 0,377 * & 0,070 & $-0,113$ & $-0,202$ \\
\hline \multirow{2}{*}{$95 \%$} & PPP & 0,359 * & $0,365^{\star}$ & 0,209 & 0,118 & $-0,075$ & $-0,243$ \\
\hline & PRE & $0,502 * *$ & $0,469 * *$ & 0,323 & 0,091 & $-0,125$ & $-0,211$ \\
\hline \multirow{2}{*}{$98 \%$} & PPP & $0,404^{* *}$ & $0,347^{* *}$ & 0,301 * & 0,005 & $-0,051$ & $-0,148$ \\
\hline & PRE & 0,487 & 0,391 * & $0,373^{*}$ & 0,048 & $-0,069$ & $-0,132$ \\
\hline 2003 & Anual & $-0,17^{* *}$ & $-0,14^{*}$ & $-0,22^{* *}$ & $-0,080$ & 0,026 & $-0,040$ \\
\hline \multirow{2}{*}{$90 \%$} & PPP & $0,520^{* *}$ & $0,741^{* *}$ & $-0,031$ & 0,342 & $-0,237$ & $-0,720$ ** \\
\hline & PRE & 0,506 & $0,577^{* *}$ & $-0,055$ & 0,231 & $-0,288$ & $-0,805^{* *}$ \\
\hline \multirow{2}{*}{$95 \%$} & PPP & $0,402 * *$ & $0,633 * *$ & $-0,109$ & $0,42 * *$ & $-0,215$ & $-0,752 * *$ \\
\hline & PRE & 0,420 & 0,485 & $-0,055$ & 0,207 & $-0,085$ & $-0,829 * *$ \\
\hline \multirow{2}{*}{$98 \%$} & PPP & 0,232 & $0,327 *$ & 0,046 & 0,150 & $-0,172$ & $-0,404 * *$ \\
\hline & PRE & $0,511 * *$ & $0,463^{* *}$ & 0,315 & 0,279 & $-0,226$ & $-0,563^{* *}$ \\
\hline 2004 & Anual & $-0,28 * *$ & $-0,24 * *$ & $-0,33$ ** & $-0,102$ & - & 0,002 \\
\hline \multirow{2}{*}{$90 \%$} & PPP & $0,484^{* *}$ & $0,510^{* *}$ & $0,336^{*}$ & 0,121 & $-0,039$ & $-0,006$ \\
\hline & PRE & $0,458 *$ & $0,443^{*}$ & 0,354 & $-0,069$ & 0,076 & 0,244 \\
\hline \multirow{2}{*}{$95 \%$} & PPP & $0,436 * *$ & $0,405^{* *}$ & $0,361^{* *}$ & $-0,042$ & 0,070 & 0,089 \\
\hline & PRE & $0,444^{*}$ & $0,398 *$ & 0,341 & $-0,069$ & 0,049 & 0,236 \\
\hline \multirow{2}{*}{$98 \%$} & PPP & $0,425^{* *}$ & 0,391 ** & $0,351 * *$ & $-0,042$ & 0,068 & 0,080 \\
\hline & PRE & $0,437 * *$ & $0,397 *$ & 0,334 & $-0,035$ & 0,034 & 0,194 \\
\hline 2005 & Anual & $-0,107^{*}$ & $-0,075$ & $-0,14^{* *}$ & $-0,068$ & 0,065 & $-0,019$ \\
\hline (90\% & PPP & 0,113 & $-0,087$ & 0,298 & $-0,032$ & 0,233 & $-0,030$ \\
\hline $90 \%$ & PRE & 0,099 & $-0,069$ & 0,371 & $-0,137$ & 0,248 & 0,011 \\
\hline $050 \%$ & PPP & 0,092 & 0,139 & $-0,065$ & 0,194 & $-0,117$ & $-0,257$ \\
\hline $95 \%$ & PRE & 0,099 & $-0,069$ & 0,371 & $-0,137$ & 0,248 & 0,011 \\
\hline $880 \%$ & PPP & $0,349 *$ & $0,382^{*}$ & 0,297 & $-0,218$ & 0,118 & $-0,011$ \\
\hline $98 \%$ & PRE & $0,712^{* *}$ & 0,561 * & $0,743^{* *}$ & $-0,47^{*}$ & 0,317 & 0,112 \\
\hline 2006 & Anual & $-0,15^{\star *}$ & $-0,124^{\star}$ & $-0,15^{* *}$ & - & 0,047 & $-0,012$ \\
\hline & PPP & $0,574^{* *}$ & $0,513^{*}$ & 0,115 & - & $-0,172$ & $-0,127$ \\
\hline $90 \%$ & PRE & $0,810^{* *}$ & $0,680 * *$ & 0,030 & - & $-0,597$ * & $-0,451$ \\
\hline 050 & PPP & 0,457 * & 0,405 & 0,108 & - & $-0,134$ & $-0,082$ \\
\hline $95 \%$ & PRE & $0,778 * *$ & $0,672^{* *}$ & 0,030 & - & $-0,584 *$ & $-0,462$ \\
\hline Q०० & PPP & 0,332 & 0,339 & $-0,151$ & - & $-0,211$ & $-0,185$ \\
\hline $98 \%$ & PRE & $0,725^{* *}$ & $0,545^{*}$ & $-0,051$ & - & $-0,423$ & $-0,393$ \\
\hline 2007 & Anual & $-0,20$ ** & $-0,17^{* *}$ & $-0,27$ ** & $-0,057$ & 0,082 & 0,025 \\
\hline סחקר & PPP & $0,494 * *$ & 0,371 * & 0,167 & 0,095 & $-0,089$ & 0,012 \\
\hline $90 \%$ & PRE & 0,467 & 0,191 & 0,335 & $-0,6 * *$ & 0,341 & 0,252 \\
\hline $050 \%$ & PPP & 0,212 & 0,124 & $-0,011$ & 0,115 & $-0,164$ & $-0,079$ \\
\hline $95 \%$ & PRE & 0,461 * & 0,167 & 0,364 & $-0,6$ ** & 0,351 & 0,268 \\
\hline $880 \%$ & PPP & $-0,33 * *$ & $-0,264$ * & $-0,40 * *$ & $-0,066$ & $-0,163$ & - \\
\hline $98 \%$ & PRE & $0,46 * *$ & 0,139 & 0,372 & $-0,6$ ** & 0,360 & 0,280 \\
\hline Total & Anual & $-0,20$ ** & $-0,16$ ** & $-0,24$ ** & $-0,1^{* *}$ & $0,039 *$ & $-0,010$ \\
\hline
\end{tabular}

Tabla 5.2.2.18. Coeficientes de correlación de Spearman entre Populus y las variables climatológicas. Tmed, Tmax, Tmin (temperatura media, máxima y mínima), Hrelativa (humedad relativa). Significación: 95\%(*), $99 \%(* *) .(-)$ Ausencia de correlaciones. 


\begin{tabular}{|c|c|c|c|c|c|c|c|}
\hline \multicolumn{2}{|c|}{ Populus } & Vemed & FrecCalm & VICuadr & V2Cuadr & V3Cuadr & V4Cuadr \\
\hline 2000 & Anual & $-0,111^{*}$ & $0,111^{*}$ & $0,159 * \star$ & 0,096 & $-0,112^{\star}$ & $-0,034$ \\
\hline \multirow{2}{*}{$90 \%$} & PPP & $-0,140$ & 0,203 & $-0,191$ & $-0,046$ & 0,140 & 0,075 \\
\hline & PRE & 0,012 & 0,201 & $-0,280$ & $-0,134$ & 0,148 & 0,095 \\
\hline \multirow{2}{*}{$95 \%$} & PPP & $-0,216$ & 0,280 & $-0,031$ & $-0,014$ & $-0,023$ & $-0,013$ \\
\hline & PRE & $-0,069$ & 0,251 & $-0,208$ & 0,012 & 0,011 & $-0,014$ \\
\hline \multirow{2}{*}{$98 \%$} & PPP & $-0,203$ & $0,326 *$ & 0,113 & 0,066 & $-0,118$ & $-0,099$ \\
\hline & PRE & $-0,006$ & 0,211 & $-0,234$ & $-0,038$ & 0,067 & 0,031 \\
\hline 2001 & Anual & $0,227^{\star *}$ & $-0,163^{\star \star}$ & $-0,324$ ** & $-0,164^{* *}$ & 0,330 ** & $-0,098$ \\
\hline \multirow{2}{*}{$90 \%$} & PPP & $0,524^{\star \star}$ & $-0,170$ & $-0,166$ & 0,103 & 0,240 & $-0,304$ \\
\hline & PRE & 0,266 & 0,021 & $-0,055$ & 0,288 & 0,001 & 0,026 \\
\hline \multirow{2}{*}{$95 \%$} & PPP & 0,508 ** & $-0,403^{* *}$ & $-0,524$ ** & $-0,340^{*}$ & $0,543^{* *}$ & $-0,027$ \\
\hline & PRE & 0,321 & $-0,248$ & $-0,421$ * & $-0,256$ & $0,363^{*}$ & 0,199 \\
\hline \multirow{2}{*}{$98 \%$} & PPP & $0,303^{*}$ & $-0,251$ * & $-0,380$ ** & $-0,224$ & $0,432 * \star$ & $-0,100$ \\
\hline & PRE & 0,151 & $-0,111$ & $-0,274$ & $-0,133$ & 0,252 & 0,079 \\
\hline 2002 & Anual & $-0,025$ & 0,071 & 0,052 & 0,101 & $-0,040$ & $-0,239$ ** \\
\hline \multirow{2}{*}{$90 \%$} & PPP & $-0,231$ & 0,178 & $-0,013$ & 0,169 & 0,026 & $-0,227$ \\
\hline & PRE & $-0,251$ & 0,216 & $-0,040$ & 0,094 & 0,091 & $-0,154$ \\
\hline \multirow{2}{*}{$95 \%$} & PPP & $-0,177$ & 0,098 & $-0,005$ & 0,129 & 0,030 & $-0,221$ \\
\hline & PRE & $-0,272$ & 0,248 & $-0,021$ & 0,095 & 0,071 & $-0,154$ \\
\hline \multirow{2}{*}{$98 \%$} & PPP & $-0,132$ & 0,113 & 0,055 & 0,125 & $-0,047$ & $-0,302^{*}$ \\
\hline & PRE & $-0,164$ & 0,190 & $-0,027$ & 0,015 & 0,075 & $-0,199$ \\
\hline 2003 & Anual & $-0,004$ & 0,019 & 0,008 & $0,158^{* \star}$ & 0,003 & $-0,086$ \\
\hline \multirow{2}{*}{$90 \%$} & PPP & $-0,311$ & $-0,027$ & 0,383 & $0,616^{* *}$ & $-0,290$ & $-0,104$ \\
\hline & PRE & $-0,349$ & 0,005 & 0,435 & $0,574^{*}$ & $-0,216$ & $-0,067$ \\
\hline \multirow{2}{*}{$95 \%$} & PPP & $-0,240$ & $-0,059$ & $0,403^{* *}$ & 0,436 * & $-0,257$ & $-0,059$ \\
\hline & PRE & $-0,293$ & $-0,034$ & 0,386 & $0,568^{*}$ & $-0,194$ & $-0,113$ \\
\hline \multirow{2}{*}{$98 \%$} & PPP & $-0,131$ & 0,067 & $-0,092$ & $0,307^{* *}$ & 0,116 & $-0,056$ \\
\hline & PRE & $-0,048$ & $-0,117$ & $-0,091$ & 0,291 & 0,187 & $-0,041$ \\
\hline 2004 & Anual & $-0,070$ & $-0,062$ & $0,123^{*}$ & $-0,091$ & $-0,085$ & $-0,051$ \\
\hline \multirow{2}{*}{$90 \%$} & PPP & $-0,093$ & $0,235^{\star *}$ & 0,154 & 0,118 & $-0,073$ & 0,056 \\
\hline & PRE & $-0,184$ & 0,039 & 0,266 & $-0,068$ & $-0,131$ & $-0,138$ \\
\hline \multirow{2}{*}{$95 \%$} & PPP & 0,043 & 0,290 & $-0,020$ & 0,032 & 0,083 & 0,158 \\
\hline & PRE & $-0,163$ & 0,016 & 0,277 & $-0,079$ & $-0,163$ & $-0,167$ \\
\hline \multirow{2}{*}{$98 \%$} & PPP & 0,071 & 0,191 & $-0,026$ & 0,010 & 0,100 & 0,172 \\
\hline & PRE & $-0,109$ & 0,013 & 0,256 & $-0,088$ & $-0,135$ & $-0,119$ \\
\hline 2005 & Anual & 0,094 & $-0,139$ ** & $-0,085$ & 0,101 & $0,154^{\star *}$ & $-0,085$ \\
\hline $90 \%$ & PPP & $0,521^{*}$ & $-0,213$ & $-0,177$ & $-0,052$ & 0,205 & $-0,367$ \\
\hline $40 \%$ & PRE & $0,636^{*}$ & $-0,244$ & $-0,286$ & $-0,016$ & 0,231 & $-0,356$ \\
\hline $95 \%$ & PPP & $0,522 *$ & $-0,066$ & $-0,154$ & $-0,118$ & 0,183 & $-0,494$ * \\
\hline & PRE & $0,636 *$ & $-0,244$ & $-0,286$ & $-0,016$ & 0,231 & $-0,356$ \\
\hline $98 \%$ & PPP & 0,292 & $-0,260$ & $-0,522 * *$ & $-0,066$ & 0,376 * & $-0,183$ \\
\hline $78 \%$ & PRE & 0,389 & $-0,356$ & $-0,691$ ** & 0,151 & 0,358 & $-0,063$ \\
\hline 2006 & Anual & 0,069 & 0,002 & 0,071 & 0,016 & $-0,053$ & $-0,020$ \\
\hline ( & PPP & $-0,006$ & - & - & - & - & - \\
\hline $90 \%$ & PRE & 0,176 & - & - & - & - & - \\
\hline $95 \%$ & PPP & 0,027 & - & - & - & - & - \\
\hline $95 \%$ & PRE & 0,171 & - & - & - & - & - \\
\hline 980\% & PPP & $-0,137$ & - & - & - & - & - \\
\hline $98 \%$ & PRE & 0,130 & - & - & - & - & - \\
\hline 2007 & Anual & $0,155^{* *}$ & $-0,258^{* *}$ & 0,017 & $0,140^{* *}$ & 0,052 & 0,085 \\
\hline $90 \%$ & PPP & 0,176 & $-0,232$ & $-0,265$ & 0,077 & 0,301 & $-0,194$ \\
\hline $90 \%$ & PRE & 0,430 & $-0,416$ & $-0,509 *$ & $-0,269$ & $0,494 *$ & 0,297 \\
\hline $95 \%$ & PPP & $0,296^{*}$ & $-0,357^{*}$ & $-0,266$ & 0,051 & 0,270 & $-0,258$ \\
\hline & PRE & 0,443 & $-0,415$ & $-0,473^{*}$ & $-0,273$ & $0,457^{\star}$ & 0,286 \\
\hline $98 \%$ & PPP & $0,392 * *$ & $-0,553^{* *}$ & $-0,152$ & $-0,136$ & 0,252 & $-0,158$ \\
\hline $98 \%$ & PRE & $0,465^{\star}$ & $-0,421$ & $-0,477^{*}$ & $-0,295$ & 0,461 * & 0,302 \\
\hline Total & Anual & 0,029 & $-0,049^{\star \star}$ & $-0,004$ & 0,028 & 0,033 & $-0,065^{\star *}$ \\
\hline
\end{tabular}

Tabla 5.2.2.18. (Continuación). Coeficientes de correlación de Spearman entre Populus y las variables climatológicas. Vemed (velocidad media), FrecCalmas (frecuencia de calmas), V1Cuad, V2Cuad, V3Cuad, V4Cuad (vientos procedentes del I, II, III y IV cuadrante). Significación: $95 \%(*), 99 \%\left(^{* *}\right)$. (-) Ausencia de correlaciones. 


\subsubsection{Quercus}

El tipo de polen que incluye al género Quercus L. incrementó sus niveles polínicos a través del período analizado, con una variación interanual (Fig. 5.2.2.28.) que pasó de un total de 1982 en el año 2000 a los 9357 del año 2007. Esta evolución en el número total de granos de polen (un $372 \%$ más en los ocho años) dio lugar a un índice de determinación $\left(\mathrm{R}^{2}=0,74\right)$, propio de la regresión lineal que indicó también una tendencia al incremento. Los porcentajes de representación sobre el total de pólenes contabilizados en cada anualidad estudiada variaron del 8,5\% de 2001 al $38,4 \%$ de 2005 , con un porcentaje medio del 23,5\%.

La distribución de estos granos de polen a lo largo del año se localizó entre finales de marzo e inicios de abril hasta finales de junio, por lo que la variación estacional (Tabla 5.2.2.19) tuvo un PPP promedio de 48 a 77 días, en función del modelo empleado para su cálculo. No obstante, el uso de estas metodologías para delimitar el PPP mostró diferencias en las fechas de inicio y finalización para los diferentes años incluidos, dejando el 19 de marzo del año 2000 (método 98\%) y el 30 de abril del año 2005 (método 90\%) como
Tipo de polen: Quercus spp.

Especie(s): Quercus faginea Lam., Quercus ilex subsp. ballota (Desf.) Samp., Quercus pyrenaica Willd., Quercus robur L. y Quercus suber L. (Fagaceae).

Distribución: Incluye a unas 600 especies presentes en el hemisferio Norte, que en la Península Ibérica dominan gran parte de las formaciones boscosas (encinares, robledales etc). En la provincia de Salamanca, abundan las dehesas y bosques de Quercus ilex subsp. ballota (Desf.) Samp. en el centro, y los robledales de Quercus pyrenaica Willd. al oeste y el sur. Esta formaciones se encuentran a veces mezcladas con pequeños bosquetes de alcornoques $(Q$. suber L.), al noroeste $y$ al sur, quejigos ( $Q$. faginea Lam.), al oeste e incluso de roble pedunculado (Q. robur L.), al sur.

Época de floración: De marzo a junio.

Polinización: Anemófila.

Morfología polínica (Lámina III): Polen trizonocolporado, isopolar y radiosimétrico, con una forma circular-angular en vista polar y subcircular-elíptica en vista ecuatorial (de prolato a suboblato), y un tamaño pequeñomediano $(P=20-30 \mu \mathrm{m})$. Las ectoaberturas tipo colpo son largas y estrechas, y las endoaberturas tipo poro son poco definidas, junto a una membrana abertural granulosa. La exina $(2 \mu \mathrm{m})$ posee una superficie granulado-verrucosa.

fechas más tempranas y tardías de inicio, respectivamente, mientras que el 1 de junio de 2006 (método 90\%) resultó ser la fecha de finalización más temprana y el 12 de julio de 2003 (método 98\%) como fecha de fin más tardía.

Los granos de polen de este género comenzaron a contabilizarse en la atmósfera de la ciudad de Salamanca (Fig. 5.2.2.29.D.) a partir de marzo y experimentaron un notable ascenso a finales de abril, manteniéndose en niveles altos hasta la segunda semana de junio, 
como indica el valor medio más elevado en los años analizados (252 granos $/ \mathrm{m}^{3}$ el 27 de mayo), gracias a la dinámica aportada por las concentraciones medias de los cincos días anteriores para el conjunto de anualidades. Asimismo, las mayores concentraciones diarias registradas en los ocho años estudiados, localizadas entre la segunda mitad de mayo e inicios de junio, variaron entre los 50 granos $/ \mathrm{m}^{3}$ (21 de mayo de 2001) y los 904 granos $/ \mathrm{m}^{3}$ (27 de mayo de 2005). Posteriormente, los niveles polínicos disminuyeron a mediados de junio y mostrando concentraciones anecdóticas en julio (Fig. 5.2.2.29. A. B. C.).

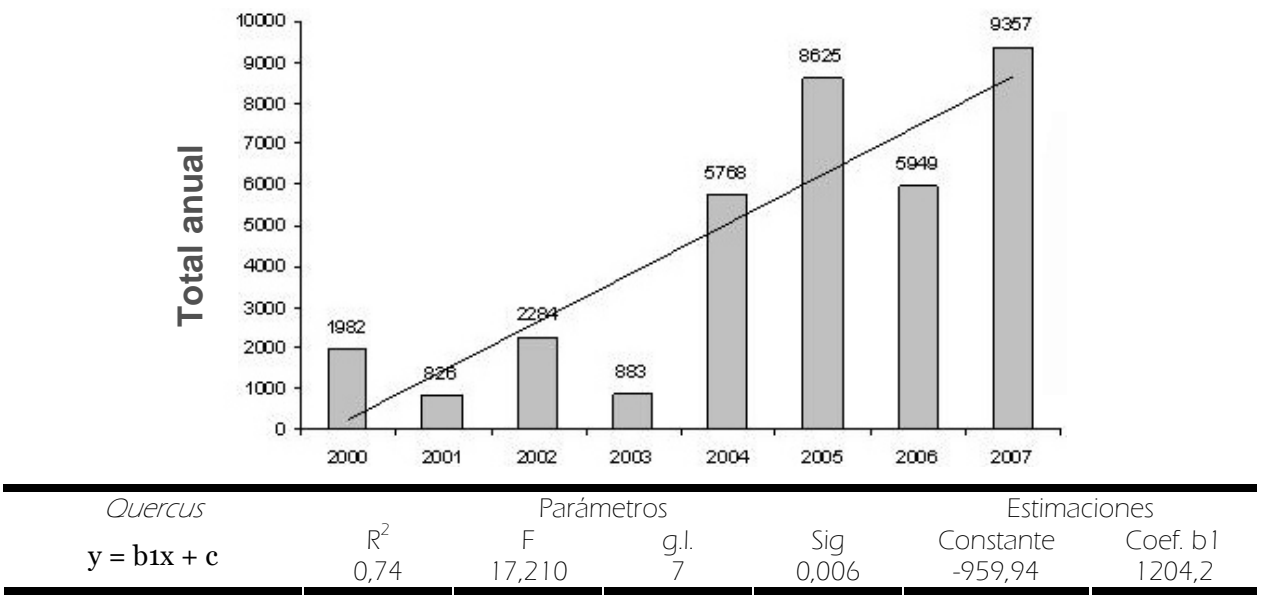

Fig. 5.2.2.28. Evolución anual del número total de pólenes de Quercus y tendencias (análisis de regresión).

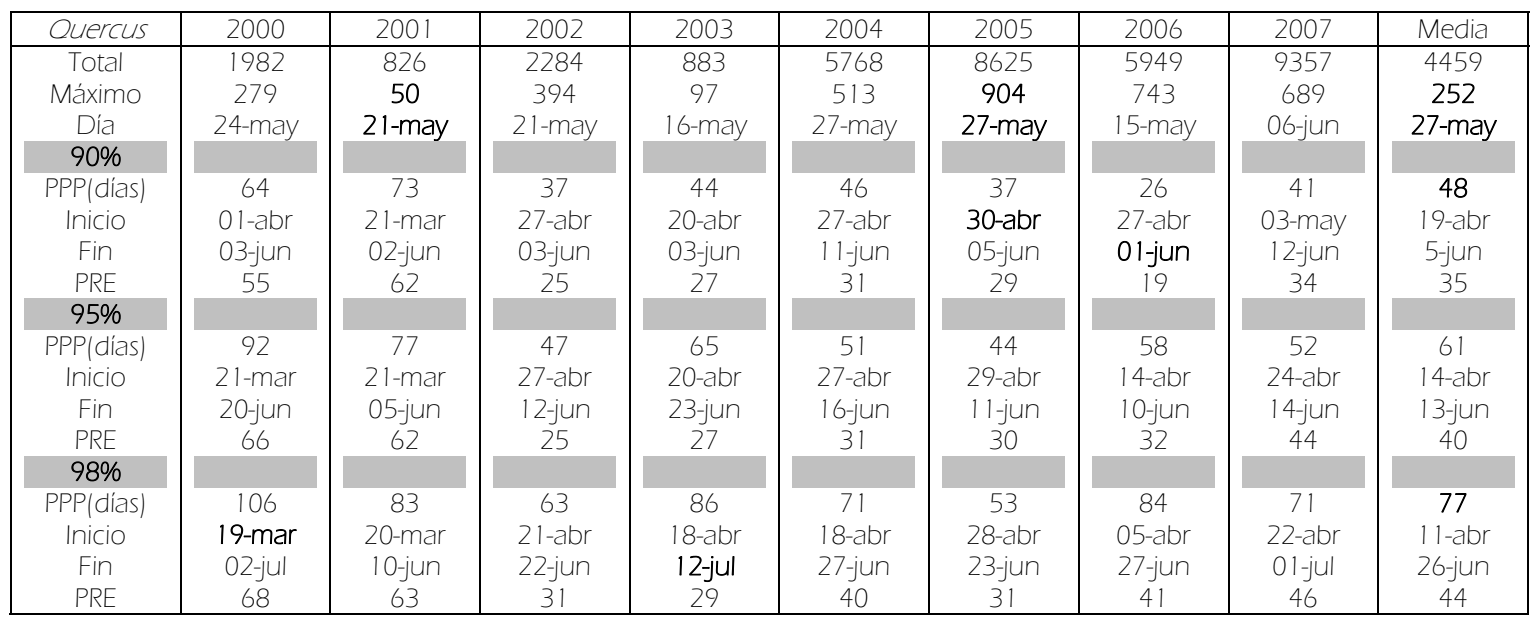

Tabla 5.2.2.19. Totales, concentraciones máximas diarias, períodos principales de polinización (PPP; fecha de inicio y fin) y días precedentes al valor máximo (PRE) durante los ocho años de estudio y el promedio de todos los parámetros para Quercus.

La variación intradiaria (Fig. 22. B.) mostró un claro patrón a lo largo de un día promedio para los últimos tres años estudiados, por el que los niveles de polen aumentaron desde las 5 horas del día hasta las 15 horas centrales del día, manteniéndose en porcentajes más elevados hasta las 20 horas. A partir de esta hora, las concentraciones disminuyeron 
hasta la hora indicada. Por tanto, las mayores concentraciones polínicas de Quercus se localizaron en las horas centrales del día.
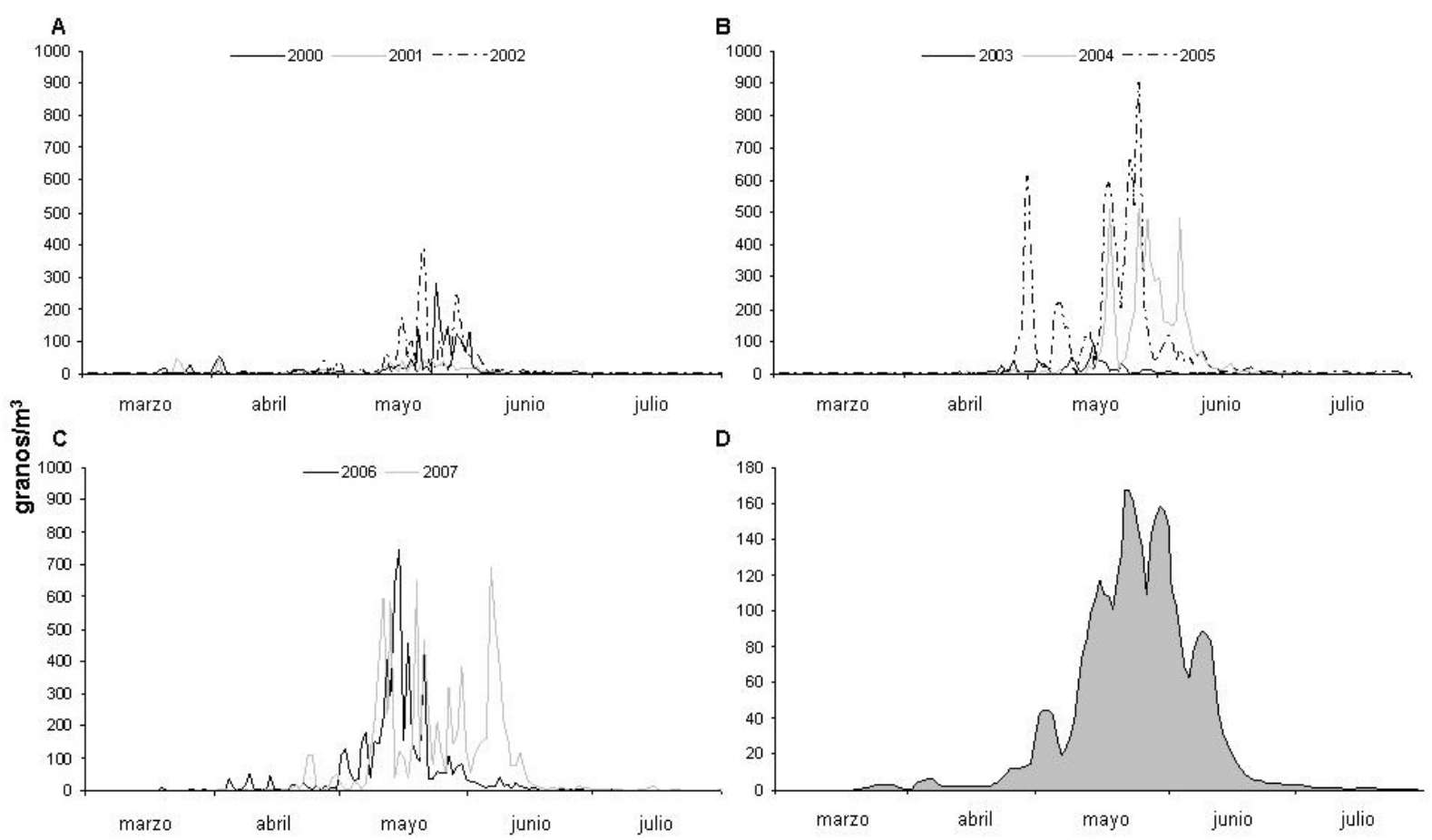

Fig. 5.2.2.29.. Variación de las concentraciones medias diarias de Quercus durante el período 2000-2002 (A), 2003-2005 (B) y 2006-2007 (C). Medias móviles de los cinco días anteriores para las concentraciones diarias promedio de los ocho años estudiados (D).

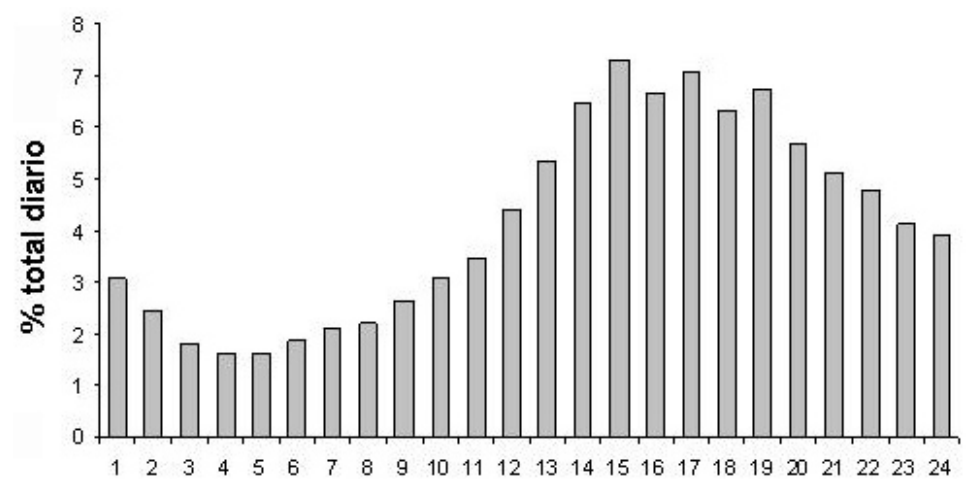

Fig. 5.2.2.30. Variación intradiaria del polen de Quercus.

Las temperaturas medias, máximas y mínimas junto a la insolación, los vientos procedentes del III y IV cuadrante y, en menor medida, de la velocidad media del viento tuvieron una influencia positiva en los niveles de Quercus durante los ocho años analizados, así como el efecto negativo que ejercieron las precipitaciones, la humedad relativa, la frecuencia de las calmas y los vientos del I y II cuadrante, tras el análisis de correlación (Tabla 5.2.2.20.). Este mismo tipo de correlaciones se observó al aplicar este tipo de estadísticos de correlación no paramétricos en el PPP y el PRE de las tres metodologías empleadas para los años analizados, pese a que se obtuvieron correlaciones de mayor significación en los PPP y PRE definidos para el 90\% de los totales anuales obtenidos en un 
buen número de los años, y sobretodo con la temperatura, las precipitaciones y la humedad relativa. Con otro tipo de metodologías y años, se localizaron correlaciones de signo contrario para la velocidad media y la frecuencia de calmas del viento, así como con los vientos del II cuadrante en el año 2004.

\begin{tabular}{|c|c|c|c|c|c|c|c|}
\hline \multicolumn{2}{|c|}{ Quercus } & Tmed & Tmax & Tmin & Insolación & Precipitación & Hrelativa \\
\hline 2000 & Anual & $0,234^{* *}$ & $0,209 * *$ & $0,242^{* *}$ & $0,16^{* \star}$ & 0,013 & $-0,286^{* *}$ \\
\hline \multirow{2}{*}{$90 \%$} & PPP & $0,546^{* *}$ & $0,531^{* *}$ & $0,467 * *$ & $0,38 * *$ & $-0,346^{* *}$ & $-0,380$ ** \\
\hline & PRE & $0,347^{*}$ & $0,344^{\star}$ & $0,275^{*}$ & $0,310^{*}$ & $-0,231$ & $-0,271$ * \\
\hline \multirow{2}{*}{$95 \%$} & PPP & 0,306 ** & $0,282^{* *}$ & $0,303^{* *}$ & 0,141 & $-0,211$ * & $-0,072$ \\
\hline & PRE & 0,338 ** & $0,342 * *$ & $0,277^{\star}$ & 0,297 * & $-0,232$ & $-0,194$ \\
\hline \multirow{2}{*}{$98 \%$} & PPP & 0,143 & 0,145 & 0,151 & 0,087 & $-0,165$ & 0,003 \\
\hline & PRE & $0,281^{*}$ & $0,339 * *$ & 0,215 & $0,32^{\star \star}$ & $-0,258^{*}$ & $-0,235$ \\
\hline 2001 & Anual & $0,175^{\star *}$ & $0,181^{* *}$ & $0,148^{* *}$ & $0,24^{\star \star}$ & $-0,039$ & $-0,283^{* *}$ \\
\hline \multirow{2}{*}{$90 \%$} & PPP & $0,543^{* *}$ & $0,477^{* *}$ & $0,537^{* *}$ & $0,275^{*}$ & 0,014 & $-0,319$ ** \\
\hline & PRE & $0,339 * *$ & 0,243 & 0,343 ** & 0,041 & 0,144 & $-0,041$ \\
\hline \multirow{2}{*}{$95 \%$} & PPP & 0,562 ** & 0,500 ** & $0,553^{* *}$ & 0,31 ** & $-0,005$ & $-0,350$ ** \\
\hline & PRE & $0,339 * *$ & 0,243 & 0,343 ** & 0,041 & 0,144 & $-0,041$ \\
\hline \multirow{2}{*}{$98 \%$} & PPP & $0,555^{* *}$ & $0,512^{* *}$ & 0,526 ** & $0,32 * *$ & $-0,040$ & $-0,364$ ** \\
\hline & PRE & $0,322^{*}$ & 0,247 & $0,314^{*}$ & 0,057 & 0,129 & $-0,053$ \\
\hline 2002 & Anual & $0,292^{* *}$ & $0,316^{* *}$ & $0,214^{* *}$ & 0,36 ** & $-0,096$ & $-0,473^{* *}$ \\
\hline \multirow{2}{*}{$90 \%$} & PPP & $0,593^{* *}$ & $0,580^{* \star}$ & $0,499 * *$ & 0,236 & $-0,299$ & $-0,425$ ** \\
\hline & PRE & $0,445^{*}$ & $0,453^{*}$ & 0,365 & 0,095 & $-0,318$ & $-0,397^{*}$ \\
\hline \multirow{2}{*}{$95 \%$} & PPP & $0,502^{* *}$ & 0,484 ** & $0,372^{*}$ & 0,152 & $-0,262$ & $-0,367 *$ \\
\hline & PRE & $0,445^{*}$ & $0,453^{*}$ & 0,365 & 0,095 & $-0,318$ & $-0,397$ * \\
\hline \multirow{2}{*}{$98 \%$} & PPP & 0,049 & 0,017 & 0,102 & $-0,077$ & $-0,097$ & 0,050 \\
\hline & PRE & 0,180 & 0,138 & 0,348 & $-0,095$ & $-0,183$ & $-0,061$ \\
\hline 2003 & Anual & $0,362^{\star *}$ & $0,335^{\star *}$ & $0,315^{\star \star}$ & $0,34^{\star \star}$ & $-0,102$ & $-0,447$ ** \\
\hline \multirow{2}{*}{$90 \%$} & PPP & $0,429 * *$ & $0,412^{\star \star}$ & 0,269 & $0,32^{* *}$ & $-0,354^{*}$ & $-0,398 * *$ \\
\hline & PRE & 0,626 ** & $0,629 * *$ & 0,260 & 0,440 * & $-0,367$ & $-0,563^{* *}$ \\
\hline \multirow{2}{*}{$95 \%$} & PPP & $-0,302^{*}$ & $-0,274^{*}$ & $-0,318^{*}$ & $-0,046$ & $-0,169$ & 0,144 \\
\hline & PRE & 0,626 ** & 0,629 ** & 0,260 & 0,440 * & $-0,367$ & $-0,563^{* *}$ \\
\hline \multirow{2}{*}{$98 \%$} & PPP & $-0,40 * *$ & $-0,36 * *$ & $-0,39 * *$ & $-0,183$ & $-0,064$ & $0,249 *$ \\
\hline & PRE & $0,634^{* *}$ & $0,664^{* *}$ & 0,182 & 0,51 ** & $-0,490 * *$ & $-0,626$ ** \\
\hline 2004 & Anual & $0,525^{* *}$ & $0,496^{* *}$ & $0,527^{* *}$ & $0,45^{*}$ & $-0,020$ & $-0,439$ ** \\
\hline \multirow{2}{*}{$90 \%$} & PPP & $0,752^{* *}$ & $0,724 * \star$ & $0,737^{* *}$ & $0,40^{\star \star}$ & $-0,274$ & $-0,368^{*}$ \\
\hline & PRE & $0,673^{* *}$ & 0,696 ** & $0,602 * *$ & 0,291 & $-0,079$ & $-0,251$ \\
\hline \multirow{2}{*}{$95 \%$} & PPP & $0,710^{* *}$ & 0,670 ** & $0,725 * *$ & $0,324^{*}$ & $-0,246$ & $-0,317^{*}$ \\
\hline & PRE & $0,673^{* *}$ & 0,696 ** & $0,602 * *$ & 0,291 & $-0,079$ & $-0,251$ \\
\hline \multirow{2}{*}{$98 \%$} & PPP & $0,603^{* *}$ & 0,556 ** & 0,616 ** & $0,278^{*}$ & $-0,067$ & $-0,180$ \\
\hline & PRE & $0,565^{* *}$ & $0,481^{* *}$ & 0,606 ** & 0,185 & 0,117 & $-0,033$ \\
\hline 2005 & Anual & $0,531^{* *}$ & $0,508^{* *}$ & $0,490^{* *}$ & $0,44^{\star *}$ & $-0,093$ & $-0,492^{* *}$ \\
\hline $90 \%$ & PPP & $0,504^{* *}$ & $0,452^{* *}$ & 0,263 & 0,311 & $-0,328^{*}$ & $-0,551$ ** \\
\hline $90 \%$ & PRE & $0,771^{* *}$ & 0,739 ** & $0,425^{*}$ & $0,463^{*}$ & $-0,498 * *$ & $-0,747$ ** \\
\hline $95 \%$ & PPP & 0,271 & 0,202 & 0,150 & 0,110 & $-0,290$ & $-0,290$ \\
\hline $95 \%$ & PRE & $0,735^{* *}$ & $0,698 * *$ & $0,416^{*}$ & $0,447^{*}$ & $-0,488 * *$ & $-0,715^{* *}$ \\
\hline $98 \%$ & PPP & $-0,136$ & $-0,151$ & $-0,201$ & 0,018 & $-0,227$ & $-0,153$ \\
\hline $98 \%$ & PRE & 0,728 ** & $0,667^{* *}$ & 0,420 * & $0,432^{*}$ & $-0,478^{* *}$ & $-0,700$ ** \\
\hline 2006 & Anual & $0,260^{* *}$ & $0,247^{* *}$ & $0,214^{* *}$ & $-0,035$ & 0,010 & $-0,444^{* *}$ \\
\hline $90 \%$ & PPP & $0,542^{* *}$ & $0,430^{\star \star *}$ & $0,435^{* *}$ & - & $-0,066$ & $-0,108$ \\
\hline $70 \%$ & PRE & 0,726 ** & $0,606^{* *}$ & $0,541^{*}$ & - & $-0,080$ & $-0,329$ \\
\hline $95 \%$ & PPP & $0,414^{* *}$ & $0,311^{*}$ & $0,342^{* *}$ & - & $-0,223$ & $-0,244$ \\
\hline $75 \%$ & PRE & $0,652^{* *}$ & $0,569 * *$ & $0,433^{*}$ & - & $-0,221$ & $-0,444^{*}$ \\
\hline $98 \%$ & PPP & 0,122 & 0,099 & $-0,038$ & - & $-0,228^{*}$ & $-0,387 * *$ \\
\hline $78 \%$ & PRE & $0,712^{* *}$ & $0,650^{* *}$ & $0,388 *$ & - & $-0,238$ & $-0,390^{*}$ \\
\hline 2007 & Anual & $0,461^{* *}$ & $0,411^{* *}$ & $0,471^{* *}$ & $0,30^{* *}$ & 0,057 & $-0,346^{* *}$ \\
\hline $90 \%$ & PPP & $0,383^{*}$ & $0,368^{*}$ & $0,406^{* *}$ & $-0,099$ & 0,071 & $-0,172$ \\
\hline $70 \%$ & PRE & 0,387 * & $0,359 *$ & $0,419 *$ & $-0,035$ & 0,019 & $-0,198$ \\
\hline $95 \%$ & PPP & $0,572^{* *}$ & $0,545^{\star *}$ & 0,428 ** & 0,258 & $-0,252$ & $-0,403 * *$ \\
\hline $75 \%$ & PRE & 0,594 ** & $0,543^{* *}$ & $0,404^{* *}$ & 0,296 & $-0,291$ & $-0,414$ ** \\
\hline 98 & PPP & 0,161 & 0,172 & 0,195 & $-0,005$ & $-0,075$ & $-0,153$ \\
\hline $78 \%$ & PRE & $0,560^{* *}$ & $0,500^{* *}$ & $0,415^{* *}$ & 0,275 & $-0,277$ & $-0,381$ ** \\
\hline Total & Anual & $0,361^{* *}$ & $0,344^{* *}$ & $0,328^{* *}$ & $0,33^{* *}$ & $-0,036^{*}$ & $-0,383^{*}$ \\
\hline
\end{tabular}

Tabla 5.2.2.20. Coeficientes de correlación de Spearman entre Quercus y las variables climatológicas. Tmed, Tmax, Tmin (temperatura media, máxima y mínima), Hrelativa (humedad relativa). Significación: 95\%(*), $99 \%(* *) .(-)$ Ausencia de correlaciones. 


\begin{tabular}{|c|c|c|c|c|c|c|c|}
\hline \multicolumn{2}{|c|}{ Quercus } & Vemed & FrecCalm & VICuadr & V2Cuadr & V3Cuadr & V4Cuadr \\
\hline 2000 & Anual & $0,161^{* *}$ & $-0,259 * *$ & 0,001 & $-0,013$ & 0,023 & 0,054 \\
\hline \multirow{2}{*}{$90 \%$} & PPP & $-0,111$ & 0,062 & $-0,021$ & $-0,007$ & $-0,136$ & 0,221 \\
\hline & PRE & $-0,082$ & $-0,003$ & 0,098 & 0,088 & $-0,138$ & 0,014 \\
\hline \multirow{2}{*}{$95 \%$} & PPP & $-0,089$ & 0,059 & $-0,125$ & $-0,009$ & $-0,003$ & 0,195 \\
\hline & PRE & $-0,071$ & $-0,001$ & 0,081 & 0,059 & $-0,127$ & $-0,011$ \\
\hline \multirow{2}{*}{$98 \%$} & PPP & $-0,048$ & 0,016 & $-0,076$ & $-0,001$ & $-0,022$ & 0,099 \\
\hline & PRE & $-0,072$ & $-0,003$ & 0,130 & 0,065 & $-0,161$ & $-0,037$ \\
\hline 2001 & Anual & $0,164^{* *}$ & $-0,150^{* *}$ & $-0,107^{*}$ & $-0,176^{* *}$ & $0,139^{* *}$ & $0,235^{* *}$ \\
\hline \multirow{2}{*}{$90 \%$} & PPP & $-0,079$ & 0,113 & $-0,025$ & 0,121 & 0,085 & 0,007 \\
\hline & PRE & 0,157 & $-0,033$ & $-0,045$ & 0,025 & 0,203 & $-0,153$ \\
\hline \multirow{2}{*}{$95 \%$} & PPP & $-0,083$ & 0,123 & $-0,035$ & 0,121 & 0,096 & 0,027 \\
\hline & PRE & 0,157 & $-0,033$ & $-0,045$ & 0,025 & 0,203 & $-0,153$ \\
\hline \multirow{2}{*}{$98 \%$} & PPP & $-0,112$ & 0,143 & $-0,026$ & 0,137 & 0,070 & 0,052 \\
\hline & PRE & 0,134 & $-0,018$ & $-0,026$ & 0,038 & 0,175 & $-0,131$ \\
\hline 2002 & Anual & 0,021 & 0,090 & $-0,107^{\star}$ & $-0,186^{* *}$ & $0,150^{* \star}$ & 0,094 \\
\hline \multirow{2}{*}{$90 \%$} & PPP & $-0,059$ & $-0,047$ & $-0,230$ & 0,122 & 0,282 & $-0,036$ \\
\hline & PRE & 0,110 & $-0,063$ & $-0,383$ & 0,057 & $0,504^{*}$ & $-0,015$ \\
\hline \multirow{2}{*}{$95 \%$} & PPP & $-0,030$ & $-0,030$ & $-0,228$ & 0,094 & 0,281 & $-0,122$ \\
\hline & PRE & 0,110 & $-0,063$ & $-0,383$ & 0,057 & $0,504^{*}$ & $-0,015$ \\
\hline \multirow{2}{*}{ 98\% } & PPP & 0,194 & $-0,242$ & $-0,367^{* *}$ & $-0,136$ & $0,403 * *$ & 0,048 \\
\hline & PRE & 0,280 & $-0,167$ & $-0,435^{\star}$ & $-0,161$ & $0,551 * *$ & 0,052 \\
\hline 2003 & Anual & $0,138^{* *}$ & $-0,149 * *$ & $-0,101$ & $-0,120^{*}$ & $0,131^{*}$ & 0,100 \\
\hline \multirow{2}{*}{$90 \%$} & PPP & $-0,319 *$ & 0,235 & $-0,174$ & 0,028 & 0,099 & $0,556 * *$ \\
\hline & PRE & $-0,53^{* *}$ & 0,158 & $-0,001$ & 0,075 & $-0,093$ & $0,529 * *$ \\
\hline \multirow{2}{*}{$95 \%$} & PPP & $-0,033$ & 0,170 & $-0,291$ * & $-0,076$ & 0,165 & $0,364^{* *}$ \\
\hline & PRE & $-0,53 * *$ & 0,158 & $-0,001$ & 0,075 & $-0,093$ & $0,529 * *$ \\
\hline \multirow{2}{*}{$98 \%$} & PPP & 0,115 & $-0,014$ & $-0,215^{*}$ & 0,022 & 0,099 & 0,064 \\
\hline & PRE & $-0,53 * *$ & 0,144 & 0,018 & 0,152 & $-0,135$ & $0,373^{*}$ \\
\hline 2004 & Anual & $0,154^{* *}$ & $-0,151^{\star *}$ & $-0,101$ & $-0,047$ & 0,040 & $0,210^{\star *}$ \\
\hline \multirow{2}{*}{$90 \%$} & PPP & $0,344^{\star}$ & $0,332^{*}$ & $-0,222$ & $0,336^{*}$ & $0,349 *$ & 0,270 \\
\hline & PRE & 0,433 * & $0,502 * *$ & $-0,200$ & $0,512^{* *}$ & 0,327 & 0,186 \\
\hline \multirow{2}{*}{$95 \%$} & PPP & $0,338 *$ & $0,364 * *$ & $-0,234$ & $0,376 * *$ & $0,339 *$ & 0,263 \\
\hline & PRE & $0,433^{*}$ & $0,502 * *$ & $-0,200$ & $0,512 * *$ & 0,327 & 0,186 \\
\hline \multirow{2}{*}{$98 \%$} & PPP & 0,156 & $0,241^{*}$ & $-0,047$ & $0,363^{* *}$ & 0,104 & 0,092 \\
\hline & PRE & $0,327^{*}$ & 0,275 & $-0,181$ & $0,443^{*}$ & 0,211 & 0,121 \\
\hline 2005 & Anual & $0,111^{*}$ & $-0,201 * *$ & $-0,105^{\star}$ & $-0,082$ & $0,166 * *$ & $0,243^{* *}$ \\
\hline ०००\% & PPP & $-0,089$ & 0,262 & $-0,324$ & 0,295 & 0,317 & 0,102 \\
\hline $90 \%$ & PRE & $-0,138$ & 0,170 & $-0,179$ & 0,319 & 0,160 & $-0,024$ \\
\hline $95 \%$ & PPP & $-0,084$ & 0,309 * & $-0,421^{\star *}$ & 0,235 & 0,396 ** & 0,159 \\
\hline $95 \%$ & PRE & $-0,131$ & 0,147 & $-0,182$ & 0,289 & 0,169 & $-0,002$ \\
\hline $980 \%$ & PPP & $-0,008$ & $-0,184$ & $-0,260$ & 0,055 & 0,260 & 0,043 \\
\hline $78 \%$ & PRE & $-0,110$ & 0,138 & $-0,192$ & 0,265 & 0,171 & $-0,015$ \\
\hline 2006 & Anual & $-0,021$ & $-0,231^{* *}$ & $-0,065$ & $-0,056$ & 0,094 & $0,150^{\star *}$ \\
\hline ๑n\% & PPP & $-0,165$ & 0,277 & $-0,532^{* *}$ & 0,391 * & $0,616^{* *}$ & 0,162 \\
\hline $90 \%$ & PRE & $-0,022$ & 0,248 & $-0,617^{* *}$ & 0,401 & 0,736 ** & 0,246 \\
\hline $95 \%$ & PPP & $-0,154$ & 0,019 & $-0,584 * *$ & 0,163 & $0,485^{* *}$ & $0,382^{* \star}$ \\
\hline $75 \%$ & PRE & $-0,194$ & 0,015 & $-0,782^{* *}$ & 0,243 & $0,818^{* *}$ & 0,496 * \\
\hline ๑8०\% & PPP & $-0,264 *$ & $-0,128$ & $-0,275^{\star}$ & 0,121 & $0,266^{*}$ & 0,014 \\
\hline & PRE & $-0,168$ & 0,015 & $-0,782^{* *}$ & 0,243 & $0,818^{* *}$ & 0,496 * \\
\hline 2007 & Anual & $0,147^{* *}$ & $-0,044$ & $-0,191^{\star *}$ & 0,004 & $0,205^{*}$ & $0,111^{\star}$ \\
\hline & PPP & 0,194 & $-0,218$ & $-0,258$ & 0,154 & 0,282 & $-0,164$ \\
\hline $90 \%$ & PRE & 0,312 & $-0,273$ & $-0,302$ & 0,047 & 0,341 & $-0,224$ \\
\hline & PPP & 0,135 & $-0,116$ & $-0,071$ & 0,043 & 0,153 & $-0,321^{*}$ \\
\hline & PRE & 0,235 & $-0,176$ & $-0,105$ & $-0,075$ & 0,188 & $-0,382^{*}$ \\
\hline & PPP & 0,029 & $-0,076$ & 0,128 & 0,144 & 0,015 & $-0,330$ ** \\
\hline $48 \%$ & PRE & 0,239 & $-0,192$ & $-0,103$ & $-0,112$ & 0,205 & $-0,342^{*}$ \\
\hline Total & Anual & 0,039 * & $-0,114^{* *}$ & $-0,078 * *$ & $-0,074$ ** & $0,102 * *$ & $0,152^{\star *}$ \\
\hline
\end{tabular}

Tabla 5.2.2.20. (Continuación). Coeficientes de correlación de Spearman entre Quercus y las variables climatológicas. Vemed (velocidad media), FrecCalmas (frecuencia de calmas), V1Cuad, V2Cuad, V3Cuad,

V4Cuad (vientos procedentes del I, II, III y IV cuadrante). Significación: $95 \%\left(^{*}\right), 99 \%(* *)$. (-) Ausencia de correlaciones. 


\subsubsection{Rumex}

La variación interanual (Fig. 5.2.2.31.) de este tipo polínico en la atmósfera registró un incremento en sus niveles anuales durante el período 20002007. Este aumento se vio reflejado en el total anual, pues en el año 2000 se contabilizaron 474 pólenes y en el año 2007, 1011 (un 113\% más), si bien en el año 2006 se registró un mayor valor anual (1036 pólenes). De igual forma, el índice de determinación $\left(\mathrm{R}^{2}=0,69\right)$, descriptivo de la regresión lineal, indicó también una tendencia al incremento de las concentraciones de polen de Rumex. Por otro lado, el porcentaje de representación sobre el total de pólenes contabilizados en cada anualidad estudiada osciló entre el $2,2 \%$ de 2002 al 5,2\% de 2003, siendo 3,6\% el porcentaje medio.

La variación estacional, previo análisis a partir del PPP y los tres métodos utilizados (Tabla 5.2.2.21.) estuvo circunscrita al abanico temporal que comprenden los meses de marzo y agosto, fundamentalmente entre abril y junio. A través de cualquier metodología empleada, la duración media fue muy variable y se situó entre los 62 y los 110 días. De todos modos, el uso de estos métodos para
Tipo polínico: Rumex conglomeratus.

Especie(s): Rumex acetosa L., Rumex bucephalophorus L., Rumex crispus L. y Rumex conglomeratus Murray., entre otras (Poligonaceae).

Distribución: Preferentemente en zonas templadas del hemisferio Norte, desarrollándose en prados antropizados (ricos en nitrógeno), pequeños valles o vegas $\mathrm{y}$ a orillas de ríos riachuelos. En la Península Ibérica, y consiguientemente en la provincia de Salamanca, también abundan en los entornos urbanos, tanto en cunetas como terreno abandonados y/o baldíos e incluso en céspedes.

Época de floración: Primavera y verano, fundamentalmente entre abril y junio.

Polinización: Anemófila.

Morfología polínica (Lámina III): Polen trizonocolporado (a veces tetrazonocolporado), isopolar y radiosimétrico, con una forma circular-tri(tetra)lobulada en vista polar $y$ subcircular en vista ecuatorial (de esferoidal a subprolato), y un tamaño pequeño-mediano $(P=16-29 \mu \mathrm{m})$. Las ectoaberturas tipo colpo son terminales y muy estrechas, y las endoaberturas tipo poro de diámetro igual a $1 \mu \mathrm{m}$. La exina (2 $\mu \mathrm{m})$ posee una superficie escábrida. El citoplasma posee vesículas distribuidas de forma densa a través de toda la superficie que al microscopio óptico aparecen refringentes.

delimitar el PPP marcó diferencias en las fechas de inicio y finalización para los diferentes años incluidos, siendo los días 12 de marzo de 2002 y 2003 (método 98\%) y 14 de mayo del año 2000 (método 90\%) las fechas más tempranas y tardías de inicio, y el 10 de junio de 2005 (método 90\%) como fecha de finalización más temprana y el 8 de agosto de 2003 (método 98\%) como fecha de fin más tardía. 
La evolución de los niveles de polen a través de las concentraciones promedio para los cinco días anteriores durante el período 2000-2007 indicó un aumento desde la segunda mitad de abril hasta la primera semana de junio (Fig. 5.2.2.32.D.), presentando una concentración máxima de 19 granos/m³ $\mathrm{m}^{3}$ los días 26 y 27 de mayo como media de los ocho años estudiados (Tabla 5.2.2.21.). Las mayores concentraciones diarias (Tabla 5.2.2.21.; Fig. 5.2.2.32. A. B. C.) oscilaron entre 12 granos $/ \mathrm{m}^{3}$ (18 mayo de 2002) y 75 granos $/ \mathrm{m}^{3}$ (15 mayo de 2006). Después, las concentraciones de polen fueron disminuyendo durante el mes de julio, con registros puntuales en el mes de agosto.

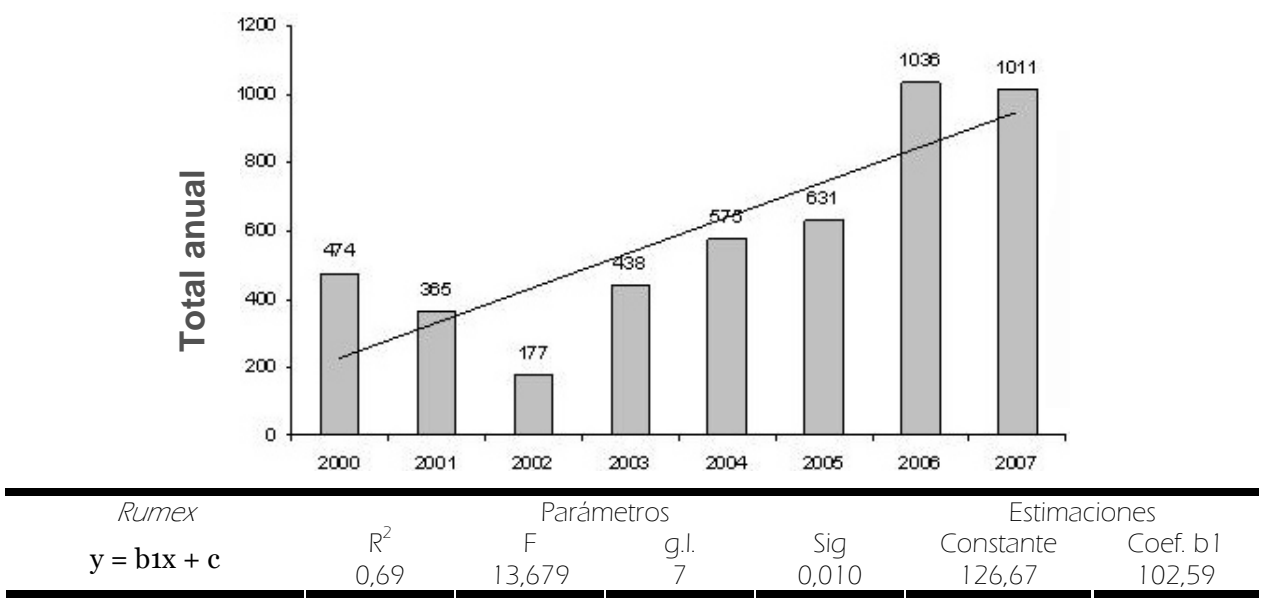

Fig. 5.2.2.31. Evolución anual del número total de pólenes de Rumex y tendencias (análisis de regresión).

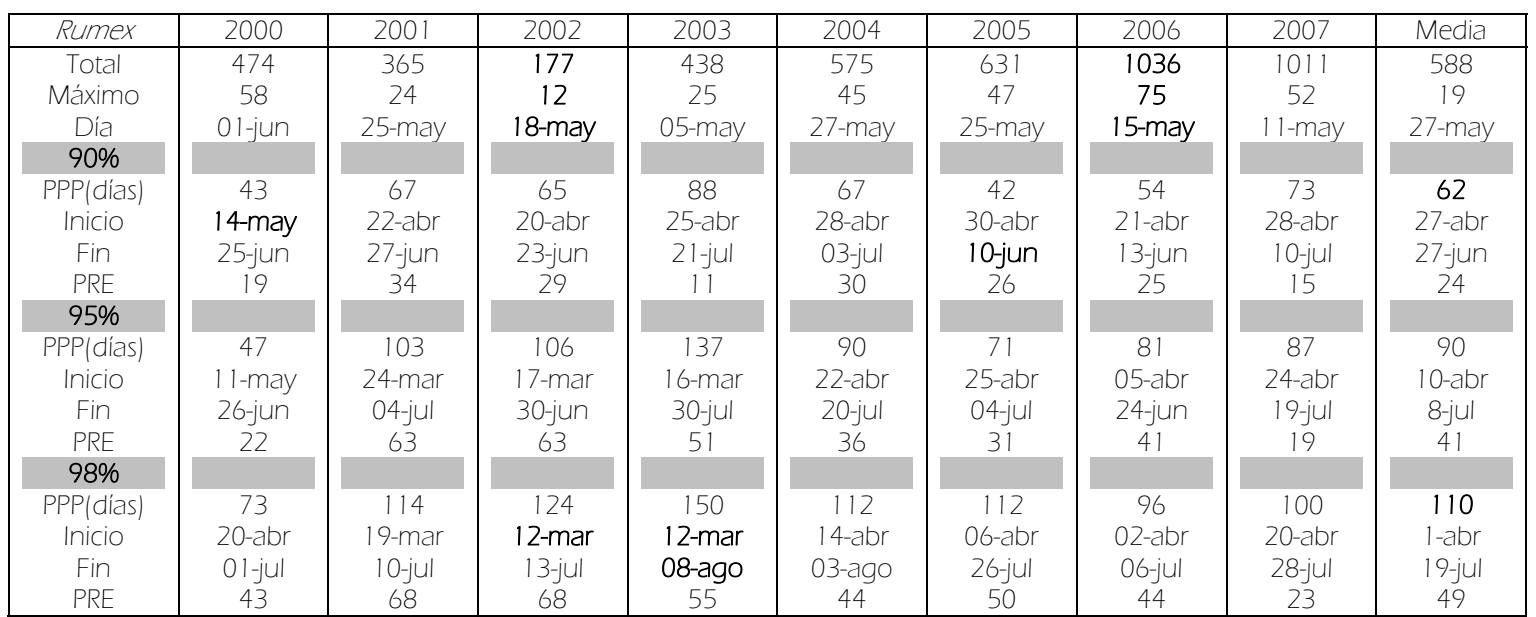

Tabla 5.2.2.21. Totales, concentraciones máximas diarias, períodos principales de polinización (PPP; fecha de inicio y fin) y días precedentes al valor máximo (PRE) durante los ocho años de estudio y el promedio de todos los parámetros para Rumex.

La variación intradiaria (Fig. 5.2.2.33.), presentada con un día promedio durante los años 2005, 2006 y2007, registró mayores niveles en las horas centrales del día, desde las 10 horas hasta las 16 horas, descendiendo su representación porcentual hasta la medianoche. 


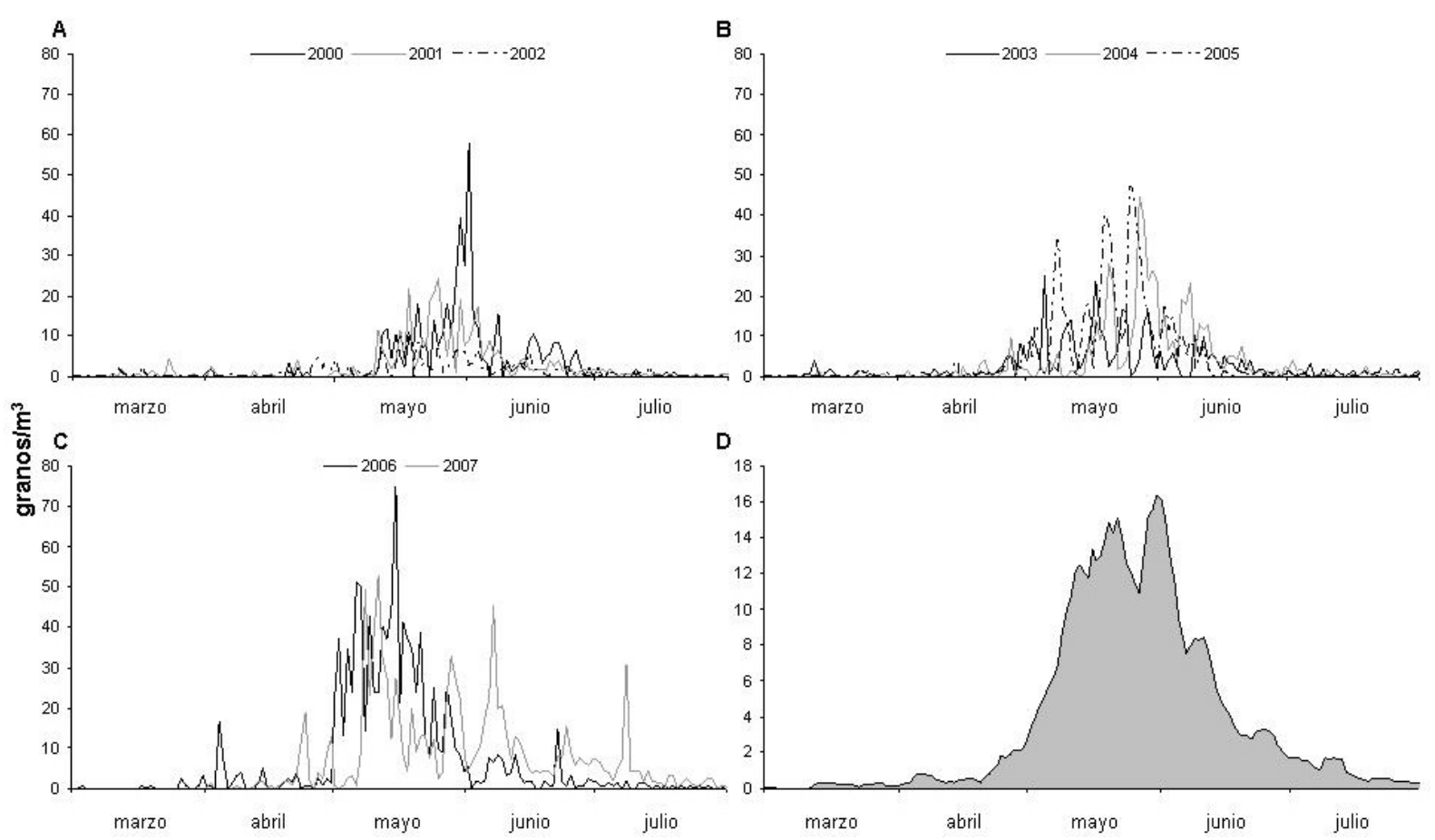

Fig. 5.2.32. Variación de las concentraciones medias diarias de Rumex durante el período 2000-2002 (A), 2003-2005 (B) y 2006-2007 (C). Medias móviles de los cinco días anteriores para las concentraciones diarias promedio de los ocho años estudiados (D).

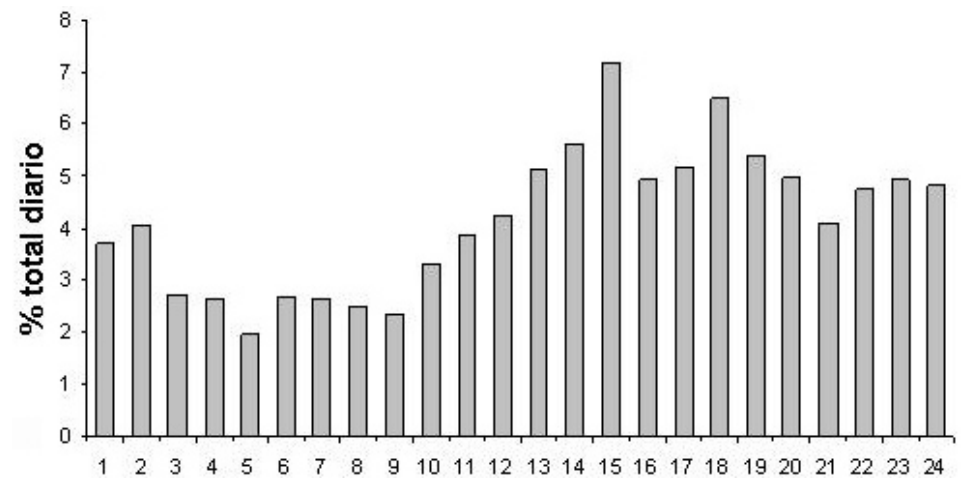

Fig. 5.2.2.33. Variación intradiaria del polen de Rumex.

El análisis de correlación (Tabla 5.2.2.22.) mostró que las temperaturas medias, máximas y mínimas, junto a la insolación y los vientos procedentes del III y IV cuadrante influyeron positivamente en los niveles polínicos durante los ocho años analizados, mientras que la humedad relativa, las precipitaciones, la frecuencia de las calmas y los vientos del I y II cuadrante tuvieron un efecto negativo, aunque algunos de ellos presentasen coeficientes de correlación bajos. Al analizar los años estudiados y métodos empleados para delimitar el PPP, se obtuvieron coeficientes más elevados a lo registrado para el período de estudio completo, como los que presentaron las temperaturas en el PRE de las diferentes metodologías empleadas en la mayor parte de los años estudiados. Esta misma tendencia se observó con los vientos procedentes del III y IV cuadrante en los PPP y PRE de los años 2002 y 2006, y con los vientos del I cuadrante en idénticos períodos, pero con influencia negativa. 


\begin{tabular}{|c|c|c|c|c|c|c|c|}
\hline \multicolumn{2}{|c|}{ Rumex } & Tmed & Tmax & Tmin & Insolación & Precipitación & Hrelativa \\
\hline 2000 & Anual & $0,395 * *$ & $0,357^{* *}$ & $0,410 * *$ & $0,28^{* \star}$ & $-0,061$ & $-0,301 * \star$ \\
\hline \multirow{2}{*}{$90 \%$} & PPP & 0,265 & 0,167 & $0,325^{*}$ & $-0,143$ & 0,028 & 0,111 \\
\hline & PRE & 0,361 & 0,442 & 0,103 & 0,298 & $-0,092$ & $-0,514^{*}$ \\
\hline \multirow{2}{*}{$95 \%$} & PPP & 0,219 & 0,162 & 0,245 & $-0,111$ & $-0,074$ & 0,098 \\
\hline & PRE & 0,363 & $0,493^{*}$ & 0,066 & 0,315 & $-0,247$ & $-0,521^{*}$ \\
\hline \multirow{2}{*}{$98 \%$} & PPP & $0,549 * *$ & 0,521 ** & 0,490 ** & $0,34 * *$ & $-0,409 * *$ & $-0,346$ ** \\
\hline & PRE & $0,761^{* *}$ & 0,730 ** & $0,600 * *$ & $0,52^{* *}$ & $-0,471^{* *}$ & $-0,543 * *$ \\
\hline 2001 & Anual & $0,385^{* *}$ & $0,375^{\star *}$ & $0,362^{* *}$ & $0,34^{\star \star}$ & $-0,033$ & $-0,425$ ** \\
\hline \multirow{2}{*}{$90 \%$} & PPP & $0,535^{* *}$ & 0,489 ** & $0,533^{* *}$ & $0,35^{* *}$ & $-0,210$ & $-0,294^{\star}$ \\
\hline & PRE & 0,627 ** & $0,545^{* *}$ & 0,627 ** & 0,308 & $-0,148$ & $-0,301$ \\
\hline \multirow{2}{*}{$95 \%$} & PPP & $0,593 * *$ & $0,555 * *$ & $0,593 * *$ & $0,38 * *$ & $-0,127$ & $-0,406 * *$ \\
\hline & PRE & $0,388 * *$ & $0,322^{*}$ & 0,408 ** & 0,117 & 0,012 & $-0,213$ \\
\hline \multirow{2}{*}{$98 \%$} & PPP & $0,564 * *$ & $0,537 * *$ & 0,523 ** & $0,37 * \star$ & $-0,139$ & $-0,430$ ** \\
\hline & PRE & 0,386 ** & $0,313^{* *}$ & $0,373^{* *}$ & 0,094 & 0,040 & $-0,238$ \\
\hline 2002 & Anual & $0,299 * *$ & $0,307 * *$ & $0,240 * *$ & $0,34^{\star *}$ & $-0,100$ & $-0,441$ ** \\
\hline \multirow{2}{*}{$90 \%$} & PPP & $0,248^{*}$ & 0,217 & $0,273^{*}$ & 0,141 & $-0,156$ & $-0,136$ \\
\hline & PRE & 0,252 & 0,236 & 0,297 & 0,212 & $-0,255$ & $-0,155$ \\
\hline \multirow{2}{*}{$95 \%$} & PPP & $0,471^{* *}$ & $0,390 * *$ & $0,499 * *$ & $0,34^{* *}$ & $-0,150$ & $-0,296$ ** \\
\hline & PRE & $0,445 * *$ & $0,350 * *$ & $0,469 * *$ & $0,35 * *$ & $-0,162$ & $-0,248$ \\
\hline \multirow{2}{*}{$98 \%$} & PPP & $0,376 * *$ & 0,319 ** & $0,395^{* *}$ & $0,29 * *$ & $-0,171$ & $-0,254$ ** \\
\hline & PRE & $0,422 * *$ & $0,326 * *$ & 0,451 ** & $0,33 * *$ & $-0,176$ & $-0,248^{*}$ \\
\hline 2003 & Anual & $0,401^{* *}$ & $0,382^{* *}$ & $0,352^{* *}$ & $0,35^{\star *}$ & $-0,115^{*}$ & $-0,452^{* *}$ \\
\hline \multirow{2}{*}{$90 \%$} & PPP & $-0,27^{\star \star}$ & $-0,22^{\star \star}$ & $-0,26 * *$ & $-0,187$ & 0,003 & $0,212^{*}$ \\
\hline & PRE & $-0,630^{*}$ & $-0,479$ & $-0,553$ & $-0,146$ & 0,151 & 0,100 \\
\hline \multirow{2}{*}{$95 \%$} & PPP & $0,206 *$ & $0,174^{*}$ & 0,166 & 0,103 & $-0,075$ & $-0,105$ \\
\hline & PRE & $0,428^{* *}$ & 0,048 & 0,252 & $-0,083$ & 0,051 & 0,039 \\
\hline \multirow{2}{*}{$98 \%$} & PPP & 0,144 & 0,111 & 0,104 & 0,124 & $-0,058$ & $-0,068$ \\
\hline & PRE & $0,414^{* *}$ & 0,078 & 0,221 & $-0,065$ & 0,024 & 0,037 \\
\hline 2004 & Anual & 0,421 ** & $0,410 * \star$ & $0,406 * *$ & 0,36 ** & $-0,006$ & $-0,349 * \star$ \\
\hline \multirow{2}{*}{$90 \%$} & PPP & 0,210 & 0,207 & $0,259^{*}$ & 0,074 & $-0,175$ & $-0,119$ \\
\hline & PRE & $0,603^{* *}$ & $0,692 * *$ & $0,459 *$ & 0,450 * & $-0,269$ & $-0,399 *$ \\
\hline \multirow{2}{*}{$95 \%$} & PPP & 0,098 & 0,067 & 0,146 & $-0,048$ & $-0,006$ & 0,101 \\
\hline & PRE & $0,574 * *$ & $0,559 * *$ & $0,474 * *$ & 0,275 & 0,033 & $-0,098$ \\
\hline \multirow{2}{*}{$98 \%$} & PPP & $-0,066$ & $-0,070$ & $-0,028$ & $-0,011$ & 0,097 & 0,186 \\
\hline & PRE & $0,574^{* *}$ & $0,559 * *$ & $0,474^{* *}$ & 0,275 & 0,033 & $-0,098$ \\
\hline 2005 & Anual & $0,384^{* *}$ & $0,368^{* *}$ & $0,345^{* *}$ & 0,29 ** & $-0,019$ & $-0,353^{* *}$ \\
\hline $900 \%$ & PPP & 0,277 & 0,230 & 0,175 & 0,102 & $-0,278$ & $-0,205$ \\
\hline $90 \%$ & PRE & 0,459 * & $0,513^{* *}$ & 0,165 & 0,211 & $-0,444^{*}$ & $-0,375$ \\
\hline 950 & PPP & $-0,246$ * & $-0,193$ & $-0,32 * *$ & $-0,152$ & $-0,061$ & $-0,019$ \\
\hline $95 \%$ & PRE & $0,392^{*}$ & $0,365^{*}$ & 0,305 & 0,113 & $-0,325$ & $-0,301$ \\
\hline 980 & PPP & $-0,085$ & $-0,080$ & $-0,134$ & $-0,152$ & 0,035 & $-0,005$ \\
\hline $78 \%$ & PRE & 0,150 & 0,176 & 0,070 & 0,051 & $-0,073$ & $-0,238$ * \\
\hline 2006 & Anual & $0,389 * *$ & $0,382^{* *}$ & $0,327^{* *}$ & $-0,091$ & $-0,086$ & $-0,528 * *$ \\
\hline $90 \%$ & PPP & 0,118 & $-0,042$ & 0,222 & - & $-0,021$ & 0,060 \\
\hline $70 \%$ & PRE & 0,366 & 0,211 & $0,417^{*}$ & - & $-0,031$ & $-0,134$ \\
\hline $95 \%$ & PPP & 0,296 ** & 0,230 * & 0,164 & - & $-0,264^{*}$ & $-0,343 * *$ \\
\hline $75 \%$ & PRE & 0,627 ** & $0,547^{* *}$ & $0,414^{* *}$ & - & $-0,206$ & $-0,263$ \\
\hline $980 \%$ & PPP & 0,182 & 0,137 & 0,061 & - & $-0,171$ & $-0,322^{* *}$ \\
\hline $78 \%$ & PRE & $0,616^{* *}$ & $0,519 * *$ & 0,427 ** & - & $-0,178$ & $-0,256$ \\
\hline 2007 & Anual & 0,519 ** & $0,475^{* *}$ & $0,503^{* *}$ & $0,39 * \star$ & $-0,012$ & $-0,393^{* *}$ \\
\hline $90 \%$ & PPP & 0,120 & 0,144 & 0,040 & 0,073 & $-0,146$ & $-0,198$ \\
\hline $70 \%$ & PRE & $0,631^{*}$ & $0,604^{*}$ & 0,379 & 0,460 & $-0,581$ * & $-0,557^{*}$ \\
\hline $95 \%$ & PPP & 0,079 & 0,070 & $-0,033$ & 0,096 & $-0,193$ & $-0,124$ \\
\hline $75 \%$ & PRE & $0,690 * *$ & $0,702 * *$ & 0,149 & $0,563^{*}$ & $-0,677 * *$ & $-0,656$ ** \\
\hline $98 \%$ & PPP & $-0,019$ & $-0,041$ & 0,004 & 0,001 & $-0,126$ & 0,012 \\
\hline & PRE & $0,648^{* *}$ & $0,621^{* *}$ & 0,240 & $0,47^{* *}$ & $-0,591^{* *}$ & $-0,601 * *$ \\
\hline Total & Anual & $0,403^{* *}$ & $0,385^{* *}$ & $0,365^{* *}$ & $0,34^{* *}$ & $-0,057^{* *}$ & $-0,381^{* *}$ \\
\hline
\end{tabular}

Tabla 5.2.2.22. Coeficientes de correlación de Spearman entre Rumex y las variables climatológicas. Tmed, Tmax, Tmin (temperatura media, máxima y mínima), Hrelativa (humedad relativa). Significación: $95 \%(*)$, $99 \%(* *)$. (-) Ausencia de correlaciones. 


\begin{tabular}{|c|c|c|c|c|c|c|c|}
\hline \multicolumn{2}{|c|}{ Rumex } & Vemed & FrecCalm & VlCuadr & V2Cuadr & V3Cuadr & V4Cuadr \\
\hline 2000 & Anual & 0,051 & $-0,119^{*}$ & 0,018 & 0,049 & $-0,021$ & 0,101 \\
\hline \multirow{2}{*}{$90 \%$} & PPP & $-0,223$ & $0,318^{*}$ & $-0,420 * *$ & 0,095 & 0,214 & 0,249 \\
\hline & PRE & 0,134 & 0,122 & $-0,309$ & $-0,171$ & 0,025 & 0,226 \\
\hline \multirow{2}{*}{$95 \%$} & PPP & $-0,252$ & $0,336 *$ & $-0,359 *$ & 0,143 & 0,153 & 0,229 \\
\hline & PRE & 0,066 & 0,125 & $-0,206$ & $-0,068$ & $-0,091$ & 0,227 \\
\hline \multirow{2}{*}{$98 \%$} & PPP & $-0,209$ & 0,154 & $-0,015$ & 0,049 & $-0,113$ & 0,130 \\
\hline & PRE & $-0,189$ & 0,114 & $-0,011$ & $-0,167$ & $-0,163$ & 0,277 \\
\hline 2001 & Anual & 0,083 & $-0,130^{*}$ & $-0,089$ & $-0,100$ & $0,113^{*}$ & $0,308^{* *}$ \\
\hline \multirow{2}{*}{$90 \%$} & PPP & $-0,191$ & 0,098 & 0,013 & 0,004 & $-0,023$ & 0,067 \\
\hline & PRE & $-0,129$ & 0,036 & $-0,017$ & 0,019 & 0,032 & $-0,022$ \\
\hline \multirow{2}{*}{$95 \%$} & PPP & $-0,222^{*}$ & 0,167 & $-0,025$ & 0,102 & 0,011 & 0,149 \\
\hline & PRE & $-0,143$ & 0,149 & $-0,003$ & 0,156 & 0,055 & 0,096 \\
\hline \multirow{2}{*}{$98 \%$} & PPP & $-0,224$ * & 0,182 & 0,031 & 0,161 & $-0,028$ & 0,127 \\
\hline & PRE & $-0,118$ & 0,128 & 0,003 & 0,194 & 0,047 & 0,086 \\
\hline 2002 & Anual & 0,023 & 0,089 & $-0,157^{\star \star}$ & $-0,190^{* *}$ & $0,195^{\star \star}$ & 0,064 \\
\hline \multirow{2}{*}{$90 \%$} & PPP & $-0,055$ & 0,042 & $-0,275^{\star}$ & $-0,049$ & $0,268^{\star}$ & 0,099 \\
\hline & PRE & $-0,069$ & 0,164 & $-0,457^{*}$ & $-0,217$ & $0,468 *$ & 0,268 \\
\hline \multirow{2}{*}{$95 \%$} & PPP & 0,025 & 0,093 & $-0,397 * *$ & $-0,243^{* *}$ & $0,428 * *$ & $0,337^{* *}$ \\
\hline & PRE & $-0,062$ & 0,240 & $-0,353^{* *}$ & $-0,299 * *$ & $0,372^{* *}$ & $0,399 * *$ \\
\hline \multirow{2}{*}{ 98\% } & PPP & $-0,015$ & 0,123 & $-0,298 * *$ & $-0,217^{*}$ & $0,378 * *$ & $0,236 * *$ \\
\hline & PRE & $-0,069$ & 0,222 & $-0,320$ ** & $-0,321^{* *}$ & $0,343^{* *}$ & 0,389 ** \\
\hline 2003 & Anual & 0,091 & $-0,147^{\star *}$ & $-0,088$ & $-0,055$ & $0,120^{*}$ & 0,048 \\
\hline \multirow{2}{*}{$90 \%$} & PPP & 0,083 & $-0,009$ & $-0,096$ & 0,146 & 0,084 & $-0,022$ \\
\hline & PRE & $-0,397$ & 0,170 & 0,028 & $-0,447$ & $-0,420$ & 0,598 \\
\hline \multirow{2}{*}{$95 \%$} & PPP & 0,066 & $-0,061$ & $-0,130$ & $-0,023$ & $0,192^{*}$ & 0,041 \\
\hline & PRE & 0,159 & $-0,058$ & $-0,538 * *$ & $-0,089$ & $0,510 * *$ & 0,043 \\
\hline \multirow{2}{*}{$98 \%$} & PPP & 0,071 & $-0,075$ & $-0,147$ & $-0,043$ & 0,201 * & 0,018 \\
\hline & PRE & 0,143 & $-0,077$ & $-0,485 * *$ & $-0,048$ & $0,455 * *$ & 0,010 \\
\hline 2004 & Anual & 0,096 & $-0,107^{*}$ & $-0,054$ & $-0,057$ & 0,009 & $0,189^{* *}$ \\
\hline \multirow{2}{*}{$90 \%$} & PPP & 0,190 & 0,205 & $-0,128$ & $0,308^{*}$ & 0,176 & 0,106 \\
\hline & PRE & $0,462 *$ & 0,459 * & $-0,183$ & 0,439 * & 0,275 & 0,212 \\
\hline \multirow{2}{*}{$95 \%$} & PPP & 0,098 & 0,156 & $-0,132$ & $0,235^{*}$ & 0,175 & 0,051 \\
\hline & PRE & $0,358 *$ & $0,357^{*}$ & $-0,113$ & $0,368 *$ & 0,161 & 0,169 \\
\hline \multirow{2}{*}{$98 \%$} & PPP & 0,041 & 0,113 & $-0,060$ & 0,112 & 0,026 & 0,072 \\
\hline & PRE & $0,358 *$ & $0,357^{*}$ & $-0,113$ & $0,368^{*}$ & 0,161 & 0,169 \\
\hline 2005 & Anual & $0,126^{*}$ & $-0,171^{* *}$ & $-0,152 * *$ & $-0,059$ & $0,180^{* *}$ & $0,249 * *$ \\
\hline ००० & PPP & $-0,195$ & $0,312^{*}$ & $-0,392^{*}$ & 0,167 & $0,330^{*}$ & $0,352^{\star}$ \\
\hline $90 \%$ & PRE & $-0,202$ & 0,132 & $-0,255$ & 0,214 & 0,093 & 0,376 \\
\hline $95 \%$ & PPP & $-0,003$ & 0,095 & $-0,013$ & 0,114 & 0,005 & $-0,031$ \\
\hline $95 \%$ & PRE & $-0,028$ & 0,024 & $-0,247$ & 0,078 & 0,116 & 0,260 \\
\hline $980 \%$ & PPP & $-0,124$ & 0,177 & $-0,082$ & 0,184 & 0,128 & 0,096 \\
\hline $78 \%$ & PRE & $-0,179$ & 0,175 & 0,033 & 0,162 & 0,034 & $-0,014$ \\
\hline 2006 & Anual & 0,017 & $-0,208^{* \star}$ & 0,017 & $-0,034$ & 0,010 & $0,233^{* \star}$ \\
\hline ๑n\% & PPP & $-0,061$ & 0,047 & $-0,730^{* *}$ & 0,051 & $0,583^{* *}$ & 0,520 ** \\
\hline $90 \%$ & PRE & $-0,107$ & $-0,039$ & $-0,814^{\star *}$ & 0,023 & $0,788 * *$ & $0,567^{* *}$ \\
\hline $95 \%$ & PPP & $-0,164$ & $-0,069$ & $-0,532 * *$ & 0,099 & $0,419 * *$ & $0,283^{*}$ \\
\hline $75 \%$ & PRE & $-0,148$ & $-0,039$ & $-0,814^{* *}$ & 0,023 & $0,788^{* *}$ & $0,567^{* *}$ \\
\hline $98 \%$ & PPP & $-0,178$ & $-0,040$ & $-0,311$ ** & 0,203 & $0,238^{*}$ & 0,103 \\
\hline & PRE & $-0,093$ & $-0,039$ & $-0,814^{* *}$ & 0,023 & $0,788^{* *}$ & $0,567^{* *}$ \\
\hline 2007 & Anual & 0,095 & 0,003 & $-0,204^{\star *}$ & $-0,083$ & $0,227^{* *}$ & $0,168^{* *}$ \\
\hline & PPP & 0,081 & 0,010 & $-0,155$ & 0,052 & 0,176 & $-0,153$ \\
\hline $90 \%$ & PRE & $-0,069$ & 0,308 & $-0,464$ & 0,018 & 0,381 & $-0,174$ \\
\hline & PPP & 0,106 & $-0,020$ & $-0,123$ & 0,022 & 0,174 & $-0,238$ * \\
\hline & PRE & $-0,147$ & 0,384 & $-0,339$ & 0,095 & 0,432 & $-0,384$ \\
\hline & PPP & 0,174 & $-0,113$ & $-0,135$ & $-0,011$ & $0,206^{*}$ & $-0,249 *$ \\
\hline $98 \%$ & PRE & $-0,137$ & 0,333 & $-0,335$ & $-0,012$ & 0,359 & $-0,268$ \\
\hline Total & Anual & 0,001 & $-0,090 * *$ & $-0,075 * *$ & $-0,055^{* *}$ & $0,092 * *$ & $0,178^{\star *}$ \\
\hline
\end{tabular}

Tabla 5.2.2.22. (Continuación). Coeficientes de correlación de Spearman entre Rumex y las variables climatológicas. Vemed (velocidad media), FrecCalmas (frecuencia de calmas), V1Cuad, V2Cuad, V3Cuad,

V4Cuad (vientos procedentes del I, II, III y IV cuadrante). Significación: $95 \%\left(^{*}\right), 99 \%(* *)$. (-) Ausencia de correlaciones. 


\subsubsection{Urticaceae}

Los niveles de este tipo de polen en la atmósfera de Salamanca, experimentaron un ascenso durante el período analizado, ya que si en el año 2000 los totales anuales fueron 430 pólenes, en el año 2007 alcanzó 1002, pese a que el mayor total anual se registró en el año 2006 con 1197 granos. Todo ello supuso que la variación interanual (Fig. 5.2.2.34.) llevase consigo un aumento del $133 \%$ en las concentraciones anuales de esta familia botánica, un hecho confirmado a través del análisis de regresión de tipo lineal y el valor que tomó por su índice de determinación $\left(\mathrm{R}^{2}=0,61\right)$. La representación media de los pólenes de género botánico a lo largo de los ocho años fue de 2,5\%, con un máximo de 4,6\% en 2007 y un mínimo de $2,2 \%$ en 2002.

La distribución de estos granos de polen a lo largo de los años estudiados se localizó, principalmente, entre febrero y octubre por lo que la variación estacional fue muy amplia (Tabla 5.2.2.23.) y tuvo un PPP promedio de 174 a 246 días, en función del modelo empleado para su cálculo. Esta evidente variación en función del año analizado y del modelo
Tipo de polen: Urticaceae.

Especie(s): Parietaria judaica L., Parietaria lusitanica L., Urtica dioica L. y Urtica urens L. (Urticaceae), entre otras.

Distribución: Familia botánica cosmopolita. En la Península Ibérica y en la provincia de Salamanca, el género Parietaria L. se encuentra sobre muros, rocas, fisuras y caminos nitrificadas, mientras que las especies del género Urtica L., ocupan terrenos baldíos con cierto nivel de humedad y nitrofilia.

Época de floración: Entre los meses de enero y octubre.

Polinización: Anemófila.

Morfología polínica (Lámina IV): Polen trizonoporado (a veces tetrazonoporado), isopolar y radiosimétrico, con una forma circular o circular-triangular en vista polar y circular-elíptica en vista ecuatorial (de oblatoesferoidal a esferoidal), y un tamaño pequeño $(P=11-16 \mu \mathrm{m})$. Las aberturas tipo poro de diámetro entre 1,5 y $2 \mu \mathrm{m}$, presentan un anillo y un opérculo, poco visible al microscopio óptico, pues se desprende con facilidad. La exina de escaso grosor (menor a $1 \mu \mathrm{m}$ ) posee una superficie microequinulada-verrucosa, con espinas y verrugas de tamaño variable que se distribuyen irregularmente por toda la superficie. usado, se presentó en las fechas de inicio, teniendo el 2 de enero de 2003 como fecha más temprana (método 98\%) y el 23 de marzo de 2005 como la más tardía (90\%), y en las fechas de finalización del PPP, con un intervalo entre el 22 de julio de 2001 (90\%) y el 23 de noviembre de 2002 (98\%).

La dinámica de las concentraciones polínicas de Urticaceae (Fig. 5.2.2.35.D.) mostrada con las concentraciones promedio para los cinco días anteriores durante los años analizados presentó un incremento de las concentraciones desde mediados de febrero hasta 
mediados de junio, con una concentración máxima de 9 granos $/ \mathrm{m}^{3}$ el día 3 de junio como media del período 2000-2007 (Tabla 5.2.2.23.). Posteriormente, se registró una disminución en los niveles de polen a finales de junio, manteniéndose en la atmósfera durante el resto del año, especialmente en los meses de julio y agosto. Las concentraciones diarias más elevadas dentro de los ocho años (Tabla 5.2.2.23.; Fig. 5.2.2.35.A. B. C.), localizadas fundamentalmente en junio (en ocasiones en febrero y marzo), variaron entre los 59 granos $/ \mathrm{m}^{3}$ (31 de marzo de 2007) y los 4 granos $/ \mathrm{m}^{3}$ (19 de junio de 2002).

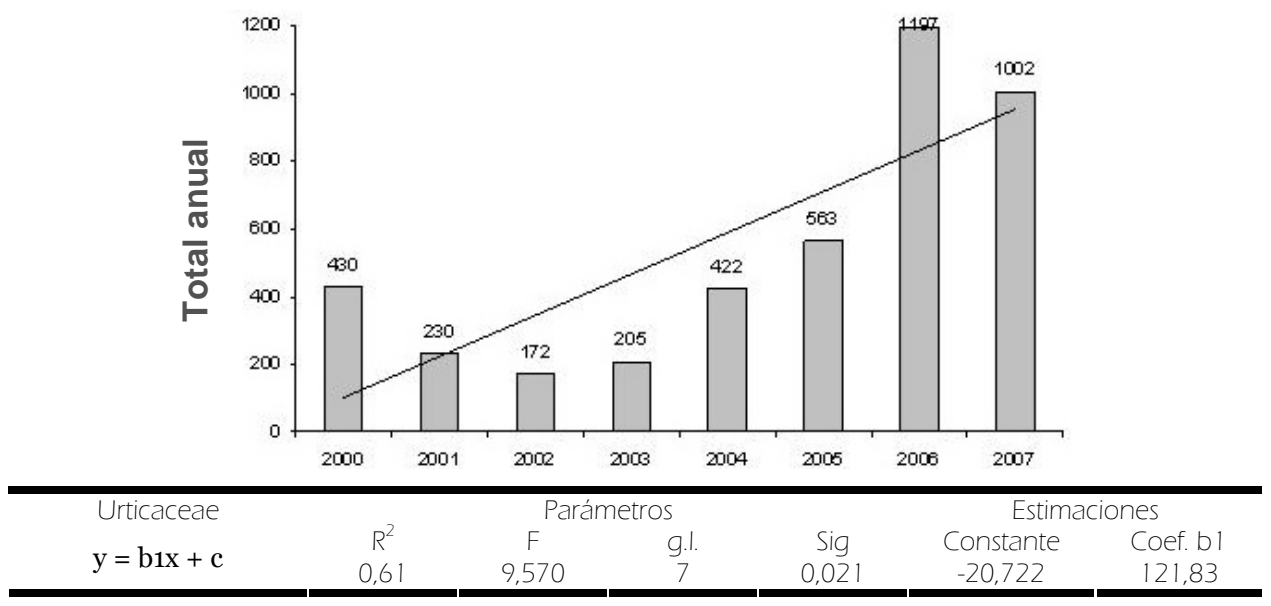

Fig. 5.2.34. Evolución anual del número total de pólenes de Urticaceae y tendencias (análisis de regresión).

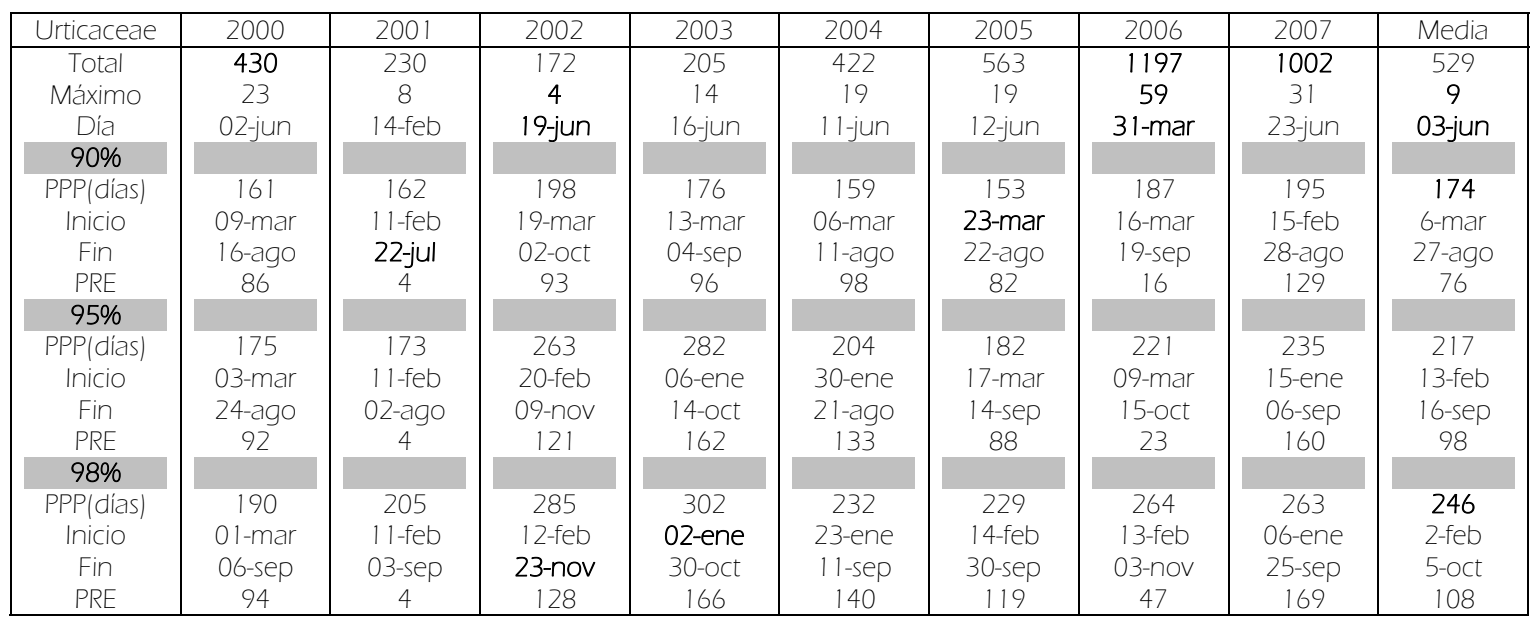

Tabla 5.2.2.23. Totales, concentraciones máximas diarias, períodos principales de polinización (PPP; fecha de inicio y fin) y días precedentes al valor máximo (PRE) durante los ocho años de estudio y el promedio de todos los parámetros para Urticaceae.

Los niveles de polen mostraron porcentajes de representación variables a lo largo del día, con una mayor representación entre las 15 y las 17 horas, y una menor entre las 5 y las 11 horas. Así pues la variación intradiaria (Fig. 5.2.2.36.) durante un día promedio para el trienio 2005-2007, mostró un patrón de distribución horaria muy irregular durante el día. 


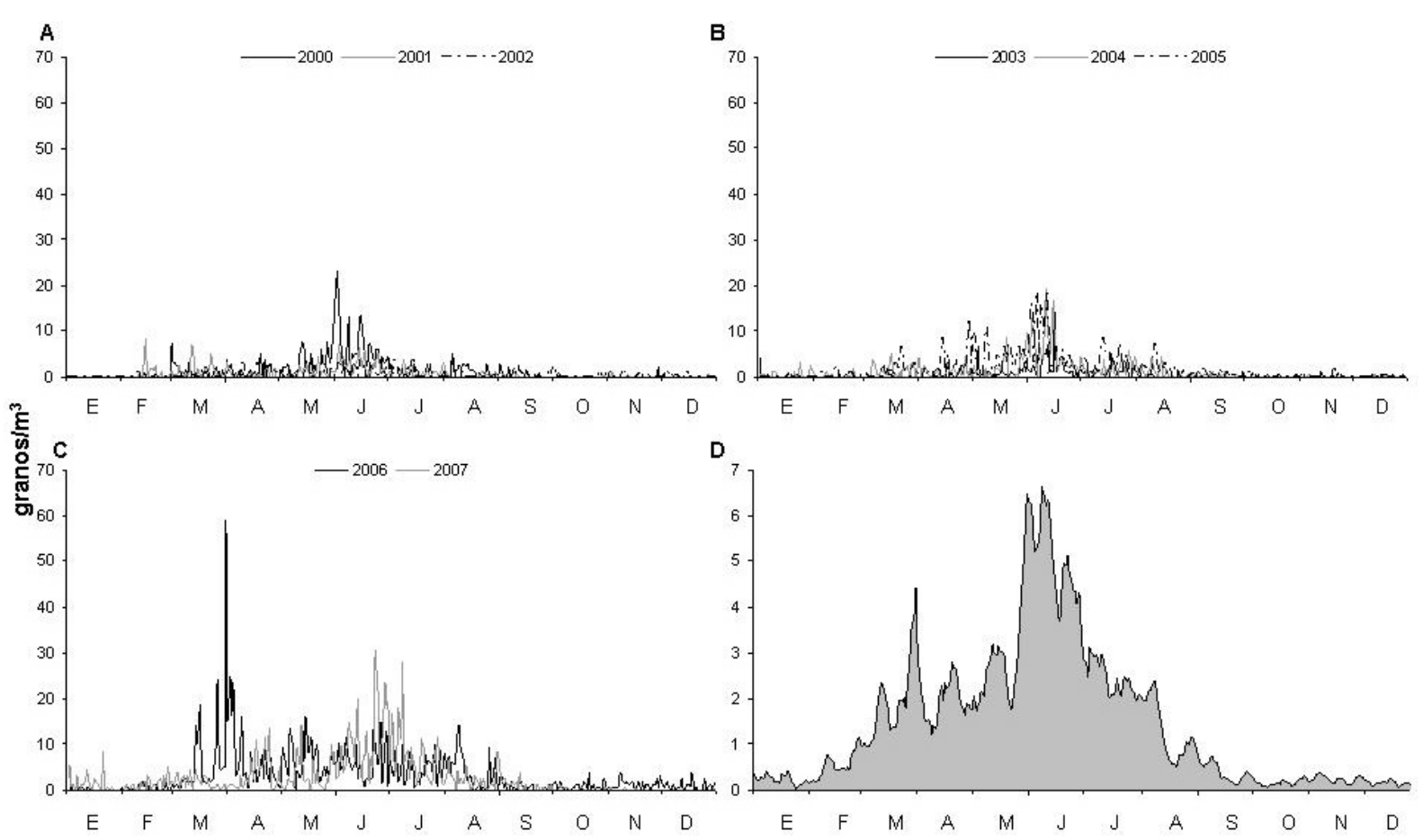

Fig. 5.2.2.35. Variación de las concentraciones medias diarias de Urticaceae durante el período 2000-2002 (A), 2003-2005 (B) y 2006-2007 (C). Medias móviles de los cinco días anteriores para las concentraciones diarias promedio de los ocho años estudiados (D).

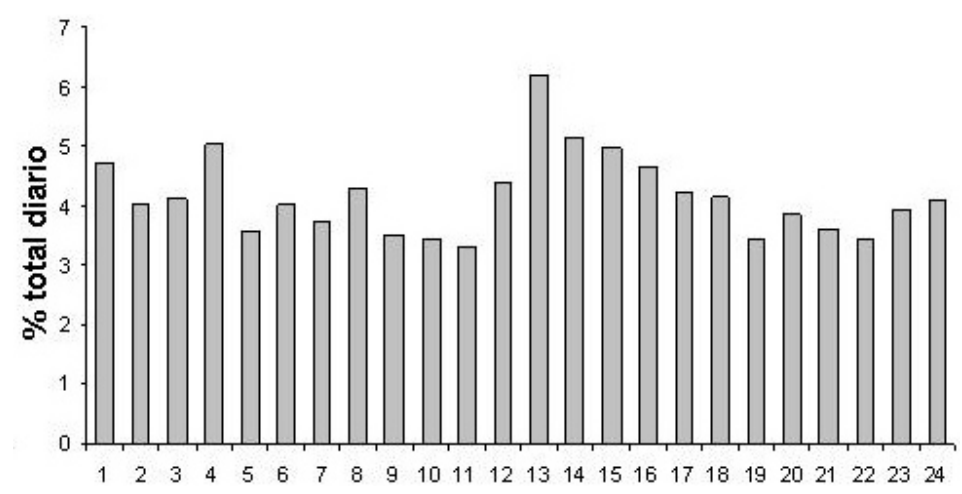

Fig. 5.2.2.36. Variación intradiaria del polen de Urticaceae.

Las temperaturas medias, máximas y mínimas junto a la insolación y los vientos procedentes del IV cuadrante (también del III cuadrante, pero con bajos valores del índice de correlación) tuvieron una influencia positiva en las concentraciones polínicas de la familia Urticaceae durante los ocho años analizados, mientras que las precipitaciones, la humedad relativa y, en menor medida, la velocidad media del viento, la frecuencia de las calmas y los vientos procedentes del I cuadrante lo hicieron de forma negativa, tras el análisis de correlación (Tabla 28). Debe reseñarse que se obtuvieron coeficientes más elevados a lo registrado para el período de estudio completo, como los registrados para las temperaturas en el PRE de las diferentes metodologías empleadas en la mayor parte de los años estudiados. Este comportamiento se observó con los vientos procedentes del III y IV cuadrante en los 
años 2001, 2002, 2005 y 2007, y con los vientos del I cuadrante en idénticos períodos, pero con un efecto negativo.

\begin{tabular}{|c|c|c|c|c|c|c|c|}
\hline \multicolumn{2}{|c|}{ Urticaceae } & Tmed & Tmax & Tmin & Insolación & Precipitación & Hrelativa \\
\hline 2000 & Anual & $0,426 * *$ & $0,418 * *$ & $0,394 * *$ & $0,335^{*}$ & $-0,086$ & $-0,443^{* *}$ \\
\hline \multirow{2}{*}{$90 \%$} & PPP & $0,317^{* *}$ & $0,300 * *$ & $0,304 * *$ & $0,162^{*}$ & $-0,141$ & $-0,186^{\star}$ \\
\hline & PRE & $0,487 * *$ & $0,454 * *$ & 0,425 ** & $0,29 * *$ & $-0,111$ & $-0,150$ \\
\hline \multirow{2}{*}{$95 \%$} & PPP & 0,280 ** & $0,279 * *$ & 0,254 ** & 0,160 * & $-0,141$ & $-0,174^{*}$ \\
\hline & PRE & 0,432 ** & $0,449 * *$ & $0,352 * *$ & 0,31 ** & $-0,120$ & $-0,151$ \\
\hline \multirow{2}{*}{$98 \%$} & PPP & 0,226 ** & 0,223 ** & $0,218^{* *}$ & 0,107 & $-0,121$ & $-0,172^{*}$ \\
\hline & PRE & 0,386 ** & $0,418 * *$ & $0,314^{* *}$ & 0,30 ** & $-0,139$ & $-0,162$ \\
\hline 2001 & Anual & $0,361^{* *}$ & $0,344^{* *}$ & $0,345^{* *}$ & $0,31^{* *}$ & $-0,058$ & $-0,354$ ** \\
\hline \multirow{2}{*}{$90 \%$} & PPP & $0,317^{* *}$ & $0,263^{* *}$ & $0,331^{* *}$ & $0,180^{*}$ & $-0,053$ & $-0,205$ ** \\
\hline & PRE & 0,258 & 0,775 & $-0,775$ & 0,775 & $-0,333$ & $-0,775$ \\
\hline \multirow{2}{*}{$95 \%$} & PPP & 0,297 ** & 0,250 ** & $0,305^{* *}$ & $0,164^{*}$ & $-0,043$ & $-0,210$ ** \\
\hline & PRE & 0,258 & 0,775 & $-0,775$ & 0,775 & $-0,333$ & $-0,775$ \\
\hline \multirow{2}{*}{$98 \%$} & PPP & 0,130 & 0,099 & 0,139 * & 0,100 & 0,010 & $-0,133$ \\
\hline & PRE & 0,258 & 0,775 & $-0,775$ & 0,775 & $-0,333$ & $-0,775$ \\
\hline 2002 & Anual & $0,272^{\star \star}$ & $0,292^{\star \star}$ & $0,202^{* \star}$ & $0,28 * \star$ & $-0,164^{\star \star}$ & $-0,343^{\star *}$ \\
\hline \multirow{2}{*}{$90 \%$} & PPP & 0,092 & 0,102 & 0,073 & $0,136^{*}$ & $-0,155^{\star}$ & $-0,220$ ** \\
\hline & PRE & 0,326 ** & $0,287^{* *}$ & $0,330 * *$ & 0,250 * & $-0,197$ & $-0,238$ * \\
\hline \multirow{2}{*}{$95 \%$} & PPP & $0,123^{*}$ & $0,146^{*}$ & 0,071 & 0,19 ** & $-0,145^{*}$ & $-0,281$ ** \\
\hline & PRE & 0,452 ** & 0,402 ** & 0,451 ** & $0,29 * *$ & $-0,204^{*}$ & $-0,339$ ** \\
\hline \multirow{2}{*}{$98 \%$} & PPP & $0,161^{* *}$ & $0,186^{* *}$ & 0,102 & 0,21 ** & $-0,147^{*}$ & $-0,289$ ** \\
\hline & PRE & $0,477 * *$ & $0,435^{* *}$ & $0,465 * *$ & $0,29 * *$ & $-0,174 * *$ & $-0,341 * *$ \\
\hline 2003 & Anual & $0,459 * *$ & $0,438^{* *}$ & $0,416^{* *}$ & 0,36 ** & $-0,170^{\star *}$ & $-0,478 * *$ \\
\hline \multirow{2}{*}{$90 \%$} & PPP & 0,260 ** & $0,230^{* *}$ & $0,221^{* *}$ & $0,165^{*}$ & $-0,183^{*}$ & $-0,257^{* *}$ \\
\hline & PRE & $0,532^{* *}$ & $0,439 * *$ & $0,504 * *$ & 0,038 & $-0,058$ & $-0,163$ \\
\hline \multirow{2}{*}{$95 \%$} & PPP & 0,426 ** & 0,400 ** & $0,387 * *$ & $0,33^{* *}$ & $-0,153^{*}$ & $-0,470 * *$ \\
\hline & PRE & $0,633^{* *}$ & $0,583^{* *}$ & $0,581^{* *}$ & $0,29 * *$ & $-0,082$ & $-0,464 * *$ \\
\hline \multirow{2}{*}{$98 \%$} & PPP & 0,440 ** & 0,414 ** & 0,397 * & 0,34 ** & $-0,168 * \star$ & $-0,476 * *$ \\
\hline & PRE & $0,634^{* *}$ & $0,581^{* *}$ & $0,584^{* *}$ & $0,29 * *$ & $-0,086$ & $-0,461$ ** \\
\hline 2004 & Anual & $0,449 * *$ & 0,426 ** & $0,423^{* *}$ & $0,39^{\star *}$ & $-0,136^{* *}$ & $-0,417^{* *}$ \\
\hline \multirow{2}{*}{$90 \%$} & PPP & $0,365^{* *}$ & $0,361^{* *}$ & $0,344^{* *}$ & $0,32^{\star *}$ & $-0,207^{* *}$ & $-0,198^{\star}$ \\
\hline & PRE & 0,390 ** & $0,404 * *$ & $0,330 * *$ & $0,34 * \star$ & $-0,185$ & $-0,223^{*}$ \\
\hline \multirow{2}{*}{$95 \%$} & PPP & $0,459 * *$ & $0,443^{* *}$ & 0,447 ** & 0,34 ** & $-0,155^{\star}$ & $-0,296 * *$ \\
\hline & PRE & 0,456 ** & $0,417^{* *}$ & 0,457 ** & $0,27 * *$ & $-0,075$ & $-0,260$ ** \\
\hline \multirow{2}{*}{$98 \%$} & PPP & $0,367^{* *}$ & $0,343^{* *}$ & $0,372^{* *}$ & $0,32^{* *}$ & $-0,141^{\star}$ & $-0,229 * *$ \\
\hline & PRE & 0,444 ** & $0,418^{* *}$ & 0,438 ** & $0,26 * *$ & $-0,092$ & $-0,258 * *$ \\
\hline 2005 & Anual & $0,632^{* *}$ & $0,611^{* *}$ & $0,592 * *$ & $0,45^{\star *}$ & $-0,078$ & $-0,574^{* *}$ \\
\hline ९००\% & PPP & $0,430^{* *}$ & $0,404 * \star$ & $0,364^{* *}$ & $0,195^{\star}$ & $-0,146$ & $-0,357^{* *}$ \\
\hline $90 \%$ & PRE & $0,635^{* *}$ & 0,627 ** & $0,591^{* *}$ & $0,33^{* *}$ & $-0,226$ * & $-0,495$ ** \\
\hline $950 \%$ & PPP & $0,336 * *$ & 0,301 ** & $0,265 * *$ & $0,21 * *$ & $-0,082$ & $-0,285^{* *}$ \\
\hline $95 \%$ & PRE & $0,602^{* *}$ & $0,583^{* *}$ & $0,568 * *$ & 0,30 ** & $-0,207$ & $-0,455^{* *}$ \\
\hline $980 \%$ & PPP & $0,474 * *$ & $0,422 * *$ & $0,449 * *$ & 0,26 ** & $-0,001$ & $-0,361 * *$ \\
\hline $98 \%$ & PRE & 0,712 ** & $0,690 * *$ & $0,687 * *$ & $0,24 * *$ & $-0,042$ & $-0,373 * *$ \\
\hline 2006 & Anual & $0,478^{* *}$ & $0,500^{* \star}$ & $0,413^{* *}$ & 0,134 & $-0,170^{* *}$ & $-0,571^{* *}$ \\
\hline Q & PPP & 0,013 & $-0,034$ & $-0,019$ & - & $-0,137$ & $-0,143$ \\
\hline $70 \%$ & PRE & 0,671 ** & $0,812^{* *}$ & $-0,125$ & - & $-0,515^{\star}$ & $-0,289$ \\
\hline $95 \%$ & PPP & 0,104 & 0,088 & 0,049 & - & $-0,156^{* *}$ & $-0,324 * *$ \\
\hline $75 \%$ & PRE & $0,707^{* *}$ & $0,674^{* *}$ & 0,008 & - & $-0,367$ & $-0,469 *$ \\
\hline $980 \%$ & PPP & $0,265^{* *}$ & $0,273 * *$ & $0,196 * *$ & $-0,169$ & $-0,218 * *$ & $-0,460 * *$ \\
\hline $98 \%$ & PRE & $0,804^{* *}$ & $0,786 * *$ & $0,545^{* *}$ & $-0,169$ & $-0,143$ & $-0,406^{* *}$ \\
\hline 2007 & Anual & $0,544 * *$ & $0,524 * *$ & 0,456 ** & $0,48^{* *}$ & $-0,131^{\star}$ & $-0,484^{* *}$ \\
\hline $90 \%$ & PPP & $0,473^{* *}$ & $0,476^{* *}$ & $0,341^{* *}$ & $0,47^{\star *}$ & $-0,341^{* \star}$ & $-0,401^{* *}$ \\
\hline $90 \%$ & PRE & $0,584 * *$ & $0,591 * *$ & $0,399 * *$ & $0,42 * *$ & $-0,281 * *$ & $-0,400 * *$ \\
\hline & PPP & $0,519 * *$ & $0,525^{* *}$ & $0,400 * *$ & $0,52 * *$ & $-0,339 * *$ & $-0,468 * *$ \\
\hline $95 \%$ & PRE & $0,627 * *$ & $0,643 * *$ & $0,444 * *$ & $0,47 * *$ & $-0,260 * *$ & $-0,465 * *$ \\
\hline & PPP & $0,425^{* *}$ & $0,434 * *$ & $0,295 * *$ & $0,50 * *$ & $-0,311 * *$ & $-0,446 * *$ \\
\hline $48 \%$ & PRE & $0,598 * *$ & $0,633 * *$ & $0,419 * *$ & $0,48 * *$ & $-0,243 * *$ & $-0,455 * *$ \\
\hline Total & Anual & $0,427 * *$ & $0,424 * *$ & $0,383^{* *}$ & $0,37 \star \star$ & $-0,121^{\star \star}$ & $-0,390 * *$ \\
\hline
\end{tabular}

Tabla 5.2.2.24. Coeficientes de correlación de Spearman entre Urticaceae y las variables climatológicas. Tmed,

Tmax, Tmin (temperatura media, máxima y mínima), Hrelativa (humedad relativa). Significación: $95 \%{ }^{*}$ ), $99 \%(* *) .(-)$ Ausencia de correlaciones. 


\begin{tabular}{|c|c|c|c|c|c|c|c|}
\hline \multicolumn{2}{|c|}{ Urticaceae } & Vemed & FrecCalm & VICuadr & V2Cuadr & V3Cuadr & V4Cuadr \\
\hline 2000 & Anual & 0,075 & $-0,111^{*}$ & 0,028 & $-0,009$ & $-0,043$ & $0,103^{*}$ \\
\hline \multirow{2}{*}{$90 \%$} & PPP & 0,029 & 0,007 & $-0,045$ & 0,072 & $-0,042$ & 0,015 \\
\hline & PRE & $-0,117$ & 0,171 & $-0,128$ & 0,117 & $-0,008$ & 0,135 \\
\hline \multirow{2}{*}{$95 \%$} & PPP & 0,004 & $-0,014$ & $-0,027$ & 0,065 & $-0,067$ & 0,031 \\
\hline & PRE & $-0,122$ & 0,179 & $-0,112$ & 0,110 & $-0,011$ & 0,123 \\
\hline \multirow{2}{*}{$98 \%$} & PPP & 0,045 & $-0,039$ & $-0,048$ & 0,035 & $-0,025$ & 0,034 \\
\hline & PRE & $-0,102$ & 0,165 & $-0,099$ & 0,105 & $-0,012$ & 0,130 \\
\hline 2001 & Anual & $0,130^{*}$ & $-0,116^{*}$ & $-0,138^{* *}$ & $-0,124^{\star}$ & $0,165^{\star \star}$ & $0,199 * \star$ \\
\hline \multirow{2}{*}{$90 \%$} & PPP & 0,104 & $-0,036$ & $-0,205^{* *}$ & $-0,029$ & 0,261 ** & 0,046 \\
\hline & PRE & $-0,775$ & 0,775 & $-0,258$ & $-0,28$ & 0,258 & $-0,554$ \\
\hline \multirow{2}{*}{$95 \%$} & PPP & 0,118 & $-0,030$ & $-0,192^{*}$ & $-0,010$ & 0,250 ** & 0,025 \\
\hline & PRE & $-0,775$ & 0,775 & $-0,258$ & $-0,28$ & 0,258 & $-0,554$ \\
\hline \multirow{2}{*}{$98 \%$} & PPP & $0,187^{* *}$ & $-0,120$ & $-0,194 * \star$ & $-0,034$ & $0,300 * *$ & $-0,010$ \\
\hline & PRE & $-0,775$ & 0,775 & $-0,258$ & $-0,28$ & 0,258 & $-0,554$ \\
\hline 2002 & Anual & $-0,067$ & 0,095 & $-0,026$ & $-0,068$ & 0,057 & $0,117^{*}$ \\
\hline \multirow{2}{*}{$90 \%$} & PPP & $-0,059$ & 0,124 & $-0,182^{\star \star}$ & $-0,097$ & $0,181^{* \star}$ & 0,056 \\
\hline & PRE & $-0,076$ & 0,106 & $-0,274$ ** & $-0,081$ & 0,269 ** & $0,226^{*}$ \\
\hline \multirow{2}{*}{$95 \%$} & PPP & $-0,047$ & 0,108 & $-0,133^{*}$ & $-0,096$ & $0,142^{*}$ & 0,053 \\
\hline & PRE & $-0,092$ & 0,136 & $-0,255^{* *}$ & $-0,098$ & 0,256 ** & $0,210^{*}$ \\
\hline \multirow{2}{*}{$98 \%$} & PPP & $-0,078$ & $0,134^{*}$ & $-0,109$ & $-0,063$ & 0,106 & 0,086 \\
\hline & PRE & $-0,105$ & 0,148 & $-0,289 * *$ & $-0,097$ & $0,287^{* *}$ & $0,237^{* *}$ \\
\hline 2003 & Anual & 0,017 & $-0,076$ & $-0,184^{* *}$ & $-0,052$ & $0,186^{* *}$ & $0,170^{* *}$ \\
\hline \multirow{2}{*}{$90 \%$} & PPP & $-0,031$ & 0,009 & $-0,324^{\star *}$ & 0,004 & 0,289 ** & $0,150^{*}$ \\
\hline & PRE & $-0,094$ & 0,039 & $-0,422^{* *}$ & 0,127 & $0,419 * *$ & $0,216^{*}$ \\
\hline \multirow{2}{*}{$95 \%$} & PPP & $-0,002$ & $-0,061$ & $-0,233^{* *}$ & $-0,008$ & 0,226 ** & $0,187^{* *}$ \\
\hline & PRE & $-0,031$ & $-0,049$ & $-0,247^{* *}$ & 0,090 & $0,273^{* *}$ & $0,179 *$ \\
\hline \multirow{2}{*}{$98 \%$} & PPP & 0,002 & $-0,080$ & $-0,217^{* *}$ & $-0,015$ & 0,206 ** & $0,190 * *$ \\
\hline & PRE & $-0,032$ & $-0,054$ & $-0,238 * *$ & 0,095 & $0,251^{* *}$ & $0,171^{*}$ \\
\hline 2004 & Anual & $0,122^{*}$ & $-0,129 *$ & $-0,045$ & $-0,089$ & 0,020 & $0,199 * *$ \\
\hline \multirow{2}{*}{$90 \%$} & PPP & 0,018 & 0,018 & 0,018 & 0,088 & $-0,036$ & 0,024 \\
\hline & PRE & 0,089 & 0,163 & $-0,055$ & $0,216^{*}$ & 0,052 & 0,028 \\
\hline \multirow{2}{*}{$95 \%$} & PPP & 0,060 & $-0,075$ & $-0,030$ & $-0,008$ & 0,005 & 0,096 \\
\hline & PRE & 0,101 & $-0,008$ & $-0,090$ & 0,040 & 0,094 & 0,080 \\
\hline \multirow{2}{*}{$98 \%$} & PPP & 0,044 & $-0,121$ & $-0,018$ & $-0,052$ & $-0,009$ & 0,076 \\
\hline & PRE & 0,103 & 0,017 & $-0,078$ & 0,035 & 0,086 & 0,101 \\
\hline 2005 & Anual & $0,128^{*}$ & $-0,212^{\star \star}$ & $-0,164^{\star \star}$ & $-0,078$ & $0,225^{\star *}$ & $0,261^{* *}$ \\
\hline $90 \%$ & PPP & $-0,125$ & $0,197^{*}$ & $-0,076$ & 0,130 & 0,142 & 0,153 \\
\hline $90 \%$ & PRE & $-0,167$ & $0,298 * *$ & $-0,045$ & 0,074 & 0,103 & 0,179 \\
\hline $95 \%$ & PPP & $-0,053$ & 0,079 & $-0,061$ & 0,105 & $0,164^{*}$ & 0,070 \\
\hline & PRE & $-0,151$ & $0,293^{* *}$ & $-0,059$ & 0,029 & 0,145 & 0,188 \\
\hline $98 \%$ & PPP & 0,020 & $-0,064$ & $-0,194$ ** & 0,038 & 0,251 ** & $0,149 *$ \\
\hline $78 \%$ & PRE & $-0,084$ & 0,102 & $-0,301^{* *}$ & 0,029 & 0,297 ** & 0,296 ** \\
\hline 2006 & Anual & 0,024 & $-0,166^{\star \star}$ & 0,083 & $-0,037$ & $-0,061$ & $0,132^{\star}$ \\
\hline $90 \%$ & PPP & 0,055 & $-0,282^{* *}$ & $-0,028$ & $-0,150$ & 0,094 & $-0,074$ \\
\hline $70 \%$ & PRE & 0,214 & - & - & - & - & \\
\hline $95 \%$ & PPP & - & $-0,242^{* *}$ & 0,114 & $-0,099$ & $-0,088$ & $-0,021$ \\
\hline & PRE & 0,058 & - & - & - & - & \\
\hline 980\% & PPP & $-0,049$ & $-0,159$ * & $0,185^{* *}$ & $-0,073$ & $-0,159$ * & 0,081 \\
\hline $70 \%$ & PRE & $-0,134$ & 0,586 & 0,584 & 0,598 & $-0,562$ & 0,325 \\
\hline 2007 & Anual & $0,197^{* *}$ & $-0,159^{* *}$ & $-0,183^{* *}$ & $-0,071$ & $0,251^{* *}$ & $0,140^{\star *}$ \\
\hline $90 \%$ & PPP & $-0,107$ & $0,306^{* *}$ & $-0,161^{* *}$ & $-0,025$ & $0,144^{\star}$ & $-0,085$ \\
\hline $70 \%$ & PRE & 0,005 & $0,227 * *$ & $-0,146$ & 0,019 & 0,161 & $-0,282^{* *}$ \\
\hline & PPP & $-0,102$ & $0,292 * *$ & $-0,128 *$ & $-0,012$ & 0,087 & $-0,069$ \\
\hline & PRE & $-0,016$ & $0,228 * *$ & $-0,156^{*}$ & 0,046 & 0,146 & $-0,229$ ** \\
\hline $98 \%$ & PPP & $-0,032$ & $0,198 * *$ & $-0,139 *$ & $-0,025$ & 0,112 & $-0,056$ \\
\hline $78 \%$ & PRE & $-0,019$ & $0,235^{* *}$ & $-0,136$ & 0,041 & 0,127 & $-0,213^{* *}$ \\
\hline Total & Anual & $-0,08^{* *}$ & $-0,085^{* *}$ & $-0,046^{* *}$ & $-0,036$ & $0,068^{* *}$ & $0,164^{* *}$ \\
\hline
\end{tabular}

Tabla 5.2.2.24. (Continuación). Coeficientes de correlación de Spearman entre Urticaceae y las variables climatológicas. Vemed (velocidad media), FrecCalmas (frecuencia de calmas), V1Cuad, V2Cuad, V3Cuad, V4Cuad (vientos procedentes del I, II, III y IV cuadrante). Significación: $95 \%\left({ }^{*}\right), 99 \%(* *)$. (-) Ausencia de correlaciones. 


\subsubsection{Tipos de polen con una representación superior o igual al 1\% (al menos 1 año)}

\subsubsection{Acer}

La variación interanual (Fig. 5.2.3.1.) nos indica que durante los ocho años de estudio hubo un descenso en las concentraciones de este tipo polínico en la atmósfera de la ciudad de Salamanca, aunque se registró un pequeño aumento en el año 2005. Así pues, el total anual disminuyó desde los 322 a los 96 granos de polen, suponiendo un descenso del 235\% en todo el período estudiado, refrendado ligeramente por el análisis de tendencias a través de la regresión lineal $\left(\mathrm{R}^{2}=0,30\right)$. La representación media de los granos de polen de Acer a lo largo de los ocho años fue de 1,05\%, con un máximo de 2,8\% en 2000 y un mínimo de 0,3\% en 2007.

\section{La variación estacional,} analizada a partir del PPP obtenido a través del 95\% de cada uno de los totales anuales (Tabla 5.2.3.1) mostró una delimitación entre los meses de marzo y junio, con una duración media de 83 días. El comienzo de este PPP experimentó una variación de aproximadamente un mes (11 de marzo de 2002 - 14 abril de 2005), mientras que la fecha de finalización lo hizo en más de dos
Tipo de polen: Acer spp.

Especie(s): Acer monspessulanum L., Acer negundo L., Acer platanoides L., Acer pseudoplatanus L., entre otros. (Aceraceae).

Distribución: Principalmente por las regiones templadas del hemisferio Norte. En la Península Ibérica, aparece como especies acompañantes dentro de formaciones como robledales hayedos o fresnedas en la mitad septentrional. En la provincia de Salamanca, A. monspessulanum $\mathrm{L}$. se localiza en las sierras meridionales entre melojares $\mathrm{y}$, en menor medida, en valles de la zona de Las Arribes. En la ciudad ha sido muy cultivado $A$. negundo $L$. Época de floración: Entre marzo y abril, dependiendo de las especies.

Polinización: Anemófila.

Morfología polínica (Lámina I): Polen trizonocolpado, isopolar y radiosimétrico, con una forma circular a triangular en vista polar $y$ elíptica en vista ecuatorial (de prolato a subprolato), y un tamaño mediano $(P=25-30$ $\mu \mathrm{m})$. Las ectoaberturas tipo colpo se disponen sobre la zona ecuatorial y alcanzan la proximidad de los polos. La exina $(2 \mu \mathrm{m})$, posee una superficie que varía de estriada a rugulada en función de la especie. meses (12 de mayo de 2003 - 21 de julio de 2007), teniendo como fechas promedio de inicio y fin, el 20 de marzo y el 11 de junio.

Los niveles polínicos de este género en la atmósfera de la ciudad de Salamanca (Fig. 5.2.3.2.D.) aumentaron a partir de mediados de marzo hasta alcanzar los valores más elevados a finales de mayo, como muestra el valor medio más elevado en los años analizados (8 granos $/ \mathrm{m}^{3}$ el 25 de mayo), gracias a la dinámica aportada por el porcentaje de 
representación que tuvieron las concentraciones medias de los cincos días anteriores para el total promediado del conjunto de años estudiados. Asimismo, las mayores concentraciones diarias registradas dentro de este período oscilaron entre los 53 granos/m³ (27 de mayo de 2000) y los 4 granos $/ \mathrm{m}^{3}$ (26 de abril de 2002). Posteriormente, estos niveles disminuyeron a inicios de junio, presentándose en niveles bajos durante el resto del mes y en julio (Fig. 5.2.3.2. A. B. C.)

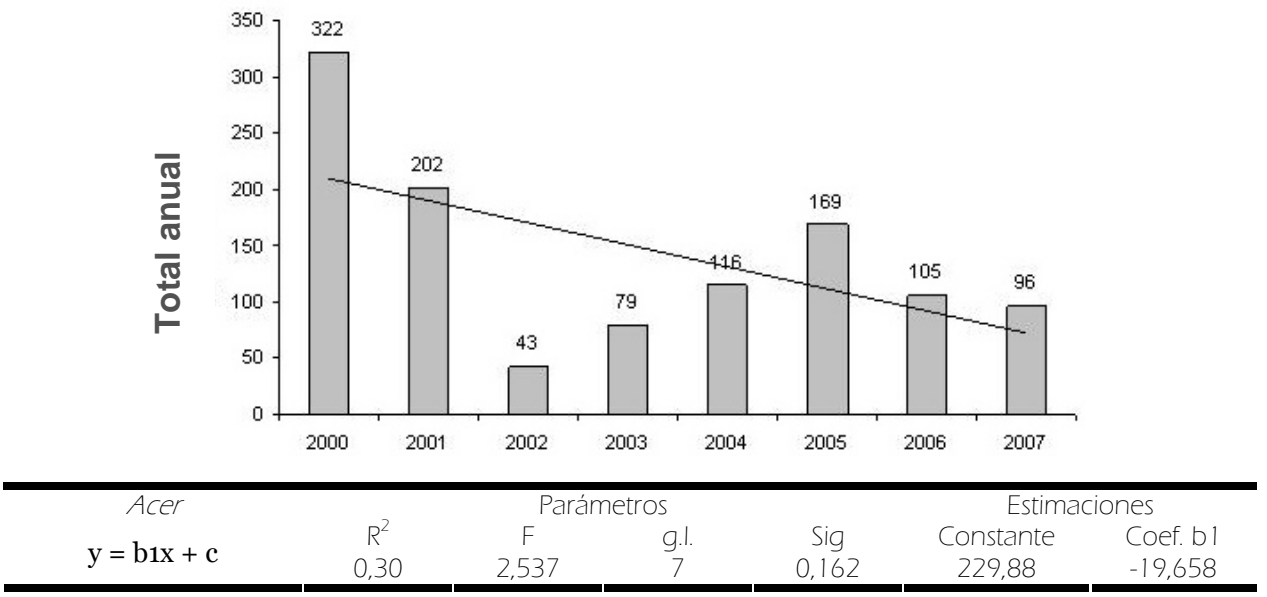

Fig. 5.2.3.1. Evolución anual del número total de pólenes de Acer y tendencias (análisis de regresión).

\begin{tabular}{|c|c|c|c|c|c|c|c|c|c|}
\hline Acer & 2000 & 2001 & 2002 & 2003 & 2004 & 2005 & 2006 & 2007 & Media \\
\hline Total & 322 & 202 & 43 & 79 & 116 & 169 & 105 & 96 & 141 \\
\hline Día & 27-may & 25-may & 26-abr & 12-abr & 03-jun & 14-abr & 31-may & 04-jul & 25-may \\
\hline PPP(días) & 65 & 93 & 83 & 50 & 93 & 62 & 91 & 130 & 83 \\
\hline Inicio & 25-mar & 14-mar & 11-mar & 24-mar & 17-mar & 14-abr & 16-mar & 14-mar & 20-mar \\
\hline $\begin{array}{l}\text { Fin } \\
\text { PRE }\end{array}$ & $\begin{array}{c}28-m a y \\
64\end{array}$ & $\begin{array}{c}\text { 14-jun } \\
73\end{array}$ & $\begin{array}{c}01-j u n \\
47\end{array}$ & $\begin{array}{c}12-m a y \\
20\end{array}$ & $\begin{array}{c}17-j u n \\
78\end{array}$ & 14-jun & $\begin{array}{c}14-j u n \\
77\end{array}$ & $21-j u l$ & $\begin{array}{c}11-j u n \\
67\end{array}$ \\
\hline
\end{tabular}

Tabla 5.2.3.1. Totales, concentraciones máximas diarias, período principal de polinización (PPP; fecha de inicio y fin) y días precedentes al valor máximo (PRE) durante los ocho años de estudio y el promedio de todos los parámetros para Acer.

La variación intradiaria (Fig. 5.2.3.3.) durante un día promedio para el trienio 2005-2007, presentó los mayores niveles horarios en la segunda mitad del día y mostró elevadas concentraciones en la franja horaria entre las 12 y las 13 horas.

El análisis de correlación (Tabla 5.2.3.2.) indicó que las temperaturas medias, máximas y mínimas junto a la insolación influyeron de forma positiva en los niveles polínicos durante los ocho años analizados, mientras que la humedad relativa tuvo un efectos negativos y el resto de parámetros mostraron valores bajos. En todo caso, los coeficientes de correlación de Spearman mostraron valores más elevados durante algunas anualidades (años 2004 y 2005), y dentro de los PPP y PRE de otros años (2000 y 2001), e incluso variaron de signo en los año 2005 y 2007 con la temperatura, o en el año 2005 con la humedad relativa. 
Asimismo, deben reseñarse los distintos signos que presentaron las correlaciones significativas con la dirección del viento en las diferentes anualidades analizadas y en los PPP y PRE de las mismas.

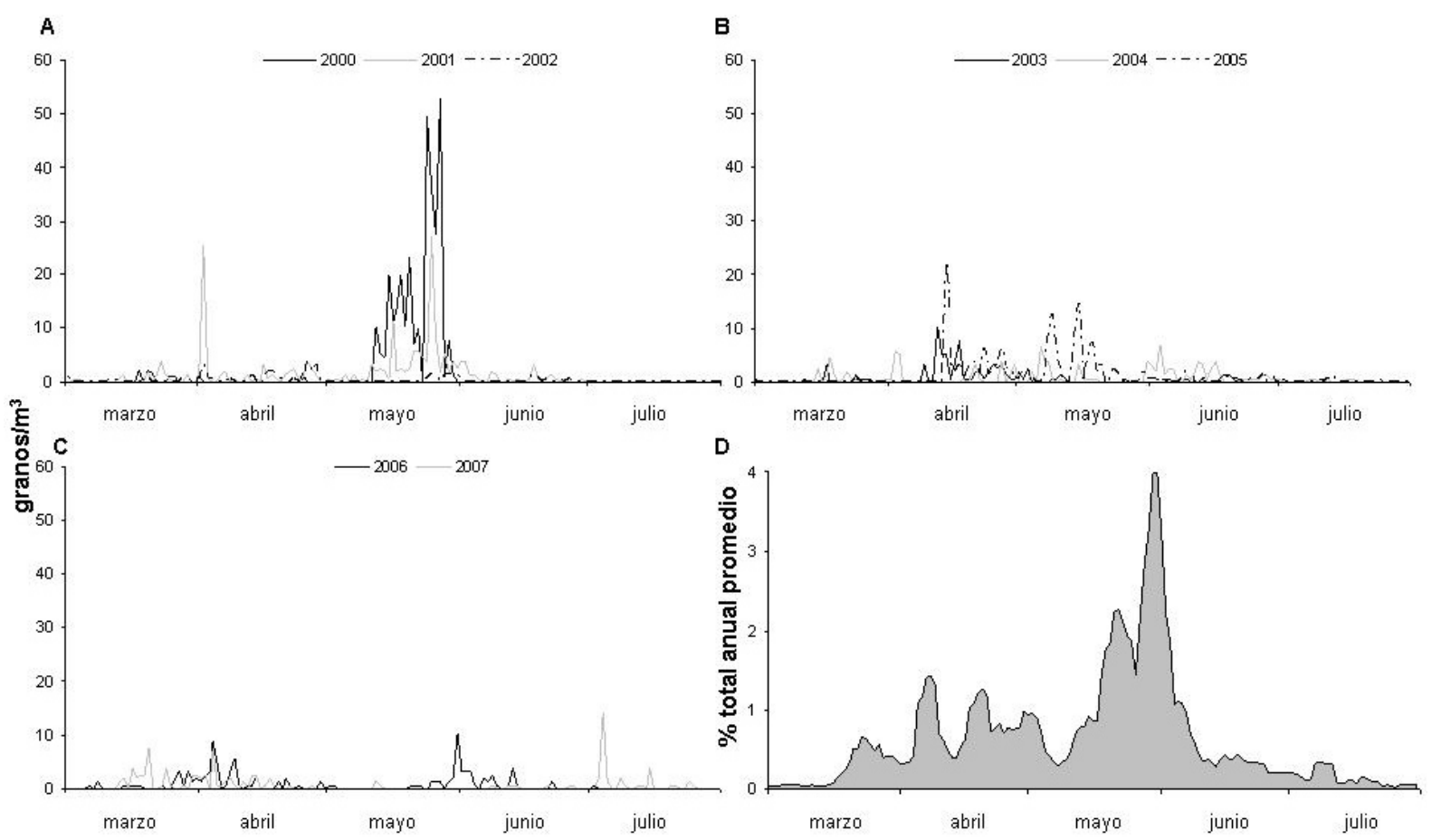

Fig. 5.2.3.2. Variación de las concentraciones medias diarias de Acer durante el período 2000-2002 (A), 20032005 (B) y 2006-2007 (C). Porcentajes de representación diarios para la media de los cinco días anteriores dentro del promedio de los ocho años analizados (D).

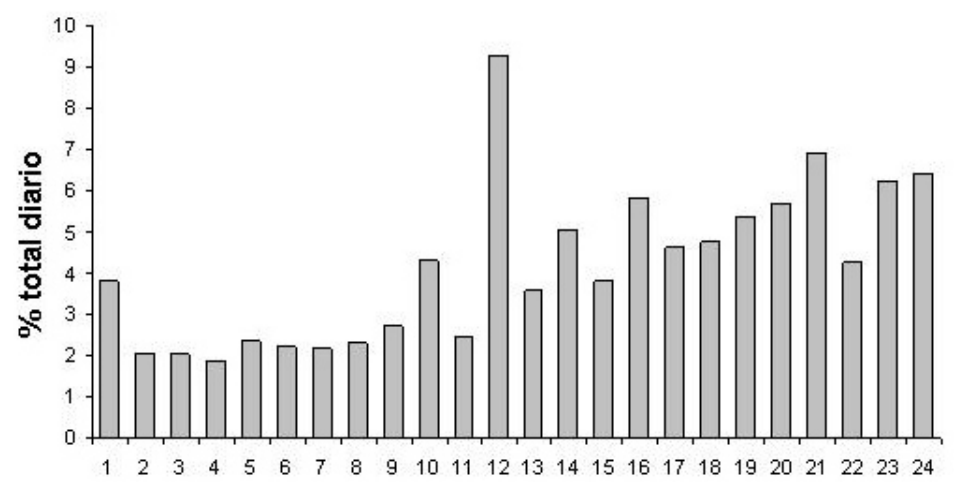

Fig. 5.2.3.3. Variación intradiaria del polen de Acer. 


\begin{tabular}{|c|c|c|c|c|c|c|c|}
\hline \multicolumn{2}{|c|}{ Acer } & Tmed & Tmax & Tmin & Insolación & Precipitación & Hrelativa \\
\hline 2000 & Anual & $0,108^{*}$ & 0,102 & $0,124^{*}$ & 0,079 & $-0,050$ & $-0,050$ \\
\hline \multirow{2}{*}{$95 \%$} & PPP & $0,633^{* *}$ & $0,650^{* *}$ & 0,519 ** & 0,401 ** & $-0,360^{* \star}$ & $-0,294^{* *}$ \\
\hline & PRE & $0,620 * *$ & $0,638 * *$ & $0,506 * *$ & $0,433^{* *}$ & $-0,352 * *$ & $-0,308 * *$ \\
\hline 2001 & Anual & $0,167^{* *}$ & $0,177^{* *}$ & $0,128^{*}$ & $0,251^{* *}$ & $-0,077$ & $-0,285^{\star *}$ \\
\hline \multirow{2}{*}{$95 \%$} & PPP & $0,468 * *$ & $0,453^{* \star}$ & $0,414^{* *}$ & $0,284 * \star$ & $-0,197$ & $-0,355^{* *}$ \\
\hline & PRE & $0,514 * *$ & $0,504 * *$ & $0,385 * *$ & $0,324 * *$ & $-0,182$ & $-0,380 * *$ \\
\hline 2002 & Anual & 0,091 & $0,117^{\star}$ & 0,026 & $0,173^{\star *}$ & $-0,031$ & $-0,272^{\star \star}$ \\
\hline \multirow{2}{*}{$95 \%$} & PPP & $0,249^{*}$ & $0,240^{\star}$ & 0,197 & $0,225^{*}$ & $-0,092$ & $-0,156$ \\
\hline & PRE & 0,208 & 0,181 & 0,269 & 0,171 & 0,009 & $-0,123$ \\
\hline 2003 & Anual & 0,076 & 0,050 & 0,054 & 0,040 & $-0,011$ & $-0,159 * \star$ \\
\hline \multirow{2}{*}{$95 \%$} & PPP & $0,485^{* *}$ & 0,253 & $0,338^{*}$ & $-0,005$ & $-0,117$ & $-0,156$ \\
\hline & PRE & 0,156 & $-0,199$ & 0,396 & $-0,450 * *$ & 0,180 & 0,292 \\
\hline 2004 & Anual & $0,231^{* *}$ & $0,238^{\star \star}$ & $0,191^{* *}$ & $0,296 * \star$ & $-0,029$ & $-0,299$ * \\
\hline \multirow{2}{*}{$95 \%$} & PPP & $0,234 * *$ & $0,253^{* *}$ & 0,199 & $0,243^{*}$ & $-0,060$ & $-0,177$ \\
\hline & PRE & 0,076 & 0,079 & 0,074 & 0,076 & $-0,050$ & $-0,046$ \\
\hline 2005 & Anual & $0,231^{* *}$ & $0,221^{\star \star}$ & $0,199 * *$ & $0,225^{\star *}$ & $-0,041$ & $-0,225^{\star \star}$ \\
\hline \multirow{2}{*}{$95 \%$} & PPP & $-0,44^{\star \star}$ & $-0,36$ * & $-0,50$ ** & $-0,211$ & $-0,103$ & $0,365^{\star \star}$ \\
\hline & PRE & - & - & - & - & - & - \\
\hline 2006 & Anual & $0,104^{* *}$ & $0,131^{\star *}$ & 0,029 & - & $-0,025$ & $-0,330 * \star$ \\
\hline \multirow{2}{*}{$95 \%$} & PPP & 0,060 & 0,108 & $-0,107$ & - & $-0,013$ & $-0,175$ \\
\hline & PRE & $-0,044$ & 0,003 & $-0,214$ & - & 0,010 & $-0,056$ \\
\hline 2007 & Anual & 0,072 & 0,084 & 0,017 & $0,118^{*}$ & 0,025 & $-0,191^{* \star}$ \\
\hline \multirow{2}{*}{$95 \%$} & PPP & $-0,24^{* *}$ & $-0,20$ ** & $-0,28^{* \star}$ & $-0,071$ & $-0,042$ & $-0,026$ \\
\hline & PRE & $-0,36$ ** & $-0,30$ ** & $-0,39 * *$ & $-0,148$ & $-0,014$ & 0,038 \\
\hline Total & Anual & 0,140 ** & $0,144^{\star \star}$ & $0,103^{\star *}$ & $0,183^{\star \star}$ & $-0,035$ & $-0,231^{\star *}$ \\
\hline
\end{tabular}

\begin{tabular}{|c|c|c|c|c|c|c|c|}
\hline \multicolumn{2}{|c|}{ Acer } & Vemed & FrecCalm & VICuadr & V2Cuadr & V3Cuadr & V4Cuadr \\
\hline 2000 & Anual & 0,009 & $-0,098$ & $-0,005$ & $-0,013$ & $-0,011$ & $0,113^{*}$ \\
\hline \multirow{2}{*}{$95 \%$} & PPP & $-0,33 * *$ & 0,149 & 0,139 & 0,032 & $-0,266^{*}$ & $0,278^{*}$ \\
\hline & PRE & $-0,34 * *$ & 0,167 & 0,157 & 0,047 & $-0,287^{*}$ & $0,286 *$ \\
\hline 2001 & Anual & 0,093 & $-0,051$ & $-0,076$ & $-0,141^{* *}$ & $0,107^{\star}$ & $0,191 * \star$ \\
\hline \multirow{2}{*}{$95 \%$} & PPP & $-0,155$ & $0,240^{*}$ & $-0,003$ & 0,047 & $-0,004$ & 0,159 \\
\hline & PRE & $-0,097$ & 0,226 & $-0,019$ & 0,058 & 0,063 & 0,128 \\
\hline 2002 & Anual & $-0,031$ & 0,065 & $-0,062$ & $-0,013$ & 0,099 & $-0,051$ \\
\hline \multirow{2}{*}{$95 \%$} & PPP & $-0,099$ & 0,052 & $-0,139$ & $-0,029$ & 0,111 & 0,186 \\
\hline & PRE & $-0,115$ & 0,139 & $-0,212$ & $-0,063$ & 0,204 & 0,249 \\
\hline 2003 & Anual & $0,123^{*}$ & $-0,109 *$ & $-0,14^{\star \star}$ & 0,061 & $0,112^{*}$ & $-0,075$ \\
\hline \multirow{2}{*}{$95 \%$} & PPP & $-0,037$ & 0,203 & $-0,50$ ** & $0,366^{* *}$ & $0,372^{\star \star}$ & $-0,013$ \\
\hline & PRE & $-0,058$ & 0,116 & $-0,560$ * & 0,293 & $0,468 *$ & $-0,162$ \\
\hline 2004 & Anual & 0,107 * & $-0,079$ & $-0,059$ & $-0,149 * \star$ & 0,021 & $0,162^{\star \star}$ \\
\hline \multirow{2}{*}{$95 \%$} & PPP & $0,214^{\star}$ & 0,118 & $-0,162$ & $-0,072$ & $0,223^{\star}$ & 0,183 \\
\hline & PRE & $0,321^{* *}$ & 0,109 & $-0,31$ ** & $-0,081$ & $0,358 * *$ & $0,255^{* *}$ \\
\hline 2005 & Anual & $0,157^{* *}$ & $-0,197 * \star$ & $-0,19$ ** & $-0,138^{\star \star}$ & $0,193^{\star \star}$ & 0,276 ** \\
\hline \multirow{2}{*}{$95 \%$} & PPP & 0,102 & 0,105 & $-0,312^{*}$ & $-0,037$ & 0,176 & $0,330^{* *}$ \\
\hline & PRE & - & - & - & - & - & - \\
\hline 2006 & Anual & 0,054 & $-0,120^{*}$ & $0,165^{* *}$ & 0,022 & $-0,127^{*}$ & $-0,047$ \\
\hline \multirow{2}{*}{$95 \%$} & PPP & 0,138 & $-0,274^{*}$ & $0,455 * \star$ & $-0,048$ & $-0,360 * *$ & $-0,477^{* *}$ \\
\hline & PRE & 0,166 & $-0,192$ & $0,374^{\star}$ & $-0,060$ & $-0,336$ * & $-0,527 * *$ \\
\hline 2007 & Anual & $0,126^{*}$ & $-0,119 *$ & 0,047 & 0,008 & 0,007 & 0,051 \\
\hline \multirow{2}{*}{$95 \%$} & PPP & $0,177^{\star}$ & $-0,178^{*}$ & $0,200^{*}$ & $-0,004$ & $-0,135$ & $-0,102$ \\
\hline & PRE & 0,167 & $-0,184$ & $0,192^{*}$ & 0,028 & $-0,122$ & $-0,119$ \\
\hline Total & Anual & $0,055^{* *}$ & $-0,072^{* *}$ & $-0,044^{*}$ & $-0,065^{\star *}$ & $0,045^{\star}$ & $0,092 * *$ \\
\hline
\end{tabular}

Tabla 5.2.3.2. Coeficientes de correlación de Spearman entre Acer y las variables climatológicas. Tmed, Tmax,

Tmin (temperatura media, máxima y mínima), Hrelativa (humedad relativa), Vemed (velocidad media),

FrecCalmas (frecuencia de calmas), V1Cuad, V2Cuad, V3Cuad, V4Cuad (vientos procedentes del I, II, III y IV cuadrante). Significación: $95 \%(*), 99 \%(* *)$. (-) Ausencia de correlaciones. 


\subsubsection{Ailanthus}

Los niveles del tipo polínico Ailanthus altissima en la atmósfera de Salamanca, experimentaron un descenso durante el período analizado, ya que si en el año 2000 el total anual alcanzó los 190 pólenes, en el año 2007 fue de 14. Esto supuso que la variación interanual (Fig. 5.2.3.4.) supusiese una gran caída en los niveles de polen de este género (un 1257\% menos). El análisis de regresión de tipo lineal confirma esta tendencia a través del valor que tomó su índice de determinación $\left(\mathrm{R}^{2}=0,68\right)$. La representación media de los pólenes de Ailanthus a lo largo de los ocho años fue de 0,63\%, con un máximo de 1,7\% en 2000 y un mínimo inferior al $0,1 \%$ en 2007.

La distribución de estos granos de polen a lo largo del año se localizó entre mediados de mayo y finales de junio, por lo que la variación estacional (Tabla 5.2.3.3.) tuvo un PPP promedio de 41 días. El inicio de este PPP experimentó una leve variación en la mayor parte de los años estudiados, salvo en los años 2004 y 2007
Tipo polínico: Ailanthus altissima.

Especie(s): Ailanthus altissima (Miller) Swingle. (Simaroubaceae).

Distribución: Originario de las regiones templadas de China, el árbol del cielo ha sido cultivado como ornamental en la Península lbérica, también en la provincia de Salamanca. En la actualidad se ha naturalizado en cunetas, taludes o márgenes de ríos.

Época de floración: Finales de primavera e inicios de veranos (meses de mayo y junio).

Polinización: Entomófila, y de forma secundaria, anemófila.

Morfología polínica: Polen trizonocolporado isopolar y radiosimétrico, con una forma triangular en vista polar y subcircular en vista ecuatorial (de prolato-esferoidal a subprolato) y un tamaño mediano $(P=25-30 \mu \mathrm{m})$. Las ectoaberturas tipo colpo son largas y con constricción ecuatorial, mientras que las endoaberturas tipo poro están ligeramente granuladas en su superficie $y$ poseen un opérculo que se desprende con facilidad. La exina $(2 \mu \mathrm{m})$, posee una superficie estriadoreticulada, casi estriada en las proximidades de las aberturas.

donde se retrasó aproximadamente un mes con respecto a la fecha del resto de años. Así pues, el comienzo varió entre el 12 de mayo de 2003 y el 16 de junio de 2004, al igual que la fecha de finalización, que se situó entre el 28 de mayo de 2002 y el 4 de julio de 2004.

La dinámica de las concentraciones polínicas de Ailanthus (Fig. 5.2.3.5.D.), representada con el porcentaje de representación de las concentraciones medias móviles de los cincos días anteriores con respecto al total anual, presentó un incremento de las concentraciones desde mediados de mayo hasta finales de mayo e inicio de junio, con una concentración máxima de 5 granos/ $\mathrm{m}^{3}$ el día 24 de mayo como media del período 2000-2007 (Tabla 5.2.3.3.). Posteriormente, se registró una disminución en los niveles de polen a finales de junio, manteniéndose en la atmósfera durante la primera mitad de julio. Las 
concentraciones diarias más elevadas dentro de los ocho años (Tabla 5.2.3.3.; Fig. 5.2.3.5.A. B. C.), variaron entre los 40 granos $/ \mathrm{m}^{3}$ (1 de junio de 2000) y los 2 granos $/ \mathrm{m}^{3}$ (21 de junio de 2004).

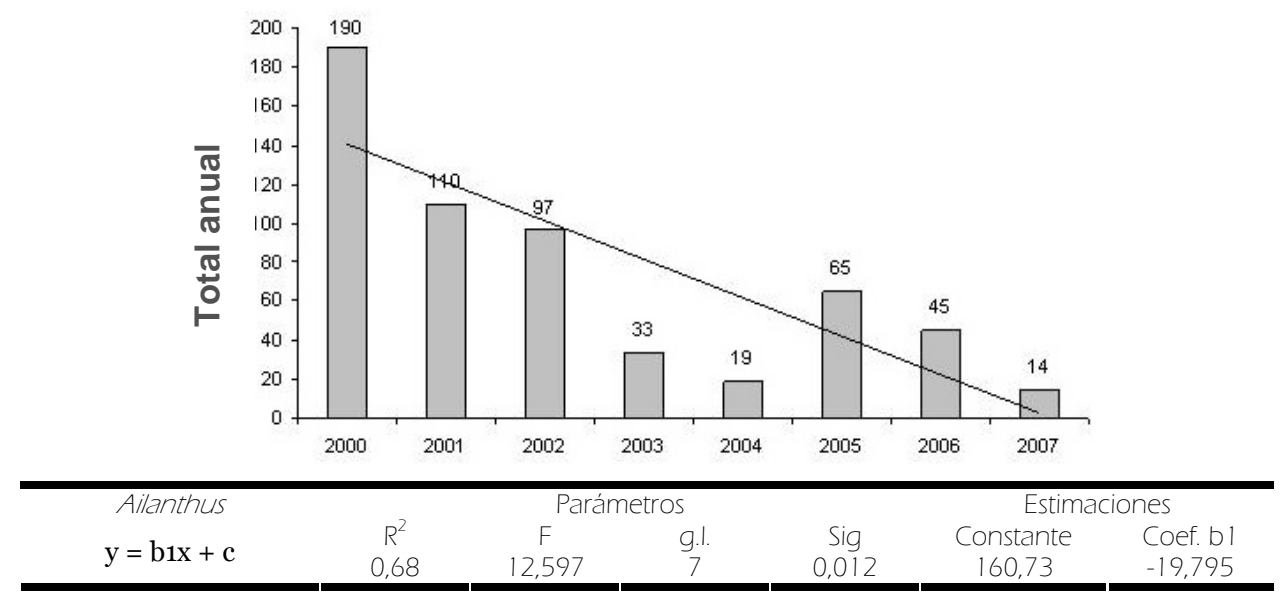

Fig. 5.2.3.4. Evolución anual del número total de pólenes de Ailanthus y tendencias (análisis de regresión).

\begin{tabular}{|c|c|c|c|c|c|c|c|c|c|}
\hline Ailanthus & 2000 & 2001 & 2002 & 2003 & 2004 & 2005 & 2006 & 2007 & Media \\
\hline Total & 190 & 110 & 97 & 33 & 19 & 65 & 45 & 14 & 72 \\
\hline Máximo & 40 & 15 & 21 & 4 & 2 & 4 & 8 & 5 & 5 \\
\hline Día & 01-jun & 24-may & 21-may & 19-may & 21-jun & 21-may & 12-jun & 28-jun & 24-may \\
\hline PPP(días) & 26 & 26 & 17 & 33 & 19 & 45 & 26 & 18 & 41 \\
\hline Inicio & 19-may & 22-may & 12-may & 12-may & 16-jun & 13-may & 28-may & 13-jun & 14-may \\
\hline $\begin{array}{l}\text { Fin } \\
\text { PRE }\end{array}$ & $\begin{array}{c}\text { 13-jun } \\
14\end{array}$ & $\underset{3}{16-j u n}$ & $\begin{array}{c}\text { 28-may } \\
10\end{array}$ & $\begin{array}{c}13-j u n \\
8\end{array}$ & 04-jul & $\begin{array}{c}26-j u n \\
9\end{array}$ & $\begin{array}{c}\text { 22-jun } \\
16\end{array}$ & $\begin{array}{c}30-j u n \\
16\end{array}$ & $\begin{array}{c}\text { 23-jun } \\
10\end{array}$ \\
\hline
\end{tabular}

Tabla 5.2.3.3. Totales, concentraciones máximas diarias, período principal de polinización (PPP; fecha de inicio y fin) y días precedentes al valor máximo (PRE) durante los ocho años de estudio y el promedio de todos los parámetros para Ailanthus.

Las concentraciones de polen presentaron mayores porcentajes de representación en las horas centrales del día, por lo que la variación intradiaria (Fig. 5.2.3.6.) durante un día promedio para el trienio 2005-2007, indicó los mayores niveles entre las 9 y las 17 horas, con más de un $15 \%$ del total diario medio entre las 13 y las 14 horas.

El análisis de correlación (Tabla 5.2.3.4.) reflejó que las temperaturas medias, máximas y mínimas junto a la insolación y los vientos procedentes del IV cuadrante influyeron positivamente en los niveles polínicos de Ailanthus durante los ocho años analizados. Por el contrario, la precipitación y la humedad relativa tuvieron un efecto negativo sobre las concentraciones polínicas. Debe reseñarse que en el PPP del año 2004, los coeficientes de correlación entre los niveles de polen y la temperatura fueron significativamente negativos, algo que también ocurrió con los vientos procedentes del I cuadrante en el PPP del año 2000. 

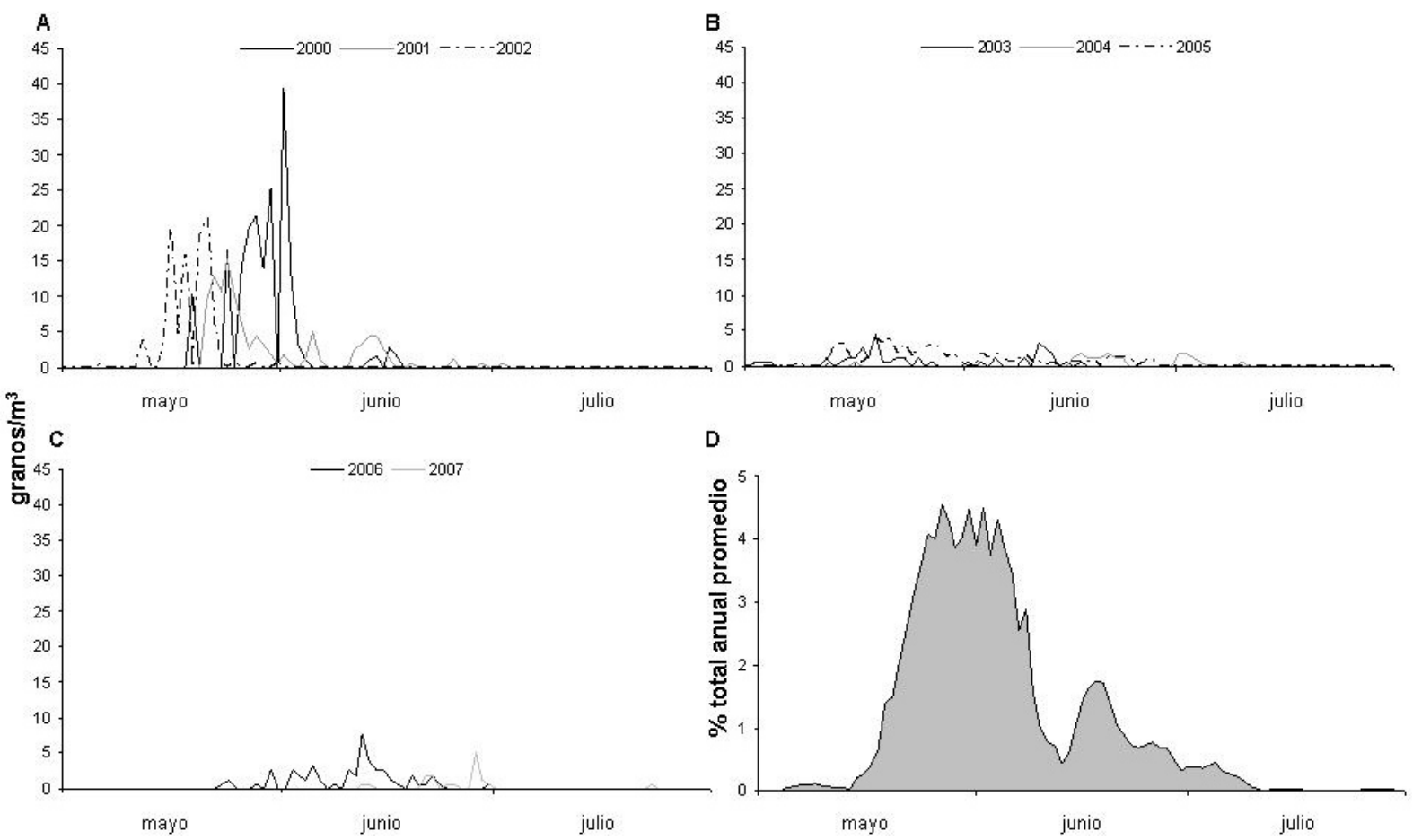

Fig. 5.2.3.5. Variación de las concentraciones medias diarias de Ailanthus durante el período 2000-2002 (A), 2003-2005 (B) y 2006-2007 (C). Porcentajes de representación diarios para la media de los cinco días anteriores dentro del promedio de los ocho años analizados (D).

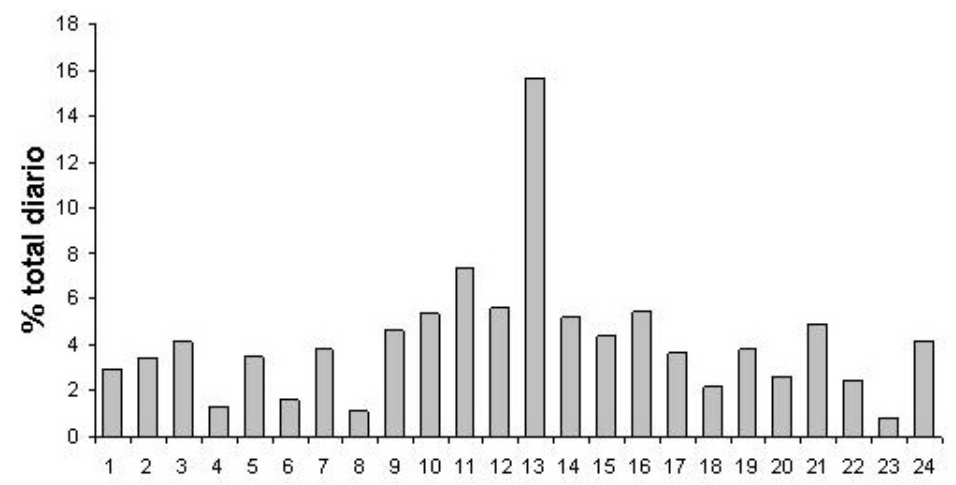

Fig. 5.2.3.6. Variación intradiaria del polen de Ailanthus. 


\begin{tabular}{|c|c|c|c|c|c|c|c|}
\hline \multicolumn{2}{|c|}{ Ailanthus } & Tmed & Tmax & Tmin & Insolación & Precipitación & Hrelativa \\
\hline 2000 & Anual & $0,181^{* *}$ & 0,154 ** & $0,205^{* *}$ & 0,102 & $-0,041$ & $-0,129 *$ \\
\hline \multirow{2}{*}{$95 \%$} & PPP & $0,397^{\star}$ & 0,199 & $0,463^{*}$ & $-0,247$ & 0,123 & 0,192 \\
\hline & PRE & 0,329 & 0,279 & 0,286 & $-0,042$ & 0,092 & $-0,268$ \\
\hline 2001 & Anual & $0,299 * *$ & $0,307^{* *}$ & $0,257^{* *}$ & $0,337 * *$ & $-0,158^{* \star}$ & $-0,340^{* *}$ \\
\hline \multirow{2}{*}{$95 \%$} & PPP & $-0,099$ & $-0,051$ & $-0,230$ & 0,135 & $-0,406^{*}$ & 0,099 \\
\hline & PRE & 0,500 & 0,500 & 0,866 & $-0,500$ & - & $-0,500$ \\
\hline 2002 & Anual & 0,069 & 0,081 & 0,039 & 0,094 & 0,014 & $-0,166^{* *}$ \\
\hline \multirow{2}{*}{$95 \%$} & PPP & 0,244 & 0,178 & 0,359 & $-0,366$ & 0,265 & $-0,145$ \\
\hline & PRE & 0,204 & 0,161 & 0,239 & $-0,443$ & 0,059 & $-0,312$ \\
\hline 2003 & Anual & $0,202^{* *}$ & $0,216^{* *}$ & $0,154^{* *}$ & $0,257 * *$ & $-0,093$ & $-263^{* *}$ \\
\hline \multirow{2}{*}{$95 \%$} & PPP & $-0,010$ & 0,100 & 0,024 & $-0,163$ & 0,041 & 0,014 \\
\hline & PRE & 0,504 & $-0,114$ & 0,520 & $-0,198$ & - & $-0,051$ \\
\hline 2004 & Anual & $0,218^{* *}$ & $0,214^{\star \star}$ & 0,201 ** & $0,237 * *$ & $-0,107^{\star}$ & $-0,227^{\star \star}$ \\
\hline \multirow{2}{*}{$95 \%$} & PPP & $-0,66^{* *}$ & $-0,62^{* \star}$ & $-0,63^{* *}$ & $-0,286$ & - & 0,063 \\
\hline & PRE & - & 0,207 & $-0,207$ & 0,105 & - & $-0,207$ \\
\hline 2005 & Anual & $0,341^{* *}$ & $0,319 * *$ & $0,307^{* *}$ & $0,275^{* *}$ & $-0,035$ & $-0,335^{\star *}$ \\
\hline \multirow{2}{*}{$95 \%$} & PPP & $-0,203$ & $-0,181$ & $-0,264$ & $-0,059$ & $-0,049$ & $-0,057$ \\
\hline & PRE & 0,630 & $0,689 *$ & $0,672^{*}$ & $-0,042$ & $-0,368$ & $-0,570$ \\
\hline 2006 & Anual & 0,257 ** & $0,255^{* *}$ & 0,230 ** & - & 0,022 & $-0,299 * \star$ \\
\hline \multirow{2}{*}{$95 \%$} & PPP & $-0,027$ & $-0,024$ & 0,113 & - & $0,398^{*}$ & 0,098 \\
\hline & PRE & $-0,071$ & $-0,093$ & - & - & 0,429 & 0,239 \\
\hline 2007 & Anual & $0,176^{* *}$ & $0,159 * *$ & $0,144^{* *}$ & $0,157^{* *}$ & $-0,066$ & $-0,154^{\star \star}$ \\
\hline \multirow{2}{*}{$95 \%$} & PPP & 0,225 & 0,362 & $-0,201$ & 0,294 & $-0,451$ & $-0,452$ \\
\hline & PRE & 0,110 & 0,263 & $-0,133$ & 0,212 & $-0,428$ & $-0,358$ \\
\hline Total & Anual & 0,231 ** & 0,223 ** & $0,207 * *$ & $0,217^{* *}$ & $-0,062^{* *}$ & $-0,235$ ** \\
\hline
\end{tabular}

\begin{tabular}{|c|c|c|c|c|c|c|c|}
\hline \multicolumn{2}{|c|}{ Ailanthus } & Vemed & FrecCalm & VICuadr & V2Cuadr & V3Cuadr & V4Cuadr \\
\hline 2000 & Anual & $0,118^{\star}$ & $-0,097$ & $-0,074$ & $-0,057$ & 0,018 & 0,027 \\
\hline \multirow{2}{*}{$95 \%$} & PPP & 0,092 & 0,301 & $-0,50^{* *}$ & $-0,054$ & 0,280 & 0,200 \\
\hline & PRE & 0,430 & 0,102 & $-0,458$ & $-0,116$ & 0,216 & 0,215 \\
\hline 2001 & Anual & $-0,059$ & 0,019 & $-0,045$ & $-0,021$ & 0,014 & $0,248^{* *}$ \\
\hline \multirow{2}{*}{$95 \%$} & PPP & $-0,419$ * & 0,274 & $-0,148$ & 0,151 & $-0,025$ & 0,145 \\
\hline & PRE & 0,500 & $1 * *$ & $-1 * *$ & $-0,500$ & $-1 * *$ & 0,500 \\
\hline 2002 & Anual & $0,110^{*}$ & $-0,034$ & $-0,102$ & $-0,080$ & $0,130^{*}$ & $-0,026$ \\
\hline \multirow{2}{*}{$95 \%$} & PPP & 0,078 & 0,238 & 0,147 & 0,131 & $-0,267$ & 0,157 \\
\hline & PRE & 0,419 & $-0,308$ & $-0,204$ & $-0,437$ & 0,324 & 0,374 \\
\hline 2003 & Anual & 0,044 & $-0,101$ & 0,055 & $-0,046$ & $-0,001$ & 0,018 \\
\hline \multirow{2}{*}{$95 \%$} & PPP & 0,114 & $-0,109$ & $-0,138$ & $-0,084$ & 0,133 & 0,100 \\
\hline & PRE & 0,381 & $-0,281$ & $-0,746 *$ & $-0,274$ & 0,786 * & 0,761 * \\
\hline 2004 & Anual & $-0,036$ & $-0,067$ & $-0,024$ & $-0,033$ & 0,009 & $0,136 * *$ \\
\hline \multirow{2}{*}{$95 \%$} & PPP & $-0,49 * *$ & $-0,381$ & 0,243 & $-0,085$ & $-0,017$ & $-0,357$ \\
\hline & PRE & 0,105 & $0,880^{*}$ & - & 0,420 & 0,414 & $-0,207$ \\
\hline 2005 & Anual & 0,033 & $-0,106^{*}$ & $-0,061$ & $-0,006$ & 0,093 & $0,193^{* *}$ \\
\hline \multirow{2}{*}{$95 \%$} & PPP & $-0,068$ & 0,120 & $-0,201$ & $-0,038$ & 0,043 & 0,150 \\
\hline & PRE & $-0,102$ & 0,453 & $-0,342$ & $-0,013$ & 0,089 & 0,101 \\
\hline 2006 & Anual & $-0,021$ & $-0,036$ & $0,125^{*}$ & 0,040 & $-0,069$ & 0,077 \\
\hline \multirow{2}{*}{$95 \%$} & PPP & 0,031 & $-0,110$ & 0,150 & 0,285 & $-0,165$ & $-0,074$ \\
\hline & PRE & $-0,087$ & 0,136 & 0,123 & 0,061 & $-0,064$ & $-0,079$ \\
\hline 2007 & Anual & 0,069 & 0,012 & $-0,21 * *$ & $-0,140^{* *}$ & $0,186^{\star *}$ & $0,109^{*}$ \\
\hline \multirow{2}{*}{$95 \%$} & PPP & $-0,400$ & 0,222 & 0,018 & $-0,268$ & $-0,237$ & $0,502^{\star}$ \\
\hline & PRE & $-0,312$ & 0,134 & $-0,041$ & $-0,318$ & $-0,183$ & 0,443 \\
\hline Total & Anual & 0,005 & $-0,046^{* *}$ & $-0,029$ & $-0,032$ & 0,033 & $0,107^{* *}$ \\
\hline
\end{tabular}

Tabla 5.2.3.4. Coeficientes de correlación de Spearman entre Ailanthus y las variables climatológicas. Tmed,

Tmax, Tmin (temperatura media, máxima y mínima), Hrelativa (humedad relativa), Vemed (velocidad media), FrecCalmas (frecuencia de calmas), V1Cuad, V2Cuad, V3Cuad, V4Cuad (vientos procedentes del I, II, III y IV cuadrante). Significación: 95\%(*), 99\%(**). (-) Ausencia de correlaciones. 


\subsubsection{Alnus}

La variación interanual (Fig. 5.2.3.7.) de este tipo polínico en la atmósfera de la ciudad de Salamanca indicó un incremento en los niveles polínicos anuales durante el período 2000-2007, reflejados en los totales anuales con 122 granos de polen del año 2000 y 189 del año 2007, aunque fueron los años 2001 y 2005, con 74 y 255, respectivamente, los que presentaron los menores y mayores valores anuales . Esto supuso un aumento del 55\% y, tras aplicar el análisis de tendencias mediante regresión lineal, un índice de determinación $\left(\mathrm{R}^{2}=0,49\right)$, que confirma esta dinámica. Por otro lado, el porcentaje de representación sobre el total de pólenes contabilizados en cada anualidad analizada osciló entre el 1,9\% del año 2002 al o,6\% de los años 2004 y 2007, siendo $1 \%$ el porcentaje medio.

La variación estacional de Alnus en la atmósfera de Salamanca, a través del cálculo del PPP con el método del 95\% del total anual (Tabla 5.2.3.5.) se localizó en febrero y marzo, con una duración media de
Tipo polínico: Alnus glutinosa.

Especie(s): Alnus glutinosa (L.) Gaertner (Betulaceae).

Distribución: Extendido por gran parte de Europa, Asia y noroeste de África. En la Península lbérica se presenta fundamentalmente en su mitad norte $y$ occidental $y$, al igual, que en la provincia de Salamanca, prospera en márgenes de ríos y zonas de umbría, formando parte de bosques de galería.

Época de floración: Invernal, en los meses de enero y febrero.

Polinización: Anemófila.

Morfología polínica (Lámina I): Polen pentazonocolporado (a veces, con 4, 6 ó 7 aberturas), subisopolar y radiosimétrico, con forma de cuadrangular a heptagonal en vista polar y elíptica-plano convexa en vista ecuatorial, $y$ un tamaño pequeño-mediano $(P=$ 13-38 $\mu \mathrm{m})$. Las ectoaberturas tipo colpo poseen bordes engrosados por la formación de un vestíbulo y coinciden con las endoaberturas tipo poro. La fina exina $(1 \mu \mathrm{m})$, posee una superficie rugulada, escábrida o levemente equinulada en los elementos supratectales y punteada en los arcos. 41 días. Por tanto, el PPP promedio se localizó entre el 15 de enero y el 25 de febrero, mostrando variaciones en la fecha de inicio (4 de enero de 2004 - 31 de enero de 2000) y de finalización (14 de febrero de 2004 - 10 de marzo de 2006).

La evolución de los niveles de polen a través del porcentaje de representación de la media de los 5 días anteriores promedio con respecto al total promediado, nos mostró un aumento desde la segunda semana de enero hasta mediados de febrero (Fig. 5.2.3.8.D.), presentando una concentración máxima de 11 granos $/ \mathrm{m}^{3}$ el día 13 de febrero como media de los ocho años estudiados (Tabla 5.2.3.5.). Las mayores concentraciones diarias para los años estudiados variaron tanto en número como en la fecha en la que se produjeron (Tabla 5.2.3.5.; Fig. 5.2.3.8. A.B.C.), oscilando entre 57 granos $/ \mathrm{m}^{3}$ (13 febrero de 2005) у 8 
granos $/ \mathrm{m}^{3}$ (28 enero de 2003). Posteriormente, las concentraciones de polen fueron disminuyendo a finales de febrero, con registros puntuales en el mes de marzo.

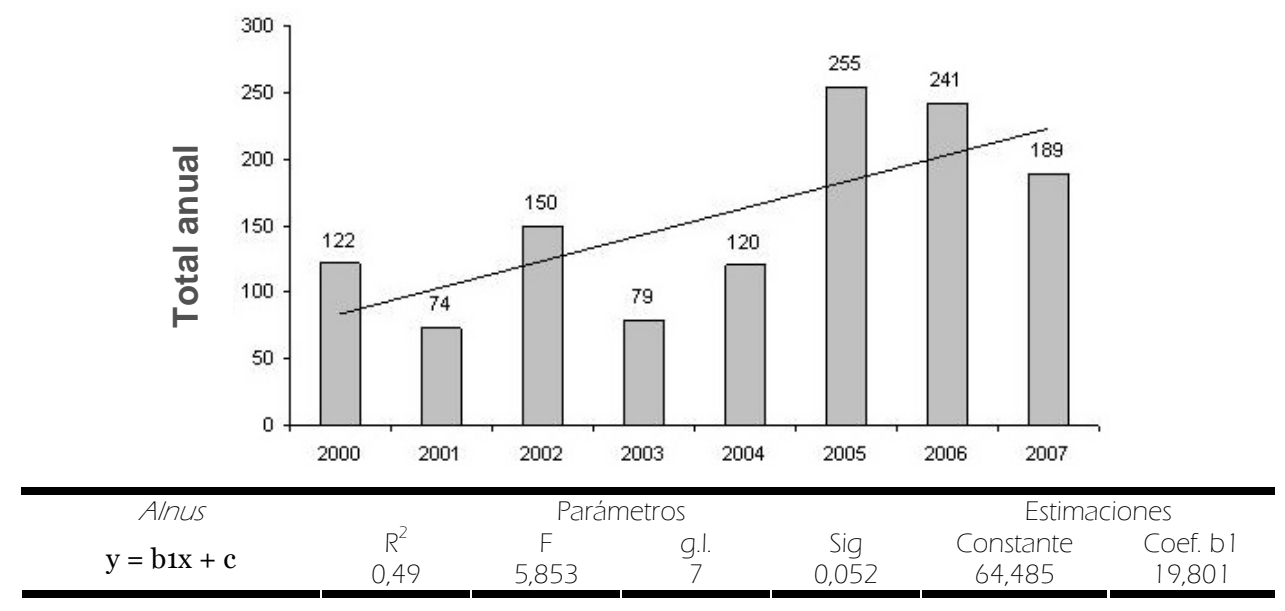

Fig. 5.2.3.7. Evolución anual del número total de pólenes de Alnus y tendencias (análisis de regresión).

\begin{tabular}{|c|c|c|c|c|c|c|c|c|c|}
\hline AlnuS & 2000 & 2001 & 2002 & 2003 & 2004 & 2005 & 2006 & 2007 & Media \\
\hline Total & 122 & 74 & 150 & 79 & 120 & 255 & 241 & 189 & 154 \\
\hline \multicolumn{10}{|l|}{$95 \%$} \\
\hline PPP(días) & 28 & 46 & 35 & 33 & 42 & 45 & 57 & 42 & 41 \\
\hline Inicio & 31-ene & o6-ene & 19-ene & 21-ene & 04-ene & 15-ene & 14-ene & 17-ene & 15-ene \\
\hline Fin & 27-feb & 20-feb & 22-feb & 22-feb & 14-feb & 28-feb & 10-mar & 27-feb & 25 -feb \\
\hline
\end{tabular}

Tabla 5.2.3.5. Totales, concentraciones máximas diarias, período principal de polinización (PPP; fecha de inicio y fin) y días precedentes al valor máximo (PRE) durante los ocho años de estudio y el promedio de todos los parámetros para Alnus.

Las concentraciones de polen a lo largo del día se incrementaron a partir de las 17 horas hasta la medianoche. Por tanto, la variación intradiaria (Fig. 5.2.3.9.) durante un día promedio en el período 2005-2007, presentó los mayores niveles horarios durante las últimas horas de la tarde y las primeras horas de la noche.

La humedad relativa ejerció una influencia positiva en las concentraciones de polen de Alnus durante los ocho años analizados, mientras que las temperaturas medias, máximas y mínimas junto a la insolación lo hicieron de forma negativa, después de efectuar el análisis de correlación (Tabla 5.2.3.6.). No obstante, el signo de estas correlaciones varió durante los PPP y PRE de algunos años, como en el PPP de los años 2002 y 2007 o en el PRE de los años 2004 y 2006 para la temperatura, o en el PPP y PRE del año 2006 para la humedad relativa. Algo similar ocurre con los vientos procedentes del I y III cuadrante, durante el PPP y el PRE de los años 2005 y 2007, con influencia negativa y positiva, respectivamente sobre los niveles de polen. 


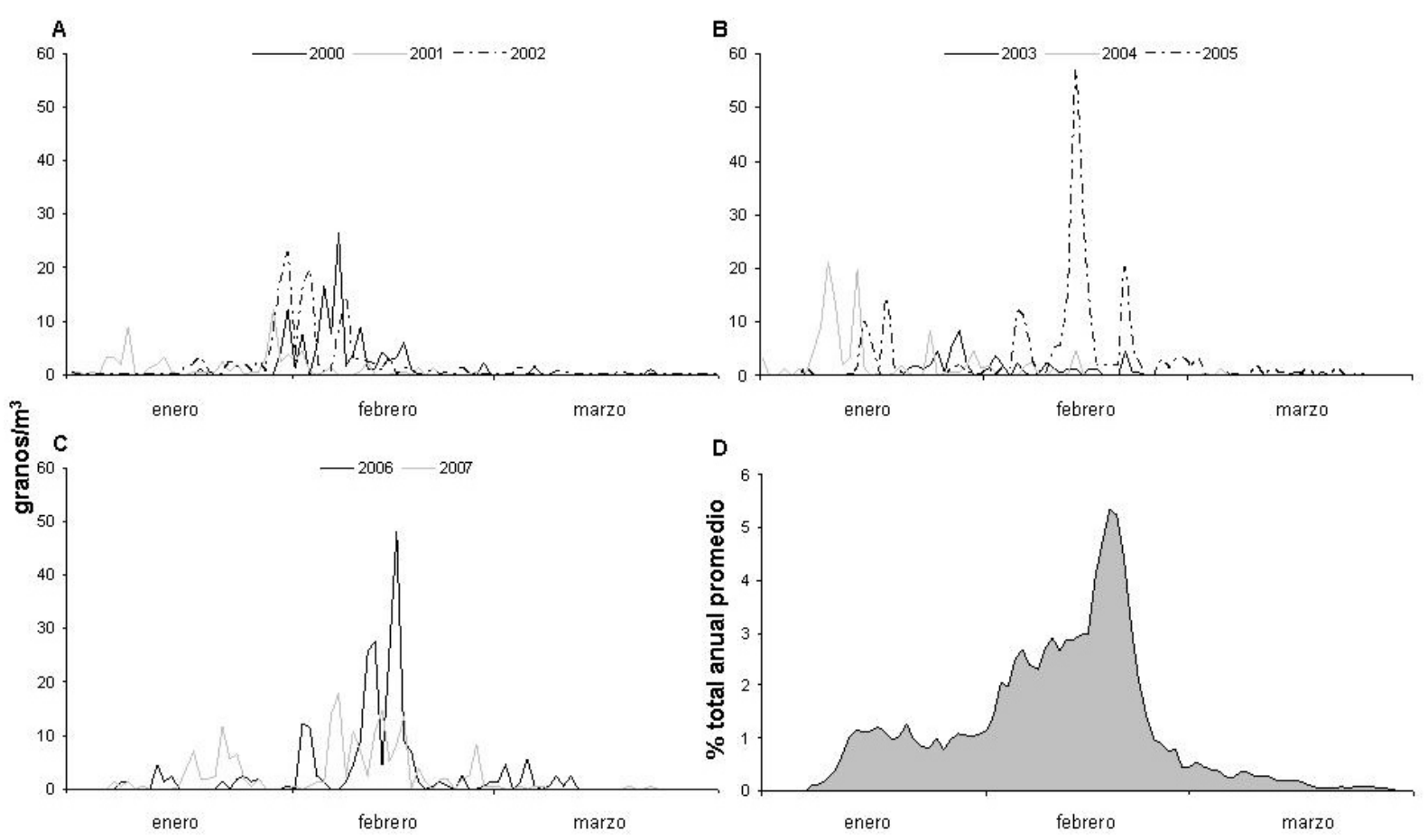

Fig. 5.2.3.8. Variación de las concentraciones medias diarias de Alnus durante el período 2000-2002 (A), 20032005 (B) y 2006-2007 (C). Porcentajes de representación diarios para la media de los cinco días anteriores dentro del promedio de los ocho años analizados (D).

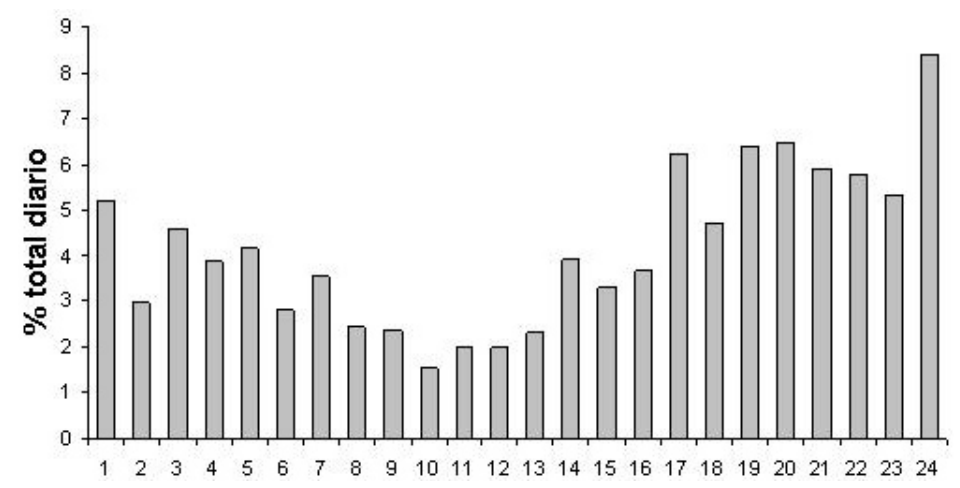

Fig. 5.2.3.9. Variación intradiaria del polen de Alnus. 


\begin{tabular}{|c|c|c|c|c|c|c|c|}
\hline \multicolumn{2}{|c|}{ Alnus } & Tmed & Tmax & Tmin & Insolación & Precipitación & Hrelativa \\
\hline 2000 & Anual & $-0,20$ ** & $-0,13^{*}$ & $-0,24 * *$ & $-0,090$ & $-0,076$ & 0,101 \\
\hline \multirow{2}{*}{$95 \%$} & PPP & $-0,158$ & $-0,343$ & 0,124 & $-0,475^{\star}$ & $-0,070$ & 0,335 \\
\hline & PRE & 0,252 & 0,199 & 0,074 & $-0,012$ & $-0,415$ & $-0,657$ \\
\hline 2001 & Anual & $-0,30$ ** & $-0,34^{* *}$ & $-0,25$ ** & $-0,22^{* *}$ & $0,118^{*}$ & $0,331^{* *}$ \\
\hline \multirow{2}{*}{$95 \%$} & PPP & $-0,050$ & 0,136 & $-0,206$ & 0,266 & $-0,185$ & $-0,201$ \\
\hline & PRE & $-0,308$ & $-0,066$ & $-0,448 *$ & 0,300 & $-0,306$ & $-0,304$ \\
\hline 2002 & Anual & $-0,34$ ** & $-0,26$ ** & $-0,37 * *$ & $-0,183^{* \star}$ & $-0,095$ & $0,125^{*}$ \\
\hline \multirow{2}{*}{$95 \%$} & PPP & $0,391^{*}$ & $0,349 *$ & 0,321 & $-0,148$ & 0,008 & 0,015 \\
\hline & PRE & 0,306 & 0,284 & 0,227 & $-0,097$ & $-0,091$ & $-0,441$ \\
\hline 2003 & Anual & $-0,39$ ** & $-0,37^{* *}$ & $-0,38^{* *}$ & $-0,148^{\star *}$ & $-0,023$ & $0,246^{* *}$ \\
\hline \multirow{2}{*}{$95 \%$} & PPP & 0,160 & $0,351^{*}$ & $-0,013$ & 0,326 & 0,136 & $-0,040$ \\
\hline & PRE & 0,205 & 0,315 & $-0,012$ & 0,461 & $-0,221$ & 0,542 \\
\hline 2004 & Anual & $-0,24$ * & $-0,23^{\star \star}$ & $-0,24$ ** & $-0,204^{\star \star}$ & 0,019 & $0,238^{\star \star}$ \\
\hline \multirow{2}{*}{$95 \%$} & PPP & 0,209 & 0,031 & $0,345^{*}$ & $-0,379 *$ & 0,217 & 0,246 \\
\hline & PRE & $0,811 *$ & $0,757^{*}$ & $0,826 *$ & $-0,847$ * & 0,206 & $-0,464$ \\
\hline 2005 & Anual & $-0,39 *$ & $-0,34^{* *}$ & $-0,42^{* *}$ & $-0,159^{* *}$ & $-0,083$ & $0,145^{* *}$ \\
\hline \multirow{2}{*}{$95 \%$} & PPP & 0,254 & $0,300^{*}$ & $-0,245$ & 0,262 & 0,025 & $-0,339$ * \\
\hline & PRE & 0,291 & 0,320 & $-0,114$ & $-0,052$ & 0,246 & $-0,089$ \\
\hline 2006 & Anual & $-0,38^{* *}$ & $-0,36^{* *}$ & $-0,38$ ** & $0,379 * *$ & $-0,069$ & $0,185^{* *}$ \\
\hline \multirow{2}{*}{$95 \%$} & PPP & 0,243 & $0,46^{* *}$ & 0,036 & $0,368^{* *}$ & $-0,157$ & $-0,430^{\star \star}$ \\
\hline & PRE & $0,388^{*}$ & 0,570 ** & 0,146 & 0,343 & $-0,210$ & $-0,493^{* *}$ \\
\hline 2007 & Anual & $-0,30^{* *}$ & $-0,36^{* *}$ & $-0,23^{* *}$ & $-0,280^{* *}$ & $0,166^{* *}$ & $0,323^{* *}$ \\
\hline \multirow{2}{*}{$95 \%$} & PPP & 0,406 ** & $0,422^{* *}$ & 0,249 & $0,330^{*}$ & 0,068 & $-0,224$ \\
\hline & PRE & 0,377 & 0,290 & $0,435^{*}$ & 0,077 & 0,079 & $-0,055$ \\
\hline Total & Anual & $-0,32^{* \star}$ & $-0,31$ ** & $-0,31$ ** & $-0,178^{\star \star}$ & $-0,007$ & $0,209 * *$ \\
\hline
\end{tabular}

\begin{tabular}{|c|c|c|c|c|c|c|c|}
\hline \multicolumn{2}{|c|}{ Alnus } & Vemed & FrecCalm & VICuadr & V2Cuadr & V3Cuadr & V4Cuadr \\
\hline 2000 & Anual & $-0,084$ & 0,098 & 0,017 & 0,054 & $-0,006$ & 0,034 \\
\hline \multirow{2}{*}{$95 \%$} & PPP & 0,163 & $-0,077$ & $-0,360$ & $-0,247$ & $0,452^{*}$ & 0,183 \\
\hline & PRE & $-0,299$ & 0,012 & $-0,476$ & $-0,299$ & 0,373 & 0,323 \\
\hline 2001 & Anual & 0,056 & $-0,026$ & $-0,15^{\star *}$ & $-0,064$ & $0,143^{* *}$ & $-0,041$ \\
\hline \multirow{2}{*}{$95 \%$} & PPP & $-0,119$ & $0,353^{*}$ & 0,060 & 0,134 & $-0,188$ & $0,433^{\star *}$ \\
\hline & PRE & 0,054 & 0,443 & 0,471 * & 0,288 & $-0,625 * *$ & $0,512^{*}$ \\
\hline 2002 & Anual & $-0,080$ & $0,136 *$ & $-0,012$ & $0,124 *$ & $-0,002$ & $-0,158 * *$ \\
\hline \multirow{2}{*}{$95 \%$} & PPP & $-0,192$ & $-0,031$ & $-0,152$ & 0,155 & 0,156 & $-0,053$ \\
\hline & PRE & $-0,177$ & $-0,191$ & 0,241 & 0,143 & $-0,194$ & 0,017 \\
\hline 2003 & Anual & $-0,063$ & 0,071 & 0,012 & 0,007 & $-0,043$ & 0,026 \\
\hline \multirow{2}{*}{$95 \%$} & PPP & $-0,040$ & 0,215 & $-0,082$ & $-0,186$ & 0,296 & 0,072 \\
\hline & PRE & 0,299 & $-0,127$ & 0,600 & $-0,253$ & $-0,158$ & 0,424 \\
\hline 2004 & Anual & 0,039 & 0,026 & $-0,105^{\star}$ & 0,018 & $0,139 * *$ & $-0,081$ \\
\hline \multirow{2}{*}{$95 \%$} & PPP & $0,353^{*}$ & $-0,304$ & $-0,371^{*}$ & $-0,260$ & $0,326^{*}$ & 0,122 \\
\hline & PRE & 0,468 & $-0,855^{*}$ & $-0,764^{*}$ & $-0,673$ & 0,595 & 0,541 \\
\hline 2005 & Anual & $-0,008$ & 0,003 & 0,075 & 0,098 & $-0,032$ & $-0,064$ \\
\hline \multirow{2}{*}{$95 \%$} & PPP & $-0,111$ & 0,142 & $-0,50$ ** & 0,244 & $0,445^{* *}$ & $0,427 * \star$ \\
\hline & PRE & $-0,313$ & 0,196 & $-0,60 * *$ & 0,328 & $0,508 * *$ & $0,488 * *$ \\
\hline 2006 & Anual & $-0,032$ & $0,116^{*}$ & 0,005 & 0,019 & $-0,028$ & $-0,032$ \\
\hline \multirow{2}{*}{$95 \%$} & PPP & 0,100 & $-0,070$ & $-0,270$ & 0,009 & 0,201 & 0,178 \\
\hline & PRE & 0,095 & $-0,055$ & $-0,273$ & 0,070 & 0,192 & 0,170 \\
\hline 2007 & Anual & 0,270 ** & $-0,346$ ** & $-0,26 * *$ & $-0,065$ & 0,283 ** & 0,058 \\
\hline \multirow{2}{*}{$95 \%$} & PPP & 0,249 & $-0,038$ & $-0,375^{*}$ & $-0,128$ & $0,422 * *$ & 0,151 \\
\hline & PRE & 0,218 & $-0,026$ & $-0,75 * *$ & $-0,338$ & $0,744 * *$ & 0,258 \\
\hline Total & Anual & $-0,013$ & $-0,010$ & $-0,048^{*}$ & 0,031 & $0,058 *$ & $-0,033$ \\
\hline
\end{tabular}

Tabla 5.2.3.6. Coeficientes de correlación de Spearman entre Alnus y las variables climatológicas. Tmed,

Tmax, Tmin (temperatura media, máxima y mínima), Hrelativa (humedad relativa), Vemed (velocidad media), FrecCalmas (frecuencia de calmas), V1Cuad, V2Cuad, V3Cuad, V4Cuad (vientos procedentes del I, II, III y IV cuadrante). Significación: 95\%(*), 99\%(**). (-) Ausencia de correlaciones. 


\subsubsection{Artemisia}

El tipo de polen que incluye al género Artemisia L., incrementó sus niveles polínicos durante el período analizado, con una variación interanual (Fig. 5.2.3.10.) que pasó de un total de 19 en el año 2000 a los 67 del año 2007. Esta evolución en el número total de granos de polen de este género (un 253\% más en los ocho años) dio lugar a un índice de determinación $\left(\mathrm{R}^{2}=0,44\right)$, propio de la regresión lineal que indicó también una tendencia al incremento. Los porcentajes de representación sobre el total de pólenes contabilizados en cada anualidad estudiada variaron del 1\% del año 2003 al 0,1\% de 2002 a 2004, con un porcentaje medio del $0,3 \%$.

La distribución de estos granos de polen a lo largo del año fue amplia, localizándose principalmente entre junio y septiembre, por lo que la variación estacional (Tabla 5.2.3.7.) tuvo un PPP para las concentraciones medias de los ocho años de 92 días. Esta variación se hizo
Tipo de polen: Artemisia spp.

Especie(s): Artemisia campestris L., Artemisia vulgaris L., de forma principal (Compositae).

Distribución: Género diversificado por toda Europa que, en la Península Ibérica y la provincia de Salamanca, se localiza sobre hábitats diversos, principalmente, en lugares secos, bordes de caminos, terrenos alterados o suelos salinos.

Época de floración: De mayo a octubre, en función de la especie, aunque la mayoría florece a finales de verano y comienzo de otoño.

Polinización: anemófila.

Morfología polínica (Lámina l): polen trizonocolporado, isopolar y radiosimétrico, con una forma de circular-lobulada a subtriangular en vista polar y circular en vista ecuatorial (de suboblato a prolato-esferoidal), y un tamaño pequeño-mediano $(\mathrm{P}=18-28 \mu \mathrm{m})$. Las ectoaberturas tipo colpo son estrechas, $y$ las endoaberturas tipo poro se disponen en el ecuador. La exina gruesa $(2-4,5 \mu \mathrm{m})$ posee una superficie equinulado-granulada, con elementos ornamentales a modo de espínulas, nunca superiores a $1 \mu \mathrm{m}$. evidente al observar las diferencias en las fechas de inicio del PPP (31 de mayo de $2000-8$ de agosto de 2002), calculado con el método del 95\% de las concentraciones totales anuales y finalización (5 de agosto de 2004 - 25 de octubre de 2005).

Atendiendo al porcentaje que representó la media diaria de los cinco días anteriores para el conjunto de años estudiados con respecto al total promedio, los granos de polen de este género comenzaron a contabilizarse en la atmósfera de la ciudad de Salamanca (Fig. 5.2.3.11.D.) a finales de mayo e inicios de junio, experimentando un ascenso en los meses de agosto y septiembre, como indica el valor medio más elevado en los años analizados (2 granos $/ \mathrm{m}^{3}$ el 8 de septiembre). Estas mayores concentraciones diarias registradas en los ocho años estudiados, variables en número y fecha (Tabla 5.2.3.7.; Fig. 5.2.3.11. A. B. C.), oscilaron entre los 9 granos $/ \mathrm{m}^{3}$ (12 de septiembre de 2003) y los 2 granos $/ \mathrm{m}^{3}$ (8 de agosto de 2002). 
Posteriormente, los niveles polínicos disminuyeron a finales de septiembre, mostrando bajas concentraciones en octubre.

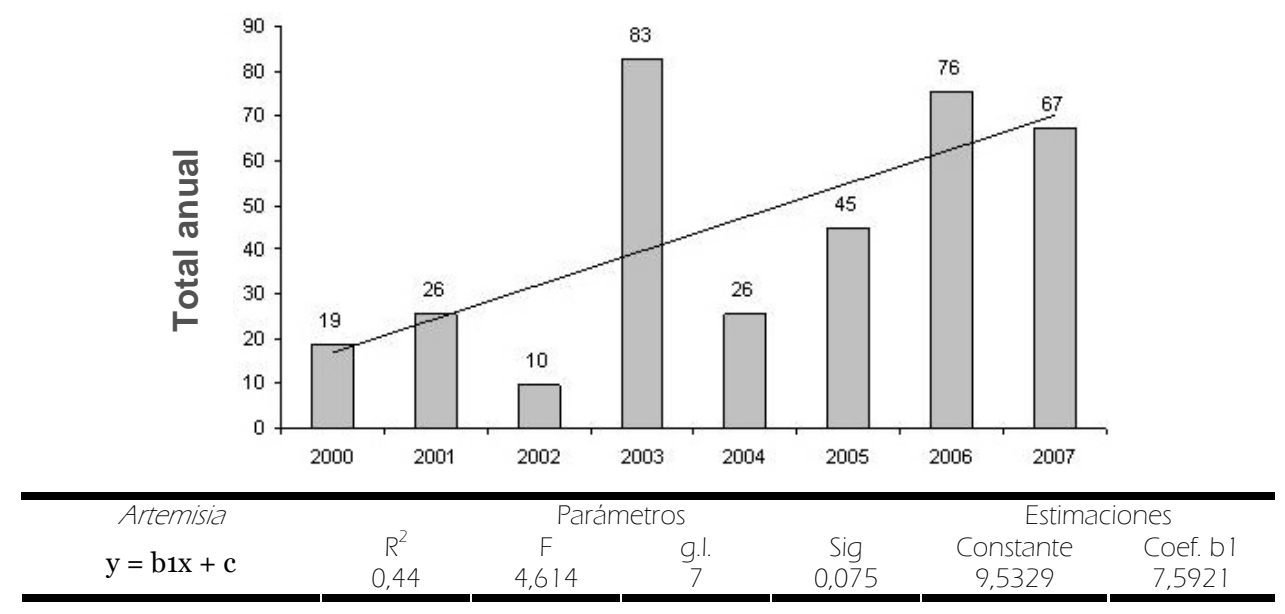

Fig. 5.2.3.10. Evolución anual del número total de pólenes de Artemisia y tendencias (análisis de regresión).

\begin{tabular}{|c|c|c|c|c|c|c|c|c|c|}
\hline Artemisia & 2000 & 2001 & 2002 & 2003 & 2004 & 2005 & 2006 & 2007 & Media \\
\hline Total & 19 & 26 & 10 & 83 & 26 & 45 & 76 & 67 & 44 \\
\hline Máximo & 4 & 3 & 2 & 9 & 3 & 4 & 6 & 4 & 2 \\
\hline Día & 01-jun & 10-sep & 08-ago & 12-sep & 04-sep & 26-jul & 08-sep & 02-sep & 08-sep \\
\hline PPP(días) & 89 & 74 & 75 & 89 & 61 & 96 & 70 & 95 & 92 \\
\hline Inicio & 31-may & 21-jul & 08-ago & 23-jul & 01 -ago & 22-jul & 12-jul & 27-jun & 22-jun \\
\hline $\begin{array}{l}\text { Fin } \\
\text { PRE }\end{array}$ & $\begin{array}{c}27 \text {-ago } \\
2\end{array}$ & $\begin{array}{c}\text { 02-oct } \\
52\end{array}$ & $\begin{array}{c}21-\mathrm{oct} \\
1\end{array}$ & $\begin{array}{c}19-\text { oct } \\
52\end{array}$ & $\begin{array}{c}05 \text {-ago } \\
5\end{array}$ & $\begin{array}{c}25 \text {-oct } \\
5\end{array}$ & $\begin{array}{c}19-\text { sep } \\
59\end{array}$ & $\begin{array}{c}29-\text { sep } \\
68\end{array}$ & $\begin{array}{c}21-\text { sep } \\
79\end{array}$ \\
\hline
\end{tabular}

Tabla 5.2.3.7. Totales, concentraciones máximas diarias, período principal de polinización (PPP; fecha de inicio y fin) y días precedentes al valor máximo (PRE) durante los ocho años de estudio y el promedio de todos los parámetros para Artemisia.

La variación intradiaria (Fig. 5.2.3.12.) mostró un claro patrón a lo largo de un día promedio para los últimos tres años estudiados, por el que los niveles de polen aumentaron desde las 12 horas del día hasta las 20 horas, momento en el que comienzan a disminuir las concentraciones hasta las últimas horas del día. Así pues, las mayores concentraciones polínicas de Artemisia se concentraron en las segunda mitad del día.

El análisis de correlación (Tabla 5.2.3.8.) reflejó que las temperaturas medias, máximas y mínimas junto a la insolación y los vientos procedentes del I cuadrante influyeron positivamente en los niveles polínicos durante los ocho años analizados. Por el contrario, la precipitación, la humedad relativa, la velocidad media del viento, así como los vientos procedentes del III cuadrante ejercieron un efecto negativo sobre las concentraciones polínicas. Los coeficientes de correlación obtenidos en los años analizados y los PPP y PRE definidos no aportaron, salvo casos particulares como la influencia negativa de la temperatura mínima durante el PRE del año 2005, mayor información. 


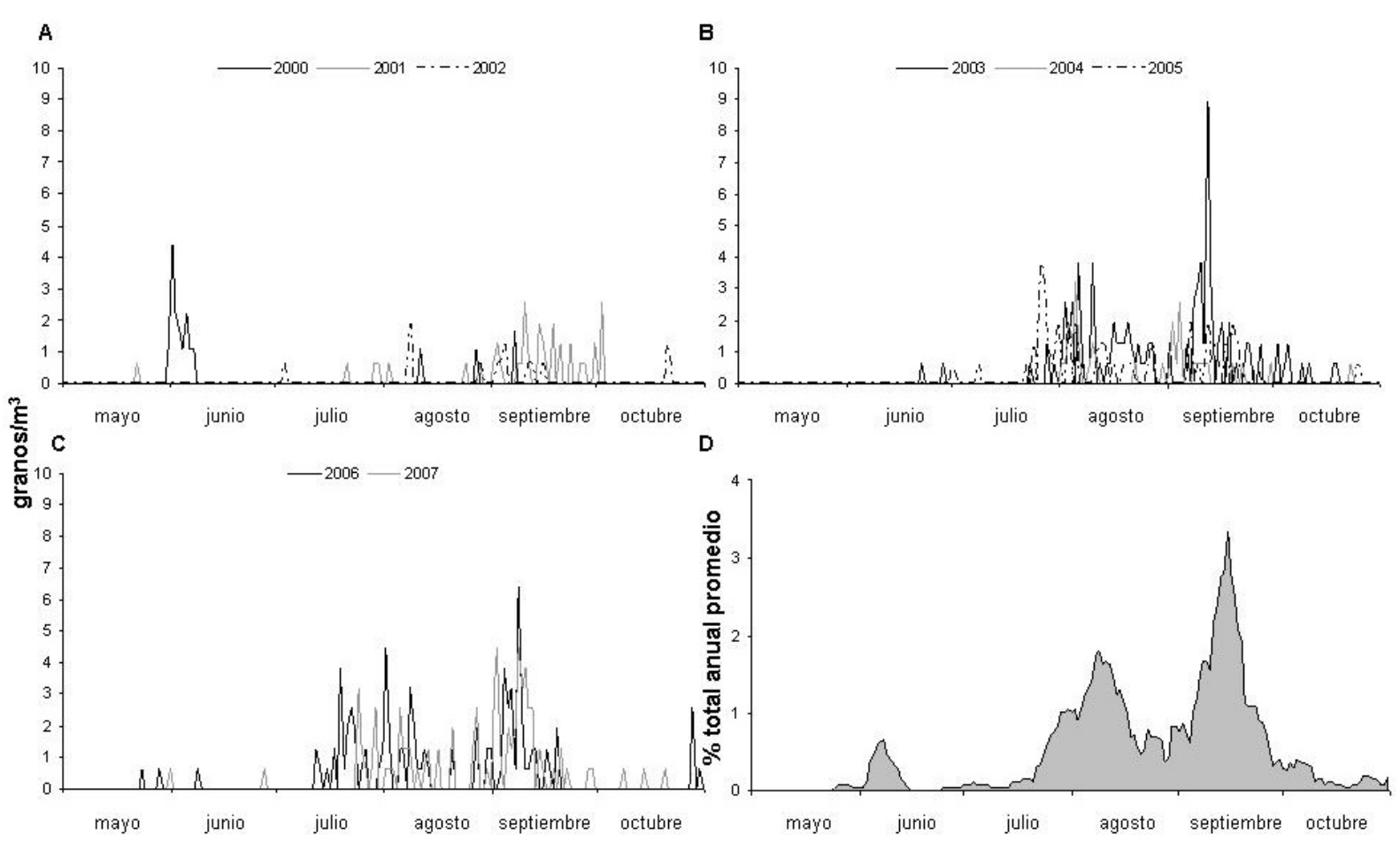

Fig. 5.2.3.11. Variación de las concentraciones medias diarias de Artemisia durante el período 2000-2002 (A), 2003-2005 (B) y 2006-2007 (C). Porcentajes de representación diarios para la media de los cinco días anteriores dentro del promedio de los ocho años analizados (D).

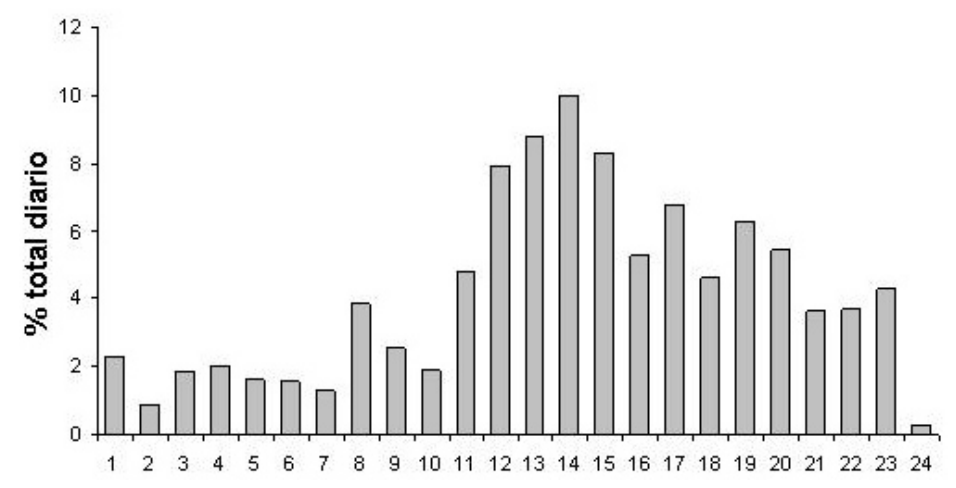

Fig. 5.2.3.12. Variación intradiaria del polen de Artemisia. 


\begin{tabular}{|c|c|c|c|c|c|c|c|}
\hline \multicolumn{2}{|c|}{ Artemisia } & Tmed & Tmax & Tmin & Insolación & Precipitación & Hrelativa \\
\hline 2000 & Anual & $0,191^{* *}$ & 0,184 ** & $0,178^{* *}$ & $0,140 * *$ & $-0,030$ & $-0,157^{\star \star}$ \\
\hline \multirow{2}{*}{$95 \%$} & PPP & $-0,106$ & $-0,138$ & $-0,050$ & $-0,151$ & 0,112 & 0,117 \\
\hline & PRE & - & - & - & - & - & - \\
\hline 2001 & Anual & $0,223^{* *}$ & $0,244^{* *}$ & $0,165^{* *}$ & $0,113^{*}$ & $-0,086$ & $-0,157^{* *}$ \\
\hline \multirow{2}{*}{$95 \%$} & PPP & $-0,33^{\star \star}$ & $-0,25^{\star \star}$ & $-0,35$ ** & $-0,149$ & $-0,088$ & 0,144 \\
\hline & PRE & $-0,180$ & $-0,110$ & $-0,173$ & $-0,132$ & $-0,009$ & 0,138 \\
\hline 2002 & Anual & $0,148^{\star *}$ & $0,138^{\star \star}$ & 0,146 ** & 0,043 & $-0,019$ & $-0,024$ \\
\hline \multirow{2}{*}{$95 \%$} & PPP & 0,164 & 0,164 & 0,053 & 0,050 & 0,007 & $-0,118$ \\
\hline & PRE & - & - & - & - & - & - \\
\hline 2003 & Anual & $0,368 * *$ & $0,377^{* *}$ & $0,340^{* *}$ & $0,213^{* *}$ & $-0,095$ & $-0,195^{* *}$ \\
\hline \multirow{2}{*}{$95 \%$} & PPP & $0,274^{\star \star}$ & $0,308^{\star \star}$ & 0,074 & $0,310^{* *}$ & $-0,177$ & $-0,297$ * \\
\hline & PRE & 0,016 & 0,093 & $-0,130$ & 0,056 & $-0,202$ & $-0,115$ \\
\hline 2004 & Anual & $0,240^{* *}$ & $0,226^{* *}$ & $0,244^{* *}$ & 0,080 & $-0,052$ & $-0,093$ \\
\hline \multirow{2}{*}{$95 \%$} & PPP & 0,251 & 0,053 & $0,324^{*}$ & $-0,149$ & 0,072 & 0,158 \\
\hline & PRE & $-0,632$ & $-0,564$ & $-0,98 * *$ & $-0,308$ & - & 0,667 \\
\hline 2005 & Anual & $0,242^{* *}$ & $0,244 * *$ & $0,236^{* *}$ & $0,201 * *$ & $-0,133^{*}$ & $-0,177^{* *}$ \\
\hline \multirow{2}{*}{$95 \%$} & PPP & $0,205^{*}$ & 0,155 & 0,200 & $0,343^{* *}$ & $-0,258^{*}$ & $-0,168$ \\
\hline & PRE & $-0,564$ & $-0,410$ & $-0,98 * *$ & $-0,103$ & - & 0,359 \\
\hline 2006 & Anual & $0,416^{* *}$ & $0,438^{* *}$ & $0,361^{* *}$ & - & $-0,160$ ** & $-0,328 * \star$ \\
\hline \multirow{2}{*}{$95 \%$} & PPP & $0,248^{*}$ & $0,253^{*}$ & 0,131 & - & $-0,145$ & $-0,239 *$ \\
\hline & PRE & $0,319 *$ & 0,306 * & 0,176 & - & $-0,141$ & $-0,260^{*}$ \\
\hline 2007 & Anual & $0,396 * *$ & $0,407 * \star$ & 0,338 ** & $0,279 * *$ & $-0,148^{* \star}$ & $-0,340^{\star \star}$ \\
\hline \multirow{2}{*}{$95 \%$} & PPP & 0,101 & $0,214^{* *}$ & 0,015 & $-0,089$ & $-0,153$ & 0,008 \\
\hline & PRE & 0,136 & 0,208 & 0,147 & $-0,046$ & $-0,138$ & 0,114 \\
\hline Total & Anual & $0,289 * *$ & $0,295^{* *}$ & $0,262 * *$ & $0,181^{* *}$ & $-0,097^{* *}$ & $-0,165^{* *}$ \\
\hline
\end{tabular}

\begin{tabular}{|c|c|c|c|c|c|c|c|}
\hline \multicolumn{2}{|c|}{ Artemisia } & Vemed & FrecCalm & VICuadr & V2Cuadr & V3Cuadr & V4Cuadr \\
\hline 2000 & Anual & $-0,040$ & 0,022 & 0,101 & $0,109 *$ & $-0,113^{*}$ & 0,054 \\
\hline \multirow{2}{*}{$95 \%$} & PPP & $-0,053$ & 0,007 & 0,116 & $0,276 * *$ & $-0,126$ & $-0,017$ \\
\hline & PRE & - & - & - & - & - & - \\
\hline 2001 & Anual & $-0,068$ & 0,087 & $0,147^{* *}$ & 0,100 & $-0,128$ & $-0,118^{*}$ \\
\hline \multirow{2}{*}{$95 \%$} & PPP & 0,130 & $-0,055$ & 0,213 & 0,095 & $-0,112$ & $-0,435^{* *}$ \\
\hline & PRE & $-0,002$ & $-0,040$ & 0,231 & 0,050 & $-0,214$ & $-0,294^{*}$ \\
\hline 2002 & Anual & $-0,019$ & $-0,025$ & $-0,010$ & 0,017 & $-0,031$ & 0,094 \\
\hline \multirow{2}{*}{$95 \%$} & PPP & 0,022 & $-0,064$ & $-0,080$ & 0,056 & 0,034 & 0,011 \\
\hline & PRE & - & - & - & - & - & - \\
\hline 2003 & Anual & $-0,15^{* *}$ & $0,129^{*}$ & $0,143^{* *}$ & 0,072 & $-0,121^{*}$ & 0,039 \\
\hline \multirow{2}{*}{$95 \%$} & PPP & $-0,047$ & $-0,001$ & $0,217^{\star}$ & 0,133 & $-0,131$ & $-0,113$ \\
\hline & PRE & $-0,105$ & 0,133 & $0,282^{*}$ & 0,139 & $-0,123$ & $-0,266$ \\
\hline 2004 & Anual & 0,037 & $0,112^{*}$ & $-0,038$ & 0,072 & 0,071 & 0,046 \\
\hline \multirow{2}{*}{$95 \%$} & PPP & 0,136 & $-0,045$ & $-0,090$ & 0,010 & 0,220 & 0,021 \\
\hline & PRE & 0,632 & 0,526 & $-0,95 * *$ & $-0,684$ & $-0,410$ & 0,667 \\
\hline 2005 & Anual & $-0,025$ & 0,039 & $0,142^{\star \star}$ & $-0,062$ & $-0,114^{*}$ & $-0,074$ \\
\hline \multirow{2}{*}{$95 \%$} & PPP & 0,154 & $-0,211^{*}$ & $0,214^{*}$ & $-0,076$ & $-0,097$ & $-0,155$ \\
\hline & PRE & 0,649 & 0,459 & 0,459 & 0,616 & 0,821 & $-0,872$ \\
\hline 2006 & Anual & 0,044 & 0,025 & $0,134^{*}$ & $0,160 * *$ & $-0,109$ & 0,029 \\
\hline \multirow{2}{*}{$95 \%$} & PPP & 0,197 & 0,123 & 0,195 & $0,347^{* *}$ & $-0,132$ & $-0,218$ \\
\hline & PRE & 0,204 & 0,061 & 0,149 & $0,269 *$ & $-0,155$ & $-0,156$ \\
\hline 2007 & Anual & $-0,061$ & 0,070 & $0,191^{* *}$ & $-0,098$ & $-0,141$ ** & 0,015 \\
\hline \multirow{2}{*}{$95 \%$} & PPP & $-0,218^{*}$ & 0,154 & $0,246^{*}$ & 0,116 & $-0,210^{*}$ & $-0,104$ \\
\hline & PRE & $-0,164$ & 0,103 & $0,258^{*}$ & 0,130 & $-0,265^{*}$ & $-0,038$ \\
\hline Total & Anual & $-0,10^{* *}$ & $0,050^{* *}$ & $0,117^{* *}$ & $0,059 * \star$ & $-0,096$ ** & 0,020 \\
\hline
\end{tabular}

Tabla 5.2.3.8. Coeficientes de correlación de Spearman entre Artemisia y las variables climatológicas. Tmed,

Tmax, Tmin (temperatura media, máxima y mínima), Hrelativa (humedad relativa), Vemed (velocidad media), FrecCalmas (frecuencia de calmas), V1Cuad, V2Cuad, V3Cuad, V4Cuad (vientos procedentes del I, II, III y IV cuadrante). Significación: 95\%(*), 99\%(**). (-) Ausencia de correlaciones. 


\subsubsection{Chenopodiaceae / Amaranthaceae}

Los niveles de este tipo de polen en la atmósfera de Salamanca, experimentaron un ascenso durante el período analizado, ya que si en el año 2000 el total anual fue de 64 pólenes, en el año 2007 alcanzó 228, pese a que el mayor total anual se registró en el año 2006 con 474 granos de polen. Todo ello supuso que la variación interanual (Fig. 5.2.3.13.) llevase consigo un aumento del 256\% en las concentraciones anuales de estas familias botánicas, un hecho confirmado a través del análisis de regresión de tipo lineal y el valor que tomó por su índice de determinación $\left(\mathrm{R}^{2}=0,56\right)$. La representación media de los pólenes de género botánico a lo largo de los ocho años fue de $1,2 \%$, con un máximo de 3,1\% en 2003 y un mínimo de 0,6\% en 2000.

La distribución de estos granos de polen a lo largo de los años estudiados se localizó entre marzo y octubre por lo que la variación estacional fue muy amplia (Tabla 5.2.3.9.), con un PPP promedio de

\section{Tipo de polen: Chenopodiaceae} Amaranthaceae.

Especie(s): Amaranthus albus L., Beta vulgaris L., Chenopodium album L., Chenopodium murale L. (Chenopodiaceae-Amaranthaceae) entre otras.

Distribución: Ampliamente representadas en ambos hemisferios, ya sea de forma natural o “naturalizadas". En la Península Ibérica y la provincia de Salamanca se encuentran principalmente en bordes de cultivos, caminos o terrenos baldíos.

Época de floración: Verano e inicios de otoño, en función de las especies.

Polinización: Anemófila.

Morfología polínica (Lámina I): Polen polipantoporado, apolar y radiosimétrico, con una forma circular en ambas vistas (esferoidal) y un tamaño variable $(P=10-30 \mu \mathrm{m})$. Las aberturas tipo poro, repartidas por toda la superficie en número de 30 a 60 y con un diámetro entre 2 y $3 \mu \mathrm{m}$, presentan una membrana abertural cubierta por gránulos $y$ espinas. La exina $(2-3 \mu \mathrm{m})$ posee una superficie rugulada-escábrida o equinulada. 123 días. Esta evidente variación en función del año analizado se presentó en las fechas de inicio, teniendo el 24 de mayo de 2000 como fecha más temprana y el 11 de junio de 2003 como la más tardía, y en las fechas de finalización del PPP, con un intervalo entre el 5 de septiembre de 2000 y el 12 de octubre de 2006 y 2007.

La dinámica de las concentraciones polínicas de Chenopodiaceae-Amaranthaceae (Fig. 5.2.3.14.D.) mostrada el porcentaje sobre el total anual promedio de la media de los cinco días anteriores promediados durante los años analizados, presentó un incremento de las concentraciones desde finales de abril hasta inicios de agosto, con una concentración máxima de 5 granos $/ \mathrm{m}^{3}$ el día 4 de agosto como media del período 2000-2007 (Tabla 5.2.3.9.). Posteriormente, se registró una disminución en los niveles de polen a mediados de septiembre, manteniéndose en la atmósfera durante octubre y noviembre con 
concentraciones bajas. Los valores más elevados dentro de los ocho años, con diferencias en número y fecha (Tabla 5.2.3.9.; Fig. 5.2.3.14. A. B. C.), variaron entre los 22 granos $/ \mathrm{m}^{3}$ (9 de agosto de 2006) y los 4 granos $/ \mathrm{m}^{3}$ (17 de junio de $2000-24$ de julio de 2001).

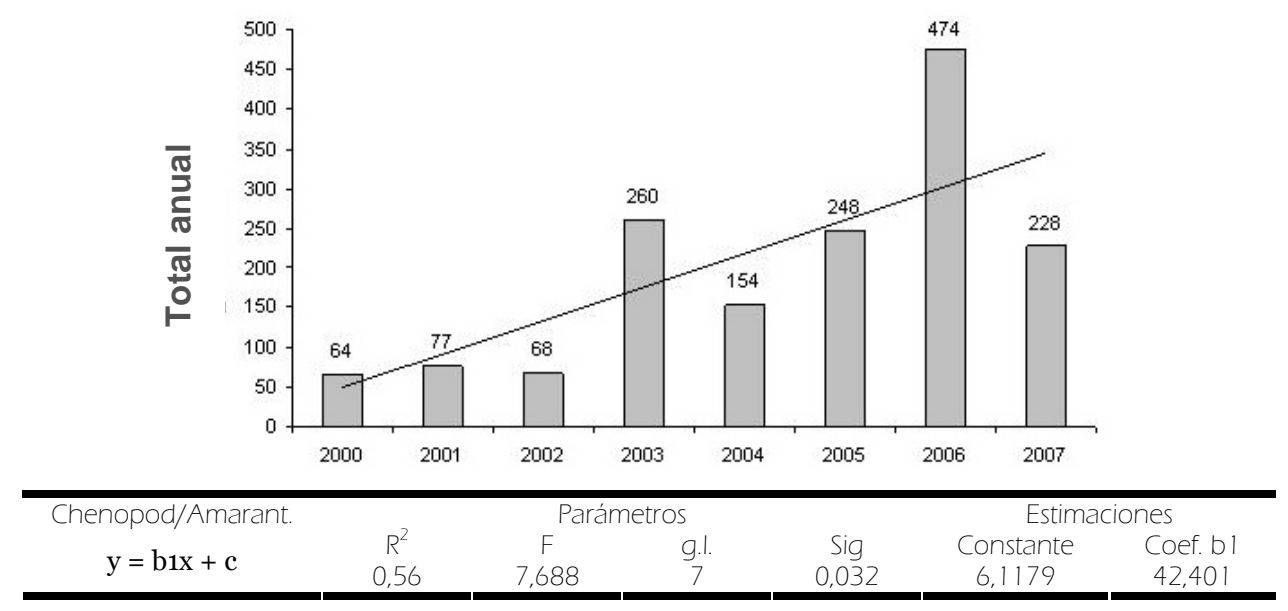

Fig. 5.2.3.13. Evolución anual del número total de pólenes de Chenopodiaceae-Amaranthaceae y tendencias (análisis de regresión).

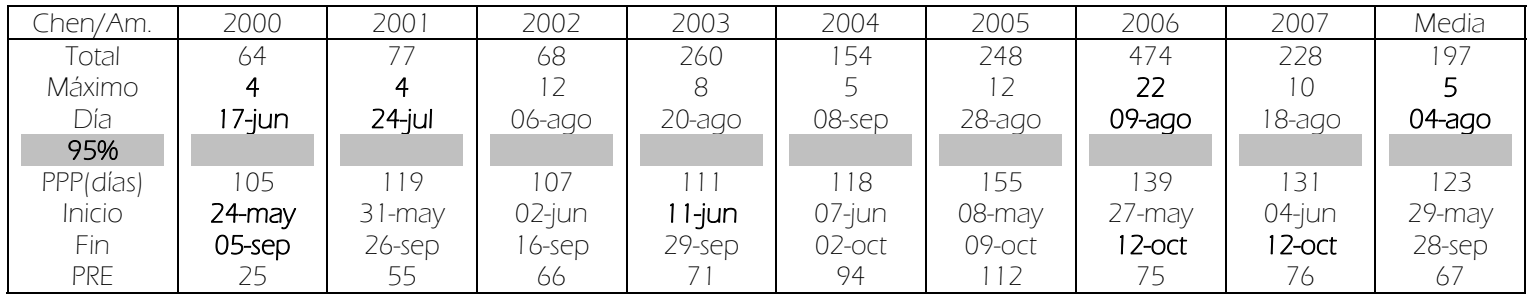

Tabla 5.2.3.9. Totales, concentraciones máximas diarias, período principal de polinización (PPP; fecha de inicio y fin) y días precedentes al valor máximo (PRE) durante los ocho años de estudio y el promedio de todos los parámetros para Chenopodiaceae-Amaranthaceae.

Las concentraciones de polen a lo largo del día mostraron los mayores porcentajes de representación entre las 11 y las 19 horas, momento a partir del cual, las concentraciones descienden hasta la medianoche. Así pues, la variación intradiaria (Fig. 5.2.3.15.) durante un día promedio para el trienio 2005-2007, presentó los mayores niveles horarios en las horas centrales del día.

Las temperaturas medias, máximas y mínimas junto a la insolación y los vientos procedentes del I y IV cuadrante tuvieron una influencia positiva en los niveles de este tipo polínico durante los ocho años analizados, así como el efecto negativo que ejercieron las precipitaciones, la humedad relativa, la velocidad media del viento y los vientos procedentes del III cuadrante, tras el análisis de correlación (Tabla 5.2.3.10.). Estas correlaciones presentaron coeficientes similares en signo y grado de significación en todas las anualidades y sus PPP y PRE, exceptuando en el PPP del año 2002 para la temperatura y la humedad 
relativa, si bien en número mostraron ciertas variaciones en función del año, presentando, en la mayoría de los casos, mayores valores numéricos.

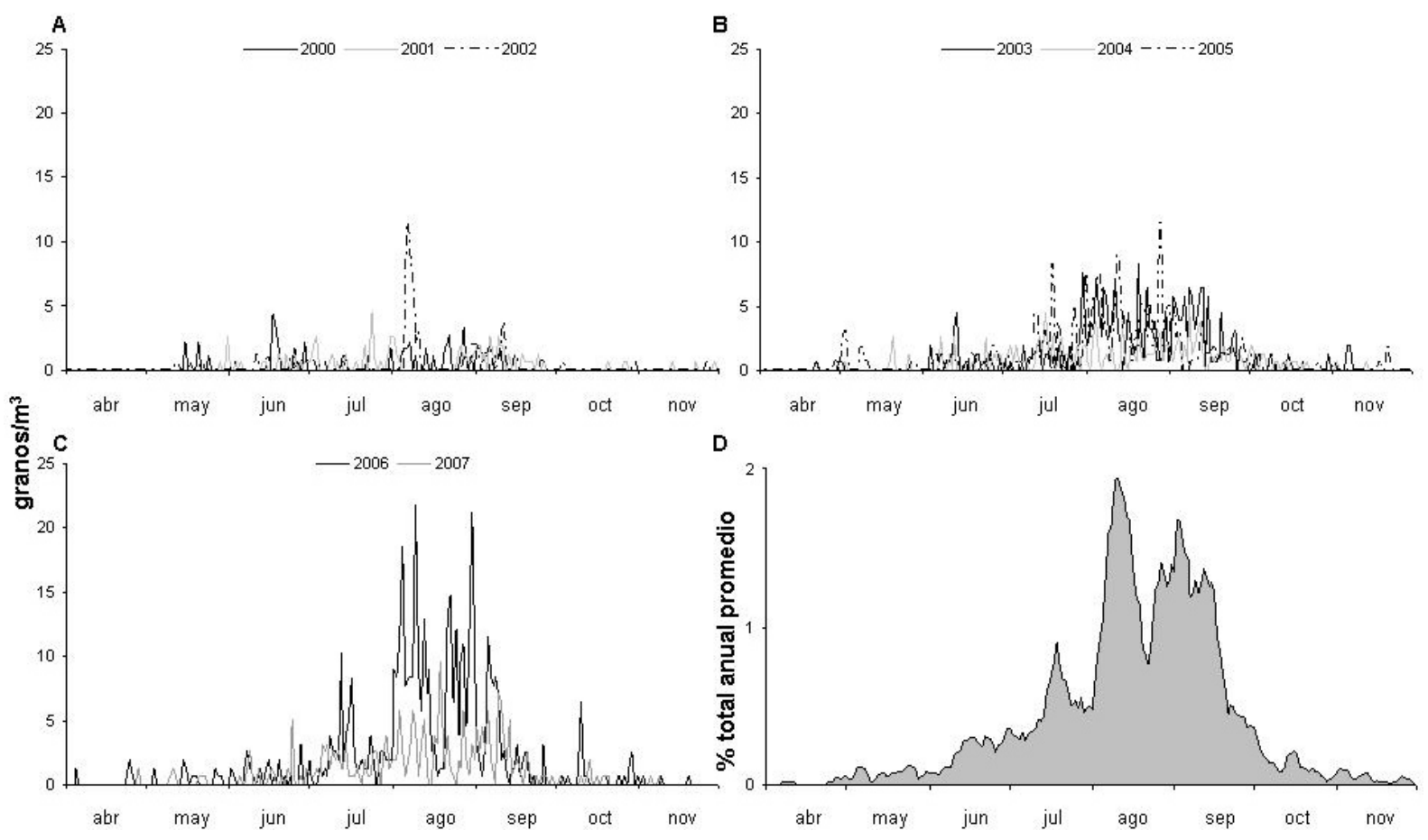

Fig. 5.2.3.14. Variación de las concentraciones medias diarias de Chenopodiaceae-Amaranthaceae durante el período 2000-2002 (A), 2003-2005 (B) y 2006-2007 (C). Porcentajes de representación diarios para la media de los cinco días anteriores dentro del promedio de los ocho años analizados (D).

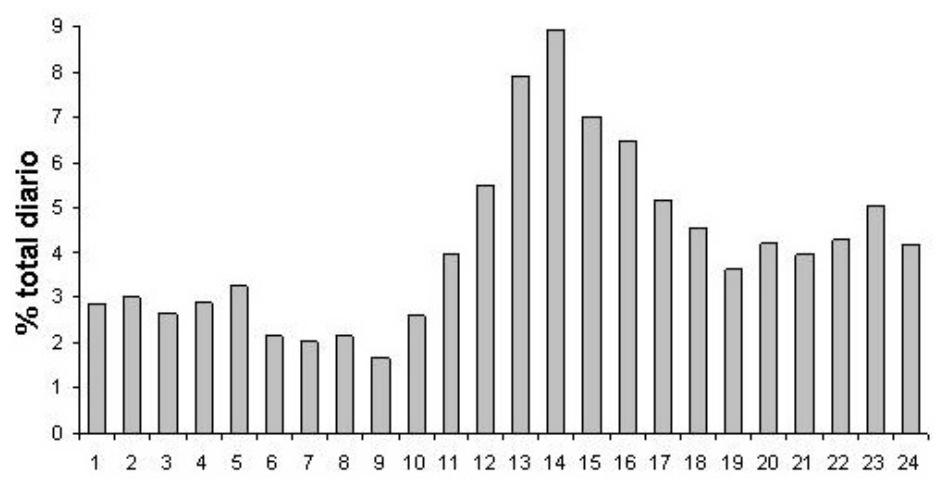

Fig. 5.2.3.15. Variación intradiaria del polen de Chenopodiaceae-Amaranthaceae. 


\begin{tabular}{|c|c|c|c|c|c|c|c|}
\hline \multicolumn{2}{|c|}{ Chenopodiaceae } & Tmed & Tmax & Tmin & Insolación & Precipitación & Hrelativa \\
\hline 2000 & Anual & $0,323^{* *}$ & $0,343^{* *}$ & $0,260 * \star$ & $0,325^{\star \star}$ & $-0,182^{\star \star}$ & $-0,307$ * \\
\hline \multirow{2}{*}{$95 \%$} & PPP & 0,007 & 0,056 & $-0,102$ & 0,095 & $-0,129$ & $-0,028$ \\
\hline & PRE & 0,245 & 0,206 & 0,163 & 0,078 & $-0,087$ & $-0,118$ \\
\hline 2001 & Anual & 0,446 ** & $0,449 * \star$ & 0,400 ** & $0,253^{* *}$ & $-0,037$ & $-0,293^{* *}$ \\
\hline \multirow{2}{*}{$95 \%$} & PPP & 0,144 & 0,100 & 0,151 & $-0,152$ & $0,182^{*}$ & 0,143 \\
\hline & PRE & $0,493^{* *}$ & $0,448 * *$ & $0,427 * *$ & 0,032 & 0,074 & $-0,150$ \\
\hline 2002 & Anual & $0,269 * *$ & $0,269 * *$ & $0,239 * *$ & $0,219^{* *}$ & $-0,143^{* *}$ & $-0,133^{* *}$ \\
\hline \multirow{2}{*}{$95 \%$} & PPP & $-0,25 * \star$ & $-0,23 * \star$ & $-0,183$ & $-0,144$ & $-0,173$ & $0,248^{*}$ \\
\hline & PRE & $-0,043$ & $-0,027$ & $-0,009$ & 0,043 & $-0,195$ & $-0,015$ \\
\hline 2003 & Anual & $0,632 * *$ & 0,624 ** & $0,609 * *$ & $0,349 * *$ & $-0,189 * *$ & $-0,414^{* *}$ \\
\hline \multirow{2}{*}{$95 \%$} & PPP & 0,132 & 0,138 & 0,099 & $-0,235^{\star}$ & $-0,089$ & 0,108 \\
\hline & PRE & $0,489 * *$ & 0,495 ** & $0,416^{* *}$ & $-0,319 * *$ & $-0,112$ & $-0,116$ \\
\hline 2004 & Anual & $0,616^{* *}$ & $0,613^{* *}$ & $0,584 * *$ & $0,370 * *$ & $-0,132^{\star}$ & $-0,445^{* *}$ \\
\hline \multirow{2}{*}{$95 \%$} & PPP & 0,068 & 0,071 & 0,033 & $-0,205^{\star}$ & 0,006 & 0,042 \\
\hline & PRE & 0,086 & 0,073 & 0,083 & $-0,222^{*}$ & 0,021 & 0,011 \\
\hline 2005 & Anual & $0,627^{* *}$ & $0,633^{* *}$ & $0,562^{* *}$ & $0,426^{* *}$ & $-0,165^{* \star}$ & $-0,545^{* *}$ \\
\hline \multirow{2}{*}{$95 \%$} & PPP & 0,271 ** & $0,351 * *$ & 0,130 & $-0,010$ & $-0,124$ & $-0,215^{* *}$ \\
\hline & PRE & $0,270^{* *}$ & $0,357 * *$ & 0,144 & $-0,002$ & $-0,131$ & $-0,253^{* *}$ \\
\hline 2006 & Anual & $0,702^{\star *}$ & 0,704 ** & $0,640 * \star$ & $-0,021$ & $-0,182^{* \star}$ & $-0,532 * \star$ \\
\hline \multirow{2}{*}{$95 \%$} & PPP & $0,361^{* *}$ & $0,468^{* *}$ & 0,151 & - & $-0,237^{* *}$ & $-0,158$ \\
\hline & PRE & $0,408 * *$ & $0,457 * *$ & 0,197 & - & $-0,008$ & 0,259 * \\
\hline 2007 & Anual & $0,664^{* *}$ & $0,677^{* *}$ & $0,592^{\star *}$ & $0,502^{* *}$ & $-0,138^{* *}$ & $-0,548^{* *}$ \\
\hline \multirow{2}{*}{$95 \%$} & PPP & $0,509 * \star$ & $0,537 * \star$ & $0,218^{\star}$ & $0,276^{* *}$ & $-0,199 *$ & $-0,503^{* *}$ \\
\hline & PRE & $0,452^{* *}$ & $0,497 * *$ & 0,196 & 0,199 & $-0,259^{*}$ & $-0,489 * *$ \\
\hline Total & Anual & $0,548^{* *}$ & $0,548^{\star \star}$ & $0,501^{* *}$ & $0,364^{* *}$ & $-0,148^{* \star}$ & $-0,382^{* *}$ \\
\hline
\end{tabular}

\begin{tabular}{|c|c|c|c|c|c|c|c|}
\hline \multicolumn{2}{|c|}{ Chenopodiaceae } & Vemed & FrecCalm & VICuadr & V2Cuadr & V3Cuadr & V4Cuadr \\
\hline 2000 & Anual & $-0,12^{* *}$ & 0,083 & $0,130^{*}$ & 0,039 & $-0,174^{* *}$ & 0,082 \\
\hline \multirow{2}{*}{$95 \%$} & PPP & $-0,075$ & 0,056 & 0,084 & 0,116 & $-0,171$ & $-0,049$ \\
\hline & PRE & $-0,007$ & 0,131 & $-0,166$ & 0,188 & $-0,155$ & 0,025 \\
\hline 2001 & Anual & $-0,121^{*}$ & 0,055 & $0,119 *$ & 0,047 & $-0,123^{*}$ & $0,121^{*}$ \\
\hline \multirow{2}{*}{$95 \%$} & PPP & 0,019 & $-0,133$ & $0,231^{*}$ & 0,121 & $-0,141$ & $-0,178$ \\
\hline & PRE & $-0,201$ & 0,108 & 0,181 & 0,265 & 0,005 & $-0,114$ \\
\hline 2002 & Anual & $-0,035$ & 0,020 & $0,147 * *$ & $-0,029$ & $-0,175^{* *}$ & 0,093 \\
\hline \multirow{2}{*}{$95 \%$} & PPP & $-0,041$ & 0,039 & $0,204^{*}$ & 0,047 & $-0,243^{*}$ & $-0,079$ \\
\hline & PRE & $-0,096$ & 0,105 & 0,136 & $-0,056$ & $-0,261^{*}$ & $-0,094$ \\
\hline 2003 & Anual & $-0,17^{* *}$ & 0,098 & 0,079 & 0,013 & $-0,092$ & $0,240^{* *}$ \\
\hline \multirow{2}{*}{$95 \%$} & PPP & $-0,193^{*}$ & 0,110 & $0,283 * *$ & $0,285^{* *}$ & $-0,318 * *$ & $-0,086$ \\
\hline & PRE & $-0,248^{*}$ & 0,186 & $0,295^{*}$ & $0,435^{* *}$ & $-0,328$ ** & $-0,089$ \\
\hline 2004 & Anual & $0,135^{\star *}$ & 0,099 & $-0,071$ & $0,107^{\star}$ & 0,048 & $0,199 * *$ \\
\hline \multirow{2}{*}{$95 \%$} & PPP & 0,072 & 0,098 & 0,056 & $0,205^{*}$ & $-0,051$ & $-0,011$ \\
\hline & PRE & 0,086 & 0,062 & 0,043 & 0,175 & $-0,029$ & 0,008 \\
\hline 2005 & Anual & $-0,082$ & 0,065 & $0,127^{*}$ & 0,001 & $-0,062$ & 0,054 \\
\hline \multirow{2}{*}{$95 \%$} & PPP & $-0,107$ & $0,194^{*}$ & $0,286 *$ & 0,143 & $-0,204 *$ & $-0,279 * *$ \\
\hline & PRE & $-0,064$ & 0,140 & $0,350^{* *}$ & 0,149 & $-0,253^{* *}$ & $-0,383^{* *}$ \\
\hline 2006 & Anual & $-0,045$ & $-0,020$ & $0,161^{* *}$ & $0,117^{*}$ & $-0,125^{\star}$ & 0,106 \\
\hline \multirow{2}{*}{$95 \%$} & PPP & 0,021 & 0,126 & $0,406^{* *}$ & $0,201^{*}$ & $-0,386^{* *}$ & $-0,142$ \\
\hline & PRE & $-0,199$ & 0,020 & $0,247^{*}$ & 0,195 & $-0,177$ & $-0,173$ \\
\hline 2007 & Anual & $-0,043$ & 0,102 & $0,141^{* *}$ & $-0,115^{*}$ & $-0,071$ & 0,059 \\
\hline \multirow{2}{*}{$95 \%$} & PPP & $-0,057$ & $-0,012$ & $0,321^{* \star}$ & 0,052 & $-0,254^{\star *}$ & $-0,001$ \\
\hline & PRE & $-0,273^{*}$ & 0,144 & $0,502^{* *}$ & 0,116 & $-0,449 * *$ & $-0,007$ \\
\hline Total & Anual & $-0,15^{\star \star}$ & 0,041 * & $0,116^{* \star}$ & $0,053^{* *}$ & $-0,102^{\star \star}$ & $0,138^{* *}$ \\
\hline
\end{tabular}

Tabla 5.2.3.10. Coeficientes de correlación de Spearman entre Chenopodiaceae-Amaranthaceae y las variables climatológicas. Tmed, Tmax, Tmin (temperatura media, máxima y mínima), Hrelativa (humedad relativa), Vemed (velocidad media), FrecCalmas (frecuencia de calmas), V1Cuad, V2Cuad, V3Cuad, V4Cuad (vientos procedentes del I, II, III y IV cuadrante). Significación: 95\%(*), 99\%(**). (-) Ausencia de correlaciones. 


\subsubsection{Compositae (= Asteraceae)}

La variación interanual (Fig. 5.2.3.16.) de este tipo polínico en la atmósfera mostró un incremento en los niveles polínicos anuales durante el período 2000-2007. Este aumento, desde la perspectiva numérica, supuso el paso de los 118 granos en el año 2000 a los 225 del año 2007, lo cual conllevó un aumento del 91\%. El valor del índice de determinación $\left(\mathrm{R}^{2}=0,46\right)$, también refrendó de manera estadística, mediante regresión lineal, esta tendencia. Los porcentajes de representación sobre el total de pólenes contabilizados en cada anualidad estudiada variaron del o,4\% de 2005 al 1,7\% de 2003, con un porcentaje medio de $0,9 \%$.

La variación estacional, fue muy amplia (Tabla 5.2.3.11.), abarcando, principalmente, desde el mes de mayo hasta septiembre, con un PPP promedio de 112 días, que varió en sus fechas de inicio (2 abril de 2001 - 16 de mayo de 2002) y de finalización (13 de julio de $2002-23$ de septiembre de 2005) entre uno y dos meses.

La dinámica que presentaron las concentraciones polínicas de Compositae (Fig. 5.2.3.17.D.) representada con el porcentaje promedio dentro de la media móvil los cinco días anteriores sobre el total promediado para los años analizados, fue la siguiente: aumento de las concentraciones a principios de mayo hasta las primeras semanas de junio, presentando una concentración máxima de 4 granos $/ \mathrm{m}^{3}$ el día 8 de junio como media del período 2000-2007 (Tabla 5.2.3.11.). Después, se produjo una disminución en los niveles de polen en la segunda mitad de junio, manteniéndose en la atmósfera hasta finales del mes de octubre, especialmente en julio y agosto. Las concentraciones diarias más elevadas dentro de los ocho años (Tabla 5.2.3.11.; Fig. 5.2.3.17. A. B. C.), con una variación en la fecha que superó el mes de diferencia,
Tipo de polen: Compositae (excluido Artemisia).

Especie(s): Gran número de especies dentro de, entre otros, géneros como Anthemis L., Bellis L. Carduus L., Centaurea L. O Senecio L. (Compositae), entre otros.

Distribución: Familia botánica cosmopolita con más de 2000 especies que en la Península lbérica y en la provincia de Salamanca, se presentan, en su mayoría, como especies espontáneas en numerosos hábitats preferentemente en pastizales, cultivos, dehesas, herbazales y ambientes urbanos o ruderalizados. Época de floración: Muy amplia, desde primavera hasta otoño, según las especies.

Polinización: Entomófila.

Morfología polínica (Lámina II): Polen trizonocolporado, isopolar y radiosimétrico, con una forma de circular a triangular en vista polar, de circular a hexagonal en vista ecuatorial (esferoidal), y un tamaño variable $(P=18-45$ $\mu \mathrm{m})$. Tanto las aberturas tipo colpo como las tipo poro son difíciles de apreciar, debido al grosor de la exina $(3-6 \mu \mathrm{m})$, y a la profusión y gran tamaño de elementos ornamentales (con espinas de entre 2 y $6 \mu \mathrm{m})$, sobre una superficie de ornamentación variable (equinada, equinulada, escábrida,...). 
se localizaron entre los 4 granos $/ \mathrm{m}^{3}$ (13 de junio de 2005) y los 16 granos $/ \mathrm{m}^{3}$ (21 de mayo de 2002).

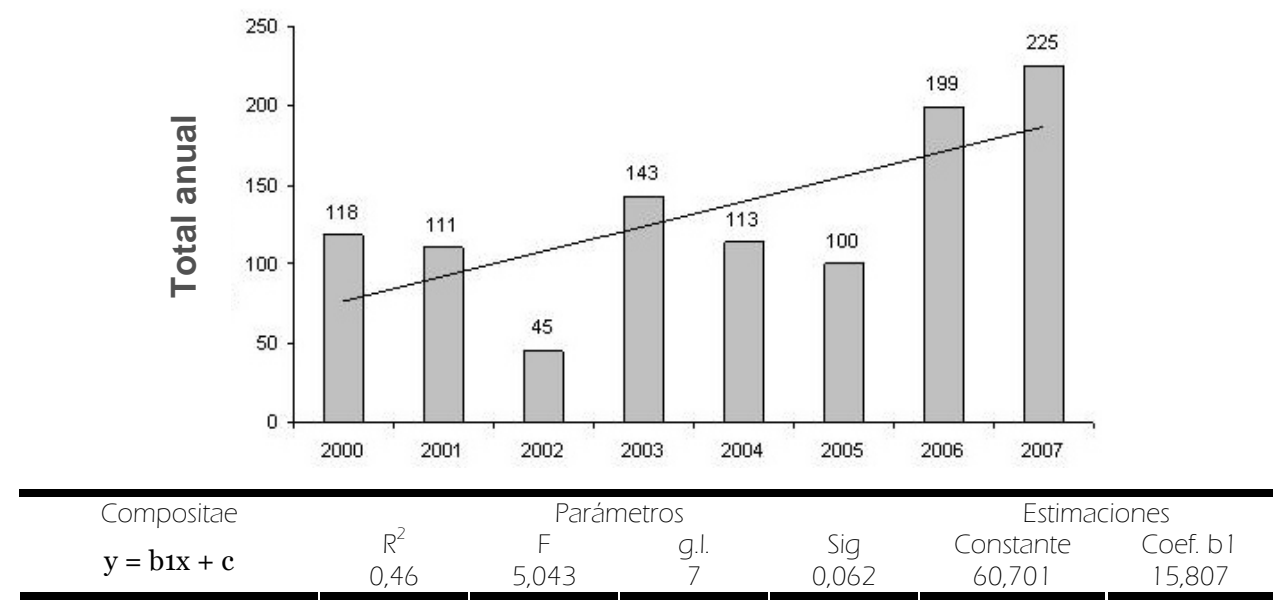

Fig. 5.2.3.16. Evolución anual del número total de pólenes de Compositae y tendencias (análisis de regresión).

\begin{tabular}{|c|c|c|c|c|c|c|c|c|c|}
\hline Compositae & 2000 & 2001 & 2002 & 2003 & 2004 & 2005 & 2006 & 2007 & Media \\
\hline Día & 08-jun & 02-jul & 21-may & 29-jun & 14-jul & 13-jun & 08-jun & 24-jun & 08-jun \\
\hline PPP(días) & 88 & 114 & 59 & 133 & 112 & 149 & 120 & 119 & 112 \\
\hline Inicio & 12-may & 02-abr & 16-may & 28-abr & 04-may & 28-abr & 07-may & 13-may & 02-may \\
\hline $\begin{array}{l}\text { Fin } \\
\text { PRE }\end{array}$ & $\begin{array}{c}07-\text {-ago } \\
28\end{array}$ & $\begin{array}{c}24-j u l \\
92\end{array}$ & 13-jul & $\begin{array}{c}07-s e p \\
63\end{array}$ & $\begin{array}{c}23 \text {-ago } \\
72\end{array}$ & $\begin{array}{c}\text { 23-sep } \\
47\end{array}$ & $\begin{array}{c}\text { 03-sep } \\
33\end{array}$ & $\begin{array}{c}\text { 08-sep } \\
43\end{array}$ & $\begin{array}{c}21 \text {-ago } \\
38\end{array}$ \\
\hline
\end{tabular}

Tabla 5.2.3.11. Totales, concentraciones máximas diarias, período principal de polinización (PPP; fecha de inicio y fin) y días precedentes al valor máximo (PRE) durante los ocho años de estudio y el promedio de todos los parámetros para Compositae.

La variación intradiaria (Fig. 5.2.2.18.) no mostró un claro patrón a lo largo de un día promedio para los últimos tres años estudiados, aunque podemos señalar mayores niveles en la segunda mitad del día, especialmente en dos franjas horarias, entre las 12 y las 14 horas, y entre las 20 y las 24 horas.

El análisis de correlación (Tabla 5.2.2.12.) indicó que las temperaturas medias, máximas y mínimas junto a la insolación y, en menor grado, los vientos procedentes del IV cuadrante, tuvieron una influencia positiva en los niveles polínicos durante los ocho años analizados, mientras que la precipitación, la humedad relativa, en conjunto, aunque con menor significación, a la velocidad media y la frecuencia de las calmas, ejercieron un efecto positivo. Este tipo de correlaciones se repiten en cada una de las anualidades estudiadas, al menos en signo y grado de significación, con excepciones puntuales en cuanto al número que adquirieron los coeficientes, y al analizar ciertos PPP y PRE que, generalmente, dieron coeficientes de menor valor y significación $\mathrm{y}$, en ocasiones, de distinto signo a las correlaciones establecidas. 


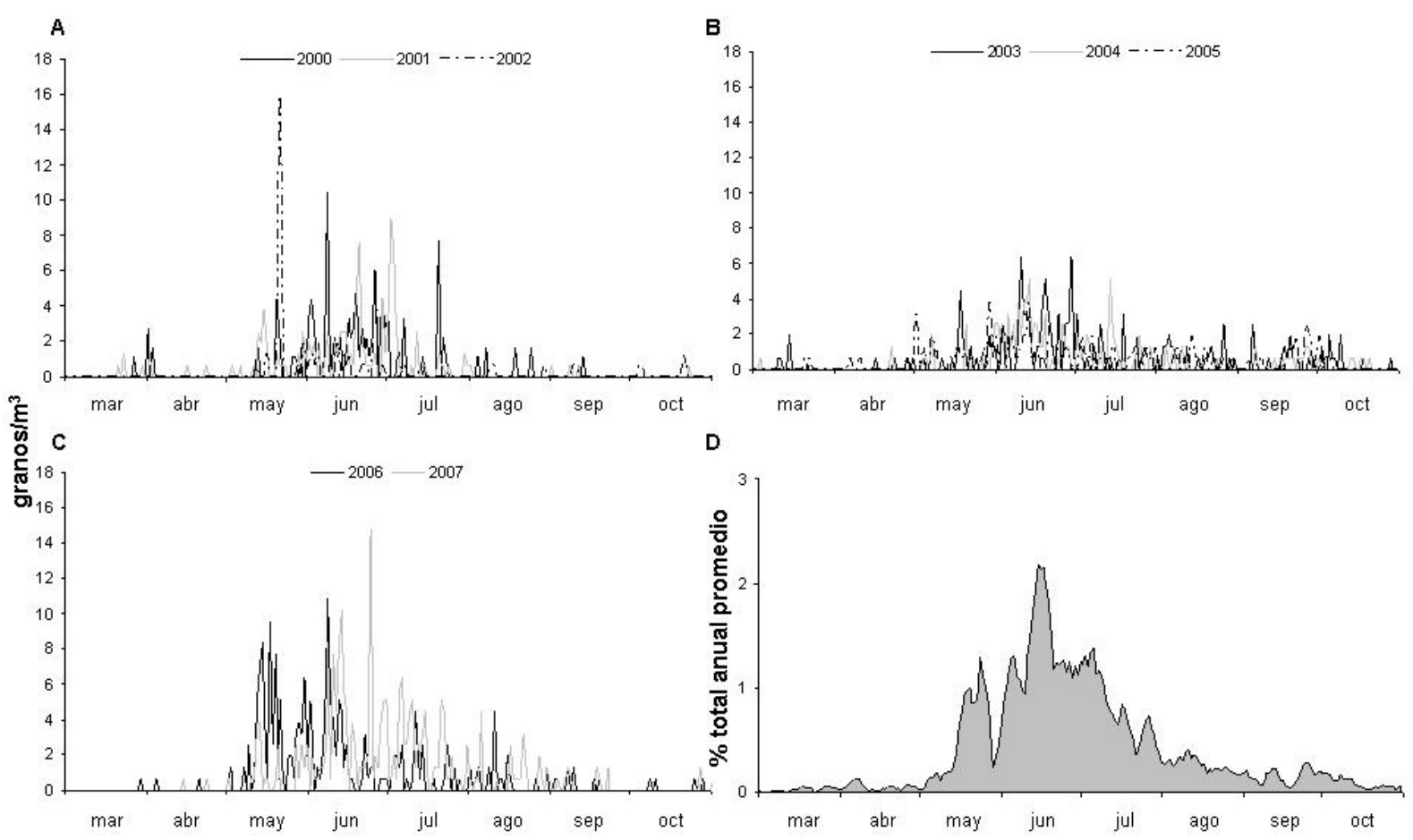

Fig. 5.2.3.17. Variación de las concentraciones medias diarias de Compositae durante el período 2000-2002 (A), 2003-2005 (B) y 2006-2007 (C). Porcentajes de representación diarios para la media de los cinco días anteriores dentro del promedio de los ocho años analizados (D).

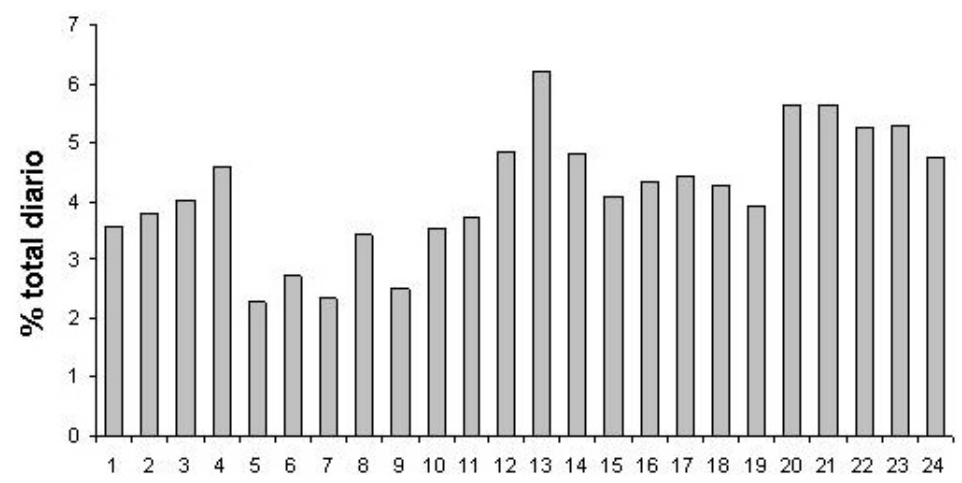

Fig. 5.2.3.18. Variación intradiaria del polen de Compositae. 


\begin{tabular}{|c|c|c|c|c|c|c|c|}
\hline \multicolumn{2}{|c|}{ Compositae } & Tmed & Tmax & Tmin & Insolación & Precipitación & Hrelativa \\
\hline 2000 & Anual & $0,37 * *$ & $0,36 * *$ & $0,35 * *$ & $0,33 * *$ & $-0,127^{\star}$ & $-0,371$ ** \\
\hline \multirow{2}{*}{$95 \%$} & PPP & 0,156 & 0,200 & 0,040 & 0,130 & $-0,197$ & $-0,348 * *$ \\
\hline & PRE & 0,024 & 0,156 & $-0,084$ & 0,133 & $-0,049$ & $-0,275$ \\
\hline 2001 & Anual & 0,406 ** & $0,407 * *$ & 0,362 ** & $0,376 * *$ & $-0,141^{* *}$ & $-0,447 * \star$ \\
\hline \multirow{2}{*}{$95 \%$} & PPP & $0,478 * *$ & $0,456 * *$ & 0,433 ** & $0,253^{* *}$ & $-0,161$ & $-0,451$ ** \\
\hline & PRE & $0,557 * *$ & 0,516 ** & $0,524 * *$ & $0,320 * *$ & $-0,212^{*}$ & $-0,501 * *$ \\
\hline 2002 & Anual & $0,299 * *$ & $0,295 * *$ & $0,269 * *$ & $0,262^{* \star}$ & $-0,138^{* *}$ & $-0,254^{* \star}$ \\
\hline \multirow{2}{*}{$95 \%$} & PPP & $0,315^{*}$ & $0,330^{*}$ & 0,200 & 0,094 & $-0,181$ & $-0,313^{*}$ \\
\hline & PRE & 0,304 & 0,309 & 0,309 & $-0,270$ & $-0,310$ & $-0,144$ \\
\hline 2003 & Anual & $0,572^{* *}$ & $0,557^{* *}$ & 0,526 ** & $0,439 * *$ & $-0,220^{* *}$ & $-0,524 * *$ \\
\hline \multirow{2}{*}{$95 \%$} & PPP & $0,301 * *$ & $0,250 * *$ & 0,240 ** & 0,132 & $-0,181^{*}$ & $-0,342 * \star$ \\
\hline & PRE & $0,550 * *$ & $0,479 * *$ & $0,479 * *$ & $0,254^{*}$ & $-0,161$ & $-0,417 * *$ \\
\hline 2004 & Anual & $0,482^{\star \star}$ & $0,478 * \star$ & $0,449 * *$ & 0,401 ** & $-0,117^{\star}$ & $-0,378^{\star \star}$ \\
\hline \multirow{2}{*}{$95 \%$} & PPP & $0,318^{* *}$ & $0,323^{* *}$ & 0,180 & $0,233^{*}$ & $-0,133$ & $-0,161$ \\
\hline & PRE & $0,663 * *$ & 0,614 ** & $0,607 * *$ & 0,257 & $-0,135$ & $-0,249$ \\
\hline 2005 & Anual & 0,526 ** & $0,516^{* \star}$ & 0,487 ** & 0,450 ** & $-0,217^{\star \star}$ & $-0,527 \star \star$ \\
\hline \multirow{2}{*}{$95 \%$} & PPP & 0,119 & 0,030 & $0,215^{* *}$ & 0,094 & $-0,129$ & $-0,183^{*}$ \\
\hline & PRE & $0,313^{*}$ & 0,193 & 0,531 ** & 0,036 & $-0,169$ & $-0,258$ \\
\hline 2006 & Anual & $0,514^{* *}$ & 0,507 ** & 0,456 ** & 0,085 & $-0,144^{\star \star}$ & $-0,577^{\star \star}$ \\
\hline \multirow{2}{*}{$95 \%$} & PPP & $-0,115$ & $-0,182^{*}$ & $-0,095$ & - & $-0,006$ & $-0,339 * *$ \\
\hline & PRE & $0,378^{*}$ & 0,286 & $0,376 *$ & - & $-0,177$ & $-0,124$ \\
\hline 2007 & Anual & 0,559 ** & $0,554^{\star *}$ & $0,485^{\star *}$ & $0,516^{* \star}$ & $-0,197^{\star \star}$ & $-0,542^{\star \star}$ \\
\hline \multirow{2}{*}{$95 \%$} & PPP & 0,047 & 0,019 & $-0,142$ & $0,240 * *$ & $-0,174$ & $-0,169$ \\
\hline & PRE & 0,301 * & 0,227 & 0,044 & 0,180 & $-0,189$ & $-0,250$ \\
\hline Total & Anual & $0,472^{\star \star}$ & $0,467 * \star$ & $0,423^{* *}$ & 0,397 ** & $-0,170^{\star \star}$ & $-0,429 * \star$ \\
\hline
\end{tabular}

\begin{tabular}{|c|c|c|c|c|c|c|c|}
\hline \multicolumn{2}{|c|}{ Compositae } & Vemed & FrecCalm & VICuadr & V2Cuadr & V3Cuadr & V4Cuadr \\
\hline 2000 & Anual & 0,065 & $-0,111^{*}$ & 0,057 & $-0,029$ & $-0,065$ & 0,052 \\
\hline \multirow{2}{*}{$95 \%$} & PPP & 0,113 & $-0,076$ & $-0,009$ & 0,088 & $-0,039$ & $-0,107$ \\
\hline & PRE & 0,134 & $-0,231$ & 0,181 & $-0,072$ & $-0,126$ & $-0,356$ \\
\hline 2001 & Anual & 0,026 & $-0,049$ & $-0,024$ & - & 0,046 & $0,211^{* *}$ \\
\hline \multirow{2}{*}{$95 \%$} & PPP & $-0,106$ & 0,107 & $-0,032$ & $0,225^{*}$ & 0,062 & $-0,017$ \\
\hline & PRE & $-0,119$ & 0,134 & $-0,100$ & 0,183 & 0,110 & 0,038 \\
\hline 2002 & Anual & 0,035 & 0,031 & 0,005 & $-0,055$ & 0,029 & 0,020 \\
\hline \multirow{2}{*}{$95 \%$} & PPP & $-0,105$ & 0,249 & 0,138 & $0,283^{*}$ & 0,039 & $-0,334^{*}$ \\
\hline & PRE & 0,676 & $-0,439$ & $-0,051$ & $-0,034$ & 0,507 & $-0,463$ \\
\hline 2003 & Anual & $-0,009$ & $-0,086$ & 0,041 & $-0,076$ & 0,011 & $0,137^{* *}$ \\
\hline \multirow{2}{*}{$95 \%$} & PPP & 0,065 & $-0,146$ & 0,017 & $-0,010$ & 0,062 & $-0,039$ \\
\hline & PRE & 0,057 & $-0,093$ & $-0,028$ & 0,060 & 0,098 & $-0,006$ \\
\hline 2004 & Anual & $0,125^{*}$ & $-0,022$ & 0,004 & $-0,031$ & $-0,024$ & $0,195^{\star *}$ \\
\hline \multirow{2}{*}{$95 \%$} & PPP & 0,050 & $-0,045$ & $0,199 *$ & $-0,002$ & $-0,207^{*}$ & 0,059 \\
\hline & PRE & 0,158 & 0,089 & 0,006 & $-0,028$ & 0,060 & 0,234 \\
\hline 2005 & Anual & 0,024 & $-0,097$ & $-0,033$ & $-0,081$ & 0,049 & $0,182^{* \star}$ \\
\hline \multirow{2}{*}{$95 \%$} & PPP & 0,139 & $-0,146$ & $-0,125$ & $-0,042$ & 0,152 & 0,081 \\
\hline & PRE & 0,266 & $-0,274$ & $-0,100$ & $-0,012$ & 0,119 & $-0,028$ \\
\hline 2006 & Anual & 0,025 & $-0,160 * *$ & 0,052 & 0,015 & 0,001 & $0,141^{*}$ \\
\hline \multirow{2}{*}{$95 \%$} & PPP & 0,144 & $-0,225^{*}$ & 0,011 & 0,021 & 0,097 & $-0,139$ \\
\hline & PRE & 0,092 & 0,069 & $-0,103$ & 0,078 & 0,287 & $-0,179$ \\
\hline 2007 & Anual & 0,102 & 0,030 & $-0,112^{*}$ & $-0,197^{* *}$ & $0,145^{\star \star}$ & 0,085 \\
\hline \multirow{2}{*}{$95 \%$} & PPP & 0,062 & 0,170 & $-0,29^{* *}$ & $-0,025$ & $0,303^{* *}$ & $-0,059$ \\
\hline & PRE & 0,225 & 0,010 & $-0,42^{* *}$ & $-0,285$ & $0,489 * *$ & $-0,216$ \\
\hline Total & Anual & $-0,046 *$ & $-0,043^{*}$ & 0,010 & $-0,037$ & 0,012 & $0,147^{* *}$ \\
\hline
\end{tabular}

Tabla 5.2.3.12. Coeficientes de correlación de Spearman entre Compositae y las variables climatológicas. Tmed,

Tmax, Tmin (temperatura media, máxima y mínima), Hrelativa (humedad relativa), Vemed (velocidad media), FrecCalmas (frecuencia de calmas), V1Cuad, V2Cuad, V3Cuad, V4Cuad (vientos procedentes del I, II, III y IV cuadrante). Significación: 95\%(*), 99\%(**). (-) Ausencia de correlaciones. 
A continuación, se tratan por separado los tipos de polen Liguliflorae y Helianthus, contabilizados durante los años 2004-2007, aunque estos resultados hayan sido incluidos dentro del tratamiento realizado para el tipo de polen Compositae y que, ambos tipos, se encuentren dentro del grupo de pólenes con una representación superior o igual al o,1\%.

\subsection{Helianthus}

Los niveles del tipo polínico Calendula arvensis en la atmósfera de Salamanca, a pesar de su bajo número, se incrementaron durante el período 20042007, ya que si en el año 2004 el total anual fue de 10 pólenes, en el año 2007 alcanzó los 18. Esto supuso que la variación interanual (Fig. 5.2.3.19.) llevó consigo un aumento del $80 \%$ en las concentraciones anuales de este tipo polínico. El análisis de regresión de tipo lineal confirma esta tendencia a través del valor que tomó su índice de determinación $\left(\mathrm{R}^{2}=0,85\right)$. $\mathrm{La}$ representación media de este tipo fue inferior al $0,1 \%$ en el bienio 2005-2006, pero igual a este porcentaje en los otros dos años (2004, 2007).

Las concentraciones polínicas de este tipo (Fig. 5.2.3.20.C.) comenzaron a contabilizarse durante finales del mes de mayo e inicios de junio hasta el comienzo de noviembre, como muestra la dinámica aportada por el porcentaje de representación que alcanzó la media de los
Tipo polínico: Calendula arvensis.

Especie(s): Calendula arvensis L., Helianthus annus L. (Compositae), entre otras.

Distribución: El girasol es una planta procedente de Norteamérica que en la Península lbérica, al igual que en la provincia de Salamanca, se cultiva en terrenos de regadío. Las caléndulas, por otra parte, son espontáneas y crecen en zonas nitrificadas como cultivos, bordes de caminos o terrenos baldíos, aunque existen también variedades ornamentales.

Época de floración: Variable según las especies, desde finales de primavera hasta inicios de otoño.

Polinización: Entomófila.

Morfología polínica (Lámina II): Polen trizonocolporado, isopolar y radiosimétrico, con una forma triangular en vista polar, circular en vista ecuatorial (esferoidal), y un tamaño variable $(P=22-45 \mu \mathrm{m})$. Endoaberturas tipo poro dispuestas de forma perpendiucular a las ectoaberturas tipo colpo, en cuya intersección se localizan poros de forma rectangular. La exina gruesa $(3 \mu \mathrm{m})$, presenta una superficie equinada, con espinas de 5-6 $\mu \mathrm{m}$, muy agudas. cincos días anteriores para el total promediado de las cuatro anualidades. Las mayores concentraciones diarias registradas (Tabla 5.2.3.13.; Fig. 5.2.3.20. A. B.), variaron entre los 3 granos $/ \mathrm{m}^{3}$ (26 de septiembre de 2005, 21 de julio de 2007) y 1 grano/m³ (varios días en el año 2004), siendo 1 grano/m³ (varios días), la mayor concentración polínica promediada. 


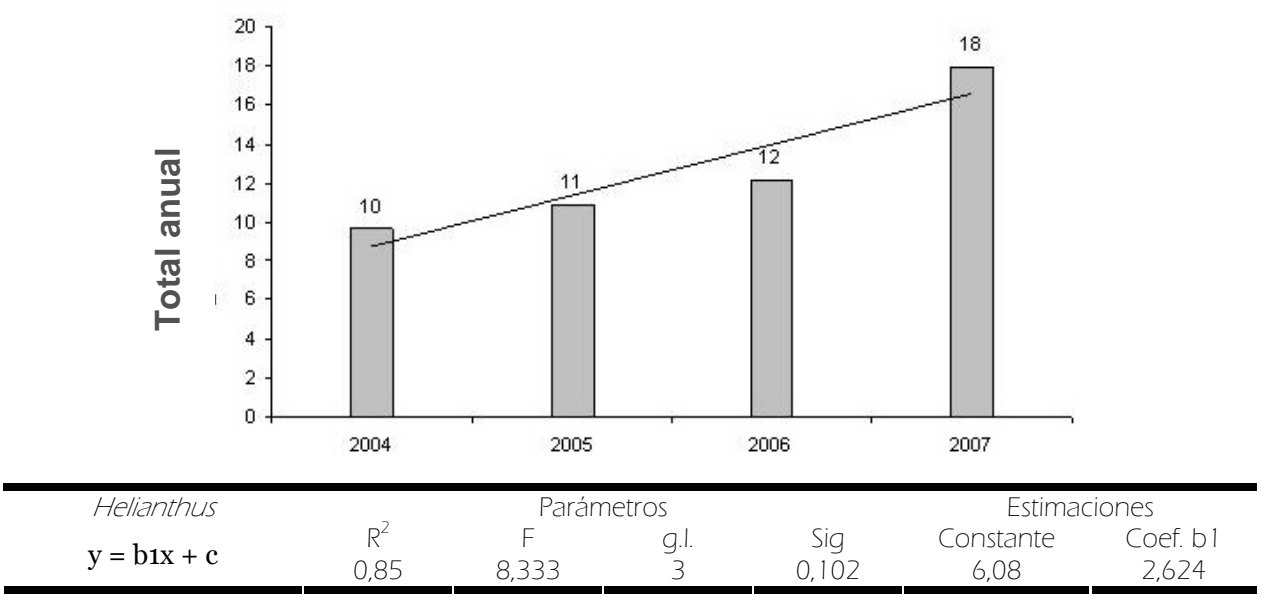

Fig. 5.2.3.19. Evolución anual del número total de pólenes de Helianthus y tendencias (análisis de regresión).

\begin{tabular}{|c|c|c|c|c|c|}
\hline Helianthus & 2004 & 2005 & 2006 & 2007 & Media \\
\hline Total & 10 & 11 & 12 & 18 & 13 \\
Máximo & 1 & 3 & 2 & 3 & 1 \\
Día & varios & $26-s e p$ & $23-j u l$ & $21-j u l$ & varios \\
\hline
\end{tabular}

Tabla 5.2.3.13. Totales y concentraciones máximas diarias y promedio para Helianthus.
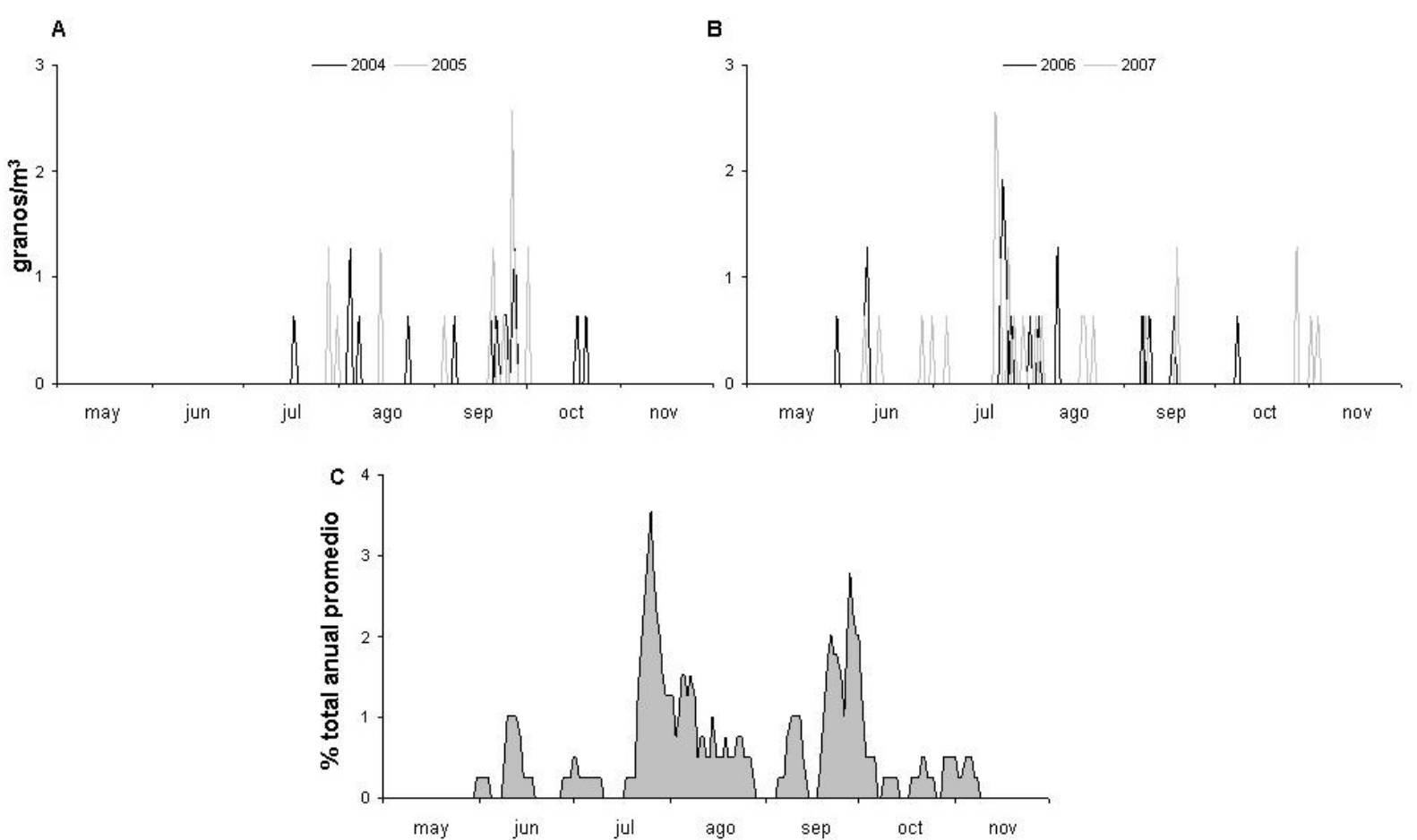

Fig. 5.2.3.20. Variación de las concentraciones medias diarias de Helianthus durante el período 2004-2005 (A) y 2006-2007 (B). Porcentajes de representación diarios para la media de los cinco días anteriores dentro del promedio de los ocho años analizados $(\mathbf{C})$. 


\subsection{Liguliflorae}

La variación interanual (Fig. 5.2.3.21.) de este tipo de polen en la atmósfera registró un aumento en sus niveles anuales durante el período 20042007, pues en el año 2004 se contabilizaron 33 pólenes y en el año 2007, 96 (un 191\% más). Esta evolución en el número total de granos de polen dio lugar a un índice de determinación $\left(\mathrm{R}^{2}=\mathrm{O}, 81\right)$, propio de la regresión lineal que indicó también una tendencia al incremento. Por otro lado, el porcentaje de representación sobre el total de pólenes contabilizados en cada anualidad estudiada osciló entre el o,3\% de 2006 y 2007, al 0,1\% de 2005, siendo 0,2\% el porcentaje medio.

La evolución de los niveles de polen a través del porcentaje promedio dentro de la media móvil los cinco días anteriores sobre el total promediado para los años analizados, indicó un aumento desde inicios de mayo hasta finales de junio (Fig. 5.2.3.22.C.), presentando una concentración máxima de 4 granos $/ \mathrm{m}^{3}$ el día 24 de junio para el conjunto de años estudiados con respecto al total promedio (Tabla 5.2.3.14.). Las mayores concentraciones diarias oscilaron entre 13 granos $/ \mathrm{m}^{3}$ (24 junio de 2007) y 3 granos $/ \mathrm{m}^{3}$ (29 mayo de 2005) (Tabla 5.2.3.14.; Fig. 5.2.3.22. A.B.). Después, las concentraciones de polen fueron disminuyendo durante el mes de julio, manteniéndose en la atmósfera hasta inicios de otoño.
Tipo de polen: Liguliflorae.

Especie(s): Numerosas dentro de la tribu Lactucaceae, y pertenecientes a los géneros Chondrilla L., Cichorium L., Crepis L., Lactuca L. Leontodon L., o Taraxacum Weber (Compositae), entre otros.

Distribución: Prácticamente cosmpolitas, bien se desarrollen como espontáneas o cultivadas, algo que ocurre en la Península Ibérica y en la provincia de Salamanca, donde se encuentran desde pastizales y dehesas hasta medios antropizados, como cultivos o bordes de caminos.

Época de floración: Variable según las especies, principalmente a finales de primavera y verano.

Polinización: Entomófila.

Morfología polínica (Lámina II): Polen trizonocolporado, isopolar y radiosimétrico, con una forma circular en vista polar, poligonal en vista ecuatorial (esferoidal), y un tamaño variable $(P=20-45 \mu \mathrm{m})$. Ectoaberturas tipo colpo, poco elípticas, y endoaberturas tipo poro dispuestas perpendicularmente a las anteriores. La exina gruesa (hasta $4 \mu \mathrm{m}$ ), presenta una superficie equinolofada, con una serie de crestas anastomosadas, sobre las que se disponen pequeñas espinas (hasta $2 \mu \mathrm{m}$ ) con numerosas lagunas. 

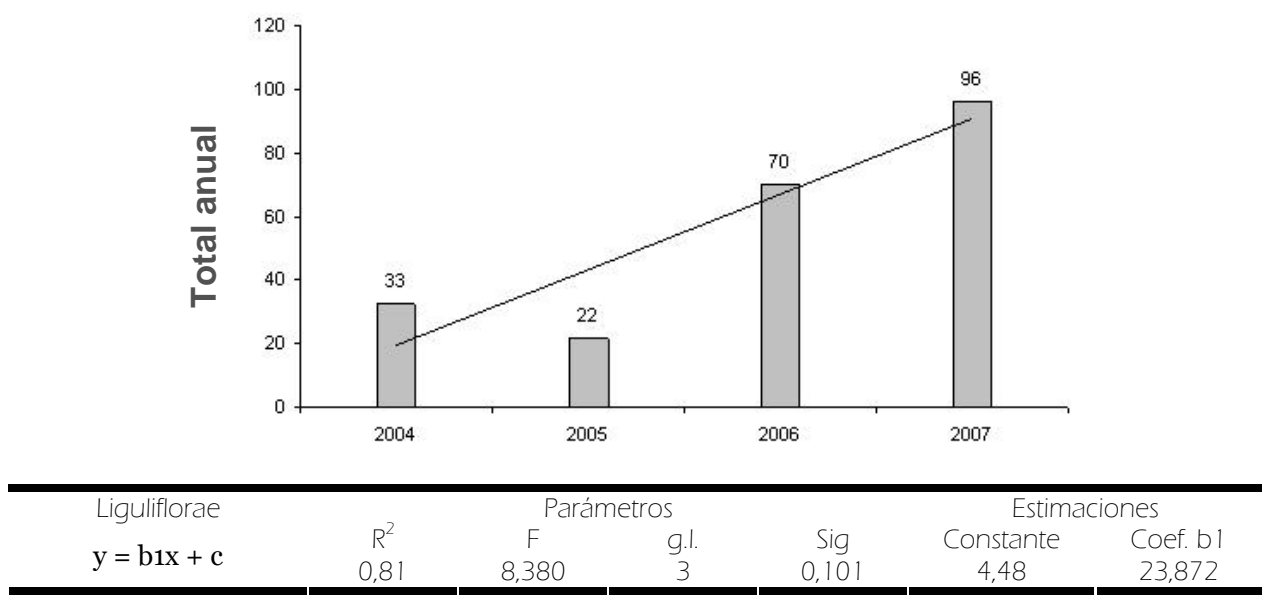

Fig. 5.2.3.21. Evolución anual del número total de pólenes de Liguliflorae y tendencias (análisis de regresión).

\begin{tabular}{|c|c|c|c|c|c|}
\hline Liguliflorae & 2004 & 2005 & 2006 & 2007 & Media \\
\hline Total & 33 & 22 & 70 & 96 & 55 \\
Máximo & 4 & 3 & 7 & 13 & 4 \\
Día & $14-j u l$ & 29-may & 13-may & 24-jun & 24-jun \\
\hline
\end{tabular}

Tabla 5.2.3.14. Totales y concentraciones máximas diarias y promedio para Liguliflorae.
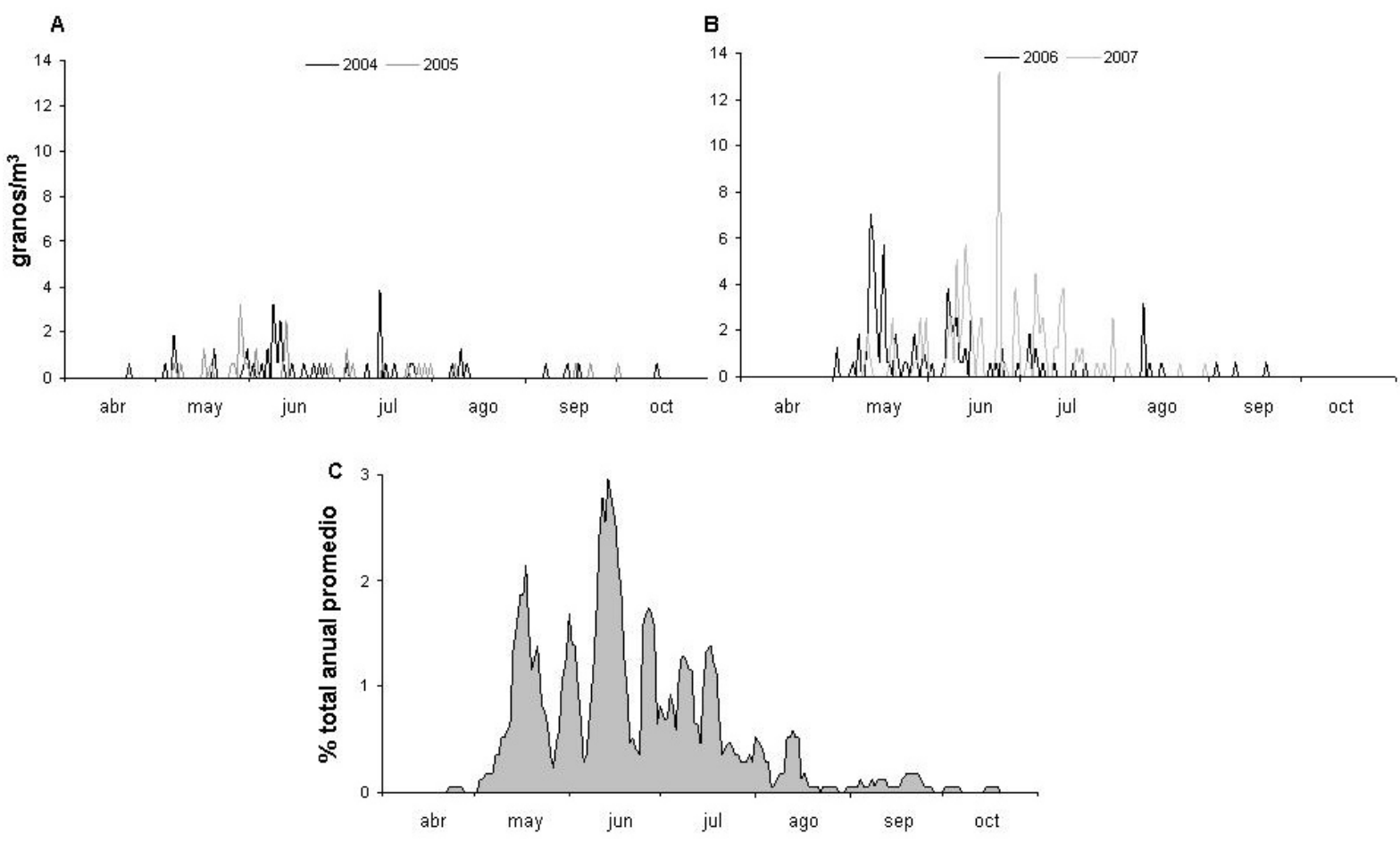

Fig. 5.2.3.22. Variación de las concentraciones medias diarias de Liguliflorae durante el período 2004-2005 (A) y 2006-2007 (B). Porcentajes de representación diarios para la media de los cinco días anteriores dentro del promedio de los ocho años analizados (C). 


\subsubsection{Cyperaceae}

El tipo de polen que engloba a la familia Cyperaceae, experimentó un descenso en sus niveles polínicos a través de los ocho años analizados, con una variación interanual (Fig. 5.2.3.23.) que pasó de un total de 169 pólenes en el año 2000 a los 80 del año 2007. Esta evolución en el número total de granos de polen (un $55 \%$ menos), dio lugar a un índice de determinación $\left(\mathrm{R}^{2}=0,31\right)$, propio de la regresión lineal que, pese a indicar también el decrecimiento de las concentraciones de polen de Cyperaceae, tuviera un valor más bajo que con otros tipos. Los porcentajes de representación sobre el total de pólenes contabilizados en cada anualidad estudiada variaron del 0,2\% de 2007 al 1,5\% de 2000, con un porcentaje medio de $0,6 \%$.

La distribución de estos granos de polen a lo largo del año se localizó entre mayo y principios de agosto, por lo que la variación estacional (Tabla 5.2.3.15.) tuvo un PPP promedio de 92 días, dejando diferencias en la fecha de inicio (14 abril de 2003 - 10 junio de 2000), y en la fecha de finalización (22 de julio de 2005 - 10 de agosto de 2002).

Los niveles polínicos de esta familia botánica en la atmósfera de la ciudad de Salamanca (Fig. 5.2.3.24.D.) experimentaron un ascenso a partir de mediados de abril hasta finales de junio, momento en el que alcanzan las mayores concentraciones, como indica el valor medio más elevado en los años analizados ( 2 granos $/ \mathrm{m}^{3}$ el 22 de junio), gracias a la dinámica aportada por el porcentaje promedio dentro de la media móvil los cinco días anteriores sobre el total promediado para los años analizados (Tabla 5.2.3.15). En todo caso, las mayores concentraciones diarias registradas en los ocho años estudiados oscilaron en más de un mes, y con valores entre los 2 granos $/ \mathrm{m}^{3}$ ( 8 de junio de 2002) y los 10 granos $/ \mathrm{m}^{3}$ (22 de junio de 2000). Después, estos niveles disminuyeron a finales del mes de junio, 
manteniéndose en la atmósfera durante julio y agosto y presentando concentraciones anecdóticas en septiembre (Fig. 5.2.3.24. A. B. C.).

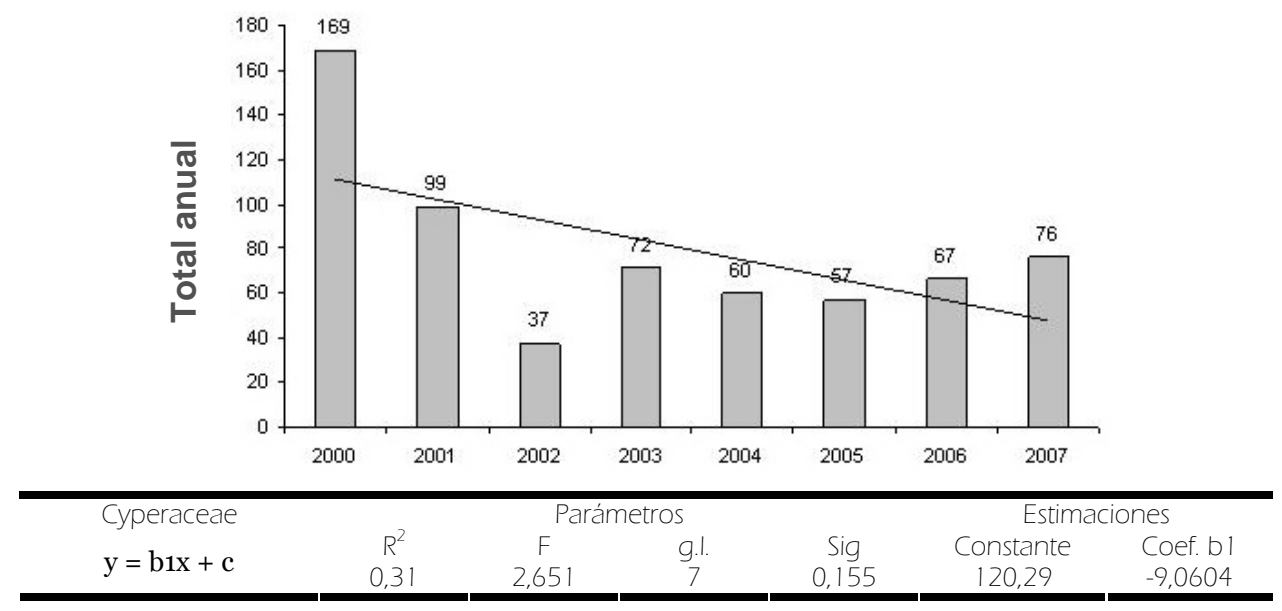

Fig. 5.2.3.23. Evolución anual del número total de pólenes de Cyperaceae y tendencias (análisis de regresión).

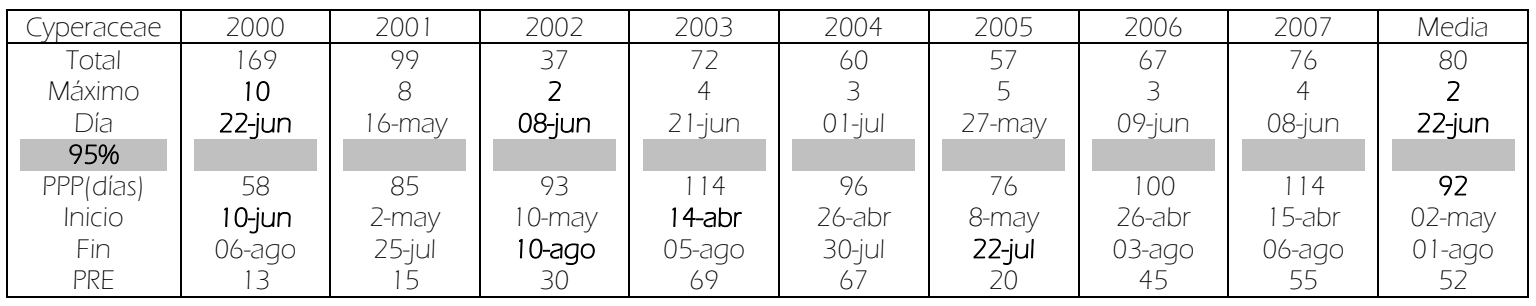

Tabla 5.2.3.15. Totales, concentraciones máximas diarias, período principal de polinización (PPP; fecha de inicio y fin) y días precedentes al valor máximo (PRE) durante los ocho años de estudio y el promedio de todos los parámetros para Cyperaceae.

Las concentraciones de polen a lo largo del día se incrementaron a partir de las 11 horas hasta las 15 horas, momento en el que las concentraciones horarias disminuyeron hasta la medianoche. Por tanto, la variación intradiaria (Fig. 5.2.3.25.) durante un día promedio para el trienio 2005-2007, presentó los mayores niveles horarios en la segunda mitad del día, y en especial, en las horas posteriores al mediodía.

Las temperaturas medias, máximas y mínimas junto a la insolación y los vientos procedentes del IV cuadrante tuvieron una influencia positiva en los niveles de este tipo de polen durante los ocho años analizados, así como el efecto negativo que ejercieron las precipitaciones, la humedad relativa y, en menor medida, los vientos del II cuadrante, tras el análisis de correlación (Tabla 5.2.3.16.). Este mismo tipo de correlaciones, en cuanto al signo y grado de significación, se observó en las distintas anualidades, así como en un buen número de PPP y PRE de dichas anualidades. 


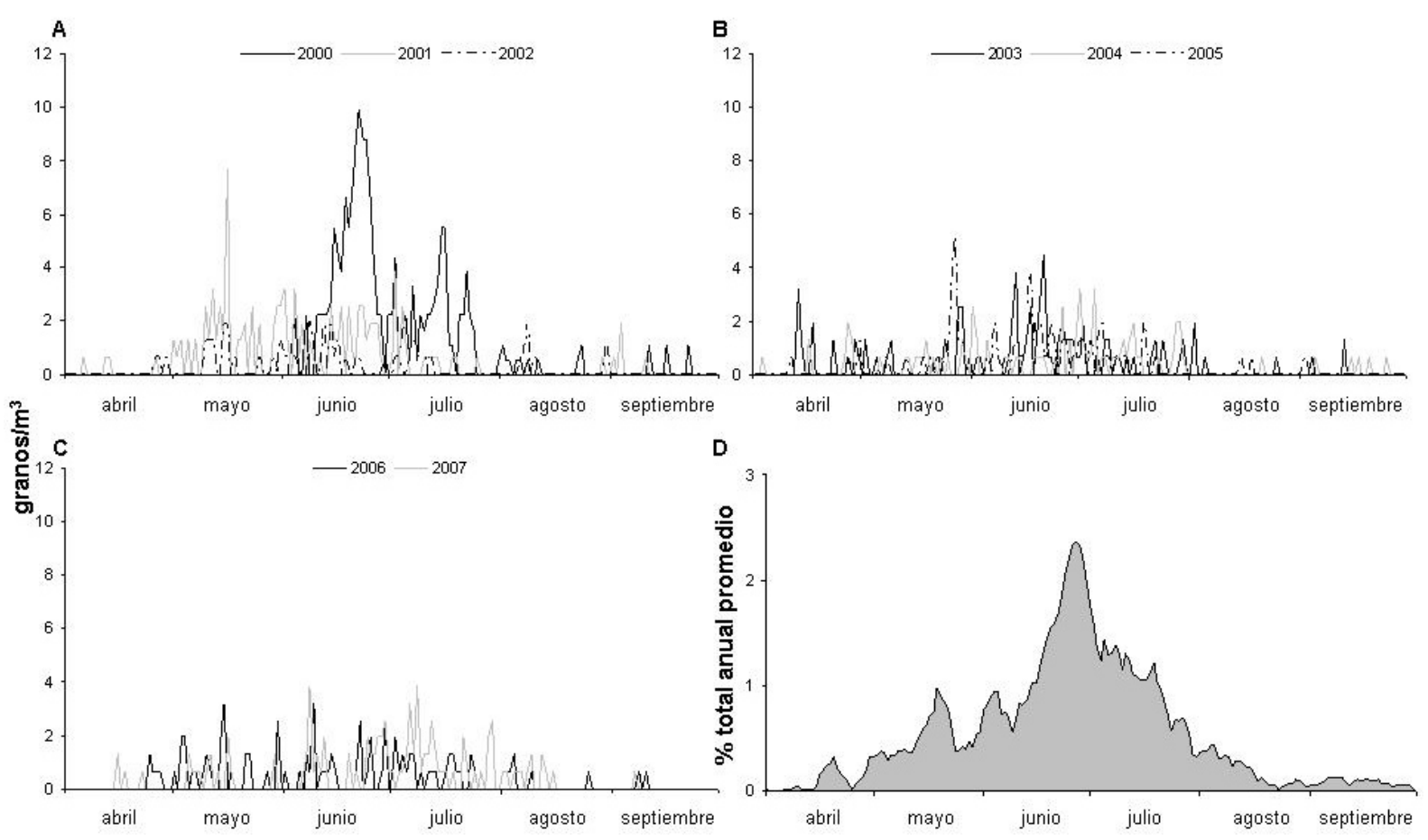

Fig. 5.2.3.24. Variación de las concentraciones medias diarias de Cyperaceae durante el período 2000-2002 (A), 2003-2005 (B) y 2006-2007 (C). Porcentajes de representación diarios para la media de los cinco días anteriores dentro del promedio de los ocho años analizados (D).

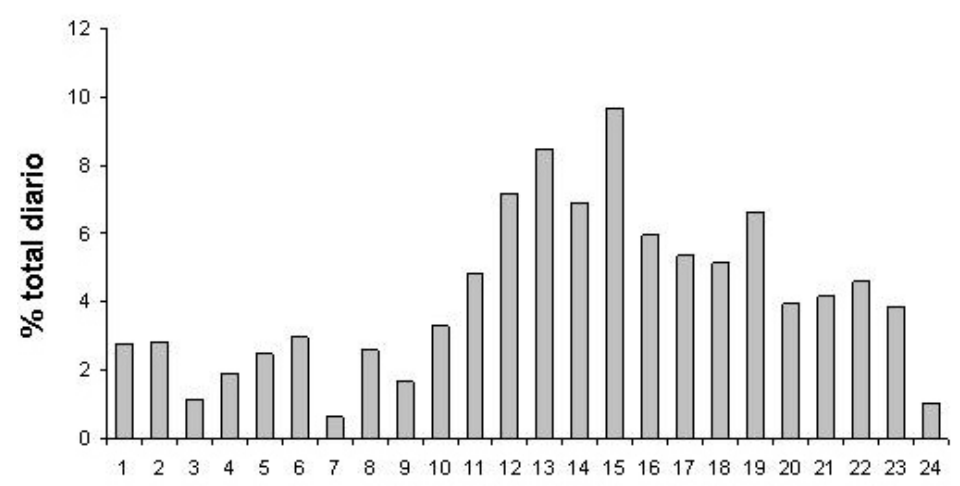

Fig. 5.2.3.25. Variación intradiaria del polen de Cyperaceae. 


\begin{tabular}{|c|c|c|c|c|c|c|c|}
\hline \multicolumn{2}{|c|}{ Cyperaceae } & Tmed & Tmax & Tmin & Insolación & Precipitación & Hrelativa \\
\hline 2000 & Anual & $0,499 * *$ & $0,485 * *$ & $0,473^{* *}$ & $0,417^{* *}$ & $-0,131^{\star}$ & $-0,471^{* *}$ \\
\hline \multirow{2}{*}{$95 \%$} & PPP & 0,114 & 0,166 & 0,033 & $-0,150$ & $-0,223$ & $-0,336 *$ \\
\hline & PRE & 0,416 & 0,215 & $0,577^{*}$ & $-0,620 *$ & - & 0,151 \\
\hline 2001 & Anual & $0,335^{\star *}$ & $0,342^{\star \star}$ & $0,301^{* *}$ & $0,358^{* \star}$ & $-0,123^{\star}$ & $-0,385^{\star \star}$ \\
\hline \multirow{2}{*}{$95 \%$} & PPP & 0,022 & $-0,004$ & 0,071 & $-0,027$ & $-0,160$ & $-0,061$ \\
\hline & PRE & 0,425 & 0,438 & 0,406 & 0,125 & $-0,246$ & $-0,388$ \\
\hline 2002 & Anual & $0,338 * *$ & $0,333^{* *}$ & $0,303^{* *}$ & $0,325^{* *}$ & $-0,113^{*}$ & $-0,348 * \star$ \\
\hline \multirow{2}{*}{$95 \%$} & PPP & 0,013 & $-0,008$ & 0,008 & $-0,081$ & 0,018 & $-0,024$ \\
\hline & PRE & 0,181 & 0,186 & 0,183 & 0,146 & $-0,056$ & $-0,156$ \\
\hline 2003 & Anual & $0,392 * *$ & $0,366^{* *}$ & $0,364^{* *}$ & $0,306^{* *}$ & $-0,126^{\star}$ & $-0,420 * \star$ \\
\hline \multirow{2}{*}{$95 \%$} & PPP & $0,221^{\star}$ & $0,187^{\star}$ & $0,239^{*}$ & $-0,009$ & $-0,062$ & $-0,133$ \\
\hline & PRE & 0,217 & 0,171 & 0,234 & $-0,024$ & $-0,064$ & $-0,103$ \\
\hline 2004 & Anual & $0,398^{* *}$ & $0,396 * *$ & $0,370^{* *}$ & $0,435^{\star *}$ & $-0,127^{\star}$ & $-0,392^{\star \star}$ \\
\hline \multirow{2}{*}{$95 \%$} & PPP & $0,220^{*}$ & $0,241^{\star}$ & 0,155 & $0,287^{* *}$ & $-0,196$ & $-0,243^{*}$ \\
\hline & PRE & 0,219 & $0,260^{*}$ & 0,178 & $0,306^{*}$ & $-0,226$ & $-0,322 * *$ \\
\hline 2005 & Anual & 0,460 ** & 0,441 ** & $0,419 * *$ & $0,398^{* *}$ & $-0,064$ & $-0,430^{\star \star}$ \\
\hline \multirow{2}{*}{$95 \%$} & PPP & $0,362^{* \star}$ & $0,323^{* *}$ & 0,335 ** & 0,072 & 0,083 & $-0,093$ \\
\hline & PRE & $0,478 *$ & $0,545^{*}$ & 0,267 & $0,587 * *$ & $-0,300$ & $-0,671 * *$ \\
\hline 2006 & Anual & $0,458^{* *}$ & $0,435^{* *}$ & $0,442^{* *}$ & - & $-0,087$ & $-0,422^{* *}$ \\
\hline \multirow{2}{*}{$95 \%$} & PPP & 0,080 & 0,048 & 0,147 & - & 0,193 & $-0,077$ \\
\hline & PRE & 0,185 & 0,079 & $0,339 *$ & - & $0,320^{*}$ & $-0,111$ \\
\hline 2007 & Anual & $0,489 * *$ & $0,480 * *$ & 0,401 ** & $0,460 * *$ & $-0,160 * \star$ & $-0,473^{* *}$ \\
\hline \multirow{2}{*}{$95 \%$} & PPP & $0,470^{* *}$ & $0,474^{* *}$ & $0,232^{\star}$ & $0,398^{* *}$ & $-0,333^{* *}$ & $-0,461^{* *}$ \\
\hline & PRE & $0,268 *$ & 0,341 * & $-0,122$ & $0,396 * *$ & $-0,276$ * & $-0,404 * \star$ \\
\hline Total & Anual & $0,419 * *$ & $0,410 * *$ & $0,377 * *$ & $0,374 * \star$ & $-0,119 * *$ & $-0,398 * *$ \\
\hline
\end{tabular}

\begin{tabular}{|c|c|c|c|c|c|c|c|}
\hline \multicolumn{2}{|c|}{ Cyperaceae } & Vemed & FrecCalm & VICuadr & V2Cuadr & V3Cuadr & V4Cuadr \\
\hline 2000 & Anual & 0,053 & $-0,055$ & $0,152 * \star$ & $-0,025$ & $-0,126^{*}$ & 0,040 \\
\hline \multirow{2}{*}{$95 \%$} & PPP & 0,097 & $-0,175$ & 0,116 & 0,206 & 0,010 & $-0,246$ \\
\hline & PRE & $-0,352$ & $0,612^{*}$ & $-0,603^{*}$ & 0,258 & 0,499 & 0,268 \\
\hline 2001 & Anual & 0,042 & $-0,084$ & $-0,064$ & $-0,117^{*}$ & 0,042 & 0,301 ** \\
\hline \multirow{2}{*}{$95 \%$} & PPP & $0,237^{*}$ & $-0,151$ & $-0,207$ & $-0,076$ & 0,291 ** & 0,017 \\
\hline & PRE & 0,334 & 0,261 & $-0,75^{* *}$ & $-0,164$ & $0,606^{*}$ & $-0,017$ \\
\hline 2002 & Anual & 0,003 & 0,064 & $-0,060$ & $-0,148 * *$ & 0,081 & 0,101 \\
\hline \multirow{2}{*}{$95 \%$} & PPP & $-0,042$ & $0,227^{*}$ & $-0,136$ & $-0,070$ & $0,217^{\star}$ & $-0,079$ \\
\hline & PRE & $-0,300$ & 0,346 & $0,379 *$ & 0,218 & $-0,447 *$ & $-0,141$ \\
\hline 2003 & Anual & 0,038 & $-0,129 *$ & $-0,051$ & $-0,029$ & 0,043 & 0,100 \\
\hline \multirow{2}{*}{$95 \%$} & PPP & $-0,095$ & $-0,087$ & 0,006 & 0,094 & $-0,049$ & $-0,011$ \\
\hline & PRE & $-0,193$ & $-0,067$ & 0,005 & 0,230 & $-0,082$ & $-0,026$ \\
\hline 2004 & Anual & 0,041 & $-0,062$ & 0,013 & $-0,014$ & $-0,097$ & $0,146 * *$ \\
\hline \multirow{2}{*}{$95 \%$} & PPP & $-0,030$ & 0,086 & 0,018 & 0,087 & $-0,071$ & 0,045 \\
\hline & PRE & $-0,062$ & $0,256 *$ & $-0,036$ & 0,154 & 0,003 & 0,006 \\
\hline 2005 & Anual & 0,027 & $-0,114^{*}$ & 0,031 & $-0,022$ & 0,024 & $0,122^{*}$ \\
\hline \multirow{2}{*}{$95 \%$} & PPP & $-0,021$ & $-0,024$ & 0,165 & 0,126 & $-0,127$ & $-0,223$ \\
\hline & PRE & $-0,025$ & $-0,245$ & $-0,018$ & 0,112 & 0,105 & $-0,296$ \\
\hline 2006 & Anual & 0,003 & $-0,125^{\star}$ & 0,055 & 0,057 & $-0,045$ & $0,147^{*}$ \\
\hline \multirow{2}{*}{$95 \%$} & PPP & 0,172 & $-0,068$ & $-0,053$ & 0,152 & 0,039 & $-0,049$ \\
\hline & PRE & $-0,024$ & 0,005 & $-0,222$ & 0,219 & 0,300 * & $-0,044$ \\
\hline 2007 & Anual & 0,057 & 0,034 & $-0,049$ & $-0,082$ & 0,092 & $0,105^{*}$ \\
\hline \multirow{2}{*}{$95 \%$} & PPP & $-0,074$ & 0,111 & 0,098 & $-0,033$ & $-0,46$ & $-0,018$ \\
\hline & PRE & $-0,044$ & 0,120 & 0,091 & 0,109 & $-0,116$ & $-0,233$ \\
\hline Total & Anual & 0,018 & $-0,036$ & 0,004 & $-0,050 * \star$ & $-0,004$ & 0,140 ** \\
\hline
\end{tabular}

Tabla 5.2.3.16. Coeficientes de correlación de Spearman entre Cyperaceae y las variables climatológicas. Tmed,

Tmax, Tmin (temperatura media, máxima y mínima), Hrelativa (humedad relativa), Vemed (velocidad media), FrecCalmas (frecuencia de calmas), V1Cuad, V2Cuad, V3Cuad, V4Cuad (vientos procedentes del I, II, III y IV cuadrante). Significación: 95\%(*), 99\%(**). (-) Ausencia de correlaciones. 


\subsubsection{Echium}

La variación interanual (Fig. 5.2.3.26.) de este tipo polínico en la atmósfera de la ciudad de Salamanca indicó un incremento en los niveles polínicos anuales durante el período 2000-2007, reflejados en las totales anuales: 124 granos de polen del año 2000 y 248 del año 2007. Esto supuso un aumento del $100 \% \mathrm{y}$, tras aplicar el análisis de tendencias mediante regresión lineal, un índice de determinación bajo( $\left.\mathrm{R}^{2}=0,39\right)$, que confirma esta dinámica. Por otro lado, el porcentaje de representación sobre el total de pólenes contabilizados en cada anualidad analizada osciló entre el 0,2\% de los años 2001, 2002 y 2005 al 1,3\% de 2003, siendo 0,7\% el porcentaje medio.

La variación estacional de Echium en la atmósfera de Salamanca, (Tabla 5.2.3.17.) se localizó entre los meses de mayo y julio, salvo en los dos últimos años, en los que aparecieron pólenes a finales del año 2006 y en los primeros meses de 2007. Por todo ello, la duración media del PPP se situó en 89 días que, pese a las diferencias que nos dejó esos dos últimos años $\mathrm{y}$ que condicionaron esta duración promedio del PPP, y las
Tipo polínico: Echium plantagineum.

Especie(s): Echium asperrimum Lam., Echium plantagineum L. O Echium vulgare L. (Boraginaceae), entre otras.

Distribución: Género originario de Eurasia, enclavado en el sur y el oeste de Europa, habita tanto en la Península Ibérica, como en la provincia de Salamanca, en terrenos alterados como son cunetas y cultivos, y formando parte del cortejo florístico de numerosos encinares adehesados.

Época de floración: Desde mediados de primavera hasta los meses estivales.

Polinización: Entomófila, levemente anemófila debido a la disposición de los estambres fuera de la corola.

Morfología polínica (Lámina II): Polen trizonocolporado, heteropolar y radiosimétrico, con forma circular levemente trilobulada en vista polar y piriforme en vista ecuatorial (prolato), y un tamaño pequeño $(P=13-25$ $\mu \mathrm{m})$. Las ectoaberturas tipo colpo, dispuestas en la zona ecuatorial son largas y alcanzan la proximidad de los polos, y las endoaberturas tipo poro, de 2 a $4 \mu \mathrm{m}$ de diámetro, se sitúan hacia el polo distal. La exina, $(1 \mu \mathrm{m})$, presenta una superficie perforada, ligeramente reticulada, con lúmenes redondeados de menos de $1 \mu \mathrm{m}$ y escasos gránulos dispersos sobre los muros. variaciones existentes en sus fechas de inicio (24 de enero de 2007 - 18 de mayo de 2004) y finalización (26 de junio de 2002 y 2005 - 7 de diciembre de 2006).

La dinámica que presentaron las concentraciones polínicas de Echium (Fig. 5.2.3.27.D.) mostrada a través del porcentaje de representación que tuvieron las concentraciones medias de los cincos días anteriores para el total promediado del conjunto de años estudiados, fue la siguiente, con un incremento de las concentraciones desde finales de abril hasta inicios de junio, siendo el 9 de junio (6 granos $/ \mathrm{m}^{3}$ ), la fecha con la 
concentración máxima (Tabla 5.2.3.17.), como el promedio de las concentraciones de los años estudiados. Posteriormente, estos niveles disminuyeron, manteniéndose dichos granos de polen presentes en la atmósfera durante julio y agosto. Cabe reseñar, como ya se ha señalado, la particular distribución en la atmósfera que mostró este tipo polínico durante finales de 2006 e inicios de 2007 (Fig. 5.2.3.27. C. D.). Todo ello condicionó también que las concentraciones diarias más elevadas dentro de los ocho años (Tabla 5.2.3.17.; Fig. 5.2.3.27. A. B. C.) variasen entre los 3 granos $/ \mathrm{m}^{3}$ (31 de mayo de 2001, 12 de mayo de 2002) y los 31 granos $/ \mathrm{m}^{3}$ (18 de noviembre de 2006).

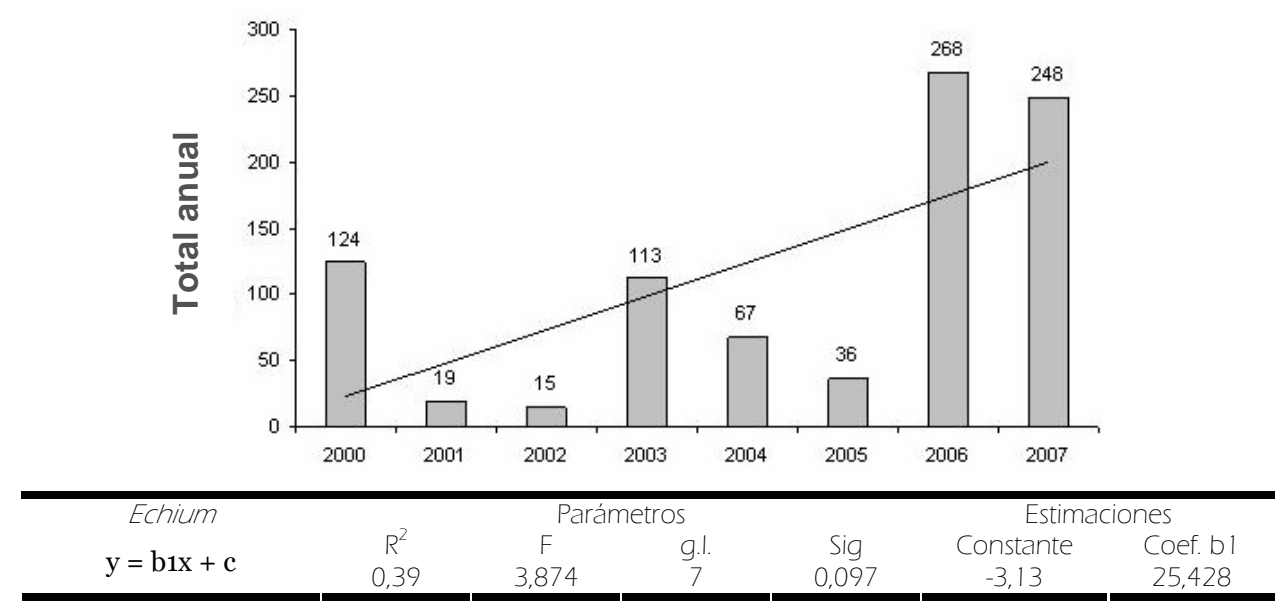

Fig. 5.2.3.26. Evolución anual del número total de pólenes de Echium y tendencias (análisis de regresión).

\begin{tabular}{|c|c|c|c|c|c|c|c|c|c|}
\hline Echium & 2000 & 2001 & 2002 & 2003 & 2004 & 2005 & 2006 & 2007 & Media \\
\hline $\begin{array}{c}\text { PPP(días) } \\
\text { Inicio } \\
\text { Fin } \\
\text { PRE }\end{array}$ & $\begin{array}{c}43 \\
16-m a y \\
27-j u n \\
10\end{array}$ & $\begin{array}{c}46 \\
16-m a y \\
30-j u n \\
16\end{array}$ & $\begin{array}{c}46 \\
12-m a y \\
26-j u n \\
1\end{array}$ & $\begin{array}{c}60 \\
09-m a y \\
07-j u l \\
34\end{array}$ & $\begin{array}{c}53 \\
\text { 18-may } \\
09-j u l \\
23\end{array}$ & $\begin{array}{c}51 \\
07-m a y \\
26-j u n \\
23\end{array}$ & $\begin{array}{c}220 \\
02-m a y \\
07-d i c \\
201 \\
\end{array}$ & $\begin{array}{c}196 \\
\text { 24-ene } \\
\text { 06-ago } \\
138 \\
\end{array}$ & $\begin{array}{c}89 \\
28-a b r \\
25-j u l \\
43 \\
\end{array}$ \\
\hline
\end{tabular}

Tabla 5.2.3.17. Totales, concentraciones máximas diarias, período principal de polinización (PPP; fecha de inicio y fin) y días precedentes al valor máximo (PRE) durante los ocho años de estudio y el promedio de todos los parámetros para Echium.

La variación intradiaria (Fig. 5.2.3.28.) no mostró un claro patrón a lo largo de un día promedio para los últimos tres años estudiados, pero sí se observaron mayores niveles en la segunda mitad del día, a partir de las 11 horas y hasta la medianoche.

El análisis de correlación (Tabla 5.2.3.18.) mostró que las temperaturas medias, máximas y mínimas, junto a la insolación y, en menor medida, los vientos procedentes del III y IV cuadrante influyeron positivamente en los niveles polínicos durante los ocho años analizados, mientras que la humedad relativa, las precipitaciones, la frecuencia de las calmas y los vientos del I cuadrante tuvieron un efecto negativo, aunque algunos de ellos presentasen 
coeficientes de correlación bajos. Este patrón se mantuvo en todos los años analizados, exceptuando el caso de la velocidad media del viento, ya que mostró coeficientes de correlación positivos durante los años 2004 y 2007, y también durante ciertos PPP y PRE definidos en cada una de las anualidades, como ocurrió con los vientos procedentes del II cuadrante en el año 2003.
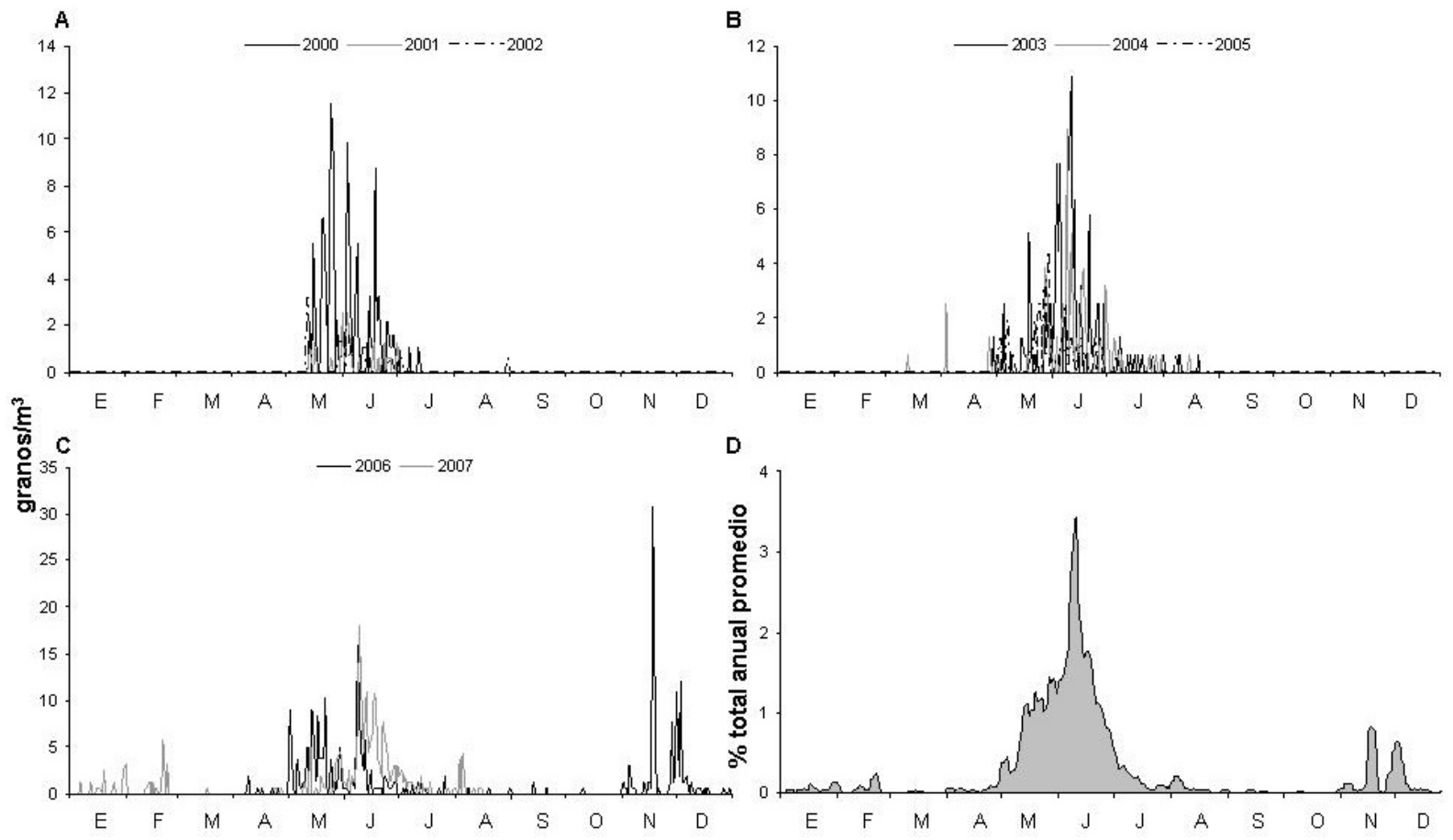

Fig. 5.2.3.27. Variación de las concentraciones medias diarias de Echium durante el período 2000-2002 (A), 2003-2005 (B) y 2006-2007 (C). Porcentajes de representación diarios para la media de los cinco días anteriores dentro del promedio de los ocho años analizados (D).

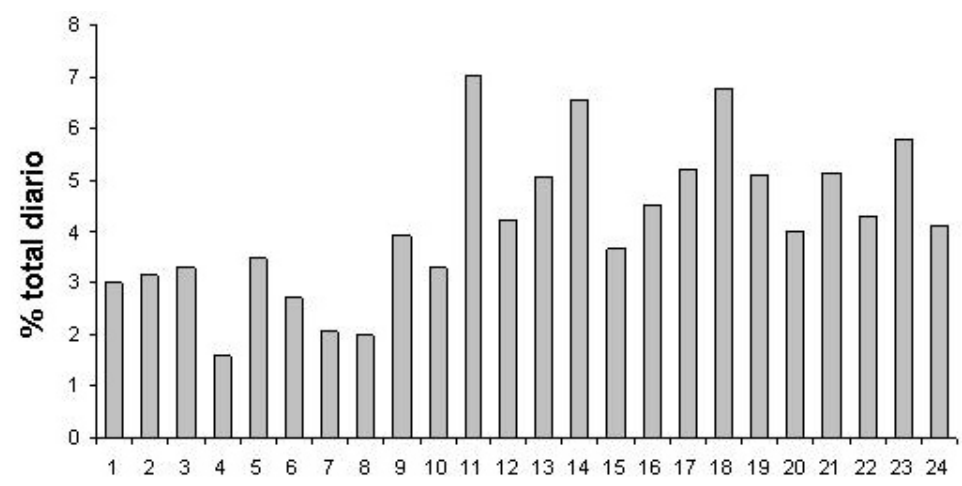

Fig. 5.2.3.28. Variación intradiaria del polen de Echium. 


\begin{tabular}{|c|c|c|c|c|c|c|c|}
\hline \multicolumn{2}{|c|}{ Echium } & Tmed & Tmax & Tmin & Insolación & Precipitación & Hrelativa \\
\hline 2000 & Anual & $0,369 * *$ & $0,344 * *$ & $0,380 * *$ & $0,269 * *$ & $-0,112^{\star}$ & $-0,297 * \star$ \\
\hline \multirow{2}{*}{$95 \%$} & PPP & 0,123 & $-0,012$ & $0,350^{*}$ & $-0,454^{* *}$ & 0,240 & 0,119 \\
\hline & PRE & $-0,100$ & $-0,156$ & 0,256 & $-0,621$ & 0,245 & 0,066 \\
\hline 2001 & Anual & $0,242^{* *}$ & $0,238^{* *}$ & $0,231^{* *}$ & $0,255^{* *}$ & $-0,086$ & $-0,256^{* *}$ \\
\hline \multirow{2}{*}{$95 \%$} & PPP & 0,286 & 0,197 & $0,398 * *$ & 0,190 & $-0,021$ & $-0,245$ \\
\hline & PRE & 0,073 & $-0,039$ & 0,363 & $-0,205$ & $-0,123$ & 0,238 \\
\hline 2002 & Anual & $0,195 * \star$ & $0,187^{\star \star}$ & 0,184 ** & $0,142^{\star \star}$ & $-0,006$ & $-0,188 * \star$ \\
\hline \multirow{2}{*}{$95 \%$} & PPP & 0,063 & 0,032 & 0,114 & $-0,181$ & 0,224 & 0,046 \\
\hline & PRE & - & - & - & - & - & - \\
\hline 2003 & Anual & 0,391 ** & $0,372^{\star \star}$ & 0,370 ** & $0,310^{* *}$ & $-0,095$ & $-0,413^{\star *}$ \\
\hline \multirow{2}{*}{$95 \%$} & PPP & $0,395^{\star \star}$ & $0,305^{\star \star}$ & 0,466 ** & $-0,330 *$ & 0,155 & $-0,143$ \\
\hline & PRE & $0,418^{*}$ & 0,269 & $0,540 * *$ & $-0,464^{* *}$ & 0,272 & 0,030 \\
\hline 2004 & Anual & $0,373^{* \star}$ & $0,362^{\star \star}$ & $0,361^{* *}$ & $0,334 * *$ & $-0,102$ & $-0,289$ ** \\
\hline \multirow{2}{*}{$95 \%$} & PPP & $0,354 * *$ & $0,319 *$ & $0,281^{*}$ & 0,084 & $-0,132$ & $-0,104$ \\
\hline & PRE & $0,468 * *$ & 0,343 & 0,532 ** & 0,021 & $-0,149$ & 0,063 \\
\hline 2005 & Anual & $0,322^{\star *}$ & $0,295^{\star \star}$ & $0,288^{* *}$ & $0,263^{* *}$ & $-0,054$ & $-0,324^{\star *}$ \\
\hline \multirow{2}{*}{$95 \%$} & PPP & 0,251 & 0,223 & 0,150 & $0,348^{*}$ & $-0,169$ & $-0,411^{\star *}$ \\
\hline & PRE & $0,508^{*}$ & $0,498 *$ & 0,321 & 0,219 & $-0,111$ & $-0,467$ * \\
\hline 2006 & Anual & $0,208^{* *}$ & $0,192^{\star \star}$ & $0,194^{* *}$ & - & $-0,027$ & $-0,193^{* *}$ \\
\hline \multirow{2}{*}{$95 \%$} & PPP & $-0,117$ & $-0,135^{\star}$ & $-0,128$ & - & $-0,010$ & $-0,095$ \\
\hline & PRE & $-0,020$ & $-0,043$ & $-0,039$ & - & $-0,021$ & $-0,224$ ** \\
\hline 2007 & Anual & $0,329 * *$ & $0,282^{\star \star}$ & 0,360 ** & $0,199 * \star$ & 0,008 & $-0,188^{* *}$ \\
\hline \multirow{2}{*}{$95 \%$} & PPP & $0,434^{* *}$ & $0,384 * *$ & 0,487 ** & $0,222^{* *}$ & $-0,117$ & $-0,209$ ** \\
\hline & PRE & 0,340 ** & $0,272^{* *}$ & $0,382 * *$ & 0,110 & $-0,045$ & $-0,095$ \\
\hline Total & Anual & $0,288^{* *}$ & $0,272^{\star \star}$ & $0,279 * *$ & $0,217^{\star \star}$ & $-0,053^{\star \star}$ & $-0,211^{\star *}$ \\
\hline
\end{tabular}

\begin{tabular}{|c|c|c|c|c|c|c|c|}
\hline \multicolumn{2}{|c|}{ Echium } & Vemed & FrecCalm & VICuadr & V2Cuadr & V3Cuadr & V4Cuadr \\
\hline 2000 & Anual & 0,049 & $-0,126^{\star}$ & 0,067 & 0,047 & $-0,040$ & 0,063 \\
\hline \multirow{2}{*}{$95 \%$} & PPP & 0,026 & $-0,134$ & $-0,217$ & 0,171 & $0,401 * *$ & $-0,028$ \\
\hline & PRE & 0,598 & $-0,649 *$ & $-0,263$ & $-0,644^{*}$ & $0,661^{*}$ & 0,368 \\
\hline 2001 & Anual & 0,021 & $-0,030$ & $-0,060$ & $-0,058$ & 0,081 & $0,186^{* \star}$ \\
\hline \multirow{2}{*}{$95 \%$} & PPP & 0,165 & $-0,095$ & $-0,140$ & $-0,119$ & 0,229 & 0,127 \\
\hline & PRE & 0,326 & $-0,397$ & $-0,181$ & $-0,265$ & 0,141 & 0,047 \\
\hline 2002 & Anual & 0,016 & $-0,035$ & $-0,052$ & $-0,012$ & 0,051 & 0,046 \\
\hline \multirow{2}{*}{$95 \%$} & PPP & 0,028 & $-0,067$ & 0,087 & 0,183 & $-0,023$ & $-0,068$ \\
\hline & PRE & - & - & - & - & - & - \\
\hline 2003 & Anual & 0,013 & $-0,060$ & $-0,094$ & $-0,020$ & $0,136^{* *}$ & $0,124^{\star}$ \\
\hline \multirow{2}{*}{$95 \%$} & PPP & $-0,114$ & 0,115 & $-0,189$ & $0,397 * *$ & $0,274^{*}$ & 0,003 \\
\hline & PRE & $-0,053$ & 0,164 & $-0,244$ & $0,413^{*}$ & $0,462 * *$ & $-0,004$ \\
\hline 2004 & Anual & $0,121^{*}$ & $-0,017$ & $-0,085$ & $-0,010$ & $-0,003$ & $0,237^{* *}$ \\
\hline \multirow{2}{*}{$95 \%$} & PPP & 0,051 & $-0,012$ & $-0,134$ & $-0,006$ & 0,019 & 0,201 \\
\hline & PRE & 0,285 & $-0,185$ & $-0,377$ & $-0,157$ & 0,283 & 0,315 \\
\hline 2005 & Anual & 0,022 & $-0,046$ & $-0,050$ & 0,025 & 0,097 & $0,120^{*}$ \\
\hline \multirow{2}{*}{$95 \%$} & PPP & $-0,011$ & 0,102 & 0,041 & 0,027 & 0,011 & $-0,162$ \\
\hline & PRE & 0,010 & $-0,033$ & 0,029 & 0,043 & 0,078 & $-0,303$ \\
\hline 2006 & Anual & $-0,002$ & $-0,135^{\star}$ & $-0,127^{\star}$ & $-0,023$ & $0,137^{\star}$ & 0,091 \\
\hline \multirow{2}{*}{$95 \%$} & PPP & $-0,033$ & $-0,094$ & $-0,078$ & $-0,015$ & 0,117 & 0,035 \\
\hline & PRE & 0,001 & $-0,089$ & $-0,042$ & $-0,004$ & 0,093 & 0,053 \\
\hline 2007 & Anual & $0,165^{* *}$ & $-0,125^{\star}$ & $-0,29$ ** & $-0,096$ & 0,351 ** & 0,088 \\
\hline \multirow{2}{*}{$95 \%$} & PPP & 0,035 & 0,087 & $-0,24 * \star$ & $-0,121$ & $0,291^{* \star}$ & $-0,112$ \\
\hline & PRE & $-0,015$ & 0,053 & $-0,122$ & $-0,033$ & 0,163 & $-0,150$ \\
\hline Total & Anual & $-0,06 * *$ & $-0,058 * \star$ & $-0,07$ * & 0,001 & 0,090 ** & $0,124^{\star \star}$ \\
\hline
\end{tabular}

Tabla 5.2.3.18. Coeficientes de correlación de Spearman entre Echium y las variables climatológicas. Tmed,

Tmax, Tmin (temperatura media, máxima y mínima), Hrelativa (humedad relativa), Vemed (velocidad media), FrecCalmas (frecuencia de calmas), V1Cuad, V2Cuad, V3Cuad, V4Cuad (vientos procedentes del I, II, III y IV cuadrante). Significación: $95 \%(*), 99 \%\left({ }^{* *}\right)$. (-) Ausencia de correlaciones. 


\subsubsection{Ligustrum}

Los niveles del tipo polínico Ligustrum vulgare en la atmósfera de Salamanca, experimentaron un descenso durante el período analizado, ya que si en el año 2000 el total anual fue de 75 pólenes, en el año 2007 alcanzó los 9, si bien la mayor concentración se presentó en el año 2001 (157 granos de polen). Esto supuso que la variación interanual (Fig. 5.2.3.29.) llevase consigo un descenso del $733 \%$ en las concentraciones anuales de este tipo polínico, confirmado con el análisis de regresión de tipo lineal $\left(\mathrm{R}^{2}=0,22\right)$, a pesar de su bajo índice. La representación media de los pólenes de este tipo a lo largo de los ocho años fue de $0,4 \%$, con un máximo de 1,6\% en 2001 y menor al o,1\% en 2007.

La distribución de estos granos de polen a lo largo del año se localizó entre junio e inicios de agosto, por lo que la variación estacional (Tabla 5.2.3.19.) tuvo un PPP promedio de 61 días, con diferencias en las fechas de inicio (30 mayo de 2003 - 23 de junio de 2002) y finalización (13 de julio de $2002-1$ de septiembre de 2001).

En todo caso, los niveles polínicos de este género botánico en la atmósfera de la
Tipo polínico: Ligustrum vulgare.

Especie(s): Ligustrum lucidum Aiton, Ligustrum vulgare L. y Syringa vulgaris L., entre otras, (Oleaceae).

Distribución: El género Ligustrum L., con una 20 especies, habita en Europa en gargantas $y$ zonas montañosas. En la Península Ibérica, Ligustrum vulgare L., es más abundante en el centro y el noreste (en valles meridionales y occidentales de la provincia de Salamanca), aunque, al igual que Ligustrum lucidum Aiton. se utiliza como ornamental. El lilo (Syringa vulgaris L.), oriundo del sureste europeo, también se cultiva en la Península Ibérica y la provincia salmantina.

Época de floración: Junio - julio en la mitad septentrional peninsular, y mayo-junio en la meridional.

Polinización: Entomófila.

Morfología polínica (Lámina II): Polen trizonocolporado, isopolar y radiosimétrico, con una forma circular en vista polar y elíptica en vista ecuatorial (de esferoidal a oblatoesferoidal), $y$ un tamaño mediano $(P=25-30$ $\mu \mathrm{m})$. Las ectoaberturas tipo colpo poco definidas, contrastan con las endoaberturas tipo poro, mejor definidas. La exina, de gran grosor (3-4 $\mu \mathrm{m})$, presenta una superficie reticulada, con lúmenes de menor tamaño en los polos.

ciudad de Salamanca (Fig. 5.2.3.30.D.) aumentaron a partir de la primera semana de junio hasta alcanzar los valores más elevados a finales de junio e inicios de julio, como muestra el valor medio más elevado en los años analizados (4 granos $/ \mathrm{m}^{3}$, el 30 de junio), gracias a la dinámica aportada por el porcentaje que representó la media diaria de los cinco días anteriores para el conjunto de años estudiados con respecto al total promedio. Asimismo, las mayores concentraciones diarias registradas dentro del período 2000-2007 oscilaron entre los 24 granos $/ \mathrm{m}^{3}$ (30 de junio de 2001) y los 2 granos $/ \mathrm{m}^{3}$ (9 de julio de 2002, 12 de julio de 
2003 y 18 de junio de 2007). Posteriormente, estos niveles disminuyeron durante el mes de julio, presentándose en niveles bajos durante los meses de agosto y septiembre (Fig. 5.2.3.30. A. B. C.).

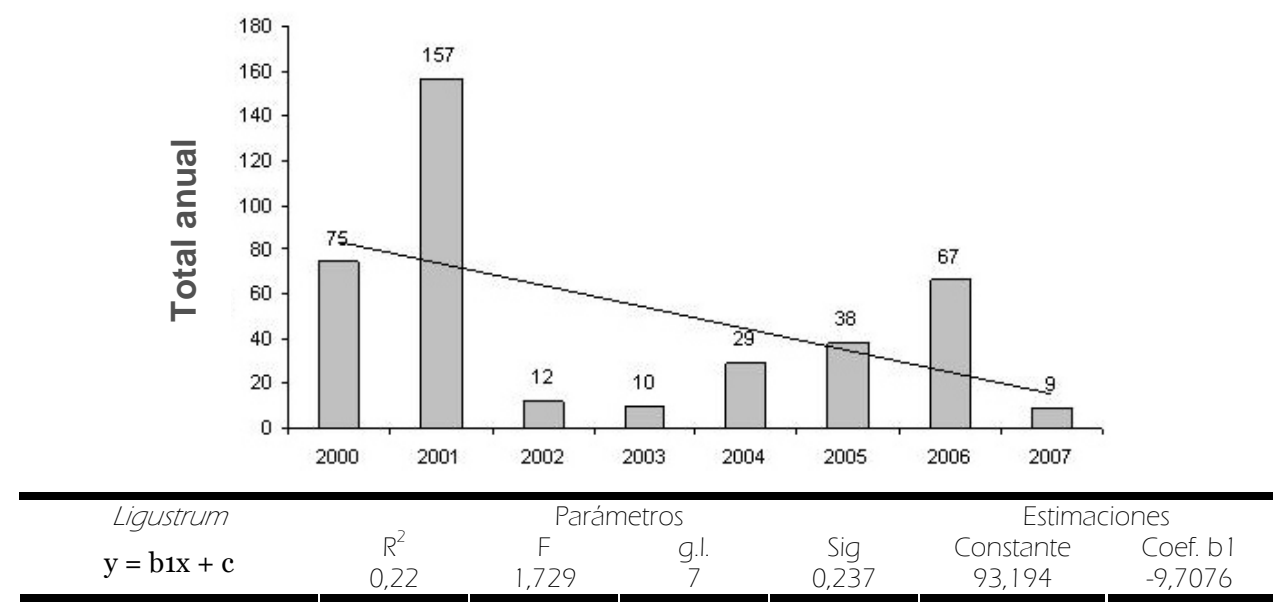

Fig. 5.2.3.29. Evolución anual del número total de pólenes de Ligustrum y tendencias (análisis de regresión).

\begin{tabular}{|c|c|c|c|c|c|c|c|c|c|}
\hline Ligustrum & 2000 & 2001 & 2002 & 2003 & 2004 & 2005 & 2006 & 2007 & Media \\
\hline Día & 20-jun & 30-jun & 09-jul & 12-jul & 19-jul & 19-jul & 12-jul & 18-jun & 30-jun \\
\hline PPP(días) & 41 & 83 & 21 & 72 & 54 & 84 & 75 & - & 61 \\
\hline Inicio & 19-jun & 11-jun & 23-jun & 30-may & 22-jun & 06-jun & 02-jun & - & 11-jun \\
\hline Fin & 29-jul & 01-sep & 13-jul & 09-ago & 14-ago & 28-ago & 15-ago & - & 11 -ago \\
\hline
\end{tabular}

Tabla 5.2.3.19. Totales, concentraciones máximas diarias, período principal de polinización (PPP; fecha de inicio y fin) y días precedentes al valor máximo (PRE) durante los ocho años de estudio y el promedio de todos los parámetros para Ligustrum.

Los niveles de polen a lo largo del día tuvieron un comportamiento irregular, por lo que la variación intradiaria (Fig. 5.2.3.31.) durante un día promedio para el trienio 20052007, no mostró ningún patrón de distribución horaria.

Las temperaturas medias, máximas y mínimas junto a la insolación y los vientos procedentes del IV cuadrante ejercieron una influencia positiva en las concentraciones de polen de Ligustrum durante los ocho años analizados, mientras que la humedad relativa, la precipitación y, en menor media, los vientos procedentes del II cuadrante, lo hicieron de forma negativa, después de efectuar el análisis de correlación (Tabla 5.2.3.20.). Estas correlaciones tuvieron unos coeficientes similares en signo y grado de significación durante los años estudiados, exceptuando el año 2007, en el que, debido a su bajo número, no se realizó el análisis estadístico. No ocurrió lo mismo en los PPP y PRE definidos en todos estos años, pues mostraron coeficientes bajos, o bien coeficientes altos, como para los vientos procedentes del III cuadrante en el PRE del III cuadrante. 

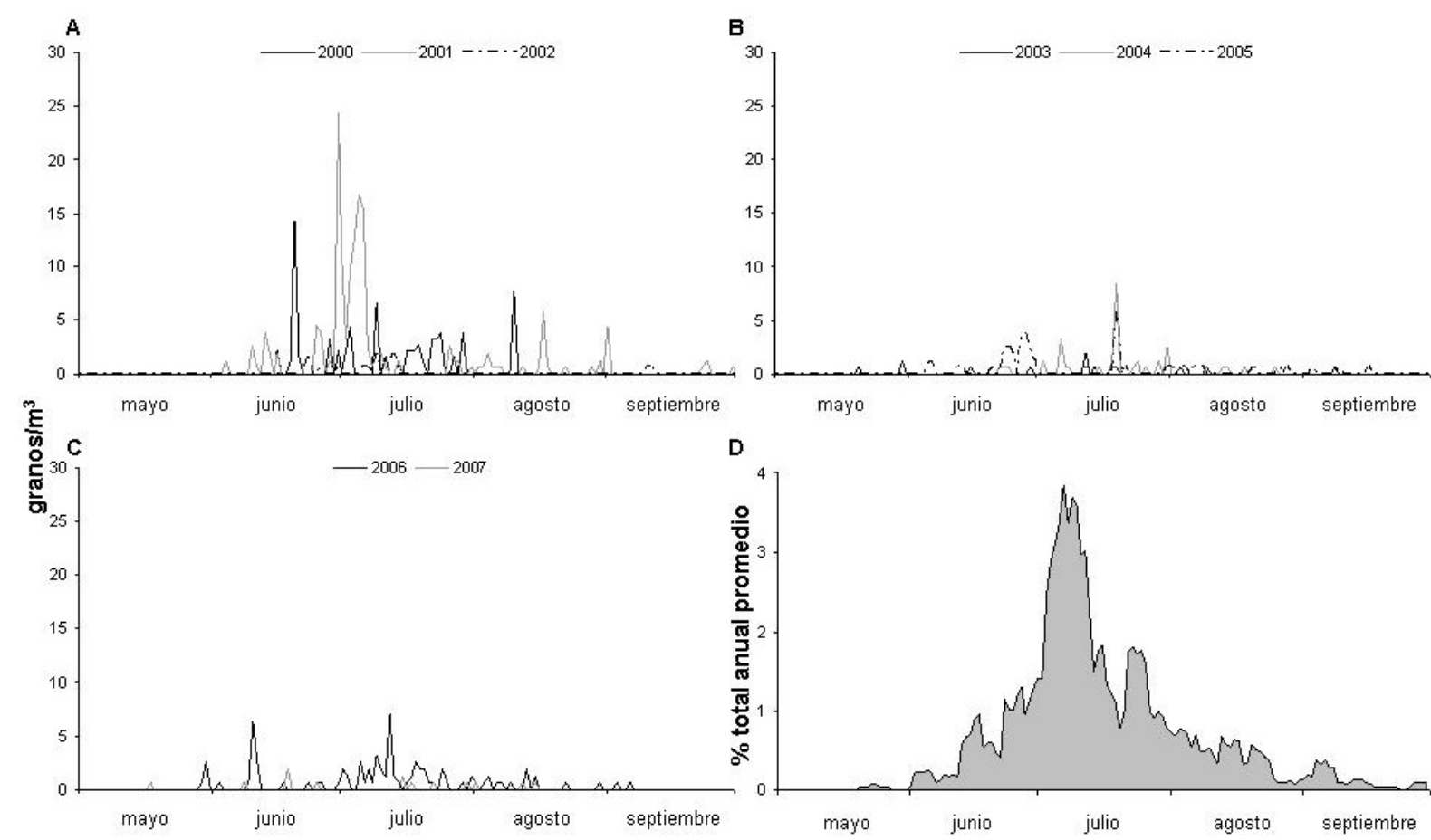

Fig. 5.2.3.30. Variación de las concentraciones medias diarias de Ligustrum durante el período 2000-2002 (A), 2003-2005 (B) y 2006-2007 (C). Porcentajes de representación diarios para la media de los cinco días anteriores dentro del promedio de los ocho años analizados (D).

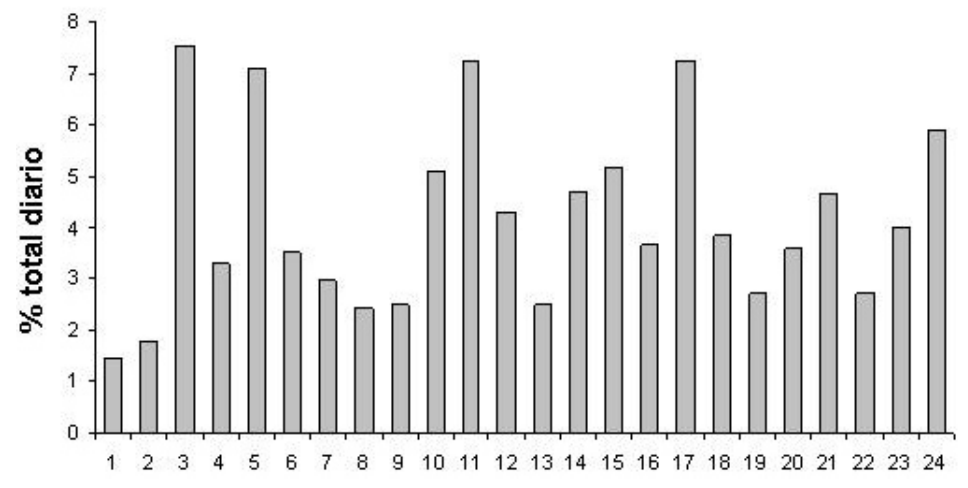

Fig. 5.2.3.31. Variación intradiaria del polen de Ligustrum. 


\begin{tabular}{|c|c|c|c|c|c|c|c|}
\hline \multicolumn{2}{|c|}{ Ligustrum } & Tmed & Tmax & Tmin & Insolación & Precipitación & Hrelativa \\
\hline 2000 & Anual & $0,309 * *$ & $0,292 * \star$ & $0,318 * *$ & $0,227 * *$ & $-0,052$ & $-0,267 * *$ \\
\hline \multirow{2}{*}{$95 \%$} & PPP & $-0,040$ & $-0,056$ & 0,133 & $-0,225$ & 0,215 & 0,203 \\
\hline & PRE & - & - & - & - & - & - \\
\hline 2001 & Anual & $0,385^{* *}$ & $0,364 * \star$ & 0,386 ** & $0,206^{* \star}$ & $-0,033$ & $-0,274^{\star \star}$ \\
\hline \multirow{2}{*}{$95 \%$} & PPP & $-0,147$ & $-0,181$ & $-0,004$ & $-0,105$ & 0,072 & 0,080 \\
\hline & PRE & $-0,048$ & $-0,130$ & 0,144 & 0,212 & - & 0,053 \\
\hline 2002 & Anual & $0,199 * *$ & $0,204^{* *}$ & $0,172^{* *}$ & $0,182^{\star \star}$ & $-0,075$ & $-0,159^{* *}$ \\
\hline \multirow{2}{*}{$95 \%$} & PPP & $-0,175$ & $-0,082$ & $-0,017$ & $-0,101$ & 0,115 & 0,275 \\
\hline & PRE & 0,063 & 0,087 & 0,185 & $-0,072$ & 0,452 & 0,091 \\
\hline 2003 & Anual & $0,198^{* *}$ & $0,202^{* *}$ & $0,177 * *$ & $0,106^{*}$ & $-0,049$ & $-0,178^{* \star}$ \\
\hline \multirow{2}{*}{$95 \%$} & PPP & 0,070 & 0,085 & 0,132 & $-0,186$ & 0,126 & $-0,155$ \\
\hline & PRE & 0,053 & 0,065 & 0,215 & $-0,257$ & $0,313^{*}$ & $-0,112$ \\
\hline 2004 & Anual & $0,272^{* *}$ & $0,250^{* *}$ & $0,278^{* *}$ & $0,202^{* *}$ & $-0,081$ & $-0,229 * \star$ \\
\hline \multirow{2}{*}{$95 \%$} & PPP & $-0,038$ & $-0,051$ & 0,033 & $-0,215$ & $-0,056$ & 0,185 \\
\hline & PRE & $-0,305$ & $-0,410^{*}$ & 0,191 & $-0,48 * *$ & 0,196 & $0,593 * *$ \\
\hline 2005 & Anual & $0,338^{* *}$ & $0,329 * *$ & $0,320^{* *}$ & $0,255^{\star *}$ & $-0,072$ & $-0,297 * \star$ \\
\hline \multirow{2}{*}{$95 \%$} & PPP & $-0,033$ & $-0,081$ & $-0,031$ & $-0,049$ & 0,068 & 0,090 \\
\hline & PRE & $-0,182$ & $-0,322^{*}$ & 0,036 & $-0,103$ & 0,122 & 0,371 * \\
\hline 2006 & Anual & $0,490^{* *}$ & $0,467^{* *}$ & $0,484^{* *}$ & - & $-0,108^{\star}$ & $-0,395^{* *}$ \\
\hline \multirow{2}{*}{$95 \%$} & PPP & $0,284^{*}$ & 0,188 & $0,304^{* *}$ & - & $-0,009$ & $-0,088$ \\
\hline & PRE & 0,279 & 0,200 & 0,239 & - & $-0,185$ & $-0,114$ \\
\hline 2007 & Anual & - & - & - & - & - & - \\
\hline \multirow{2}{*}{$95 \%$} & PPP & - & - & - & - & - & - \\
\hline & PRE & - & - & - & - & - & - \\
\hline Total & Anual & $0,313^{* *}$ & $0,297 * *$ & $0,309 * *$ & $0,214^{* *}$ & $-0,066^{* *}$ & $-0,246^{\star *}$ \\
\hline
\end{tabular}

\begin{tabular}{|c|c|c|c|c|c|c|c|}
\hline \multicolumn{2}{|c|}{ Ligustrum } & Vemed & FrecCalm & VICuadr & V2Cuadr & V3Cuadr & V4Cuadr \\
\hline 2000 & Anual & $-0,013$ & 0,008 & 0,003 & $-0,039$ & 0,004 & $0,105^{\star}$ \\
\hline \multirow{2}{*}{$95 \%$} & PPP & 0,017 & 0,047 & $-0,244$ & 0,011 & 0,223 & 0,065 \\
\hline & PRE & - & - & - & - & - & - \\
\hline 2001 & Anual & $-0,054$ & 0,032 & $-0,077$ & $-0,028$ & 0,007 & $0,267 * \star$ \\
\hline \multirow{2}{*}{$95 \%$} & PPP & 0,080 & $-0,178$ & $-0,162$ & $-0,097$ & 0,105 & 0,203 \\
\hline & PRE & 0,061 & $-0,030$ & $-0,183$ & 0,094 & 0,220 & 0,175 \\
\hline 2002 & Anual & $-0,006$ & $-0,069$ & 0,082 & $-0,085$ & $-0,109 *$ & $0,146 * *$ \\
\hline \multirow{2}{*}{$95 \%$} & PPP & $-0,015$ & 0,068 & 0,075 & $-0,166$ & 0,030 & 0,039 \\
\hline & PRE & 0,218 & 0,034 & $-0,013$ & $-0,182$ & 0,174 & 0,049 \\
\hline 2003 & Anual & 0,035 & - & $-0,039$ & $-0,037$ & 0,007 & 0,093 \\
\hline \multirow{2}{*}{$95 \%$} & PPP & 0,134 & 0,006 & $-0,136$ & 0,060 & 0,118 & 0,023 \\
\hline & PRE & 0,145 & $-0,043$ & $-0,066$ & 0,005 & 0,046 & 0,033 \\
\hline 2004 & Anual & $0,123^{*}$ & $-0,073$ & $-0,095$ & $-0,048$ & 0,080 & $0,166^{* *}$ \\
\hline \multirow{2}{*}{$95 \%$} & PPP & 0,089 & $-0,178$ & $-0,040$ & $-0,100$ & 0,012 & 0,172 \\
\hline & PRE & 0,138 & $-0,369$ & $-0,388 *$ & $-0,475^{*}$ & $0,505 * *$ & 0,196 \\
\hline 2005 & Anual & 0,024 & $-0,072$ & 0,010 & $-0,048$ & 0,016 & 0,071 \\
\hline \multirow{2}{*}{$95 \%$} & PPP & 0,146 & $-0,080$ & $-0,083$ & 0,015 & 0,109 & $-0,024$ \\
\hline & PRE & 0,243 & $-0,041$ & $-0,324 *$ & $-0,072$ & 0,285 & 0,102 \\
\hline 2006 & Anual & $-0,048$ & $-0,106$ & 0,069 & $-0,051$ & $-0,031$ & 0,087 \\
\hline \multirow{2}{*}{$95 \%$} & PPP & $-0,227$ * & $-0,004$ & $-0,135$ & 0,063 & 0,116 & $-0,073$ \\
\hline & PRE & $-0,220$ & 0,065 & $-0,073$ & 0,046 & 0,056 & $-0,151$ \\
\hline 2007 & Anual & - & - & - & - & - & - \\
\hline \multirow{2}{*}{$95 \%$} & PPP & - & - & - & - & - & - \\
\hline & PRE & - & - & - & - & - & - \\
\hline Total & Anual & 0,019 & $-0,012$ & $-0,023$ & $-0,053^{\star \star}$ & 0,002 & 0,130 ** \\
\hline
\end{tabular}

Tabla 5.2.3.20. Coeficientes de correlación de Spearman entre Ligustrum y las variables climatológicas. Tmed,

Tmax, Tmin (temperatura media, máxima y mínima), Hrelativa (humedad relativa), Vemed (velocidad media), FrecCalmas (frecuencia de calmas), V1Cuad, V2Cuad, V3Cuad, V4Cuad (vientos procedentes del I, II, III y IV cuadrante). Significación: 95\%(*), 99\%(**). (-) Ausencia de correlaciones. 


\subsubsection{Mercurialis}

Los niveles de este tipo polínico en la atmósfera de Salamanca, experimentaron un descenso durante el período analizado, ya que si en el año 2000 el total anual fue de 113, en el año 2007 alcanzó 17 pólenes. Todo ello supuso que la variación interanual (Fig. 5.2.3.32.) llevase consigo un descenso del $555 \%$ en las concentraciones anuales de Mercurialis, un hecho que también revela el valor tomado por el índice de determinación, propio de la regresión lineal $\left(\mathrm{R}^{2}=0,39\right)$. La representación media de los pólenes de este género botánico a lo largo de los ocho años fue de o,3\%, con un máximo de $1 \%$ en 2000 y un mínimo de $0,1 \%$ en 2004, 2006 y 2007.

La distribución de estos granos de polen a lo largo de los años estudiados se localizó, fundamentalmente, entre mediados-finales de marzo y agosto, por lo que la variación estacional (Tabla 5.2.3.21.) tuvo un PPP promedio de 151 días, cuyas fechas de inicio tuvieron diferencias

Tipo polínico: Mercurialis tomentosa.

Especie(s): Mercurialis annua L. y Mercurialis tomentosa L., entre otras (Euphorbiaceae).

Distribución: Género que incluye a plantas herbáceas que viven en zonas nitrófilas $y$ ruderales, al pie de muros o solares, en gran parte de localidades de la Península Ibérica y la provincia de Salamanca.

Época de floración: Casi todo el año, preferentemente de marzo a octubre.

Polinización: Anemófila.

Morfología polínica (Lámina III): Polen trizonocolporado, isopolar y radiosimétrico, con forma circular en vista polar y de circular a elíptica en vista ecuatorial (de suboblato a subprolato), y un tamaño pequeño $(P=22-27$ $\mu \mathrm{m})$. Las ectoaberturas tipo colpo son terminales, y las endoaberturas tipo poro de forma variable. La exina, de grosor medio (2 $\mu \mathrm{m})$, presenta una superficie reticulada con lúmenes pequeños (de menos de $1 \mu \mathrm{m}$ ) e irregulares y muros más estrechos que los lúmenes, levemente granulados. de casi medio año (14 de marzo de 2000 - 18 de agosto de 2004), al igual que ocurrió con las fechas de finalización, con 5 meses de diferencia (25 de junio de 2000 - 27 de octubre de 2005).

Los niveles polínicos de Mercurialis en la atmósfera de la ciudad de Salamanca (Fig. 5.2.3.33.D.) comenzaron a aumentar a partir de mediados de marzo, experimentando un patrón irregular de aumentos y descensos hasta mediados de octubre, como muestra la dinámica aportada por el porcentaje de representación de las concentraciones medias móviles de los cincos días anteriores con respecto al total anual. En todo caso, las mayores concentraciones diarias de los ocho años estudiados (Tabla 5.2.3.21.; Fig. 5.2.3.33.A. B. C.) oscilaron entre los 11 granos $/ \mathrm{m}^{3}$ (2 de abril de 2000) y los 3 granos $/ \mathrm{m}^{3}$ (8 de septiembre de 2004, 29 de agosto de 2005, y 9 de junio de 2006). Posteriormente, estos niveles 
disminuyeron en la última mitad octubre, presentándose en niveles bajos durante la primera mitad de noviembre.

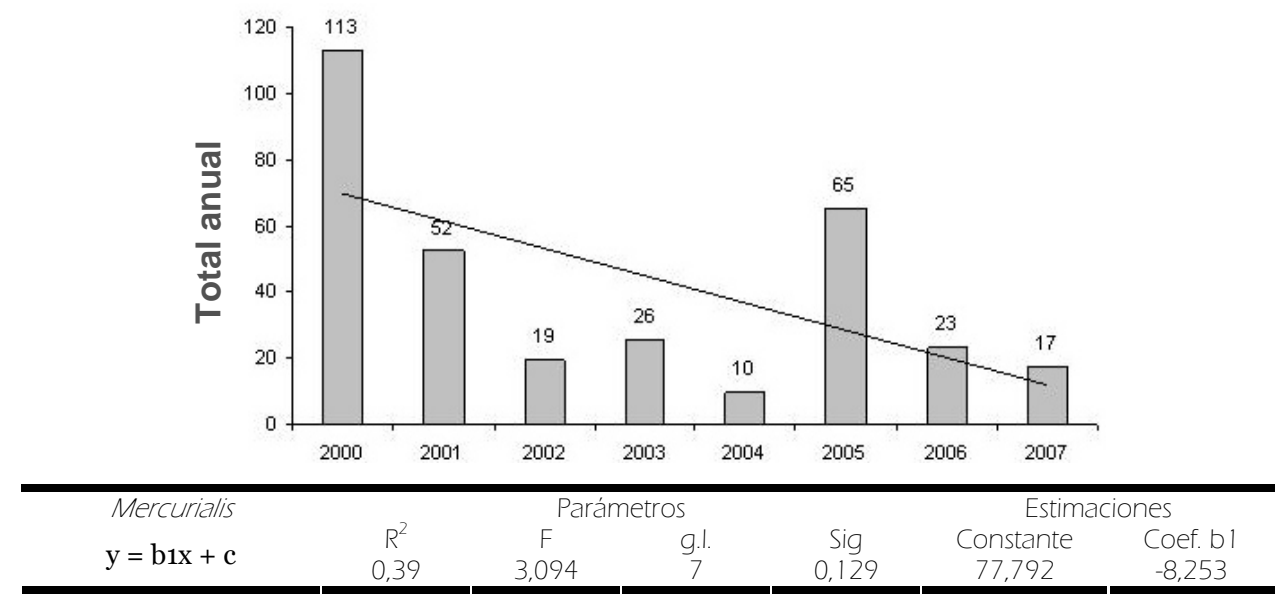

Fig. 5.2.3.32. Evolución anual del número total de pólenes de Mercurialis y tendencias (análisis de regresión).

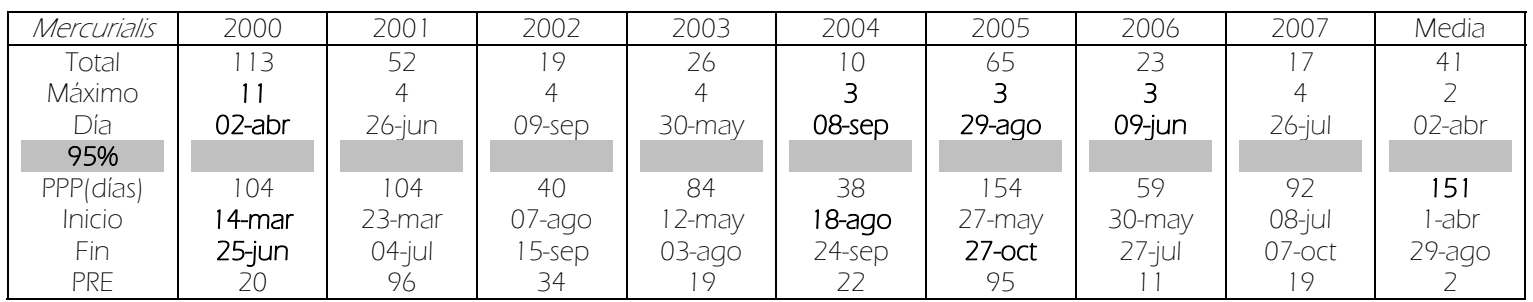

Tabla 5.2.3.21. Totales, concentraciones máximas diarias, período principal de polinización (PPP; fecha de inicio y fin) y días precedentes al valor máximo (PRE) durante los ocho años de estudio y el promedio de todos los parámetros para Mercurialis.

La variación intradiaria (Fig. 5.2.3.34.), presentada con un día promedio durante los años 2005, 2006 y2007, registró mayores niveles en la segunda mitad del día, principalmente desde las 17 horas hasta la medianoche.

El análisis de correlación (Tabla 5.2.3.22.) mostró que las temperaturas medias, máximas y mínimas, junto a la insolación y los vientos procedentes del IV cuadrante influyeron positivamente en los niveles polínicos durante los ocho años analizados, mientras que la humedad relativa, tuvo un efecto negativo. Este patrón se repitió a lo largo de todas las anualidades estudiadas por separado, si bien en los PPP y PRE definidos en dichas anualidades, no hubo correlaciones significativas, salvo en el PPP y PRE del año 2004, con la influencia negativa de la frecuencia de calmas, y positivas con los vientos procedentes del III cuadrante. 


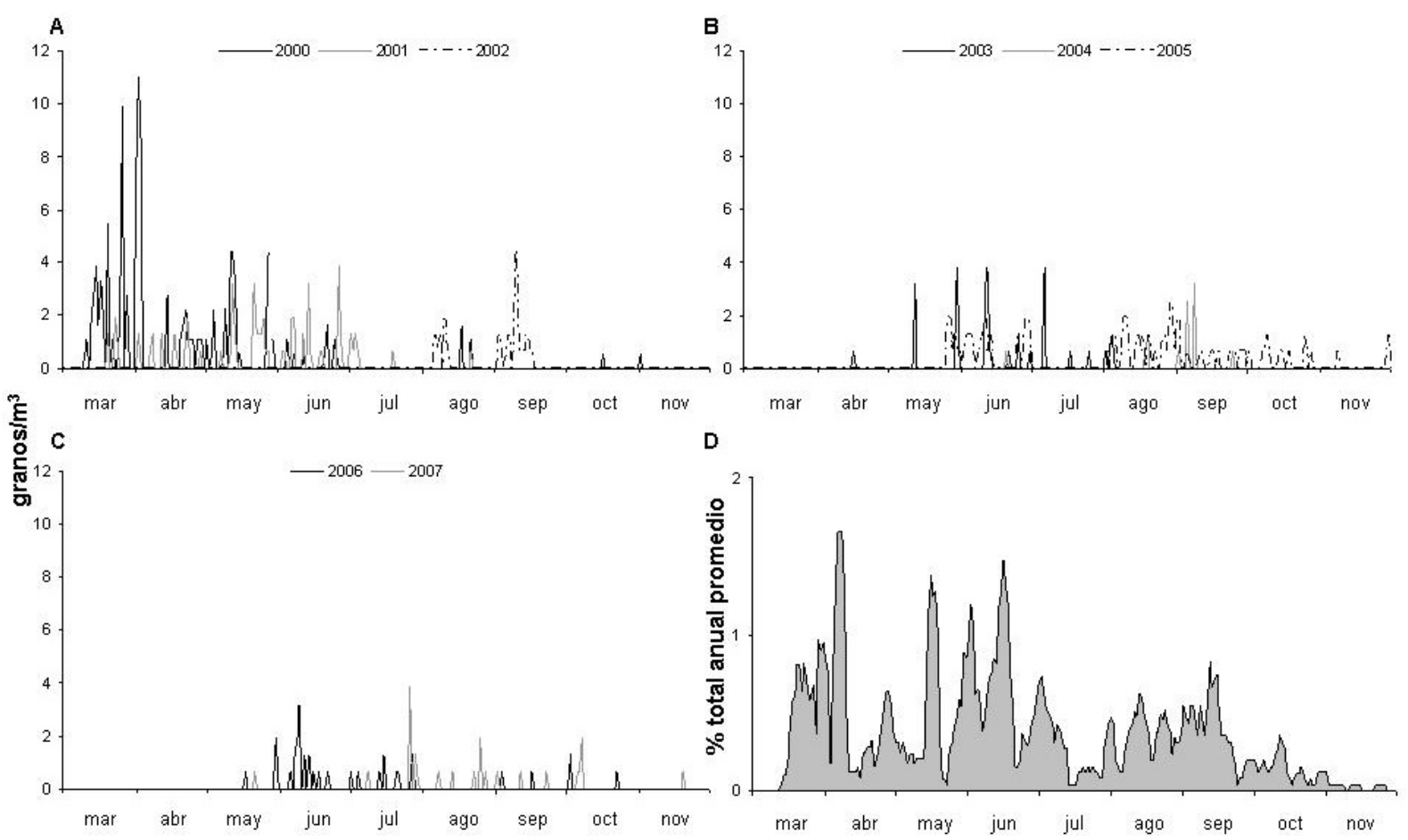

Fig. 5.2.3.33. Variación de las concentraciones medias diarias de Mercurialis durante el período 2000-2002

(A), 2003-2005 (B) y 2006-2007 (C). Porcentajes de representación diarios para la media de los cinco días anteriores dentro del promedio de los ocho años analizados (D).

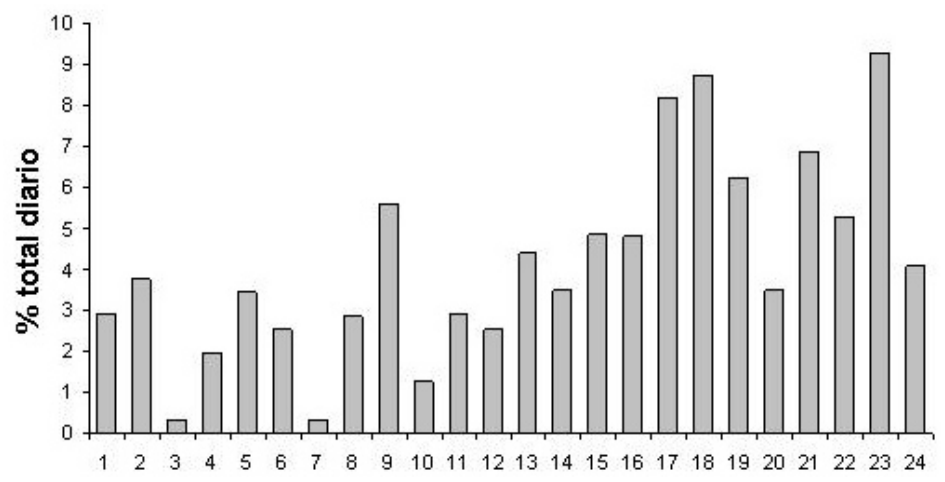

Fig. 5.2.3.34. Variación intradiaria del polen de Mercurialis. 


\begin{tabular}{|c|c|c|c|c|c|c|c|}
\hline \multicolumn{2}{|c|}{ Mercurialis } & Tmed & Tmax & Tmin & Insolación & Precipitación & Hrelativa \\
\hline 2000 & Anual & 0,007 & 0,012 & $-0,013$ & $-0,041$ & 0,097 & $-0,100$ \\
\hline \multirow{2}{*}{$95 \%$} & PPP & $-0,230^{*}$ & $-0,168$ & $-0,27$ * & $-0,197^{\star}$ & 0,089 & 0,088 \\
\hline & PRE & 0,232 & 0,441 & $-0,232$ & 0,250 & $-0,279$ & $-0,317$ \\
\hline 2001 & Anual & 0,200 ** & $0,213^{* \star}$ & $0,157^{* *}$ & $0,279 * \star$ & $-0,109$ * & $-0,326$ ** \\
\hline \multirow{2}{*}{$95 \%$} & PPP & 0,189 & 0,190 & 0,148 & $0,230^{*}$ & $-0,109$ & $-0,274^{\star \star}$ \\
\hline & PRE & 0,171 & 0,181 & 0,110 & $0,267 * *$ & $-0,100$ & $-0,269 * *$ \\
\hline 2002 & Anual & $0,198^{* *}$ & 0,186 ** & $0,193^{* *}$ & 0,059 & $-0,028$ & $-0,010$ \\
\hline \multirow{2}{*}{$95 \%$} & PPP & $-0,370^{*}$ & $-0,335^{*}$ & $-0,272$ & $-0,241$ & 0,010 & 0,220 \\
\hline & PRE & $-0,398 *$ & $-0,372^{*}$ & $-0,245$ & $-0,113$ & 0,033 & 0,190 \\
\hline 2003 & Anual & $0,243^{* *}$ & 0,249 ** & $0,215^{\star *}$ & $0,173^{\star \star}$ & $-0,101$ & $-0,262^{* *}$ \\
\hline \multirow{2}{*}{$95 \%$} & PPP & 0,159 & 0,200 & 0,131 & $-0,139$ & $-0,012$ & $-0,135$ \\
\hline & PRE & 0,176 & 0,277 & 0,208 & $-0,371$ & - & $-0,334$ \\
\hline 2004 & Anual & $0,131^{*}$ & $0,110^{*}$ & 0,156 ** & 0,070 & $-0,020$ & $-0,107$ * \\
\hline \multirow{2}{*}{$95 \%$} & PPP & 0,182 & $-0,132$ & $0,418^{*}$ & $-0,085$ & 0,085 & $-0,078$ \\
\hline & PRE & 0,091 & $-0,295$ & $0526^{*}$ & $-0,183$ & 0,020 & 0,155 \\
\hline 2005 & Anual & $0,394 * *$ & $0,385^{\star \star}$ & $0,376^{* *}$ & 0,228 ** & $-0,028$ & $-0,336^{\star \star}$ \\
\hline \multirow{2}{*}{$95 \%$} & PPP & $-0,006$ & $-0,034$ & 0,046 & $-0,112$ & 0,044 & $-0,017$ \\
\hline & PRE & $-0,220$ * & $-0,230^{*}$ & $-0,035$ & $-0,235^{*}$ & $0,210^{*}$ & 0,141 \\
\hline 2006 & Anual & $0,274^{* *}$ & 0,259 ** & $0,277^{* *}$ & - & 0,014 & $-0,235^{* *}$ \\
\hline \multirow{2}{*}{$95 \%$} & PPP & $-0,050$ & $-0,054$ & $-0,039$ & - & 0,049 & $-0,150$ \\
\hline & PRE & 0,586 & 0,293 & $0,865^{* *}$ & - & - & $-0,121$ \\
\hline 2007 & Anual & $0,218^{* *}$ & $0,210^{* *}$ & $0,216^{* *}$ & $0,105^{* *}$ & $-0,023$ & $-0,111^{*}$ \\
\hline \multirow{2}{*}{$95 \%$} & PPP & 0,084 & 0,070 & 0,082 & 0,002 & $-0,116$ & 0,092 \\
\hline & PRE & 0,348 & 0,266 & 0,306 & 0,328 & $-0,139$ & 0,038 \\
\hline Total & Anual & $0,202^{* *}$ & $0,197^{* *}$ & 0,189 ** & $0,128^{* *}$ & $-0,025$ & $-0,188 * *$ \\
\hline
\end{tabular}

\begin{tabular}{|c|c|c|c|c|c|c|c|}
\hline \multicolumn{2}{|c|}{ Mercurialis } & Vemed & FrecCalm & VICuadr & V2Cuadr & V3Cuadr & V4Cuadr \\
\hline 2000 & Anual & $0,139^{* \star}$ & $-0,165^{\star \star}$ & $-0,003$ & $-0,010$ & 0,080 & $-0,022$ \\
\hline \multirow{2}{*}{$95 \%$} & PPP & 0,100 & $-0,042$ & $-0,036$ & $-0,033$ & 0,132 & $-0,088$ \\
\hline & PRE & 0,025 & 0,199 & 0,216 & 0,285 & $-0,125$ & $-0,436$ \\
\hline 2001 & Anual & 0,098 & $-0,070$ & $-0,071$ & $-0,065$ & 0,089 & $0,158^{\star \star}$ \\
\hline \multirow{2}{*}{$95 \%$} & PPP & 0,064 & 0,018 & $-0,078$ & 0,137 & 0,101 & $-0,020$ \\
\hline & PRE & 0,035 & 0,084 & $-0,066$ & 0,148 & 0,131 & $-0,069$ \\
\hline 2002 & Anual & $-0,094$ & 0,002 & $0,109 *$ & 0,093 & $-0,080$ & 0,098 \\
\hline \multirow{2}{*}{$95 \%$} & PPP & $-0,276$ & 0,095 & $-0,006$ & $0,367^{*}$ & 0,142 & $-0,038$ \\
\hline & PRE & $-0,066$ & $-0,065$ & 0,061 & 0,223 & 0,137 & 0,049 \\
\hline 2003 & Anual & $-0,044$ & 0,009 & 0,024 & 0,065 & 0,020 & 0,036 \\
\hline \multirow{2}{*}{$95 \%$} & PPP & $-0,108$ & 0,113 & 0,033 & $0,253^{*}$ & 0,025 & $-0,099$ \\
\hline & PRE & $-0,135$ & $0,525^{*}$ & $-0,306$ & 0,079 & 0,219 & 0,237 \\
\hline 2004 & Anual & 0,006 & $-0,034$ & $-0,060$ & $-0,022$ & 0,087 & 0,033 \\
\hline \multirow{2}{*}{$95 \%$} & PPP & $-0,006$ & $-0,366^{*}$ & $-0,312$ & $-0,168$ & $0,470^{* *}$ & $-0,172$ \\
\hline & PRE & 0,009 & $-0,423^{*}$ & $-0,511$ * & $-0,223$ & 0,710 ** & $-0,308$ \\
\hline 2005 & Anual & $-0,093$ & 0,066 & $-0,021$ & $-0,054$ & 0,047 & $0,183^{* *}$ \\
\hline \multirow{2}{*}{$95 \%$} & PPP & $-0,029$ & 0,030 & $-0,100$ & $-0,023$ & 0,109 & $0,180^{*}$ \\
\hline & PRE & - & 0,053 & $-0,119$ & $-0,022$ & 0,146 & 0,091 \\
\hline 2006 & Anual & $-0,033$ & $-0,051$ & $-0,019$ & 0,061 & 0,081 & 0,015 \\
\hline \multirow{2}{*}{$95 \%$} & PPP & 0,057 & $-0,068$ & $-0,102$ & 0,193 & 0,150 & $-0,217$ \\
\hline & PRE & 0,178 & 0,105 & $-0,467$ & 0,215 & 0,585 & 0,015 \\
\hline 2007 & Anual & $-0,043$ & 0,081 & 0,050 & $-0,059$ & $-0,037$ & 0,064 \\
\hline \multirow{2}{*}{$95 \%$} & PPP & $-0,106$ & 0,144 & $-0,010$ & $-0,042$ & $-0,036$ & 0,086 \\
\hline & PRE & 0,023 & 0,074 & $-0,114$ & $-0,202$ & 0,081 & 0,288 \\
\hline Total & Anual & 0,020 & 0,001 & $-0,007$ & $-0,017$ & 0,032 & $0,075^{* *}$ \\
\hline
\end{tabular}

Tabla 5.2.3.22. Coeficientes de correlación de Spearman entre Mercurialis y las variables climatológicas. Tmed, Tmax, Tmin (temperatura media, máxima y mínima), Hrelativa (humedad relativa), Vemed (velocidad media), FrecCalmas (frecuencia de calmas), V1Cuad, V2Cuad, V3Cuad, V4Cuad (vientos procedentes del I, II, III y IV cuadrante). Significación: 95\%(*), 99\%(**). (-) Ausencia de correlaciones. 


\subsubsection{Papaver}

Los niveles de este tipo polínico en la atmósfera de Salamanca mostraron una variación muy irregular a lo largo de los ocho años estudiados, ya que si en el año 2000 no se contabilizó ningún grano o en el 2001 sólo se encontró un único polen, pasamos a 106 pólenes del año 2003 o los 80 de 2005. Por lo tanto, la variación interanual (Fig. 5.2.3.35.) no tuvo un patrón regular en el número anual, un hecho confirmado a través del análisis de regresión de tipo lineal y el escaso valor que tomó por su índice de determinación $\left(\mathrm{R}^{2}=0,03\right)$ y un supuesto ascenso. La representación media de los pólenes de género botánico a lo largo de los ocho años fue de $0,2 \%$, con un máximo de 1,2\% en 2003 y teniendo en cuenta que no se registraron granos de polen en el año 2000, o los bajos valores del año 2001, 2002 y 2007.

La distribución de estos granos de polen a lo largo de los años estudiados se (Tabla 5.2.3.23.) y tuvo un PPP promedio de 45 días, que en los años en los que se pudo definir este PPP hubo pequeñas diferencias en la fecha de inicio (28 de marzo de 2004 - 14 de abril de 2005), y en las fechas de finalización del PPP (8 de mayo de 2004 - 30 de mayo de 2003).

La dinámica de las concentraciones polínicas de Papaver (Fig. 5.2.3.36.D.) mostrada con el porcentaje de representación de las concentraciones medias móviles de los cincos días anteriores con respecto al total anual, presentó un incremento de las concentraciones desde mediados de la primera semana de abril hasta mediados de mayo, con una concentración máxima de 2 granos/ $\mathrm{m}^{3}$ el día 16 de mayo como media del período 2000-2007 (Tabla 5.2.3.23.). Posteriormente, se registró una disminución en los niveles de polen a finales de junio, no contabilizándose a partir de mediados de julio. Las concentraciones diarias más elevadas dentro de los ocho años (Tabla 5.2.3.23.; Fig. 5.2.3.36.A. B. C.), localizadas 
fundamentalmente en mayo, oscilaron entre los 17 granos $/ \mathrm{m}^{3}$ (16 de mayo de 2003) у 1 grano/m³ (31 de mayo de 2001, 3 de mayo de 2006 y 30 de abril de 2007).

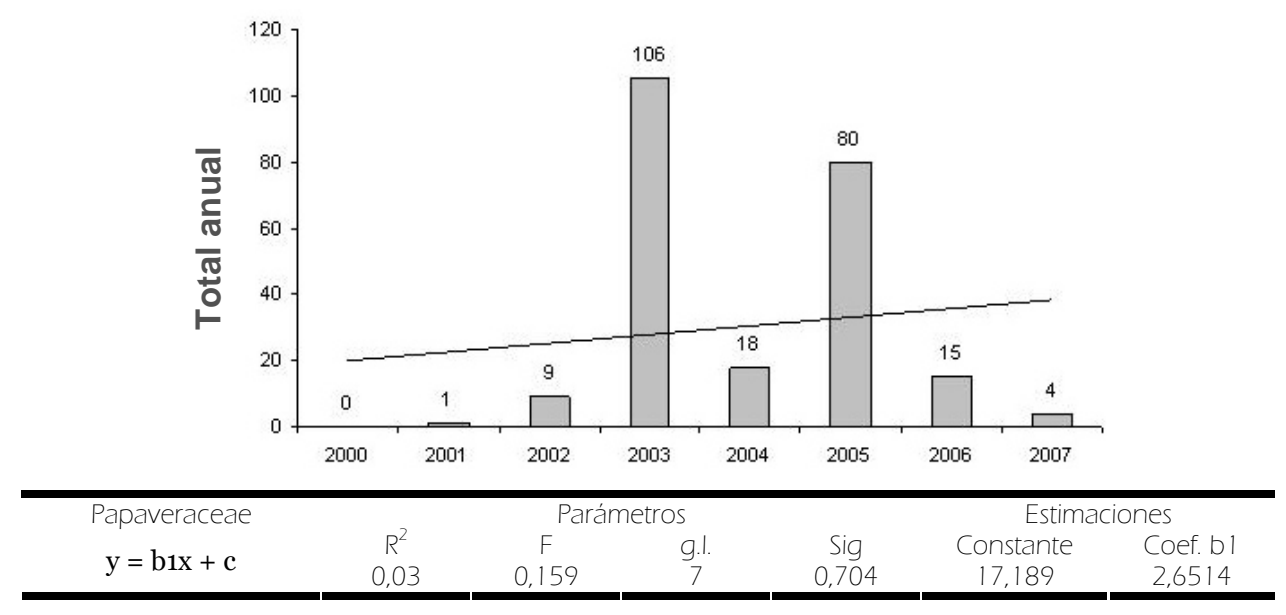

Fig. 5.2.3.35. Evolución anual del número total de pólenes de Papaver y tendencias (análisis de regresión).

\begin{tabular}{|c|c|c|c|c|c|c|c|c|c|}
\hline Papaveraceae & 2000 & 2001 & 2002 & 2003 & 2004 & 2005 & 2006 & 2007 & Media \\
\hline Día & - & 31-may & 26-abr & 16-may & 04-may & 30-abr & 03-may & 30-abr & 16-may \\
\hline PPP(días) & - & - & - & 50 & 42 & 44 & 45 & - & 45 \\
\hline Inicio & - & - & - & $11-a b r$ & 28-mar & 14-abr & 05-abr & - & 6-abr \\
\hline Fin & - & - & - & 30-may & 08-may & 27-may & 19-may & - & 21-may \\
\hline
\end{tabular}

Tabla 5.2.3.23. Totales, concentraciones máximas diarias, período principal de polinización (PPP; fecha de inicio y fin) y días precedentes al valor máximo (PRE) durante los ocho años de estudio (salvo los años con bajo número anual o sin presencia de este tipo), y el promedio de todos los parámetros para Papaver.

Las concentraciones de polen a lo largo del día no siguieron un patrón claro, ni siquiera existió un mayor porcentaje en algunas franjas horarias, por lo que la variación intradiaria (Fig. 5.2.3.37.) durante un día promedio para el trienio 2005-2007, mostró una dinámica irregular.

Las temperaturas medias, máximas y mínimas junto a la insolación y los vientos procedentes del III y IV cuadrante tuvieron una influencia positiva, con bajos coeficientes, en los niveles de este tipo de polen durante los ocho años analizados, así como el efecto negativo que ejercieron la humedad relativa, la frecuencia de las calmas y los vientos del I cuadrante, también con coeficientes bajos, tras el análisis de correlación (Tabla 5.2.3.24.). No obstante, durante algunos PPP y PREE definidos en las distintas anualidades estudiadas, se registraron mayores coeficientes de correlación, como, por ejemplo, en el año 2003 para la temperatura, la insolación, precipitación y la humedad relativa, o en el año 2005, con la velocidad media, año en el que, para la frecuencia de las calmas, la correlación cambió de signo. 


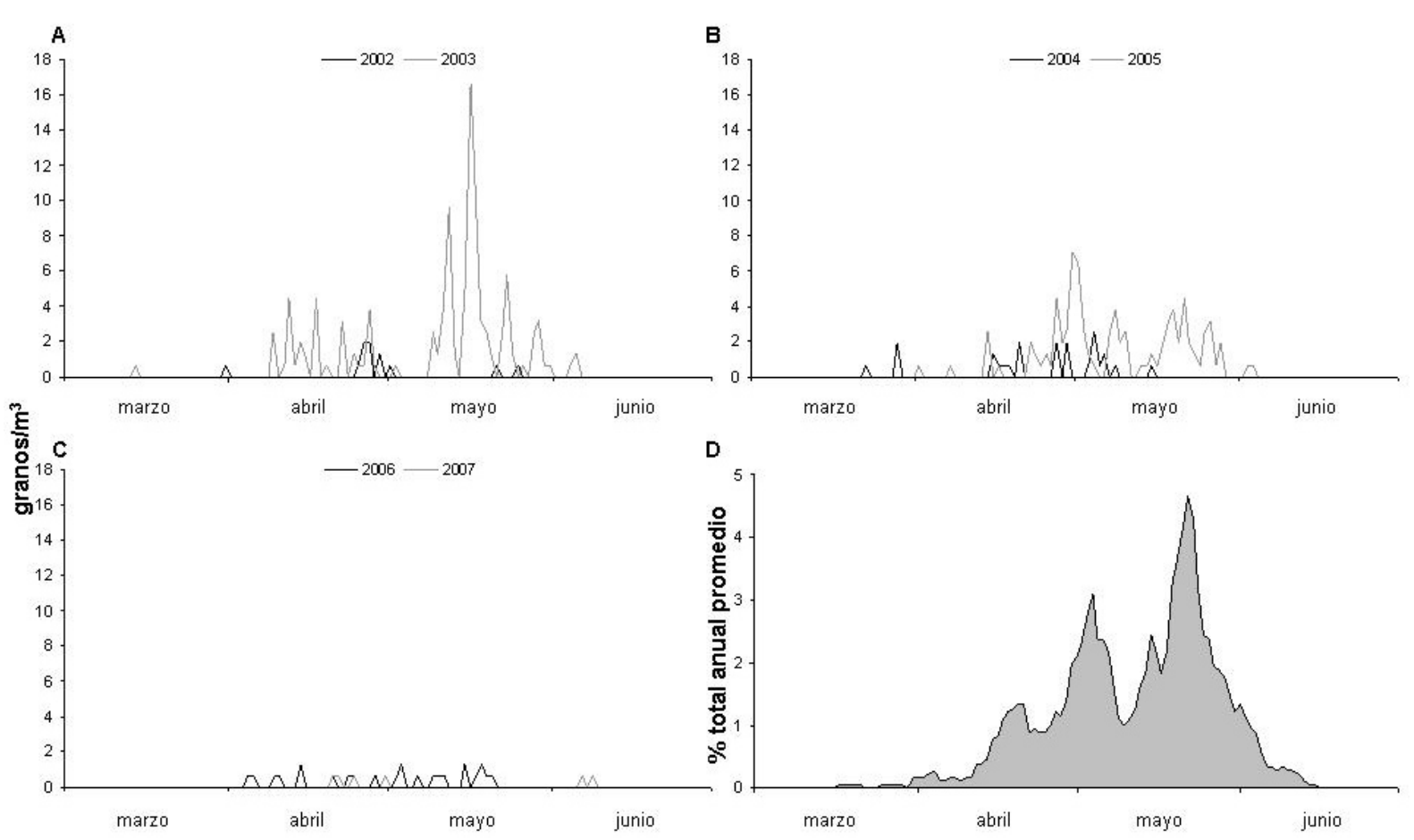

Fig. 5.2.3.33. Variación de las concentraciones medias diarias de Papaver durante el período 2002-2003 (A), 2004-2005 (B) y 2006-2007 (C). Porcentajes de representación diarios para la media de los cinco días anteriores dentro del promedio de los ocho años analizados (D).

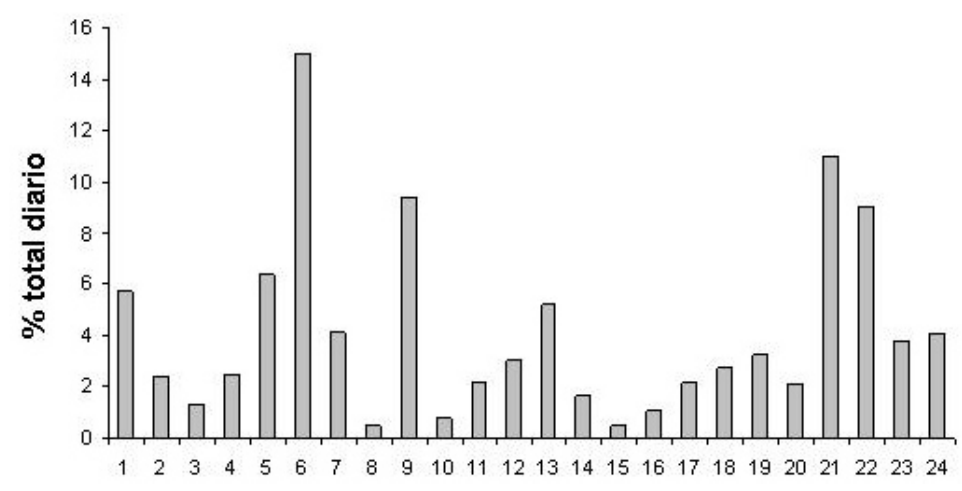

Fig. 5.2.3.34. Variación intradiaria del polen de Papaver. 


\begin{tabular}{|c|c|c|c|c|c|c|c|}
\hline \multicolumn{2}{|c|}{ Papaveraceae } & Tmed & Tmax & Tmin & Insolación & Precipitación & Hrelativa \\
\hline 2002 & Anual & - & - & - & - & - & - \\
\hline \multirow{2}{*}{$95 \%$} & PPP & - & - & - & - & - & - \\
\hline & PRE & - & - & - & - & - & - \\
\hline 2003 & Anual & $0,127^{*}$ & $0,118^{*}$ & 0,091 & $0,183^{* *}$ & $-0,088$ & $-0,216^{* *}$ \\
\hline \multirow{2}{*}{$95 \%$} & PPP & $0,494^{* *}$ & $0,433^{* *}$ & $0,423^{* *}$ & $0,303^{*}$ & $-0,352^{*}$ & $-0,373^{* *}$ \\
\hline & PRE & $0,424 *$ & $0,400 *$ & $0,358 *$ & 0,315 & $-0,342^{*}$ & $-0,367^{*}$ \\
\hline 2004 & Anual & $-0,059$ & $-0,047$ & $-0,081$ & $-0,017$ & 0,081 & $-0,073$ \\
\hline \multirow{2}{*}{$95 \%$} & PPP & 0,173 & 0,136 & 0,190 & $-0,189$ & 0,237 & 0,016 \\
\hline & PRE & 0,206 & 0,171 & 0,236 & $-0,188$ & 0,229 & 0,003 \\
\hline 2005 & Anual & $0,142^{\star *}$ & $0,142^{\star *}$ & $0,104^{* *}$ & $0,174^{* *}$ & $-0,005$ & $-0,157^{* *}$ \\
\hline \multirow{2}{*}{$95 \%$} & PPP & $0,610^{* \star}$ & 0,581 ** & 0,401 ** & 0,276 & $-0,427^{\star \star}$ & $-0,534$ * \\
\hline & PRE & 0,690 ** & $0,745^{* *}$ & 0,421 & $0,552^{*}$ & $-0,381$ & $-0,611^{* *}$ \\
\hline 2006 & Anual & 0,062 & 0,064 & 0,028 & - & 0,041 & $-0,165^{\star \star}$ \\
\hline \multirow{2}{*}{$95 \%$} & PPP & $0,383^{* *}$ & $0,295^{*}$ & 0,257 & - & 0,106 & $-0,274$ \\
\hline & PRE & $0,383^{*}$ & 0,218 & 0,205 & - & 0,242 & $-0,075$ \\
\hline 2007 & Anual & - & - & - & - & - & - \\
\hline \multirow{2}{*}{$95 \%$} & PPP & - & - & - & - & - & - \\
\hline & PRE & - & - & - & - & - & - \\
\hline Total & Anual & $0,077^{* *}$ & $0,070^{* *}$ & $0,055^{\star *}$ & $0,099 * *$ & $-0,010$ & $-0,133^{* *}$ \\
\hline
\end{tabular}

\begin{tabular}{|c|c|c|c|c|c|c|c|}
\hline \multicolumn{2}{|c|}{ Papaveraceae } & Vemed & FrecCalm & VICuadr & V2Cuadr & V3Cuadr & V4Cuadr \\
\hline 2002 & Anual & - & - & - & - & - & - \\
\hline \multirow{2}{*}{$95 \%$} & PPP & - & - & - & - & - & - \\
\hline & PRE & - & - & - & - & - & - \\
\hline 2003 & Anual & 0,061 & $-0,031$ & $-0,130^{*}$ & $-0,019$ & 0,101 & $0,112^{*}$ \\
\hline \multirow{2}{*}{$95 \%$} & PPP & $-0,254$ & $0,357^{*}$ & $-0,182$ & 0,151 & 0,061 & $0,376^{* *}$ \\
\hline & PRE & $-0,261$ & 0,259 & $-0,119$ & 0,097 & $-0,059$ & 0,263 \\
\hline 2004 & Anual & 0,042 & $-0,141^{\text {** }}$ & $-0,046$ & $-0,132^{*}$ & 0,020 & 0,085 \\
\hline \multirow{2}{*}{$95 \%$} & PPP & 0,250 & $-0,103$ & $-0,134$ & $-0,088$ & 0,114 & 0,229 \\
\hline & PRE & 0,218 & $-0,112$ & $-0,086$ & $-0,084$ & 0,063 & 0,155 \\
\hline 2005 & Anual & 0,072 & $-0,088$ & $-0,24$ ** & $-0,029$ & 0,219 ** & $0,290^{* *}$ \\
\hline \multirow{2}{*}{$95 \%$} & PPP & $-0,357^{*}$ & $0,455^{* \star}$ & 0,208 & 0,460 ** & $-0,050$ & $-0,025$ \\
\hline & PRE & $-0,63 * *$ & $0,703^{* *}$ & $0,677 * *$ & $0,627^{*}$ & $-0,429$ & $-0,205$ \\
\hline 2006 & Anual & 0,011 & $-0,074$ & $-0,034$ & 0,041 & 0,026 & 0,106 \\
\hline \multirow{2}{*}{$95 \%$} & PPP & $-0,229$ & $-0,201$ & $-0,077$ & 0,216 & 0,127 & 0,091 \\
\hline & PRE & $-0,047$ & $-0,519$ & $-0,199$ & 0,202 & 0,331 & 0,176 \\
\hline 2007 & Anual & - & - & - & - & - & - \\
\hline \multirow{2}{*}{$95 \%$} & PPP & - & - & - & - & - & - \\
\hline & PRE & - & - & - & - & - & - \\
\hline Total & Anual & $-0,001$ & $-0,060 * *$ & $-0,10$ ** & $-0,018$ & $0,083^{* *}$ & $0,135^{* *}$ \\
\hline
\end{tabular}

Tabla 5.2.3.24. Coeficientes de correlación de Spearman entre Papaver y las variables climatológicas. Tmed,

Tmax, Tmin (temperatura media, máxima y mínima), Hrelativa (humedad relativa), Vemed (velocidad media), FrecCalmas (frecuencia de calmas), V1Cuad, V2Cuad, V3Cuad, V4Cuad (vientos procedentes del I, II, III y IV cuadrante). Significación: $95 \%\left({ }^{*}\right), 99 \%\left({ }^{* *}\right)$. (-) Ausencia de correlaciones. 


\subsubsection{Robinia}

La variación interanual (Fig.

5.2.3.35.) nos indica que durante los ocho años de estudio hubo un descenso en las concentraciones de este tipo polínico en la atmósfera de Salamanca, a pesar del aumento observado en los tres primeros años. Así pues, el total anual experimentó un descenso de los 78 a los 23 granos de polen (un 239\% menos), tal y como muestra también el análisis de tendencias a través de la regresión lineal $\left(\mathrm{R}^{2}=0,48\right)$. Estos valores supusieron entre un 1,8\% (en 2001) y un 0,1\% (en los dos últimos años) del total de pólenes contabilizados (promedio:0,7\%).

La variación estacional, (Tabla 5.2.2.1) mostró una clara delimitación entre finales de abril y mediados-finales de junio, con 31 días como duración promedio del PPP, y consiguientemente, variaciones en la fecha de inicio (30 de abril de 2002 - 26 de mayo de 2000) y en la fecha de finalización (25 de mayo de 2006 - 23 de junio de 2004).

La evolución de las concentraciones a través del porcentaje que representó la media diaria de los cinco días anteriores para el conjunto de años estudiados con respecto al total promedio, refrendó esta dinámica ya que los niveles de polen aumentan desde la primera semana de mayo hasta mediados del mismo mes (Fig. 5.2.3.36.D.), presentando una concentración máxima de 6 granos $/ \mathrm{m}^{3}$ el día 16 de mayo como media de los ocho años estudiados (Tabla 5.2.3.25.). Las mayores concentraciones diarias para los años estudiados oscilaron entre los 30 granos $/ \mathrm{m}^{3}$ (16 de mayo de 2002) y los 3 granos $/ \mathrm{m}^{3}$ (9 de mayo de 2005), con escasa variación en los días en los que se produjeron (Tabla 5.2.3.25.; Fig. 5.2.3.36.A. B. C.). Posteriormente, las concentraciones de polen fueron disminuyendo hasta valores anecdóticos a finales del mes de julio.
Tipo polínico: Robinia pseudoacacia.

Especie(s): Robinia pseudoacacia

(Leguminosae).

Distribución: Originario de Estados Unidos, se extiende por toda Europa, incluyendo también a la Península Ibérica, así como a la provincia de Salamanca, donde crece cultivada en numerosas localidades e incluso como naturalizada, considerándose como una planta invasora.

Época de floración: De abril a junio.

Polinización: Entomófila.

Morfología polínica: Polen trizonocolporado (trizonocolporoidado), isopolar radiosimétrico, con una forma subtriangular en vista polar y de elíptica a circular en vista ecuatorial (prolato), y un tamaño mediano $(P=$ 25-31 $\mu \mathrm{m})$. Las ectoaberturas tipo colpo son terminales, mientras que las endoaberturas tipo poro son poco perceptibles al microscopio óptico, con membrana abertural psilada. La superficie psilado-perforada. exina, de grosor fino $(1,5-2 \mu \mathrm{m})$, posee una 


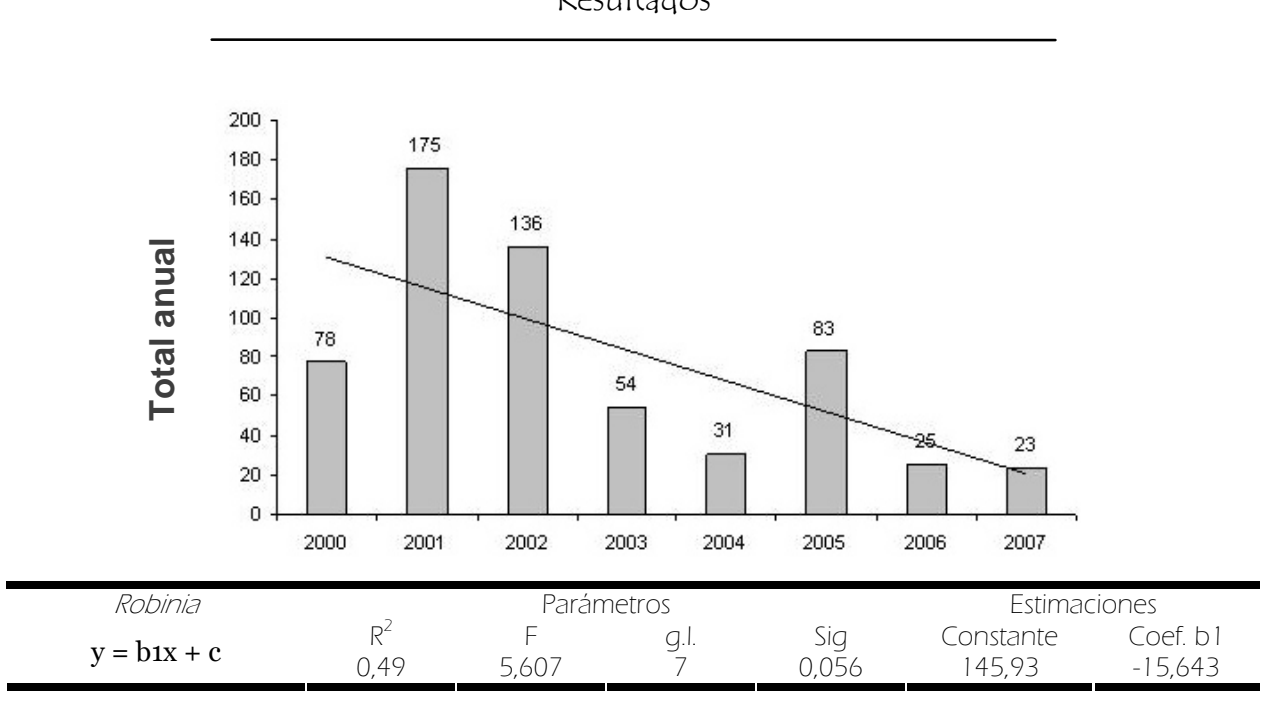

Fig. 5.2.3.35. Evolución anual del número total de pólenes de Robinia y tendencias (análisis de regresión).

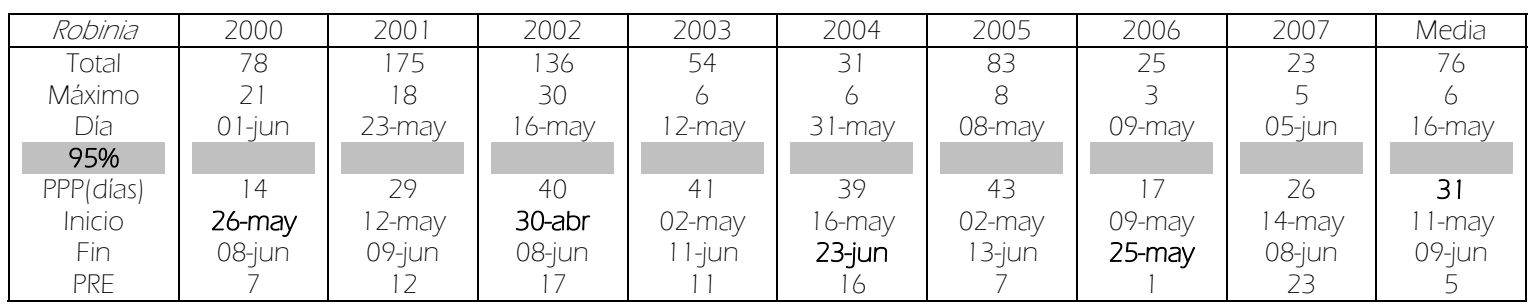

Tabla 5.2.3.25. Totales, concentraciones máximas diarias, período principal de polinización (PPP; fecha de inicio y fin) y días precedentes al valor máximo (PRE) durante los ocho años de estudio, y el promedio de todos los parámetros para Robinia.

En lo referente a la variación intradiaria (Fig. 5.2.3.37.), las mayores concentraciones se localizaron entre las 15 y las 24 horas, ya que suponen más el $50 \%$ del total de pólenes contabilizados a lo largo de un día promedio para los años 2005, 2006 y 2007. El resto de las horas mostraron porcentajes inferiores, que alcanzaron valores mínimos entre las 6y las 9 horas, salvo la franja horaria entre las 2 y 3 horas, con un 10\% del total.

El análisis de correlación (Tabla 5.2.3.26.) reflejó que las temperaturas medias, máximas y mínimas junto a la insolación y, en menor medida, la velocidad media del viento y los vientos procedentes del III y IV cuadrante, influyeron positivamente en los niveles polínicos durante los ocho años analizados. Por el contrario, la precipitación, la humedad relativa, la frecuencia de las calmas y, en menor grado, los vientos del I y II cuadrante, ejercieron un efecto negativo sobre las concentraciones polínicas. Si analizamos cada año y los PPP y PRE definidos en cada uno de ellos por separado, se observa un patrón similar, aunque es reseñable el alto coeficiente de correlación obtenido durante el PRE del año 2001 con las temperaturas medias y máximas, en los PPP de los años 2002 y 2004, con la precipitación, o en el PRE del año 2003 para la humedad relativa. 


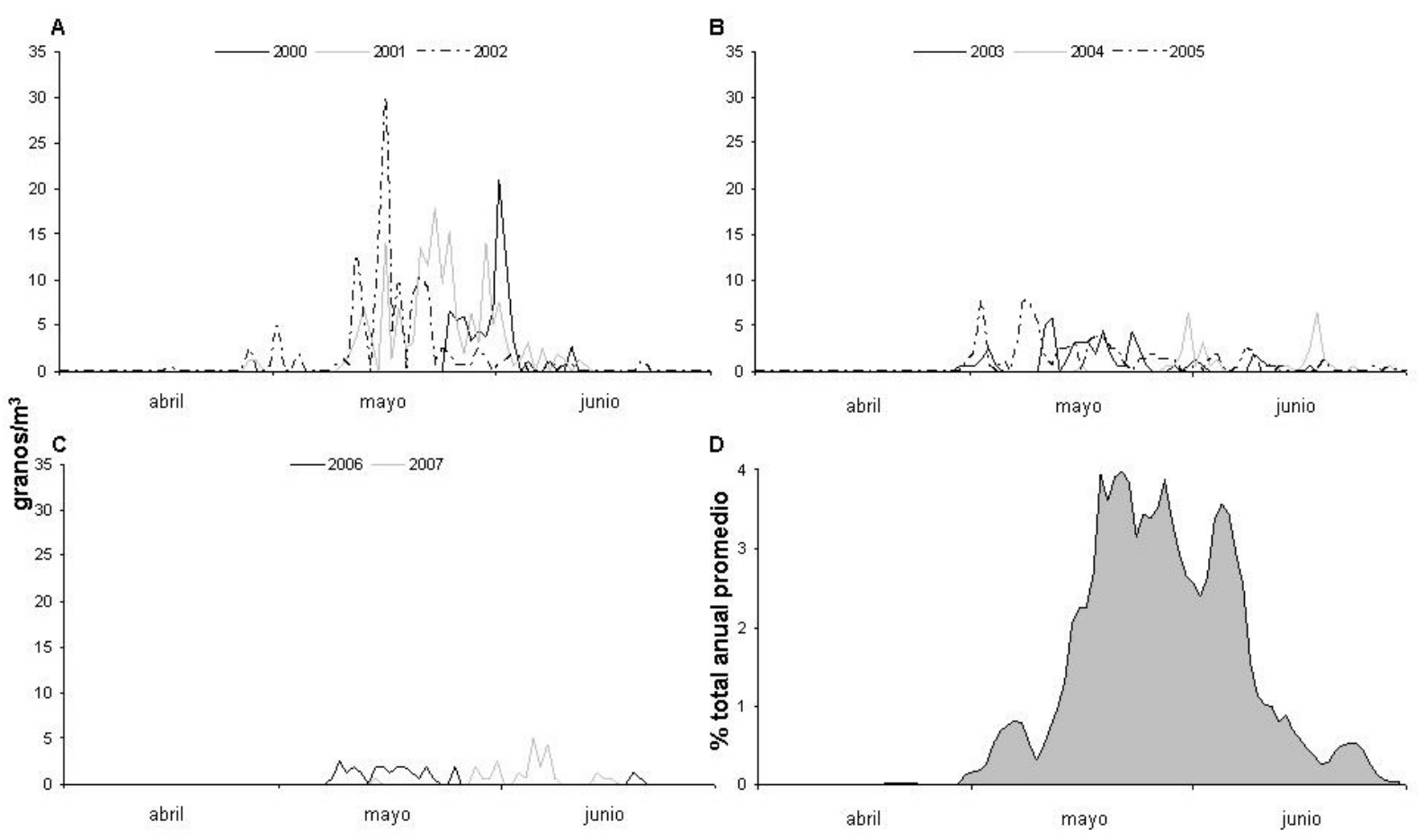

Fig. 5.2.3.36. Variación de las concentraciones medias diarias de Robinia durante el período 2000-2002 (A), 2003-2005 (B) y 2006-2007 (C). Porcentajes de representación diarios para la media de los cinco días anteriores dentro del promedio de los ocho años analizados (D).

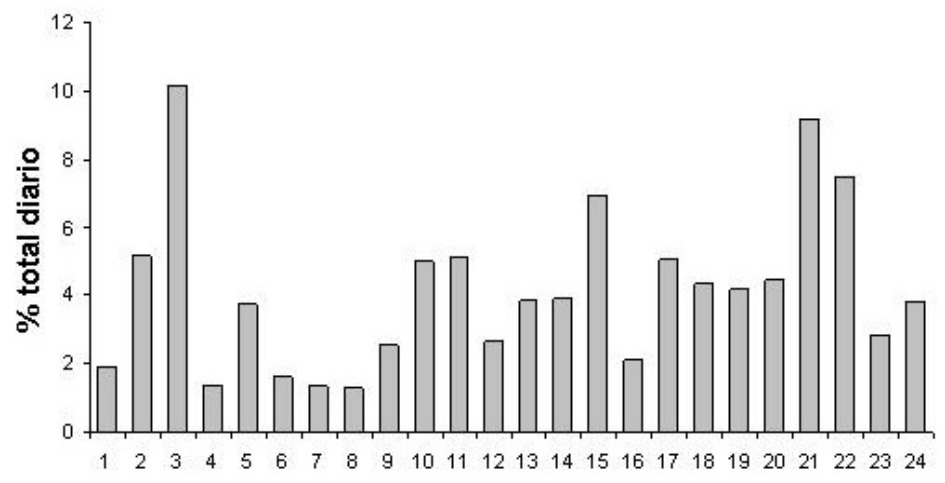

Fig. 5.2.3.37. Variación intradiaria del polen de Robinia. 


\begin{tabular}{|c|c|c|c|c|c|c|c|}
\hline \multicolumn{2}{|c|}{ Robinia } & Tmed & Tmax & Tmin & Insolación & Precipitación & Hrelativa \\
\hline 2000 & Anual & $0,183^{* *}$ & $0,163 * *$ & 0,201 ** & 0,100 & $-0,078$ & $-0,126^{*}$ \\
\hline \multirow{2}{*}{$95 \%$} & PPP & 0,419 & 0,295 & $0,566^{*}$ & $-0,142$ & 0,006 & 0,209 \\
\hline & PRE & 0,407 & 0,536 & 0,170 & 0,252 & 0,581 & $-0,494$ \\
\hline 2001 & Anual & $0,242^{* *}$ & $0,252^{* *}$ & $0,206^{* *}$ & $0,258^{* *}$ & $-0,070$ & $-0,267^{* *}$ \\
\hline \multirow{2}{*}{$95 \%$} & PPP & $-0,011$ & 0,022 & $-0,023$ & $-0,117$ & $-0,189$ & 0,161 \\
\hline & PRE & 0,302 & 0,449 & 0,299 & 0,162 & $-0,327$ & $-0,221$ \\
\hline 2002 & Anual & $0,131^{*}$ & 0,137 ** & 0,096 & $0,223^{* *}$ & $-0,093$ & $-0,274^{\star \star}$ \\
\hline \multirow{2}{*}{$95 \%$} & PPP & $0,391^{*}$ & $0,385^{\star}$ & $0,334^{\star}$ & 0,259 & $-0,480^{* *}$ & $-0,347^{*}$ \\
\hline & PRE & $0,635 * *$ & $0,603 * *$ & 0,420 & 0,213 & $-0,592^{*}$ & $-0,408$ \\
\hline 2003 & Anual & 0,189 ** & $0,190^{\star \star}$ & $0,143^{* *}$ & $0,266^{* *}$ & $-0,086$ & $-0,276^{\star *}$ \\
\hline \multirow{2}{*}{$95 \%$} & PPP & 0,051 & 0,083 & 0,086 & 0,062 & $-0,163$ & $-0,246$ \\
\hline & PRE & $0,639 *$ & $0,758 * *$ & 0,513 & $0,715^{*}$ & $-0,520$ & $-0,848^{* *}$ \\
\hline 2004 & Anual & $0,211^{\star *}$ & $0,198^{\star \star}$ & $0,207 * \star$ & $0,238^{* \star}$ & $-0,122^{\star}$ & $-0,207^{\star \star}$ \\
\hline \multirow{2}{*}{$95 \%$} & PPP & 0,156 & 0,146 & 0,057 & $0,323^{*}$ & $-0,424^{\star \star}$ & $-0,300$ \\
\hline & PRE & 0,546 * & 0,295 & 0,409 & 0,248 & $-0,437$ & $-0,192$ \\
\hline 2005 & Anual & $0,241^{* *}$ & $0,212^{* *}$ & $0,227^{* *}$ & $0,207^{* *}$ & 0,007 & $-0,227^{\star \star}$ \\
\hline \multirow{2}{*}{$95 \%$} & PPP & $-0,156$ & $-0,191$ & $-0,189$ & $-0,090$ & $-0,067$ & 0,216 \\
\hline & PRE & 0,418 & $-0,018$ & 0,236 & $-0,145$ & - & $-0,204$ \\
\hline 2006 & Anual & $0,131^{*}$ & $0,124^{\star}$ & 0,099 & - & $-0,073$ & $-0,232^{\star \star}$ \\
\hline \multirow{2}{*}{$95 \%$} & PPP & 0,471 & 0,417 & 0,264 & - & 0,214 & $-0,038$ \\
\hline & PRE & - & - & - & - & - & - \\
\hline 2007 & Anual & $0,125^{\star \star}$ & $0,106^{* \star}$ & $0,149 * *$ & 0,083 & 0,034 & $-0,112^{\star}$ \\
\hline \multirow{2}{*}{$95 \%$} & PPP & 0,047 & 0,154 & $-0,117$ & 0,355 & $-0,260$ & $-0,415^{\star}$ \\
\hline & PRE & $-0,268$ & $-0,104$ & $-0,240$ & 0,295 & $-0,234$ & $-0,331$ \\
\hline Total & Anual & 0,187 ** & $0,176 * \star$ & $0,169 * *$ & 0,191 ** & $-0,061 * *$ & $-0,211^{\star *}$ \\
\hline
\end{tabular}

\begin{tabular}{|c|c|c|c|c|c|c|c|}
\hline \multicolumn{2}{|c|}{ Robinia } & Vemed & FrecCalm & VICuadr & V2Cuadr & V3Cuadr & V4Cuadr \\
\hline 2000 & Anual & 0,049 & $-0,056$ & $-0,077$ & $-0,051$ & 0,052 & $0,153^{\star \star}$ \\
\hline \multirow{2}{*}{$95 \%$} & PPP & $-0,162$ & 0,296 & $-0,384$ & 0,002 & 0,145 & 0,325 \\
\hline & PRE & $-0,407$ & 0,012 & 0,453 & 0,530 & $-0,488$ & $-0,072$ \\
\hline 2001 & Anual & $-0,012$ & $-0,001$ & $-0,044$ & $-0,079$ & 0,058 & $0,232^{* *}$ \\
\hline \multirow{2}{*}{$95 \%$} & PPP & $-0,125$ & 0,055 & 0,054 & 0,079 & $-0,079$ & 0,021 \\
\hline & PRE & $-0,067$ & 0,120 & $-0,247$ & 0,276 & 0,069 & 0,102 \\
\hline 2002 & Anual & 0,074 & 0,024 & $-0,16^{* \star}$ & $-0,149^{* *}$ & $0,220^{* *}$ & 0,044 \\
\hline \multirow{2}{*}{$95 \%$} & PPP & 0,031 & 0,134 & $-0,325^{*}$ & 0,066 & $0,325^{*}$ & $-0,009$ \\
\hline & PRE & $-0,107$ & 0,350 & $-0,532^{*}$ & 0,327 & $0,549 *$ & $-0,071$ \\
\hline 2003 & Anual & 0,072 & $-0,077$ & $-0,050$ & $-0,070$ & 0,064 & 0,047 \\
\hline \multirow{2}{*}{$95 \%$} & PPP & 0,190 & 0,011 & $-0,42^{* *}$ & $-0,231$ & 0,286 & $0,372^{*}$ \\
\hline & PRE & $-0,055$ & 0,489 & $-0,575$ & $-0,137$ & 0,511 & 0,426 \\
\hline 2004 & Anual & $-0,017$ & $-0,105^{\star \star}$ & 0,029 & $-0,079$ & $-0,072$ & 0,047 \\
\hline \multirow{2}{*}{$95 \%$} & PPP & $-0,066$ & $-0,352^{*}$ & $-0,017$ & $-0,451$ ** & $-0,042$ & 0,119 \\
\hline & PRE & 0,290 & $-0,390$ & $-0,562^{*}$ & $-0,532^{*}$ & 0,463 & 0,459 \\
\hline 2005 & Anual & 0,082 & $-0,107 * \star$ & $-0,128^{*}$ & $-0,043$ & $0,161^{* *}$ & $0,176^{* *}$ \\
\hline \multirow{2}{*}{$95 \%$} & PPP & 0,120 & 0,287 & $-0,379^{*}$ & $-0,002$ & $0,345^{\star}$ & 0,245 \\
\hline & PRE & 0,183 & 0,327 & $-0,436$ & 0,578 & 0,743 & $-0,064$ \\
\hline 2006 & Anual & $-0,051$ & $-0,048$ & $-0,123^{*}$ & 0,017 & 0,087 & $0,177^{* *}$ \\
\hline \multirow{2}{*}{$95 \%$} & PPP & $-0,363$ & 0,323 & 0,123 & $0,549 *$ & 0,023 & $-0,560^{*}$ \\
\hline & PRE & - & - & - & - & - & - \\
\hline 2007 & Anual & 0,074 & $-0,087$ & $-0,091$ & $-0,122^{*}$ & 0,083 & 0,008 \\
\hline \multirow{2}{*}{$95 \%$} & PPP & 0,074 & $-0,190$ & $-0,143$ & $-0,256$ & 0,066 & $-0,005$ \\
\hline & PRE & 0,395 & $-0,453^{*}$ & $-0,142$ & $-0,600 * *$ & 0,123 & 0,023 \\
\hline Total & Anual & $0,037 * *$ & $-0,049 * *$ & $-0,08 * *$ & $-0,075^{* *}$ & $0,088^{* *}$ & $0,107^{* *}$ \\
\hline
\end{tabular}

Tabla 5.2.3.26. Coeficientes de correlación de Spearman entre Robinia y las variables climatológicas. Tmed,

Tmax, Tmin (temperatura media, máxima y mínima), Hrelativa (humedad relativa), Vemed (velocidad media), FrecCalmas (frecuencia de calmas), V1Cuad, V2Cuad, V3Cuad, V4Cuad (vientos procedentes del I, II, III y IV cuadrante). Significación: 95\%(*), 99\%(**). (-) Ausencia de correlaciones. 


\subsubsection{Rosaceae}

El tipo de polen que incluye a la familia Rosaceae, experimentó un descenso en sus niveles polínicos a través de los ocho años analizados, con una variación interanual (Fig. 5.2.3.38.) que pasó de un total de 18 en el año 2000 a los 6 pólenes del año 2007, algo que se hizo más evidente con respecto a los años 2001 y 2002, con un total de 143 y 113, respectivamente. Este descenso (un 200\% menos) en el número total de granos de polen dio lugar a un bajo índice de determinación $\left(\mathrm{R}^{2}=0,12\right)$, propio de la regresión lineal. Los porcentajes de representación sobre el total de pólenes contabilizados en cada anualidad estudiada variaron del 1,5\% de 2001 a un porcentaje inferior al $0,1 \%$ en el año 2007, con un porcentaje medio de $0,5 \%$.

La distribución de estos granos de polen a lo largo del año se localizó entre mediados de marzo hasta mediados de junio, por lo que la variación estacional (Tabla 5.2.3.27.) tuvo un PPP promedio de 81 días, con diferencias en la fecha de inicio (12 de marzo de 2000 y 2003 - 18 de abril de 2002), y finalización (6 de mayo de 2000 - 27 de junio de 2001) para los diferentes años incluidos.

Los niveles polínicos de esta familia botánica en la atmósfera de la ciudad de
Salamanca
(Fig.
5.2.3.39.D.),

experimentaron un ascenso en marzo hasta el mes de mayo, mes en el que experimentaron las mayores concentraciones, como indica el valor medio más elevado en los años analizados (4 granos/ $\mathrm{m}^{3}$ el 1 de mayo), gracias al porcentaje de representación de las concentraciones medias móviles de los cincos días anteriores con respecto al total anual. En todo caso, las
Tipo de polen: Rosaceae.

Especie(s): Crataegus monogyna Jacq., Prunus avium L., Prunus cerasifera Ehrh., Prunus dulcis (Miller) D.A. Webb, Prunus laurocerasus L. , y diversas especies del género Rubus L., entre otras (Rosaceae).

Distribución: Familia de origen, en su mayoría Euroasiático, ampliamente cultivadas en ambos hemisferios. En la Península Ibérica y la provincia de Salamanca, además de las especies cultivadas, los principales géneros autóctonos, e incluso naturalizados, se localizan en claros de bosques formando setos o bordes de caminos, generalmente en lugares con cierto grado de humedad.

Época de floración: Desde comienzos de primavera hasta verano.

Polinización: Entomófila.

Morfología polínica (Lámina III): Polen trizonocolporado, isopolar y radiosimétrico, con forma de circular a subtriangular en vista polar, y subelíptica-elíptica en vista ecuatorial (de subprolato a prolato), y un tamaño variable $(P=16-40 \mu \mathrm{m})$. Las ectoaberturas tipo colpo son alargadas, al igual que las endoaberturas tipo poro en la dirección del ecuador, en este caso. La exina, de grosor medio-grueso $(1,5-3 \mu \mathrm{m})$, presenta una superficie estriada, con las estrías dispuestas irregularmente (tipo Crataegus) o las estrías dispuestas longitudinalmente (tipo Prunus), e incluso rugulada-perforada (tipo Rubus). 
mayores concentraciones diarias registradas en los ocho años estudiados oscilaron en más de dos meses y con valores entre los 22 granos $/ \mathrm{m}^{3}$ ( 1 de mayo de 2006) y 1 grano $/ \mathrm{m}^{3}$ (varios días de 2007). Después, estos niveles disminuyeron a finales del mes de junio y julio (Fig. 5.2.3.39. A. B. C.).

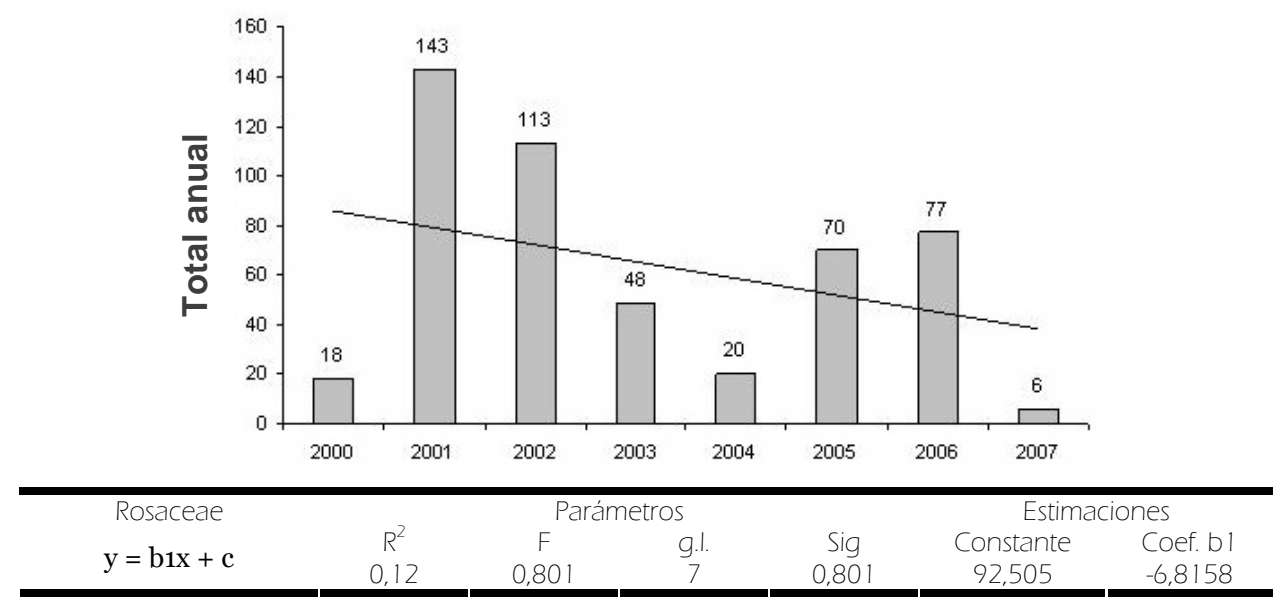

Fig. 5.2.3.38. Evolución anual del número total de pólenes de Rosaceae y tendencias (análisis de regresión).

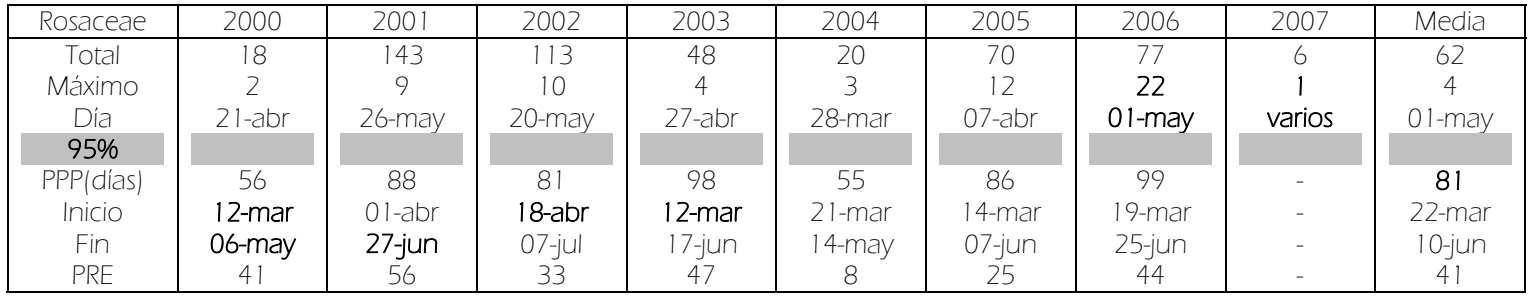

Tabla 5.2.3.27. Totales, concentraciones máximas diarias, período principal de polinización (PPP; fecha de inicio y fin) y días precedentes al valor máximo (PRE) durante los ocho años de estudio (salvo los años con bajo número anual o sin presencia de este tipo), y el promedio de todos los parámetros para Rosaceae.

La variación intradiaria (Fig. 5.2.3.40.), presentada con un día promedio durante los años 2005, 2006 y2007, mostró una distribución irregular a lo largo de las veinticuatro horas, registrándose mayores concentraciones en las primeras horas de la madrugada y las últimas horas de la tarde.

Las temperaturas medias, máximas y mínimas junto a la insolación, la velocidad media, y los vientos procedentes del III y IV cuadrante tuvieron una influencia positiva en los niveles de este tipo de polen durante los ocho años analizados, así como el efecto negativo que ejerció la humedad relativa y, en menor medida, la frecuencia de las calmas y los vientos del I y II cuadrante, tras el análisis de correlación (Tabla 5.2.3.28.). Este mismo tipo de correlaciones, en cuanto al signo y grado de significación, se observó en las distintas anualidades, pero con diferencias numéricas en los coeficientes dentro de los PPP y PRE de 
los años 2000 y 2001 para la temperatura media, o en el año 2002 para los vientos procedentes del I y II cuadrante.
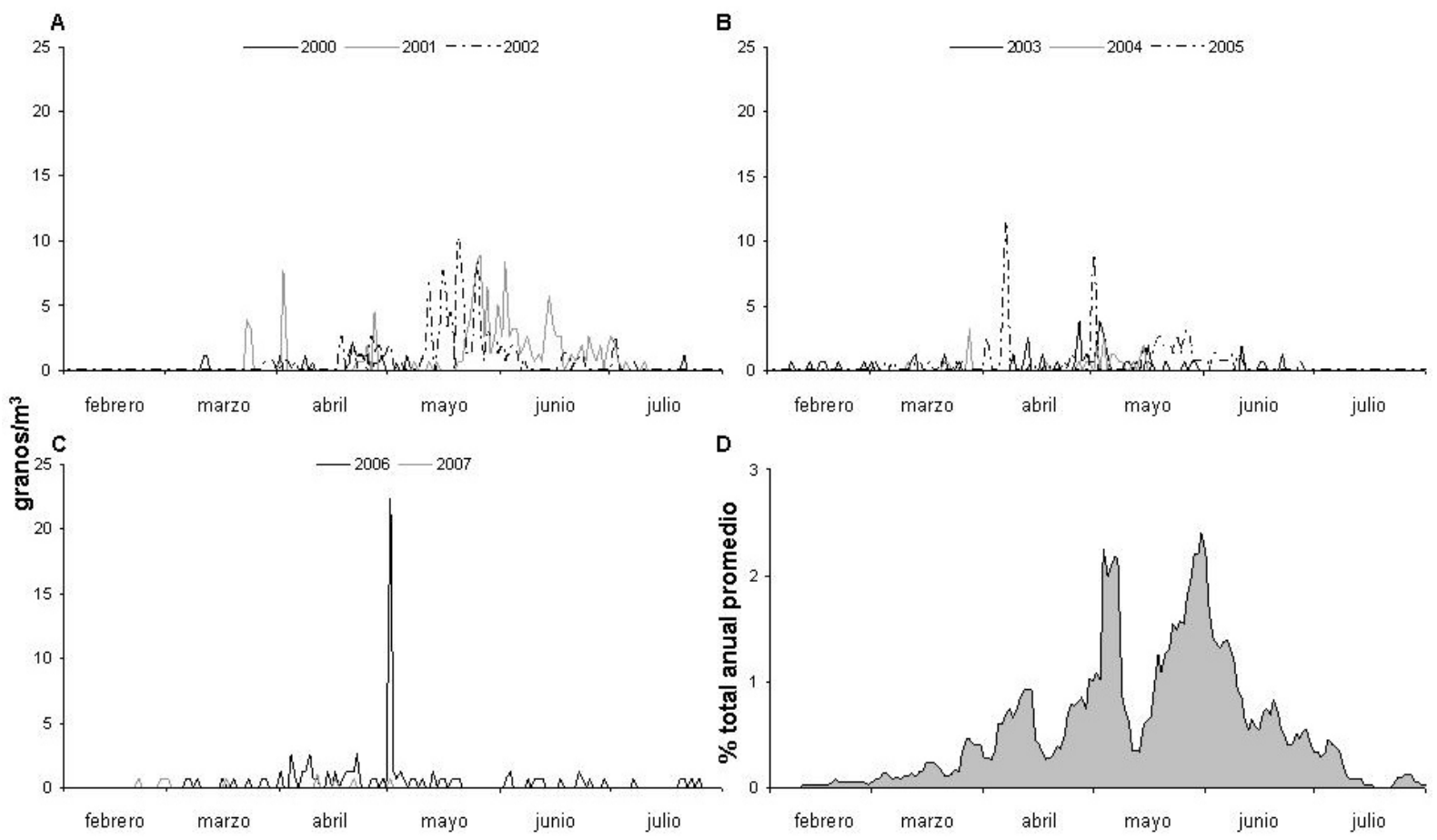

Fig. 5.2.3.39. Variación de las concentraciones medias diarias de Rosaceae durante el período 2000-2002 (A), 2003-2005 (B) y 2006-2007 (C). Porcentajes de representación diarios para la media de los cinco días anteriores dentro del promedio de los ocho años analizados (D).

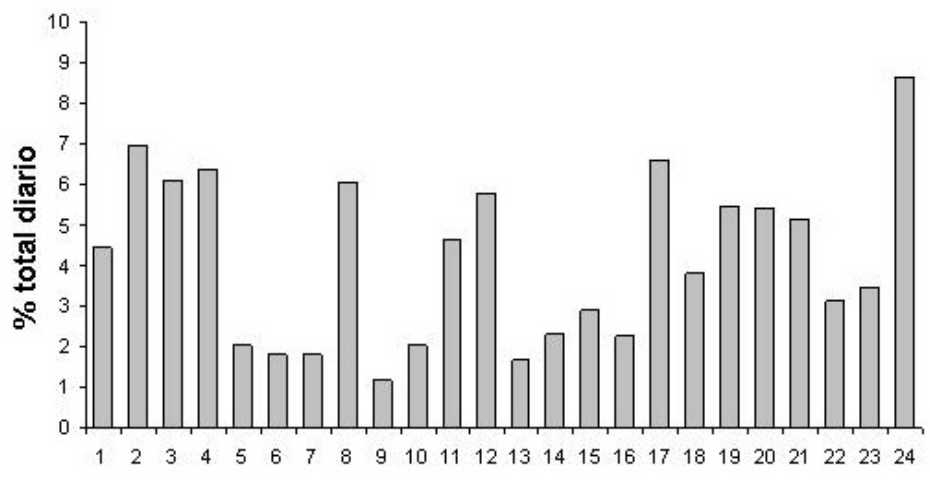

Fig. 5.2.3.40. Variación intradiaria del polen de Rosaceae. 


\begin{tabular}{|c|c|c|c|c|c|c|c|}
\hline \multicolumn{2}{|c|}{ Rosaceae } & Tmed & Tmax & Tmin & Insolación & Precipitación & Hrelativa \\
\hline 2000 & Anual & $-0,027$ & $-0,055$ & $-0,018$ & $-0,112^{\star}$ & 0,170 ** & 0,006 \\
\hline \multirow{2}{*}{$95 \%$} & PPP & $0,315^{* *}$ & 0,143 & $0,327^{*}$ & $-0,190$ & 0,184 & 0,177 \\
\hline & PRE & 0,350 * & 0,204 & 0,293 & $-0,028$ & 0,041 & 0,028 \\
\hline 2001 & Anual & $0,380^{* *}$ & $0,379^{* *}$ & $0,343^{* *}$ & $0,365^{* *}$ & $-0,094$ & $-0,409$ ** \\
\hline \multirow{2}{*}{$95 \%$} & PPP & $0,712^{\star \star}$ & $0,655^{\star *}$ & $0,713^{* *}$ & $0,485^{\star *}$ & $-0,110$ & $-0,516^{* *}$ \\
\hline & PRE & $0,475^{* *}$ & $0,346^{* *}$ & $0,534^{* *}$ & 0,089 & 0,125 & $-0,182$ \\
\hline 2002 & Anual & $0,228^{* *}$ & $0,255^{\star *}$ & $0,147^{* *}$ & $0,295^{\star *}$ & $-0,079$ & $-0,391$ ** \\
\hline \multirow{2}{*}{$95 \%$} & PPP & $-0,106$ & $-0,111$ & $-0,127$ & $-0,182$ & $-0,058$ & 0,038 \\
\hline & PRE & 0,408 ** & $0,393^{*}$ & 0,335 & 0,120 & $-0,335$ & $-0,238$ \\
\hline 2003 & Anual & 0,052 & 0,033 & 0,026 & 0,079 & $-0,027$ & $-0,134^{*}$ \\
\hline \multirow{2}{*}{$95 \%$} & PPP & 0,160 & 0,114 & 0,056 & 0,076 & $-0,098$ & $-0,045$ \\
\hline & PRE & $0,421^{* *}$ & $0,422^{* *}$ & 0,098 & 0,061 & $-0,161$ & $-0,197$ \\
\hline 2004 & Anual & $-0,067$ & $-0,051$ & $-0,091$ & $-0,001$ & 0,029 & $-0,051$ \\
\hline \multirow{2}{*}{$95 \%$} & PPP & 0,033 & 0,111 & 0,005 & 0,037 & $-0,003$ & $-0,026$ \\
\hline & PRE & 0,275 & 0,646 & 0,076 & 0,041 & 0,198 & 0,289 \\
\hline 2005 & Anual & $0,137^{* *}$ & $0,136^{\star *}$ & $0,105^{\star *}$ & $0,129 *$ & 0,020 & $-0,204^{* *}$ \\
\hline \multirow{2}{*}{$95 \%$} & PPP & $0,345^{\star *}$ & $0,317^{* *}$ & $0,276^{*}$ & $0,254^{*}$ & $-0,133$ & $-0,357^{* *}$ \\
\hline & PRE & 0,121 & 0,059 & 0,072 & 0,011 & 0,054 & $-0,013$ \\
\hline 2006 & Anual & $0,143^{* *}$ & $0,133^{* *}$ & $0,110^{*}$ & - & $-0,014$ & $-0,244^{* *}$ \\
\hline \multirow{2}{*}{$95 \%$} & PPP & $-0,162$ & $-0,196$ & $-0,134$ & - & 0,100 & 0,142 \\
\hline & PRE & 0,090 & 0,026 & $-0,030$ & - & 0,092 & $-0,093$ \\
\hline 2007 & Anual & - & - & - & - & - & - \\
\hline \multirow{2}{*}{$95 \%$} & PPP & - & - & - & - & - & - \\
\hline & PRE & - & - & - & - & - & - \\
\hline Total & Anual & $0,136^{* *}$ & $0,125^{\star *}$ & $0,115^{\star *}$ & $0,148^{* \star}$ & $-0,010$ & $-0,186^{* *}$ \\
\hline
\end{tabular}

\begin{tabular}{|c|c|c|c|c|c|c|c|}
\hline \multicolumn{2}{|c|}{ Rosaceae } & Vemed & FrecCalm & VICuadr & V2Cuadr & V3Cuadr & V4Cuadr \\
\hline 2000 & Anual & $0,148^{* *}$ & $-0,159^{* *}$ & $-0,103$ & 0,006 & $0,179 * *$ & $-0,052$ \\
\hline \multirow{2}{*}{$95 \%$} & PPP & 0,029 & $-0,119$ & $-0,157$ & 0,066 & 0,249 & 0,079 \\
\hline & PRE & $-0,024$ & 0,119 & $-0,087$ & 0,158 & 0,168 & 0,027 \\
\hline 2001 & Anual & 0,027 & $-0,050$ & $-0,101$ & $-0,065$ & $0,119^{*}$ & $0,290^{* *}$ \\
\hline \multirow{2}{*}{$95 \%$} & PPP & $-0,185$ & 0,138 & $-0,254^{*}$ & 0,016 & 0,178 & $0,329^{\star *}$ \\
\hline & PRE & $-0,033$ & 0,089 & $-0,293^{*}$ & 0,015 & $0,299 *$ & 0,146 \\
\hline 2002 & Anual & 0,063 & 0,047 & $-0,16 * *$ & $-0,149 * *$ & $0,187^{* *}$ & 0,028 \\
\hline \multirow{2}{*}{$95 \%$} & PPP & 0,115 & $-0,042$ & $-0,40^{* *}$ & $-0,127$ & $0,481^{* *}$ & 0,023 \\
\hline & PRE & 0,044 & 0,091 & $-0,46 * *$ & $-0,017$ & 0,470 ** & 0,164 \\
\hline 2003 & Anual & $0,132^{*}$ & $-0,120^{*}$ & $-0,072$ & 0,001 & $0,111^{\star}$ & $-0,073$ \\
\hline \multirow{2}{*}{$95 \%$} & PPP & 0,071 & 0,009 & $-0,205^{*}$ & 0,036 & 0,181 & 0,067 \\
\hline & PRE & 0,029 & 0,074 & $-0,191$ & 0,287 & 0,180 & 0,104 \\
\hline 2004 & Anual & 0,035 & $-0,134^{\star}$ & $-0,031$ & $-0,157^{\star \star}$ & 0,002 & 0,094 \\
\hline \multirow{2}{*}{$95 \%$} & PPP & 0,233 & 0,021 & $-0,150$ & $-0,030$ & 0,066 & $0,315^{*}$ \\
\hline & PRE & 0,042 & 0,425 & $-0,316$ & 0,730 * & 0,015 & 0,117 \\
\hline 2005 & Anual & 0,081 & $-0,122^{*}$ & $-0,084$ & - & $0,111^{\star}$ & $0,122^{*}$ \\
\hline \multirow{2}{*}{$95 \%$} & PPP & $-0,179$ & 0,091 & 0,037 & 0,048 & $-0,091$ & 0,147 \\
\hline & PRE & $-0,197$ & 0,149 & $-0,033$ & 0,177 & $-0,032$ & 0,206 \\
\hline 2006 & Anual & 0,080 & $-0,048$ & $-0,048$ & $-0,021$ & 0,055 & $0,137^{*}$ \\
\hline \multirow{2}{*}{$95 \%$} & PPP & $0,272^{* *}$ & 0,145 & $-0,198$ & $-0,035$ & 0,152 & 0,089 \\
\hline & PRE & $0,303^{*}$ & 0,465 & $-0,505$ & 0,625 & 0,217 & $-0,112$ \\
\hline 2007 & Anual & - & - & - & - & - & - \\
\hline \multirow{2}{*}{$95 \%$} & PPP & - & - & - & - & - & - \\
\hline & PRE & - & - & - & - & - & - \\
\hline Total & Anual & $0,069 * *$ & $-0,067^{* *}$ & $-0,09$ ** & $-0,051$ ** & $0,114^{* \star}$ & $0,068^{* *}$ \\
\hline
\end{tabular}

Tabla 5.2.3.28. Coeficientes de correlación de Spearman entre Rosaceae y las variables climatológicas. Tmed,

Tmax, Tmin (temperatura media, máxima y mínima), Hrelativa (humedad relativa), Vemed (velocidad media), FrecCalmas (frecuencia de calmas), V1Cuad, V2Cuad, V3Cuad, V4Cuad (vientos procedentes del I, II, III y IV cuadrante). Significación: 95\%(*), 99\%(**). (-) Ausencia de correlaciones. 


\subsubsection{Tilia}

Los niveles del tipo polínico Tilia platyphyllos en la atmósfera de Salamanca, descendieron durante el período analizado, ya que si en el año 2000 el total anual fue de 166, en el año 2007 alcanzó los 27 pólenes. Esto supuso que la variación interanual (Fig. 5.2.3.41.) llevase consigo un descenso del $515 \%$ en las concentraciones anuales de este tipo polínico. El análisis de regresión de tipo lineal confirma esta tendencia a través del valor que tomó su índice de determinación $\quad\left(\mathrm{R}^{2}=0,60\right) . \quad \mathrm{La}$ representación media de los pólenes de Tilia a lo largo de los ocho años fue de $0,6 \%$, con un máximo de $1,5 \%$ en 2000 y un mínimo de 0,1\% en los años 2004, 2006 y 2007..

La distribución de estos granos de polen a lo largo del año se localizó entre mediados-finales de mayo y finales de junio, por lo que la variación estacional (Tabla 5.2.3.29.) tuvo un PPP promedio de 35 días, que presentó pequeñas oscilaciones en la fecha de inicio (12 de mayo de $2002-5$ de junio de 2007) y finalización (19 de junio de 2002 - 1 de julio de 2001).

Tipo polínico: Tilia platyphyllos.

Especie(s): Tilia platyphyllos Scop., y Tilia $x$ vulgaris Hayne (Tiliaceae).

Distribución: Género nativo de la región centroeuropea y oeste de Asia, que se encuentra esparcido por los sistemas montañosos del norte y el centro de la Península Ibérica. En la provincia de Salamanca se encuentra cultivado en muchas poblaciones con fines ornamentales, en parques, jardines e incluso como arbolado de alineación.

Época de floración: De mayo a julio.

Polinización: Entomófila.

Morfología polínica (Lámina IV): Polen trizonocolporado (a veces tetrazonocolporado), isopolar y radiosimétrico, con una forma de subtriangular a subcircular en vista polar y elíptica en vista ecuatorial (suboblato), y un tamaño mediano( $P=27-40 \mu \mathrm{m})$. Las ectoaberturas tipo colpo, en posición subecuatorial, son cortas y rectas, $y$ las endoaberturas tipo poro, presentan una membrana abertural granulada. La exina, de grosor medio-grueso $(2-3 \mu \mathrm{m})$, presenta una superficie finamente reticulada, poco apreciable al microscopio óptico, y cuyos lúmenes difieren en tamaño en cada uno de los polos..

En todo caso, los niveles polínicos de Tilia en la atmósfera de la ciudad de Salamanca (Fig. 5.2.3.42.D.) aumentaron a partir de la segunda de mayo hasta alcanzar los valores más elevados a principios de junio, como muestra el valor medio más elevado en los años analizados (3 granos $/ \mathrm{m}^{3}$, el 10 de junio), gracias a la dinámica aportada por el porcentaje de representación que alcanzó la media de los cincos días anteriores para el total promediado de los ocho años. Asimismo, las mayores concentraciones diarias registradas dentro del período 2000-2007 (Tabla 5.2.3.29; Fig. 5.2.3.42. A. B. C.), oscilaron entre los 17 granos $/ \mathrm{m}^{3}$ (8 de junio de 2000) y los 3 granos $/ \mathrm{m}^{3}$ (15 de junio de 2005). Estos niveles disminuyeron a finales de junio, presentándose en niveles bajos durante el mes de julio. 


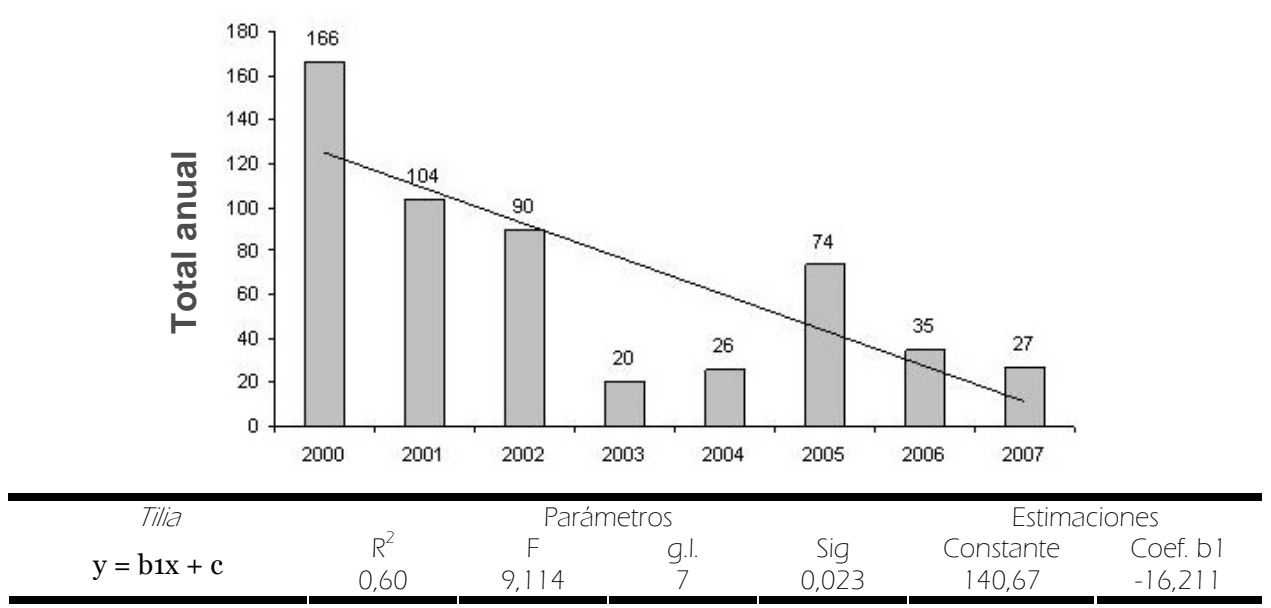

Fig. 5.2.3.41 Evolución anual del número total de pólenes de Tilia y tendencias (análisis de regresión).

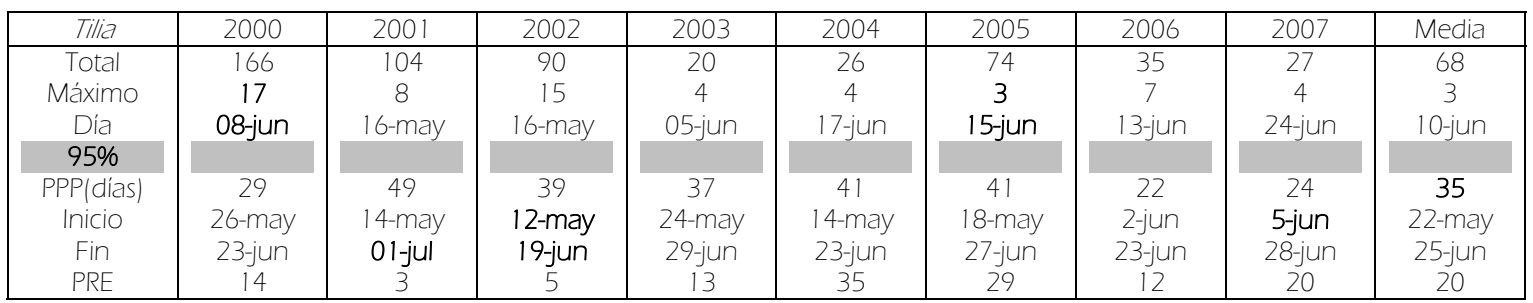

Tabla 5.2.3.29. Totales, concentraciones máximas diarias, período principal de polinización (PPP; fecha de inicio y fin) y días precedentes al valor máximo (PRE) durante los ocho años de estudio, y el promedio de todos los parámetros para Tilia.

La variación intradiaria (Fig. 5.2.3.43.) mostró mayores niveles durante la segunda mitad del día, a lo largo de un día promedio para los últimos tres años estudiados, fundamentalmente entre las 13 y las 21 horas.

El análisis de correlación (Tabla 5.2.3.30.) mostró que las temperaturas medias, máximas y mínimas, junto a la insolación y, en menor medida, la velocidad media del viento y los vientos procedentes del III y IV cuadrante influyeron positivamente en los niveles polínicos durante los ocho años analizados, mientras que la precipitación, la humedad relativa, la frecuencia de las calmas y los vientos del I y II cuadrante tuvieron un efecto negativo, aunque algunos de ellos presentasen coeficientes de correlación bajos. Este patrón se mantuvo en un buen número de años analizados, no mostrando valores significativos a lo largo de los PPP y PRE definidos en dichas anualidades. 


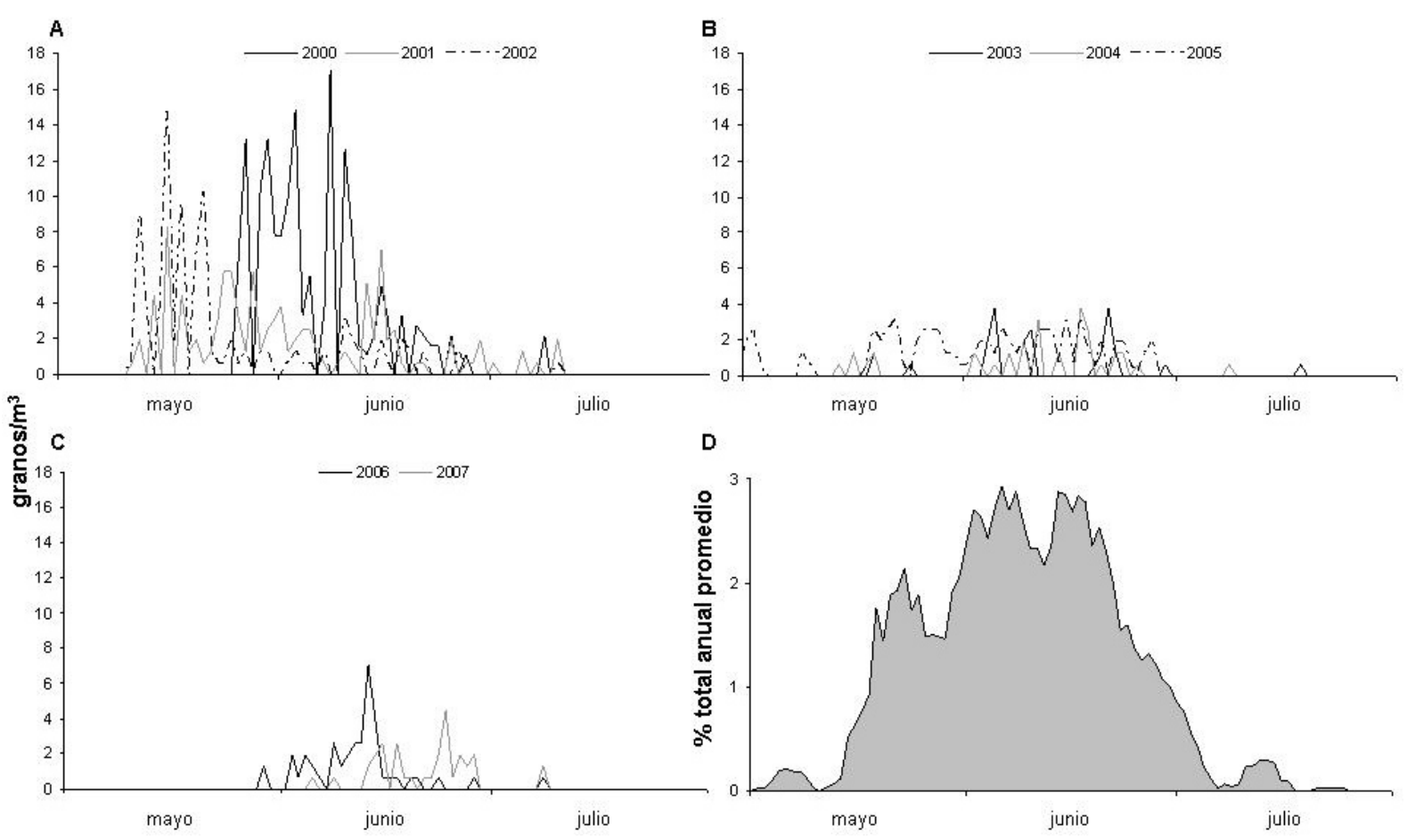

Fig. 5.2.3.42. Variación de las concentraciones medias diarias de Tilia durante el período 2000-2002 (A), 20032005 (B) y 2006-2007 (C). Porcentajes de representación diarios para la media de los cinco días anteriores dentro del promedio de los ocho años analizados (D).

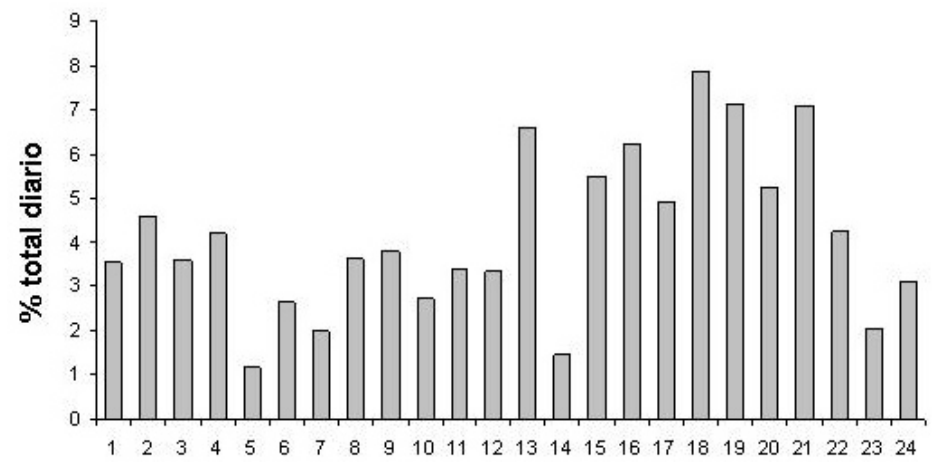

Fig. 5.2.3.43. Variación intradiaria del polen de Tilia. 


\begin{tabular}{|c|c|c|c|c|c|c|c|}
\hline \multicolumn{2}{|c|}{ Tilia } & Tmed & Tmax & Tmin & Insolación & Precipitación & Hrelativa \\
\hline 2000 & Anual & $0,287^{* *}$ & $0,274^{* *}$ & $0,274 * *$ & $0,260^{* *}$ & $-0,105^{*}$ & $-0,299 * *$ \\
\hline \multirow{2}{*}{$95 \%$} & PPP & $-0,051$ & $-0,080$ & $-0,031$ & $-0,133$ & 0,078 & 0,184 \\
\hline & PRE & 0,456 & 0,501 & 0,095 & $0,533^{*}$ & $-0,244$ & $-0,327$ \\
\hline 2001 & Anual & $0,343^{* *}$ & $0,350^{* \star}$ & $0,301^{* *}$ & $0,384^{* *}$ & $-0,113^{*}$ & $-0,356^{* *}$ \\
\hline \multirow{2}{*}{$95 \%$} & PPP & $-0,163$ & $-0,223$ & $-0,038$ & $-0,042$ & $-0,065$ & $0,348^{*}$ \\
\hline & PRE & 0,500 & 0,500 & 0,500 & 0,500 & - & 0,500 \\
\hline 2002 & Anual & $0,230^{* *}$ & $0,231^{* *}$ & $0,206 * *$ & $0,213^{* *}$ & $-0,035$ & $-0,301^{* *}$ \\
\hline \multirow{2}{*}{$95 \%$} & $\begin{array}{l}\text { PPP } \\
\end{array}$ & $-0,049$ & $\begin{array}{l}-0,049 \\
\end{array}$ & 0,004 & $\begin{array}{l}-0,089 \\
\end{array}$ & $-0,163$ & $-0,110$ \\
\hline & PRE & 0,300 & 0,500 & 0,205 & $-0,400$ & - & $-0,600$ \\
\hline 2003 & Anual & $0,209^{* *}$ & $0,194 * \star$ & $0,190^{* *}$ & $0,224^{* *}$ & $-0,077$ & $-0,254^{* *}$ \\
\hline \multirow{2}{*}{$95 \%$} & PPP & 0,145 & 0,134 & $-0,008$ & 0,183 & $-0,128$ & $-0,398^{*}$ \\
\hline & PRE & $-0,108$ & $-0,238$ & 0,078 & 0,030 & $-0,230$ & 0,004 \\
\hline 2004 & Anual & $0,231^{\text {** }}$ & 0,224 ** & 0,219 ** & $0,245^{\star \star}$ & $-0,088$ & $-0,184^{* *}$ \\
\hline \multirow{2}{*}{$95 \%$} & PPP & $0,345^{*}$ & $0,388^{*}$ & 0,172 & 0,275 & $-0,216$ & $-0,235$ \\
\hline & PRE & 0,278 & 0,334 & 0,094 & $0,355^{*}$ & $-0,194$ & $-0,270$ \\
\hline 2005 & Anual & $0,377^{* *}$ & $0,344^{* *}$ & $0,350^{\star *}$ & $0,285^{\star *}$ & $-0,065$ & $-0,360$ ** \\
\hline \multirow{2}{*}{$95 \%$} & $\begin{array}{l}\mathrm{PPP} \\
\end{array}$ & 0,002 & $-0,067$ & $-0,029$ & 0,138 & $-0,053$ & $-0,097$ \\
\hline & PRE & 0,191 & $-0,032$ & 0,227 & 0,209 & $-0,052$ & $-0,157$ \\
\hline 2006 & Anual & $0,272^{\star \star}$ & $0,264 * \star$ & $0,262^{* *}$ & - & 0,034 & $-0,274^{* \star}$ \\
\hline \multirow{2}{*}{$95 \%$} & PPP & $-0,014$ & $-0,150$ & 0,193 & - & 0,263 & $-0,215$ \\
\hline & PRE & 0,103 & $-0,146$ & 0,431 & - & $0,602 *$ & 0,556 \\
\hline 2007 & Anual & $0,214^{* *}$ & $0,194 * \star$ & $0,214^{* *}$ & $0,174 * \star$ & 0,004 & $-0,138^{* *}$ \\
\hline \multirow{2}{*}{$95 \%$} & PPP & $-0,115$ & $-0,041$ & $-0,307$ & 0,068 & 0,027 & $-0,123$ \\
\hline & PRE & $-0,184$ & $-0,158$ & $-0,167$ & $-0,033$ & 0,107 & 0,090 \\
\hline Total & Anual & $0,273^{* *}$ & $0,261^{* *}$ & $0,251^{* *}$ & $0,251^{* *}$ & $-0,060^{* *}$ & $-0,269 * * *$ \\
\hline
\end{tabular}

\begin{tabular}{|c|c|c|c|c|c|c|c|}
\hline \multicolumn{2}{|c|}{ Tilia } & Vemed & FrecCalm & VICuadr & V2Cuadr & V3Cuadr & V4Cuadr \\
\hline 2000 & Anual & 0,095 & $-0,109^{*}$ & 0,036 & $-0,022$ & $-0,040$ & 0,050 \\
\hline \multirow{2}{*}{$95 \%$} & PPP & $-0,248$ & 0,197 & $-0,269$ & $-0,022$ & 0,232 & $0,399 *$ \\
\hline & PRE & $-0,176$ & $0,533^{*}$ & $-0,328$ & 0,183 & 0,287 & 0,235 \\
\hline 2001 & Anual & $-0,015$ & $-0,075$ & $-0,032$ & $-0,085$ & 0,018 & 0,260 ** \\
\hline \multirow{2}{*}{$95 \%$} & PPP & 0,120 & $-0,253$ & $-0,061$ & $-0,291$ * & $-0,004$ & 0,178 \\
\hline & PRE & 0,500 & $-1 * *$ & - & 0,500 & $-1 * \star$ & 0,500 \\
\hline 2002 & Anual & 0,044 & 0,041 & $-0,15^{\star \star}$ & $-0,15^{\star *}$ & $0,223^{* *}$ & 0,025 \\
\hline \multirow{2}{*}{$95 \%$} & PPP & 0,051 & 0,112 & $-0,021$ & 0,015 & 0,136 & $-0,108$ \\
\hline & PRE & 0,400 & 0,200 & 0,300 & $-0,300$ & 0,100 & $-0,154$ \\
\hline 2003 & Anual & 0,052 & $-0,052$ & $-0,006$ & $-0,055$ & 0,039 & 0,032 \\
\hline \multirow{2}{*}{$95 \%$} & PPP & 0,045 & 0,189 & $-0,071$ & $-0,020$ & 0,072 & 0,049 \\
\hline & PRE & $-0,060$ & 0,100 & $-0,143$ & $-0,322$ & 0,202 & $0,670^{*}$ \\
\hline 2004 & Anual & 0,010 & $-0,031$ & 0,002 & 0,057 & $-0,042$ & 0,015 \\
\hline \multirow{2}{*}{$95 \%$} & PPP & $-0,120$ & 0,004 & 0,054 & 0,216 & $-0,133$ & $-0,160$ \\
\hline & PRE & $-0,229$ & 0,127 & 0,142 & 0,257 & $-0,319$ & $-0,244$ \\
\hline 2005 & Anual & 0,057 & $-0,121^{*}$ & $-0,077$ & $-0,016$ & $0,117^{*}$ & $0,184^{* *}$ \\
\hline \multirow{2}{*}{$95 \%$} & PPP & 0,235 & $-0,163$ & $-0,259$ & $-0,236$ & 0,160 & 0,117 \\
\hline & PRE & 0,300 & 0,048 & $-0,470^{*}$ & $-0,307$ & $0,371^{*}$ & 0,251 \\
\hline 2006 & Anual & $-0,043$ & $-0,071$ & 0,101 & 0,033 & $-0,033$ & 0,053 \\
\hline \multirow{2}{*}{$95 \%$} & PPP & 0,024 & $-0,505^{\star}$ & 0,257 & 0,299 & $-0,137$ & $-0,381$ \\
\hline & PRE & 0,492 & $-0,047$ & $-0,100$ & 0,353 & $-0,082$ & 0,164 \\
\hline 2007 & Anual & $0,119^{*}$ & $-0,041$ & $-0,14^{* *}$ & $-0,111^{*}$ & $0,145^{\star *}$ & 0,046 \\
\hline \multirow{2}{*}{$95 \%$} & PPP & 0,192 & $-0,056$ & $-0,193$ & $-0,261$ & 0,095 & 0,053 \\
\hline & PRE & 0,356 & $-0,175$ & $-0,429$ & $-0,287$ & 0,280 & $-0,073$ \\
\hline Total & Anual & $0,060 * *$ & $-0,038 *$ & $-0,041$ * & $-0,054 * \star$ & $0,054 * *$ & $0,084 * *$ \\
\hline
\end{tabular}

Tabla 5.2.3.30. Coeficientes de correlación de Spearman entre Tilia y las variables climatológicas. Tmed,

Tmax, Tmin (temperatura media, máxima y mínima), Hrelativa (humedad relativa), Vemed (velocidad media), FrecCalmas (frecuencia de calmas), V1Cuad, V2Cuad, V3Cuad, V4Cuad (vientos procedentes del I, II, III y IV cuadrante). Significación: $95 \%\left({ }^{*}\right), 99 \%\left({ }^{* *}\right)$. (-) Ausencia de correlaciones. 


\subsubsection{Ulmus}

La variación interanual (Fig. 5.2.3.44.) de este tipo polínico en la atmósfera de la ciudad de Salamanca indicó un descenso en los niveles polínicos anuales durante el período 2000-2007, reflejados en los totales anuales: 113 granos de polen del año 2000 y 84 del año 2007 (un 35\% menos), que quedó poco constatado con el análisis de tendencias mediante regresión lineal y su bajo índice de determinación $\left(\mathrm{R}^{2}=0,04\right)$. Por otro lado, el porcentaje de representación sobre el total de pólenes contabilizados en cada anualidad analizada osciló entre el 1\% de los años 2000 y el o,2\% de 2005 y 2006, siendo o,5\% el porcentaje medio.

\section{La variación estacional de} Ulmus, se localizó, principalmente, entre los meses de febrero y marzo (Fig. 5.2.2.17.D.), con una duración media (Tabla 5.2.3.31.), de 42 días en el PPP, que, a lo largo de los ocho años, mostró leves variaciones en las fechas de inicio (29 de enero de $2004-13$
Tipo polínico: Ulmus minor.

Especie(s): Ulmus minor Miller (Ulmaceae) entre otras.

Distribución: Nativo de África, el suroeste de Asia y gran parte de Europa, en la Península lbérica y en la provincia de Salamanca, se encuentra disperso por bordes de caminos, cunetas de carreteras y en plazas, avenidas y parques de numerosas localidades.

Época de floración: De enero a marzo, fundamentalmente.

Polinización: Anemófila.

Morfología polínica (Lámina IV): Polen pentazonoporado (ocasionalmente tetra- o hexaporado), subisopolar y radiosimétrico, con forma circular-penta(tetra-,hexa-)gonal en vista polar y ligeramente elíptico en vista ecuatorial (de suboblato a esferoidal), y un tamaño mediano $(\mathrm{P}=24-30 \mu \mathrm{m})$. Las aberturas simples tipo poro, de $2 \mu \mathrm{m}$ de diámetro, presentan anillo producido por un engrosamiento de la exina. Dicha exina $(1,5 \mu \mathrm{m} ; 2,5 \mu \mathrm{m}$ alrededor de los polos), presenta una superficie rugulada, con gránulos o espínulas sobre las rúgulas. de febrero de 2000) y finalización (14 de marzo de 2007 - 27 de marzo de 2002).

La dinámica que presentaron las concentraciones polínicas de Ulmus (Fig. 5.2.3.45.D.) mostrada a través del porcentaje de representación de la media de los 5 días anteriores promedio con respecto al total promediado, fue la siguiente, con un incremento de las concentraciones desde finales del mes de enero hasta mediados de marzo, que se pone de manifiesto con la concentración más elevada promedio durante los ocho años (3 granos $/ \mathrm{m}^{3}$, el 16 de marzo). Asimismo, las concentraciones diarias más elevadas dentro de los ocho años también presentaron pequeñas variaciones en número y en la fecha en la que se produjeron (Tabla 5.2.3.31.; Fig. 5.2.3.45. A. B. C.), como muestran los 15 granos $/ \mathrm{m}^{3}$ (30 de enero de 2004) y los 8 granos $/ \mathrm{m}^{3}$ (21 de marzo de 2002, 17 de marzo de 2005 y 9 de marzo de 2006). A continuación, los niveles de polen disminuyeron a finales de marzo, con concentraciones anecdóticas en el mes de abril. 


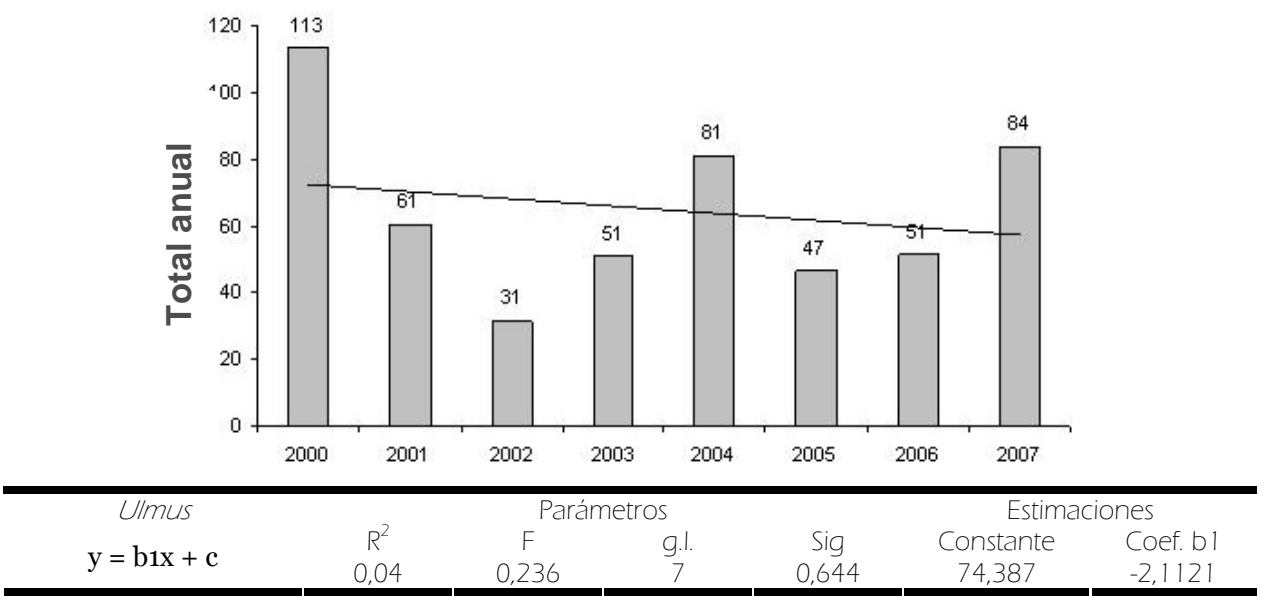

Fig. 5.2.3.44. Evolución anual del número total de pólenes de Ulmus y tendencias (análisis de regresión).

\begin{tabular}{|c|c|c|c|c|c|c|c|c|c|}
\hline UImus & 2000 & 2001 & 2002 & 2003 & 2004 & 2005 & 2006 & 2007 & Media \\
\hline Total & 113 & 61 & 31 & 51 & 81 & 47 & 51 & 84 & 65 \\
\hline Día & 08-mar & 23-mar & 21-mar & 13-mar & 30-ene & 17-mar & 09-mar & 02-mar & 16-mar \\
\hline PPP(días) & 34 & 53 & 46 & 34 & 50 & 40 & 41 & 34 & 42 \\
\hline Inicio & 13-feb & $01-f e b$ & 11 -feb & 20-feb & 29-ene & 11 -feb & 11 -feb & 10-feb & 8-feb \\
\hline Fin & 17-mar & 24-mar & 27-mar & 24-mar & 18-mar & 21-mar & 22-mar & 14-mar & 20-mar \\
\hline
\end{tabular}

Tabla 5.2.3.31. Totales, concentraciones máximas diarias, período principal de polinización (PPP; fecha de inicio y fin) y días precedentes al valor máximo (PRE) durante los ocho años de estudio, y el promedio de todos los parámetros para Ulmus.

La variación intradiaria (Fig. 5.2.3.46.) mostró mayores niveles de polen en las horas centrales del día, fundamentalmente entre las 10 y las 21 horas.

Las temperaturas medias, máximas y mínimas junto a la insolación y los vientos procedentes del IV cuadrante ejercieron una influencia negativas en las concentraciones polínicas de Ulmus durante los ocho años analizados, no existiendo correlaciones positivas significativas con algún parámetro meteorológico analizado, tras realizar el análisis de correlación (Tabla 5.2.3.32.). No obstante, durante el año 2007, si se observaron coeficientes de correlación positivos y significativos, con la velocidad media del viento y los vientos procedentes del III cuadrante, al igual que negativos con la frecuencia de las calmas y los vientos del I cuadrante. Debe también destacarse que, durante ciertos PPP y PRE, se obtuvieron correlaciones de distinto signo al patrón general descrito con la temperatura media y máxima en los años 2002, 2003, 2005 y 2006, e incluso correlaciones negativas significativas con la precipitación y la humedad relativa en 2001, 2002 y 2003. 


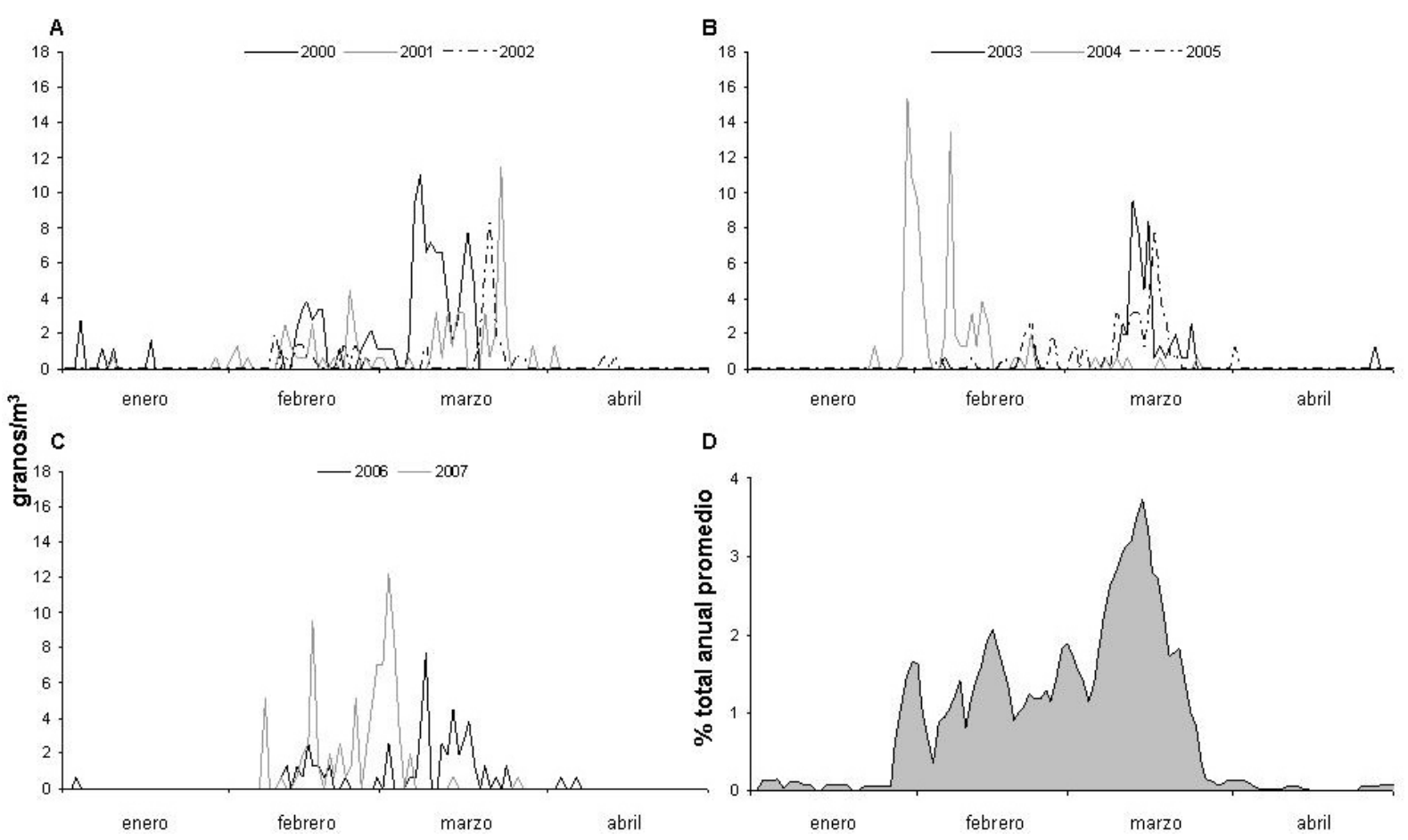

Fig. 5.2.3.45. Variación de las concentraciones medias diarias de Ulmus durante el período 2000-2002 (A), 2003-2005 (B) y 2006-2007 (C). Porcentajes de representación diarios para la media de los cinco días anteriores dentro del promedio de los ocho años analizados (D).

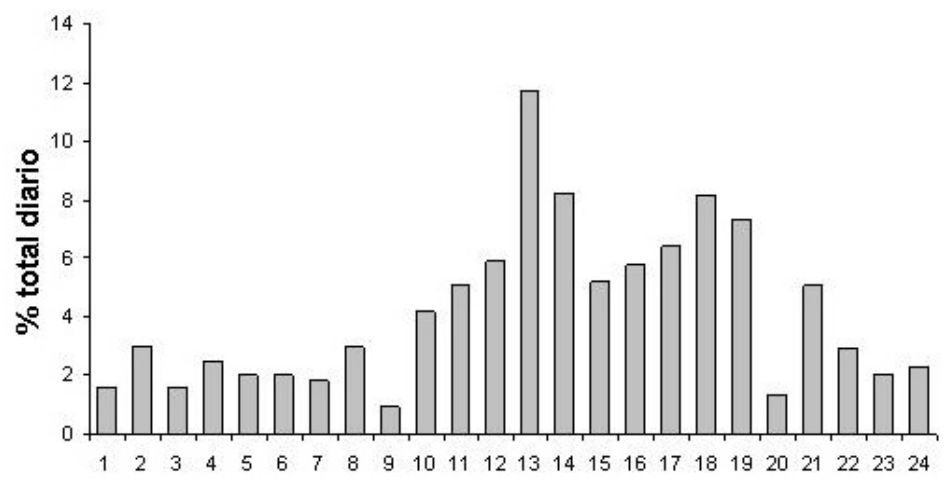

Fig. 5.2.3.46. Variación intradiaria del polen de Ulmus. 


\begin{tabular}{|c|c|c|c|c|c|c|c|}
\hline \multicolumn{2}{|c|}{ UImus } & Tmed & Tmax & Tmin & Insolación & Precipitación & Hrelativa \\
\hline 2000 & Anual & $-0,20$ ** & $-0,062$ & $-0,34$ ** & $-0,010$ & $-0,181^{* \star}$ & $-0,117^{\star}$ \\
\hline \multirow{2}{*}{$95 \%$} & PPP & $0,467 * *$ & $0,463^{* *}$ & 0,261 & $-0,095$ & - & $-0,501$ ** \\
\hline & PRE & 0,099 & 0,176 & 0,084 & $-0,102$ & - & $-0,038$ \\
\hline 2001 & Anual & $-0,17^{* *}$ & $-0,19$ ** & $-0,131^{*}$ & $-0,122^{*}$ & 0,029 & $0,181^{* *}$ \\
\hline \multirow{2}{*}{$95 \%$} & PPP & 0,188 & $0,327^{*}$ & 0,037 & $0,296^{*}$ & $-0,322^{*}$ & $-0,208$ \\
\hline & PRE & 0,168 & $0,303^{*}$ & 0,025 & $0,307 *$ & $-0,359 * *$ & $-0,213$ \\
\hline 2002 & Anual & $-0,16$ ** & $-0,091$ & $-0,25$ ** & $-0,010$ & $-0,122^{\star}$ & $-0,049$ \\
\hline \multirow{2}{*}{$95 \%$} & PPP & $0,322^{*}$ & $0,464 * \star$ & 0,001 & $0,337^{\star}$ & $-0,429 * \star$ & $-0,347^{* *}$ \\
\hline & PRE & 0,220 & $0,415 * *$ & $-0,028$ & 0,222 & $-0,427 * *$ & $-0,294$ \\
\hline 2003 & Anual & $-0,093$ & $-0,033$ & $-0,18^{\star *}$ & $-0,014$ & $-0,045$ & $-0,093$ \\
\hline \multirow{2}{*}{$95 \%$} & PPP & $0,599 * *$ & $0,675^{\star \star}$ & 0,093 & $0,346^{*}$ & $-0,217$ & $-0,709 * \star$ \\
\hline & PRE & $0,525^{\star}$ & $0,486 *$ & $-0,009$ & 0,282 & $-0,088$ & $-0,679 * *$ \\
\hline 2004 & Anual & $-0,18^{* \star}$ & $-0,15^{\star \star}$ & $-0,22^{\star *}$ & $-0,112^{\star}$ & 0,060 & 0,119 \\
\hline \multirow{2}{*}{$95 \%$} & PPP & 0,215 & 0,255 & 0,143 & 0,009 & 0,236 & 0,223 \\
\hline & PRE & - & - & - & - & - & - \\
\hline 2005 & Anual & $-0,17^{\star \star}$ & $-0,125^{\star}$ & $-0,22^{* \star}$ & $-0,095$ & $-0,018$ & $-0,020$ \\
\hline \multirow{2}{*}{$95 \%$} & PPP & $0,571^{* *}$ & $0,524 * \star$ & $0,476^{* \star}$ & $-0,276$ & 0,145 & $-0,246$ \\
\hline & PRE & 0,538 ** & $0,458 * *$ & $0,422^{*}$ & $-0,359$ * & 0,192 & $-0,130$ \\
\hline 2006 & Anual & $-0,23^{* *}$ & $-0,20^{* *}$ & $-0,24$ ** & $0,256^{*}$ & 0,044 & 0,072 \\
\hline \multirow{2}{*}{$95 \%$} & PPP & $0,576 * *$ & $0,595^{\star *}$ & 0,218 & 0,260 & $-0,068$ & $-0,183$ \\
\hline & PRE & $0,543 * *$ & $0,557 * *$ & 0,289 & 0,260 & $-0,119$ & $-0,089$ \\
\hline 2007 & Anual & $-0,129 *$ & $-0,18^{\star \star}$ & $-0,10$ ** & $-0,160$ ** & 0,186 ** & $0,252^{\star *}$ \\
\hline \multirow{2}{*}{$95 \%$} & PPP & 0,269 & 0,080 & 0,311 & $-0,218$ & $-0,016$ & 0,280 \\
\hline & PRE & 0,059 & 0,286 & $-0,016$ & 0,302 & $-0,372$ & $-0,371$ \\
\hline Total & Anual & $-0,17^{* \star}$ & $-0,13^{\star \star}$ & $-0,21^{* *}$ & $-0,084^{\star \star}$ & $-0,019$ & 0,031 \\
\hline
\end{tabular}

\begin{tabular}{|c|c|c|c|c|c|c|c|}
\hline \multicolumn{2}{|c|}{ UImus } & Vemed & FrecCalm & VICuadr & V2Cuadr & V3Cuadr & V4Cuadr \\
\hline 2000 & Anual & $-0,113^{*}$ & $0,161^{* *}$ & $0,171^{* \star}$ & 0,062 & $-0,140^{* *}$ & $-0,048$ \\
\hline \multirow{2}{*}{$95 \%$} & PPP & $-0,093$ & 0,213 & 0,035 & $-0,121$ & 0,030 & $-0,162$ \\
\hline & PRE & $-0,224$ & $0,404^{*}$ & $-0,415^{*}$ & $-0,146$ & 0,285 & 0,173 \\
\hline 2001 & Anual & 0,095 & $-0,080$ & $-0,074$ & $-0,016$ & 0,086 & $-0,122^{*}$ \\
\hline \multirow{2}{*}{$95 \%$} & PPP & $-0,138$ & 0,251 & 0,090 & 0,147 & $-0,164$ & 0,124 \\
\hline & PRE & $-0,173$ & 0,281 & 0,118 & 0,155 & $-0,181$ & 0,098 \\
\hline 2002 & Anual & $-0,081$ & $0,117^{*}$ & $0,154^{* \star}$ & 0,048 & $-0,157^{* *}$ & $-0,175^{\star *}$ \\
\hline \multirow{2}{*}{$95 \%$} & PPP & $-0,439$ * & $0,379 *$ & 0,159 & 0,080 & $-0,225$ & 0,026 \\
\hline & PRE & $-0,43^{* *}$ & $0,340^{*}$ & 0,122 & 0,031 & $-0,177$ & 0,088 \\
\hline 2003 & Anual & $-0,063$ & 0,056 & 0,071 & $0,232^{* *}$ & $-0,066$ & $-0,152^{* *}$ \\
\hline \multirow{2}{*}{$95 \%$} & PPP & $-0,266$ & 0,064 & $0,405^{\star}$ & $0,380^{*}$ & $-0,241$ & $-0,105$ \\
\hline & PRE & $-0,275$ & 0,065 & 0,461 * & 0,409 & $-0,187$ & $-0,100$ \\
\hline 2004 & Anual & $-0,006$ & 0,070 & 0,023 & $0,110^{*}$ & 0,009 & $-0,067$ \\
\hline \multirow{2}{*}{$95 \%$} & PPP & 0,069 & 0,174 & $-0,165$ & $0,326^{*}$ & 0,133 & $-0,277$ \\
\hline & PRE & - & - & - & - & - & - \\
\hline 2005 & Anual & $-0,019$ & $-0,045$ & 0,009 & $0,105^{\star}$ & 0,041 & $-0,043$ \\
\hline \multirow{2}{*}{$95 \%$} & PPP & $-0,237$ & 0,032 & $-0,257$ & 0,259 & 0,185 & 0,006 \\
\hline & PRE & $-0,310$ & 0,136 & $-0,233$ & 0,186 & 0,198 & 0,082 \\
\hline 2006 & Anual & 0,091 & $-0,017$ & $-0,099$ & $-0,020$ & 0,102 & 0,013 \\
\hline \multirow{2}{*}{$95 \%$} & PPP & 0,092 & 0,355 & 0,233 & 0,139 & $-0,222$ & 0,540 \\
\hline & PRE & 0,133 & 0,355 & 0,233 & 0,139 & $-0,222$ & 0,540 \\
\hline 2007 & Anual & $0,252^{\star \star}$ & $-0,287^{\star \star}$ & $-0,28 * \star$ & $-0,038$ & 0,320 ** & $-0,031$ \\
\hline \multirow{2}{*}{$95 \%$} & PPP & 0,077 & $-0,137$ & $-0,249$ & 0,044 & $0,434^{\star}$ & $-0,169$ \\
\hline & PRE & $-0,254$ & 0,158 & 0,184 & 0,208 & $-0,045$ & $-0,157$ \\
\hline Total & Anual & 0,028 & $-0,002$ & $-0,003$ & 0,048 & 0,021 & $-0,077^{* *}$ \\
\hline
\end{tabular}

Tabla 5.2.3.32. Coeficientes de correlación de Spearman entre Ulmus y las variables climatológicas. Tmed,

Tmax, Tmin (temperatura media, máxima y mínima), Hrelativa (humedad relativa), Vemed (velocidad media), FrecCalmas (frecuencia de calmas), V1Cuad, V2Cuad, V3Cuad, V4Cuad (vientos procedentes del I, II, III y IV cuadrante). Significación: 95\%(*), 99\%(**). (-) Ausencia de correlaciones. 


\subsubsection{Vitis}

Los niveles del tipo polínico que incluye a la vid en la atmósfera de Salamanca, no mostraron un patrón regular de crecimiento o decrecimiento, ya que si en el año 2000 no se contabilizó ningún grano de polen, en los años 2004 y 2007 los totales anuales alcanzaron los 10 granos, e incluso valores totales de 102 y 98, de los años 2002 y 2005, respectivamente. Todo ello supuso que la variación interanual (Fig. 5.2.3.47.) llevase consigo un índice de determinación muy bajo $\left(\mathrm{R}^{2}=\mathrm{O}, \mathrm{O} 1\right)$, propio del análisis de regresión de tipo lineal. La representación media de los pólenes de este género botánico a lo largo de los ocho años fue de $0,3 \%$, con un máximo de $1,3 \%$ en 2002 y un porcentaje inferior a $0,1 \%$ en 2007.

La distribución de estos granos de polen a lo largo de los años estudiados se localizó entre mediados-finales de mayo e inicios de agosto, por lo que la variación estacional (Tabla 5.2.3.33.) tuvo un PPP promedio de 70 días, con diferencias en la fecha de inicio (14 de mayo de $2005-5$ de julio de 2001) y finalización (14 de julio de 2002 - 20 de agosto de 2005).

Los niveles polínicos de Vitis en la atmósfera de la ciudad de Salamanca (Fig. 5.2.3.48.D.) comenzaron a aumentar a partir de mediados de mayo, alcanzando las concentraciones más elevadas a finales de este mes, como muestra el valor medio más elevado en los años analizados ( 2 granos $/ \mathrm{m}^{3}$ el 30 de mayo), mediante la dinámica aportada por el porcentaje de representación que tuvieron las concentraciones medias de los cincos días anteriores para el total promediado del conjunto de anualidades estudiadas. En todo caso, las mayores concentraciones diarias registradas dentro del período 2001-2007 (Tabla 5.2.3.33.), oscilaron entre los 8 granos $/ \mathrm{m}^{3}$ (30 de mayo de 2000) y los 2 granos $/ \mathrm{m}^{3}$ (25 de

\section{Tipo polínico: Vitis vinifera. \\ Especie(s): Vitis vinifera L. (Vitaceae).}

Distribución: Se trata de una antigua planta de cultivo de la que se conocen numerosas variedades, siendo uno de los tipos originarios la variedad sylvestris, que se cría en sotos ribereños de la región mediterránea y en muchos de los ríos de Europa central y occidental. En la Península lbérica, al igual que en la provincia de Salamanca, las numerosas variedades de cultivo también se localizan, principalmente, en las proximidades de las riberas fluviales con cierto grado de continentalidad.

Época de floración: Finales de primavera e inicios de verano.

Polinización: Anemófila, secundariamente entomófila.

Morfología polínica (Lámina IV): Polen trizonocolpado, isopolar y radiosimétrico, con forma triangular en vista polar y elíptica en vista ecuatorial (de prolato a suboblato), y un tamaño pequeño $(P=17-24 \mu \mathrm{m})$. Ectoaberturas tipo colpo terminales, y endoaberturas tipo poro de $2 \mu \mathrm{m}$ de diámetro. La exina, de grosor medio $(2 \mu \mathrm{m})$, presenta una superficie ondulada y perforada, con perforaciones alargadas en las zonas interaberturales. 
julio de 2004, 11 de julio de 2006). Posteriormente, estos niveles disminuyeron durante el mes de julio, presentándose en niveles bajos durante agosto, con un ligero incremento en las primeras semanas de septiembre, y desapareciendo de la atmósfera a finales de septiembre (Fig. 5.2.3.48.A. B. C.).

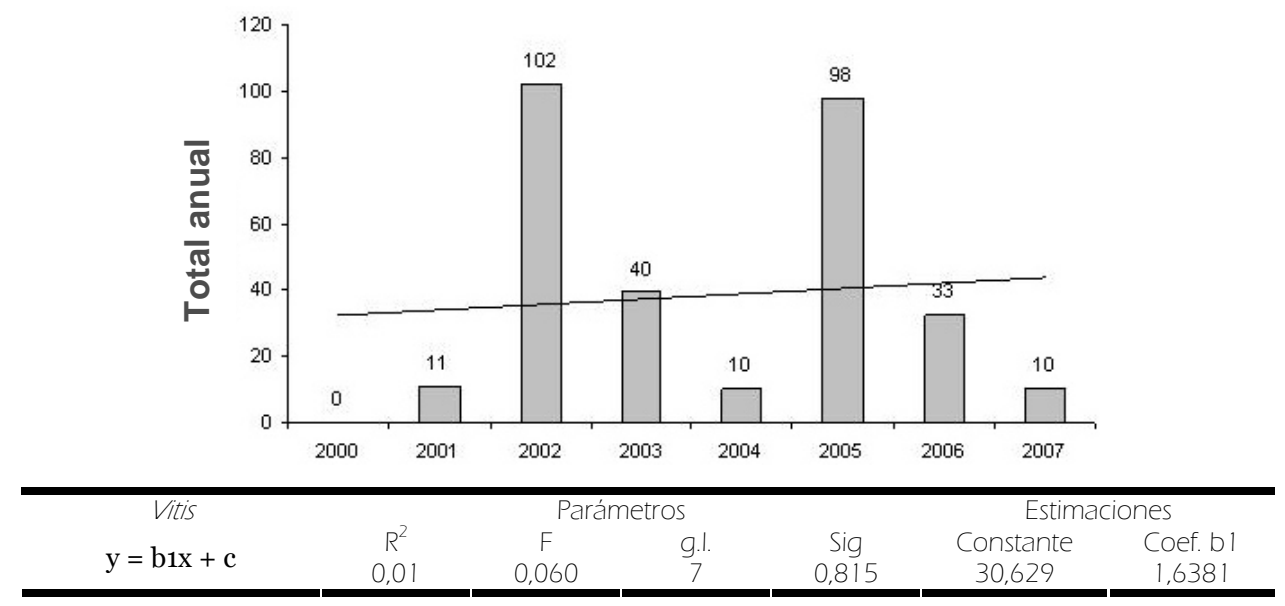

Fig. 5.2.47. Evolución anual del número total de pólenes de Vitis y tendencias (análisis de regresión).

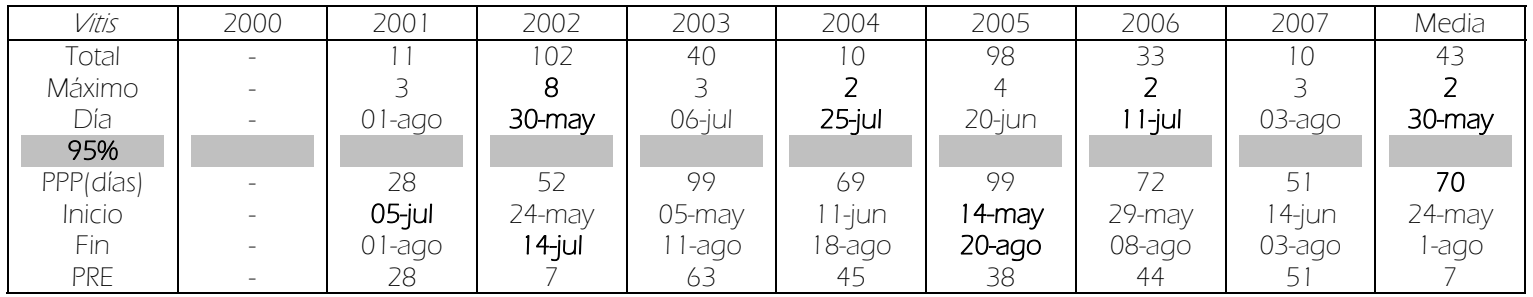

Tabla 5.2.3.33. Totales, concentraciones máximas diarias, período principal de polinización (PPP; fecha de inicio y fin) y días precedentes al valor máximo (PRE) durante los ocho años de estudio (salvo los años con bajo número anual o sin presencia de este tipo), y el promedio de todos los parámetros para Vitis.

La variación intradiaria (Fig. 5.2.3.49.) mostró una distribución algo irregular, aunque con mayores niveles entre las 10 y las 21 horas, que supusieron el $65 \%$ de las concentraciones a lo largo de un día promedio para los últimos tres años estudiados .

El análisis de correlación (Tabla 5.2.3.34.) mostró que las temperaturas medias, máximas y mínimas, junto a la insolación y, en menor medida, los vientos procedentes del IV cuadrante, influyeron positivamente en los niveles polínicos durante los ocho años analizados, mientras que la precipitación, la humedad relativa, la frecuencia de las calmas y los vientos del II cuadrante tuvieron un efecto negativo, pese a que algunos de ellos presentasen coeficientes de correlación bajos. Este patrón se mantuvo en un buen número de años analizados, no mostrando valores significativos a lo largo de los PPP y PRE definidos en dichas anualidades, salvo en el PRE del año 2002, con la temperatura media, máxima y mínima. 


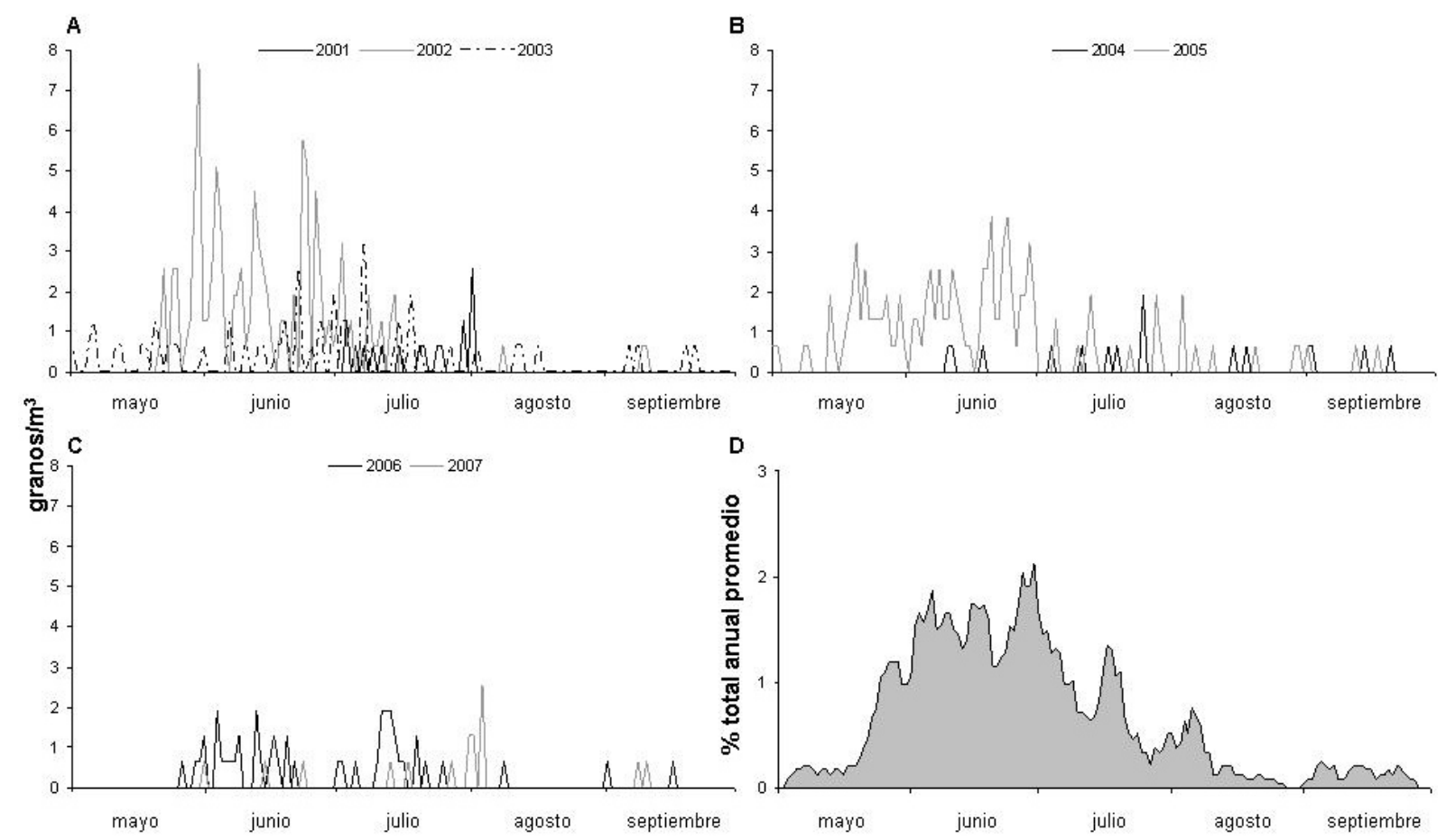

Fig. 5.2.3.48. Variación de las concentraciones medias diarias de Vitis durante el período 2001-2003 (A), 20042005 (B) y 2006-2007 (C). Porcentajes de representación diarios para la media de los cinco días anteriores dentro del promedio de los ocho años analizados (D).

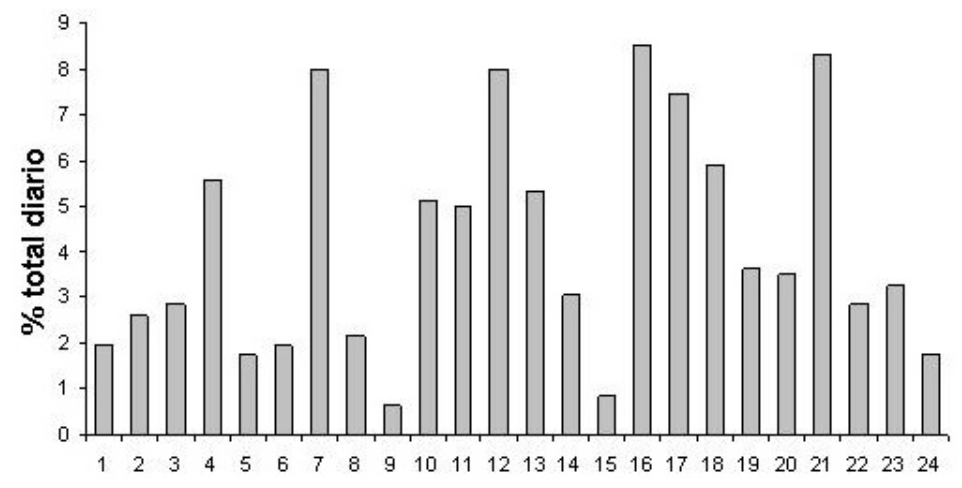

Fig. 5.2.3.49. Variación intradiaria del polen de Vitis. 


\begin{tabular}{|c|c|c|c|c|c|c|c|}
\hline \multicolumn{2}{|c|}{ Vitis } & Tmed & Tmax & Tmin & Insolación & Precipitación & Hrelativa \\
\hline 2001 & Anual & $0,210^{* *}$ & $0,202^{* *}$ & $0,203^{* *}$ & $0,147^{* *}$ & 0,030 & $-0,152^{* \star}$ \\
\hline \multirow{2}{*}{$95 \%$} & PPP & 0,047 & 0,005 & $-0,003$ & 0,004 & 0,079 & 0,015 \\
\hline & PRE & 0,047 & 0,005 & $-0,003$ & 0,004 & 0,079 & 0,015 \\
\hline 2002 & Anual & $0,364^{* *}$ & $0,353^{* *}$ & $0,341^{* *}$ & $0,359^{* *}$ & $-0,101$ & $-0,370^{* *}$ \\
\hline \multirow{2}{*}{$95 \%$} & PPP & 0,058 & $-0,015$ & 0,123 & $-0,091$ & $-0,127$ & $-0,078$ \\
\hline & PRE & 0,901 ** & $0,847^{* *}$ & $0,883^{* *}$ & - & - & - \\
\hline 2003 & Anual & $0,334^{* *}$ & $0,313^{* *}$ & $0,321^{* *}$ & 0,256 ** & $-0,155^{\star \star}$ & $-0,327$ ** \\
\hline \multirow{2}{*}{$95 \%$} & PPP & $-0,058$ & $-0,108$ & 0,023 & $-0,076$ & $-0,078$ & 0,028 \\
\hline & PRE & 0,088 & $-0,003$ & 0,161 & $-0,083$ & $-0,088$ & $-0,114$ \\
\hline 2004 & Anual & $0,242^{* *}$ & $0,226^{* *}$ & $0,250^{* *}$ & $0,145^{\star *}$ & $-0,010$ & $-0,175^{\star *}$ \\
\hline \multirow{2}{*}{$95 \%$} & PPP & 0,079 & 0,080 & 0,121 & $-0,035$ & 0,018 & $-0,064$ \\
\hline & PRE & 0,125 & 0,133 & 0,170 & $-0,127$ & $-0,065$ & $-0,029$ \\
\hline 2005 & Anual & $0,477^{* \star}$ & $0,436^{* \star}$ & $0,456^{* *}$ & $0,375^{\star *}$ & $-0,093$ & $-0,450$ ** \\
\hline \multirow{2}{*}{$95 \%$} & PPP & $-0,118$ & $-0,211^{*}$ & $-0,044$ & $-0,028$ & 0,137 & 0,145 \\
\hline & PRE & 0,315 & 0,294 & 0,257 & 0,147 & $-0,188$ & $-0,260$ \\
\hline 2006 & Anual & $0,370^{* *}$ & $0,358^{* *}$ & $0,365^{* *}$ & - & $-0,005$ & $-0,321^{* *}$ \\
\hline \multirow{2}{*}{$95 \%$} & PPP & $-0,013$ & $-0,019$ & 0,130 & - & $0,312^{\star \star}$ & $-0,007$ \\
\hline & PRE & $-0,044$ & $-0,012$ & 0,047 & - & $0,347^{*}$ & $-0,187$ \\
\hline 2007 & Anual & $0,210^{* *}$ & $0,203^{* *}$ & $0,194^{\star *}$ & $0,138^{* *}$ & $-0,036$ & $-0,171^{\star *}$ \\
\hline \multirow{2}{*}{$95 \%$} & PPP & 0,211 & 0,216 & 0,205 & $-0,087$ & $-0,024$ & $-0,066$ \\
\hline & PRE & 0,211 & 0,216 & 0,205 & $-0,087$ & $-0,024$ & $-0,066$ \\
\hline Total & Anual & $0,327^{* *}$ & $0,304^{\star *}$ & $0,316^{* *}$ & $0,243^{* *}$ & $-0,066^{* *}$ & $-0,274^{* *}$ \\
\hline
\end{tabular}

\begin{tabular}{|c|c|c|c|c|c|c|c|}
\hline \multicolumn{2}{|c|}{ Vitis } & Vemed & FrecCalm & VICuadr & V2Cuadr & V3Cuadr & V4Cuadr \\
\hline 2001 & Anual & $-0,043$ & $-0,046$ & 0,027 & 0,036 & $-0,019$ & $0,107^{*}$ \\
\hline \multirow{2}{*}{$95 \%$} & PPP & $-0,133$ & $-0,064$ & 0,241 & 0,254 & 0,012 & $-0,298$ \\
\hline & PRE & $-0,133$ & $-0,064$ & 0,241 & 0,254 & 0,012 & $-0,298$ \\
\hline 2002 & Anual & 0,068 & $-0,076$ & $-0,058$ & $-0,167^{* *}$ & 0,032 & $0,148^{* *}$ \\
\hline \multirow{2}{*}{$95 \%$} & PPP & $-0,162$ & 0,158 & $-0,093$ & 0,077 & 0,059 & $-0,001$ \\
\hline & PRE & $-0,541$ & 0,676 & $0,809 *$ & $0.809 *$ & $-0,845^{*}$ & 0,673 \\
\hline 2003 & Anual & 0,067 & $-0,095$ & $-0,118^{*}$ & $-0,130^{*}$ & 0,094 & $0,195^{* *}$ \\
\hline \multirow{2}{*}{$95 \%$} & PPP & 0,143 & $-0,133$ & $-0,178$ & $-0,181$ & 0,182 & 0,182 \\
\hline & PRE & 0,155 & $-0,092$ & $-0,222$ & $-0,221$ & 0,134 & 0,297 * \\
\hline 2004 & Anual & $0,117^{*}$ & 0,028 & $-0,062$ & $-0,010$ & 0,035 & $0,154^{* *}$ \\
\hline \multirow{2}{*}{$95 \%$} & PPP & 0,190 & 0,112 & $-0,095$ & 0,042 & $-0,040$ & 0,125 \\
\hline & PRE & 0,266 & 0,165 & $-0,127$ & 0,105 & $-0,021$ & 0,181 \\
\hline 2005 & Anual & 0,085 & $-0,145^{* *}$ & $-0,047$ & $-0,040$ & 0,088 & $0,169 * *$ \\
\hline \multirow{2}{*}{$95 \%$} & PPP & 0,144 & $-0,081$ & $-0,222^{*}$ & 0,130 & $0,227^{*}$ & 0,179 \\
\hline & PRE & 0,276 & $-0,012$ & $-0,111$ & 0,137 & 0,087 & 0,036 \\
\hline 2006 & Anual & $-0,103^{*}$ & $-0,135^{\star}$ & $0,127^{*}$ & 0,018 & $-0,047$ & 0,073 \\
\hline \multirow{2}{*}{$95 \%$} & PPP & $-0,151$ & $-0,117$ & 0,212 & 0,162 & $-0,092$ & $-0,194$ \\
\hline & PRE & $-0,263$ & $-0,040$ & 0,235 & 0,229 & $-0,224$ & $-0,216$ \\
\hline 2007 & Anual & $-0,014$ & 0,036 & $-0,072$ & $-0,064$ & 0,052 & 0,082 \\
\hline \multirow{2}{*}{$95 \%$} & PPP & $-0,099$ & 0,135 & 0,031 & 0,074 & $-0,082$ & 0,082 \\
\hline & PRE & $-0,099$ & 0,135 & 0,031 & 0,074 & $-0,082$ & 0,082 \\
\hline Total & Anual & 0,009 & $-0,088^{* *}$ & $-0,028$ & $-0,040^{*}$ & 0,039 & $0,125^{\star}$ \\
\hline
\end{tabular}

Tabla 5.2.3.34. Coeficientes de correlación de Spearman entre Vitis y las variables climatológicas. Tmed,

Tmax, Tmin (temperatura media, máxima y mínima), Hrelativa (humedad relativa), Vemed (velocidad media), FrecCalmas (frecuencia de calmas), V1Cuad, V2Cuad, V3Cuad, V4Cuad (vientos procedentes del I, II, III y IV cuadrante). Significación: $95 \%\left({ }^{*}\right), 99 \%(* *)$. (-) Ausencia de correlaciones. 


\subsubsection{Tipos de polen con una representación superior o igual al 0,5\% (al menos 1año)}

\subsubsection{Betula}

La variación interanual (Fig. 5.2.4.1.) nos indica que durante los ocho años de estudio hubo un incremento en las concentraciones de este tipo de polen en la atmósfera de la ciudad de Salamanca, pues, el total anual aumentó desde los 15 a los 150 pólenes, suponiendo un $900 \%$ en todo el período estudiado, refrendado por el análisis de tendencias a través de la regresión lineal $\left(\mathrm{R}^{2}=0,79\right) . \quad \mathrm{La}$ representación media de los pólenes de este género botánico a lo largo de los ocho años fue de $0,4 \%$, con un máximo de $0,7 \%$ en 2005 y un mínimo de 0,1\% en 2000 y 2003.

\section{La variación estacional,} analizada a partir del PPP obtenido a través del 95\% de cada uno de los totales anuales (Tabla 5.2.4.1) mostró una delimitación entre finales de marzo y mediados de mayo, con una duración media de 51 días. El comienzo de este PPP experimentó una variación de aproximadamente un mes (18 de marzo de 2005 - 14 abril de 2007), al igual que la fecha de finalización (5 de mayo de 2006 - 12 de junio de 2007).

Los niveles polínicos de este género botánico en la atmósfera de la ciudad de
Tipo de polen: Betula spp.

Especie(s): Betula alba L., Betula pendula Roth, entre otros (Betulaceae).

Distribución: Género ampliamente distribuido por las regiones templadas y frías del hemisferio Norte. En la Península Ibérica, se extiende al norte, $y$ en el caso de Betula pendula Roth subsp. fontqueri, por el centro y el sureste. En la provincia de Salamanca, existen ejemplares silvestres de Betula alba L., aislados o formando pequeños grupos en las sierras meridionales, encontrándose también cultivado como ornamental en la capital.

Época de floración: Primavera, variando en función de la latitud.

Polinización: Anemófila.

Morfología polínica (Lámina l): Polen trizonocolporado, isopolar y radiosimétrico, con una forma triangular angulaberturada en vista polar y elíptica en vista ecuatorial (suboblato), y un tamaño pequeño-mediano $(\mathrm{P}=18-28 \mu \mathrm{m})$. Las ectoaberturas tipo colpo 0 poro y endoaberturas casi coincidentes con las ectoaberturas, con vestíbulo. La exina $(1-2 \mu \mathrm{m})$ posee una superficie de verrucosa a rugulada, con microverrugas y microespínulas que, en ocasiones, se conectan entre sí formando pequeñas rúgulas. Salamanca (Fig. 5.2.4.2.D.), aumentaron a finales de marzo hasta alcanzar los valores más elevados a mediados de abril, como muestra el valor medio más elevado en los años analizados (11 granos/m³ el 14 de abril), gracias a la dinámica aportada por el porcentaje de representación que tuvieron las concentraciones medias de los cincos días anteriores para el total promediado del conjunto de años estudiados (Tabla 5.2.4.1). Asimismo, las mayores 
concentraciones diarias registradas dentro de este período oscilaron entre los 75 granos $/ \mathrm{m}^{3}$ (14 de abril de 2005), y los 2 granos/m³ (9 de abril de 2003). Posteriormente, estos niveles disminuyeron a finales de abril, manteniéndose en la atmósfera durante el mes de mayo y la primera mitad del mes de junio (Fig. 5.2.4.2. A. B. C.).

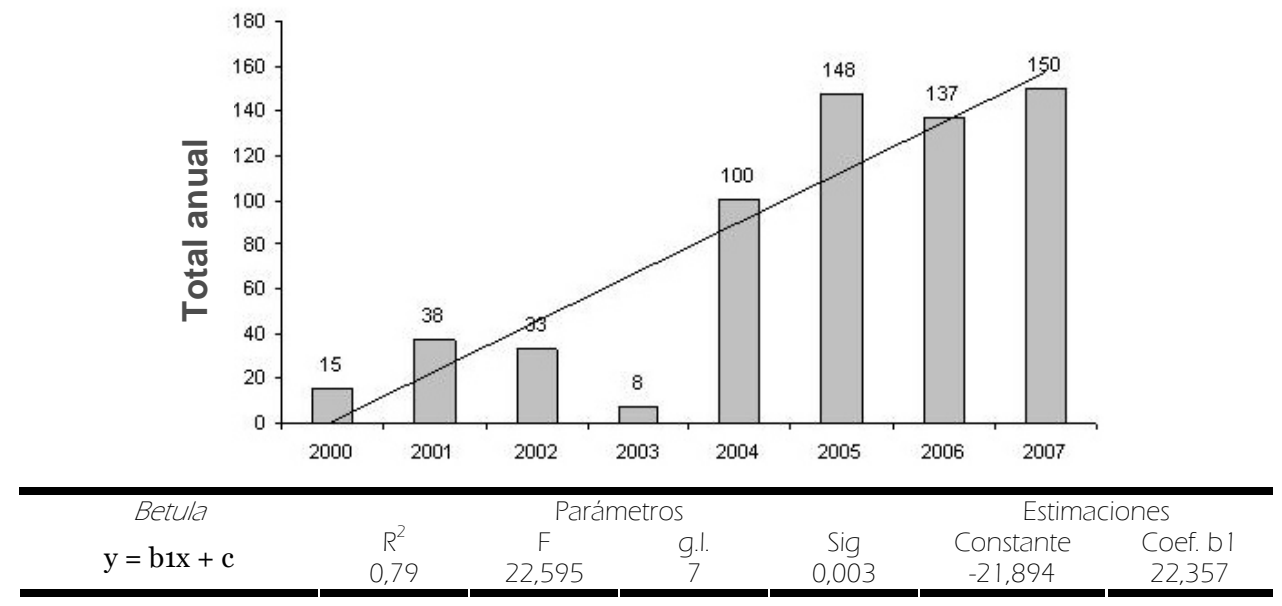

Fig. 5.2.4.1. Evolución anual del número total de pólenes de Betula y tendencias (análisis de regresión).

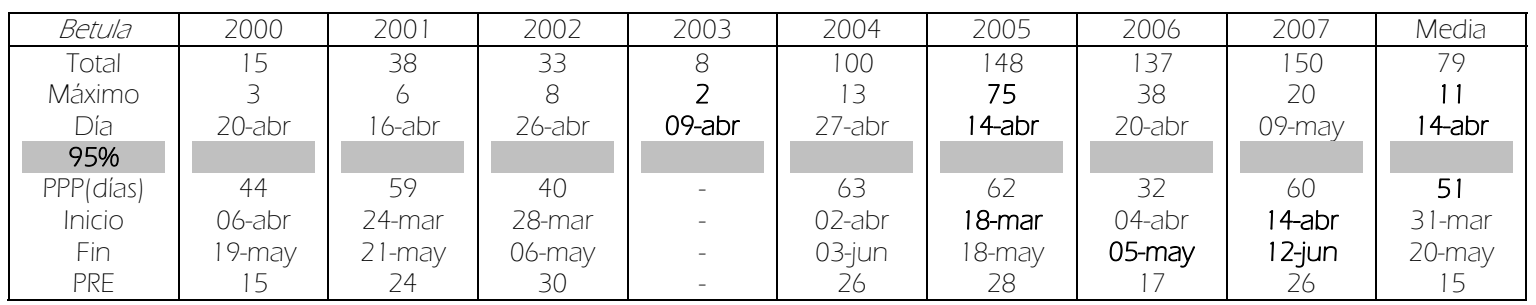

Tabla 5.2.4.1. Totales, concentraciones máximas diarias, período principal de polinización (PPP; fecha de inicio y fin) y días precedentes al valor máximo (PRE) durante los ocho años de estudio (salvo los años con bajo número anual o sin presencia de este tipo), y el promedio de todos los parámetros para Betula.

La variación intradiaria (Fig. 5.2.4.3.), presentada con un día promedio durante los años 2005, 2006 y2007, registró mayores niveles en la primera mitad del día, a causa de un incremento en estos niveles desde las 5 horas hasta las 12 horas, descendiendo su representación porcentual desde el mediodía hasta las 21 horas. 


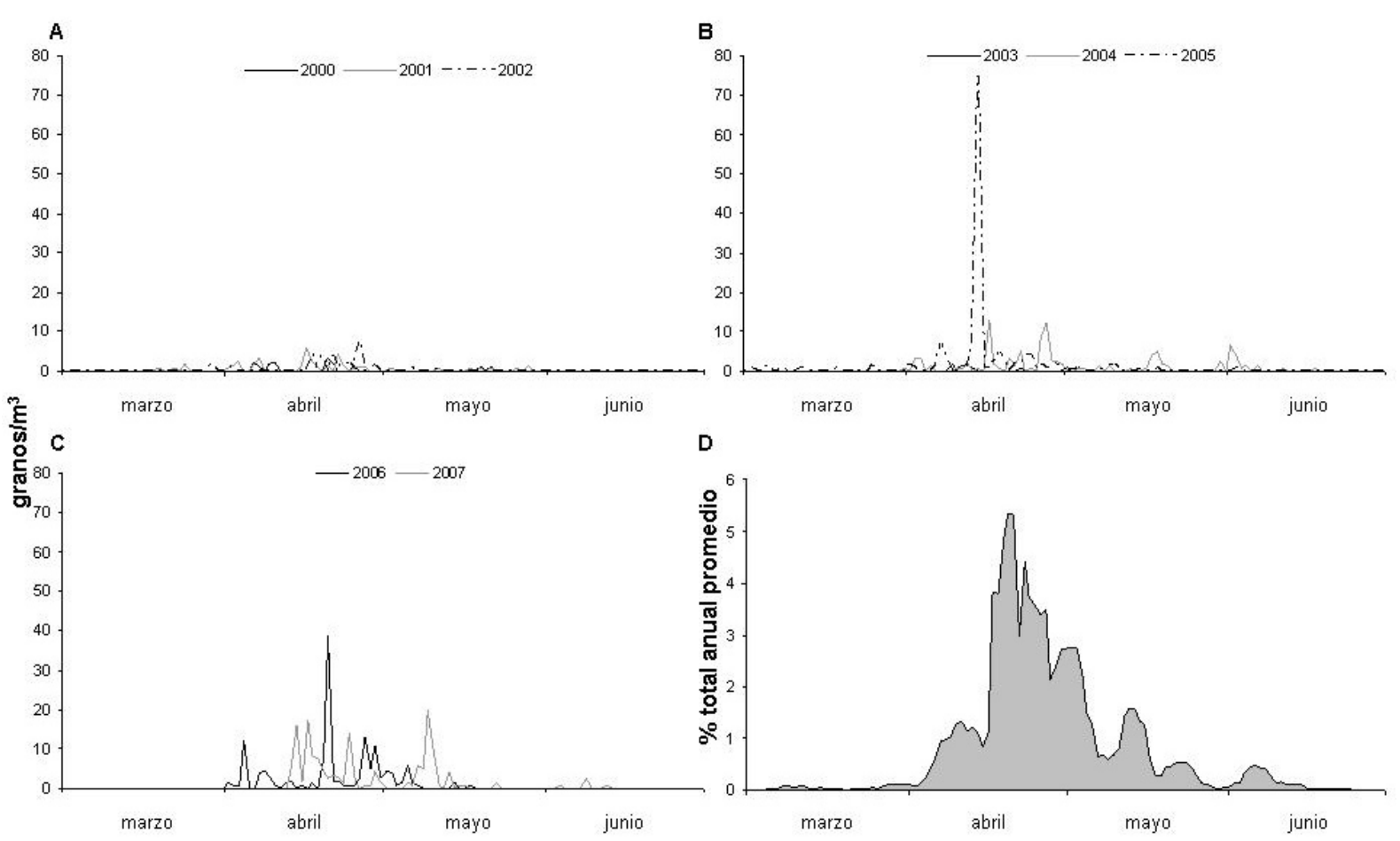

Fig. 5.2.4.2. Variación de las concentraciones medias diarias de Betula durante el período 2000-2002 (A), 2003-2005 (B) y 2006-2007 (C). Porcentajes de representación diarios para la media de los cinco días anteriores dentro del promedio de los ocho años analizados (D).

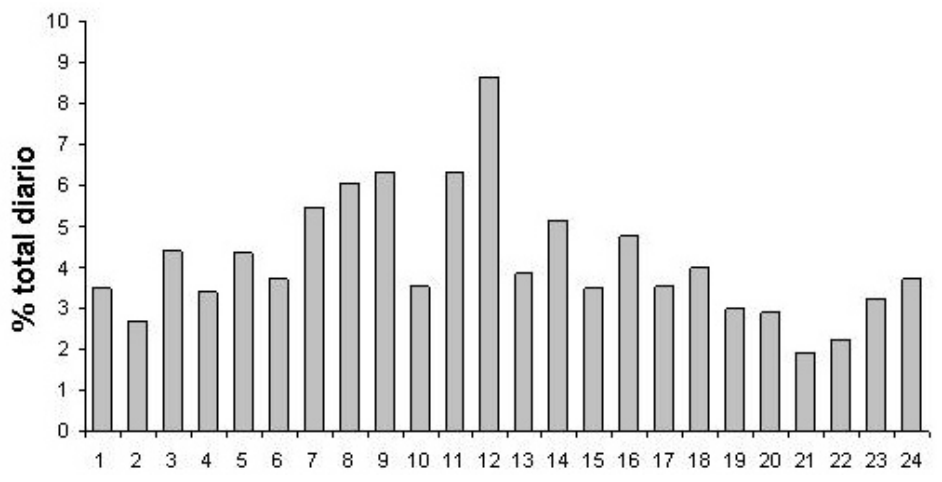

Fig. 5.2.4.3. Variación intradiaria del polen de Betula. 


\subsubsection{Cedrus}

El tipo de polen que incluye al género Cedrus L. experimentó un aumento en sus niveles polínicos durante el período analizado, con una variación interanual (Fig. 5.2.4.4.) que pasó de un total de 19 granos de polen en el año 2000 a los 62 del año 2006, si bien en el último año estudiado, no sobrepasó los 15. Por ello, el índice de determinación $\left(\mathrm{R}^{2}=0,19\right)$, propio de la regresión lineal, indicó una leve tendencia al incremento. Los porcentajes de representación sobre el total de pólenes contabilizados en cada anualidad estudiada variaron del o,6\% de 2003 a un porcentaje inferior al $0,1 \%$ en 2007 , siendo $0,2 \%$ su porcentaje medio.

La distribución de estos granos de polen a lo largo del año se localizó entre finales de septiembre hasta mediados de noviembre, por lo que la variación estacional (Tabla 5.2.4.2.) tuvo un PPP promedio de 53 días, con diferencias mayores en las fechas de inicio (3 de septiembre de 2007 - 16 de octubre de 2001) que en las de finalización (3 de
Tipo de polen: Cedrus spp.

Especie(s): Cedrus atlantica (Endl.) Carrière, Cedrus deodara (D. Don) G. Don fil., y Cedrus libani A. Richard (Pinaceae), principalmente.

Distribución: Género propio del hemisferio Norte, con diferente origen en función de la especie: norte de África (C. atlantica), Afganistán y noreste del Himalaya (C. deodara) o Líbano, Siria o Turquía oriental (C. libani). En la provincia de Salamanca, además de un reducido uso forestal, ha sido cultivado como ornamental en algunos núcleos de población como la ciudad de Salamanca.

Época de floración: Entre octubre y diciembre. Polinización: Anemófila.

Morfología polínica (Lámina I): Polen analeptomado con dos vesículas aeríferas laterales, heteropolar y bisimétrico, con forma elíptica en vista polar y plano-convexa en vista ecuatorial (de oblato a oblato-esferoidal), y un tamaño grande $(P=37-52 \mu \mathrm{m})$. La abertura tipo leptoma está situado en el polo distal. La exina, de grosor medio-grueso $(2,5-3,5 \mu \mathrm{m})$, presenta una superficie granulado-verrugosa, que en las vesículas aeríferas asemeja un retículo alveolado al microscopio óptico. noviembre de 2000 - 21 de noviembre de 2003) para los diferentes años incluidos.

Los niveles polínicos de este género en la atmósfera de la ciudad de Salamanca (Fig. 5.2.4.5.D.) experimentaron un ascenso a finales de septiembre hasta finales de octubre, momento en el que se alcanzó el valor medio más elevado en los años analizados (2 granos $/ \mathrm{m}^{3}$ el 25 de octubre, gracias al porcentaje de representación que alcanzó la media de los cincos días anteriores para el total promediado en el conjunto de anualidades. Asimismo, las mayores concentraciones diarias registradas en los ocho años estudiados tuvieron pequeñas oscilaciones cronológicas (Tabla 5.2.4.2.), con valores entre un único grano por $\mathrm{m}^{3}$ (varios días de 2002) y los 17 granos/m³ (25 de octubre de 2006). En todo caso, estos niveles 
disminuyeron durante el mes de noviembre, con concentraciones anecdóticas en diciembre (Fig. 5.2.4.5. A. B. C.).

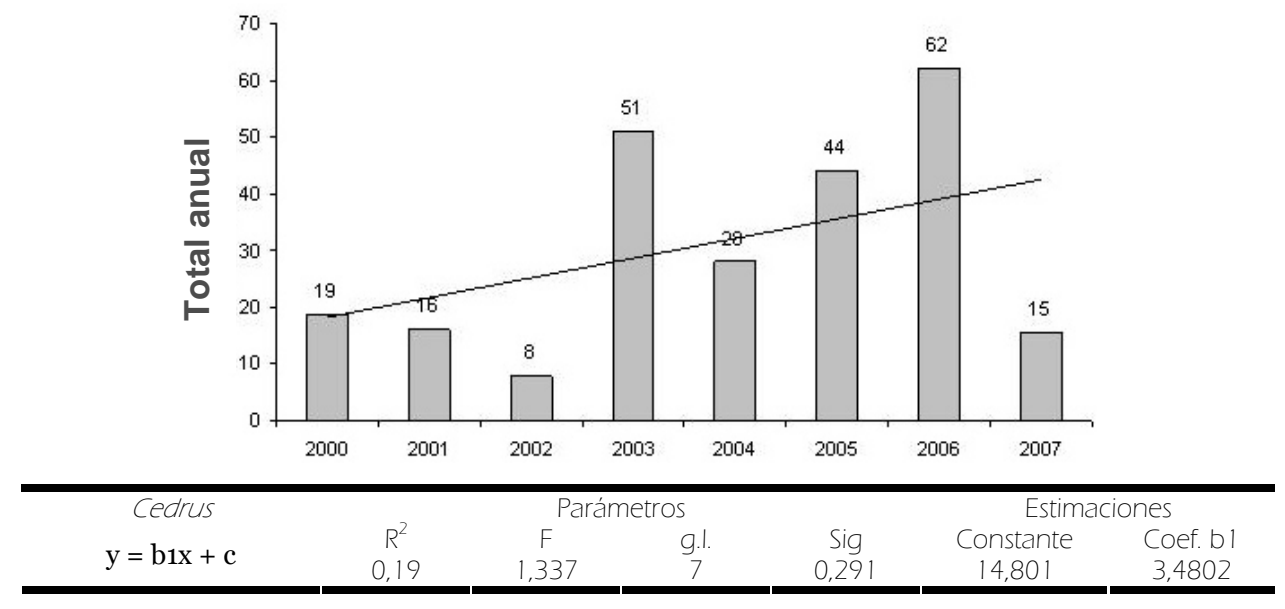

Fig. 5.2.4.4. Evolución anual del número total de pólenes de Cedrus y tendencias (análisis de regresión).

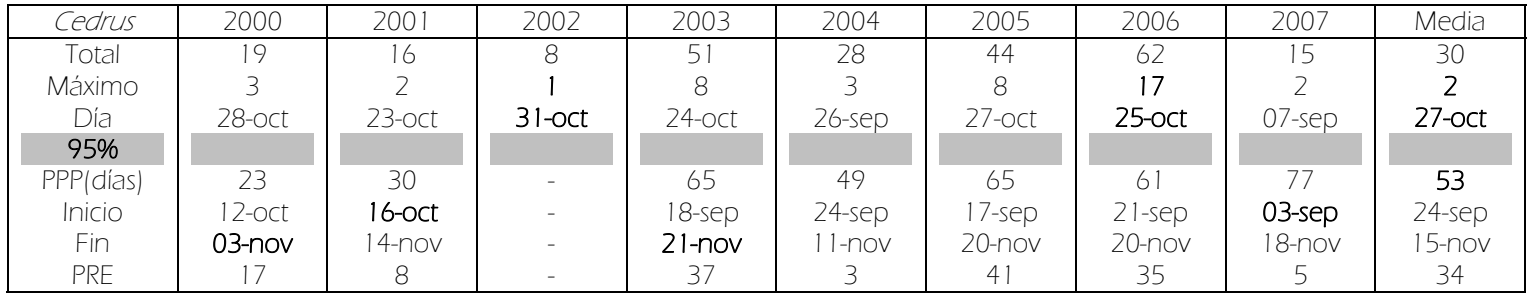

Tabla 5.2.4.2. Totales, concentraciones máximas diarias, período principal de polinización (PPP; fecha de inicio y fin) y días precedentes al valor máximo (PRE) durante los ocho años de estudio (salvo los años con bajo número anual o sin presencia de este tipo), y el promedio de todos los parámetros para Cedrus.

La variación intradiaria (Fig. 5.2.4.6.), a lo largo de un día promedio para los últimos tres años estudiados, mostró que los mayores niveles de polen del género Cedrus en la atmósfera de Salamanca se localizaron entre las 8 y las 18 horas, pues en esta franja horaria se concentró el $65 \%$ del total diario promediado. Consiguientemente, la presencia de este tipo de polen disminuyó desde las 19 horas hasta medianoche. 


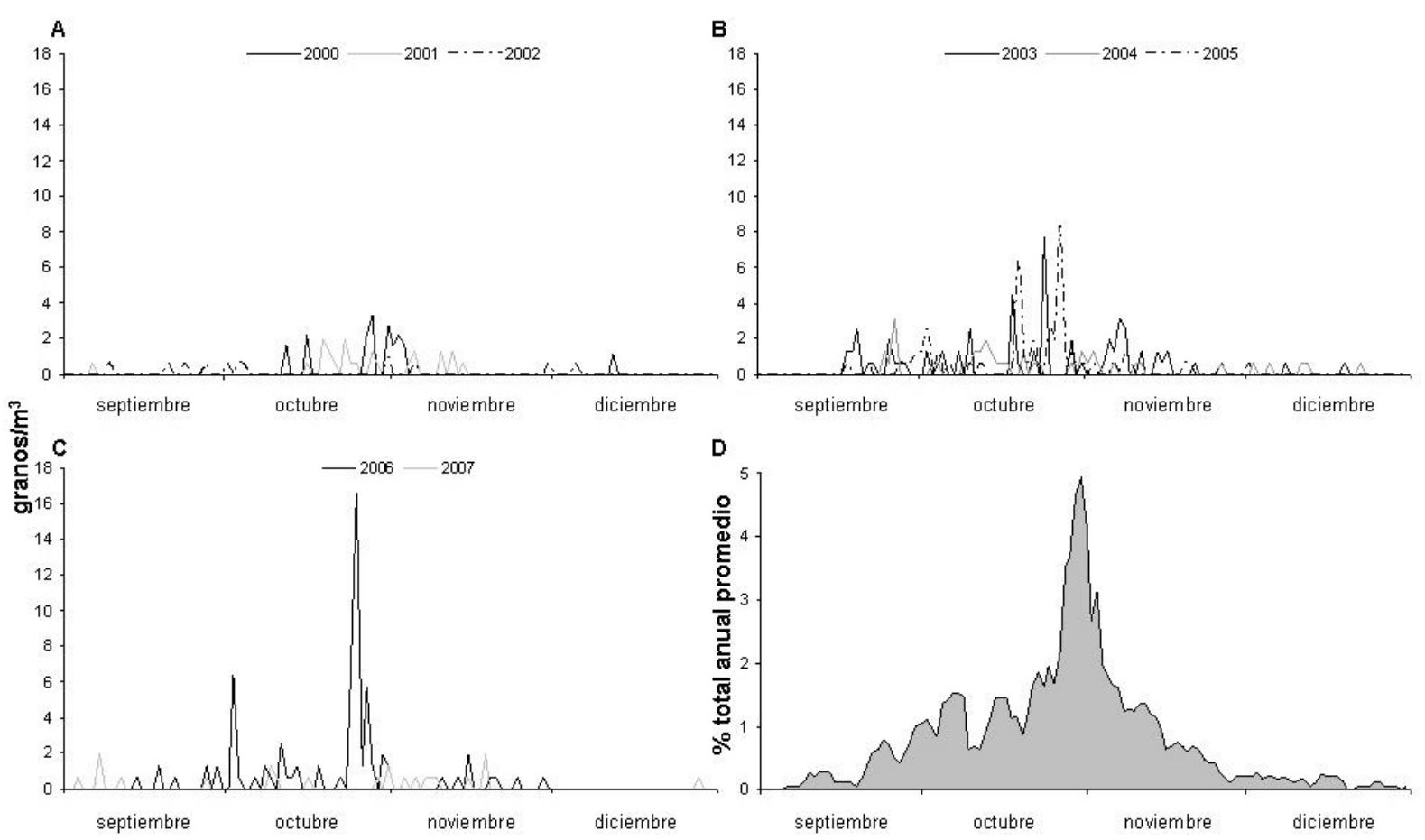

Fig. 5.2.4.5. Variación de las concentraciones medias diarias de Cedrus durante el período 2000-2002 (A), 2003-2005 (B) y 2006-2007 (C). Porcentajes de representación diarios para la media de los cinco días anteriores dentro del promedio de los ocho años analizados (D).

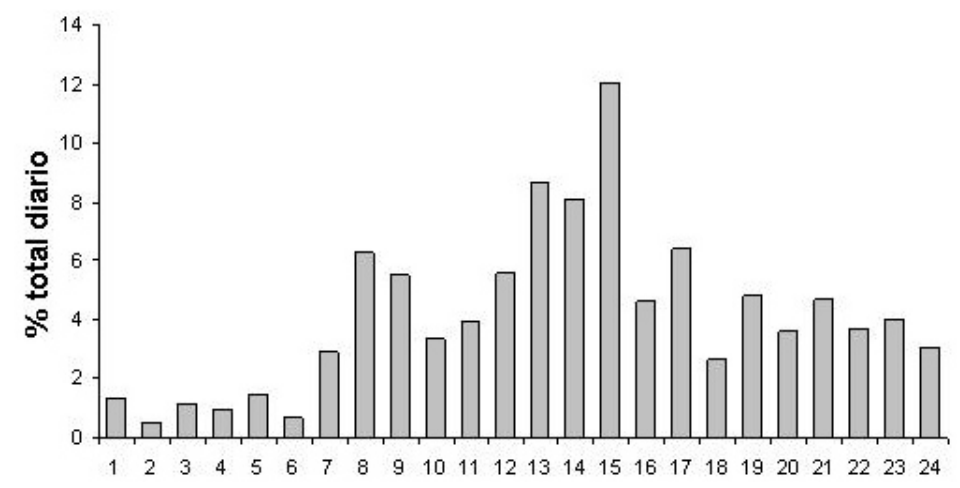

Fig. 5.2.4.6. Variación intradiaria del polen de Cedrus. 


\subsubsection{Cytisus}

\section{La variación interanual (Fig.} 5.2.4.7.) de este tipo polínico en la atmósfera de la ciudad de Salamanca indicó un incremento en los niveles polínicos anuales durante el período 2000-2007, con un máximo anual de 206 pólenes en el año 2005 y un mínimo de 24 en 2002, si bien no se contabilizó ningún grano en el año 2000. Esto supuso un índice de determinación bajo $\left(\mathrm{R}^{2}=0,14\right)$, tras aplicar el análisis de tendencias mediante regresión lineal. Por otro lado, el porcentaje de representación sobre el total de pólenes contabilizados en el período 2001-2007, osciló entre el 0,1\% del año 2007 al 0,9\% de 2005, siendo 0,4\% el porcentaje medio para los ocho años.

\section{La variación estacional de} Cytisus en la atmósfera de Salamanca, (Tabla 5.2.4.3.), abarcó desde mediadosfinales de marzo hasta mediados de junio, con una duración media del PPP de 91 días que, a su vez, presentó pequeñas variaciones en sus fechas de inicio (11 de marzo de 2007 - 29 de marzo de 2002), mayores en las de finalización (16 de mayo de 2002 - 21 de julio de 2007).

La dinámica que presentaron las
Tipo polínico: Cytisus scoparius.

Especie(s): Varias especies de los géneros Adenocarpus DC., Cytisus L., Genista L., Retama Boiss., Spartium L. o Ulex L., (Fabaceae), entre otros.

Distribución: Género localizados en ambos hemisferios que en la Península Ibérica y la provincia de Salamanca, se encuentran formando parte de formaciones de matorral, en orlas y claros de bosques, o dentro de sotobosque de formaciones boscosas. principalmente de pinares y robledales.

Época de floración: Desde inicios de primavera hasta los meses estivales.

Polinización: Entomófila, levemente anemófila en algunas especies debido a la disposición de los estambres fuera de la corola.

Morfología polínica (Lámina II): Polen trizonocolporado, levemente heteropolar y radiosimétrico, con forma circular en vista polar y de circular a elíptica en vista ecuatorial (esferoidal), y un tamaño variable $(P=14-33$ $\mu \mathrm{m})$. Las ectoaberturas tipo colpo son terminales, y las endoaberturas tipo poro, en ocasiones de contorno poco nítido. La exina (1$1,5 \mu \mathrm{m})$, presenta una superficie reticulada, con lúmenes de contorno irregular de menos de 1 $\mu \mathrm{m}$. concentraciones polínicas de este tipo (Fig. 5.2.4.8.D.) mostrada a través del porcentaje de representación que tuvieron las concentraciones medias de los cincos días anteriores para el total promediado del conjunto de años estudiados, indicó un incremento de las concentraciones desde mediados de marzo hasta finales de abril y principios de mayo, con un descenso a mediados de abril, y siendo el 29 de abril (3 granos $/ \mathrm{m}^{3}$ ), la fecha con la concentración máxima para el promedio de las concentraciones de los años estudiados (Tabla 5.2.4.3.). Posteriormente, estos niveles disminuyeron durante el mes de mayo, pero manteniéndose presentes en la atmósfera durante junio y julio (Fig. 5.2.4.8. A. B. C.). Las 
concentraciones diarias más elevadas dentro de los ocho años variaron entre los 3 granos $/ \mathrm{m}^{3}$ (26 de abril de 2002, 2 de mayo de 2006 y 23 de abril de 2007), y los 18 granos $/ \mathrm{m}^{3}$ (8 de mayo de 2005).

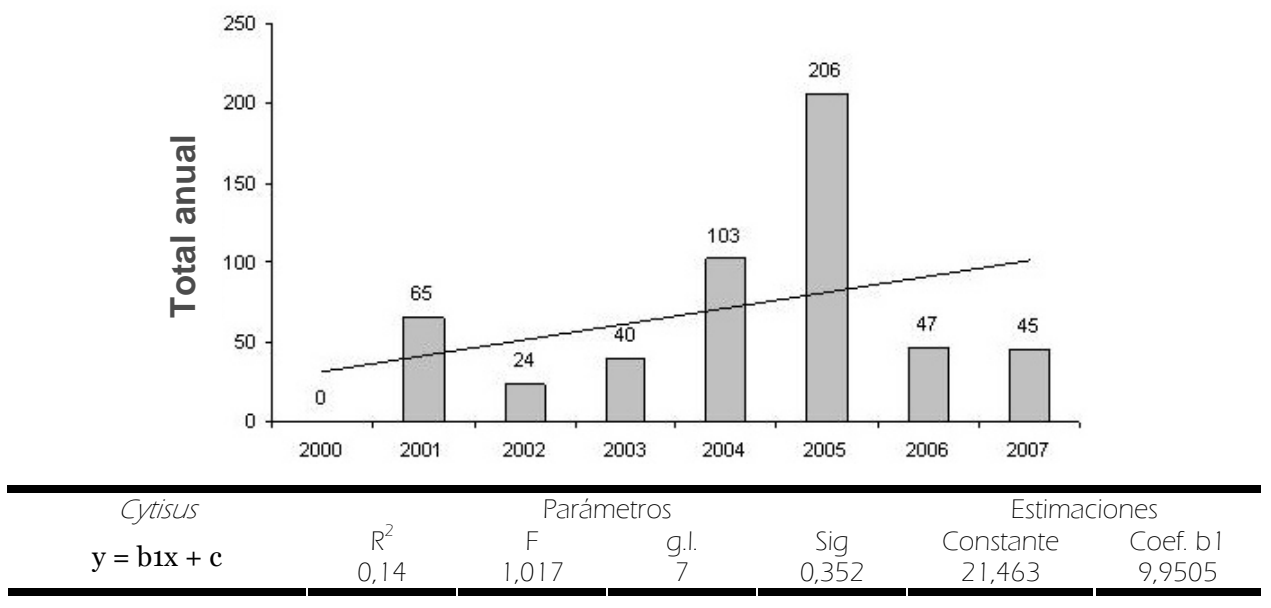

Fig. 5.2.4.7. Evolución anual del número total de pólenes de Cytisus y tendencias (análisis de regresión).

\begin{tabular}{|c|c|c|c|c|c|c|c|c|c|}
\hline Cytisus & 2000 & 2001 & 2002 & 2003 & 2004 & 2005 & 2006 & 2007 & Media \\
\hline Total & - & 65 & 24 & 40 & 103 & 206 & 47 & 45 & 76 \\
\hline Día & - & 02-abr & 26-abr & 10-may & 03-abr & 08-may & 02-may & 23-abr & 29-abr \\
\hline PPP(días) & - & 109 & 49 & 75 & 113 & 84 & 76 & 133 & 91 \\
\hline Inicio & - & 23-mar & 29-mar & 13-mar & 16-mar & 23-mar & 22-mar & 11-mar & 19-mar \\
\hline Fin & - & 09-jul & 16-may & 26-may & 06-jul & 14-jun & 05-jun & $21-j u l$ & 17-jun \\
\hline
\end{tabular}

Tabla 5.2.4.3. Totales, concentraciones máximas diarias, período principal de polinización (PPP; fecha de inicio y fin) y días precedentes al valor máximo (PRE) durante los ocho años de estudio (salvo los años con bajo número anual o sin presencia de este tipo), y el promedio de todos los parámetros para Cytisus.

Las concentraciones de polen a lo largo del día fueron más elevadas entre las 12 y las 24 horas, aunque se mostraron irregulares, sin ningún patrón muy definido. Por tanto, la variación intradiaria (Fig. 5.2.4.9.) durante un día promedio para el trienio 2005-2007, presentó los mayores niveles horarios en la segunda mitad del día. 


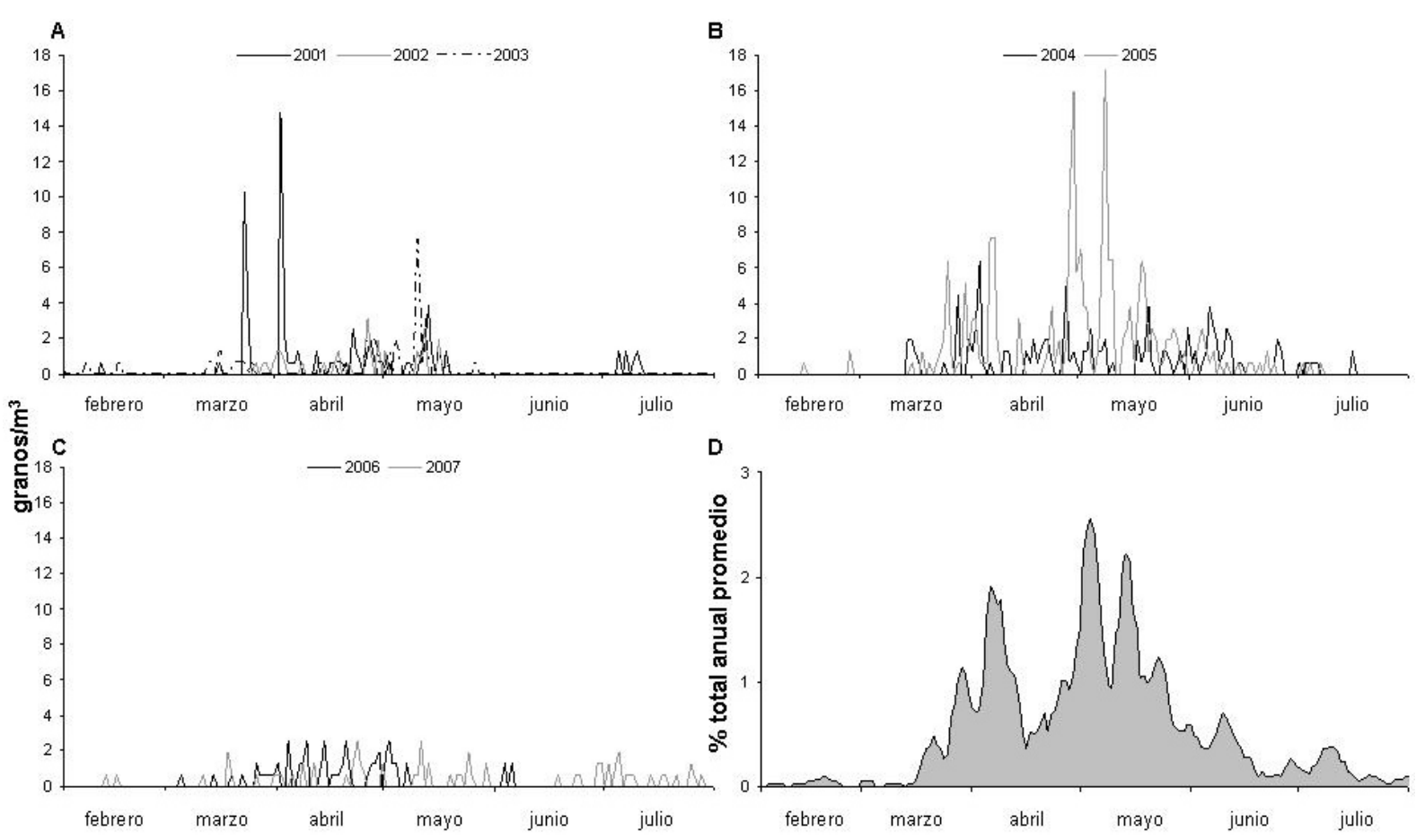

Fig. 5.2.4.8. Variación de las concentraciones medias diarias de Cytisus durante el período 2000-2002 (A), 2003-2005 (B) y 2006-2007 (C). Porcentajes de representación diarios para la media de los cinco días anteriores dentro del promedio de los ocho años analizados (D).

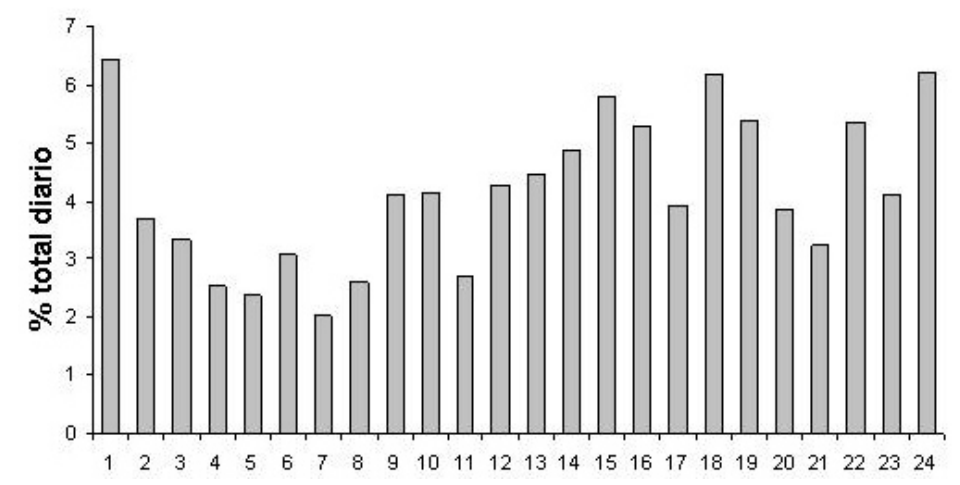

Fig. 5.2.4.9. Variación intradiaria del polen de Cytisus. 


\subsubsection{Ericaceae}

El tipo de polen en el que hemos incluido a la familia Ericaceae, incrementó sus niveles polínicos durante el período analizado, con una variación interanual (Fig. 5.2.4.10.) que pasó de un total de 46 granos de polen en el año 2000 a los 195 del año 2007. Esta evolución (un 324\% más) dio lugar a un índice de determinación $\left(\mathrm{R}^{2}=0,81\right)$, propio de la regresión lineal que indicó también una tendencia al incremento. Los porcentajes de representación sobre el total de pólenes contabilizados en cada anualidad estudiada variaron del 0,9\% del año 2004 al 0,4\% de 200o, con un porcentaje medio del o,66\%.

La distribución de estos granos de polen a lo largo del año fue amplia, localizándose principalmente entre finales de marzo y principios de julio, por lo que la variación estacional (Tabla 5.2.4.4.) tuvo un PPP para las concentraciones medias de los ocho años de 101 días. Esta variación se hizo evidente al observar las diferencias en

Tipo de polen: Ericaceae.

Especie(s): Arbutus unedo L., Calluna vulgaris (L.) Hull., Erica australis L., Erica arborea L. Erica cinerea L., entre otras (Ericaceae).

Distribución: Familia presente en ambos hemisferios, principalmente en el área atlántica europea y africana, con varios géneros bien representados en la Península Ibérica y la provincia de Salamanca.

Época de floración: De primavera a otoño debido a Calluna Salisb., e incluso invierno, con Arbutus L.

Polinización: Entomófila, fundamentalmente (Erica scoparia L. es anemófila).

Morfología polínica (Lámina II): Polen trizonocolporado, presentado generalmente en tétradas de tamaño mediano-grande $(P=27-67$ $\mu \mathrm{m})$. Las aberturas están situadas en la zona de contacto entre dos granos de polen, haciendo que la tétrada parezca recorrida por un surco. La exina $(1-2,5 \mu \mathrm{m})$ posee una superficie de ornamentación variable, que va desde psiladopunteada a escábria o verrugosa.

las fechas de inicio del PPP (11 de marzo de 2003 - 6 de abril de 2005), calculado con el método del $95 \%$ de las concentraciones totales anuales, y, sobretodo, con las fechas de finalización (11 de junio de 2006 - 7 de agosto de 2005).

Atendiendo al porcentaje que representó la media diaria de los cinco días anteriores para el conjunto de años estudiados con respecto al total promedio, los granos de polen de esta familia comenzaron a contabilizarse en la atmósfera de la ciudad de Salamanca (Fig. 5.2.4.11.D.) a mediados de marzo, experimentando un ascenso en los meses de abril y mayo, como indica el valor medio más elevado en los años analizados (6 granos $/ \mathrm{m}^{3}$ el 9 de mayo). Estas mayores concentraciones diarias registradas en los ocho años estudiados, variables en número y ligeramente en la fecha (Tabla 5.2.4.4.), oscilaron entre los 39 granos $/ \mathrm{m}^{3}$ (9 de mayo de 2007) y los 4 granos/m³ (24 de mayo de 2000, 27 de abril de 2001, y 11 de mayo de 
2003). Posteriormente, los niveles polínicos disminuyeron en junio y julio, mostrando bajas concentraciones en agosto y septiembre (Fig. 5.2.4.11. A. B. C.).

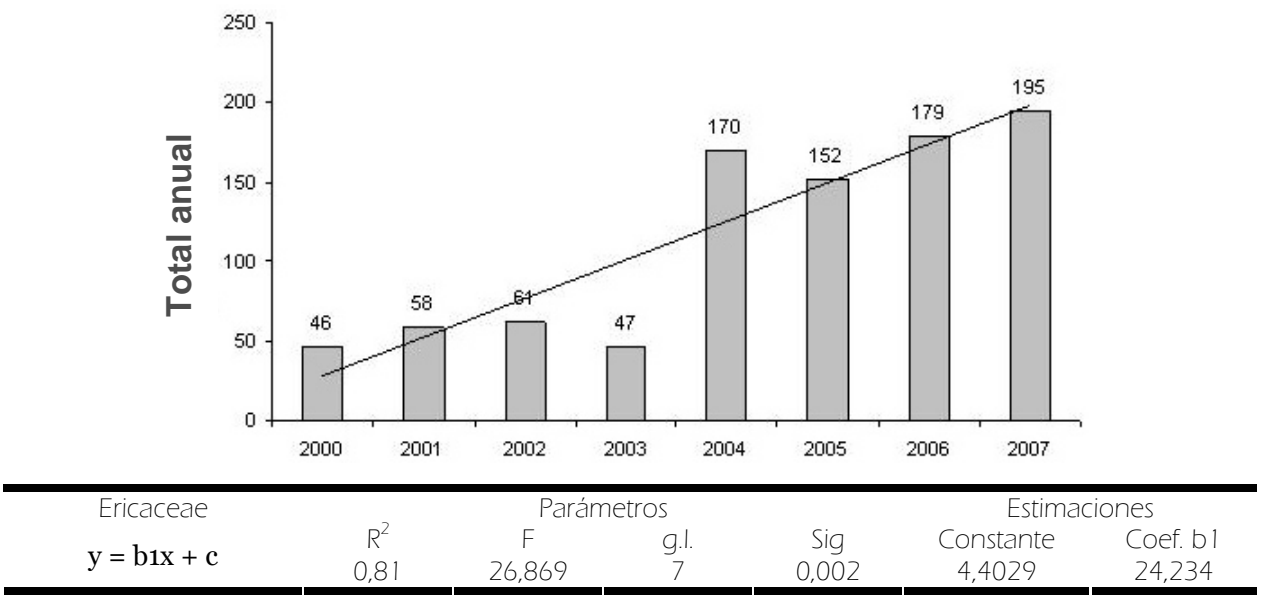

Fig. 5.2.4.10. Evolución anual del número total de pólenes de Ericaceae y tendencias (análisis de regresión).

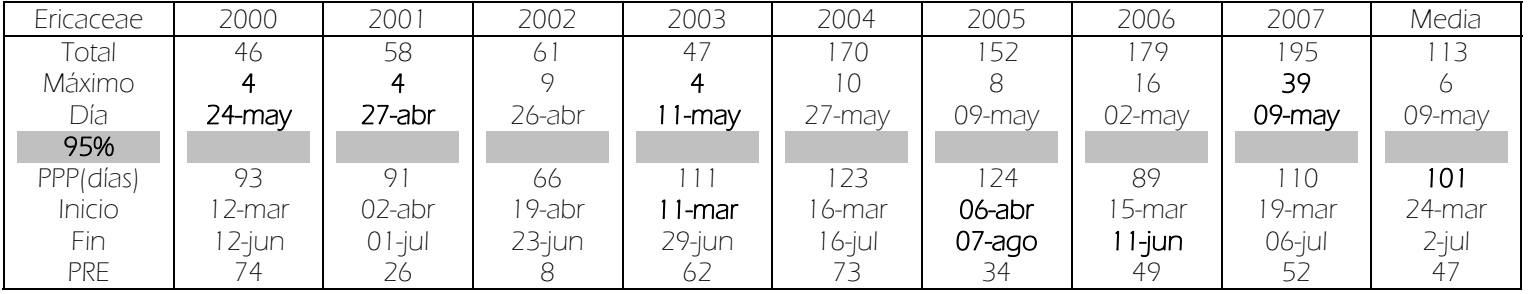

Tabla 5.2.4.4. Totales, concentraciones máximas diarias, período principal de polinización (PPP; fecha de inicio y fin) y días precedentes al valor máximo (PRE) durante los ocho años de estudio, y el promedio de todos los parámetros para Ericaceae.

Las concentraciones de polen presentaron mayores porcentajes de representación entre las 2 y las 11 horas, por lo que la variación intradiaria (Fig. 5.2.4.12.) durante un día promedio para el trienio 2005-2007, indicó los mayores niveles a lo largo de la primera mitad del día. 

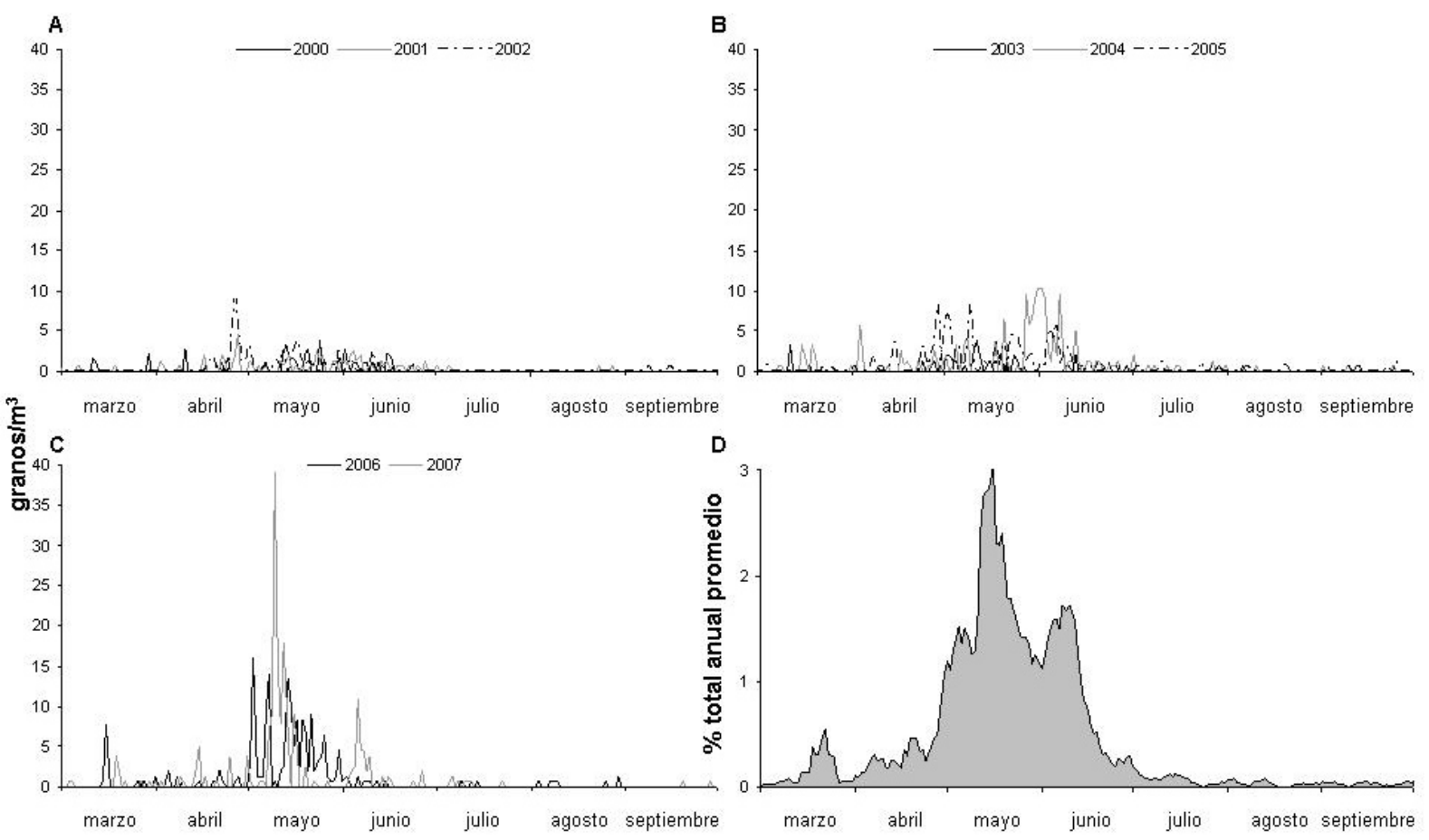

Fig. 5.2.4.11. Variación de las concentraciones medias diarias de Ericaceae durante el período 2000-2002 (A), 2003-2005 (B) y 2006-2007 (C). Porcentajes de representación diarios para la media de los cinco días anteriores dentro del promedio de los ocho años analizados (D).

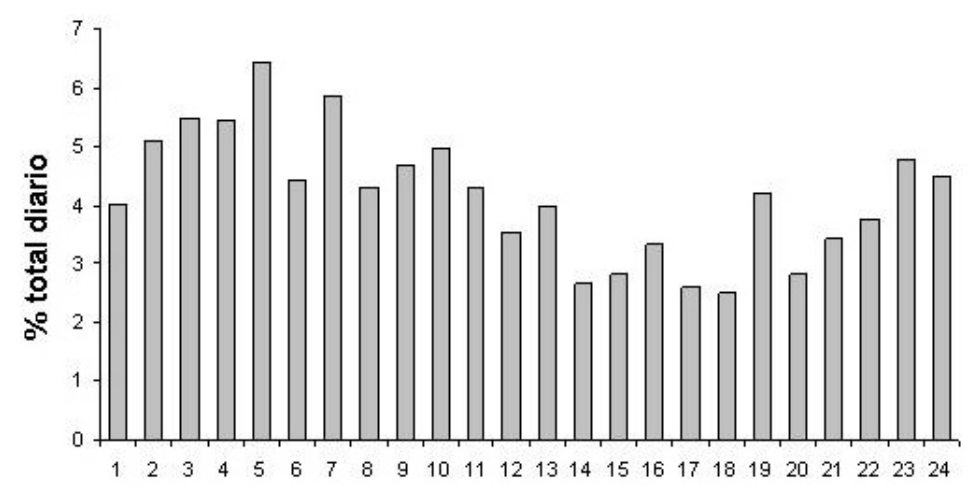

Fig. 5.2.4.12. Variación intradiaria del polen de Ericaceae. 


\subsubsection{J uglans}

Los niveles del tipo polínico J uglans regia en la atmósfera de Salamanca, descendieron durante el período analizado, ya que si en el año 2000 el total anual fue de 86, en el año 2007 alcanzó los 21 pólenes. Esto supuso que la variación interanual (Fig. 5.2.4.13.) llevase consigo un descenso del $309 \%$ en dichas concentraciones anuales, confirmado con el análisis de regresión de tipo lineal $\left(\mathrm{R}^{2}=0,23\right)$, a pesar de su bajo índice. La representación media de los pólenes de este tipo a lo largo de los ocho años fue de $0,2 \%$, con un máximo de o,8\% en 2000, y 0,1\% en 2002 y el período 2004-2007.

La distribución de estos granos de polen a lo largo del año se localizó entre principios de abril e inicios de junio, por lo que la variación estacional (Tabla 5.2.4.5.), tuvo un PPP promedio de 56 días, con diferencias en las fechas de inicio (19 marzo de 2003 - 22 de abril de 2006) y finalización (11 de mayo de $2007-2$ de julio de 2000).

En todo caso, los niveles polínicos de este género botánico en la atmósfera de la ciudad de Salamanca (Fig. 5.2.4.14.D.) aumentaron a partir de la última semana de abril hasta alcanzar los valores más elevados a mediados de mayo, como muestra el valor medio más elevado en los años analizados (4 granos $/ \mathrm{m}^{3}$, el 20 de mayo), gracias a la dinámica aportada por el porcentaje que representó la media diaria de los cinco días anteriores para el conjunto de años estudiados con respecto al total promedio. Asimismo, las mayores concentraciones diarias registradas durante las ocho anualidades (Tabla 5.2.4.5.), oscilaron entre los 13 granos $/ \mathrm{m}^{3}$ (20 de junio de 2000) y 1 grano $/ \mathrm{m}^{3}$ (varios días de 2002). Posteriormente, estos niveles disminuyeron durante el mes de junio, con concentraciones anecdóticas en julio (Fig. 5.2.4.14. A. B. C.).
Tipo polínico: Juglans regia.

Especie(s): Juglans regia L. (Juglandaceae).

Distribución: Natural del suroeste de Asia y sureste de Europa, de introducción muy antigua en otras zonas de Europa. En la Península Ibérica resulta complicado delimitar el origen espontáneo de algunos ejemplares, mientras que en la provincia de Salamanca se localiza puntualmente en suelos profundos y frescos, cerca de explotaciones agrícolas de pequeño tamaño, y siendo más frecuente al sur.

Época de floración: De abril a junio, fundamentalmente

Polinización: Anemófila.

Morfología polínica (Lámina II): Polen polipantoporado, heteropolar y asimétrico, con una forma levemente poligonal o circular en vista polar, y elíptica en vista ecuatorial (de suboblato a oblato-esferoidal), y un tamaño mediano-grande $(P=32-45 \mu \mathrm{m})$. Las aberturas tipo poro, en número de 7 a 16 , presentan anillo de $3 \mu \mathrm{m}$ de diámetro . La exina (2 $\mu \mathrm{m})$, presenta una superficie psilada. 


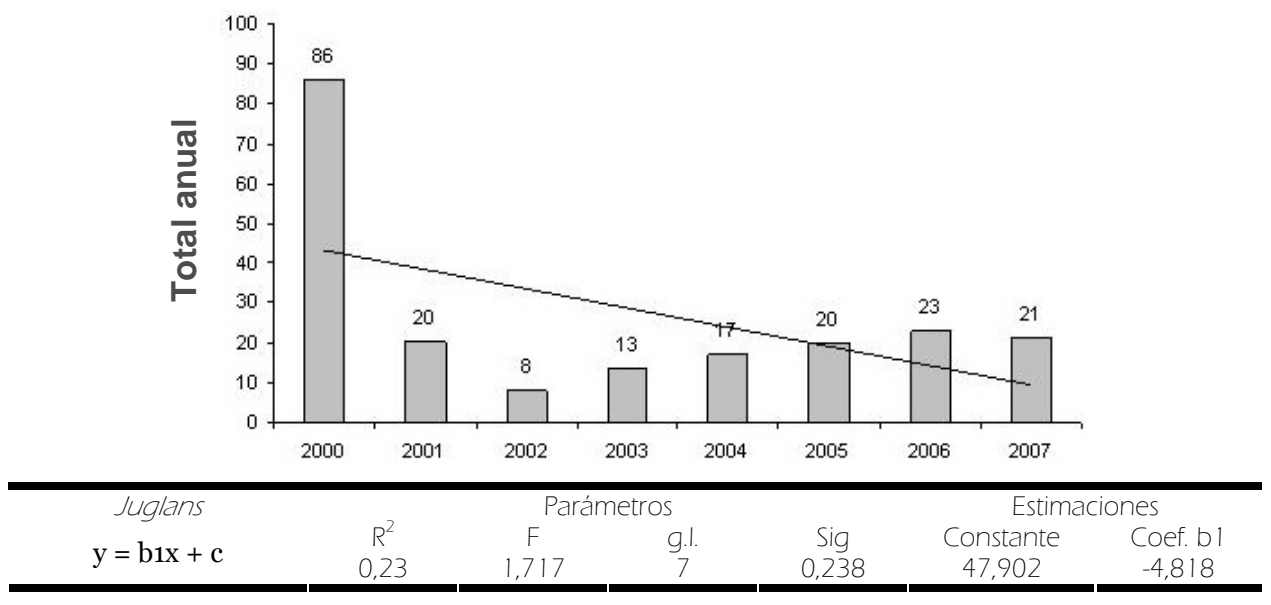

Fig. 5.2.4.13. Evolución anual del número total de pólenes de Juglans y tendencias (análisis de regresión).

\begin{tabular}{|c|c|c|c|c|c|c|c|c|c|}
\hline Juglans & 2000 & 2001 & 2002 & 2003 & 2004 & 2005 & 2006 & 2007 & Media \\
\hline Total & 86 & 20 & 8 & 13 & 17 & 20 & 23 & 21 & 26 \\
\hline Día & 20-may & 13-may & varios & 27-abr & 16-may & 17-abr & 0 1-may & 10-may & 20-may \\
\hline PPP(días) & 73 & 54 & - & 72 & 62 & 67 & 35 & 26 & 56 \\
\hline Inicio & 21-abr & 30-mar & - & 19-mar & 17-abr & 28-mar & 22-abr & 16-abr & 8-abr \\
\hline Fin & 02-jul & 22-may & - & 29-may & 17-jun & 02-jun & 26-may & 11-may & 2-jun \\
\hline
\end{tabular}

Tabla 5.2.4.5. Totales, concentraciones máximas diarias, período principal de polinización (PPP; fecha de inicio y fin) y días precedentes al valor máximo (PRE) durante los ocho años de estudio (salvo los años con bajo número anual o sin presencia de este tipo), y el promedio de todos los parámetros para Juglans.

La variación intradiaria (Fig. 5.2.4.15.) no mostró un claro patrón a lo largo de un día promedio para los últimos tres años estudiados, ya que la distribución fue irregular durante las diferentes horas que componen un día. 


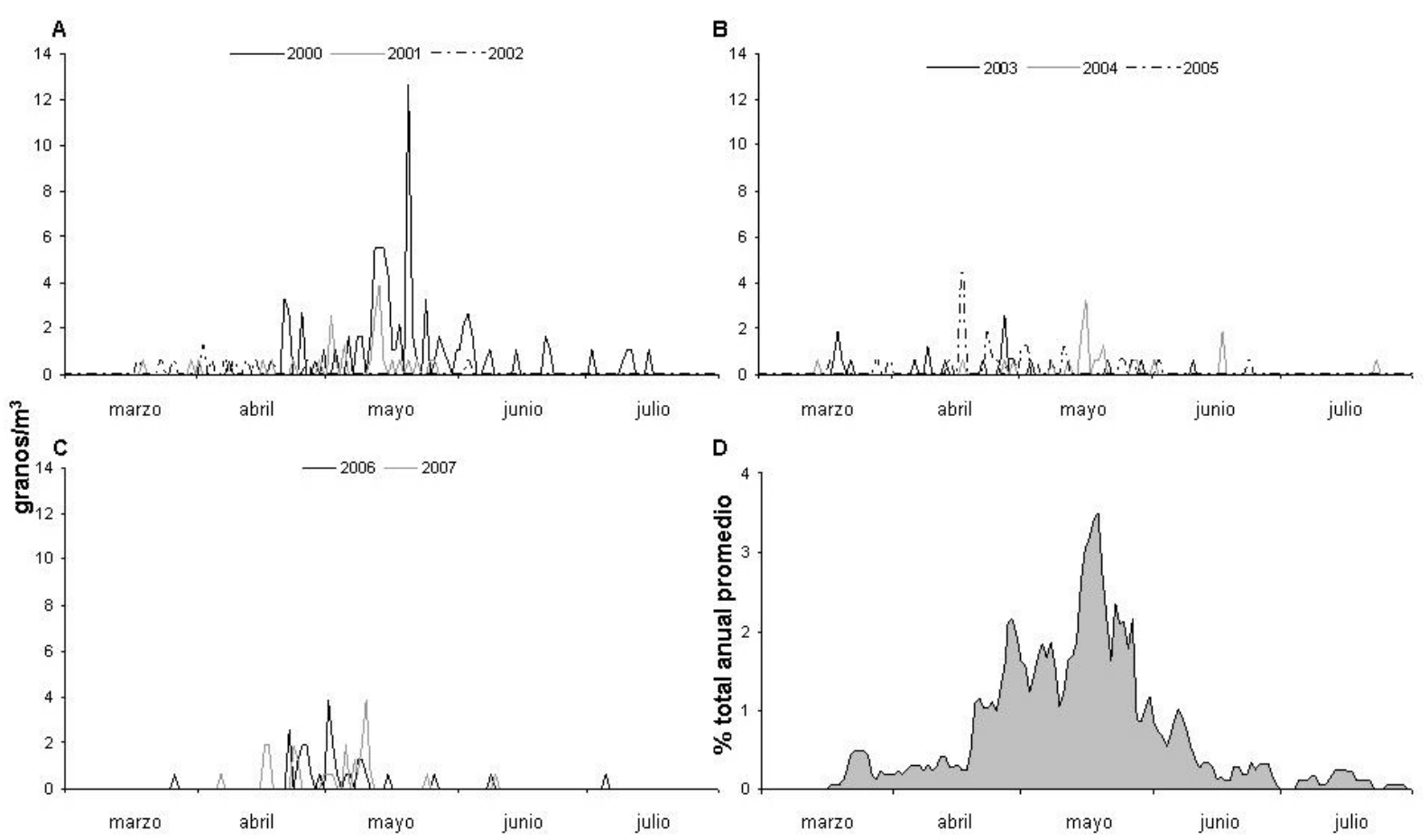

Fig. 5.2.4.14. Variación de las concentraciones medias diarias de Juglans durante el período 2000-2002 (A), 2003-2005 (B) y 2006-2007 (C). Porcentajes de representación diarios para la media de los cinco días anteriores dentro del promedio de los ocho años analizados (D).

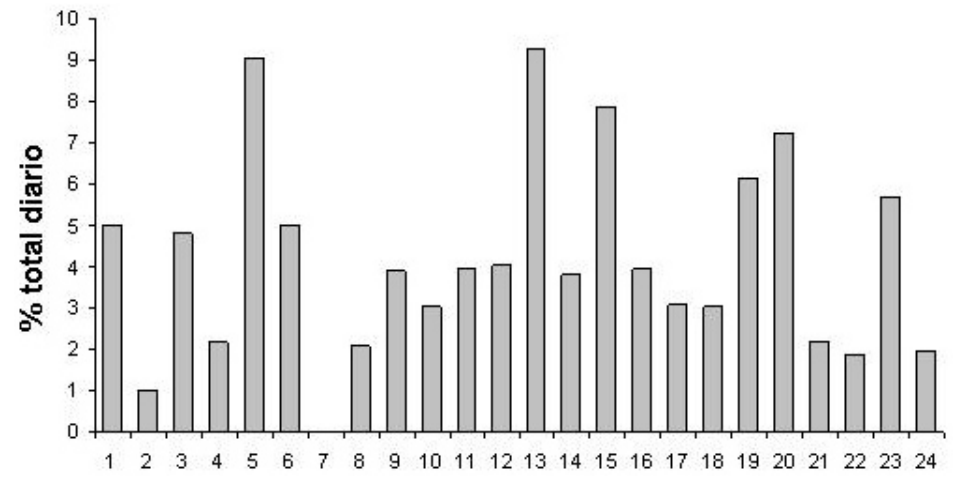

Fig. 5.2.4.15. Variación intradiaria del polen de Juglans. 


\subsubsection{Salix}

El tipo de polen que incluye al género Salix L. incrementó sus niveles polínicos a través del período analizado, con una variación interanual (Fig. 5.2.4.16.) que pasó de un total de 100 granos de polen en el año 2000 a los 118 del año 2007, si bien fue el año 2006 el que presentó un total mayor con 179. Esta evolución en el número total de granos de polen (un 18\% más en los ocho años) dio lugar a un índice de determinación $\left(\mathrm{R}^{2}=0,29\right)$, propio de la regresión lineal que indicó también una tendencia al incremento. Los porcentajes de representación sobre el total de pólenes contabilizados en cada anualidad estudiada variaron del 0,9\% de 2000 al 0,3\% de 2003, con un porcentaje medio de $0,6 \%$.

La distribución de estos granos de polen a lo largo del año se localizó entre marzo y finales de mayo, por lo que la variación estacional (Tabla 5.2.4.6), tuvo un PPP promedio de 82 días, con diferencias de, aproximadamente, un mes en las fechas de inicio (11 de febrero de 2004 - 18 de marzo de 2005), y superiores a dos meses en las de finalización (26 de abril de 2001 - 28 de junio de 2005) para los diferentes años incluidos.

Los granos de polen de este género comenzaron a contabilizarse en la atmósfera de la ciudad de Salamanca (Fig. 5.2.4.17.D.) a partir de marzo, experimentando un ascenso a finales del mismo mes y manteniéndose en niveles altos hasta finales de abril, como indica el valor medio más elevado en los años analizados (4 granos $/ \mathrm{m}^{3}$ el 22 de abril), a través del porcentaje sobre el total anual promedio de la media de los cinco días anteriores promediados durante los años analizados. Asimismo, las mayores concentraciones diarias registradas en los ocho años estudiados, localizadas principalmente en la segunda mitad de 
marzo (Tabla 5.2.4.6), variaron entre los 26 granos $/ \mathrm{m}^{3}$ (22 de abril de 2006) y los 4 granos/m³ (24 de marzo de 2003). Posteriormente, los niveles polínicos disminuyeron durante mayo, despareciendo a finales de junio (Fig. 5.2.4.17. A. B. C.).

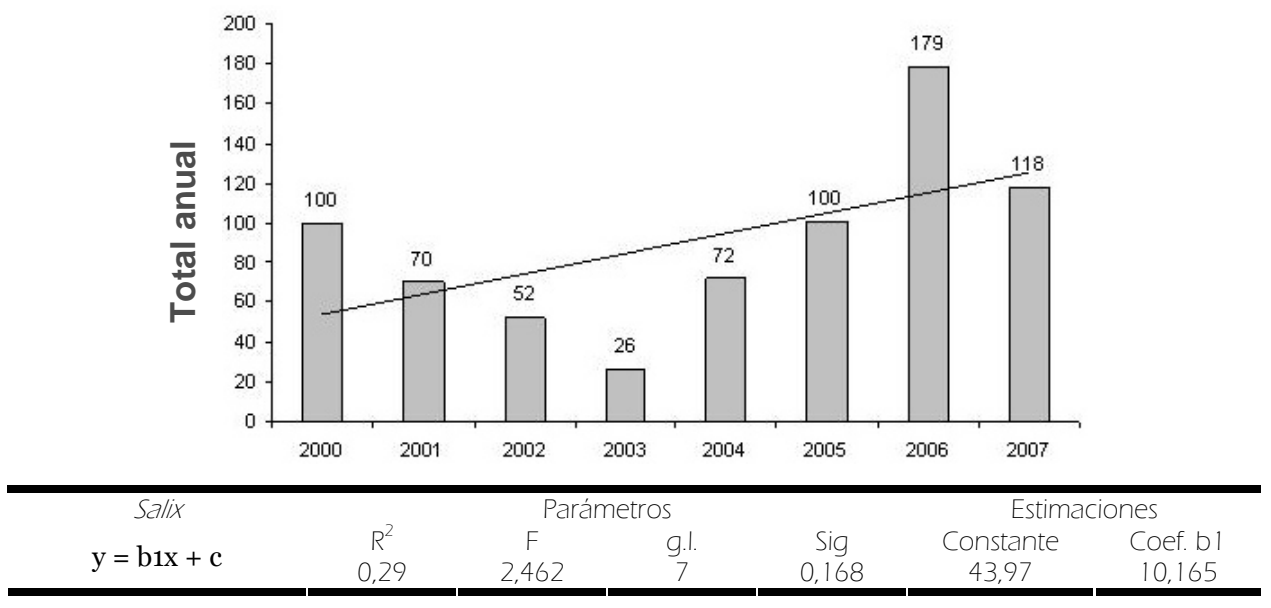

Fig. 5.2.4.16. Evolución anual del número total de pólenes de Salix y tendencias (análisis de regresión).

\begin{tabular}{|c|c|c|c|c|c|c|c|c|c|}
\hline Salix & 2000 & 2001 & 2002 & 2003 & 2004 & 2005 & 2006 & 2007 & Media \\
\hline Total & 100 & 70 & 52 & 26 & 72 & 100 & 179 & 118 & 90 \\
\hline Día & 26-mar & 23-mar & 20-mar & 24-mar & 18-mar & 23-abr & 22-abr & 07-mar & 22-abr \\
\hline PPP(días) & 90 & 51 & 79 & 65 & 126 & 103 & 65 & 78 & 82 \\
\hline Inicio & 01-mar & 07-mar & 01-mar & 12-mar & 11 -feb & 18-mar & 13-mar & 03-mar & 4-mar \\
\hline Fin & 29-may & 26-abr & 18-may & 15-may & 15-jun & 28-jun & 15-may & 19-may & 24-may \\
\hline
\end{tabular}

Tabla 5.2.4.6. Totales, concentraciones máximas diarias, período principal de polinización (PPP; fecha de inicio y fin) y días precedentes al valor máximo (PRE) durante los ocho años de estudio, y el promedio de todos los parámetros para Salix.

Las concentraciones de polen a lo largo del día se incrementaron a partir de las 13 horas hasta las 16 horas, mostrando los mayores porcentajes de representación desde esta hora hasta las 19 horas, momento en el que las concentraciones horarias disminuyeron. Por tanto, la variación intradiaria (Fig. 5.2.4.18.) durante un día promedio para el trienio 2005-2007, presentó los mayores niveles horarios en las horas vespertinas. 


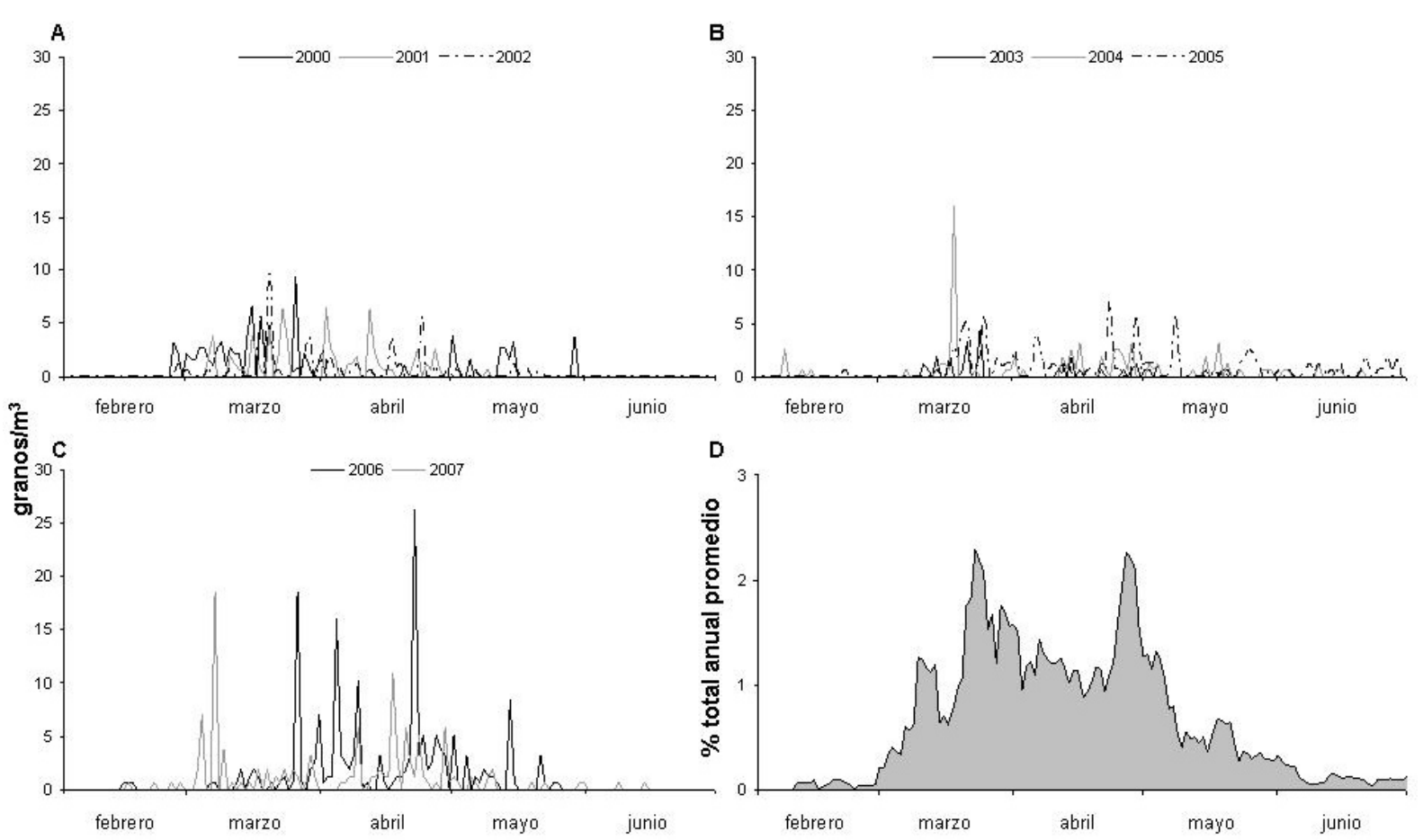

Fig. 5.2.4.17. Variación de las concentraciones medias diarias de Salix durante el período 2000-2002 (A), 20032005 (B) y 2006-2007 (C). Porcentajes de representación diarios para la media de los cinco días anteriores dentro del promedio de los ocho años analizados (D).

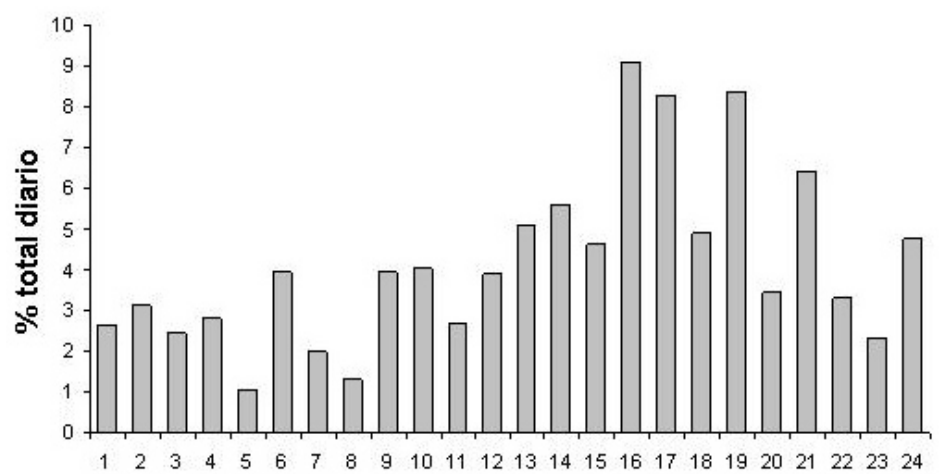

Fig. 5.2.4.18. Variación intradiaria del polen de Salix. 


\subsubsection{Sambucus}

La variación interanual (Fig. 5.2.4.19.) nos indica que durante los ocho años de estudio hubo un descenso en las concentraciones de este tipo polínico en la atmósfera de Salamanca, pues el total anual pasó de los 73 del año 2000 a los 17 pólenes de 2007 (un 329\% menos), tal y como muestra también el análisis de tendencias a través de la regresión lineal $\left(\mathrm{R}^{2}=0,62\right)$. Estos valores supusieron entre un 0,9\% (en 2002) y un $0,1 \%$ (en los cuatro últimos años) del total de pólenes contabilizados (promedio:0,3\%).

La variación estacional (Tabla 5.2.4.7), mostró una clara delimitación entre finales de mayo y principios de julio, con 37 días como duración promedio del PPP, y consiguientemente, variaciones de un mes en la fecha de inicio (8 de mayo de 2006 - 9 de junio de 2003) y finalización (12 de junio de 2006 - 20 de julio de 2005).

La evolución de las concentraciones a través del porcentaje que representó la media diaria de los cinco días anteriores para el conjunto de años estudiados con respecto al total promedio, refrendó esta dinámica ya que los niveles de polen aumentan desde la segunda mitad de mayo hasta el inicio de junio (Fig. 5.2.4.20.D.), presentando una concentración máxima de 5 granos/ $\mathrm{m}^{3}$ el día 1 de junio como media de los ocho años estudiados (Tabla 5.2.4.7.). Las mayores concentraciones diarias para los años estudiados (Tabla 5.2.4.7.), oscilaron entre los 36 granos $/ \mathrm{m}^{3}$ (1 de junio de 2000) y 1 grano $/ \mathrm{m}^{3}$ (varios días de los años 2004 y 2007). Posteriormente, las concentraciones de polen fueron disminuyendo durante el mes de junio, encontrándose en valores bajos en el mes de julio (Fig. 5.2.4.20.A. B. C.).
Tipo polínico: Sambucus nigra.

Especie(s): Sambucus nigra L. (Caprifoliaceae).

Distribución: Especie nativa de bosques húmedos de Europa, Asia y norte de África, siendo frecuente, principalmente, en la mitad septentrional de la Península Ibérica sobre suelos con un nivel freático elevado $y$ en bordes de ríos. En la provincia de Salamanca, es también frecuente en zonas húmedas o como planta ornamental.

Época de floración: Finales de primavera e inicio de verano, sobretodo en mayo y junio.

Polinización: Entomófila.

Morfología polínica (Lámina III): Polen trizonocolporado, isopolar y radiosimétrico, con una forma circular-triangular en vista polar y elíptica en vista ecuatorial (de prolato a suboblato), y un tamaño mediano $(P=25-31$ $\mu \mathrm{m})$. Las ectoaberturas tipo colpo son terminales, y las endoaberturas tipo poro son circulares, a veces difusas. La exina $(2 \mu \mathrm{m})$, posee una superficie reticulada, con lúmenes circulares o elípticos de $1 \mu \mathrm{m}$, y muros estrechos. 


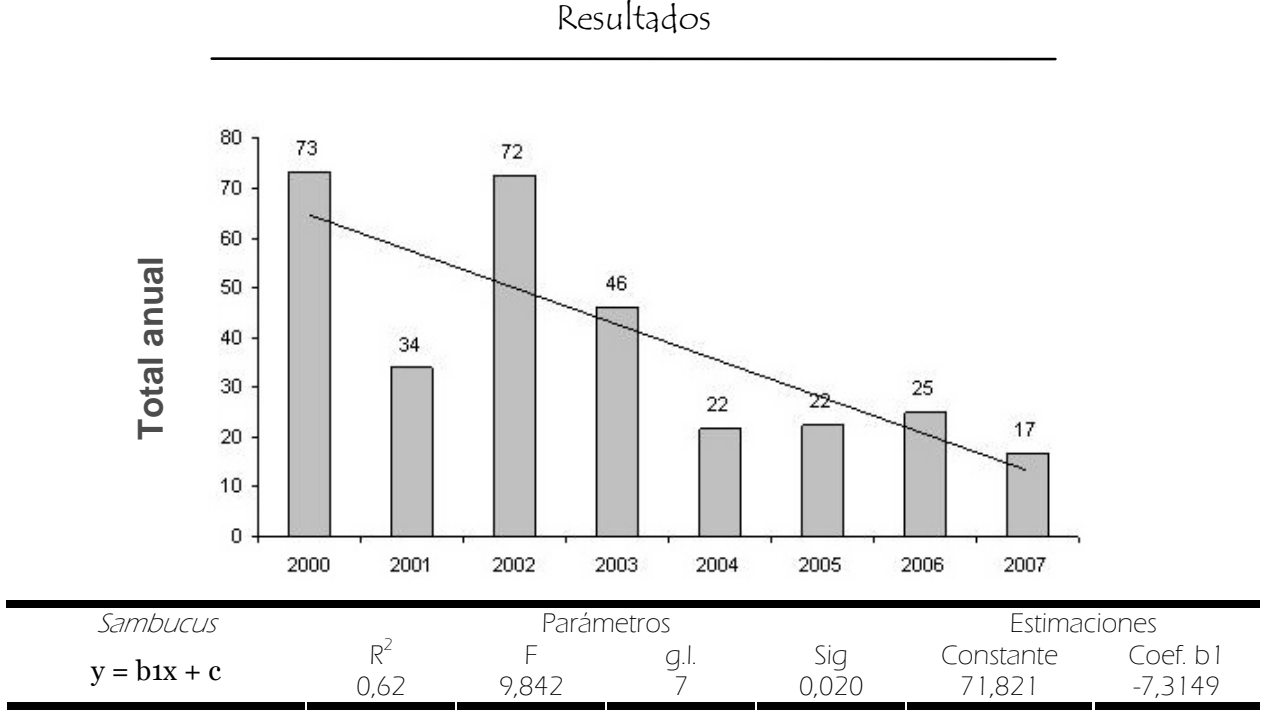

Fig. 5.2.4.19. Evolución anual del número total de pólenes de Sambucus y tendencias (análisis de regresión).

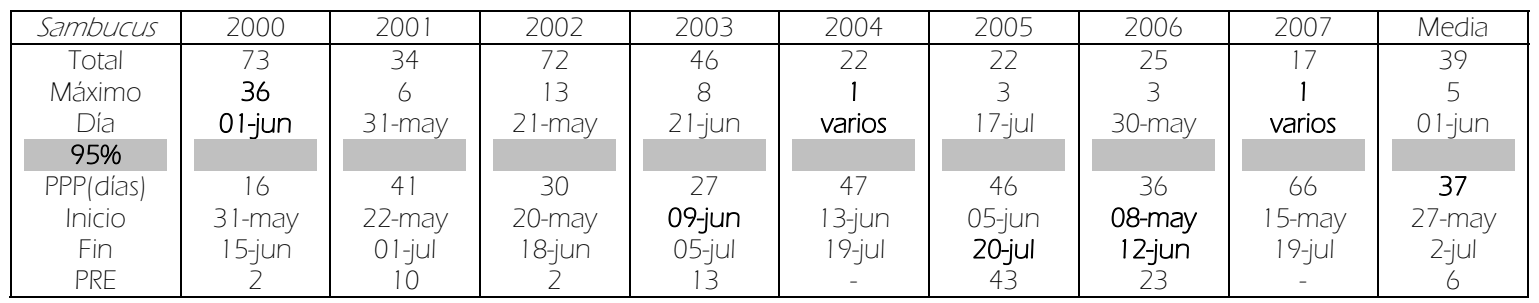

Tabla 5.2.4.7. Totales, concentraciones máximas diarias, período principal de polinización (PPP; fecha de inicio y fin) y días precedentes al valor máximo (PRE) durante los ocho años de estudio, y el promedio de todos los parámetros para Sambucus.

En lo referente a la variación intradiaria (Fig. 5.2.4.21.), no mostró un patrón regular a lo largo de un día promedio para los años 2005, 2006 y 2007, aunque hubo mayores concentraciones durante la segunda mitad del día. 

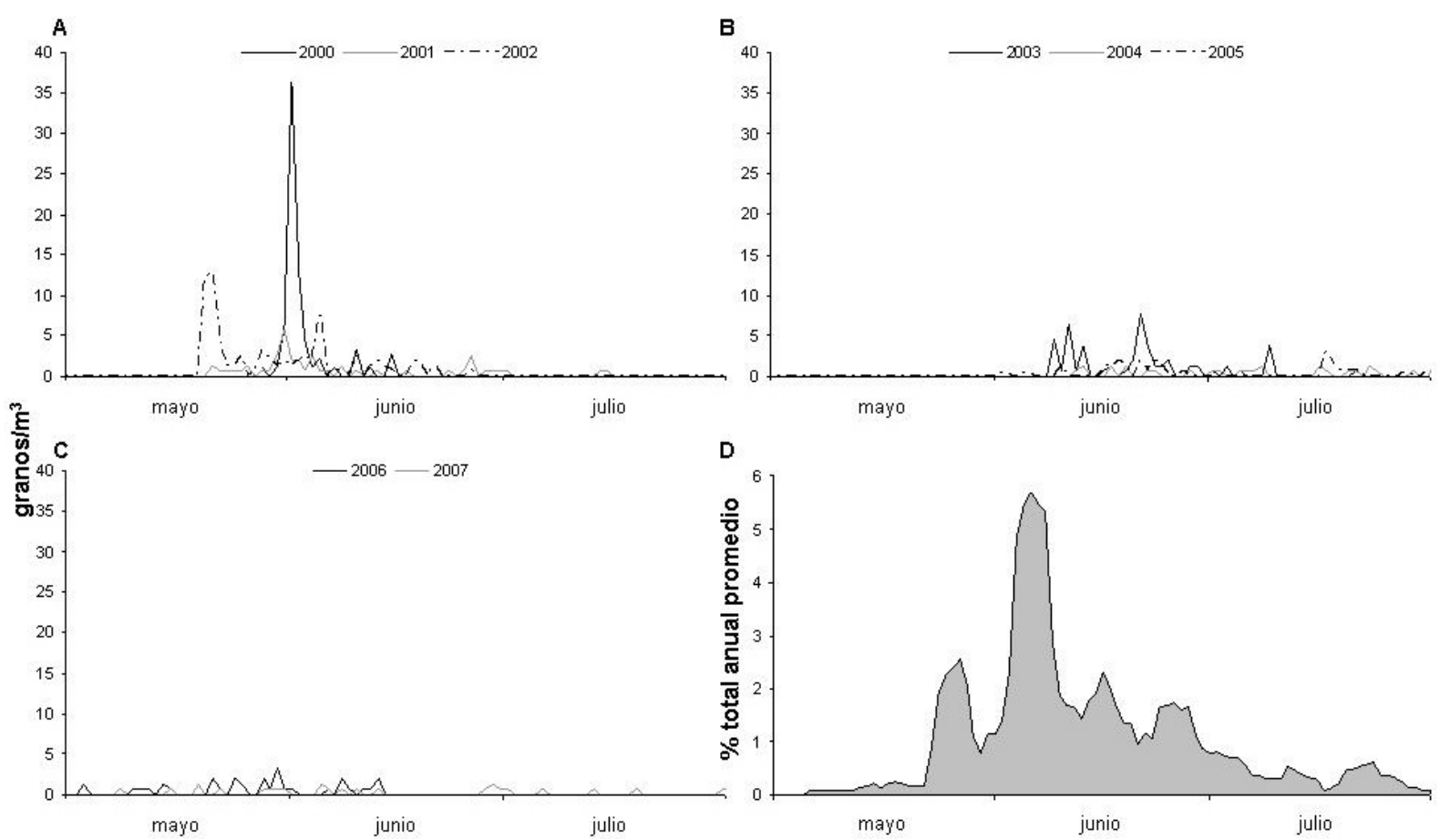

Fig. 5.2.4.20. Variación de las concentraciones medias diarias de Sambucus durante el período 2000-2002 (A), 2003-2005 (B) y 2006-2007 (C). Porcentajes de representación diarios para la media de los cinco días anteriores dentro del promedio de los ocho años analizados (D).

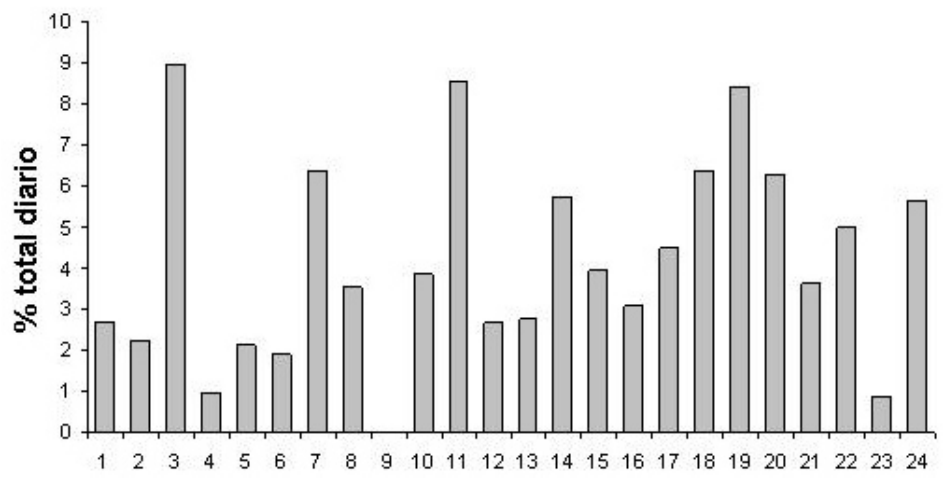

Fig. 5.2.4.21. Variación intradiaria del polen de Sambucus. 


\subsubsection{Trifolium}

El tipo de polen que incluye al género Trifolium L., experimentó un descenso en sus niveles polínicos a través de los ocho años analizados, con una variación interanual (Fig. 5.2.4.22.) que pasó de un total de 20 granos de polen en el año 2000 a los 9 del año 2007, si bien el mayores total anual se contabilizó durante el año 2001, con 82 pólenes. Esta evolución en el número total de granos de polen (un 122\% menos), dio lugar a un índice de determinación $\left(\mathrm{R}^{2}=\mathrm{O}, 24\right)$, propio de la regresión lineal que, pese a indicar también el decrecimiento en las concentraciones de polen de Trifolium, tuviera un valor más bajo que con otros tipos. Los porcentajes de representación sobre el total de pólenes contabilizados en cada anualidad estudiada variaron del $0,8 \%$ de 2001 a un porcentaje inferior al 0,1\% en 2005 y 2007, con un porcentaje medio de $0,3 \%$.

La distribución de estos granos de polen a lo largo del año se localizó entre finales de mayo y finales de agosto, por lo
Tipo de polen: Trifolium spp.

Especie(s): Trifolium arvense L., Trifolium campestre Schereber, Trifolium pratense L., Trifolium repens L., entre otras (Fabaceae).

Distribución: Género prácticamente cosmopolita, bien sea como nativo o introducido, que, en la Península Ibérica y la provincia de Salamanca, se localiza en prados y herbazales de diferente tipo, incluyendo los céspedes de los núcleos urbanos.

Época de floración: Primavera y verano, desde mayo hasta septiembre.

Polinización: Entomófila.

Morfología polínica (Lámina IV): Polen trizonocolporado, heteropolar y radiosimétrico, con forma circular en vista polar y elíptica en vista ecuatorial (prolato o subprolato), y un tamaño grande $(P=23-49 \mu \mathrm{m})$. Las ectoaberturas tipo colpo son terminales, $y$ las endoaberturas tipo poro con membrana abertural granulada. La exina $(0,5-2 \mu \mathrm{m})$ presenta una superficie reticulada o fosulada con lúmenes de contorno irregular de $1,5 \mu \mathrm{m}$, que disminuye en las zonas polares y desaparece en la proximidad de las aberturas.

que la variación estacional (Tabla 5.2.4.8.), tuvo un PPP promedio de 87 días, dejando diferencias superiores a un mes, tanto en la fecha de inicio (5 de mayo de $2004-19$ junio de 2005), como en la fecha de finalización (3 de agosto de 2004 - 22 de septiembre de 2000).

Los niveles polínicos de esta familia botánica en la atmósfera de la ciudad de Salamanca (Fig 5.2.4.23.D.) experimentaron un ascenso a partir de la segunda semana de mayo hasta finales de junio y principios de julio, momento en el que alcanzan las mayores concentraciones, como indica el valor medio más elevado en los años analizados (2 granos $/ \mathrm{m}^{3}$ el 30 de junio), a través del porcentaje promedio dentro de la media móvil los cinco días anteriores sobre el total promediado para los años analizados. En todo caso, las mayores concentraciones diarias registradas en los ocho años estudiados oscilaron en varios meses (Tabla 5.2.4.8.), y con valores entre los 8 granos $/ \mathrm{m}^{3}$ (30 de junio de 2001) y los 2 
granos $/ \mathrm{m}^{3}$ (varios días del año 2000, 9 de mayo de 2004, y 13 de agosto de 2007). Después, estos niveles disminuyeron a finales del mes de julio, manteniéndose en la atmósfera durante los meses de agosto y septiembre (Fig. 5.2.4.23. A. B. C.).

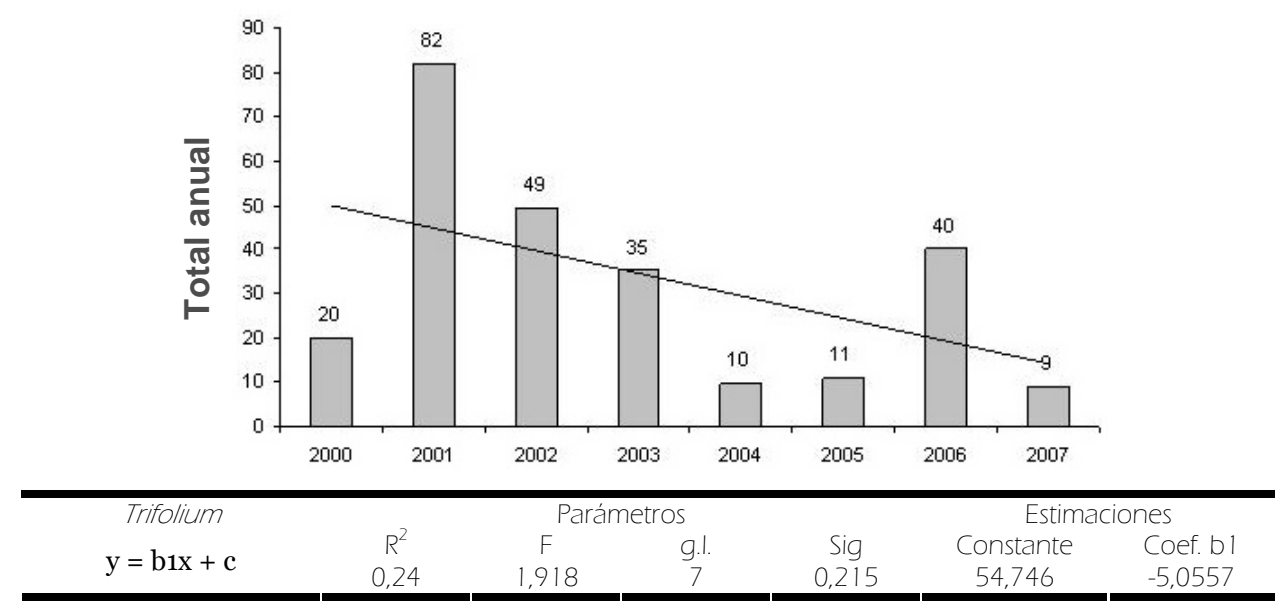

Fig. 5.2.4.22. Evolución anual del número total de pólenes de Trifolium y tendencias (análisis de regresión).

\begin{tabular}{|c|c|c|c|c|c|c|c|c|c|}
\hline Trifolium & 2000 & 2001 & 2002 & 2003 & 2004 & 2005 & 2006 & 2007 & Media \\
\hline Total & 20 & 82 & 49 & 35 & 10 & 11 & 40 & 9 & 32 \\
\hline Día & varios & 30-jun & 25-may & 12-may & 09-may & 26-jul & 20-jul & 13-ago & 30-jun \\
\hline PPP(días) & 97 & 103 & 103 & 93 & 91 & 47 & 88 & - & 87 \\
\hline Inicio & 18-jun & 31-may & 22-may & 12-may & 05-may & 19-jun & 25-may & - & 27-may \\
\hline Fin & 22-sep & 10-sep & 01-sep & 12-ago & 03-ago & 04-ago & 20-ago & - & 21-ago \\
\hline
\end{tabular}

Tabla 5.2.4.8. Totales, concentraciones máximas diarias, período principal de polinización (PPP; fecha de inicio y fin) y días precedentes al valor máximo (PRE) durante los ocho años de estudio (salvo los años con bajo número anual o sin presencia de este tipo), y el promedio de todos los parámetros para Trifolium.

La variación intradiaria (Fig. 5.2.4.24.) mostró un patrón irregular a lo largo de un día promedio para los últimos tres años estudiados, si bien las mayores concentraciones de polen de este género se localizaron entre las 12 y las 18 horas, pues en esa franja horaria fue contabilizada la mitad de los grano de polen. 


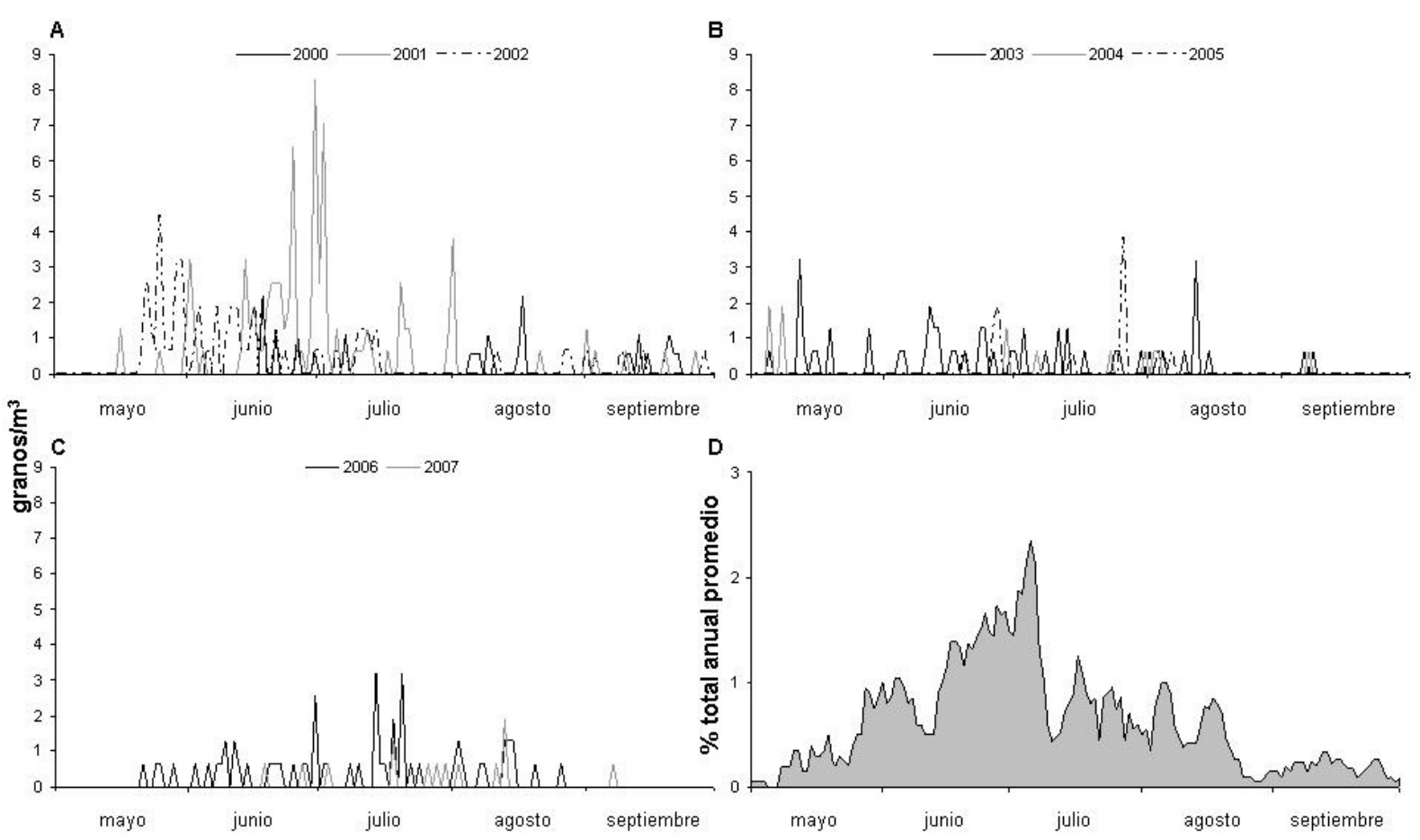

Fig. 5.2.4.23. Variación de las concentraciones medias diarias de Trifolium durante el período 2000-2002 (A), 2003-2005 (B) y 2006-2007 (C). Porcentajes de representación diarios para la media de los cinco días anteriores dentro del promedio de los ocho años analizados (D).

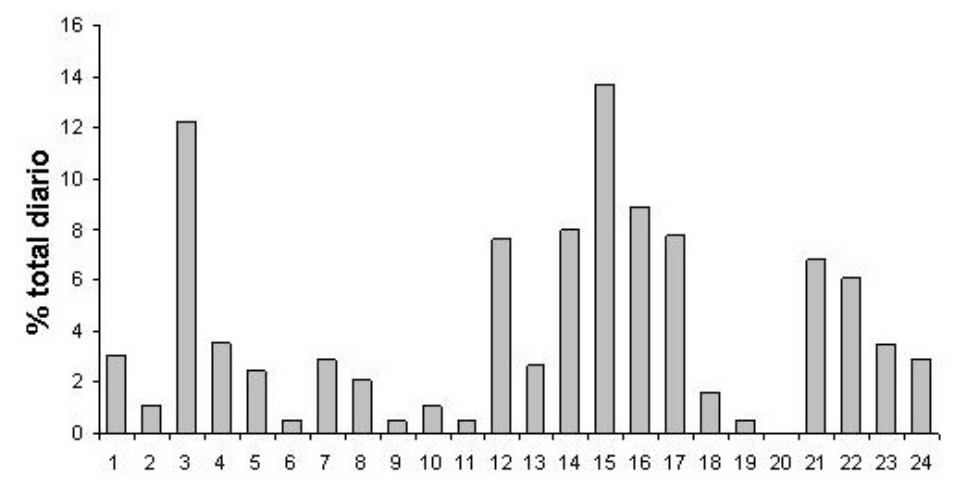

Fig. 5.2.4.24. Variación intradiaria del polen de Trifolium. 


\subsubsection{Tipos de polen con una representación superior o igual al $0,1 \%$ (al menos 3 años)}

\subsubsection{Aesculus}

\section{La variación interanual}

(Fig.

5.2.5.1.) de este tipo polínico en la atmósfera registró un aumento en sus niveles anuales durante el período 2003-2007 (un 77\% más), ya que en los primeros tres años analizados no se contabilizaron pólenes de Aesculus, y los mayores totales anuales se encontraron en los años 2005 y 2006, con 84 y 67 pólenes, respectivamente. Así pues, en el año 2003 el total anual fue de 22 granos de polen, mientras que en 2007 ascendió a 39. Esta evolución en el número total de granos de polen dio lugar a un índice de determinación $\left(\mathrm{R}^{2}=0,62\right)$, propio de la regresión lineal que indicó también una tendencia al incremento. Por otro lado, el porcentaje de representación sobre el total de pólenes contabilizados en cada anualidad estudiada osciló entre el o,4\% de 2005, al 0,1\% de 2004 y 2007, siendo 0,3\% el porcentaje medio en los últimos cuatro años (o,15\% para todo el período).

La evolución de los niveles de polen
Tipo polínico: Aesculus hippocastanum.

Especie(s): Aesculus hippocastanum (Hippocastanaceae).

Distribución: Especie originaria de los Balcanes $y$ el este de Bulgaria, se cultiva como ornamental en la Península Ibérica y la provincia de Salamanca, donde es muy común, sobretodo en los últimos años, también como arbolado de alineación y/o de sombra.

Época de floración: Primavera, principalmente entre los meses de abril y mayo.

Polinización: Entomófila.

Morfología polínica (Lámina I): Polen trizonocolporado, isopolar y radiosimétrico, con una forma triangular en vista polar, elíptica en vista ecuatorial (esferoidal), y un tamaño

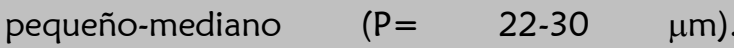
Ectoaberturas tipo colpo alargadas, y endoaberturas tipo poro dispuestas en el centro de los colpos, con una membrana abertural equinada (mayores en número en la superficie de los colpos). La exina delgada (0,5-1 $\mu \mathrm{m})$, presenta una superficie granular-estriada, con largas estrías que se entrecruzan.

a través del porcentaje promedio dentro de la media móvil los cinco días anteriores sobre el total promediado para los años analizados, indicó un aumento desde finales de abril hasta mediados de mayo (Fig. 5.2.5.2.C.), presentando una concentración máxima de 3 granos $/ \mathrm{m}^{3}$ el día 21 de mayo para el conjunto de años estudiados con respecto al total promedio (Tabla 5.2.5.1.). Las mayores concentraciones diarias oscilaron entre 12 granos $/ \mathrm{m}^{3}$ ( 21 mayo de 2005) y 3 granos $/ \mathrm{m}^{3}$ (varios días de 2004). Después, las concentraciones de polen fueron disminuyendo durante el mes de junio, manteniéndose en la atmósfera hasta el mes de julio, pero con concentraciones muy esporádicas (Fig. 5.2.5.2.A.B.). 


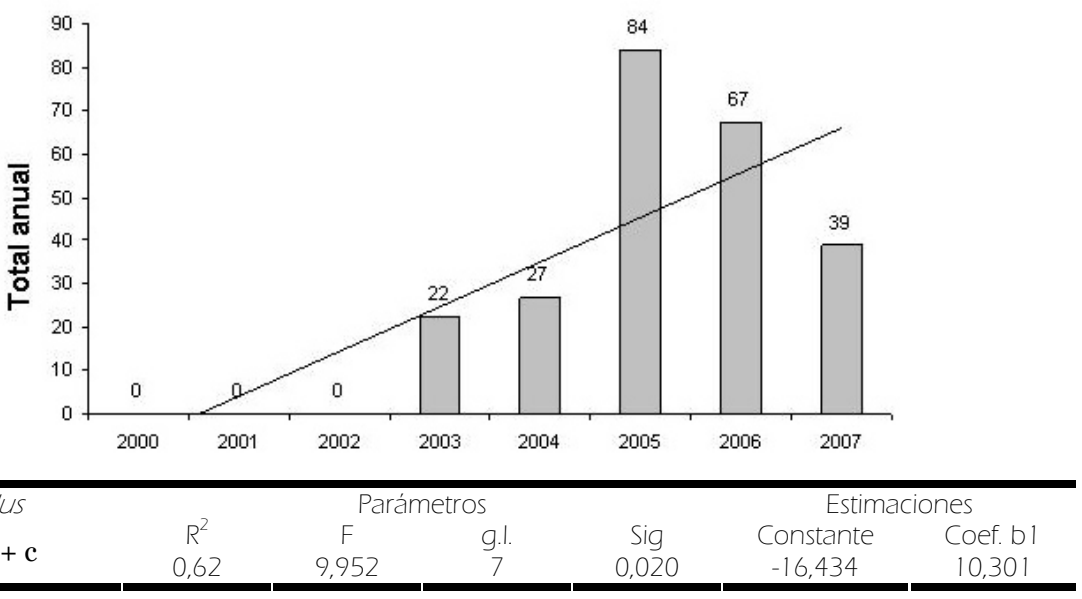

Fig. 5.2.5.1 Evolución anual del número total de pólenes de Aesculus y tendencias (análisis de regresión).

\begin{tabular}{|c|c|c|c|c|c|c|c|c|c|}
\hline Aesculus & 2000 & 2001 & 2002 & 2003 & 2004 & 2005 & 2006 & 2007 & Media \\
\hline Total & - & - & - & 22 & 27 & 84 & 67 & 39 & 48 \\
Máximo & - & - & - & 4 & 3 & 8 & 12 & 8 & 3 \\
Día & - & - & - & $04-j u n$ & varios & varios & 21 -may & 10-may & 21-may \\
\hline
\end{tabular}

Tabla 5.2.5.1. Totales y concentraciones máximas diarias y promedio para Aesculus.

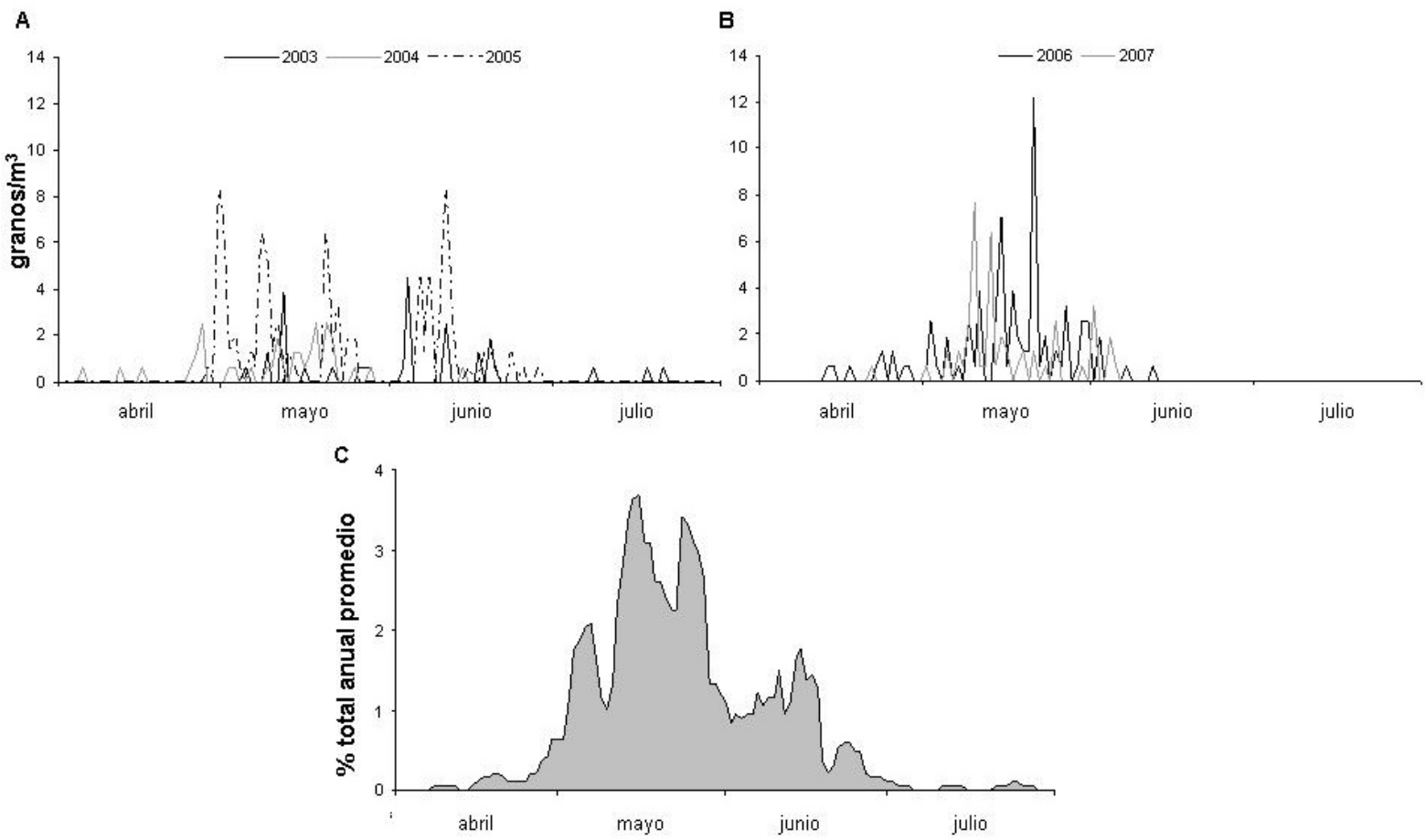

Fig. 5.2.5.2. Variación de las concentraciones medias diarias de Aesculus durante el período 2003-2005 (A) y 2006-2007 (B). Porcentajes de representación diarios para la media de los cinco días anteriores dentro del promedio de los ocho años analizados (C). 


\subsubsection{Campanula}

Los niveles del tipo de polen en el que se ha englobado al género Campanula L., se incrementaron a lo largo de los ocho años estudiados en la atmósfera de Salamanca, puesto que si en el año 2000 no se contabilizó ningún grano, existió un aumento entre los años 2001 y 2005, pasando de un total anual de 10 a 22 granos de polen, y un posterior descenso en los últimos dos años. Por tanto, la variación interanual (Fig. 5.2.5.3.) indicó un leve aumento, un hecho confirmado a través del análisis de regresión de tipo lineal y el bajo valor que tomó por su índice de determinación $\left(\mathrm{R}^{2}=0,24\right)$. La representación media de los pólenes de género botánico a lo largo de los ocho años fue inferior a $0,1 \%$, con un máximo de 0,2\% en 2003 y teniendo en cuenta que no se registraron granos de polen en el año 2000.

La dinámica de las concentraciones polínicas de este género (Fig. 5.2.5.4.D.), mostrada con el porcentaje de

Tipo de polen: Campanula spp..

Especie(s): Campanula lusitanica L., Campanula erinus L. (Campanulaceae), entre otras.

Distribución: Plantas herbáceas localizadas en las regiones templadas del hemisferio Norte que, en la Península lbérica y la provincia de Salamanca, habita en diversos ambientes que van desde prados basófilos hasta bordes de caminos, bosques, etc.

Época de floración: Variable en función de las especies, principalmente de abril a agosto.

Polinización: Entomófila.

Morfología polínica (Lámina I): Polen trizonoporado (a veces tetrazonoporado o bizonopoado), isopolar y radiosimétrico, con una forma subtriangular en vista polar, circular o ligeramente elíptica en vista ecuatorial (de soboblato a oblato-esferoidal), y un tamaño pequeño-mediano $(\mathrm{P}=18-33 \mu \mathrm{m})$. Las aberturas tipo poro tienen un diámetro de 3 a $5 \mu \mathrm{m}$. La exina de grosor variable $(1,5-4 \mu \mathrm{m})$ posee una superficie rugulado-perforada y equinulada, con espínulas de tamaño y distribución variable, entorno a $1 \mu \mathrm{m}$ de longitud. representación de las concentraciones medias móviles de los cincos días anteriores con respecto al total anual, presentó un incremento de las concentraciones desde finales de abril y principios de mayo, manteniendo una distribución irregular con ascensos y descensos en sus niveles polínicos hasta finales de julio, donde se registró una disminución, contabilizándose en bajo número durante los meses de agosto y septiembre. Las concentraciones diarias más elevadas dentro de los ocho años (Fig. 5.2.5.4.A. B. C.; Tabla 5.2.5.2.), no tuvieron grandes oscilaciones, puesto que se situaron entre los 2 granos $/ \mathrm{m}^{3}$ ( 28 de mayo de 2002, varios días de 2003 y 2005, y 9 de junio de 2007) y 1 grano/m³ (varios días de 2001, 2004 y 2006). 


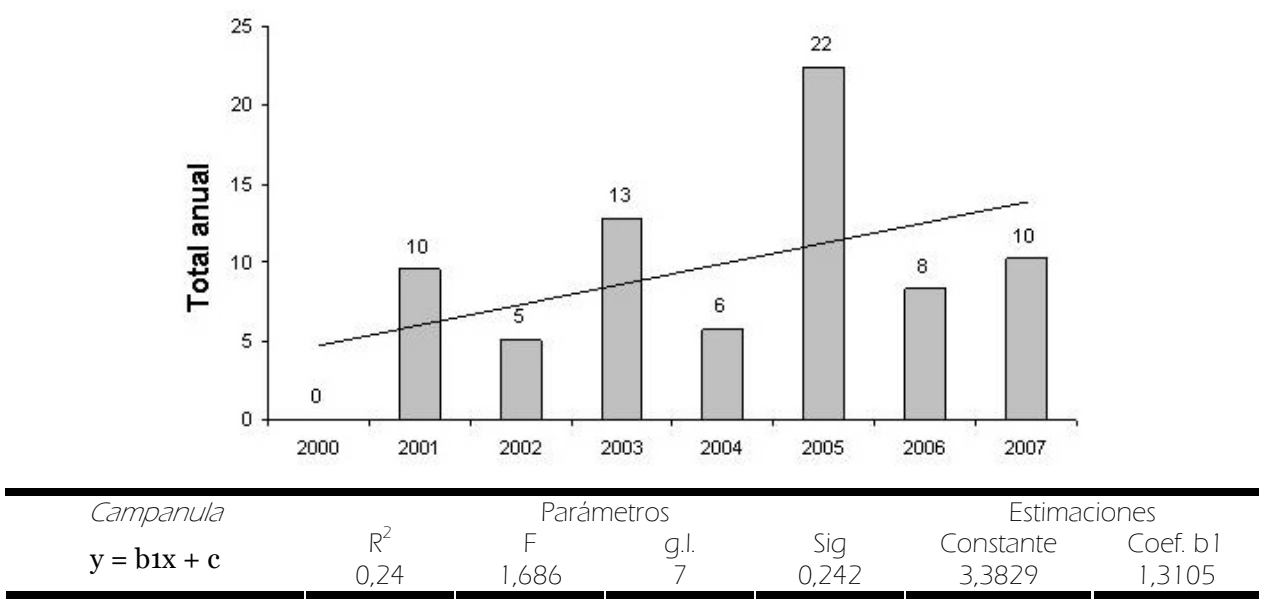

Fig. 5.2.5.3. Evolución anual del número total de pólenes de Campanula y tendencias (análisis de regresión).

\begin{tabular}{|c|c|c|c|c|c|c|c|c|c|}
\hline Campanula & 2000 & 2001 & 2002 & 2003 & 2004 & 2005 & 2006 & 2007 & Media \\
\hline Total & - & 10 & 5 & 13 & 6 & 22 & 8 & 10 & 11 \\
Máximo & - & 1 & 2 & 2 & 1 & 2 & 1 & 2 & 1 \\
Día & - & varios & $28-m a y$ & varios & varios & varios & varios & $09-j u n$ & varios \\
\hline
\end{tabular}

Tabla 5.2.5.2. Totales y concentraciones máximas diarias y promedio para Campanula.

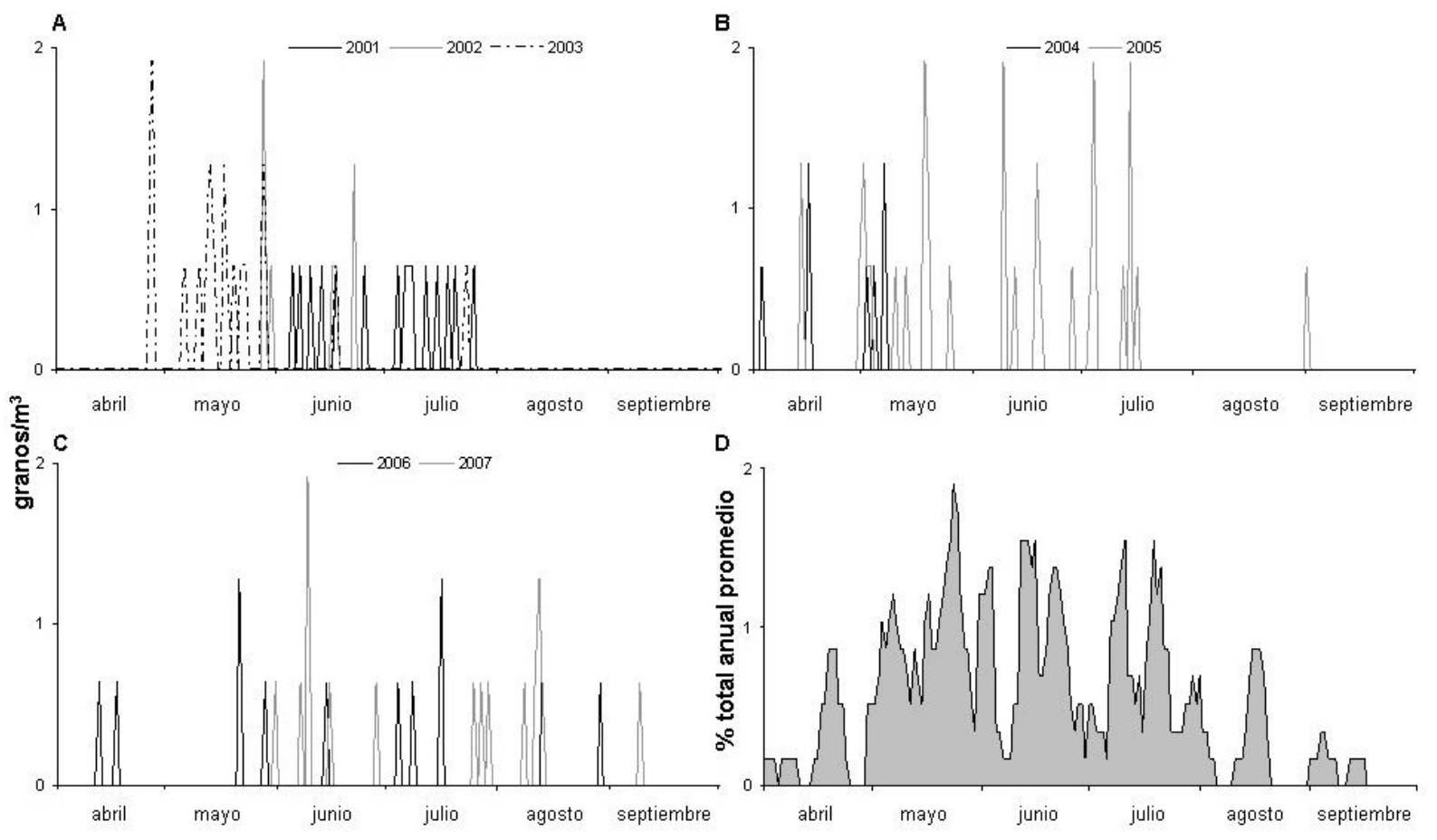

Fig. 5.2.5.4. Variación de las concentraciones medias diarias de Campanula durante el período 2001-2003 (A), 2004-2005 (B) y 2006-2007 (C). Porcentajes de representación diarios para la media de los cinco días anteriores dentro del promedio de los ocho años analizados (D). 


\subsubsection{Corylus}

Los niveles del tipo polínico Corylus avellana en la atmósfera de Salamanca, experimentaron un descenso durante el período analizado, ya que si en el año 2000 el total anual fue de 23 pólenes, en el año 2007 alcanzó los 2. Esto supuso que la variación interanual (Fig. 5.2.5.5.) llevase consigo un descenso en las concentraciones anuales de este tipo polínico, confirmado con el análisis de regresión de tipo lineal $\left(\mathrm{R}^{2}=0,17\right)$, a pesar de su bajo índice. La representación media de los pólenes de este tipo a lo largo de los ocho años fue de $0,1 \%$, con un máximo de $0,2 \%$ en 2000 y 2002, y menor al 0,1\% en 2003, 2006 у 2007.

En todo caso, los niveles polínicos de Corylus en la atmósfera de la ciudad de Salamanca (Fig. 5.2.5.6.D.) aumentaron a mediados de febrero hasta alcanzar los valores más elevados a mediados de marzo, con un ligero descenso a finales de este mes y un nuevo incremento a mediados de abril,

Tipo polínico: Corylus avellana.

Especie(s): Corylus avellana L. (Betulaceae).

Distribución: Especie extendida por gran parte de Europa y Asia occidental, que en la Península lbérica es más abundante, de forma natural, en el norte y el centro, viéndose cultivada por el resto con fines agrícolas y ornamentales. En la provincia de Salamanca, aparece de manera silvestre en algunos puntos de las sierras meridionales

Época de floración: De enero a abril.

Polinización: anemófila.

Morfología polínica (Lámina II): polen trizonoporado, isopolar y radiosimétrico, con una forma subtriangular en vista polar y elíptica en vista ecuatorial (de oblato a oblatoesferoidal), y un tamaño pequeño $(P=19-21$ $\mu \mathrm{m})$. Las aberturas simples tipo poro, circulares de $2 \mu \mathrm{m}$ diámetro, poseen un vestíbulo y están provistos además de un opérculo granulado. La exina $(2-2,5 \mu \mathrm{m})$, presenta una superficie granulado-equinulada, con gránulos y espínulas de menos de $1 \mu \mathrm{m}$, de diferente tamaño $y$ distribución. gracias a la dinámica aportada por el porcentaje que representó la media diaria de los cinco días anteriores para el conjunto de años estudiados con respecto al total promedio. Asimismo, las mayores concentraciones diarias registradas (Tabla 5.2.5.3.) dentro del período 2000-2007 oscilaron entre los 9 granos $/ \mathrm{m}^{3}$ (14 de abril de 2005) y un grano/m (varios días de 2001, 2003, 2006 y 2007). Posteriormente, estos niveles disminuyeron a finales de abril (Fig. 5.2.5.6. A. B. C.). 


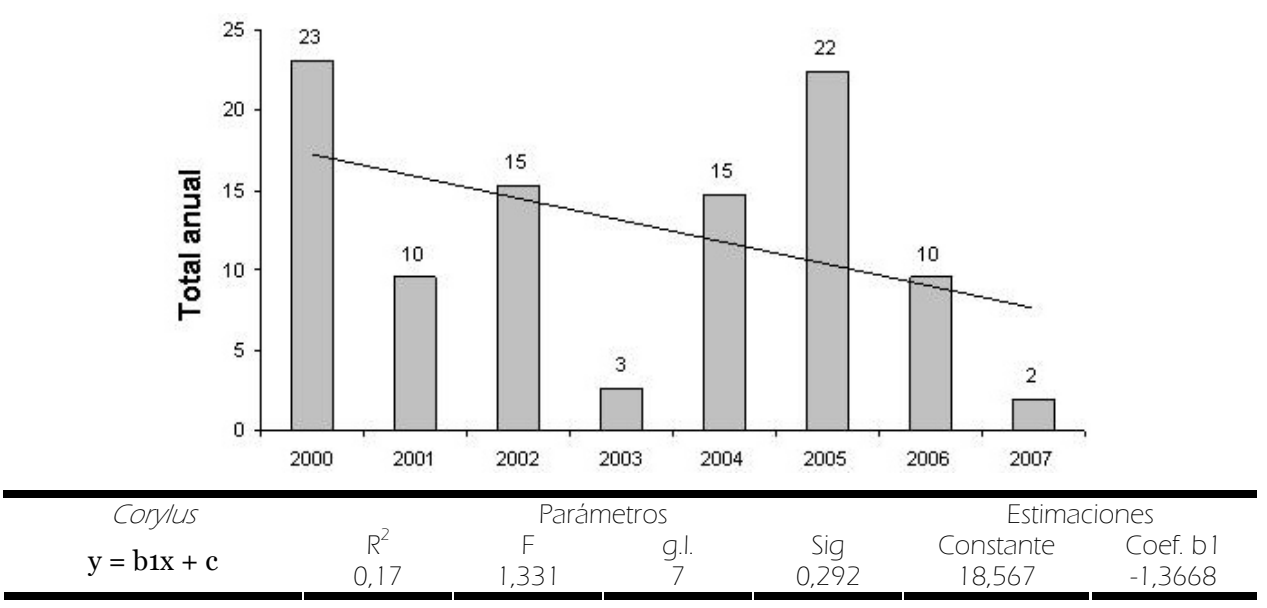

Fig. 5.2.5.5. Evolución anual del número total de pólenes de Corylus y tendencias (análisis de regresión).

\begin{tabular}{|c|c|c|c|c|c|c|c|c|c|}
\hline Cory/us & 2000 & 2001 & 2002 & 2003 & 2004 & 2005 & 2006 & 2007 & Media \\
\hline Total & 23 & 10 & 15 & 3 & 15 & 22 & 10 & 2 & 12 \\
Máximo & 4 & 1 & 2 & 1 & 3 & 9 & 1 & 1 & 1 \\
Día & $18-m a r$ & varios & $20-$ mar & varios & 02-abr & 14-abr & varios & varios & varios \\
\hline
\end{tabular}

Tabla 5.2.5.3. Totales y concentraciones máximas diarias y promedio para Corylus.
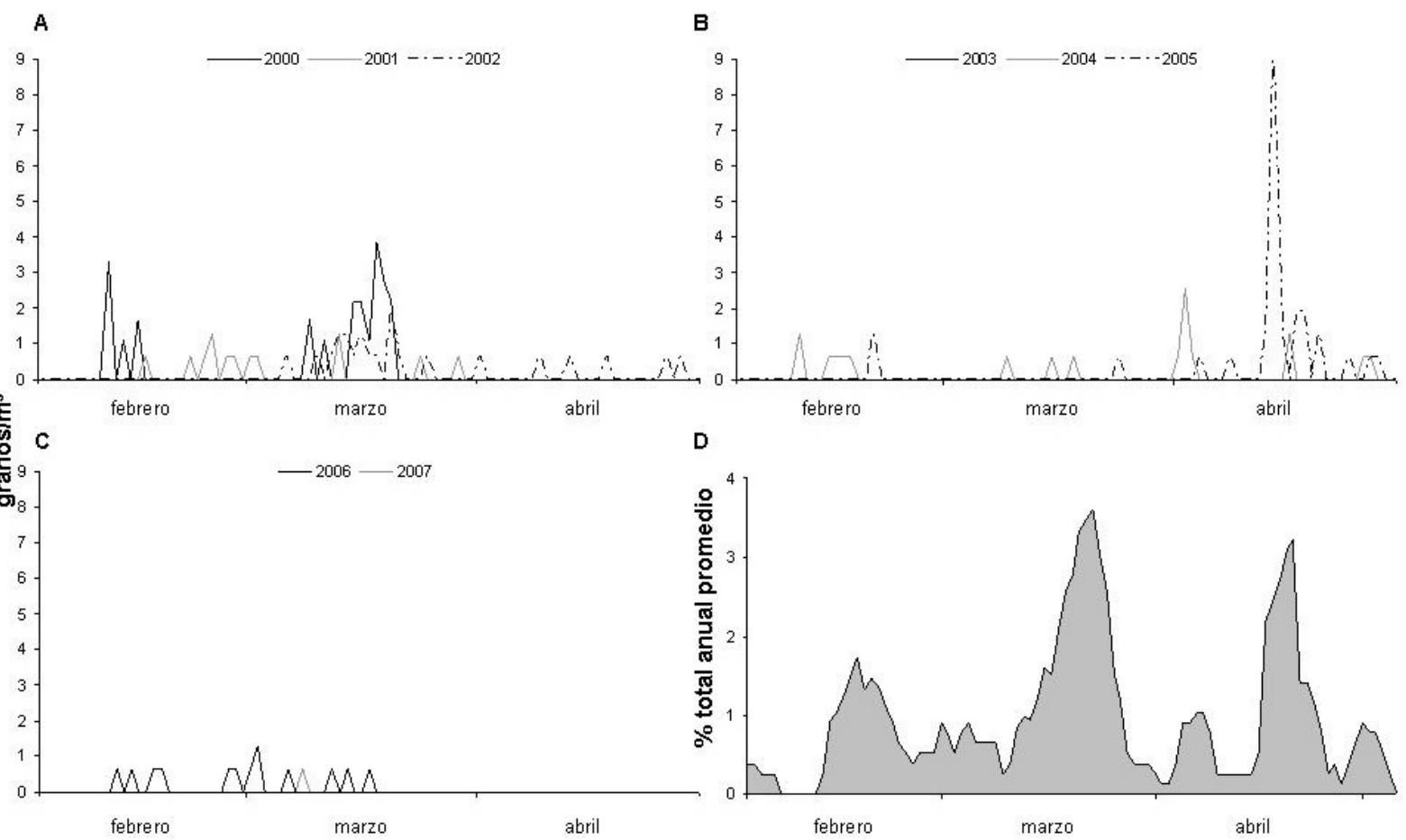

Fig. 5.2.5.6. Variación de las concentraciones medias diarias de Corylus durante el período 2000-2002 (A), 2003-2005 (B) y 2006-2007 (C). Porcentajes de representación diarios para la media de los cinco días anteriores dentro del promedio de los ocho años analizados (D). 


\subsubsection{Cruciferae (= Brassicaceae)}

Este tipo de polen experimentó un aumento en sus niveles polínicos a través de los ocho años analizados, con una variación interanual (Fig. 5.2.5.7.) que pasó de un total de 15 pólenes en el año 2003 a los 49 del año 2007, si bien cabe señalar que no se contabilizaron granos de esta familia durante los tres primeros años. Esta evolución en el número total de granos de polen (un 227\% más, en el período 20032007), dio lugar a un índice de determinación $\left(\mathrm{R}^{2}=0,69\right)$, propio de la regresión lineal, que indicó también el aumento de las concentraciones de polen de Cruciferae. Los porcentajes de representación sobre el total de pólenes contabilizados en cada anualidad estudiada variaron del 0,3\% de 2006 al o,1\% de 2005, con un porcentaje medio de $0,2 \%$ en el período 2003-2007 (o,12\% para los ocho años analizados).

Los niveles polínicos de esta familia botánica en la atmósfera de la ciudad de

\section{Tipo de polen: Cruciferae.}

Especie(s): Se incluyen distintas especies de los géneros Brassica L., Diplotaxis DC., Raphanus L. y Sinapis L. (Cruciferae), entre otras.

Distribución: Familia botánica cosmopolita bien diversificada en regiones templadas de hemisferio Norte $y$, especialmente, en la Península Ibérica, donde, además de estar presentes en numerosos ambientes, algunas especies poseen usos agrícolas.

Época de floración: De marzo a junio, fundamentalmente.

Polinización: entomófila.

Morfología polínica (Lámina II): polen trizonocolpado, isopolar y radiosimétrico, con forma circular a levemente lobulada en vista polar y circular-elíptica en vista ecuatorial (de suboblato a prolato), y un tamaño variable ( $\mathrm{P}=$ 15-40 $\mu \mathrm{m})$. Las aberturas simples de tipo colpo son terminales, siendo la membrana abertural granulada. La exina gruesa $(1,5-3 \mu \mathrm{m})$, presenta una superficie reticulada con lúmenes irregulares, entre 1 y $3 \mu \mathrm{m}$. Salamanca (Fig. 5.2.5.8.C.) experimentaron un ascenso a partir de finales de marzo e inicios de abril, momento en el que se alcanza el valor medio más elevado en los años en los que se contabilizó este tipo de polen ( 2 granos $/ \mathrm{m}^{3}$ el 22 de abril), mediante la dinámica aportada por el porcentaje promedio dentro de la media móvil los cinco días anteriores sobre el total promediado para los años analizados. En todo caso, las mayores concentraciones diarias registradas en los ocho años estudiados (Tabla 5.2.5.4.). oscilaron entre los 6 granos $/ \mathrm{m}^{3}$ (22 de abril de 2006) y un grano/ $\mathrm{m}^{3}$ (varios días de 2003). Después, estos niveles mantuvieron una dinámica irregular, presentando altos niveles a finales de mayo e inicios de junio y disminuyendo a finales de este último mes (Fig. 5.2.5.8. A. B.). 


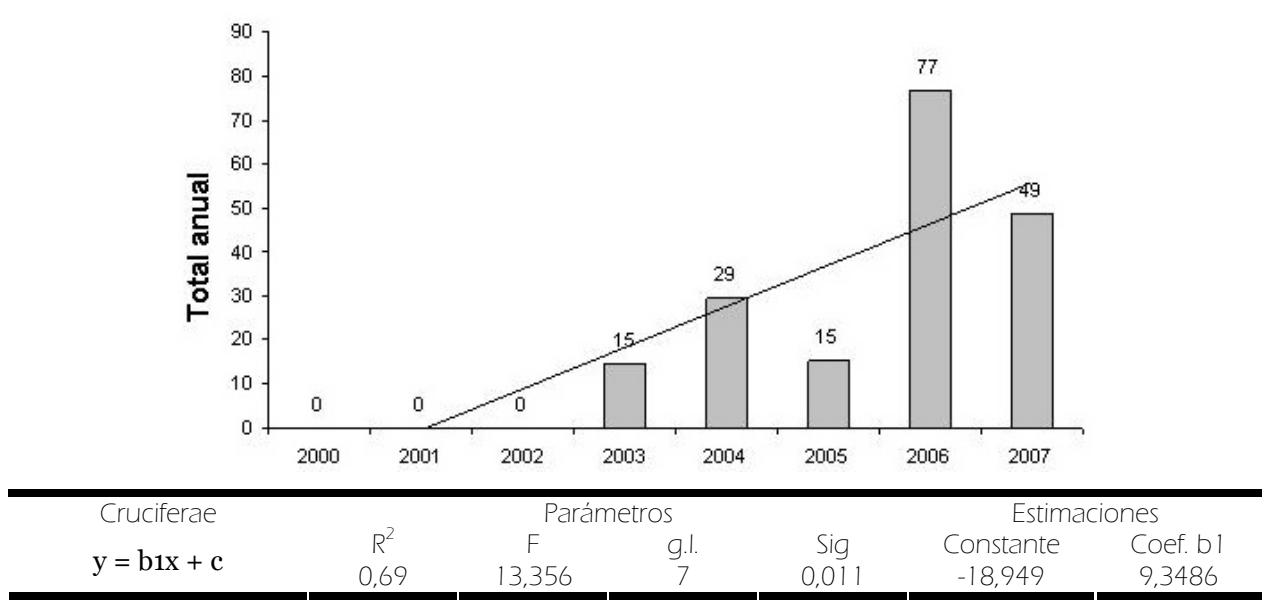

Fig. 5.2.5.7. Evolución anual del número total de pólenes de Cruciferae y tendencias (análisis de regresión).

\begin{tabular}{|c|c|c|c|c|c|c|c|c|c|}
\hline Cruciferae & 2000 & 2001 & 2002 & 2003 & 2004 & 2005 & 2006 & 2007 & Media \\
\hline Total & - & - & - & 15 & 29 & 15 & 77 & 49 & 37 \\
Máximo & - & - & - & 1 & 5 & 3 & 6 & 3 & 2 \\
Día & - & - & - & varios & 06-jun & 24-jun & 22-abr & varios & 22-abr \\
\hline
\end{tabular}

Tabla 5.2.5.4. Totales y concentraciones máximas diarias y promedio para Cruciferae.

A

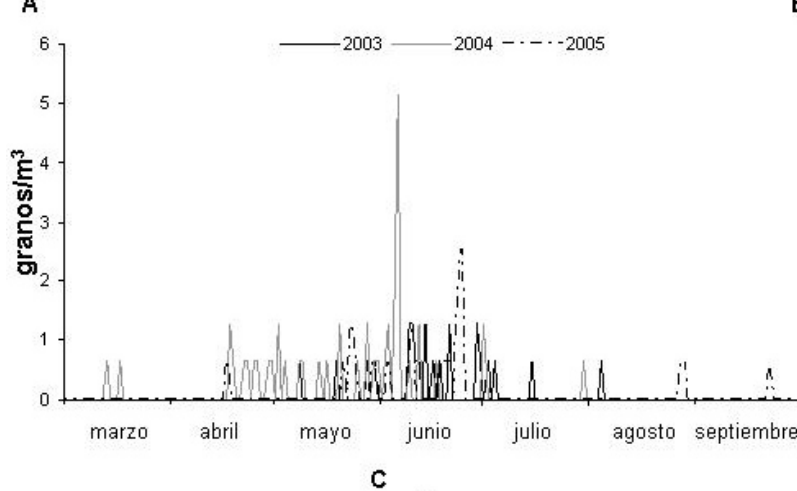

C

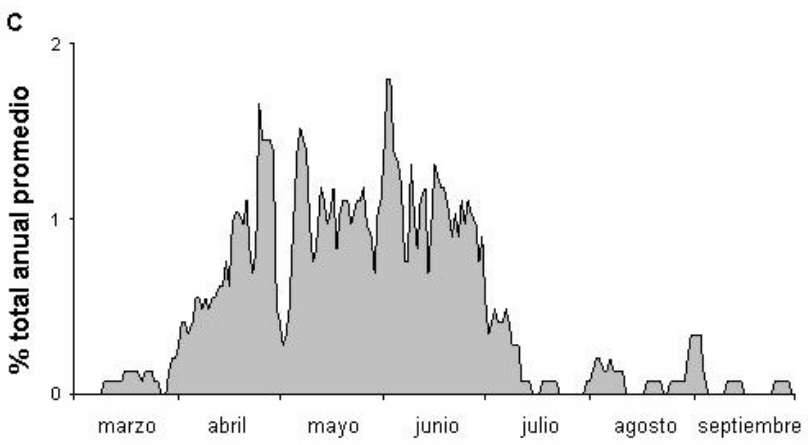

Fig. 5.2.5.8. Variación de las concentraciones medias diarias de Cruciferae durante el período 2003-2005 (A) y 2006-2007 (B). Porcentajes de representación diarios para la media de los cinco días anteriores dentro del promedio de los ocho años analizados (C). 


\subsubsection{J uncaceae}

La variación interanual (Fig. 5.2.5.9.) de este tipo polínico en la atmósfera mostró un descenso en los niveles polínicos anuales durante el período 20002007. Este descenso, desde la perspectiva numérica, supuso el paso de los 20 granos de polen en el año 2000 a los 7 de 2007 (un 122\% menos). El valor del índice de determinación $\left(\mathrm{R}^{2}=0,56\right)$, también refrenda de manera estadística mediante regresión lineal esta tendencia. Los porcentajes de representación sobre el total de pólenes contabilizados en cada anualidad estudiada variaron del $0,2 \%$ de 2000 a un porcentaje inferior al $0,1 \%$ de los últimos cuatro años, con un porcentaje medio inferior al o,1\%.

La dinámica que presentaron las concentraciones polínicas de Juncaceae (Fig. 5.2.5.10.D.) representada con el
Tipo polínico: Juncus acutus.

Especie(s): Juncus acutiflorus Ehrh. ex Hoffm., Juncus acutus L., Juncus bufonius L., Juncus effusus L., entre otras (Juncaceae).

Distribución: Familia botánica extendida por los dos hemisferios, ocupando diferentes hábitats, generalmente ambientes húmedos, como cursos de ríos, praderas inundadas parcialmente en algunas épocas del año, etc.

Época de floración: De mayo a julio, principalmente.

Polinización: anemófila.

Morfología polínica: polen en tétradas tetraédricas que presentan zonas invaginadas en las áreas distales pertenecientes a las cuatro mónadas, y un tamaño variable $(28-51 \mu \mathrm{m})$. La exina es delgada $(1 \mu \mathrm{m})$ posee una superficie finamente granulada, que en las áreas distales es granulado-verrugosa.

porcentaje promedio dentro de la media móvil los cinco días anteriores sobre el total promediado para los años analizados, mostró niveles de polen de esta familia a partir del mes de marzo con un incremento durante la última semana de mayo hasta mediados de junio (Fig. 5.2.2.5. A. B. C.). Posteriormente, se produjo una disminución en los niveles de polen en julio, manteniéndose en la atmósfera durante el mes de agosto con concentraciones puntuales. Las concentraciones diarias más elevadas dentro de los ocho años (Tabla 5.2.5.5.), variaron entre los 4 granos $/ \mathrm{m}^{3}$ (1 de marzo de 2003) y un grano/m³ (varios días de 2001, 2002 y en los últimos cuatro años estudiados). 


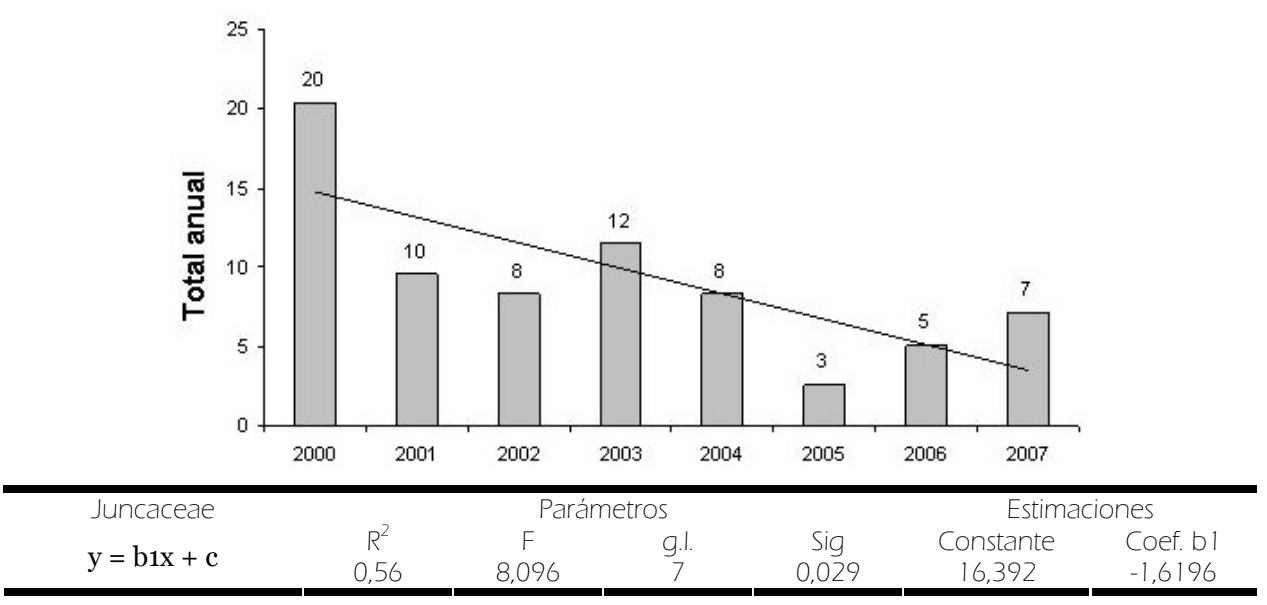

Fig. 5.2.5.9. Evolución anual del número total de pólenes de Juncaceae y tendencias (análisis de regresión).

\begin{tabular}{|c|c|c|c|c|c|c|c|c|c|}
\hline Juncaceae & 2000 & 2001 & 2002 & 2003 & 2004 & 2005 & 2006 & 2007 & Media \\
\hline Total & 20 & 10 & 8 & 12 & 8 & 3 & 5 & 7 & 9 \\
Máximo & 2 & 1 & 1 & 4 & 1 & 1 & 1 & 1 & 1 \\
Día & varios & varios & varios & $01-m a r$ & varios & varios & varios & varios & varios \\
\hline
\end{tabular}

Tabla 5.2.5.5. Totales y concentraciones máximas diarias y promedio para Juncaceae.
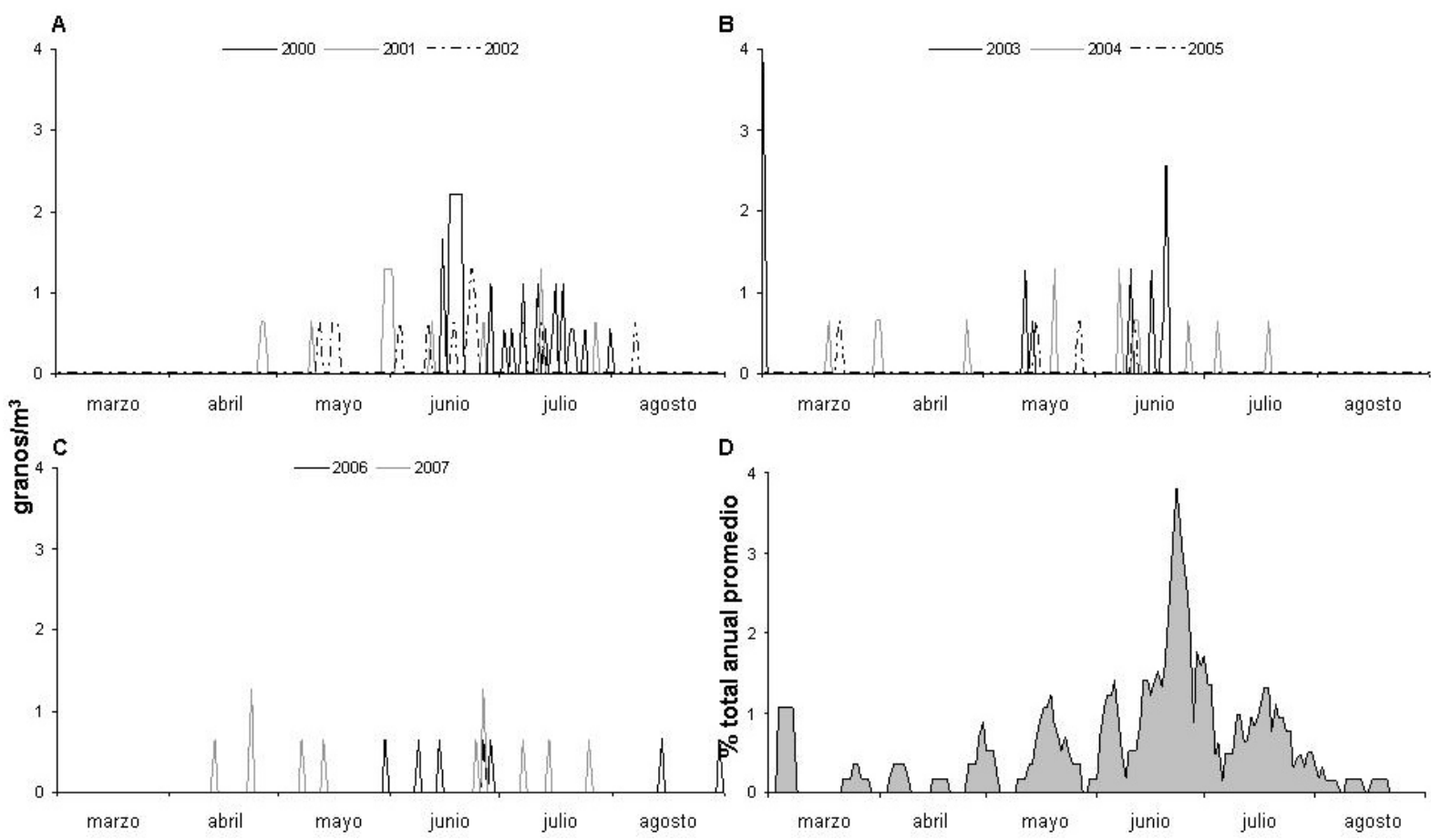

Fig. 5.2.5.10. Variación de las concentraciones medias diarias de Juncaceae durante el período 2000-2002 (A), 2003-2005 (B) y 2006-2007 (C). Porcentajes de representación diarios para la media de los cinco días anteriores dentro del promedio de los ocho años analizados (D). 


\subsubsection{Labiatae (= Lamiaceae)}

El tipo de polen que incluye a la familia Labiateae, experimentó un incremento en sus niveles polínicos a través de los ocho años analizados, con una variación interanual (Fig. 5.2.5.11.) que pasó de un total de 10 pólenes en el año 2000 a los 40 del año 2007. Este aumento (un 300\% más) en el número total de granos de polen, dio lugar a índice de determinación $\left(\mathrm{R}^{2}=0,48\right)$, propio de la regresión lineal, que confirmó esta tendencia. Los porcentajes de representación sobre el total de pólenes contabilizados en cada anualidad estudiada variaron del o,2\% de 2004 a un porcentaje inferior al o,1\% en los años 2001, 2002 y 2006, con un porcentaje medio inferior al $0,1 \%$.

Los niveles polínicos de esta familia botánica en la atmósfera de la ciudad de Salamanca

(Fig.

5.2.5.12.D.) experimentaron un ascenso a finales de abril y principios de mayo, mostrando una evolución irregular hasta mediados de agosto, gracias al porcentaje de
Tipo de polen: Labiatae.

Especie(s): Diversas especies de los géneros Lamium L., Lavandula L., Mentha L., Origanum L., Rosmarinus L., Thymus L, entre otros (Labiateae).

Distribución: Familia botánica extendida, sobretodo, en los regiones cálidas y secas, como lo es la región mediterránea $y$, consiguientemente, la Península Ibérica, donde se encuentran un buen número de especies que forman parte de diferentes ambientes.

Época de floración: De mayo a julio, principalmente.

Polinización: Entomófila.

Morfología polínica: Polen trizonocolpado o hexazonocolpado, isopolar y radiosimétrico o bisimétrco, con forma de circular a hexagonal cuadrangular y triangular en vista polar, y de circular-elíptica a rectangular en vista ecuatorial (de suboblato a prolato), y un tamaño variable $(\mathrm{P}=17-66 \mu \mathrm{m})$. Las aberturas simples tipo colpo son terminales o subterminales. La exina, de grosor variable $(1-4 \mu \mathrm{m})$, presenta una superficie perforada, reticulada o birreticulada, apareciendo en algunos casos, formas intermedias de estos tipos de ornamentación. representación de las concentraciones medias móviles de los cincos días anteriores con respecto al total anual. En todo caso, las mayores concentraciones diarias registradas en los ocho años estudiados (Fig. 5.2.5.12. A.B.C.; Tabla 5.2.5.6), oscilaron entre los 4 granos $/ \mathrm{m}^{3}$ (31 de mayo de 2004, 29 de abril de 2005 y 24 de abril de 2007) y 1 grano/m³ (varios días de 2001 y 2002). Después, estos niveles disminuyeron a finales del mes de julio y agosto. 


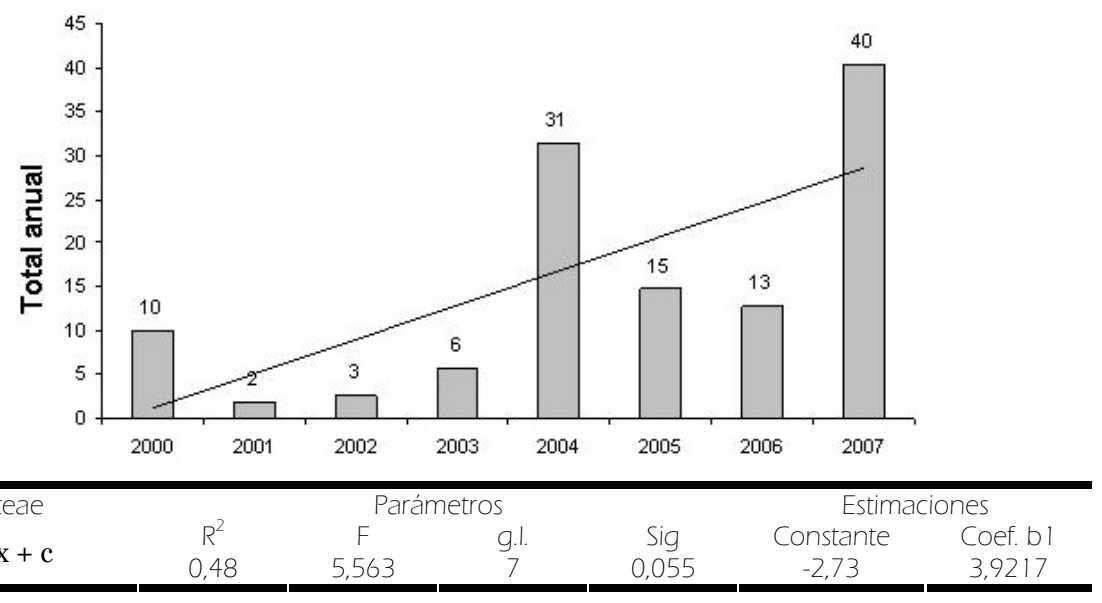

Fig. 5.2.5.11. Evolución anual del número total de pólenes de Labiatae y tendencias (análisis de regresión).

\begin{tabular}{|c|c|c|c|c|c|c|c|c|c|}
\hline Labiateae & 2000 & 2001 & 2002 & 2003 & 2004 & 2005 & 2006 & 2007 & Media \\
\hline Total & 10 & 2 & 3 & 6 & 31 & 15 & 13 & 40 & 15 \\
Máximo & 2 & 1 & 1 & 2 & 4 & 4 & 2 & 4 & 1 \\
Día & $23-j u n$ & varios & varios & 09-jul & 31-may & 29-abr & 09-jul & 24-abr & varios \\
\hline
\end{tabular}

Tabla 5.2.5.6. Totales y concentraciones máximas diarias y promedio para Labiatae.
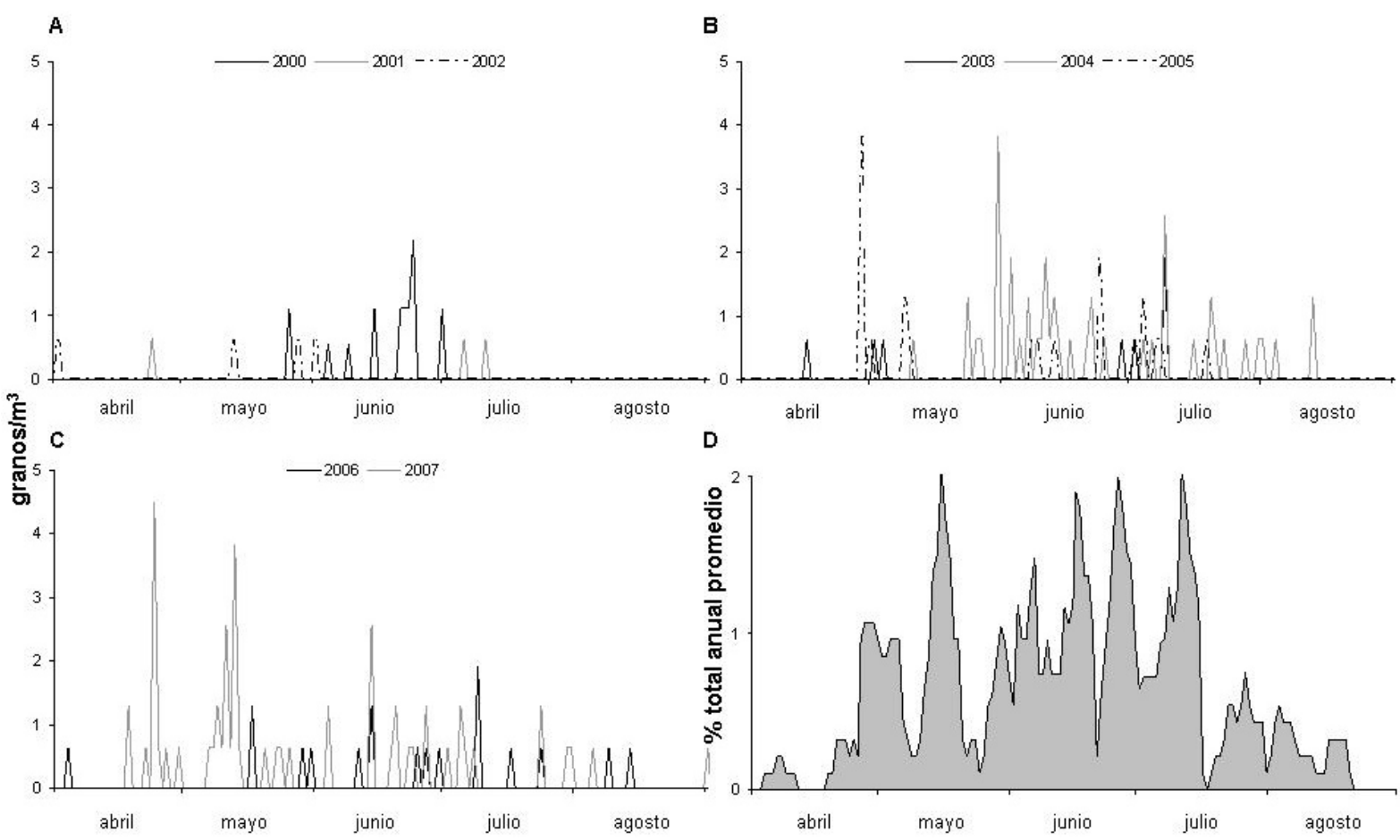

Fig. 5.2.5.12. Variación de las concentraciones medias diarias de Labiatae durante el período 2000-2002 (A), 2003-2005 (B) y 2006-2007 (C). Porcentajes de representación diarios para la media de los cinco días anteriores dentro del promedio de los ocho años analizados (D). 


\subsubsection{Lotus}

El tipo de polen que incluye al género Lotus L., mostró una distribución irregular en sus niveles atmosféricos durante el período analizado, con una variación interanual (Fig. 5.2.5.13.) que pasó de un máximo anual de 28 pólenes en el año 2003 a los 3 del año 2004 (6 en 2007), teniendo en cuenta que en los años 2000, 2005 y 2006, no se contabilizó ningún grano de polen. Esta evolución en el número total dio lugar a un índice de determinación $\left(\mathrm{R}^{2}=\mathrm{O}, \mathrm{O} 2\right)$, propio de la regresión lineal que reflejó también este patrón irregular. Los porcentajes de representación sobre el total de pólenes contabilizados en cada anualidad estudiada variaron del 0,3\% del año 2003 a un porcentaje inferior al 0,1\% de 2001, 2004 y 2007, con un porcentaje medio también inferior al $0,1 \%$.

Atendiendo al porcentaje que representó la media diaria de los cinco días anteriores para el conjunto de años estudiados con respecto al total promedio,
Tipo de polen: Lotus spp.

Especie(s): Lotus corniculatus L., Lotus pedunculatus Cav., Lotus uliginosus Schkuhr. entre otras (Fabaceae).

Distribución: Género prácticamente cosmopolita, bien sea como nativo o introducido, que, en la Península lbérica y la provincia de Salamanca, se localiza en prados y herbazales de diferente tipo, incluyendo los céspedes de los núcleos urbanos.

Época de floración: Primavera y verano, desde mayo hasta septiembre.

Polinización: Entomófila.

Morfología polínica (Lámina III): Polen trizonocolporado, heteropolar y radiosimétrico, con forma circular en vista polar y elíptica en vista ecuatorial (prolato o subprolato), y un tamaño pequeño $(P=14-20 \mu m)$. Las ectoaberturas tipo colpo son terminales, $y$ las endoaberturas tipo poro con membrana abertural granulada La exina $(0,5-2 \mu \mathrm{m})$ presenta una superficie reticulada o fosulada con lúmenes de contorno irregular de $1,5 \mu \mathrm{m}$, que disminuye en las zonas polares y desaparece en la proximidad de las aberturas.

los granos de polen de este género comenzaron a contabilizarse en la atmósfera de la ciudad de Salamanca (Fig. 5.2.5.14.C.) a finales de abril, experimentando un elevado ascenso a mediados de junio. Las mayores concentraciones diarias registradas en los ocho años estudiados (Tabla 5.2.5.7.) variaron entre los 6 granos $/ \mathrm{m}^{3}$ (11 de junio de 2003) y un grano/ $\mathrm{m}^{3}$ (varios días de 2001 y 2004). Posteriormente, los niveles polínicos disminuyeron a finales de junio y la primera mitad de julio, mostrando bajas concentraciones en el resto de julio y agosto (Fig. 5.2.5.14. A. B.). 


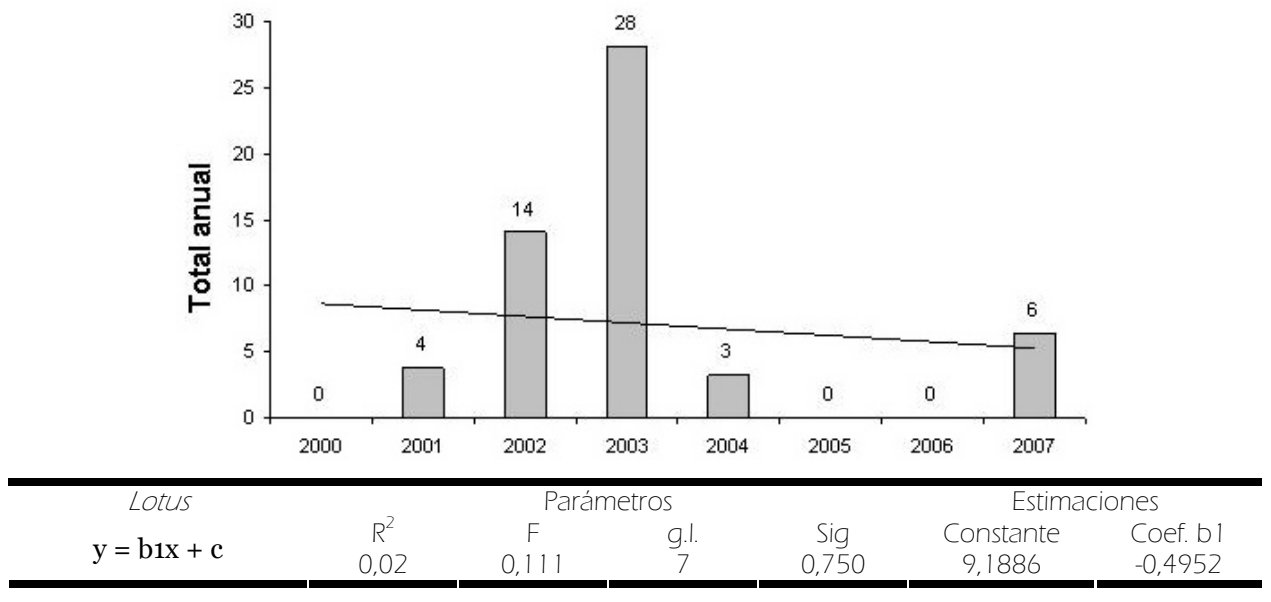

Fig. 5.2.5.13. Evolución anual del número total de pólenes de Lotus y tendencias (análisis de regresión).

\begin{tabular}{|c|c|c|c|c|c|c|c|c|c|}
\hline Lotus & 2000 & 2001 & 2002 & 2003 & 2004 & 2005 & 2006 & 2007 & Media \\
\hline Total & - & 4 & 14 & 28 & 3 & - & - & 6 & 11 \\
Máximo & - & 1 & 3 & 6 & 1 & - & - & 2 & 1 \\
Día & - & varios & varios & 11 -jun & varios & - & - & varios & varios \\
\hline
\end{tabular}

Tabla 5.2.5. Totales y concentraciones máximas diarias y promedio para Lotus.
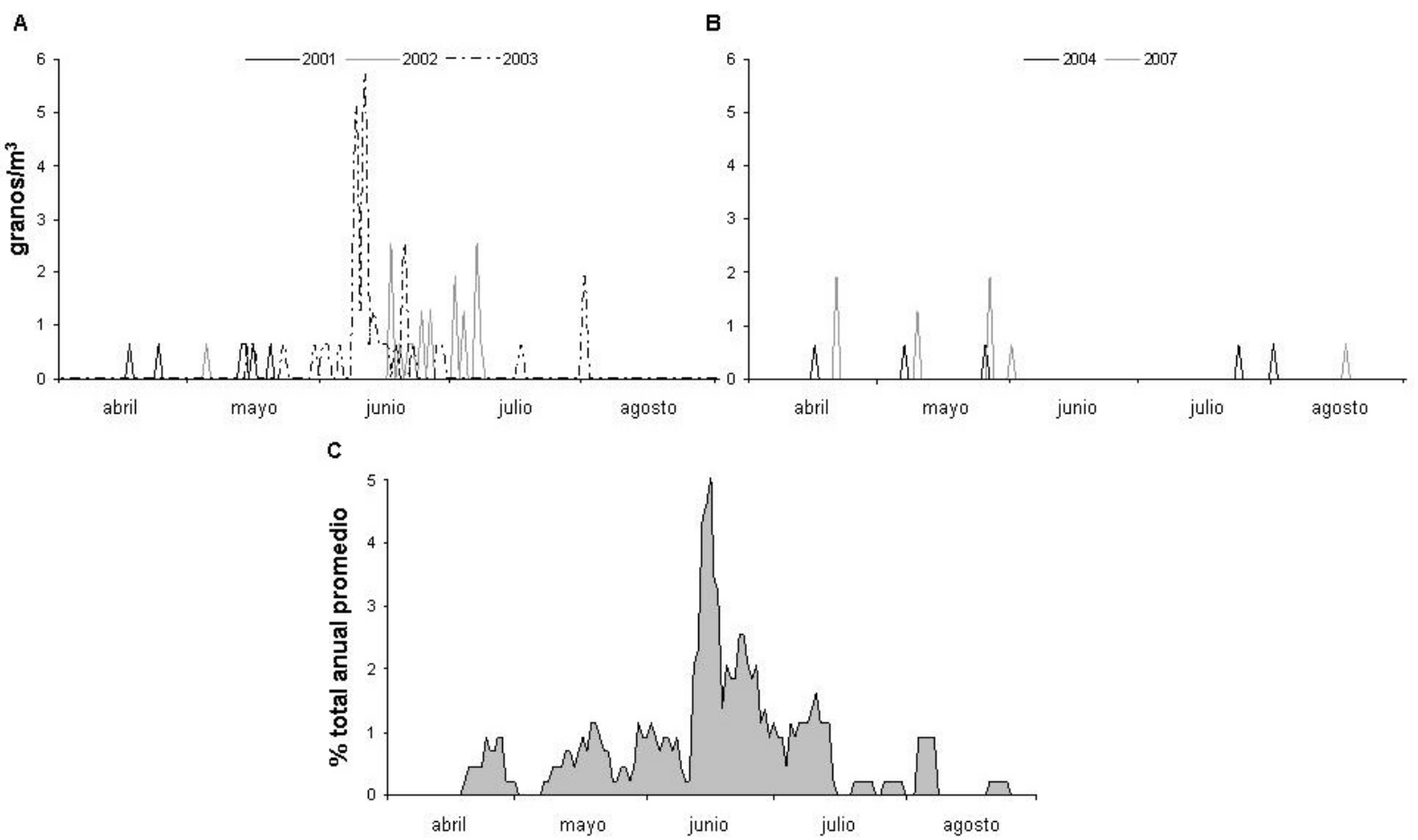

Fig. 5.2.5.14. Variación de las concentraciones medias diarias de Lotus durante el período 2001-2003 (A) y 2004, 2007 (B). Porcentajes de representación diarios para la media de los cinco días anteriores dentro del promedio de los ocho años analizados $(\mathbf{C})$. 


\subsubsection{Morus}

La variación interanual (Fig. 5.2.5.15.) nos indica que durante los ocho años de estudio hubo un incremento en las concentraciones de este tipo polínico en la atmósfera de Salamanca, pues el total anual pasó de los 2 pólenes del año 2001 a los 12 de 2007 (un 500\% más), tal y como muestra también el análisis de tendencias a través de la regresión lineal $\left(\mathrm{R}^{2}=0,41\right)$. No obstante, debe reseñarse que en los años 2000 y 2002 no se contabilizó ningún grano de polen de este tipo, y que el mayor valor total anual se correspondió con el año 2005 (33 pólenes). Estos valores supusieron entre un $0,3 \%$ (en 2003) y un porcentaje inferior al o,1\% (en 2001 y 2007) del total de pólenes contabilizados (promedio inferior al o,1\%).

La evolución de las concentraciones a través del porcentaje que representó la
Tipo polínico: Morus alba.

Especie(s): Morus alba L. y Morus nigra L. (Moraceae).

Distribución: Especies oriundas del centro y este de Asia, que en la Península Ibérica y la provincia de Salamanca se encuentra cultivada en parques, jardines, pudiéndose presentar de forma subespontánea.

Época de floración: Primaveral, sobretodo en abril y mayo.

Polinización: Anemófila.

Morfología polínica: Polen dizonoporado (a veces trizonoporado), isopolar y radiosimétrico, con una forma circular en ambas vistas (esferoidal), y un tamaño pequeño-mediano (diámetro $=16-28 \mu \mathrm{m}$ ). Las aberturas simples tipo poro son circulares, de $3 \mu \mathrm{m}$ de diámetro. La exina fina $(0,6-1 \mu \mathrm{m})$, posee una superficie granulada.

media diaria de los cinco días anteriores para el conjunto de años estudiados con respecto al total promedio, indicó que los niveles de polen aumentan desde la segunda mitad de marzo hasta el inicio de mayo (Fig. 5.2.5.16.C.), presentando una concentración máxima de 2 granos/m³ el día 1 de mayo como media de los ocho años estudiados (Tabla 5.2.5.8.). Las mayores concentraciones diarias para los años estudiados, oscilaron entre los 4 granos $/ \mathrm{m}^{3}$ (9 de mayo de 2005, 2 de mayo de 2006 y 1 de mayo de 2007) y 1 grano/m³ (varios días del año 2001). Posteriormente, las concentraciones de polen fueron disminuyendo durante el mes de mayo, encontrándose en valores bajos en junio, julio y principios de agosto (Fig. 5.2.5.16.A.B.). 


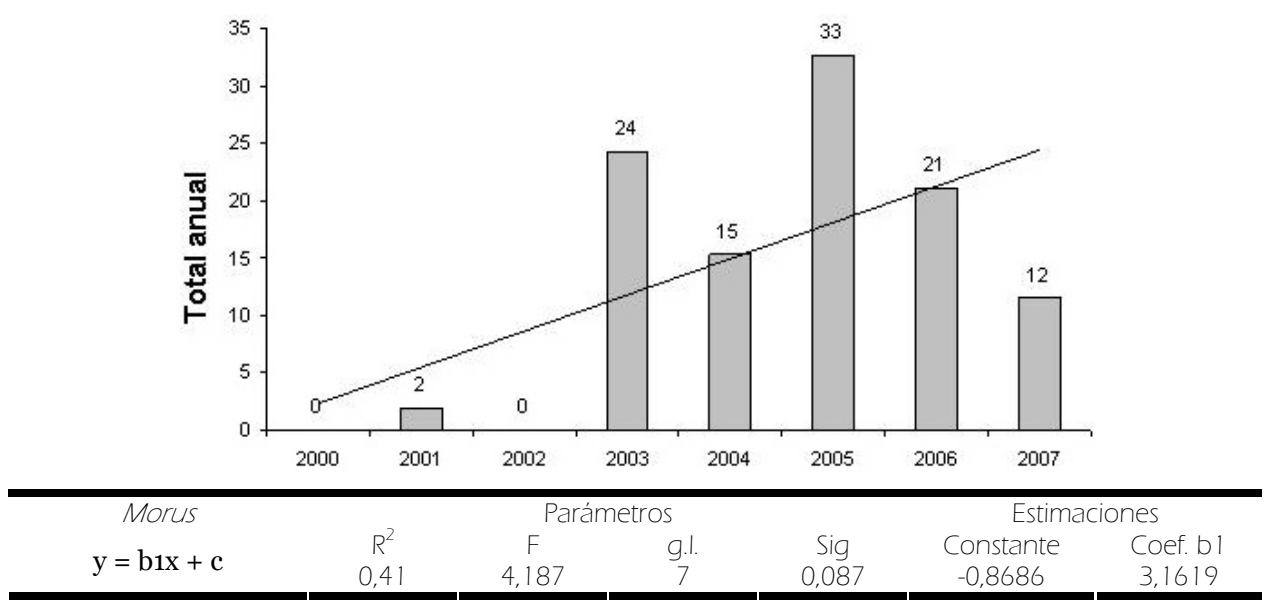

Fig. 5.2.5.15. Evolución anual del número total de pólenes de Morus y tendencias (análisis de regresión).

\begin{tabular}{|c|c|c|c|c|c|c|c|c|c|}
\hline Morus & 2000 & 2001 & 2002 & 2003 & 2004 & 2005 & 2006 & 2007 & Media \\
\hline Total & - & 2 & - & 24 & 15 & 33 & 21 & 12 & 18 \\
Máximo & - & 1 & - & 3 & 3 & 4 & 4 & 4 & 2 \\
Día & - & varios & - & varios & $27-a b r$ & 09-may & 02-may & 01 -may & $01-m a y$ \\
\hline
\end{tabular}

Tabla 5.2.5.8. Totales y concentraciones máximas diarias y promedio para Morus.

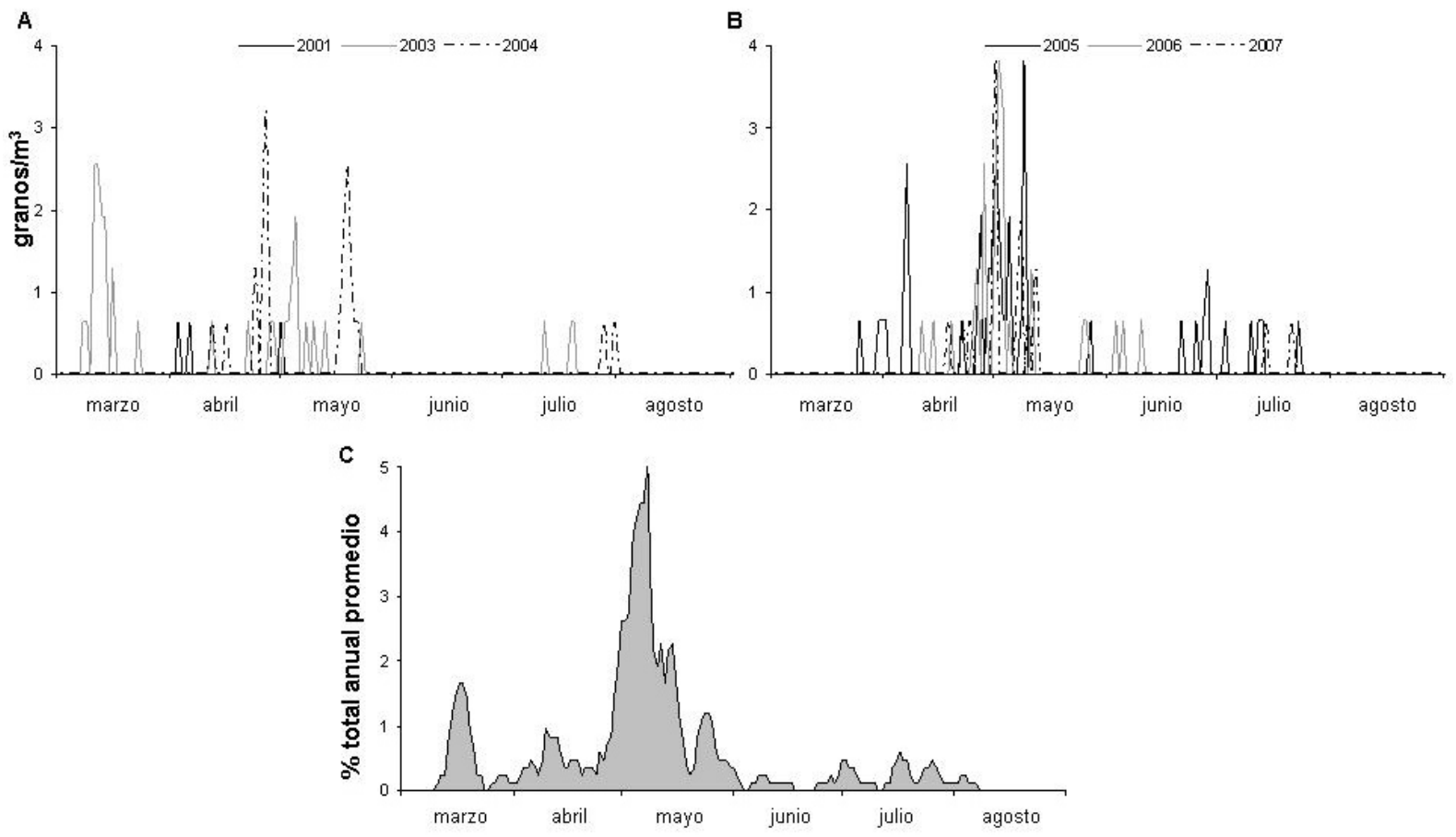

Fig. 5.2.5.16. Variación de las concentraciones medias diarias de Morus durante el período 2001, 2003-2004

(A) y 2005-2007 (B). Porcentajes de representación diarios para la media de los cinco días anteriores dentro del promedio de los ocho años analizados $(\mathbf{C})$. 


\subsubsection{Typha}

El tipo de polen que incluye al género Typha L. disminuyó sus niveles polínicos a través del período analizado, con una variación interanual (Fig. 5.2.5.17.) que pasó de un total de 28 granos de polen en el año 2000 a los 6 del año 2007. Esta evolución en el número total de granos de polen (un 366\% menos en los ocho años) dio lugar a un bajo índice de determinación $\left(\mathrm{R}^{2}=0,10\right)$, propio de la regresión lineal que indicó también una tendencia al decrecimiento. Los porcentajes de representación sobre el total de pólenes contabilizados en cada anualidad estudiada variaron del $0,2 \%$ de 2000 a un porcentaje inferior al $0,1 \%$ de 2007 , con un porcentaje medio de $0,1 \%$.

Los granos de polen de este género comenzaron a contabilizarse en la atmósfera de la ciudad de Salamanca (Fig. 5.2.5.18.D.) a partir de mayo, experimentando un ascenso a mediados de junio y manteniéndose en niveles altos hasta finales

Tipo de polen: Typha spp.

Especie(s): Typha angustifolia L., Typha latifolia L., y Typha dominguensis (Pers.) Steudel, (Typhaceae).

Distribución: Género prácticamente cosmopolita que habita en las riberas de ríos y zonas encharcadas de poca profundidad en aguas dulces, como también ocurre en la Península lbérica y la provincia de Salamanca.

Época de floración: Finales de primavera y verano, principalmente de mayo a julio.

Polinización: Anemófila.

Morfología polínica (Lámina IV): Polen monoanaporado, heteropolar y radiosimétrico o bisimétrico, con una forma circular-elíptica en ambas vistas (de oblato a suboblato), y un tamaño pequeño-mediano $(\mathrm{P}=20-26 \mu \mathrm{m})$. Las aberturas tipo poro son circulares, de 3 de diámetro y una membrana abertural verrugosa o granulada. La exina $(2-2,5 \mu \mathrm{m})$ posee una superficie insulado-rugulada o reticulada, con lúmenes irregulares $(2 \mu \mathrm{m})$ si presentan retículo. En ocasiones, puede dispersarse en tétradas. de julio, a través del porcentaje sobre el total anual promedio de la media de los cinco días anteriores promediados durante los años analizados. Asimismo, las mayores concentraciones diarias registradas en los ocho años estudiados (Tabla 5.2.5.9.), oscilaron entre los 6 granos $/ \mathrm{m}^{3}$ (18 de julio de 2005) y 1 grano/m³ (varios días de 2002 y 2007). Posteriormente, los niveles polínicos disminuyeron durante agosto, manteniéndose en la atmósfera hasta el mes de octubre (Fig. 5.2.5.18. A. B. C.). 


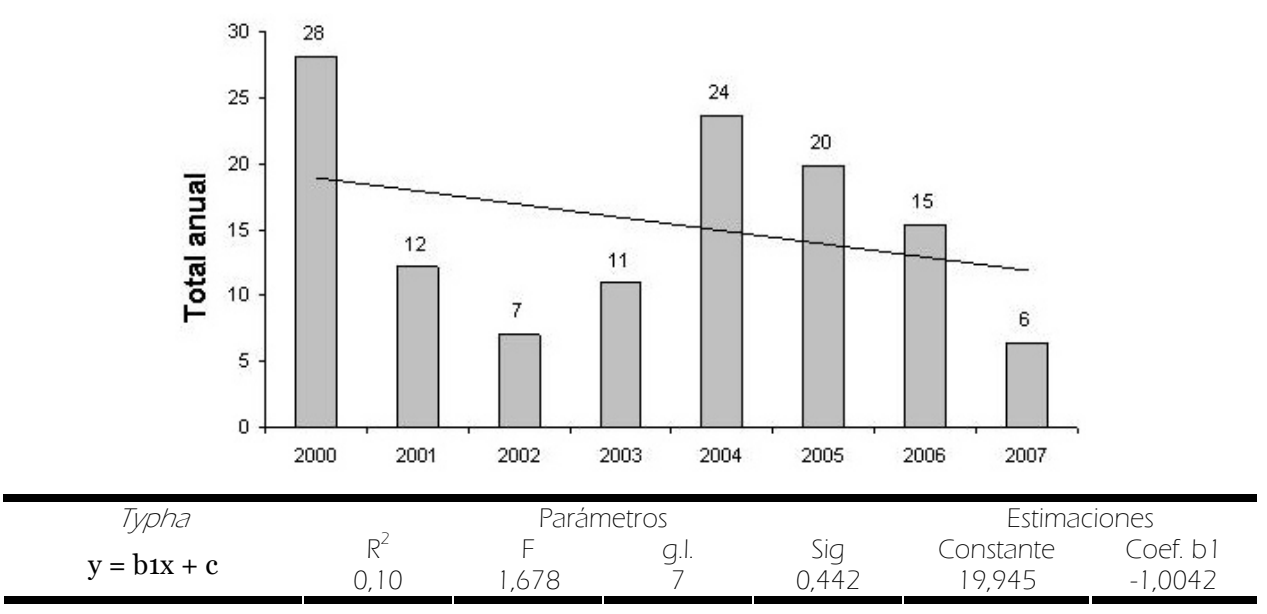

Fig. 5.2.5.17. Evolución anual del número total de pólenes de Typha y tendencias (análisis de regresión).

\begin{tabular}{|c|c|c|c|c|c|c|c|c|c|}
\hline Typha & 2000 & 2001 & 2002 & 2003 & 2004 & 2005 & 2006 & 2007 & Media \\
\hline Total & 28 & 12 & 7 & 11 & 24 & 20 & 15 & 6 & 15 \\
Máximo & 2 & 2 & 1 & 3 & 3 & 6 & 2 & 1 \\
Día & varios & $22-$ may & varios & $14-j u n$ & varios & $18-j u l$ & varios & varios & varios \\
\hline
\end{tabular}

Tabla 5.2.5.9. Totales y concentraciones máximas diarias y promedio para Typha.
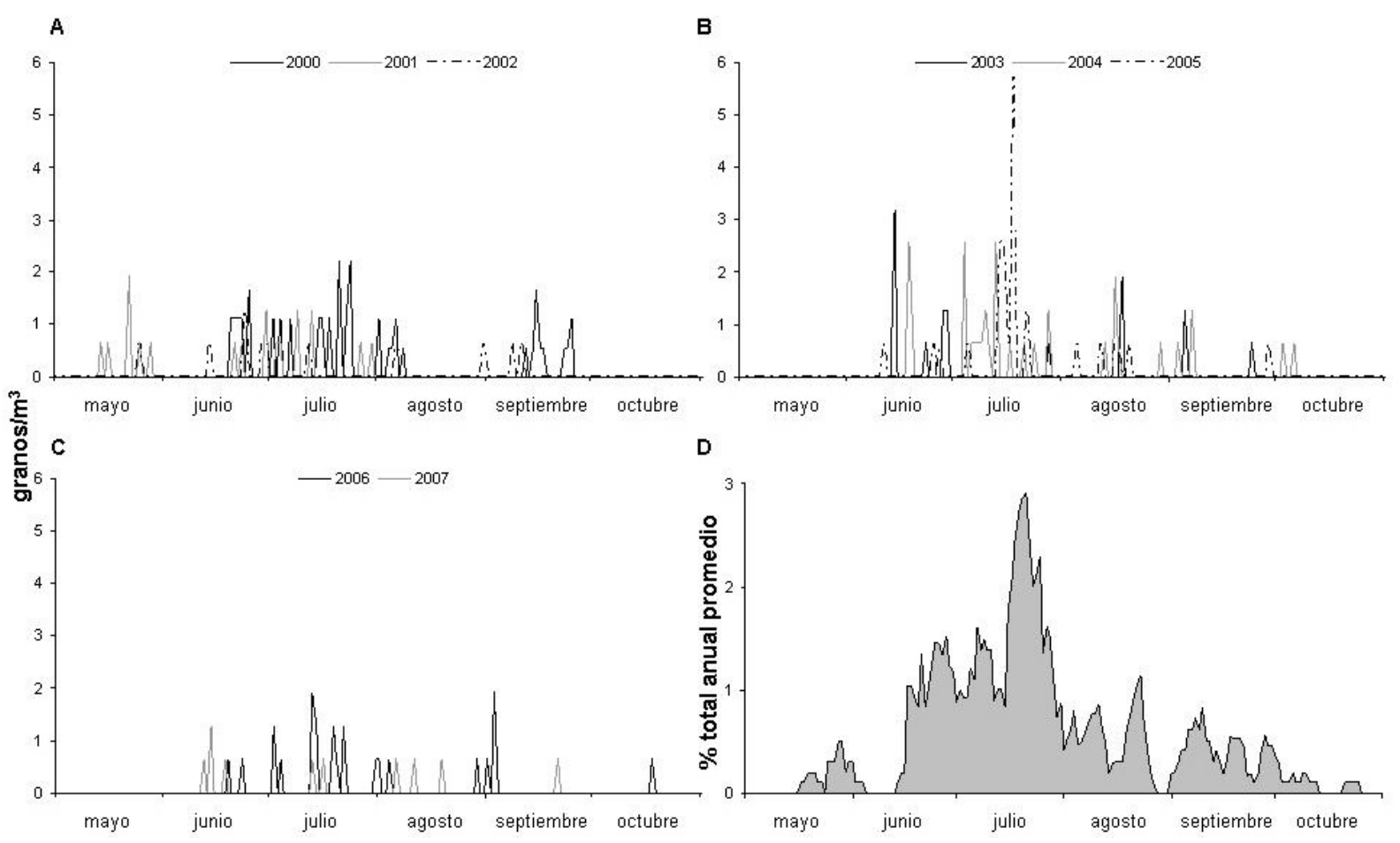

Fig. 5.2.5.18. Variación de las concentraciones medias diarias de Typha durante el período 2000-2002 (A), 2003-2005 (B) y 2006-2007 (C). Porcentajes de representación diarios para la media de los cinco días anteriores dentro del promedio de los ocho años analizados (D). 


\subsubsection{Umbelliferae (= Apiaceae)}

El tipo de polen en el que hemos incluido a la familia Umbelliferae, incrementó sus niveles polínicos durante el período analizado, con una variación interanual (Fig. 5.2.5.19.) que pasó de un total de 8 granos de polen en el año 2001 a los 58 del año 2007, si bien en los años 2000 y 2002 no se contabilizó ningún polen de este tipo, y el mayor valor anual se registró en el año 2006, con 65 pólenes. Esta evolución (un 625\% más) dio lugar a un índice de determinación $\left(\mathrm{R}^{2}=0,81\right)$, propio de la regresión lineal que indicó también una tendencia al incremento. Los porcentajes de representación sobre el total de pólenes contabilizados en cada anualidad estudiada variaron del o,3\% del año 2006 al o,1\% de los años 2001, 2004 y 2005, con un porcentaje medio de $0,125 \%$.

Atendiendo al porcentaje que representó la media diaria de los cinco días anteriores para el conjunto de años estudiados con respecto al total promedio, los granos de polen de esta familia comenzaron a contabilizarse en la atmósfera de la ciudad de Salamanca (Fig. 5.2.5.20.C.) en la primera semana de mayo, experimentando un ascenso a mediados del mismo mes. Estas mayores concentraciones diarias registradas en los ocho años estudiados (Tabla 5.2.5.10.), oscilaron entre los 6 granos $/ \mathrm{m}^{3}$ (23 de junio de 2006 y 13 de mayo de 2007) y 1 grano/m³ (varios días de 2003). A continuación, el polen de esta familia se mantuvo en la atmósfera hasta el mes de octubre (Fig. 5.2.5.20.A.B.).
Tipo de polen: Umbelliferae.

Especie(s): Numerosas especies de los géneros Apium L., Conium L.,, Conopodium Koch, Oenanthe L., Thapsia L., entre otros (Umbelliferae).

Distribución: Familia de casi 3000 especies con amplia difusión en las regiones templadas del hemisferio Norte, que al igual que en la Península Ibérica (con unas 200 especies) y la provincia de Salamanca, habitan en lugares húmedos, praderas o estepas, especialmente.

Época de floración: Variable en función de las especies, desde finales de primavera hasta finales de verano.

Polinización: Entomófila, excepcionalmente anemófila.

Morfología polínica (Lámina IV): Polen trizonocolporado, heteropolar y radiosimétrico, con forma triangular en vista polar y elíptica o subrectangular en vista ecuatorial (de prolatoesferoidal a perprolato), y un tamaño variable $(P=17-59 \mu \mathrm{m})$. Las ectoaberturas tipo colpo pueden ser largas o cortas, y las endoaberturas tipo poro a veces vestibuladas. La exina $(1,5-3$ $\mu \mathrm{m})$, presenta una superficie variable, pudiendo ser psilada, foveolada, rugulada o escábrida. 


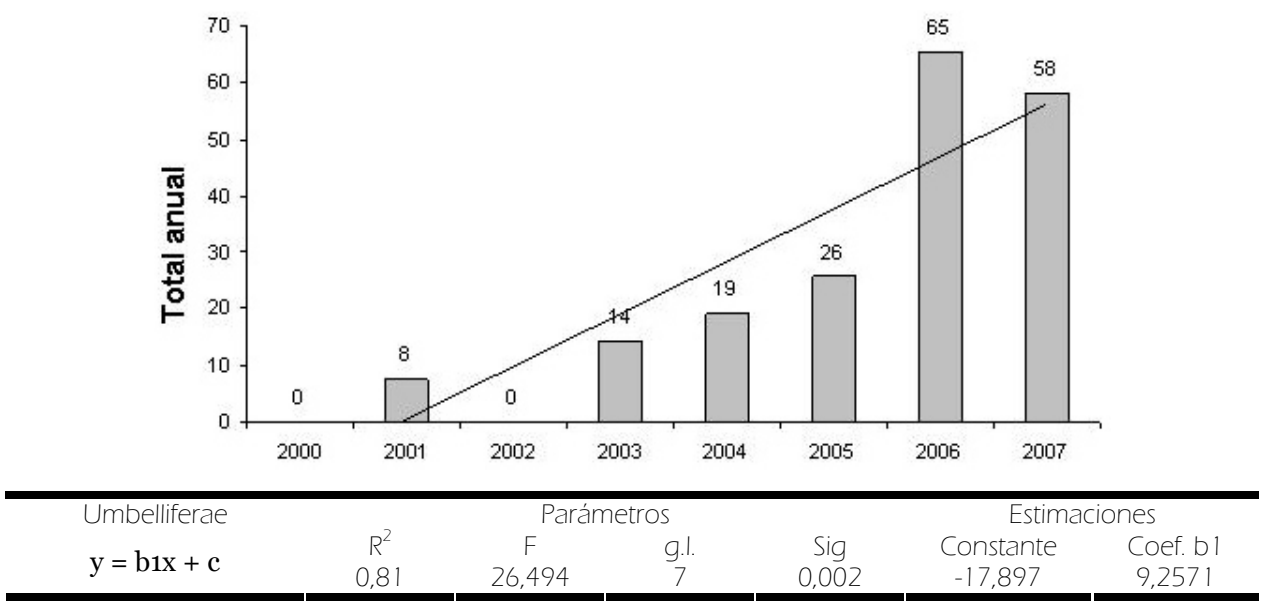

Fig. 5.2.5.19. Evolución anual del número total de pólenes de Umbelliferae y tendencias (análisis de regresión).

\begin{tabular}{|c|c|c|c|c|c|c|c|c|c|}
\hline Umbelliferae & 2000 & 2001 & 2002 & 2003 & 2004 & 2005 & 2006 & 2007 & Media \\
\hline Total & - & 8 & - & 14 & 19 & 26 & 65 & 58 & 32 \\
Máximo & - & 2 & - & 1 & 2 & 4 & 6 & 6 & 1 \\
Día & - & $25-j u n$ & - & varios & varios & 03-jun & $23-j u n$ & $13-m a y$ & varios \\
\hline
\end{tabular}

Tabla 5.2.5.10. Totales y concentraciones máximas diarias y promedio para Umbelliferae.

A
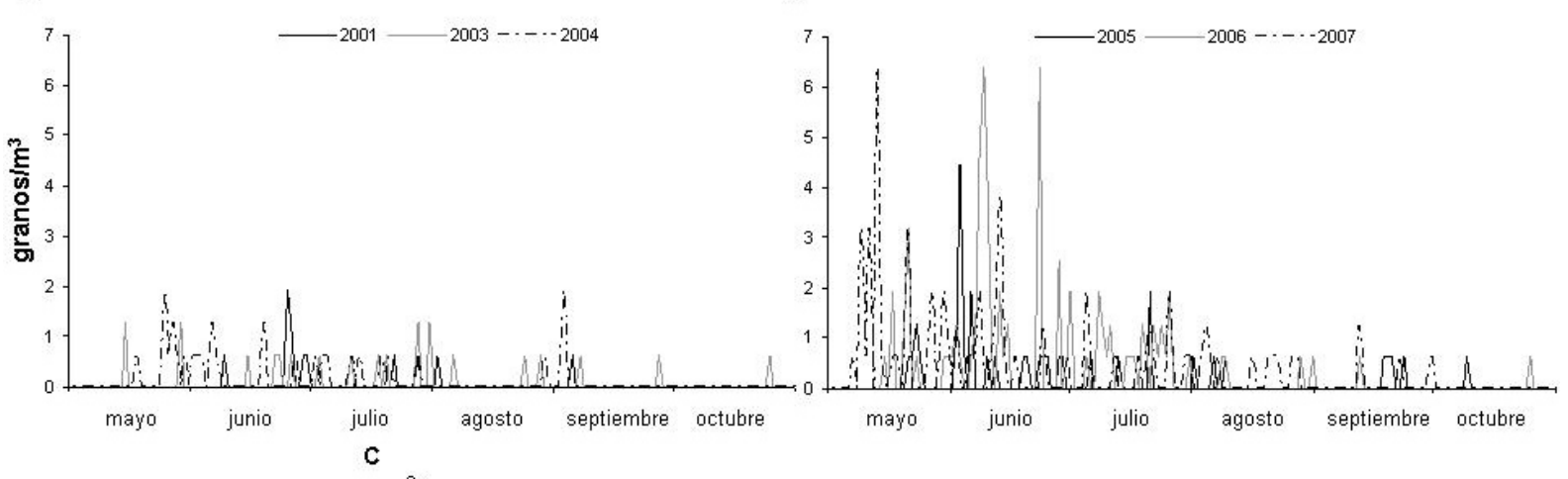

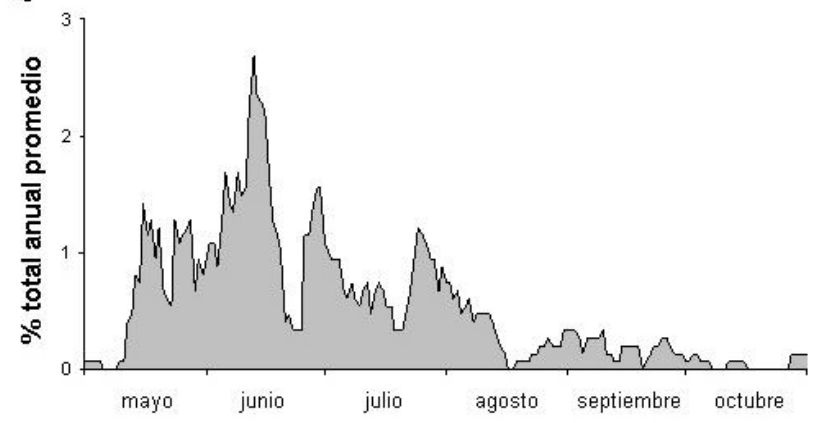

Fig. 5.2.5.20. Variación de las concentraciones medias diarias de Umbelliferae durante el período 2001, 20032004 (A) y 2005-2007 (B). Porcentajes de representación diarios para la media de los cinco días anteriores dentro del promedio de los ocho años analizados (C). 


\subsubsection{Viburnum}

La variación interanual (Fig. 5.2.5.21.) nos indica que durante los ocho años de estudio no existió un patrón definido en la evolución de los totales anuales, ya que si en los dos primeros años no se contabilizó ningún grano de polen (o un único grano en 2004), en el año 2002 se registraron 20 pólenes. Esta dinámica se vio refrendada la regresión lineal $\left(\mathrm{R}^{2}=\mathrm{O}, 01\right)$, que presentó un índice no significativo para una tendencia al incremento de este tipo polínico. La representación media de los pólenes de este género botánico a lo largo de los ocho años fue inferior a $0,1 \%$, con un máximo de $0,3 \%$ en 2002 y un mínimo inferior a 0,1\% en 2004, 2006 y 2007.

Los niveles polínicos de este género botánico en la atmósfera de la ciudad de Salamanca (Fig. 5.2.5.22.C.) aumentaron a finales de abril hasta alcanzar los valores más elevados a mediados de mayo, gracias a la dinámica aportada por el porcentaje de representación que tuvieron las concentraciones medias de los cincos días anteriores para el total promediado del conjunto de años estudiados. Asimismo, las mayores concentraciones diarias registradas dentro de este período (Tabla 5.2.5.11.), oscilaron entre los 9 granos $/ \mathrm{m}^{3}$ (18 de mayo de 2002) y 1 grano/m³ (2 de mayo de 2004, y varios días de 2006 y 2007). Posteriormente, estos niveles disminuyeron a finales de mayo, manteniéndose en la atmósfera, de forma irregular, durante el mes de junio (Fig. 5.2.5.22. A. B.). 


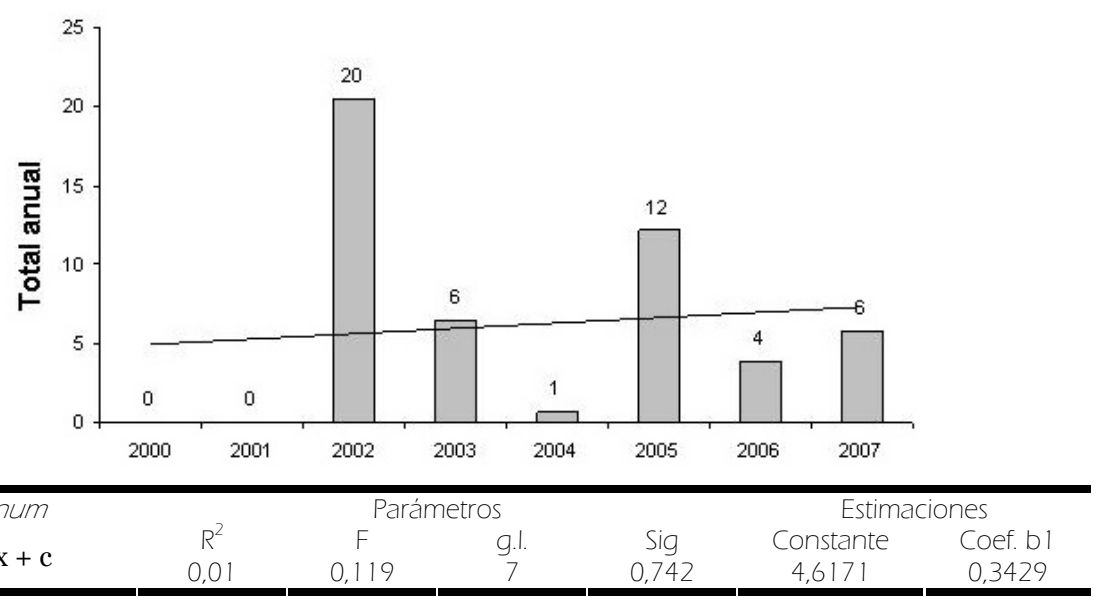

Fig. 5.2.5.21. Evolución anual del número total de pólenes de Viburnum y tendencias (análisis de regresión).

\begin{tabular}{|c|c|c|c|c|c|c|c|c|c|}
\hline Viburnum & 2000 & 2001 & 2002 & 2003 & 2004 & 2005 & 2006 & 2007 & Media \\
\hline Total & - & - & 20 & 6 & 1 & 12 & 4 & 6 & 8 \\
Máximo & - & - & 9 & 2 & 1 & 3 & 1 & 1 & 1 \\
Día & - & - & $18-m a y$ & varios & 02-may & $26-j u n$ & varios & varios & varios \\
\hline
\end{tabular}

Tabla 5.2.5.11. Totales y concentraciones máximas diarias y promedio para Viburnum.

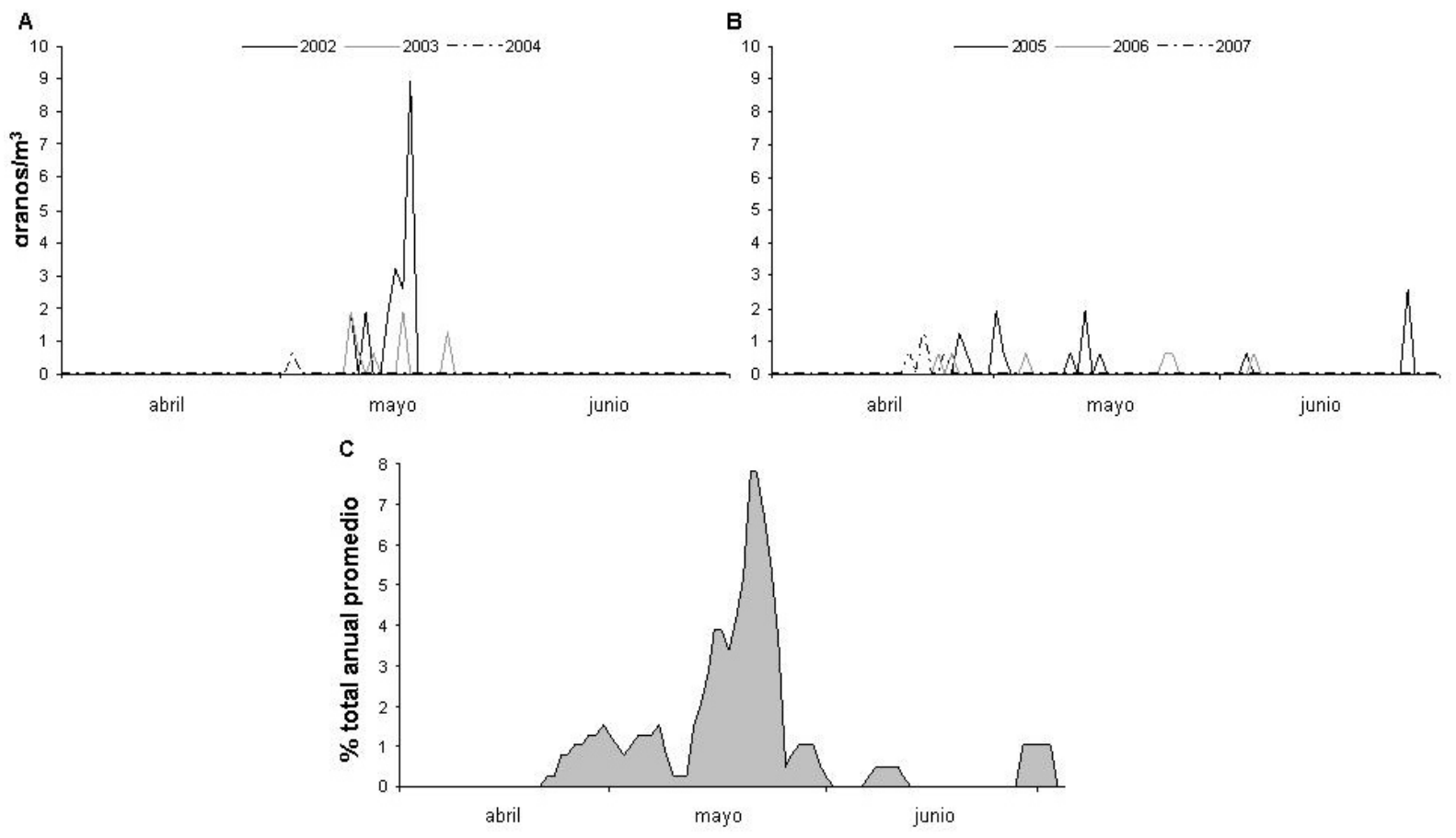

Fig. 5.2.5.22. Variación de las concentraciones medias diarias de Viburnum durante el período 2002-2004 (A) y 2005-2007 (B). Porcentajes de representación diarios para la media de los cinco días anteriores dentro del promedio de los ocho años analizados $(\mathbf{C})$. 


\subsubsection{Otros tipos de polen}

En este apartado se incluyen el resto de tipos de polen identificados en la atmósfera de la ciudad de Salamanca durante el período de estudio, que asciende a 23 tipos, que registraron totales anuales inferiores a los tipos tratados con anterioridad (Tabla 5.2.7.1.). Todos ellos se adscribieron a este grupo por no alcanzar el 0,1\% de representación total anual en más de dos años, pese a que muchos de ellos no alcanzasen este porcentaje en ninguna de las anualidades estudiadas (Tablas 5.2.1.2. y 5.2.1.3., págs. 57 y 58).

\begin{tabular}{cccc}
\hline \multicolumn{4}{c}{ Otros tipos de polen } \\
\hline Abies & Citrus & Malvaceae & Rubiaceae \\
Acacia & Convolvulus & Myrtaceae & Scrophulariaceae \\
Boraginaceae & Euphorbiaceae & Oxalis & Solanaceae \\
Caryophyllaceae & Forsythia & Pittosporum & Sophora \\
Celtis & Lagerstroemia & Ranunculaceae & Thymelaeaceae \\
Cistaceae & Liliaceae & Rhamnaceae & \\
\hline
\end{tabular}

Tabla 5.2.7.1 Otros tipos de polen identificados en Salamanca durante el período 2000-2007.

Entre todos estos tipos de polen, debemos destacar tres de ellos por alcanzar totales anuales elevados, con respecto al resto de tipos que forman parte de este grupo, durante algunos años analizados. Estos tipos se corresponden a las familias Euphorbiaceae (excluido Mercurialis), Myrtaceae (tipo polínico Myrtus communis; Lámina III), y Scrophulariaceae (Fig. 5.2.6.1.; Lámina IV), que registraron totales anuales como 28, 26 y 17 pólenes en los años 2007, 2005, y 2003, respectivamente. Todo ello conllevó que se alcanzasen también concentraciones polínicas máximas para estos tres tipos, tal y como se muestra en la Tabla 5.2.6.1., entre los 26 granos $/ \mathrm{m}^{3}$ de Euphorbiaceae (12 de junio de 2007), y los 2 granos $/ \mathrm{m}^{3} \mathrm{de}$ Scrophulariaceae (9 de julio, 29 de julio y 8 de agosto de 2003). No obstante, salvo en el caso del tipo polínico Myrtus communis, estos tipos de polen tuvieron una presencia irregular en la atmósfera de la ciudad de Salamanca, ya que no se encontraron granos de polen de los mismos en ciertos años del período 2000-2007. 


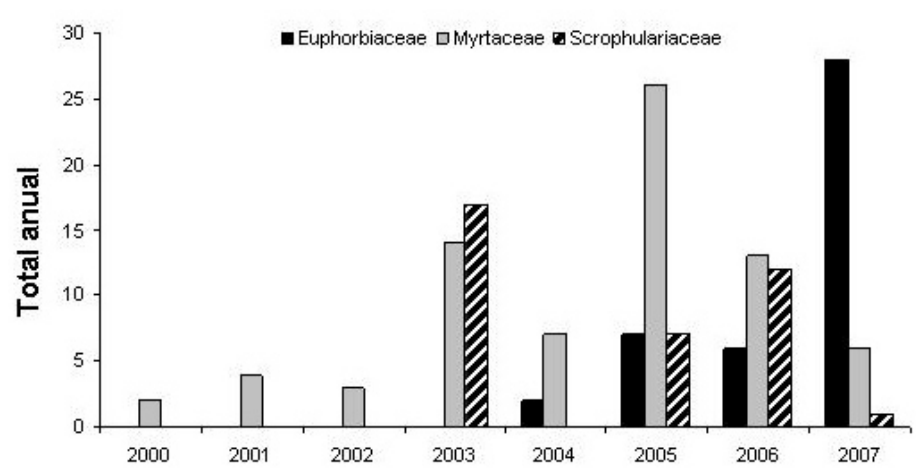

Fig. 5.2.6.1. Evolución anual del número total de pólenes de Euphorbiaceae (excluido Mercurialis), Myrtaceae y Scrophulariaceae.

El polen de otros nueve tipos se contabilizó en cinco de los ocho años incluidos en este estudio, tipos que no superaron totales anuales a 11 pólenes (Fig. 5.2.6.2.A.B.C.). Estos ocho tipos fueron Abies (Lámina I), Acacia (Lámina I), Boraginaceae (excluido Echium; Lámina I), Caryophyllaceae (Lámina I), Celtis (Tipo polínico Celtis australis), Cistaceae (Lámina I), Convolvulus (Tipo polínico Convolvulus arvensis; Lámina II), Liliaceae (Lámina II), Thymelaeaceae (Tipo polínico Thymelaea villosa; Lámina IV). Los valores máximos diarios (Tabla 5.2.6.1.) fueron bajos y no superaron los 4 granos $/ \mathrm{m}^{3}$, que alcanzó Caryophyllaceae el día 11 de julio de 2005, y que fue el total de pólenes contabilizados para este tipo en ese año.

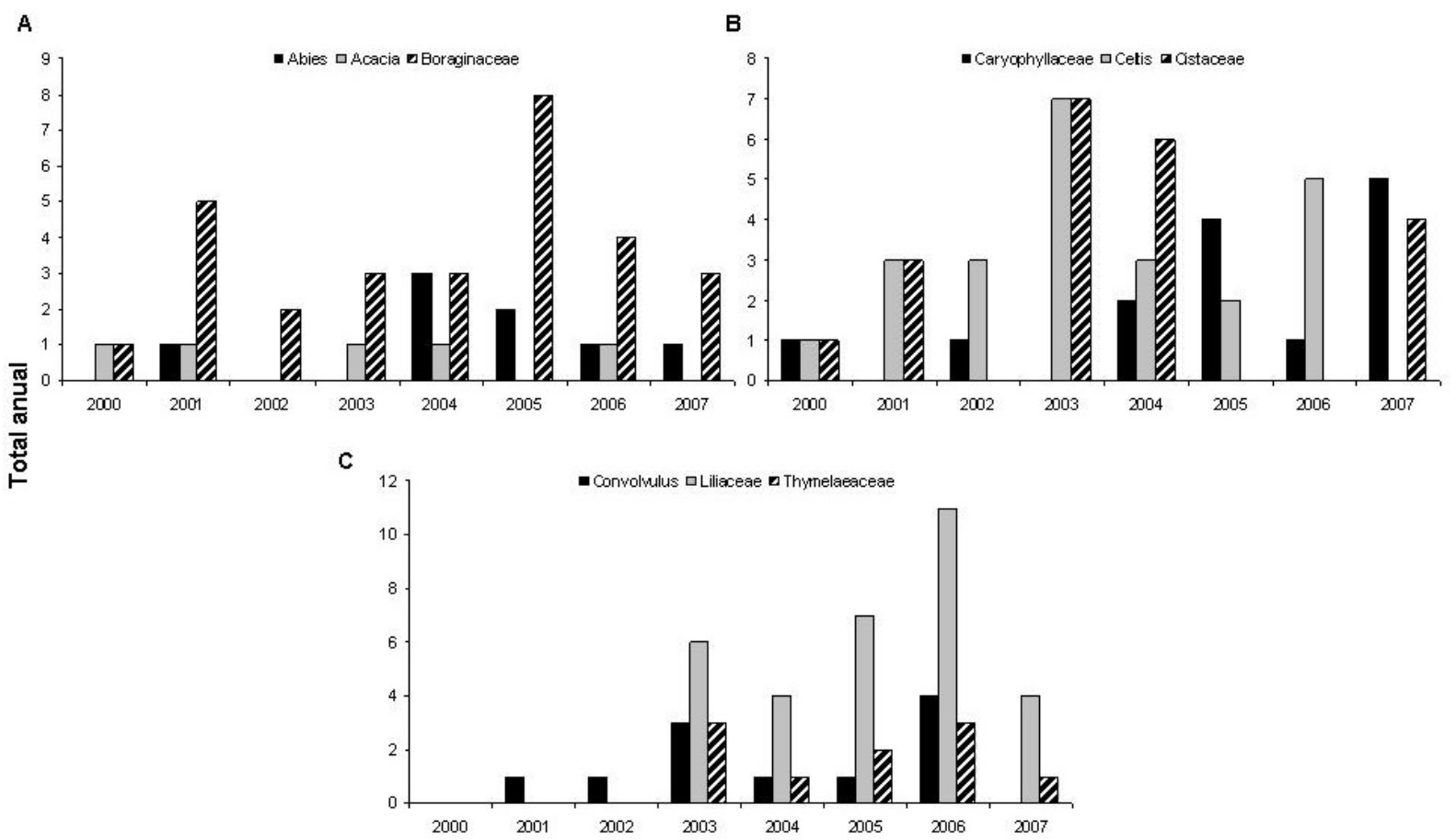

Fig. 5.2.6.2. Evolución anual del número total de pólenes de Abies, Acacia, Boraginaceae (excluido Echium) (A), Caryophyllaceae, Celtis, Cistaceae (B), Convolvulus, Liliaceae, y Thymelaeaceae (B). 


\begin{tabular}{|c|c|c|c|c|c|c|}
\hline \multicolumn{7}{|c|}{ Valores máximos diarios } \\
\hline Abies & $\begin{array}{c}\text { granos } / \mathrm{m}^{3} \\
\text { fecha }\end{array}$ & & & $\begin{array}{c}2 \\
\text { 26-abril-04 }\end{array}$ & & \\
\hline Caryophyllaceae & $\begin{array}{c}\text { granos } / \mathrm{m}^{3} \\
\text { fecha }\end{array}$ & & & $\begin{array}{c}4 \\
11-\text { julio-05 }\end{array}$ & & \\
\hline Celtis & $\begin{array}{c}\text { granos } / \mathrm{m}^{3} \\
\text { fecha }\end{array}$ & & & $\begin{array}{c}2 \\
\text { 9-abril-06 } \\
\end{array}$ & & \\
\hline Cistaceae & $\begin{array}{c}\text { granos } / \mathrm{m}^{3} \\
\text { fecha }\end{array}$ & & & $\begin{array}{c}2 \\
\text { 15-junio-07 }\end{array}$ & & \\
\hline Euphorbiaceae & $\begin{array}{c}\text { granos } / \mathrm{m}^{3} \\
\text { fecha }\end{array}$ & & $\begin{array}{l}4 \\
\text { nayo-05 }\end{array}$ & & $12-j u$ & \\
\hline Lagerstroemia & $\begin{array}{c}\text { granos } / \mathrm{m}^{3} \\
\text { fecha }\end{array}$ & & & $\begin{array}{c}4 \\
\text { 28-julio-05 } \\
\end{array}$ & & \\
\hline Myrtaceae & $\begin{array}{c}\text { granos } / \mathrm{m}^{3} \\
\text { fecha }\end{array}$ & & $\begin{array}{l}6 \\
\text { unio-03 } \\
\end{array}$ & & $27-j u$ & \\
\hline Scrophulariaceae & $\begin{array}{c}\text { granos } / \mathrm{m}^{3} \\
\text { fecha }\end{array}$ & $\begin{array}{c}2 \\
\text { 9-julio-03 }\end{array}$ & $\begin{array}{c}2 \\
\text { 29-julio-03 } \\
\end{array}$ & $\begin{array}{c}2 \\
\text { 8-agosto-03 }\end{array}$ & $\begin{array}{c}3 \\
\text { 6-junio-05 }\end{array}$ & $\begin{array}{c}3 \\
13,14-j u n i o-06 \\
\end{array}$ \\
\hline Sophora & $\begin{array}{c}\text { granos } / \mathrm{m}^{3} \\
\text { fecha }\end{array}$ & & & $\begin{array}{c}2 \\
\text { 16-julio-05 }\end{array}$ & & \\
\hline
\end{tabular}

Tabla 5.2.6.1 Valores máximos diarios y fecha en la que se produjo para el resto de tipos de polen $(<1$ grano/m3).

Durante tres o cuatro años se registraron pólenes de los tipos adscritos a Lagerstroemia, Rhamnaceae, Rubiaceae, Solanaceae y Sophora, que no tuvieron valores anuales superiores a 7 granos de polen (Fig. 5.2.6.3.), y que, consiguientemente, no alcanzaron concentraciones elevadas en la atmósfera, como ponen de manifiesto los 4 granos $/ \mathrm{m}^{3}$, que se registraron para Lagerstroemia el 28 de julio de 2005, y que supusieron el 100\% de los pólenes registrados en todo el estudio (Tabla 5.2.6.1.).

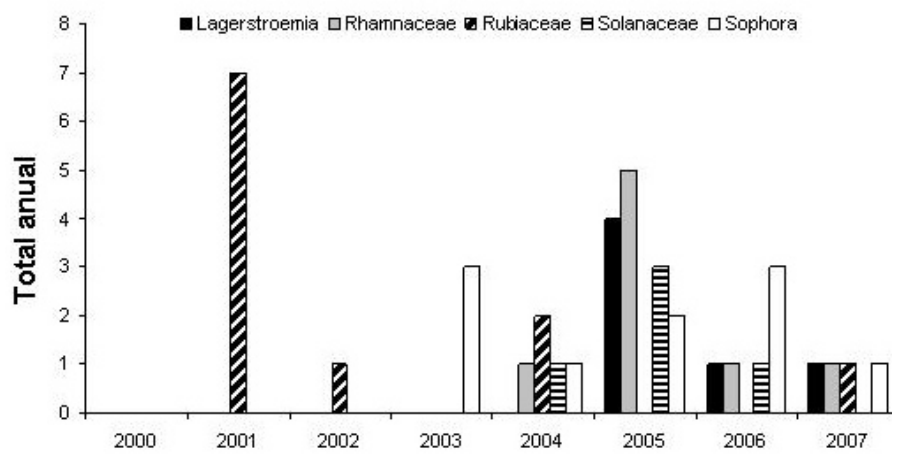

Fig. 5.2.6.3. Evolución anual del número total de pólenes de Lagerstroemia, Rhamnaceae, Rubiaceae, Solanaceae y Sophora.

Por último, debemos hacer mención a los tipos de polen que aparecieron de manera anecdótica en dos años de estudio, como es el caso de Oxalis en los años 2003 y 2005, y de Pittosporum, en el 2005 y 2007, pues sus totales anuales se situaron entre 1 y 2 pólenes (Tabla 5.2.1.2., pág. 57). De forma similar, en un único año de los estudiados se registró un único grano de polen de los tipos Citrus, Forsythia, Malvaceae y Ranunculaceae (años 2004, 2007, 2004 y 2003, respectivamente). 


\subsubsection{Calendario polínico}

Una de las herramientas más utilizadas en la relación interdisciplinar de la Aerobiología y la Medicina, sobretodo en la última década del pasado siglo XX, ha sido el calendario polínico, que permite de una forma gráfica y sencilla comprobar la presencia estacional de los tipos de polen más abundantes en la atmósfera de, generalmente, un núcleo urbano con gran densidad de población. Así pues, el calendario polínico de la ciudad de Salamanca fue elaborado a partir de los datos obtenidos tras el análisis diario de las muestras en el período 2000-2007, incluyendo a todos los tipos de polen que hayan alcanzado, al menos, el valor medio decenal de 1 grano $/ \mathrm{m}^{3}$ durante alguna época del año. Para la configuración del mismo se han seguido las clases exponenciales propuestas por Spieksma (1991), que se indican en la Fig. 5.2.7.1., y en la que aparecen un total de 32 tipos de polen, ordenados cronológicamente (Fig. 5.2.7.2.).

Atendiendo a los valores obtenidos en las medias decenales promedio para todo el período analizado, el tipo de polen Quercus registró la clase exponencial más alta, 7 (100-199 granos $/ \mathrm{m}^{3}$ ) durante las dos últimas decenas del mes de mayo. Le sigue en importancia, la familia Poaceae, que presentó elevadas concentraciones decenales (50-99 granos/m3), durante todo el mes de junio. También mostraron valores altos (24-49 granos/m³), los tipos Cupressaceae, en las dos primeras decenas de marzo, Platanus, en la primera decena de abril, y Olea, en los últimos diez días de mayo. De igual modo, los tipos Populus (últimas dos decenas de marzo), Pinus (primera decena de junio), Plantago (segunda decena de mayo) y Rumex (últimos veinte días de mayo), presentaron valores decenales promedio entre los 12 y los 23 granos $/ \mathrm{m}^{3}$. Cabe reseñar que Fraxinus, Urticaceae y Castanea, tuvieron registros dentro de la tercera clase exponencial (6-11 granos/m3), en diferentes épocas del año, como la segunda decena de febrero, los primeros veinte días de junio o la última decena de junio y la primera de julio, respectivamente. Los veinte tipos restantes no superaron los cinco granos por metro cúbico como valor medio decenal. 


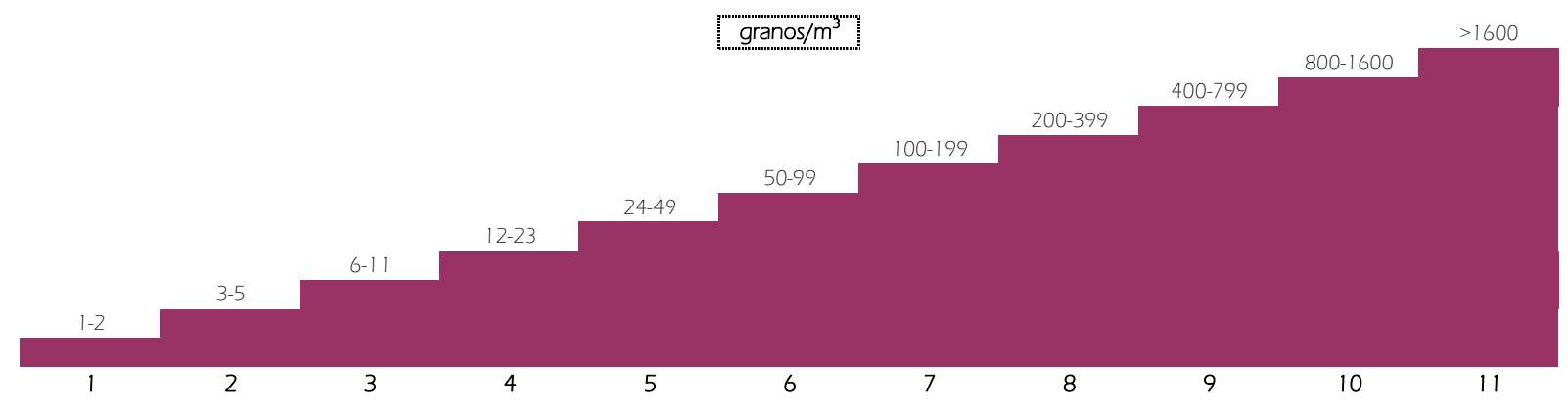

Fig. 5.2.7.1. Clases exponenciales (Spieksma, 1991), con la altura de las barras modificada.

Respecto a la permanencia en la atmósfera de la ciudad de Salamanca, destacaron notablemente las familias Poaceae, Cupressaceae y Urticaceae con respecto al resto de tipos, con una localización estacional más marcada, y que nos indicó un período de presencia muy dilatado. En el lado opuesto, se encontraron los tipos Artemisia y Sambucus, con una gran delimitación a finales de primavera y verano, respectivamente.

En último lugar, el calendario polínico permitió, además, conocer en qué meses hubo mayor variedad de tipos de polen y en cuales un menor número. En este caso, los meses de mayo y junio, con 23 tipos de los 32 incluidos, fueron los meses con más tipos, mientras que en octubre y noviembre sólo se registraron valores medios decenales superiores a $1 \mathrm{grano} / \mathrm{m}^{3}$, las familias Poaceae y Cupressaceae, respectivamente. 


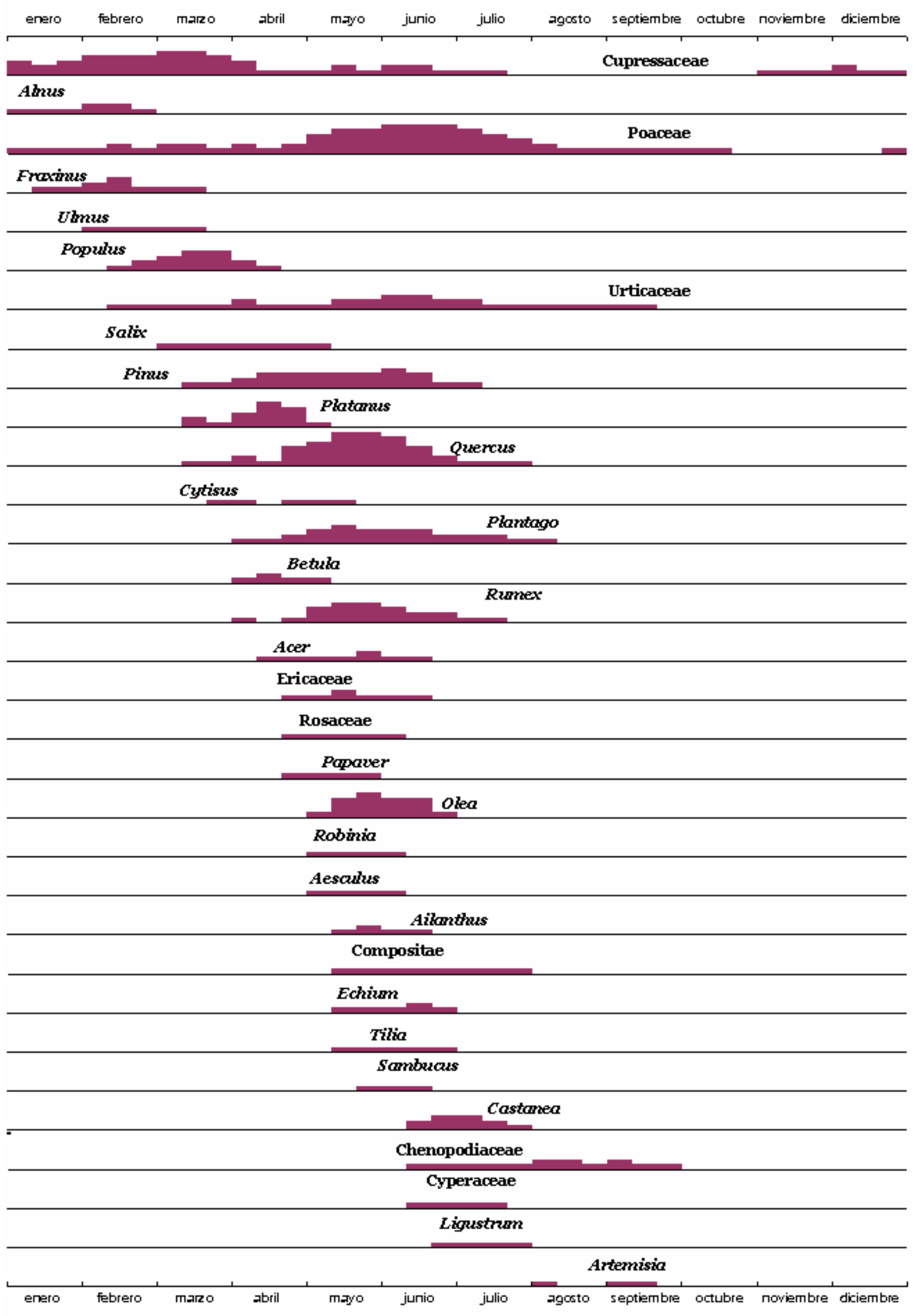

Fig. 5.2.7.2. Calendario polínico de la ciudad de Salamanca. Período 2000-2007. 


\subsection{Comparativa entre los dos captadores}

Tal y como hemos señalado en el apartado referente a la metodología de muestreo, entre el 1 de febrero de 2007 y el 7 de febrero de 2008, se comprobó el contenido polínico reflejado en dos captadores localizados en dos emplazamientos diferentes de la ciudad de Salamanca. El primero de ellos, el utilizado para evaluar las posibles diferencias interanuales, estacionales, diarias y horarias en el período 2000-2007, estuvo enclavado en el centro histórico, en la confluencia de las calles Obispo Jarrín y Pozo Amarillo, en el edificio del Patronato Municipal de la Vivienda a 20 metros sobre el nivel del suelo y a escasos metros de la Plaza Mayor (Fig. 5•3.1.). El segundo de ellos se situó en la azotea de la Facultad de Farmacia de la Universidad de Salamanca, en el Campus Miguel de Unamuno, al sur de la ciudad, próximo al río Tormes y a 2 kilómetros del anterior captador.

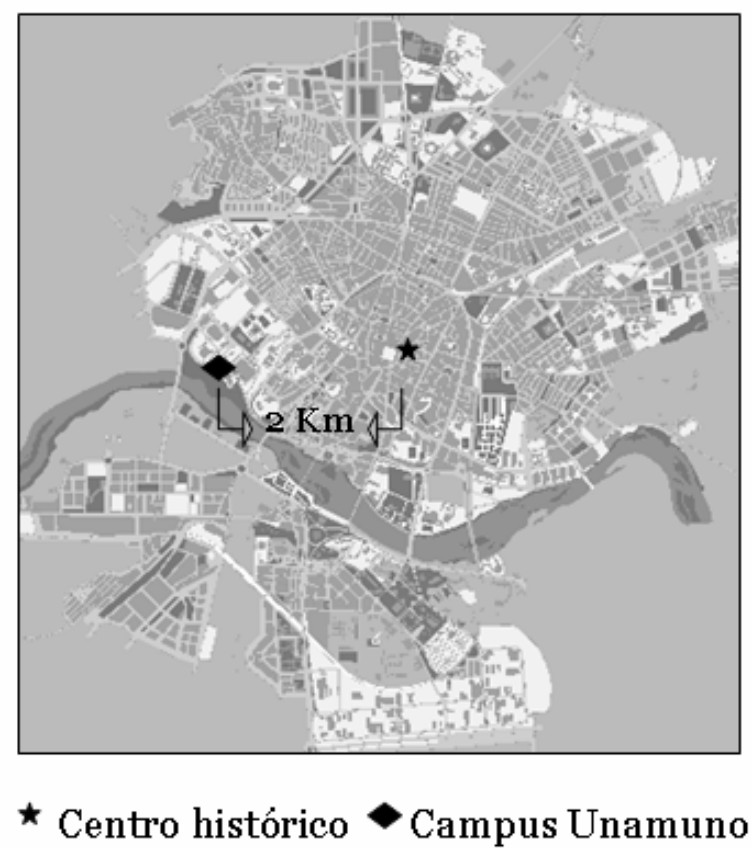

Fig. 5.3.1. Localización de los captadores utilizados entre el 1 de febrero de 2007 y el 7 de febrero de 2008, en la ciudad de Salamanca.

En el captador situado en el centro histórico se contabilizaron 31478 pólenes adscritos a 64 tipos de polen, mientras que en el captador emplazado en el Campus Miguel de Unamuno fueron 28493 granos de polen con 61 tipos. Estas diferencias cualitativas fueron debidas a que los tipos Boraginaceae, Pittosporum, Scrophulariaceae, Sophora y Thymeleaceae, no se contabilizaron en el segundo captador, al igual que Convolvulus, Medicago y Philadelphus, en el primero (Tabla 5.3.1.). 


\begin{tabular}{|c|c|c|c|c|c|c|c|c|}
\hline \multirow{2}{*}{ Tipo / Año } & \multicolumn{4}{|c|}{ Captador Centro histórico } & \multicolumn{4}{|c|}{ Captador Campus Miguel de Unamuno } \\
\hline & Total & $\%$ & Valor máx. & Fecha & Total & $\%$ & Valor máx. & Fecha \\
\hline Abies & 1 & - & 1 & 23-abr-07 & 1 & - & 1 & 17-abr-07 \\
\hline Acer & 96 & 0,3 & 14 & 04-jul-07 & 138 & 0,5 & 22 & 17-abr-07 \\
\hline Ailanthus & 14 & - & 5 & 28-jun-07 & 14 & - & 4 & 26-jun-07 \\
\hline Aesculus & 39 & 0,1 & 8 & 10-may-07 & 31 & 0,1 & 4 & 20-may-07 \\
\hline Alnus & 200 & 0,6 & 19 & 01-feb-08 & 138 & 0,5 & 12 & $01-f e b-08$ \\
\hline Artemisia & 67 & 0,2 & 4 & varios & 40 & 0,1 & 4 & 15-sep-07 \\
\hline Betula & 150 & 0,5 & 20 & 09-may-07 & 112 & 0,4 & 13 & 14-abr-07 \\
\hline Boraginaceae $^{1}$ & 3 & - & 1 & varios & & & & \\
\hline Campanula & 10 & - & 2 & 09-jun-07 & 12 & - & 2 & varios \\
\hline Castanea & 410 & 1,3 & 62 & 08-jul-07 & 374 & 1,3 & 60 & 08-jul-07 \\
\hline Caryophyllaceae & 5 & - & 1 & varios & 3 & - & 2 & 17-abr-07 \\
\hline Cedrus & 15 & - & 2 & varios & 4 & - & 1 & varios \\
\hline Chenopodiaceae & 223 & 0,7 & 10 & 18-ago-07 & 163 & 0,6 & 6 & 03-ago-07 \\
\hline Cistaceae & 4 & - & 2 & 15-jun-07 & 4 & - & 2 & 13-may-07 \\
\hline Compositae $^{2}$ & 111 & 0,4 & 6 & 12-jun-07 & 86 & 0,3 & 8 & 07-dic-07 \\
\hline Convolvulus & & & & & 2 & - & 1 & varios \\
\hline Corylus & 5 & - & 3 & 25-ene-08 & 8 & - & 2 & 22-ene-08 \\
\hline Cruciferae & 49 & 0,2 & 3 & varios & 56 & 0,2 & 4 & 24-abr-07 \\
\hline Cupressaceae & 4047 & 12,9 & 550 & 04-mar-07 & 3728 & 13,1 & 853 & 10-mar-07 \\
\hline Сyperaceae & 76 & 0,2 & 4 & varios & 74 & 0,3 & 4 & 07-jul-07 \\
\hline Cytisus & 45 & 0,1 & 3 & varios & 76 & 0,3 & 6 & 29-abr-07 \\
\hline Echium & 234 & 0,7 & 18 & 09-jun-07 & 221 & 0,8 & 14 & 13-jun-07 \\
\hline Ericaceae & 196 & 0,6 & 39 & 09-may-07 & 226 & 0,8 & 56 & 09-may-07 \\
\hline Euphorbiaceae 4 & 28 & 0,1 & 26 & 12-jun-07 & 1 & - & 1 & 25-jul-07 \\
\hline Forsythia & 1 & - & 1 & varios & 8 & - & 3 & 11 -abr-07 \\
\hline Fraxinus & 425 & 1,4 & 51 & 16-feb-07 & 504 & 1,8 & 53 & 12-feb-07 \\
\hline Helianthus & 18 & 0,1 & 3 & 21-jul-07 & 26 & 0,1 & 3 & 03-ago-07 \\
\hline Juglans & 21 & 0,1 & 4 & 10-may-07 & 16 & 0,1 & 7 & 09-may-07 \\
\hline Juncaceae & 7 & - & 1 & varios & 6 & - & 1 & varios \\
\hline Labiateae & 40 & 0,1 & 4 & 24-abr-07 & 76 & 0,3 & 9 & 24-abr-07 \\
\hline Lagerstroemia & 1 & - & 1 & 26-oct-07 & 1 & - & 1 & 06-ago-07 \\
\hline Liliaceae & 3 & - & 1 & varios & 1 & - & 1 & 09-may-07 \\
\hline Liguliflorae & 96 & 0,3 & 13 & 24-jun-07 & 72 & 0,3 & 4 & 7-jun-07 \\
\hline Ligustrum & 9 & - & 2 & 18-jun-07 & 5 & - & 1 & varios \\
\hline Lotus & 6 & - & 2 & 27-may-07 & 3 & - & 1 & varios \\
\hline Medicago & & & & & 1 & - & 1 & 30-sep-07 \\
\hline Mercurialis & 17 & - & 4 & 26-jul-07 & 9 & - & 2 & 01 -sep-07 \\
\hline Moraceae & 12 & - & 4 & 01-may-07 & 8 & - & 1 & varios \\
\hline Myrtaceae & 6 & - & 1 & varios & 10 & - & 1 & varios \\
\hline Olea & 678 & 2,2 & 162 & 08-jun-07 & 525 & 1,8 & 107 & 08-jun-07 \\
\hline Papaver & 4 & - & 1 & varios & 1 & - & 1 & 23-may-07 \\
\hline Philadelphus & & & & & 17 & 0,1 & 15 & 10-jun-07 \\
\hline Pinus & 686 & 2,2 & 79 & 05-jun-07 & 236 & 0,8 & 42 & 06-jun-07 \\
\hline Pittosporum & 2 & - & 1 & varios & & & & \\
\hline Plantago & 1706 & 5,4 & 159 & 13-jul-07 & 1437 & 5,0 & 106 & 10-may-07 \\
\hline Platanus & 1017 & 3,2 & 297 & 16-abr-07 & 751 & 2,6 & 117 & 19-abr-07 \\
\hline Poaceae $^{3}$ & 7764 & 24,7 & 355 & 30-jun-07 & 6932 & 24,3 & 282 & 30-jun-07 \\
\hline Populus & 1087 & 3,5 & 180 & 19-mar-07 & 1465 & 5,1 & 322 & 13-mar-07 \\
\hline Quercus & 9352 & 29,7 & 689 & 06-jun-07 & 8368 & 29,4 & 551 & 13-may-07 \\
\hline Rhamnus & 1 & - & 1 & varios & & & & \\
\hline Robinia & 23 & 0,1 & 5 & 05-jun-07 & 15 & 0,1 & 2 & varios \\
\hline Rosaceae & 5 & - & 1 & varios & 7 & - & 1 & varios \\
\hline Rubiaceae & 1 & - & 1 & 13-may-07 & 3 & - & 1 & varios \\
\hline Rumex & 1012 & 3,2 & 52 & 11-may-07 & 1031 & 3,6 & 58 & 11-may-07 \\
\hline Salix & 118 & 0,4 & 19 & 07-mar-07 & 104 & 0,4 & 6 & 06-abr-07 \\
\hline Sambucus & 17 & - & 1 & varios & 14 & - & 1 & varios \\
\hline Scrophulariaceae & 1 & - & 1 & 26-jun-07 & & & & \\
\hline Sophora & 1 & - & 1 & 22-jun-07 & & & & \\
\hline Thymelaeaceae & 1 & - & 1 & 11-nov-07 & & & & \\
\hline Tilia & 27 & 0,1 & 4 & 24-jun-07 & 17 & 0,1 & 3 & 14-jun-07 \\
\hline Trifolium & 9 & - & 2 & 13-ago-07 & 6 & - & 1 & varios \\
\hline Typha & 6 & - & 1 & varios & 12 & - & 1 & varios \\
\hline UImus & 112 & 0,4 & 12 & 02-mar-07 & 87 & 0,3 & 9 & 03-mar-07 \\
\hline Umbelliferae & 58 & 0,2 & 6 & 13-may-07 & 102 & 0,4 & 8 & 08-may-07 \\
\hline Urticaceae & 969 & 3,1 & 31 & 23-jun-07 & 950 & 3,3 & 43 & 29-abr-07 \\
\hline Viburnum & 6 & - & 1 & varios & 2 & - & 1 & varios \\
\hline Vitis & 10 & - & 3 & 03-ago-07 & 7 & - & 1 & varios \\
\hline Otros & 115 & 0,4 & 3 & varios & 148 & 0,5 & 3 & varios \\
\hline TOTAL & 31478 & 100 & 957 & 08-jun-07 & 28493 & 100 & 959 & 10-mar-07 \\
\hline
\end{tabular}

Tabla 5.3.1 Comparativa entre los dos captadores . ${ }^{1}$ Excluido Echium L. ${ }^{2}$ Excluido Artemisia L., Helianthus L. y Liguliflorae. 3Incluido Zea mays L. 4Excluido Mercurialis L. En negrita, los 10 tipos más abundantes. 
Los tipos de polen más representativos, según expresa su porcentaje sobre el total anual, fueron idénticos en ambos captadores, fueron Quercus, Poaceae y Cupressaceae, todos ellos con valores porcentuales también similares. No obstante, el cuarto tipo más abundante fue diferente, puesto que Populus ocupó ese lugar en el captador del Campus (5,1\%), con diferencias porcentuales con respecto al primer captador (3,5\%), donde Plantago se situó en esa misma posición. Respecto al resto de los diez tipos principales desde el punto de vista porcentual, cabe reseñar que Pinus, con un 2,2\% y un $0,8 \%$ en los dos captadores, respectivamente, alcanzó una mayor representatividad en el centro histórico.

$\mathrm{Si}$ analizamos los totales anuales y los máximos valores diarios, 34 tipos de polen presentaron resultados más elevados en el captador del centro (Tabla 5.3.1.), salvo el caso de las familias Caryophyllaceae, Compositae, Cupressaceae, Urticaceae, y el género Juglans, que, a pesar de mostrar totales anuales más elevados en el captador mencionado, tuvieron mayores registros diarios en el captador del Campus Unamuno. Dentro de estos tipos, las diferencias existentes en Alnus (200/138), Cupressaceae (4047/3728), Olea (678/525), y, sobretodo, en Pinus (686/236), Plantago (1706/1437), Platanus (1017/751), Poaceae (7764/6932), y Quercus (9352/8368), fueron más evidentes en los totales anuales y, como acabamos de señalar, en los mayores valores diarios. En este último punto, fueron reseñables las concentraciones diarias más elevadas obtenidas para Platanus en el captador del centro (297 granos $/ \mathrm{m}^{3}$, el 16 de abril de 2007) en comparación con las registradas en el segundo captador (117 granos/m³, el 19 de abril de 2007), o para Pinus (79 granos/m³, el 5 de junio de 2007; 42 granos/m³, el 6 de junio de 2007, respectivamente para los dos captadores).

Un total de 18 tipos de polen registraron valores anuales totales y concentraciones máximas diarias mayores en el captador emplazado en el Campus que en el captador del centro histórico (Tabla 5.3.1.), dentro de los cuales destacaron Acer (96/138), Cytisus (45/76), Ericaceae (196/226), Fraxinus (425/504), Labiateae (40/76), Populus (1087/1465) y Umbelliferae (58/102). Asimismo, en lo referente a las mayores concentraciones diarias en el captador del Campus con respecto al primer captador, debemos destacar las presentadas por Populus (322 granos/m³, el 13 de marzo de 2007; 180 granos/m³, el 19 de marzo de 2007, respectivamente), o las ya comentadas de Cupressaceae (853 granos/m³ , el 10 de marzo de 2007; 550 granos $/ \mathrm{m}^{3}$, el 4 de marzo de 2007, respectivamente).

Las fechas en las que se registraron las concentraciones diarias más elevadas variaron en algunos días en ambos captadores, salvo en el caso de Alnus (1 de febrero de 2008), Castanea (8 de julio de 2007), Ericaceae (9 de mayo de 2007), Labiateae (24 de abril de 2007), Olea (8 de junio de 2007), Poaceae (30 de junio de 2007), y Rumex (11 de mayo de 2007), que lo hicieron en el mismo día. Del lado contrario, en los tipos Acer (4 de julio de 2007/17 de abril de 2007), Compositae (12 de junio de 2007/7 de diciembre de 2007), Mercurialis (26 de julio de 2007/1 de septiembre de 2007), Plantago (13 de julio de 2007/10 
de mayo de 2007), Quercus (6 de junio de 2007/13 de mayo de 2007), y Urticaceae (23 de junio de 2007/29 de abril de 2007), las fechas variaron ampliamente en los registros de los dos captadores.

La elaboración de gráficas a través de las concentraciones promedio para los cinco días anteriores durante el 1 de febrero de 2007 y el 7 de febrero de 2008 y los dos captadores (Fig. 5.3.2.), nos permitió observar la dinámica que presentaron los registros de polen en dichos captadores. Estas dinámicas fueron prácticamente idénticas a lo largo de todos los días analizados, con valores más elevados para el captador del centro histórico, excepto en el mes de marzo, donde el captador del Campus Unamuno registró mayores valores, aunque con un ligero retraso de varios días con respecto a lo obtenido en el primer captador. En este sentido, también existió un pequeño desfase en las dinámicas de ambos captadores a mediados de febrero y mediados-finales de abril.

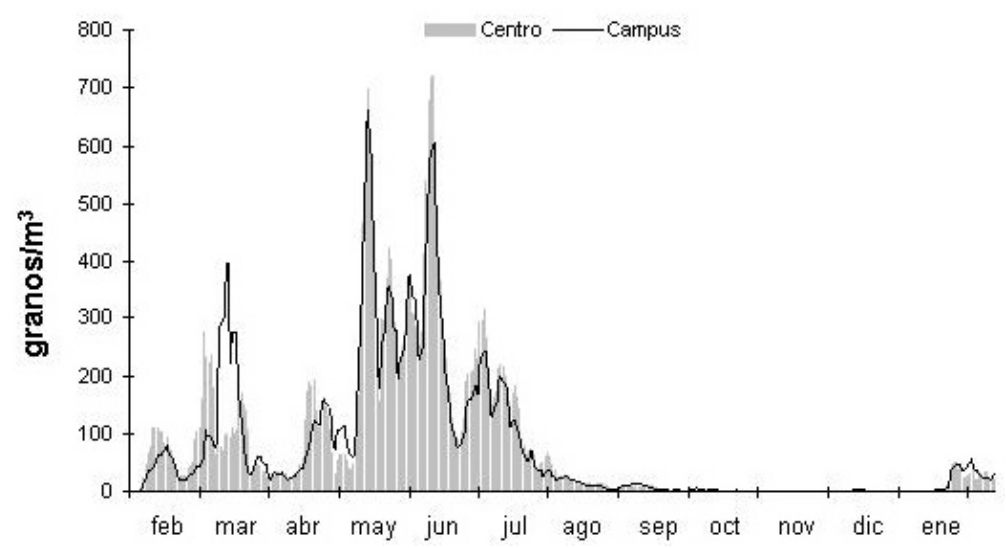

Fig. 5.3.2. Medias móviles de los cinco días anteriores para las concentraciones diarias promedio de todos los pólenes contabilizados (período 1-2-07/7-2-08), y ambos captadores (centro histórico/Campus Unamuno).

En el caso de los tipos de polen más abundantes en ambos captadores, incluyendo a Pinus pese a que no alcanzó el 1\% de representación sobre el total anual en el captador del Campus, las dinámicas que mostraron las concentraciones polínicas fueron casi idénticas, exceptuando algunos casos, como Cupressaceae (Fig. 5.3.3.C.), con un leve retraso en el incremento experimentado a mediados de mayo en el segundo captador con respecto al primero, y Populus (Fig. 5.3.4.A.), donde hubo un mayor incremento de las concentraciones a mediados de marzo en el segundo captador y uno posterior a finales de marzo en el primer captador. También puede destacarse lo acontecido en el tipo Platanus (Fig. 5.3.4.B.), con un ligero adelanto a mediados-finales de abril en el primer captador, y en Urticaceae (Fig. 5.3.5.A.), con un pequeño incremento registrado en el segundo captador a finales de abril e inicios de mayo. De todos modos, dentro de estos tipos más abundantes, hubo mayores niveles en el captador del centro histórico, especialmente en Pinus (Fig. 5.3.5.D.), y salvo en Populus (Fig. 5.3.4.A.), y Fraxinus (Fig. 5.3.5.B.), además de ciertos períodos de Cupressaceae (Fig. 5.3.3.C.), Rumex (Fig. 5.3.4.C.), y Castanea (Fig. 5.3.5.C.). 


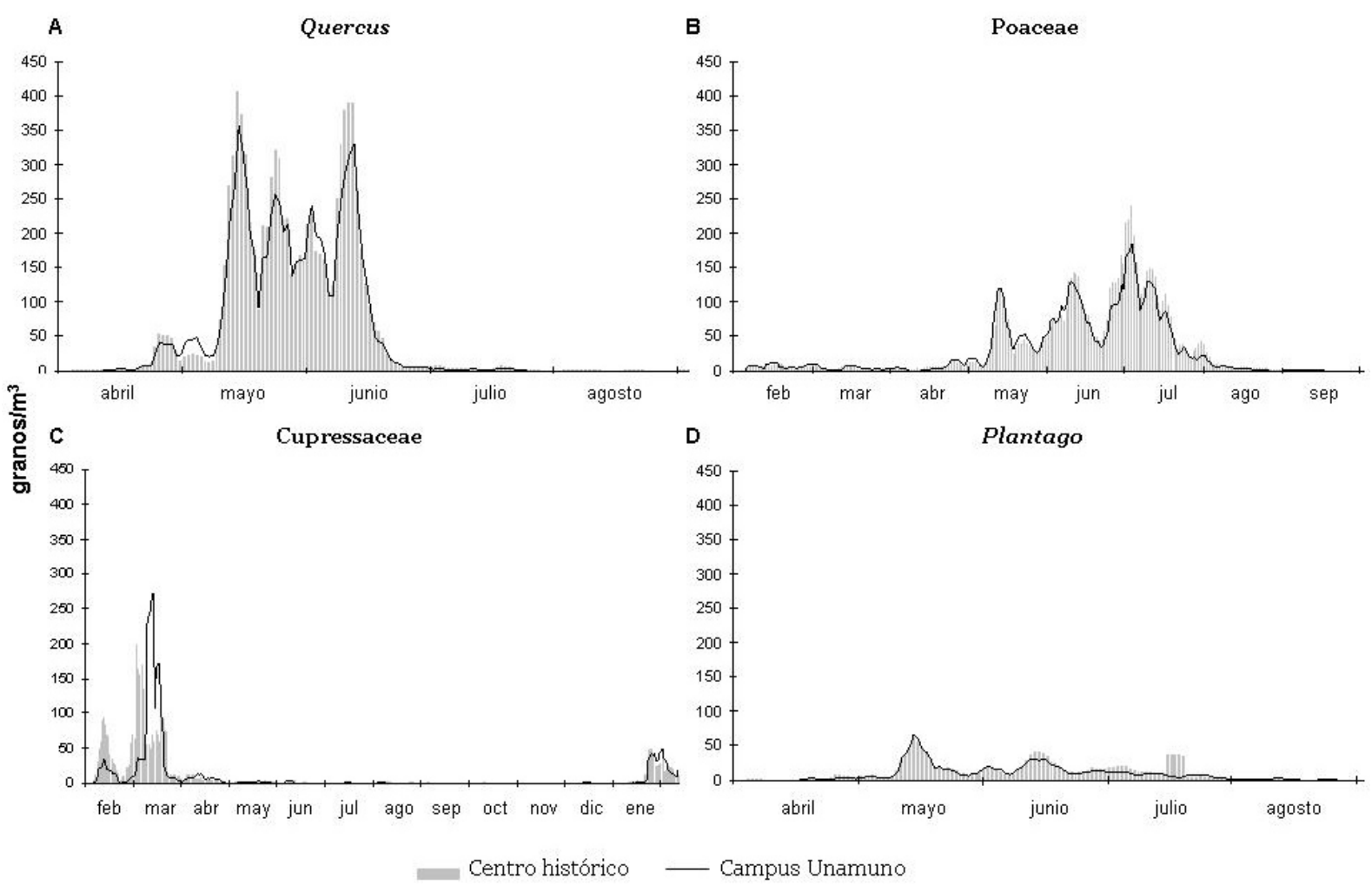

Fig. 5.3.3. Medias móviles de los cinco días anteriores para las concentraciones diarias promedio de Quercus (A), Poaceae (B), Cupressaceae (C), y Plantago (D), en ambos captadores (centro histórico/Campus Unamuno).

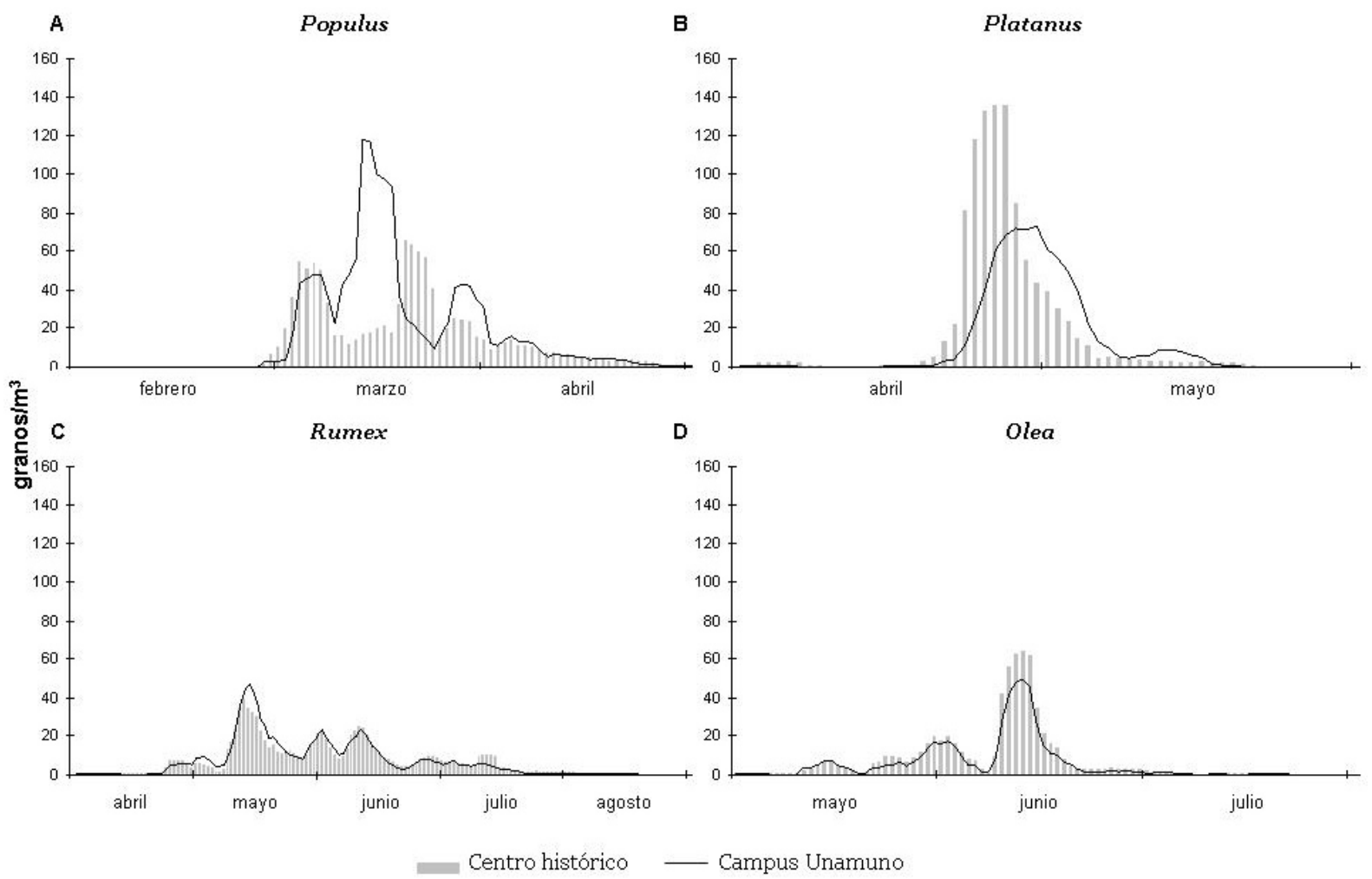

Fig. 5.3.4. Medias móviles de los cinco días anteriores para las concentraciones diarias promedio de Populus (A), Platanus (B), Rumex (C), y Olea (D), en ambos captadores (centro histórico/Campus Unamuno). 


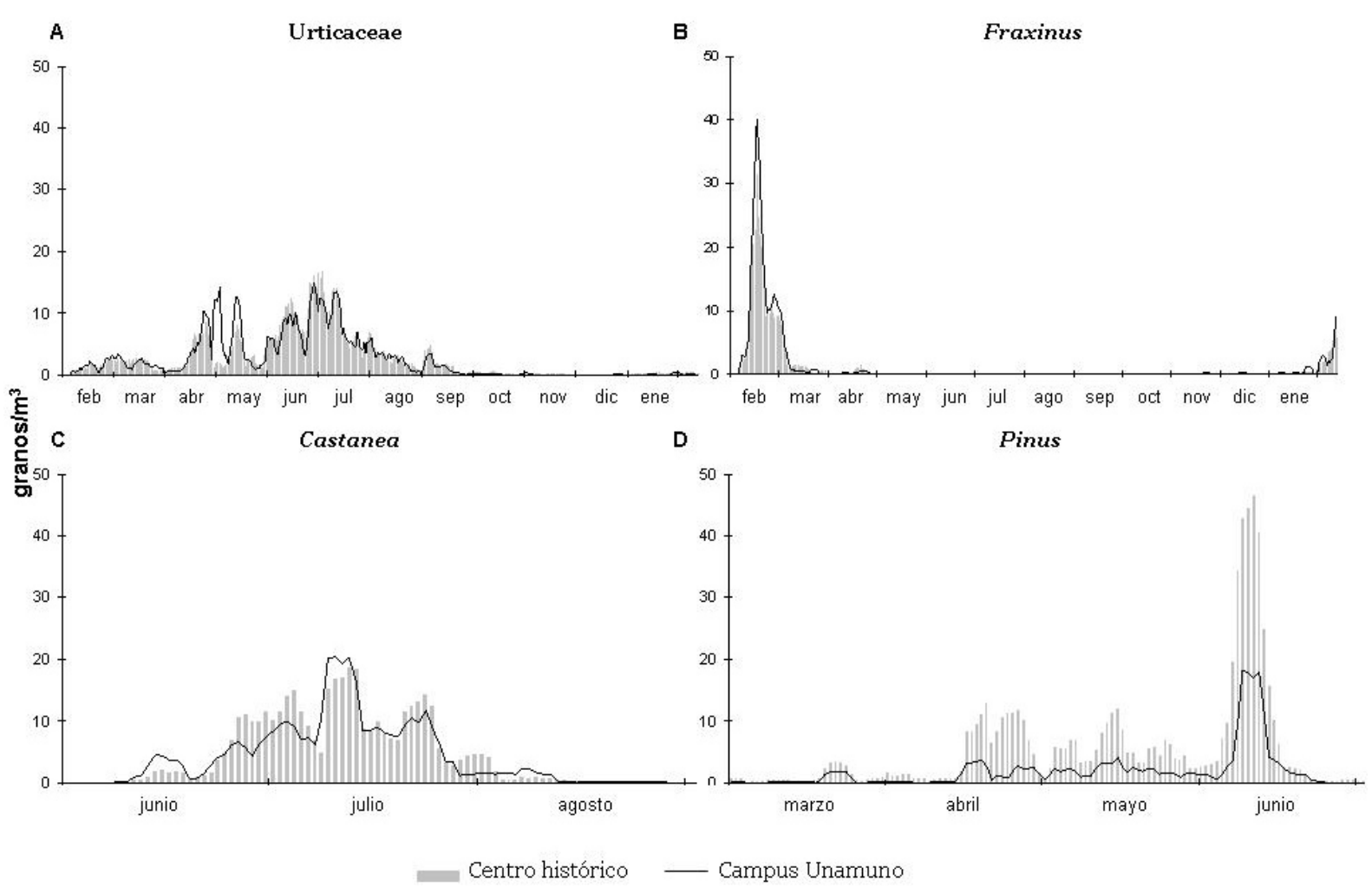

Fig. 5.3.5. Medias móviles de los cinco días anteriores para las concentraciones diarias promedio de Urticaceae (A), Fraxinus (B), Castanea (C), y Pinus (D), en ambos captadores (centro histórico/Campus Unamuno).

La variación intradiaria que experimentaron, en conjunto, todos los pólenes contabilizados, a través del porcentaje que representa la suma total anual en cada una de las 24 horas sobre el total anual en el conjunto de las 24 horas, no mostró variaciones en ambos captadores, con mayores concentraciones en las horas centrales del día (Fig. 5.3.6.), si bien pueden reseñarse porcentajes algo superiores en el captador del Campus Unamuno en las horas centrales del día, y en las últimas horas del día para el captador del centro histórico.

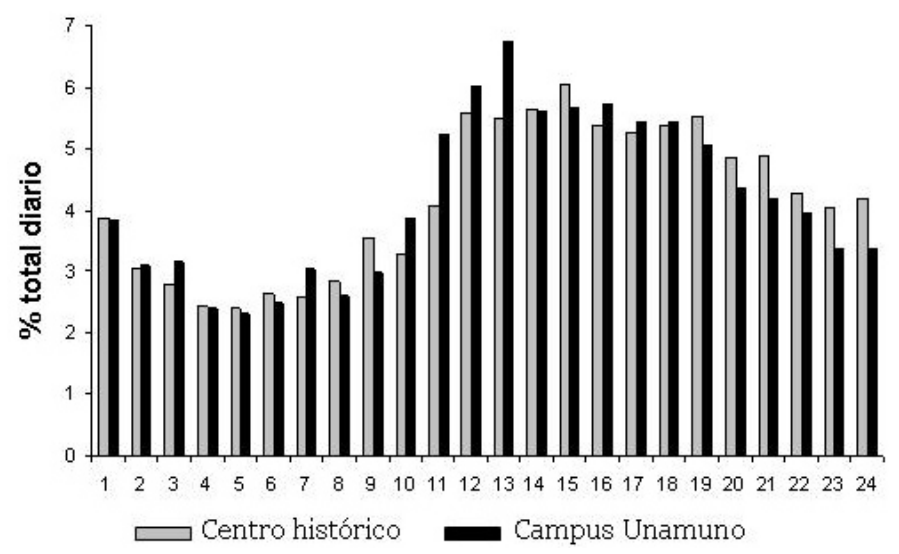

Fig. 5.3.6. Variación intradiaria de los granos de polen registrados en ambos captadores. 
Esta coincidencia en la distribución intradiaria de los pólenes contabilizados en ambos captadores, fue además reflejada en los tipos de polen más representativos (Figs. 5.3.7.; 5.3.8.; 5.3.9.), con mayores porcentajes en las horas centrales del día para los tipos Cupressaceae (Fig. 5.3.7.C.)., Plantago (Fig. 5.3.7.D.), y Populus (Fig. 5.3.8.A.), en horas vespertinas para Quercus (Fig. 5.3.7.A.), Platanus (Fig. 5.3.8.B.), y Rumex (Fig. 5.3.8.C.), y, en mayor o menor medida, sin un patrón definido para el resto. Asimismo, hubo mayores porcentajes en el captador situado en el centro histórico en diversas horas para Cupressaceae (Fig. 5.3.7.C.), y Fraxinus (Fig. 5.3.9.B.), mientras que para Plantago (Fig. 5.3.7.D.), Populus (Fig. 5.3.8.A.), Castanea (Fig. 5·3.9.C.), y Pinus (Fig. 5.3.9.D.), lo fue en el captador del Campus Unamuno.

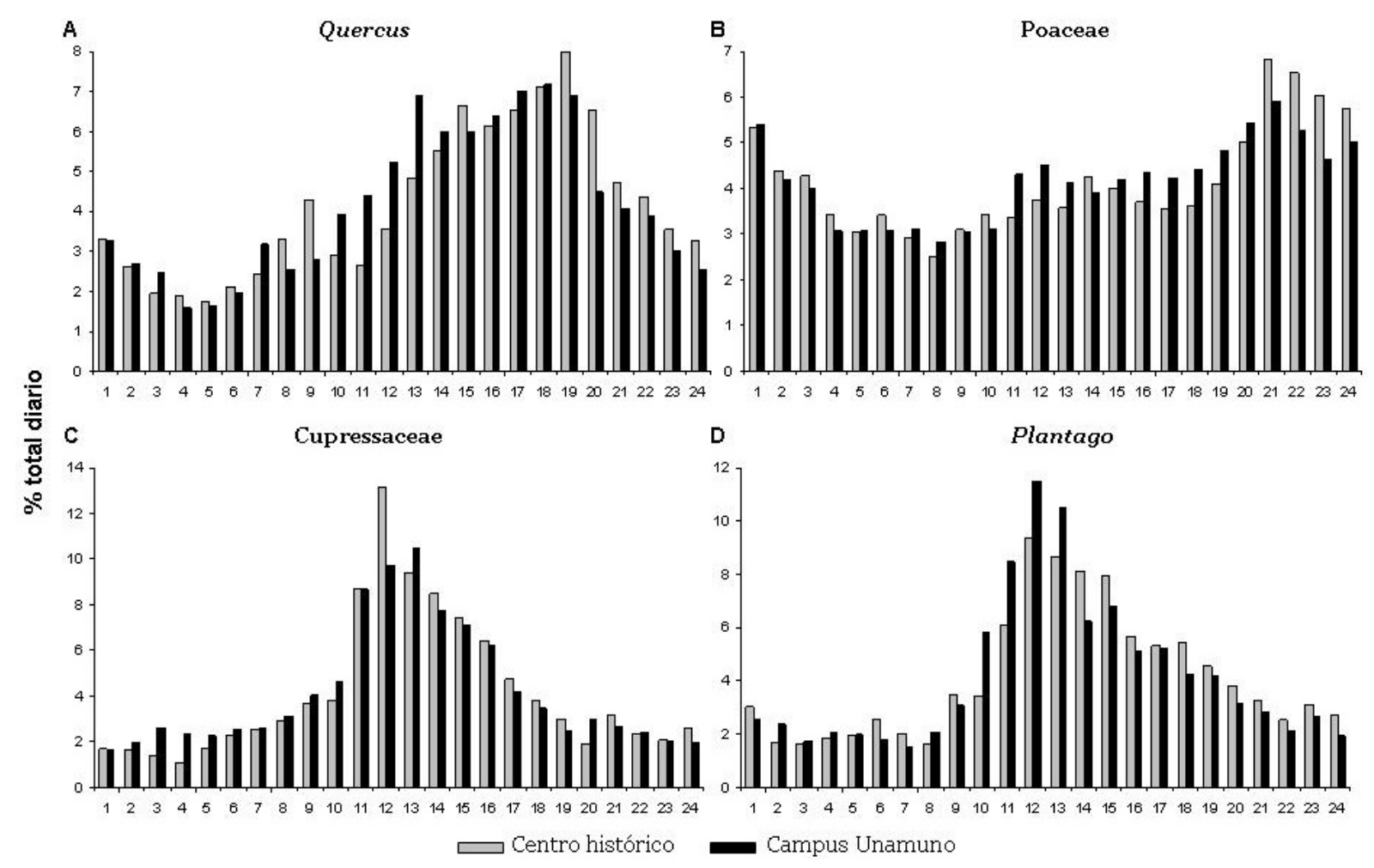

Fig. 5.3.7. Variación intradiaria de Quercus (A), Poaceae (B), Cupressaceae (C), y Plantago (D), en ambos captadores. 


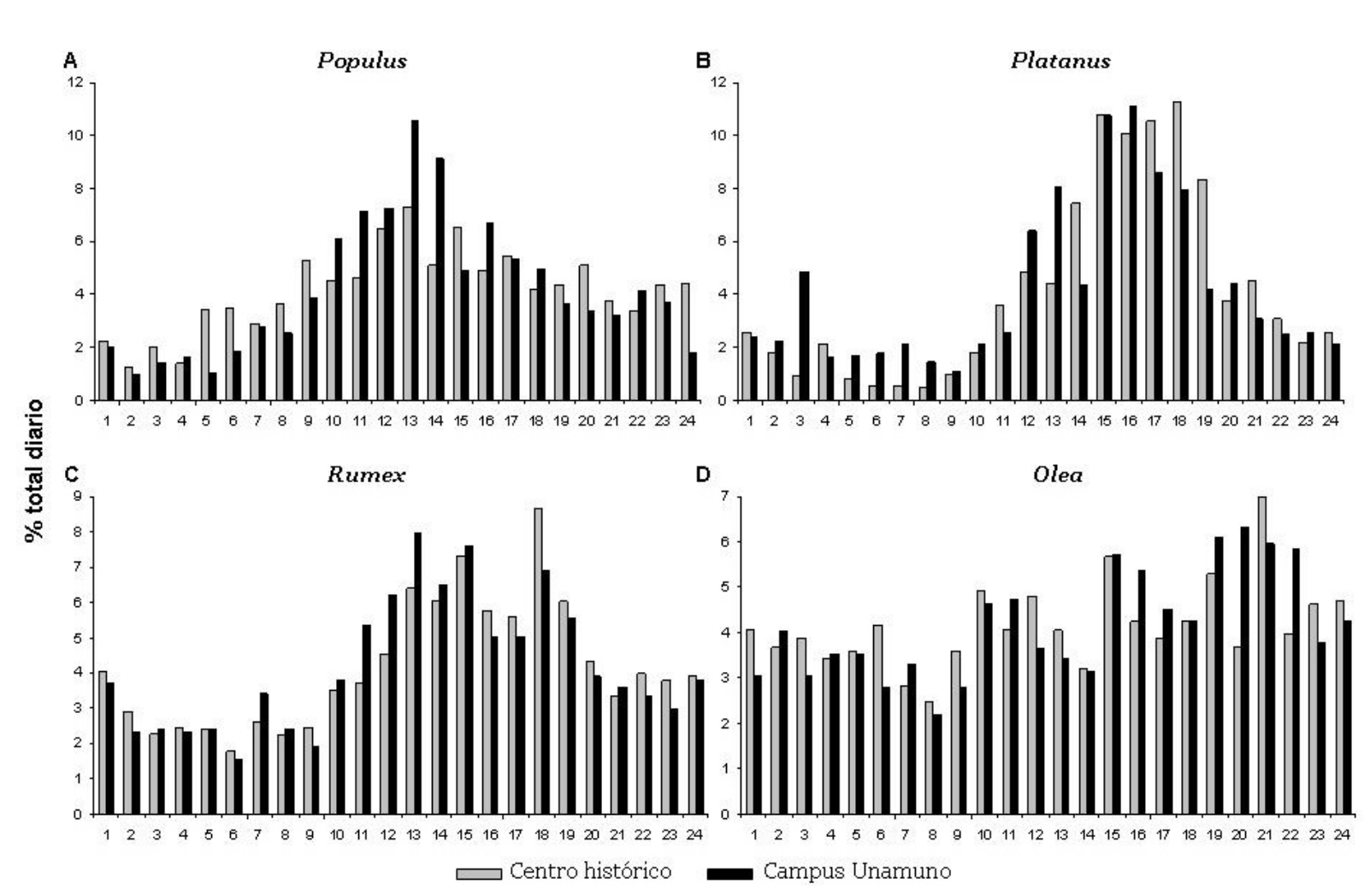

Fig. 5.3.8. Variación intradiaria de Populus (A), Platanus (B), Rumex (C), y Olea (D), en ambos captadores.

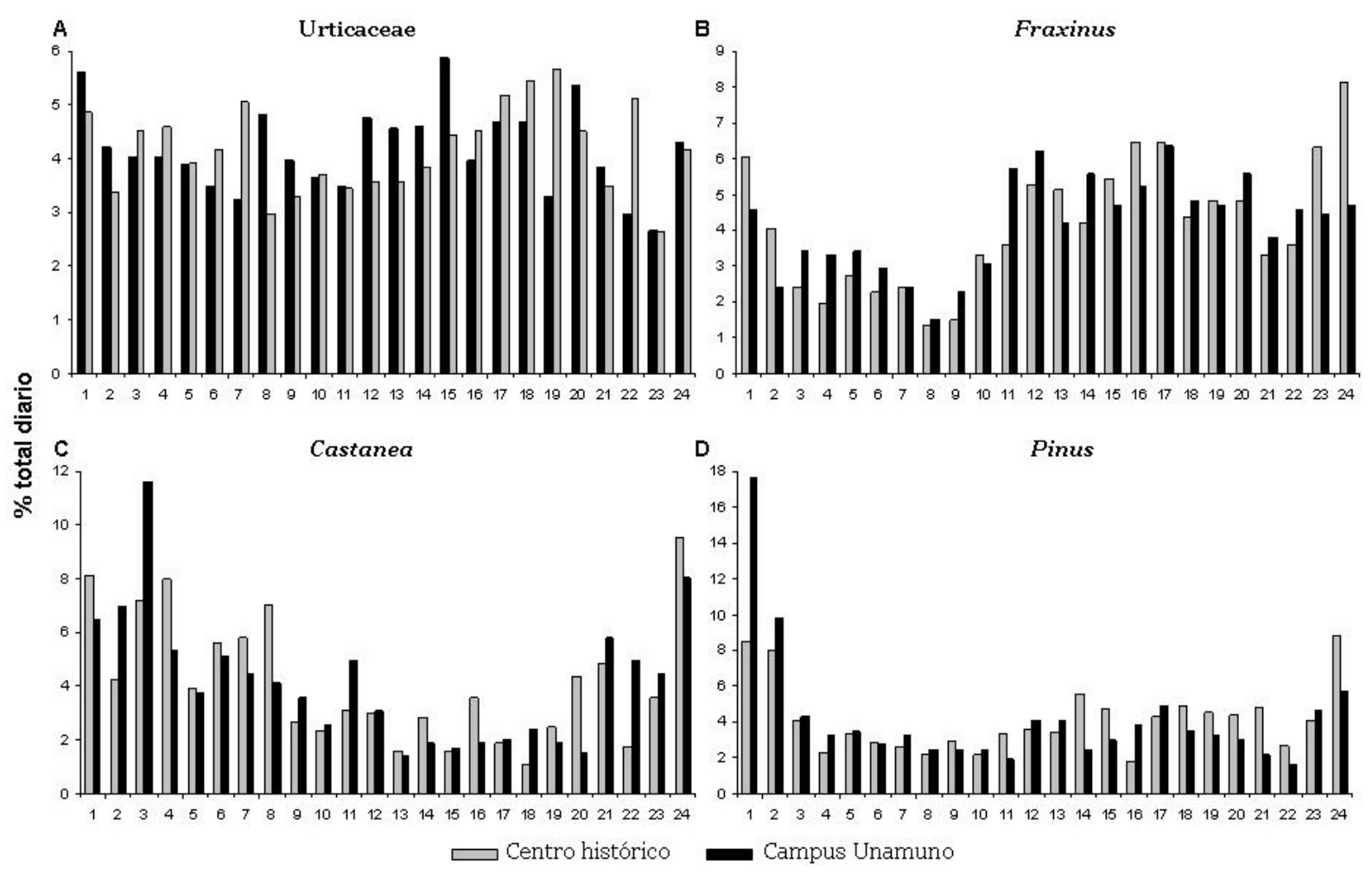

Fig. 5.3.9. Variación intradiaria de Urticaceae (A), Fraxinus (B), Castanea (C), y Pinus (D), en ambos captadores. 
Para valorar la coincidencia de los registros polínicos obtenidos en los dos captadores utilizados entre el 1 de febrero de 2007, y el 7 de febrero de 2008, hemos utilizado el Test de Spearman, que mostró un alto grado de correlación al estudiar las concentraciones totales de polen en todo el período estudiado (Tabla 5.3.2.), al igual que en el caso de Populus, Poaceae, Plantago, Rumex y Castanea. En el lado contrario, encontramos coeficientes de correlación más bajos para Pinus, Olea y Cupressaceae.

\begin{tabular}{|c|c|}
\hline Tipo centro histórico & Tipo Campus \\
\hline Total & $0,939 * *$ \\
Quercus & $0,845^{* *}$ \\
Poaceae & $0,902^{* *}$ \\
Cupressaceae & $0,700^{* *}$ \\
Plantago & $0,860^{* *}$ \\
Populus & $0,935^{* *}$ \\
Platanus & $0,789^{* *}$ \\
Rumex & $0,847^{* *}$ \\
Urticaceae & $0,799^{*}$ \\
Olea & $0,660^{*}$ \\
Fraxinus & $0,759^{* *}$ \\
Castanea & $0,843^{* *}$ \\
Pinus & $0,646^{* *}$ \\
\hline
\end{tabular}

Tabla 5.3.2. Coeficientes de correlación de Spearman entre ambos captadores para el total de polen contabilizado y los tipos de polen más abundantes, dentro del período estudiado. Significación: $95 \%\left({ }^{*}\right), 99 \%\left({ }^{* *}\right)$

Para finalizar, se utilizó dicho análisis de correlación para analizar la incidencia de los diferentes parámetros meteorológicos en el contenido polínico obtenido en ambos captadores para el total de pólenes contabilizados, y los tipos de polen más abundantes (Tabla 5.3.3.). En todos los casos, y para los dos captadores, se observó que la temperatura media, mínima y máxima influyó, en mayor o menor medida, de forma positiva en las concentraciones polínicas, excepto en Cupressaceae, Fraxinus y Populus, que lo hicieron de forma negativa, y en Platanus, que no mostró correlación alguna. De igual forma ocurrió con la insolación, aunque Cupressaceae y Populus no presentaron correlaciones significativas.

La precipitación sólo tuvo influencia negativa y significativa en Castanea, y positiva para el captador del centro, en Cupressaceae y Fraxinus, mientras que la humedad relativa presentó coeficientes negativos y significativos en todos los tipos principales, a excepción de los mismos tipos que no presentaron correlaciones positivas con la temperatura (Cupressaceae, Fraxinus, Platanus y Populus). Los parámetros que engloban al viento, velocidad, frecuencia de calmas y dirección del viento, tuvieron correlaciones de diverso signo y grado de significación en función de los tipos estudiados, si bien para el total, se observa una influencia positiva de la velocidad del viento, y los vientos procedentes del tercer y cuarto cuadrante, y negativa para la frecuencia de las calmas y los vientos procedentes del primer cuadrante. De todos modos, estos coeficientes de correlación con estos parámetros meteorológicos fueron similares en número, signo y grado de significación para ambos captadores, salvo los casos mencionados de Cupressaceae y Fraxinus con la precipitación, o 
con la dirección de los vientos en diferentes tipos. No obstante, las correlaciones efectuadas a partir de los datos obtenidos del captador del centro histórico dieron lugar, de forma general, a coeficientes levemente superiores en número.

\begin{tabular}{|c|c|c|c|c|c|c|}
\hline Tipo / parámetro & Tmed & Tmax & Tmin & Insolación & Precipitación & Hrelativa \\
\hline $\begin{array}{c}\text { Total } \\
\text { TotalCU } \\
\text { Ouercus } \\
\text { QuercusCU } \\
\text { Poaceae } \\
\text { PoaceaeCU } \\
\text { Cupressaceae } \\
\text { CupressaceaeCU } \\
\text { Plantago } \\
\text { PlantagoCU } \\
\text { Populus } \\
\text { PopulusCU } \\
\text { Platanus } \\
\text { PlatanusCU } \\
\text { Rumex } \\
\text { RumexCU } \\
\text { Urtica } \\
\text { UrticaCU } \\
\text { Olea } \\
\text { OleaCU } \\
\text { Fraxinus } \\
\text { FraxinusCU } \\
\text { Castanea } \\
\text { CastaneaCU } \\
\text { Pinus } \\
\text { PinusCU }\end{array}$ & $\begin{array}{l}0,451^{* *} \\
0,396^{* *} \\
0,478^{* *} \\
0,425^{* *} \\
0,567^{* *} \\
0,533^{* *} \\
-0,184^{* *} \\
-0,227^{* *} \\
0,632^{* *} \\
0,617^{* *} \\
-0,198^{* *} \\
-0,183^{* *} \\
0,042 \\
0,035 \\
0,523^{* *} \\
0,470^{* *} \\
0,587^{* *} \\
0,572^{* *} \\
0,351 * * \\
0,337^{* *} \\
-0,310^{* *} \\
-0,315^{* *} \\
0,484 * * \\
0,518^{* *} \\
0,249 * * \\
0,219^{* *}\end{array}$ & 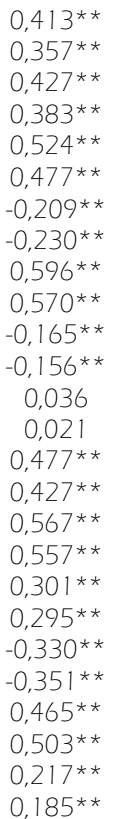 & $\begin{array}{c}0,395^{* *} \\
0,348^{* *} \\
0,476^{* *} \\
0,426^{* *} \\
0,496^{* *} \\
0,476^{* *} \\
-0,180^{* *} \\
-0,249 * * \\
0,585^{* *} \\
0,592^{* *} \\
-0,265^{* *} \\
-0,244^{* *} \\
0,01 \\
0,002 \\
0,499 * * \\
0,457 * * \\
0,484 * * \\
0,472^{* *} \\
0,357 * * \\
0,353^{* *} \\
-0,294 * * \\
-0,287 * * \\
0,434 * * \\
0,461 * * \\
0,226 * * \\
0,220 * *\end{array}$ & 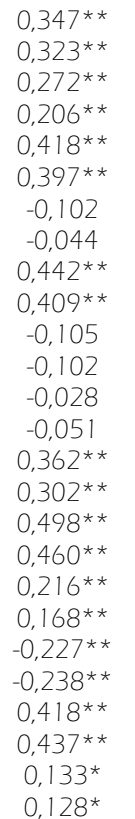 & $\begin{array}{c}0,037 \\
0,035 \\
0,037 \\
0,076 \\
-0,022 \\
-0,001 \\
0,135^{\star} \\
0,076 \\
-0,074 \\
-0,024 \\
0,067 \\
0,052 \\
0,123^{\star} \\
0,132^{*} \\
-0,027 \\
0,013 \\
-0,111^{\star} \\
-0,125^{*} \\
0,04 \\
0,054 \\
0,135^{\star *} \\
0,098 \\
-0,142^{\star *} \\
-0,153^{*} \\
0,073 \\
0,058\end{array}$ & $\begin{array}{c}-0,393^{* *} \\
-0,334^{* *} \\
-0,365^{* *} \\
-0,257^{* *} \\
-0,483^{* *} \\
-0,432^{* *} \\
0,136^{* *} \\
0,123^{*} \\
-0,495^{* *} \\
-0,486^{* *} \\
0,016^{2} \\
0,005^{-0} \\
-0,023 \\
0,006 \\
-0,392^{* *} \\
-0,361^{* *} \\
-0,550^{* *} \\
-0,521^{* *} \\
-0,219^{* *} \\
-0,198^{* *} \\
0,281^{* *} \\
0,301^{* *} \\
-0,428^{* *} \\
-0,466^{* *} \\
-0,239^{* *} \\
-0,183^{* *}\end{array}$ \\
\hline
\end{tabular}

\begin{tabular}{|c|c|c|c|c|c|c|}
\hline Tipo / parámetro & Vmed & FrecCalm & VlCuadr & V2Cuadr & V3Cuadr & V4Cuadr \\
\hline Total & $0,361^{* *}$ & $-0,339 * *$ & $-0,308 * *$ & $-0,086$ & $0,394 * *$ & $0,238 * *$ \\
\hline TotalCU & $0,353^{* *}$ & $-0,359$ ** & $-0,265^{* *}$ & $-0,052$ & $0,352 * *$ & $0,212^{* *}$ \\
\hline Quercus & $0,160 * *$ & $-0,083$ & $-0,213 * *$ & 0,026 & $0,235 * *$ & $0,126 *$ \\
\hline QuercusCU & 0,103 & $-0,039$ & $-0,203^{* *}$ & 0,044 & 0,214 ** & $0,117^{\star}$ \\
\hline Poaceae & $0,260 * *$ & $-0,233^{* *}$ & $-0,299 * *$ & $-0,097$ & $0,370 * *$ & $0,273^{* *}$ \\
\hline PoaceaeCU & $0,273 * *$ & $-0,265 * *$ & $-0,306 * *$ & $-0,122^{*}$ & $0,372 * *$ & $0,271 * *$ \\
\hline Cupressaceae & $0,369 * *$ & $-0,442 * *$ & $-0,185^{* *}$ & $-0,027$ & $0,283^{* *}$ & 0,089 \\
\hline CupressaceaeCU & $0,311 * *$ & $-0,396 * *$ & $-0,034$ & 0,056 & $0,122^{*}$ & 0,105 \\
\hline Plantago & 0,08 & $-0,008$ & $-0,209 * *$ & $-0,054$ & $0,215^{* *}$ & 0,190 ** \\
\hline PlantagoCu & $0,150 * *$ & $-0,089$ & $-0,220 * *$ & $-0,123^{*}$ & $0,237 * *$ & $0,206 * *$ \\
\hline Populus & $0,162 * *$ & $-0,289$ * * & 0,013 & $0,168^{* *}$ & 0,062 & 0,088 \\
\hline PopulusCU & $0,177^{* *}$ & $-0,291^{* *}$ & 0,012 & $0,152^{* *}$ & 0,072 & 0,094 \\
\hline Platanus & 0 & 0,026 & $-0,067$ & $0,164^{* *}$ & 0,065 & $0,109 *$ \\
\hline PlatanusCU & $-0,001$ & 0,007 & $-0,05$ & $0,187^{* *}$ & 0,033 & 00,098 \\
\hline Rumex & 0,097 & $-0,03$ & $-0,222^{* *}$ & $-0,058$ & $0,251 * *$ & $0,176^{* *}$ \\
\hline RumexCU & 0,131 * & $-0,068$ & $-0,209 * *$ & $-0,054$ & $0,225 * *$ & $0,157^{* *}$ \\
\hline Urticaceae & $0,228 * *$ & $-0,199$ * * & $-0,188^{* *}$ & $-0,089$ & $0,261 * *$ & $0,165^{* *}$ \\
\hline UrticaceaeCU & 0,233 ** & $-0,216^{* *}$ & $-0,227 * *$ & $-0,104$ & $0,285^{* *}$ & $0,204^{* *}$ \\
\hline Olea & $0,152 * *$ & $-0,075$ & $-0,233 * *$ & $-0,08$ & $0,268 * *$ & 0,065 \\
\hline OleaCU & $0,138^{*}$ & $-0,064$ & $-0,239$ ** & $-0,027$ & 0,279 ** & 0,034 \\
\hline Fraxinus & $0,281^{* *}$ & $-0,361^{* *}$ & $-0,216$ ** & 0,055 & $0,276 * *$ & 0,003 \\
\hline FraxinusCU & $0,288 * *$ & $-0,334 * *$ & $-0,260 * *$ & $-0,031$ & $0,307 * *$ & 0,022 \\
\hline Castanea & 0,066 & 0,001 & $-0,211^{* *}$ & $-0,167$ ** & $0,193^{* *}$ & $0,203^{* *}$ \\
\hline CastaneaCU & 0,061 & 0,009 & $-0,194^{* *}$ & $-0,177^{* *}$ & 0,197 ** & 0,239 ** \\
\hline Pinus & $0,118^{*}$ & $-0,108 *$ & $-0,133^{*}$ & 0,054 & 0,159 ** & $0,154^{* *}$ \\
\hline PinusCU & 0,101 & $-0,113^{*}$ & $-0,012$ & 0,034 & 0,061 & 0,003 \\
\hline
\end{tabular}

Tabla 5.3.3. Coeficientes de correlación de Spearman entre ambos captadores (CU-Campus Unamuno) para el total de polen contabilizado y los tipos de polen más abundantes con las variables climatológicas. Tmed, Tmax,

Tmin (temperatura media, máxima y mínima), Hrelativa (humedad relativa), Vemed (velocidad media),

FrecCalmas (frecuencia de calmas), V1Cuad, V2Cuad, V3Cuad, V4Cuad (vientos procedentes del I, II, III y IV cuadrante). Significación: $95 \%(*), 99 \%(* *)$. 


\subsection{Contenido de esporas de pteridófitos en la ciudad de Salamanca}

A lo largo de diez años, entre 1998 y 2007, fueron estudiadas las muestras aerobiológicas para identificar y contabilizar las esporas de pteridófitos presentes en la atmósfera. En dichas muestras todas las esporas identificadas se adscribieron a Pteridium aquilinum (L.) Kuhn., dadas las características morfológicas y ornamentales de las mismas, descritas en diversos trabajos (Andrew, 1984; Muñoz-Garmendia, 1986; Renault-Miskovsky \& Petzold, 1989; Tyron \& Lugardon, 1991), que describen esporas triletas, globosotetraédricas, de sublimas a finamente espinulosas, marrones, un tamaño mediano (28-36 $\mu \mathrm{m}$ ), con perisporio verrucoso (Lámina IV). Este helecho posee una distribución cosmopolita, fundamentalmente, formando parte de diversos bosques de hoja caduca y hoja perenne, o incluso dando lugar a grandes formaciones casi monoespecíficas como etapas de sucesión de otras series de vegetación. En la Península Ibérica suele ser más abundante en la mitad Norte, generalmente en zonas montañosas, proximidades de bosques de galería o dando lugar a formaciones seriales casi monoespecíficas, distribuyéndose de manera semejante en la provincia de Salamanca, preferentemente en las zonas meridionales orientales.

Durante el período 1998-2007 el total anual promedio de esporas de Pteridium ha sido de 67, siendo el año 2005, con 131, el que presentó un mayor número y el año 2007, con un total de 4 esporas, el año con menor contenido. En todo caso, en los diez años estudiados, la variación interanual (Fig. 5.4.1.), del número de esporas experimentó un notable descenso, desde las 111 del año 1998 a las 4 del año 2007, aunque con una distribución irregular en esta década, pues se produjeron ascensos y descensos sin un patrón claro. Esta irregularidad se puso de manifiesto tras realizar el análisis de regresión lineal, con un valor del índice de determinación muy bajo $\left(\mathrm{R}^{2}=0,06\right)$ en la tendencia al descenso en el número total de esporas en el decenio estudiado.
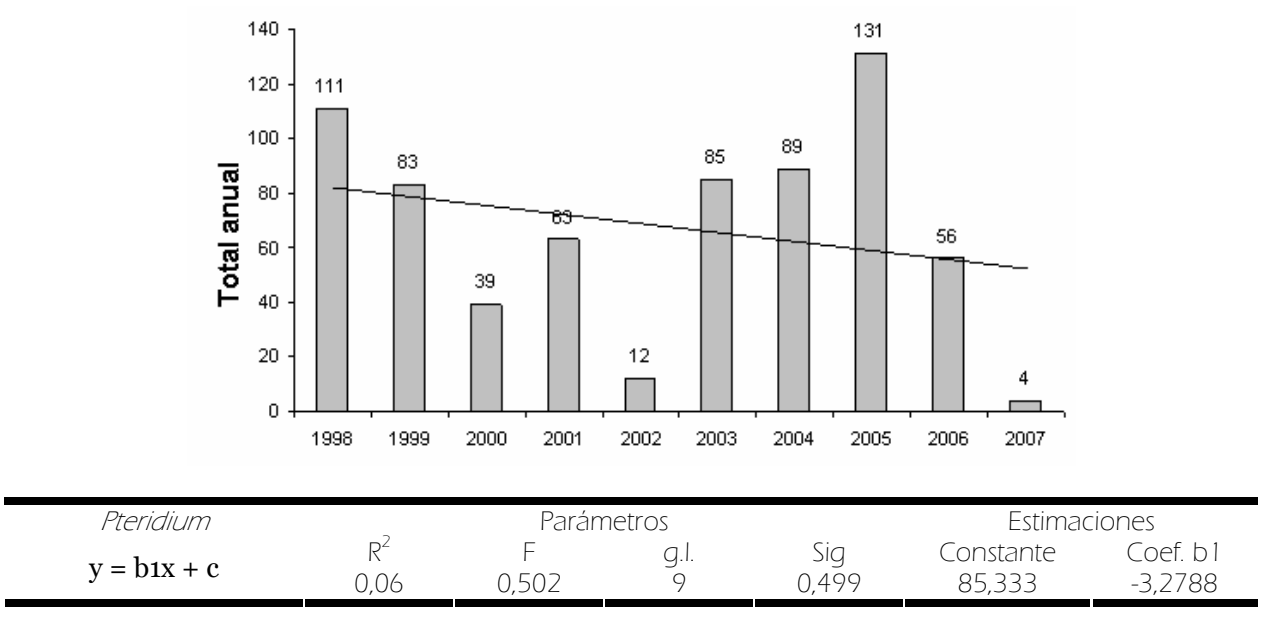

Fig. 5.4.1. Evolución anual del número total de esporas de Pteridium y tendencias (análisis de regresión). 
La distribución de estos granos de polen a lo largo del año se localizó entre mediados de agosto e inicios de octubre, por lo que la variación estacional (Tabla 5.4.1.) tuvo un PPP promedio de 48 días, que presentó ligeras diferencias en la fecha de inicio (10 de agosto de 2004 - 31 de agosto de 1998) y finalización (22 de septiembre de 2004 - 12 de octubre de 1998), que indicaron un consiguiente adelanto en el año 2004.

\begin{tabular}{|c|c|c|c|c|c|c|c|c|c|c|c|}
\hline Pteridium & 1998 & 1999 & 2000 & 2001 & 2002 & 2003 & 2004 & 2005 & 2006 & 2007 & Media \\
\hline Total & 111 & 83 & 39 & 63 & 12 & 85 & 89 & 131 & 56 & 4 & 67 \\
\hline Máximo & 20 & 8 & 4 & 4 & 4 & 19 & 15 & 20 & 7 & 1 & 4 \\
\hline Día & 29-sep & 9-sep & 25-sep & 4-oct & 3-ago & 6-sep & 12-ago & 4-sep & 23-ago & varios & 9-sep \\
\hline $95 \%$ & & & & & & & & & & & \\
\hline PPE(días) & 43 & 47 & 47 & 57 & - & 52 & 44 & 42 & 54 & - & 48 \\
\hline Inicio & 31-ago & 12-ago & 15-ago & 18-ago & - & 14-ago & 10-ago & 24-ago & 14-ago & - & 17-ago \\
\hline Fin & 12-oct & 27-sep & 30-sep & 13-oct & - & 4-oct & 22-sep & 04-oct & 6-oct & - & 5-oct \\
\hline PRE & 30 & 29 & 42 & 48 & - & 24 & 3 & 12 & 10 & - & 24 \\
\hline
\end{tabular}

Tabla 5.4.1 Totales, concentraciones máximas diarias, período principal de esporulación (PPE; fecha de inicio y fin) y días precedentes al valor máximo (PRE) durante los ocho años de estudio, y el promedio de todos los parámetros para Pteridium.

Las concentraciones de esporas de Pteridium en la atmósfera de la ciudad de Salamanca (Fig. 5.4.2.D.) aumentaron a mediados de agosto hasta alcanzar los valores más elevados durante la segunda semana de septiembre, como muestra el valor medio más elevado en los años analizados (4 esporas $/ \mathrm{m}^{3}$ el 9 de septiembre), gracias a la dinámica aportada por el porcentaje de representación que tuvieron las concentraciones medias de los cincos días anteriores para el total promediado del conjunto de años estudiados (Tabla 5.4.1.). Asimismo, las mayores concentraciones diarias registradas dentro de este período, oscilaron entre las 20 esporas $/ \mathrm{m}^{3}$ (29 de septiembre de 1998, 4 de septiembre de 2005) y 1 espora/ $\mathrm{m}^{3}$ (varios días de 2007). Posteriormente, estos niveles disminuyeron a mediados de septiembre, con un pequeño incremento a finales de septiembre y principios de octubre, disminuyendo su presencia durante el transcurso del mes de octubre (Fig. 5.4.2.A. B. C.).

La variación intradiaria (Fig. 5.4.3.) mostró un claro patrón a lo largo de un día promedio, por el que los niveles de esporas aumentaron en las primeras horas de la noche y presentaron mayores porcentajes de representación sobre un total diario promedio, en las primeras horas del día. Así pues, las mayores concentraciones esporales de Pteridium se concentraron en las horas nocturnas.

El porcentaje de esporas de Pteridium con respecto al total de granos de polen y esporas de pteridófitos fue muy bajo durante los diez años estudiados. Sin embargo, este porcentaje fue más elevado si centramos el estudio durante los meses de agosto, septiembre y octubre, meses en los que se localizan las esporas de este género. Así pues, durante estos tres meses, el porcentaje de esporas sobre el total de polen y esporas varió del o,5\% de 2007 al $24 \%$ de 1999, con un valor medio de $13 \%$. En este misma línea, los totales semanales 
promedio para todos los años estudiados (Fig. 5.4.4.), mostró que entre la última semana de agosto y la primera de octubre, las esporas tuvieron importantes porcentajes sobre el total de elementos atmosféricos procedentes de plantas vasculares.

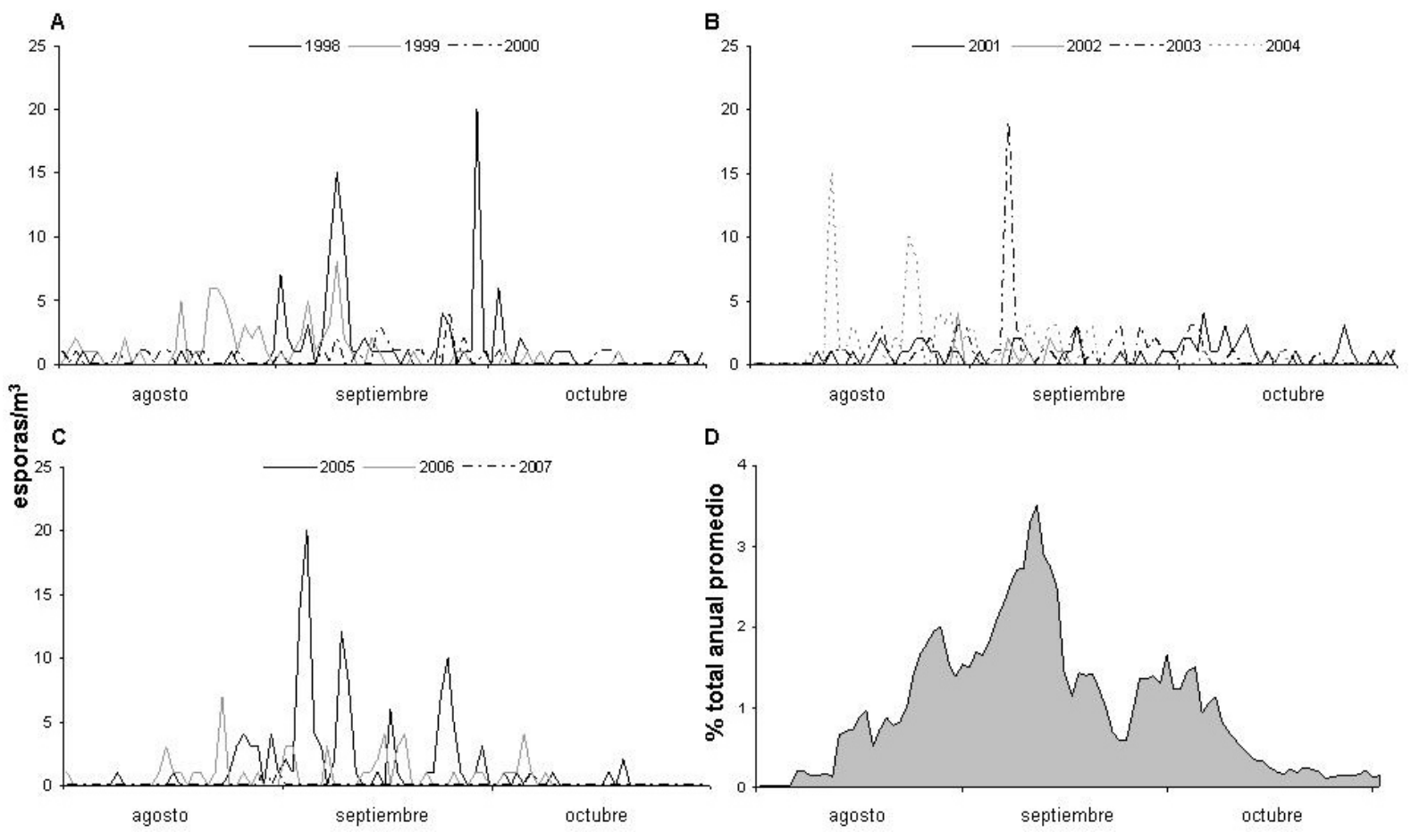

Fig. 5.4.2. Variación de las concentraciones medias diarias de Pteridium durante el período 1998-2000 (A), 2001-2004 (B) y 2005-2007 (C). Porcentajes de representación diarios para la media de los cinco días anteriores dentro del promedio de los ocho años analizados (D).

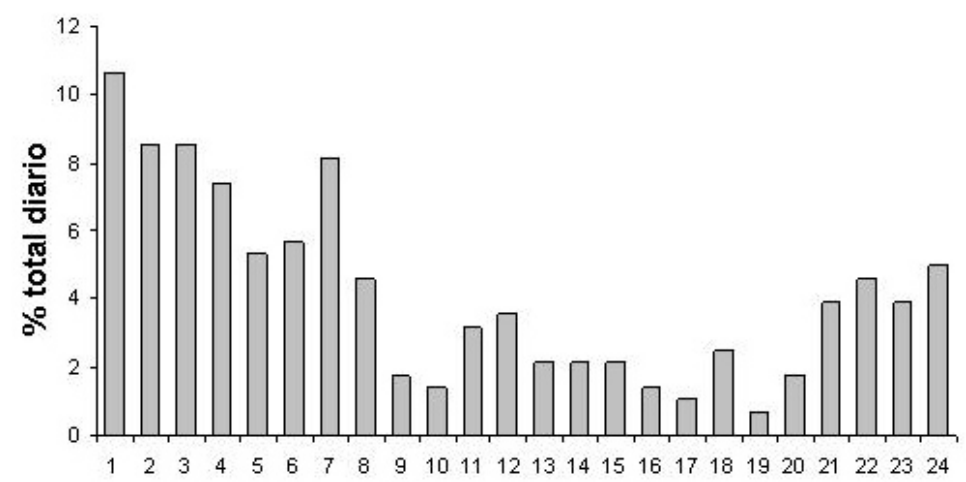

Fig. 5.4.3. Variación intradiaria del polen de Pteridium. 


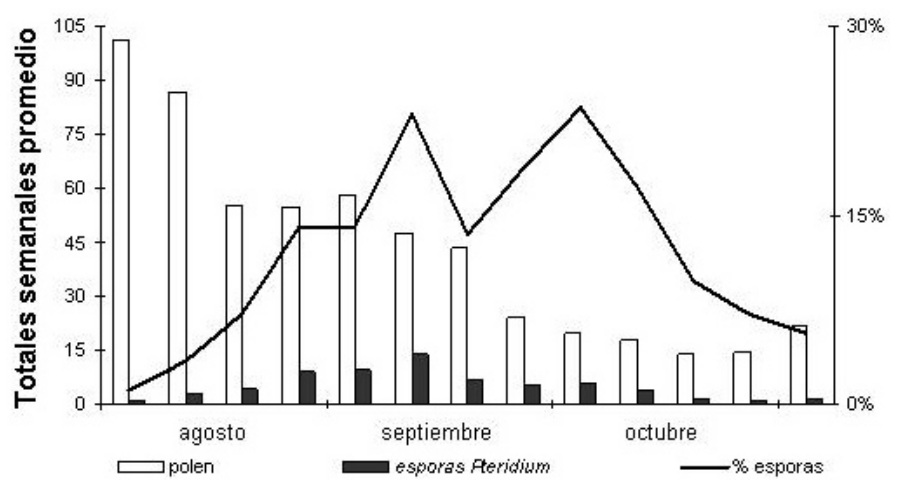

Fig. 5.4.4. Totales semanales promedio de polen y esporas de Pteridium de agosto a otubre a lo largo del período 1998-2007.

Las temperaturas medias, máximas y mínimas junto a la insolación y la frecuencia de calmas tuvieron una influencia positiva en los niveles de esporas de Pteridium durante los diez años analizados, así como el efecto negativo que ejercieron la humedad relativa, la velocidad media del viento y los vientos procedentes del III cuadrante, tras el análisis de correlación (Tabla 5.4.2.). Estas correlaciones presentaron coeficientes más bajos en número y grado de significación durante el PPE y PRE con los parámetros meteorológicos analizados, exceptuando los vientos procedentes del II cuadrante, que ejercieron una influencia positiva en las concentraciones de esporas.

\begin{tabular}{|c|c|c|c|c|c|c|c|}
\hline \multicolumn{2}{|c|}{ Pteridium } & Tmed & Tmax & Tmin & Insolación & Precipitación & Relativa \\
\hline \multirow{3}{*}{$\begin{array}{l}1998- \\
2007\end{array}$} & \begin{tabular}{|l|} 
Anual \\
\end{tabular} & $0,255^{* *}$ & $0,249 * *$ & $0,245^{* *}$ & $0,103^{* *}$ & $-0,033$ & $-0,116^{* *}$ \\
\hline & PPE & $0,119 *$ & 0,090 & 0,098 & 0,062 & $-0,095$ & $-0,107^{*}$ \\
\hline & PRE & $0,182^{*}$ & 0,131 & $0,168^{*}$ & 0,080 & $-0,069$ & $-0,161^{*}$ \\
\hline \multicolumn{2}{|c|}{ Pteridium } & Vemed & FrecCalm & VICuadr & V2Cuadr & V3Cuadr & V4Cuadr \\
\hline \multirow{3}{*}{$\begin{array}{l}1998- \\
2007\end{array}$} & Anual & $-0,07$ ** & $0,114^{* *}$ & 0,063 & 0,082 & $-0,467^{* *}$ & $0,114^{* *}$ \\
\hline & PPE & $-0,041$ & 0,067 & $-0,019$ & $0,242^{* *}$ & 0,011 & $-0,399$ \\
\hline & PRE & $-0,108$ & 0,083 & $-0,121$ & $0,299 * *$ & 0,092 & $-0,492$ \\
\hline
\end{tabular}

Tabla 5.4.2. Coeficientes de correlación de Spearman entre Pteridium y las variables climatológicas. Tmed,

Tmax, Tmin (temperatura media, máxima y mínima), Hrelativa (humedad relativa), Vemed (velocidad media), FrecCalmas (frecuencia de calmas), V1Cuad, V2Cuad, V3Cuad, V4Cuad (vientos procedentes del I, II, III y IV cuadrante). Significación: $95 \%\left({ }^{*}\right)$, 99\%(**). (-) Ausencia de correlaciones. 


\subsection{Grado de sensibilización a diferentes alérgenos de polen}

\subsubsection{Perfil demográfico y sintomatología de los pacientes estudiados}

Los 68 pacientes seleccionados según los criterios expuestos (pacientes alérgicos a polen con síntomas estacionales en los dos años previos y residentes en la misma zona durante cinco años, que no hubieran recibido inmunoterapia previa), presentaron una edad media cercana a los 30 años (Tabla 5.5.1.). Por franjas de edad, el grupo más numeroso fue el que agrupó a todos aquellos pacientes mayores de edad (casi un $81 \%$ del total), seguido de los pacientes entre 15 y 17 años (casi el 12\%), y por último, de la franja de pacientes menores de 15 años (alrededor del 7\%). De todos ellos, cerca del 56\% fueron mujeres.

Los síntomas más comúnmente diagnosticados en los pacientes analizados fueron la rinitis y la rinoconjuntivitis, con un $56 \%$, seguidos por la rinitis/rinoconjuntivitis y el asma (cerca del 43\%), quedando un único paciente con asma aislada. Ligado al diagnóstico, se evaluó la gravedad de asma en los 30 pacientes que lo presentaron, y se encontró que un 33\% presentaron asma intermitente, otro 33\% con asma leve persistente, un 30\% síntomas moderados persistentes y cerca del $3 \%$ asma grave.

\begin{tabular}{|c|c|c|c|c|c|}
\hline \multicolumn{6}{|c|}{ Resultados demográficos } \\
\hline & & media & Desv.típica & mínimo & máximo \\
\hline Edad & & 29,5 & 10,7 & 11 & 63 \\
\hline T. evolución & & 7 & 5,9 & 1 & 25 \\
\hline \multirow{4}{*}{ Edad } & & N & $\%$ & & \\
\hline & $\leq 14$ años & 5 & 7,3 & & \\
\hline & 15-17 años & 8 & 11,8 & & \\
\hline & $\geq 18$ años & 55 & 80,9 & & \\
\hline \multirow{2}{*}{ Sexo } & Mujer & 38 & 55,9 & & \\
\hline & Varón & 30 & 44,1 & & \\
\hline \multicolumn{6}{|c|}{ Resultados clínicos } \\
\hline & & $N$ & $\%$ & & \\
\hline \multirow{3}{*}{ Diagnóstico } & Asma $(A)$ & 1 & 1,5 & & \\
\hline & $\begin{array}{c}\text { Rinitis (R)/ } \\
\text { Rinoconjuntivitis (RC) }\end{array}$ & 38 & 55,9 & & \\
\hline & $R / R C+A$ & 29 & 42,6 & & \\
\hline \multirow{4}{*}{ Gravedad Asma } & Intermitente & 10 & 33,3 & & \\
\hline & Leve persistente & 10 & 33,3 & & \\
\hline & Moderado persistente & 9 & 30 & & \\
\hline & Grave persistente & 1 & 3,3 & & \\
\hline \multirow{4}{*}{ Gravedad Rinitis } & Intermitente & 10 & 14,9 & & \\
\hline & Leve persistente & 19 & 28,4 & & \\
\hline & Moderado intermitente & 7 & 10,4 & & \\
\hline & Grave persistente & 31 & 46,3 & & \\
\hline
\end{tabular}

Tabla 5.5.1. Resultados clínicos y demográficos de la población estudiada. 
En relación con la rinitis, dentro de los 67 pacientes con esta sintomatología, el 14,9\% de los pacientes que presentaron síntomas intermitentes, mientras que un $28,4 \%$ tuvieron trastornos leves persistentes, un 10,4\% moderados e intermitentes y un $46,3 \%$ trastornos graves y persistentes.

\subsubsection{Prevalencia de positivos obtenidos por los métodos utilizados}

La realización de pruebas intraepidérmicas dio como resultado a casi un 79,5\% de pacientes positivos a la mezcla de gramíneas, seguido de cerca de un $43 \%$ de positivos a olivo, alrededor de un $18 \%$ a artemisia, un $16 \%$ a Salsola, plátano, profilina y cupresáceas, cerca de un $12 \%$ a melocotón, alrededor de un $7 \%$ a Parietaria, un $6 \%$ a polcalcina, y de un $3 \%$ a abedul, aunque en este último caso el número de pacientes estudiados con esta técnica fue de 33 .

Las dos sensibilizaciones más importantes detectadas por alérgenos recombinantes fueron al alérgeno Phl p 1 (grupo 1 de gramíneas), con casi un 81\%, y de cerca de un $46 \%$ al alérgeno Phl p 5 (grupo 5 de gramíneas), siendo seguidos por los alérgenos presentes en el olivo, con un 48,5\% a Ole e 1, y un 4,4\% a Ole e 9 (Fig. 5.5.1.). De igual forma, alrededor de un $19 \%$ de pacientes presentaron un resultado positivo a Cup s 1, de un $15 \%$ a Pla 1 , de un $13 \%$ a Art v 1, de un 9\% a Sal k 1, y de un 4,5\% a los alérgenos Par j 1 y Bet v 1. Por último, el panalérgeno Pru p 3 (LTP), tuvo un 13,2\% de pacientes positivos, mientras que Mal d 4 (profilina) tuvo casi un $12 \%$ de positivos, y cerca de un $4,5 \%$ a Che a 3 (polcalcina).

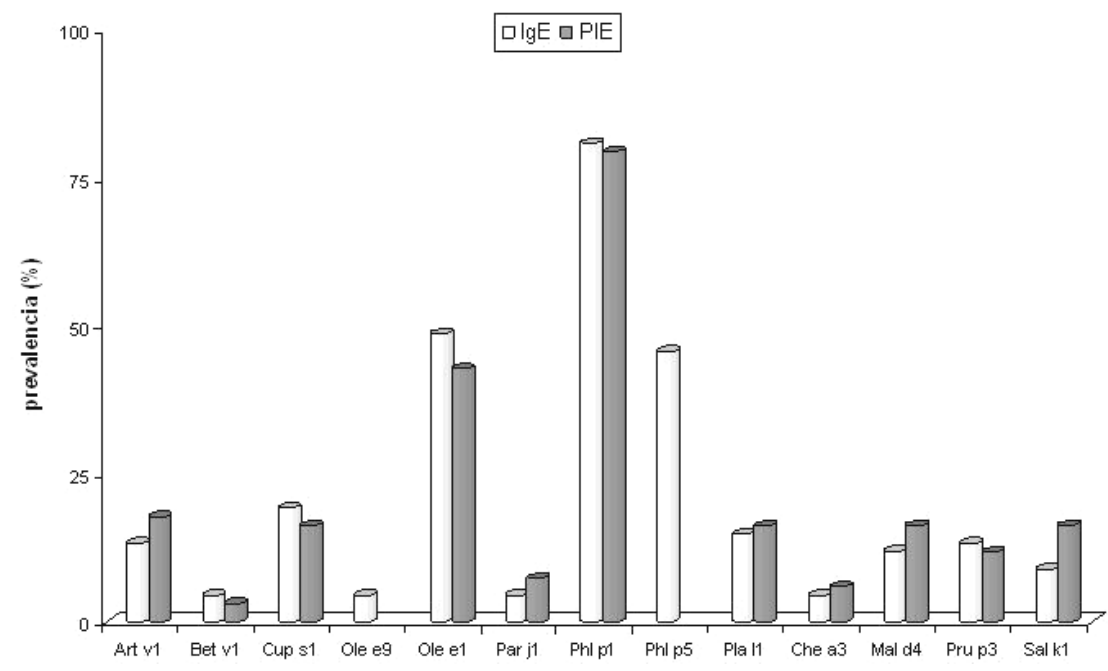

Fig. 5.5.1. Porcentaje de prevalencia de positivos tras el uso de la técnica Advia Centaur (IgE), y de las pruebas intraepidérmicas (PIE) a los diferentes alérgenos utilizados. 


\subsubsection{Valores de IgE específica}

La cantidad de IgE específica obtenida al emplear la técnica Advia Centaur, expresada como mediana de los resultados obtenidos con el suero de los pacientes positivos, fue variable en función del alérgeno empleado (Tabla 5.5.2.). Así pues, la mayor cantidad de IgE específica se presentó ante los alérgenos de gramíneas Phl p 5 y Phl p 1, con cerca de un 14,5 y un 11 de UI por ml, seguida del pan-alérgeno de polcalcina Che a 3 con cerca de $8 \mathrm{UI} / \mathrm{ml}$, de los alérgenos de olivo, Ole e 1 (algo superior a $6 \mathrm{UI} / \mathrm{ml}$ ) y Ole e 9 (valores superiores a 1 $\mathrm{UI} / \mathrm{ml}$ ), del alérgeno Pla 11 con 4,2 UI/ml, y de Cup s 1 y Sal k 1, con cerca de 3 UI/ml. El panalérgeno de LTP, Pru p 3, presentó un valor de mediana de casi 2,5 UI por ml, un valor próximo al que se obtuvo con los alérgenos Bet v 1 y Art v 1 (cercanos a 2 UI/ml), y algo superior al del pan-alérgeno de profilina Mal d 4 y de Par j 1, con valores próximos a $1 \mathrm{UI} / \mathrm{ml}$.

\begin{tabular}{c|ccc|c|c|c}
\hline \multicolumn{4}{|c|}{ IgE } & \multicolumn{2}{c}{ Pruebas intraepidérmicas (PIE) } \\
\hline Alérgeno & Mediana & Positivos & Prevalencia & Alérgeno & $N$ & $\%$ \\
\hline Art v 1 & 1,71 & 9 & 13,2 & Artemisia & 12 & 17,65 \\
\hline Bet v 1 & 1,76 & 3 & 4,4 & Betula * & 1 & 3,03 \\
\hline Cup s 1 & 2,76 & 13 & 19,1 & Cupressus & 11 & 16,18 \\
\hline Ole e 9 & 1,34 & 3 & 4,4 & Gramíneas & 54 & 79,41 \\
\hline Ole e 1 & 6,11 & 33 & 48,5 & Olea & 29 & 42,65 \\
\hline Par j 1 & 1,02 & 3 & 4,4 & Melocotón & 8 & 11,76 \\
\hline Phl p 1 & 10,83 & 55 & 80,9 & Parietaria & 5 & 7,35 \\
\hline Phl p 5 & 14,52 & 31 & 45,6 & Platanus & 11 & 16,18 \\
\hline Pla I 1 & 4,2 & 10 & 14,7 & Plantago & 24 & 35,29 \\
\hline Che a 3 & 8,05 & 3 & 4,4 & Polcalcina & 4 & 5,88 \\
\hline Mal d 4 & 1,27 & 8 & 11,8 & Profilina & 11 & 16,18 \\
\hline Pru p 3 & 2,48 & 13,2 & Salsola & 11 & 16,18 \\
\hline Sal k 1 & 2,63 & 9 & & & \\
\hline
\end{tabular}

Tabla 5.5.2. Resumen de los resultados obtenidos al aplicar la técnica Advia Centaur, expresados en la mediana de la cantidad de IgE específica contabilizada en suero (en UI/ml), número de positivos y prevalencia sobre el total, y las pruebas intraepidérmicas, con el número de pacientes positivos (N) y porcentaje sobre el total (\%).

\subsubsection{Concentraciones polínicas umbrales}

En los últimos años se han presentado estudios que reflejan niveles umbrales en las concentraciones atmosféricas diarias de diferentes tipos de polen, capaces de desencadenar síntomas en pacientes sensibilizados a diferentes alérgenos, presentes en esos tipos de polen (Florido et al., 1999; Waisel et al., 2004; Rapiejko et al., 2007). En nuestro estudio, hemos seguido los valores umbrales referidos en la Tabla 5.5.3., dentro de los tipos de polen más relevantes desde el punto de vista alergénico, para delimitar el número de días en los que los pacientes sensibilizados pudieron sufrir síntomas propios de los procesos alérgicos debido a 
las concentraciones atmosféricas de los tipos de polen referidos en los años 2006 y 2007, anteriores y posteriores al estudio realizado antes de la primavera del año 2007.

El tipo Poaceae superó en 31 y 50 días durante los años 2006 y 2007, respectivamente (Fig. 5.5.2.), los 50 granos $/ \mathrm{m}^{3}$ durante los meses de mayo (21 y 6 días), junio (9 y 26 días), y julio (1 y 18 días, respectivamente), lo cual muestra que en la gran mayoría de los días de junio y la primera mitad de julio, los pacientes sensibilizados pudieron desarrollar sintomatologías alérgicas, si bien cabe reseñar que, además del menor número de días en el año 2006, estos se centraron fundamentalmente en el mes de mayo.

\begin{tabular}{|c|c|c|c|c|c|c|c|}
\hline \multirow{2}{*}{ Tipo de polen } & \multicolumn{2}{|c|}{ \% representación } & \multirow{2}{*}{ Umbral } & \multicolumn{2}{|c|}{ Conc. máxima (día) } & \multicolumn{2}{|c|}{$\begin{array}{c}\text { No días > } \\
\text { umbral }\end{array}$} \\
\hline & 2006 & 2007 & & 2006 & 2007 & 2006 & 2007 \\
\hline Artemisia & $0,3 \%$ & $0,2 \%$ & $4-5 \mathrm{~g} / \mathrm{m}^{3}[1]$ & 6 (8-sep) & 4 (2-sep) & 2 & 1 \\
\hline Betula & $0,5 \%$ & $0,5 \%$ & $80 \mathrm{~g} / \mathrm{m}^{3}-30 \mathrm{~g} / \mathrm{m}^{3}[2]$ & 38 (20-abr) & 20 (9-may) & 0 & 0 \\
\hline Chenopodiaceae & $1,8 \%$ & $0,7 \%$ & $10-15 \mathrm{~g} / \mathrm{m}^{3}[3]$ & 22 (9-ago) & 10 (18-ago) & 10 & 1 \\
\hline Cupressaceae & $9,5 \%$ & $11,7 \%$ & $50-60 \mathrm{~g} / \mathrm{m}^{3}[1]$ & 141 (4-mar) & 550 (4-mar) & 11 & 22 \\
\hline Olea & $7,6 \%$ & $2,2 \%$ & $153 \mathrm{~g} / \mathrm{m}^{3}-34 \mathrm{~g} / \mathrm{m}^{3}[4]$ & 429 (17-may) & 162 (8-jun) & 4 & 2 \\
\hline Plantago & $3,4 \%$ & $5,5 \%$ & - & 49 (15-may) & 159 (13-jul) & & - \\
\hline Platanus* & $5,9 \%$ & $3,3 \%$ & - & 252 (10-abr) & 297 (16-abr) & - & - \\
\hline Poacaee & $20,2 \%$ & $25,2 \%$ & $50 \mathrm{~g} / \mathrm{m}^{3}[5]$ & 248 (17-may) & 355 (30-jun) & 31 & 50 \\
\hline Urticaceae & $4,6 \%$ & $3,2 \%$ & $30 \mathrm{~g} / \mathrm{m}^{3}[2]$ & 59 (31-mar) & 31 (23-jun) & 1 & 1 \\
\hline
\end{tabular}

Tabla 5.5.3. Porcentajes de representación de los tipos de polen con mayor interés en alergología sobre el total de polen registrado en el año 2007, junto a las concentraciones umbral, las concentraciones máximas (en granos $/ \mathrm{m}^{3}$ ), y el número de días en los que se superaron las concentraciones umbrales.

* Sólo en pruebas intraepidérmicas. Referencias: Waisel et al., 2004 [1], Connell, 1969 [2], Pola, 2003 [3], Feo et al., 1998 [4], Rapiejko et al., 2007 [5].

El siguiente tipo en número de días superando el umbral durante los dos años referidos(50-6o granos/m3), fue Cupressaceae (Fig. 5.5.3.), con 11 y 22 días, respectivamente, distribuidos entre febrero (3 y 9 días), marzo (7 y 12 días), y abril (1 día en 2007), además de noviembre (1 día en 2006), seguido por Chenopodiaceae, con 10 y 1 días en los años 2006 y 2007, a lo largo de los meses de julio (1 día en 2006), agosto (8 días en 2006 y 1 día en 2007), y septiembre (1 día en 2006). El tipo Olea superó el umbral establecido, 4 días en el año 2006 (3 días en mayo y 1 en junio), y 2 días en el mes de junio del año 2007, mientras que el tipo Artemisia tuvo concentraciones superiores al umbral durante 1 día del mes de agosto y de septiembre del año 2006, y durante 1 día del mes de septiembre de 2007. Por último, el tipo Urticaceae presentó niveles que superaron los valores establecidos como umbrales durante un único día en marzo de 2006 y en junio de 2007, algo que no ocurrió para el tipo Betula que no presentó concentraciones superiores a los rangos umbrales considerados. 


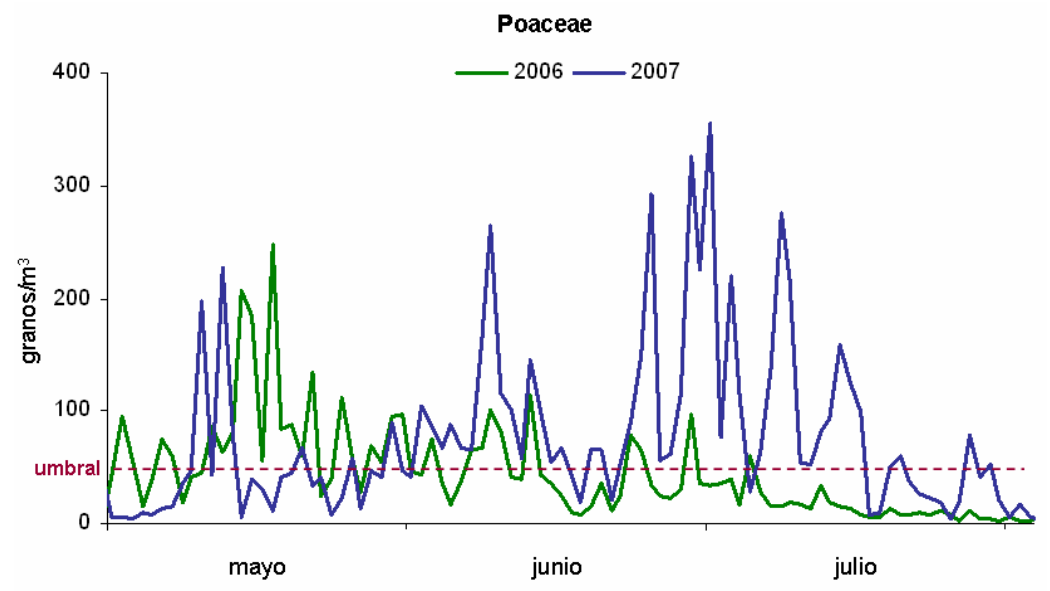

Fig. 5.5.2. Evolución de las concentraciones diarias de Poaceae de mayo a julio, y umbral de concentraciones (50 granos $/ \mathrm{m}^{3}$ ), susceptibles de desencadenar procesos alérgicos en pacientes sensibilizados durante los años 2006 y 2007.

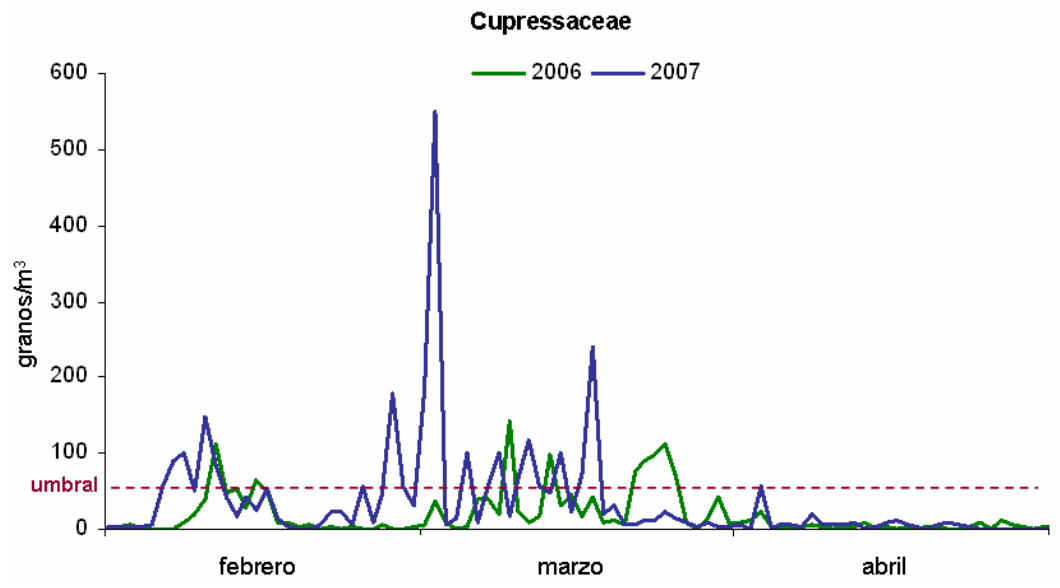

Fig. 5.5.3. Evolución de las concentraciones diarias de Cupressaceae de febrero a abril, y umbral de concentraciones (50-6o granos/m³), susceptibles de desencadenar procesos alérgicos en pacientes sensibilizados durante los años 2006 y 2007.

\subsubsection{Relación entre el polen presente en la atmósfera y los resultados obtenidos}

Para evaluar la relación entre la cantidad total de polen contabilizada en los años 2006 y 2007, y la cantidad de IgE específica localizada en el suero de pacientes sensibilizados, y expresada a través de la mediana de los resultados obtenidos, hemos relacionado la cantidad de IgE específica para cada uno de los alérgenos estudiados, salvo los 
panalérgenos Che a 3, Pru p 3 y Mal d 4, con los valores totales de los tipos de polen relacionados, tal y como se recoge en la Tabla 5.5.4. En el caso del alérgeno Ole e 1, que se encuentra presente también en Fraxinus, con el homólogo Fra e 1 (Obispo et al., 1993; Hemmer et al., 2000), hemos optado por valorar dicho alérgeno con la suma de los totales anuales de los tipos de polen Olea y Fraxinus.

\begin{tabular}{|c|c|c|c|c|}
\hline Alérgeno & Mediana lgE específica & Tipo de polen & \multicolumn{2}{|c|}{ Total anual polen } \\
\cline { 3 - 5 } & & & 2006 & 2007 \\
\hline Art vl & 1,71 & Artemisia & 76 & 67 \\
Bet v1 & 1,76 & Betula & 137 & 150 \\
Sal k1 & 2,63 & Chenopodiaceae & 474 & 228 \\
Ole e9 & 1,34 & Olea & 1954 & 678 \\
Ole el & 6,11 & Olea + Fraxinus & 2214 & 1056 \\
Par j1 & 1,02 & Urticaceae & 1197 & 1002 \\
Pla l1 & 4,2 & Plantago & 1530 & 1017 \\
Cup sl & 2,76 & Cupressacae & 2438 & 3635 \\
Phl pl & 10,83 & Poaceae & 5210 & 7832 \\
Phl p5 & 14,52 & Poaceae & 5210 & 7832 \\
\hline
\end{tabular}

Tabla 5.5.4. Mediana de IgE especifica para distintos alérgenos y el total anual para los años 2006 y 2007 de los tipos de polen en los que están presentes dichos alérgenos.

La valoración de esta relación se ha realizado a través de dos estadísticos diferentes, como son el test de correlación no paramétrico de Spearman y la regresión lineal, a través de los valores de su coeficiente de correlación y el índice de determinación, respectivamente (Fig. 5.5.4.). En ambos casos, los valores de dichos estadísticos (o,80 y o,717, en el año 2006; o,80 y 0,766 , en el año 2007, respectivamente) nos mostraron que existía una correlación entre la cantidad de IgE específica encontrada en el suero de los pacientes y la cantidad total de granos de polen presentes en la atmósfera durante el año anterior y posterior a la mencionada medición in vitro.

Para evaluar la posible relación entre el polen atmosférico y los resultados obtenidos en las pruebas intraepidérmicas, hemos realizado la comparación entre el porcentaje de prevalencia de positivos para un determinado alérgeno usado en los paneles de dichas pruebas y el porcentaje sobre el total de cada tipo de polen que contiene ese alérgeno, no considerando los panalérgenos (profilina, procalcina) ni los alérgenos asociados a alimentos (melocotón). Los resultados obtenidos tras aplicar los dos estadísticos empleados con anterioridad, nos muestran una menor relación (Fig. 5.5.5.), que en el caso de la IgE específica y los valores totales de polen (0,76 y 0,542 en el año 2006; 0,58 y 0,339 en el año 2007), aunque deba destacarse que los valores fueran más elevados en el año 2006 que en el año 2007. 


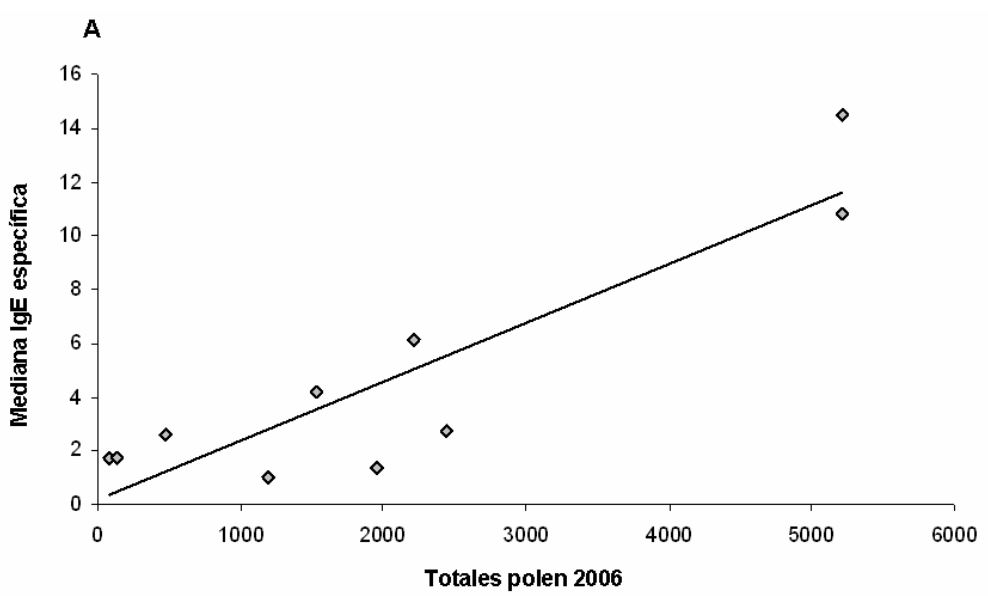

\begin{tabular}{|c|c|c|c|c|c|}
\hline \multirow{2}{*}{$\begin{array}{l}\text { Mediana IgE- total } 2006 \\
\qquad y=b 1 x+c\end{array}$} & \multicolumn{3}{|c|}{ Parámetros } & \multicolumn{2}{|c|}{ Estimaciones } \\
\hline & $\begin{array}{c}F \\
32,614\end{array}$ & $\begin{array}{c}\text { g.l. } \\
9\end{array}$ & $\begin{array}{c}\text { Sig } \\
0,001\end{array}$ & $\begin{array}{c}\text { Constante } \\
0,2069\end{array}$ & $\begin{array}{c}\text { Coef. b } 1 \\
0,0022\end{array}$ \\
\hline \multirow{2}{*}{$\begin{array}{c}\text { Mediana IgE- total polen } \\
2006\end{array}$} & \multirow{2}{*}{\multicolumn{3}{|c|}{$\begin{array}{l}\text { Coeficiente de correlación de Spearman } \\
\qquad 0,717^{\star}\end{array}$}} & \multirow{2}{*}{\multicolumn{2}{|c|}{$\underset{* *}{\text { Grado de significación }}$}} \\
\hline & & & & & $95 \%$ \\
\hline
\end{tabular}

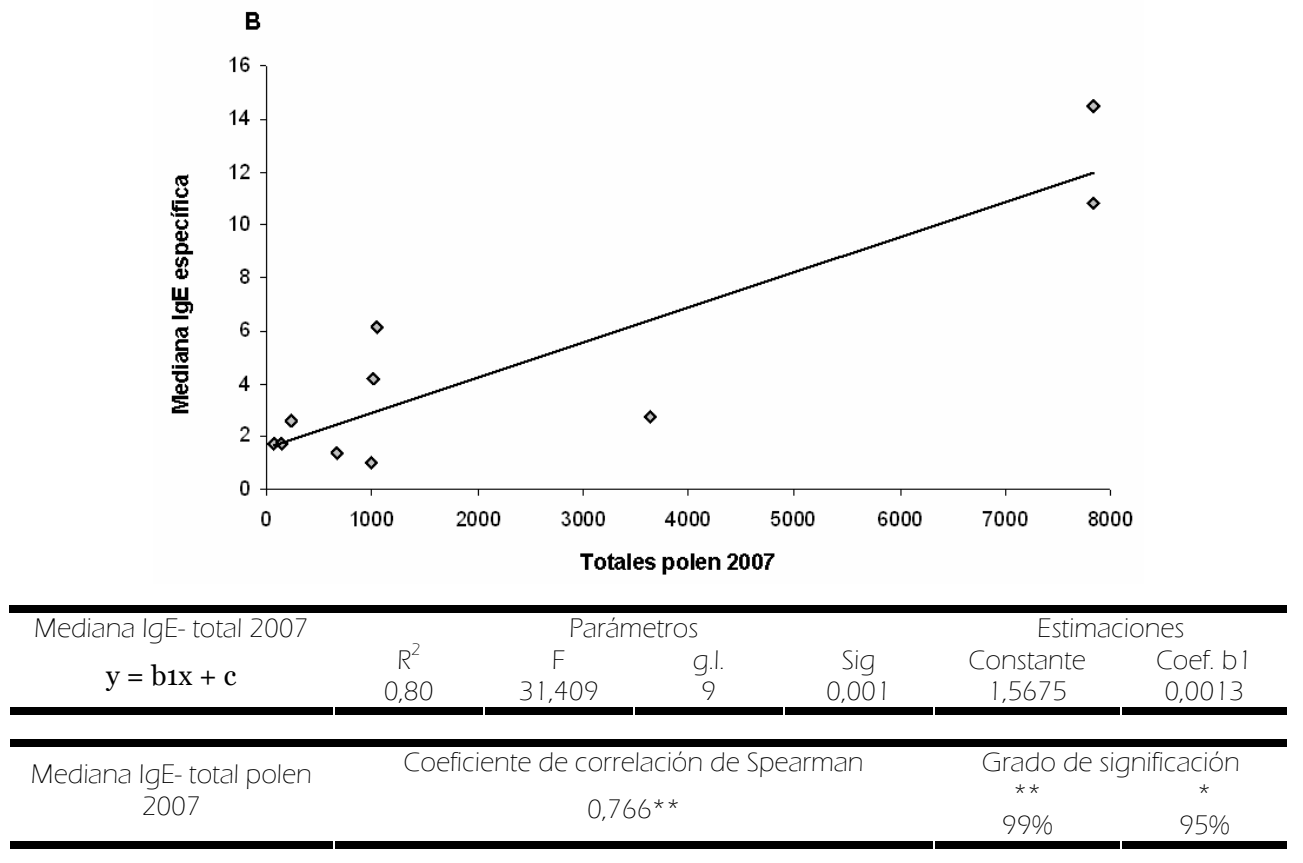

Fig. 5.5.4. Relación entre la mediana de IgE específica localizada en el suero de pacientes sensiblizados para diferentes alérgenos localizados en diferentes tipos de polen y sus valores totales anuales en los años2006 (A) y 2007 (B). Valoración de la relación mediante análisis de tendencias (regresión lineal), y el coeficiente de correlación de Spearman. 


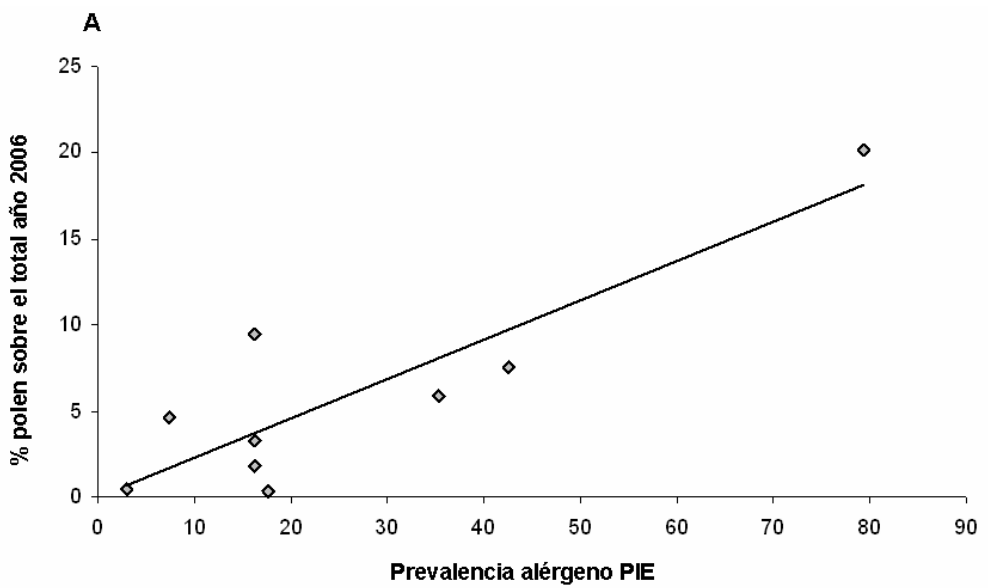

\begin{tabular}{|c|c|c|c|c|c|}
\hline \multirow{2}{*}{$\begin{array}{c}\text { Prevalencia PIE - \% } 2006 \\
\qquad \mathbf{y}=\mathbf{b} 1 \mathbf{x}+\mathbf{c}\end{array}$} & \multicolumn{3}{|c|}{ Parámetros } & \multicolumn{2}{|c|}{ Estimaciones } \\
\hline & $\begin{array}{c}F \\
22,177\end{array}$ & $\begin{array}{l}\text { g.l. } \\
8\end{array}$ & $\begin{array}{c}\text { Sig } \\
0,002\end{array}$ & $\begin{array}{c}\text { Constante } \\
0,0242\end{array}$ & $\begin{array}{c}\text { Coef. b } 1 \\
0,2286\end{array}$ \\
\hline \multirow{2}{*}{$\begin{array}{c}\text { Prevalencia PIE - \% polen } \\
2006\end{array}$} & \multicolumn{3}{|c|}{ Coeficiente de correlación de Spearman } & \multicolumn{2}{|c|}{ Grado de significación } \\
\hline & \multicolumn{3}{|c|}{0,542} & $99 \%$ & $95 \%$ \\
\hline
\end{tabular}

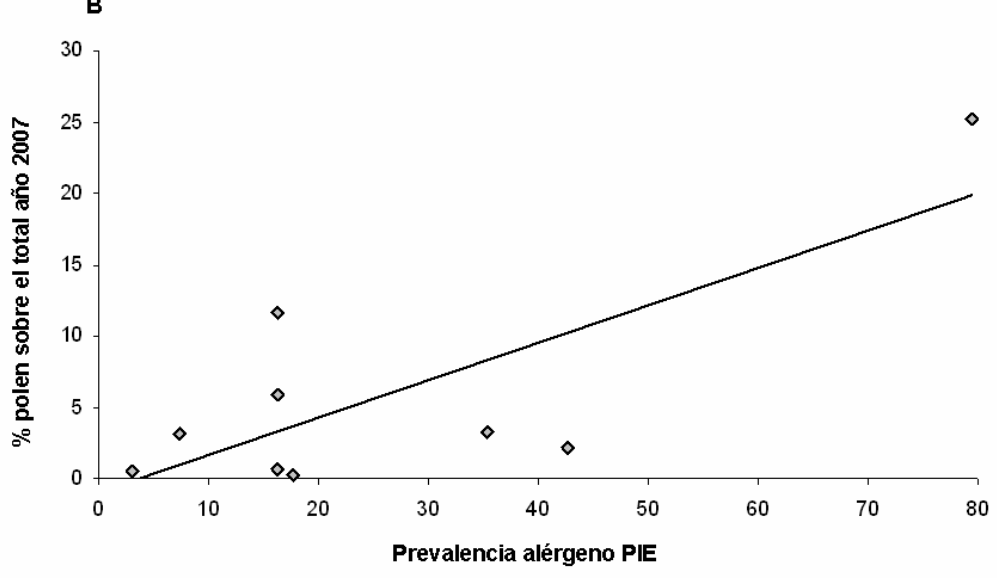

\begin{tabular}{|c|c|c|c|c|c|}
\hline \multirow{2}{*}{$\begin{array}{c}\text { Prevalencia PIE - \% } 2007 \\
\qquad \mathbf{y}=\mathrm{b} 1 \mathrm{x}+\mathrm{c}\end{array}$} & \multicolumn{3}{|c|}{ Parámetros } & \multicolumn{2}{|c|}{ Estimaciones } \\
\hline & $\begin{array}{c}F \\
9,659\end{array}$ & $\begin{array}{l}9.1 . \\
8\end{array}$ & $\begin{array}{l}\text { Sig } \\
0,0017\end{array}$ & $\begin{array}{c}\text { Constante } \\
-0,9\end{array}$ & $\begin{array}{l}\text { Coef. bl } \\
0,2609\end{array}$ \\
\hline \multirow{2}{*}{$\begin{array}{c}\text { Prevalencia PIE - \% polen } \\
2007\end{array}$} & \multicolumn{3}{|c|}{ Coeficiente de correlación de Spearman } & \multicolumn{2}{|c|}{$\underset{* \star}{\underset{*}{G}} \underset{*}{\text { Grado de significación }}$} \\
\hline & \multicolumn{3}{|c|}{0,339} & $99 \%$ & $95 \%$ \\
\hline
\end{tabular}

Fig. 5.5.5. Relación entre el porcentaje de prevalencia de positivos pacientes sensiblizados para diferentes alérgenos localizados en diferentes tipos de polen y sus valores porcentuales sobre el total de granos de polen contabilizados en los años 2006 (A) y 2007 (B). Valoración de la relación mediante análisis de tendencias (regresión lineal), y el coeficiente de correlación de Spearman. 
Discusión 



\subsection{Espectro polínico y variación interanual}

En el transcurso de los diez años analizados en esta memoria de Tesis Doctoral se han obtenido diferencias relevantes en la composición del espectro polínico de la ciudad de Salamanca, como pone de manifiesto el número de tipos de polen detectado en el año 2000 y en el año 2007, con 43 y 65 tipos, respectivamente (Fig. 6.1.). La media de tipos para el período estudiado se correspondió con 58 tipos de polen, siendo el año 2004 el que mayor número de tipos presentó (66), y el ya mencionado año 2000, el que menos (43). Todo ello implicó un incremento en el contenido cualitativo de polen en la atmósfera, tal y como refleja el análisis de tendencias realizado a través de la regresión lineal y el valor que alcanza su índice de determinación $\left(\mathrm{R}^{2}=0,80\right)$, muy similar al que mostró el incremento del contenido cuantitativo (Fig. 5.2.1.1., pág. 55). Por tanto, durante el período 2000-2007 se produjo un aumento cuantitativo y cualitativo en el contenido de polen atmosférico en la ciudad de Salamanca.

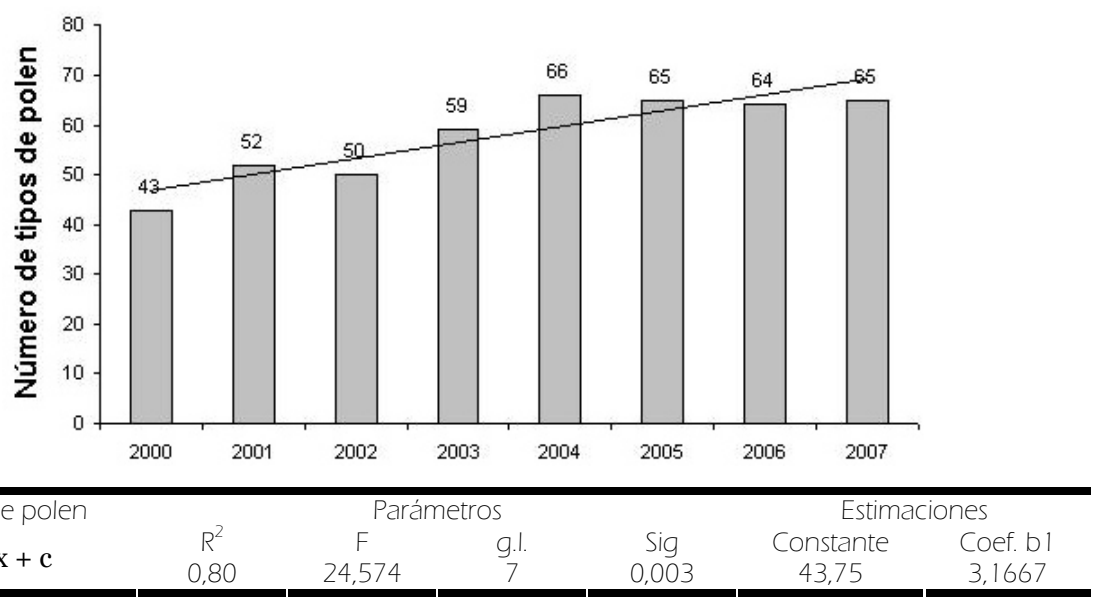

Fig. 6.1. Evolución anual del número total de tipos de polen contabilizados y tendencias (análisis de regresión).

Esta diferencia cualitativa pudo deberse a varios motivos, como el biotipo (si se trata de especies herbáceas o arbóreo-arbustivas) de las especies productoras de un determinado tipo de polen, o el uso ornamental o como arbolado de alineación en la ciudad de Salamanca o núcleos urbanos próximos. En este contexto, diversos tipos de polen procedentes de especies generalmente herbáceas, como Cruciferae, Euphorbiaceae, Liliaceae, Lotus, Malvaceae, Oxalis, Ranunculaceae, Rubiaceae, Scrophulariaceae (excluido Mercurialis), Solanaceae y Umbelliferae, pudieron estar influidas en su desarrollo y su producción polínica, así como en la liberación del mismo por las condiciones climatológicas locales y su carácter entomófilo, como se ha visto en algunas especies herbáceas (Subba \& Reddi, 1985; Bhattacharya \& Datta, 1992; Jones \& Harrison, 2004). También resulta interesante la posibilidad de incluir en este grupo al tipo Papaver, pues el número anual 
varió notablemente, si bien en este caso debemos tener en cuenta la acción antrópica en la gestión de los diferentes cultivos (uso de herbicidas) en los que aparece principalmente este género, como analizaron Hopkins \& Davies (1994) con la implicación de los cambios en los usos agrarios en el contenido polínico atmosférico de diversas especies de gramíneas utilizadas en cultivos y pastos del Reino Unido. Por otro lado, no debemos obviar que en el caso de varios géneros arbóreo-arbustivos, fundamentalmente Aesculus, Lagestroemia, Pittosporum, Rhamnus, Sophora y Viburnum, tuvo incidencia la política urbanística y la decisión de cultivar una u otra especie de forma ornamental (Sukopp et al., 1995; McKinney, 2006), que, en el ámbito de la flora ornamental, se siguió durante los años estudiados, unida a las diferencias en la producción y dispersión de los granos de polen que producen en función de las condiciones climatológicas interanuales, como se observó en Mar de Plata para diversos géneros como Acer o Liquidambar (Latorre, 1999). Estos hechos pudieron explicar la ausencia o el bajo número de ciertos tipos de polen en algunos años de este estudio, principalmente entre los años 2000 y 2003, aunque no debemos obviar que las muestras de estos años fueron analizadas años después a la fecha en la que se tomaron, lo cual dificulta la identificación de los diferentes tipos de polen.

El número de tipos de polen identificados en la atmósfera de la ciudad de Salamanca fue superior en todas las anualidades del período 2000-2007, con respecto a los dos bienios 1981-1982 y 1991-1992 (Hernández et al., 1998), y los años 1995 (Suárez et al., 2003) y 1996 (Sánchez et al., 2006), con 48, 47, y 44 tipos, respectivamente, excepto en el año 2000, donde se identificaron 43 tipos. En otras ciudades relativamente cercanas a la localidad estudiada (entorno a 200 kilómetros), el número de tipos fue similar a Cáceres durante el bienio 1996-1997 (Tavira et al., 1998), con 65 tipos y Madrid, en el bienio 2000-2001 (Gutiérrez et al., 2002), con 55 y 62 tipos, respectivamente, ambas localizadas al sur del Sistema Central, mientras que fue ligeramente superior a la ciudad de León (Vega et al., 2002), con 44 y 40 tipos en los años 2000 y 2001, situada en el noroeste peninsular y próxima a la Cordillera Cantábrica.

Los registros polínicos totales anuales contabilizados son inferiores al de algunos puntos de muestreo próximo ya indicados (Tabla 6.1.), como Cáceres (Paulino et al., 2002), con o Madrid (Gutiérrez et al., l.c.), e incluso a los presentados en otros años para la ciudad de Salamanca, con 31596 y 36629 granos de polen totales durante los años 1995 y 1996, respectivamente (Suárez et al., l.c.; Sánchez et al., l.c.). En lo referente a otras ciudades relativamente próximas, los valores anuales fueron ligeramente superiores a los registrados en León (Vega et al., l.c.) o similares a localidades como Ávila o Soria para el año 2007, con totales iguales a 28847 y 31644 granos de polen, respectivamente (Fernández-González et al., 2008). En este caso, la latitud pudo explicar la diferencia en el número anual de granos de polen, como se ha visto en estudios conjuntos para varios tipos de polen como Olea (Díaz et 
al., 1999), Plantago (Gutiérrez et al., 1999), o Quercus (García-Mozo et al., 1999), en diversas ciudades españolas, con mayor número en puntos de muestreo de la mitad sur peninsular. De este modo, la particular situación de la ciudad de Salamanca, a menos de 100 kilómetros al norte del Sistema Central y relativamente próxima a zonas termófilas, como se indicó en el apartado "Área de estudio", hizo posible que sus registros anuales fuesen levemente superiores al de otras localidades del centro y norte peninsular en alguno de los años analizados, si bien hemos de apuntar que no existen datos publicados de estas localidades durante gran parte de las anualidades del período estudiado.

\begin{tabular}{|c|c|c|c|c|c|c|c|c|c|}
\hline Ciudad & Año(s) & Cupressaceae & Olea & Plantago & Platanus & Poaceae & Populus & Quercus & Total \\
\hline Salamanca & 2000-2007 & $10,9 \%$ & $4,9 \%$ & & & $22 \%$ & & $23,5 \%$ & $16916^{*}$ \\
\hline \multirow{2}{*}{ Cáceres } & 2000 & $3 \%$ & $6 \%$ & $3 \%$ & & $38 \%$ & & $33 \%$ & 72131 \\
\hline & 2001 & $3 \%$ & $8 \%$ & $5 \%$ & & $41 \%$ & & $30 \%$ & 81184 \\
\hline \multirow{3}{*}{ Madrid } & 2000 & $15,6 \%$ & & & $25 \%$ & $11 \%$ & & $10,7 \%$ & 45966 \\
\hline & 2001 & $24,3 \%$ & & & $24,3 \%$ & $10,6 \%$ & & $16,9 \%$ & 60904 \\
\hline & 2005-2007 & $12,6 \%$ & & & $21,7 \%$ & $11,5 \%$ & & $19,1 \%$ & $27784 *$ \\
\hline \multirow{2}{*}{ León } & 2000 & $7 \%$ & & & & $7 \%$ & $8 \%$ & $42 \%$ & 16872 \\
\hline & 2001 & $7 \%$ & & & $9,9 \%$ & $10 \%$ & & $33 \%$ & 14487 \\
\hline
\end{tabular}

Tabla 6.1. Tipos de polen más abundantes y valores totales anuales en Salamanca y ciudades próximas. *Valores promedio en los años incluidos.

Los tipos de polen que han alcanzado un mayor porcentaje de representación en el espectro polínico de Salamanca a lo largo del período 2000-2007 (Tabla 6.2.), fueron Quercus, con un porcentaje de representación promedio de 23,5\% sobre el total, Poaceae (22\%), Cupressaceae (10,9\%), Olea (4,9\%), Pinus (3,8\%), Plantago (3,8\%), Populus (3,6\%), Rumex (3,6\%), Platanus (3,4\%), y Urticaceae (2,9\%). En cinco de los años analizados (2002, 2004-2007), el tipo de polen que presentó mayor incidencia fue Quercus, mientras que en los tres años restantes (2000, 2001 y 2003) fue Poaceae. Este último tipo, fue el segundo tipo de polen con mayor incidencia a lo largo de cinco años (2002, 2004-2007), seguido de Cupressaceae durante dos años (2001, 2003), y Quercus en el año 2000. Asimismo, el tercer tipo de polen fue Cupressaceae durante 6 anualidades (2000, 2002, 2004-2007), siendo el tipo Quercus el que obtuvo esta representatividad a lo largo de los años 2001 y 2003. Conviene destacar que los tipos Acer, Chenopodiaceae y Fraxinus se encontraron dentro de los diez tipos de polen con los valores anuales más elevados durante uno de los ocho años analizados (2000, 2003 y 2002, respectivamente), conllevando que los tipos Olea, Platanus y Urticaceae, no se presentaran en esas anualidades dentro de esos diez tipos más representativos.

Los datos de presencia relativa de los tipos de polen con mayor incidencia en la atmósfera, mostraron diferencias (Tabla 6.1.) con los captadores de León (Vega et al., l.c.), 
con mayor representatividad de Poaceae, Populus, Cupressaceae y Platanus, Madrid (Gutiérrez et al., l.c.), donde los tipos más abundantes fueron Platanus, Cupressaceae y Quercus, o incluso Coimbra (Brandao et al., 2008), con un espectro polínico dominado por Olea, Pinaceae, Poaceae y Urticaceae, si bien esta población portuguesa no se refleja en la Tabla 6.1. dada la ausencia de ciertos datos. La ciudad de Cáceres fue la que presentó más coincidencias en el orden de representación (Tavira et al., l.c.; Paulino et al., l.c.), ya que, al igual que en Salamanca, en función del año estudiado, los tipos más abundantes se corresponden con Poaceae o Quercus, seguidos por Plantago, Olea y Cupressaceae. No obstante, con respecto Cáceres, cabe reseñar la menor representatividad de los granos de polen de Cupressaceae, posiblemente por una menor difusión ornamental de árboles y arbustos de esta familia.

\begin{tabular}{|c|c|c|c|c|c|c|c|c|c|c|}
\hline Taxon (total y \%) & Año & 2000 & 2001 & 2002 & 2003 & 2004 & 2005 & 2006 & 2007 & Media \\
\hline & Total & 322 & 202 & 43 & 79 & 116 & 169 & 105 & 96 & 141 \\
\hline Acet & $\%$ & 2,8 & 2,1 & 0,5 & 0,9 & 0,6 & 0,8 & 0,4 & 0,3 & 0,3 \\
\hline Chenenodiaceze & Total & 64 & 77 & 68 & 260 & 154 & 248 & 474 & 228 & 197 \\
\hline 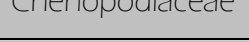 & $\%$ & 0,6 & 0,8 & 0,9 & 3,1 & 0,8 & 1,1 & 1,8 & 0,7 & 1,2 \\
\hline & Total & 855 & 1180 & 1071 & 1071 & 1839 & 2327 & 2438 & 3635 & 1802 \\
\hline cupressaceae & $\%$ & 7,6 & 12,1 & 13,6 & 12,6 & 9,9 & 10,3 & 9,5 & 11,7 & 10,9 \\
\hline Fraxinus & Total & 92 & 72 & 182 & 84 & 198 & 241 & 260 & 378 & 188 \\
\hline FIaXIIUS & $\%$ & 0,8 & 0,7 & 2,3 & 1 & 1,1 & 1,1 & 1 & 1,2 & 1,2 \\
\hline & Total & 272 & 660 & 482 & 401 & 763 & 1123 & 1954 & 678 & 792 \\
\hline Oled & $\%$ & 2,4 & 6,8 & 6,1 & 4,7 & 4,1 & 5 & 7,6 & 2,2 & 4,9 \\
\hline & Total & 380 & 334 & 322 & 211 & 1083 & 1347 & 822 & 687 & 648 \\
\hline PInus & $\%$ & 3,4 & 3,4 & 4,1 & 2,5 & 5,8 & 6 & 3,2 & 2,2 & 3,8 \\
\hline & Total & 583 & 314 & 218 & 392 & 565 & 638 & 868 & 1706 & 660 \\
\hline mantago & $\%$ & 5,2 & 3,2 & 2,8 & 4,6 & 3 & 2,8 & 3,4 & 5,5 & 3,8 \\
\hline & Total & 438 & 284 & 287 & 148 & 687 & 427 & 1530 & 1017 & 602 \\
\hline Plalanus & $\%$ & 3,9 & 2,9 & 3,6 & 1,7 & 3,7 & 1,9 & 5,9 & 3,3 & 3,4 \\
\hline Pمacea & Total & 2765 & 3046 & 1092 & 2314 & 4143 & 2602 & 5210 & 7832 & 3626 \\
\hline Podecte & $\%$ & 24,5 & 31,2 & 13,8 & 27,3 & 22,4 & 11,6 & 20,2 & 25,2 & 22 \\
\hline & Total & 686 & 422 & 184 & 308 & 370 & 707 & 941 & 1087 & 588 \\
\hline ropulis & $\%$ & 6,1 & 4,3 & 2,3 & 3,6 & 2 & 3,1 & 3,7 & 3,5 & 3,6 \\
\hline Ouercus & Total & 1982 & 826 & 2284 & 883 & 5768 & 8625 & 5949 & 9357 & 4459 \\
\hline outercus & $\%$ & 17,5 & 8,5 & 28,9 & 10,4 & 31,1 & 38,4 & 23,1 & 30,1 & 23,5 \\
\hline Pumex & Total & 474 & 365 & 177 & 438 & 575 & 631 & 1036 & 1011 & 588 \\
\hline kUחाEX & $\%$ & 4,2 & 3,7 & 2,2 & 5,2 & 3,1 & 2,8 & 4 & 3,3 & 3,6 \\
\hline & Total & 430 & 230 & 172 & 205 & 422 & 563 & 1197 & 1002 & 528 \\
\hline urticaceae & $\%$ & 3,8 & 2,4 & 2,2 & 2,4 & 2,3 & 2,5 & 4,6 & 3,2 & 2,9 \\
\hline
\end{tabular}

Tabla 6.2. Valores totales y porcentajes de representación de los tipos de polen principales durante los años estudiados y media. En negrita se disponen los datos de los tipos de polen que durante los diferentes años se encontraron dentro de los diez tipos de polen más representativos.

La mayor incidencia de polen procedente de Platanus hispanica Mill. ex Münchh. en León y Madrid, esté relacionada, además de las posibles diferencias en el número de árboles cultivados, con la gestión del arbolado de alineación en las distintas ciudades en lo referente al diferente grado de poda de los mismos en los meses o semanas precedentes a la floración (Díaz de la Guardia et al., 1999; Iglesias et al., 2007; Sabariego et al., 2008), como ya se ha puesto de manifiesto para las ciudades de Salamanca y Valladolid (Sánchez et al., 2008), con 
un descenso en los totales anuales en Salamanca con respecto a la capital de Castilla y León debido al mayor número de podas en la primera de ellas.

La presencia de ciertos tipos de polen en la atmósfera debe reseñarse por su particular distribución en la atmósfera de diversas localidades peninsulares, como el caso de Betula, cuyos granos de polen alcanzan valores anuales importantes en el noroeste de España (Jato et al., 1999), con 2332 granos de polen como total promedio entre 1993 y 1998 en Santiago de Compostela, menores en zonas fuera del ámbito eurosiberiano, como la ciudad de León (Vega et al., l.c.), con 224 granos como total promedio para el bienio 2000-2001, y que en la ciudad de Salamanca presenta totales anuales inferiores a los mencionados, pero superiores a la ciudad de Madrid (Gutiérrez et al., l.c.), donde no se identificó ningún grano en el año 2000, y 91 en 2001. La existencia de pequeñas formaciones de Betula alba L., en las sierras meridionales de la provincia, y el conocido fenómeno de transporte a media y larga distancia de sus granos de polen (Jato et al., 2007; Ranta et al., 2008), pudieran apuntar a que dichos granos procedieran de esta zona, aunque creemos que fue más significativo el aporte de los ejemplares ornamentales cultivados en la ciudad, y cuyo uso se ha incrementado a lo largo de los años, al igual que el número de granos de polen anuales.

Los tipos de polen Cytisus y Ericaceae, adscritos a especies arbustivas, han sido registrados, fundamentalmente, en captadores situados en el norte y noroeste peninsular (Fernández-González et al., 1998; Valencia-Barrera et al., 1999; Rodríguez-Rajo et al., 2005a), respectivamente, con números totales anuales similares para el tipo Cytisus, inferiores con respecto a Ericaceae en León (Vega et al., l.c.), con un total promedio de 316 granos para el bienio 2000-2001, pero superiores a los datos presentados en Madrid (Gutiérrez et al., l.c.), que presentó un total promedio de 68 granos de polen para el mismo bienio, y Valladolid (Sánchez et al., 2007), con un valor total medio de 48 granos para el bienio 2005-2006.

Los géneros herbáceos Papaver y Echium, constituyen dos tipos que han sido observados en el oeste de España (Salvador \& Sánchez, 1990; González \& Candau, 1995; Toro et al., 1996; Rodríguez et al., 1998; Muñoz et al., 2005), y que, en el primero de ellos, y al igual que aconteció en la atmósfera de Salamanca, alcanza ocasionalmente valores anuales elevados en Mérida (Moreno et al., 1999), con 182 granos de polen en el año 1998. En lo referente a Echium, debe reseñarse que el contenido polínico anual fue inferior a los registros obtenidos en Cáceres (Paulino et al., l.c.), donde se obtuvieron valores totales anuales promedio de 641 granos de polen en los años 2000 y 2001, y similares a los de Madrid (Gutiérrez et al., l.c.), con 258 granos de polen en el año 2000 y sin identificarse en el año 2001.

El número total de granos de polen contabilizados a lo largo de los ocho años de estudio experimentó un incremento notable, como se indicó en el apartado de 
"Resultados" (Tabla 5.2.1.2., pág. 57), donde el análisis de tendencias mediante regresión lineal refrendó este aumento del 275\% del contenido polínico. En otras zonas, este ascenso en las concentraciones polínicas pudo deberse fundamentalmente a la contribución de algunos de los géneros arbóreos más representativos, como Betula en el noroeste de Europa (Spieksma et al., 2003), Olea en Andalucía (Trigo et al., 2008b), Platanus en España e Italia (Jato et al., 2001b; Tedeschini et al., 2006), o Quercus en la Península Ibérica (García-Mozo et al., 2006) y en el noroeste de Europa (Spieksma et al., l.c.), en los cuales se ha registrado un incremento en sus niveles polínicos a lo largo de los últimos años, algo que pudo estar motivado por el conocido fenómeno del calentamiento global (Osborne et al., 2000; Jäeger, 2002). En la ciudad de Salamanca, es posible que este incremento en los totales anuales estuviera motivado, como acabamos de señalar, por el aumento en los niveles polínicos del género Quercus. A través del análisis de tendencias propio de la regresión lineal en cada uno de los tipos de polen identificados en la atmósfera de la ciudad de Salamanca, hemos podido constatar un incremento en los totales anuales durante el período 2000-2007 en los tipos principales, a excepción de Olea y Pinus, que no registraron índices de determinación $\left(\mathrm{R}^{2}\right)$ iguales o superiores a 0,50 (Tabla 6.3.). Este hecho contrasta, en parte, con lo acontecido en otras zonas de España, para Olea (Trigo et al., l.c.), y Pinus (Galán et al., 2006), donde sí se observó una tendencia al incremento de los valores totales anuales en los períodos 1992-2007 y 1993-2005, respectivamente, debido seguramente a una estabilización posterior al incremento del uso ornamental de olivos de gran porte en la ciudad (Rodríguez, 2003), y a la posible existencia de ritmos trianuales en el género Pinus (Atkinson \& Larsson, 1990), que pudieron influir en una menor tendencia al incremento. No obstante, debemos destacar que la presencia de ritmos de floración para este género puede ser variable en función de las especies de uso forestal presentes en la zona de estudio (Jato et al., 2002).

En el lado contrario, sólo cuatro tipos (Ailanthus, Juncaceae, Sambucus y Tilia), presentaron un descenso en sus niveles polínicos interanuales refrendado a través de la regresión lineal, con índices de determinación iguales o superiores a 0,50. Esta tendencia ya se observó en la ciudad de Salamanca para Ailanthus y Tilia entre los años 1999 y 2004 (Rodríguez et al., 2007), debido a la eliminación de muchos ejemplares del primero de ellos en solares abandonados de reciente edificación o, en el caso de Tilia, a plagas o enfermedades en sus hojas (Bernadovičová \& Ivanová, 2008), descritas para Tilia cordata Mill., con la aparición de manchas foliares por la invasión del ascomiceto Cercospora microsora Sacc., cuya actividad metabólica da como resultado la producción de una toxina, cercosporina, de elevada acción patogénica en células animales y vegetales (Daub \& Ehrenshaft, 2000), que pudo ser el causante de la mortandad de muchos de los ejemplares cultivados en la última mitad de la década de los noventa. También pudieron adscribirse causas ligadas a los diversos usos urbanísticos y las modificaciones que llevaron consigo, al descenso del género 
Sambucus, mientras que en el caso de Juncaceae, familia eminentemente anemófila con una baja producción polínica y una baja capacidad de dispersión (Muñoz et al., 2007), su descenso en las anualidades estudiadas pudo deberse a la modificación de los ambientes riparios próximos a la ciudad de Salamanca (Valle \& García-Baquero, 1996).

\begin{tabular}{ccc|c}
\hline \multicolumn{2}{c|}{ Tipos de polen con incremento $(2000-2007)$} & \multicolumn{2}{c}{ Tipos de polen con descenso (2000-2007) } \\
\hline Tipo & Índice determinación $\left(R^{2}\right)$ & Tipo & Índice determinación $\left(R^{2}\right)$ \\
\hline Cupressaceae & 0,85 & Ailanthus & 0,68 \\
Helianthus* & 0,85 & Sambucus & 0,62 \\
Ericaceae & 0,81 & Tilia & 0,60 \\
Umbelliferae & 0,81 & Juncaceae & 0,56 \\
Liguliflorae* & 0,81 & \\
Fraxinus & 0,80 & \\
Betula & 0,79 & \\
Quercus & 0,74 & \\
Cruciferae & 0,69 & \\
Rumex & 0,69 & \\
Castanea & 0,66 & \\
Aesculus & 0,62 & \\
Urticaceae & 0,61 & \\
Chenopodiaceae & 0,56 & \\
Platango & 0,56 & \\
Poaceae & 0,54 & \\
Platanus & 0,50 & \\
\hline
\end{tabular}

Tabla 6.3. Tipos de polen con índices de determinación $\left(\mathrm{R}^{2}\right)$ iguales o superiores a 0,50 , para el análisis de tendencias al incremento o al descenso a lo largo de los ocho años de estudio. *Sólo en el período 2004-2007.

\subsection{Variación estacional}

Los mayores niveles de polen se presentan en la atmósfera de Salamanca durante los meses de mayo y junio (Tabla 5.2.1.4., pág. 59), ya que suponen, como media de los años estudiados, el 63\% del total anual promedio. Por el contrario, los tres últimos meses del año, no alcanzaron el 2\% del total promedio anual. En los meses de mayor contenido polínico, mayo y junio, los tipos Quercus, con un 36\% sobre el total promedio en ambos meses, y Poaceae, con un 28\%, fueron los más representados en la atmósfera. Asimismo, cabe reseñar la notable presencia de Cupressaceae en los tres primeros meses del año, pues sus granos de polen supusieron el 53\% del total promedio para dichos meses y del tipo Platanus en abril, con un $32 \%$ sobre el total. La distribución estacional de los granos de polen contabilizados resultó muy similar a las ciudades de Cáceres (Paulino et al., 2002), y León (Vega et al., 2002), y algo diferente para Madrid (Gutiérrez et al., 2002), con una distribución más regular de enero a abril, debido fundamentalmente al elevado porcentaje que alcanzaron los granos de polen de Cupressaceae en los tres primeros meses del año, fundamentalmente en enero y febrero. En esta última ciudad se observó que los niveles polínicos en la atmósfera tuvieron un ligero adelantamiento a lo registrado en Salamanca, con mayores niveles de 
polen durante el mes de marzo, un hecho que fue mucho más acusado en Cáceres, donde Quercus y Poaceae, presentaron sus concentraciones más elevadas en marzo y abril, y mayo y junio, respectivamente. Tal y como han apuntado varios autores para la Península Ibérica (Fernández-González et al., 1999; García-Mozo et al., 2002; García-Mozo et al., 2009), existen diferencias estacionales en los niveles atmosféricos de los tipos Poaceae y Quercus, siendo Salamanca, por su particular localización, un indicador válido para valorar estas diferencias, puesto que se encuentra en la mitad norte peninsular, pero muy próxima (a unos 100 kilómetros) a la mitad sur. Por todo ello, estimamos que el Sistema Central, que divide a la península en dos mitades, norte y sur, con particularidades climáticas evidentes (RivasMartínez et al., 2004), resulta fundamental para conferir diversos comportamientos estacionales de los tipos de polen procedentes de especies de gran representación, así como diferencias cuantitativas en función de la latitud en la que se ubiquen los captadores, aunque no debamos obviar las diferencias bioclimáticas existentes en ambas mitades, que condicionan formaciones vegetales $\mathrm{y}$, de forma consiguiente, el contenido de polen en la atmósfera, junto a la influencia de la gestión urbana.

Los tipos de polen para los que se ha definido el período principal de polinización (PPP al 95\%), aquellos con una representación superior o igual al o,5\% (al menos un año), tuvieron un comportamiento similar al descrito en el conjunto de España para la gran mayoría de los mismos en los últimos años (Trigo et al., 2008a), teniendo en cuenta las diferencias que acabamos de mencionar entre las dos mitades peninsulares. Además, existe un mayor número de trabajos referentes a los tipos de polen con mayor importancia, ya sea por su incidencia numérica en el total anual de granos de polen o bien por su relevancia alergénica en la Península Ibérica. Así pues, el tipo Quercus, con un PPP conocido para la ciudad de Salamanca (Rodríguez et al., 2008), entre los meses de abril y junio, tuvo una distribución similar a ciudades próximas como León o Madrid (García-Mozo et al., 1999), observándose un adelantamiento en el inicio y la finalización del mismo en zonas más meridionales (García-Mozo et al., l. c.), e incluso en zonas septentrionales con un clima más temperado (Rodríguez-Rajo et al., 2005b), ya que, en ambos casos, sus granos de polen se localizan principalmente entre finales de marzo y mediados de junio.

La familia Poaceae presentó un amplio PPP (151 días de media), localizándose de mediados de marzo hasta la primera semana de agosto, que se asemeja al que presentaron ciudades del noroeste peninsular, como León u Orense (Fernández-González et al., 1999), resultando inferior al de otras localidades del sur peninsular, y superior si se compara con PPP definidos en núcleos de población importantes del norte peninsular (Antepara et al., 1995; Jato et al., 2008), e incluso del norte de Europa (Spieksma et al., 1985; Sánchez et al., 2003), donde los granos de polen de este tipo se presentan, principalmente, en los meses de junio y julio. El tipo Cupressaceae, con 154 días promedio para su PPP y de extensión similar 
a la de Poaceae, pero entre finales de enero y finales de junio, tuvo un comportamiento similar al de ciudades de la mitad meridional, aunque se haya señalado que el PPP no parezca necesario para definir la dinámica aerobiológica de este tipo polínico (Belmonte et al., 1999b), debido a que dentro del mismo se incluyen muchas especies con períodos de floración diferentes. Este hecho se pone de manifiesto en Ponferrada (Fuertes-Rodríguez et al., 2007), donde este tipo presentó un PPP corto, entorno a 33 días, debido a la gran representación de una única especie, Cupressus sempervirens L., en las proximidades del captador. Por tanto, puede inferirse que los tipos de polen con PPP más amplios engloben a un buen número de especies, géneros e incluso familias, con diferente fenología, teniendo en cuenta también que pueden producirse los conocidos fenómenos de resuspensión (Mandrioli et al., 1998) en polen de pequeño tamaño, como el que describe a la familia Urticaceae (VegaMaray et al., 2003). Los granos de polen pertenecientes al tipo polínico Olea europaea, presentaron un PPP promedio de 50 días, entre los meses de mayo y junio, que se corresponde con los presentados en diversas localidades de la Península Ibérica (Díaz de la Guardia et al., 1999; Gutiérrez \& Sáenz, 2000; Ribeiro et al., 2005).

Por último, resulta interesante comentar lo acontecido con el tipo Echium, con un PPP comprendido entre mayo y julio, y cuyo comienzo varía en casi un mes con respecto a los registros de captadores de Extremadura (Muñoz et al., 2005), que en los años 2006 y 2007 presentó PPP de 220 y 196 días, debido a la presencia de granos de polen de este tipo durante finales del año 2006 e inicios de 2007, como pone de manifiesto el valor máximo diario en el año 2006 (31 granos/m³ , el día 18 de noviembre). Dicha presencia, y los consiguientes PPP más amplios, pudo deberse a una floración tardía de Echium plantagineum L., pues las temperaturas medias de los meses de octubre y noviembre de $2006\left(13,9^{\circ} \mathrm{C}\right.$ y $9,9^{\circ} \mathrm{C}$, respectivamente), fueron superiores a las del período medio de referencia $\left(12,2^{\circ} \mathrm{C}\right.$ y $\left.7,3^{\circ} \mathrm{C}\right), \mathrm{y}$ estuvieron acompañadas de una mayor cantidad de precipitación (104 mm para ambos meses en 2006 frente a los $81 \mathrm{~mm}$ del período medio).

La evolución de los PPP presentados por los diferentes tipos analizados a lo largo de los ocho años estudiados, no mostró grandes diferencias en gran parte de los mismos ni ningún tipo de tendencia clara, salvo en el caso de seis tipos (Cupressaceae, Fraxinus, Olea, Platanus, Poaceae y Quercus). Los tipos Fraxinus, Olea, y Poaceae (Fig. 6.2.), experimentaron un incremento en la duración de sus PPP, como indican los índices de determinación $\left(\mathrm{R}^{2}\right)$ obtenidos con el análisis de regresión lineal $(0,25 ; 0,24$ y 0,52), y que, como han determinado diversos autores para diversos tipos de polen, este mayor PPP lleva consigo un mayor número anual de polen (Emberlin et al., 2002; Galán et al., 2005), como consecuencia de un adelantamiento en el inicio de la floración. Los dos tipos pertenecientes a la familia Oleaceae, Fraxinus y Olea, retrasaron la fecha de finalización, en contraposición al adelanto de varios días observado en otros trabajos para ambos tipos (González et al., 1999; 
Jato et al., 2004), posiblemente por el transporte de granos de polen, evidenciado para esta familia (Damialis et al., 2005), desde las diferentes zonas climáticas que presenta la provincia de Salamanca, que conllevan variaciones en la fenología de estas especies arbóreas. Sin embargo, el adelanto en el inicio del PPP, debido seguramente al aumento de la temperatura media a lo largo del período analizado (Emberlin et al., 2007), fue el responsable de su mayor duración, dentro de la familia Poaceae, al igual que ocurrió en Londres durante un período de 30 años (Emberlin et al., 1993), pero diferente a lo observado en Galicia (Jato et al., 2008), donde se relata una tendencia a una estación polínica más tardía y corta.
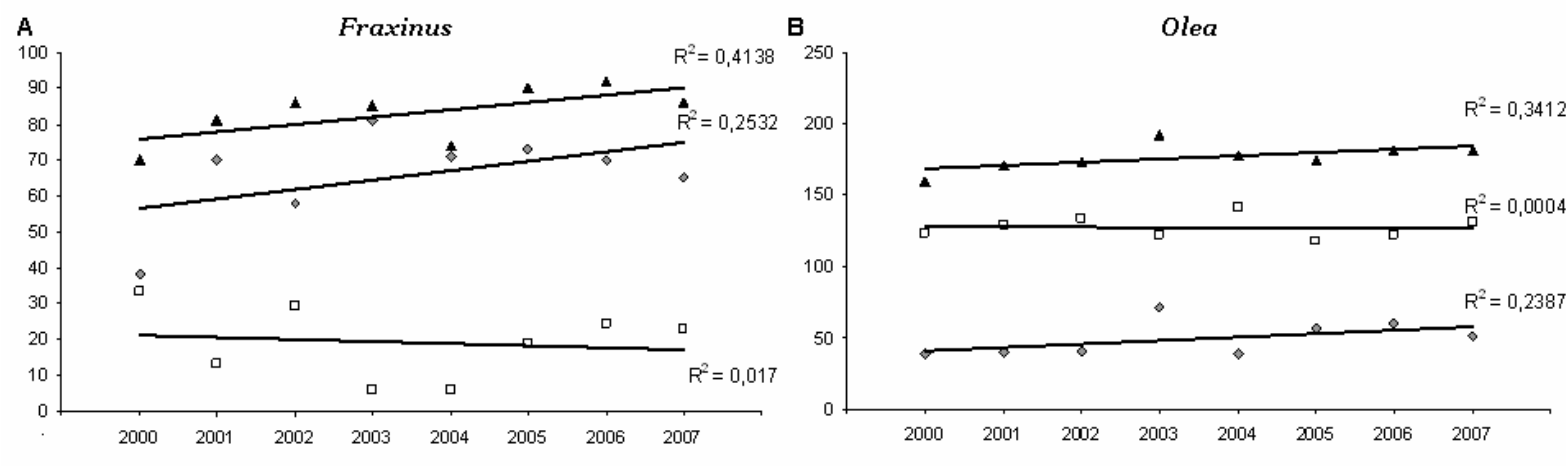

$\stackrel{\text { ng }}{\frac{\pi}{0}}$

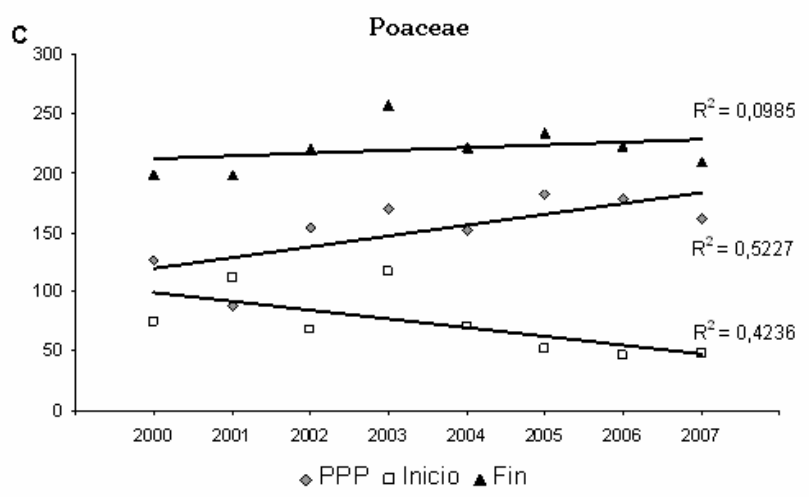

Fig. 6.2. Evolución anual del PPP (duración, inicio y fin), expresado en días a partir del 1 de enero, y tendencias (análisis de regresión) para Fraxinus (A), Olea (B) y Poaceae (C).

Por el contrario, los tipos Cupressaceae, Platanus y Quercus, con índices de determinación más altos que en los otros tres tipos mencionados (0,69; 0,79 y 0,49, respectivamente), posee una tendencia hacia una menor duración del PPP (Fig. 6.3.). Este hecho, contrario a la dinámica general hacia un incremento de la duración del PPP, presentada en los trabajos antes citados, puede corresponderse con un incremento del contenido polínico anual a través de los años estudiados, como se ha visto para Olea en Andalucía, con PPP más cortos pero de mayor intensidad en la emisión polínica (Díaz et al., 2003). De todos modos, esta tendencia hacia una menor duración del PPP, se corresponde con lo observado en diversas zonas de Italia y España para Platanus (Tedeschini et al., 
2006), al igual que para Quercus en Trieste (Rizzi-Longo et al., 2005), pese a que en el noroeste de España se indicó un aumento del mismo (Rodríguez-Rajo et al., 2005b). Conviene destacar que durante los años 2000 y 2001 se produjo un adelanto en la fecha de inicio del PPP de Quercus, y la consiguiente tendencia al descenso en la duración del mismo en los años posteriores, como consecuencia de las temperaturas medias del mes de marzo, más altas en los años mencionados que en el período medio de referencia $\left(10,3^{\circ} \mathrm{C}\right.$ y $8,4^{\circ} \mathrm{C}$, respectivamente, frente a $7,7^{\circ} \mathrm{C}$ ), tal y como se ha indicado por algunos investigadores (Rodríguez-Rajo et al., 2003b; García-Mozo et al., 2006), para varias especies del género con floración temprana debido a este incremento en la temperatura durante los meses previos al inicio e incluso el mes de comienzo de la misma.

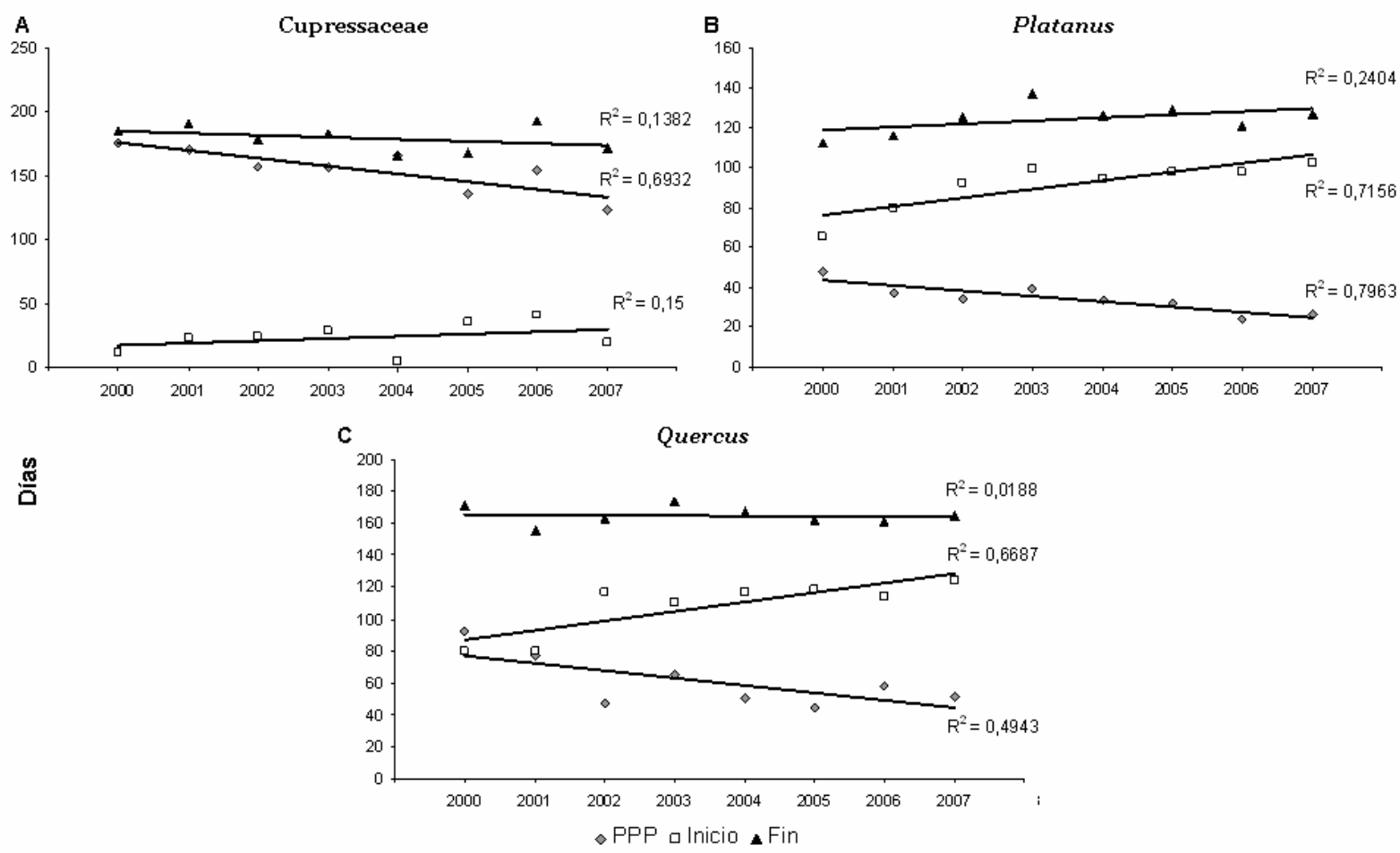

Fig. 6.3. Evolución anual del PPP (duración, inicio y fin), expresado en días a partir del 1 de enero, y tendencias (análisis de regresión) para Cupressaceae (A), Platanus (B) y Quercus (C).

\subsection{Contenido polínico y parámetros meteorológicos}

Las concentraciones de polen en la atmósfera dependen, por una parte, de factores intrínsecos a las propias especies productoras como pueden ser los procesos fisiológicos o las interacciones con el medio que les rodea y en el que se desarrollan, así como de una serie de factores extrínsecos, dentro de los cuales, además de la acción antrópica, también se incluyen las condiciones climatológicas, que, según han demostrado numerosos autores, pueden condicionar los ciclos anuales y estacionales de producción, liberación y transporte de los 
granos de polen (Agashe \& Alfadil, 1989; Candau et al., 1994; Spieksma et al., 1995; ValenciaBarrera et al., 2001; Vázquez et al., 2003; Jones \& Harrison, 2004; Makra et al., 2004; Damialis et al., 2005; Estrella et al., 2006; Silva et al., 2007).

La temperatura ejerce un efecto positivo sobre las emisiones polínicas de diferentes especies, tal y como han puesto de manifiesto diversos trabajos (Arobba et al., 1992; Recio et al., 1997; Jato et al., 2002; Weryszko-Chmielewska et al., 2006), y que coincide con lo obtenido con la gran mayoría de los 28 tipos de polen analizados (en función de su representatividad), salvo para Alnus, Cupressaceae, Fraxinus, Platanus, Populus y Ulmus (Tabla 6.4.). Estos tipos de polen proceden de especies arbóreas de fenología temprana cuya floración se realiza a principios de invierno o principios de primabera, período adverso en el que estas especies adoptan un estado fisiológico con bajo o nulo metabolismo conocido como dormición, para impedir los efectos de las bajas temperaturas propias de esta época del año, siendo inducido por las propias bajas temperaturas. De forma general, estos árboles mantienen este estado de dormición en sus yemas florales, mientras la temperatura siga siendo desfavorable, produciéndose la abertura de dichas yemas al alcanzar una suma de temperaturas propia de cada especie y lugar (Boyer, 1973; Kramer, 1994; Chuine et al., 1999). El conocimiento de esta particular adaptación fisiológica ha permitido el desarrollo de un buen número de estudios para predecir el comienzo de la floración en árboles cuya fenología se centra en los primeros meses del año (Caramiello et al., 1994; González-Minero et al., 1999; Jato et al., 2004; González-Parrado et al., 2006; Fuertes-Rodríguez et al., 2007).

Los valores obtenidos al correlacionar las concentraciones de polen atmosférico de estos seis tipos de polen (Alnus, Cupressaceae, Fraxinus, Platanus, Populus y Ulmus), y la temperatura durante el período analizado, fueron de signo negativo y significativas, pues a medida que aumentaron los niveles de estos tipos en el aire a lo largo de diferentes épocas del invierno, no hubo una correspondencia con un incremento de la temperatura media, máxima ni mínima en el ámbito de las ocho anualidades incluidas. Resultados similares se han obtenido al correlacionar la temperatura y las concentraciones de polen, en Szczecin (Polonia), para Fraxinus y Populus (Puc \& Wolski, 2002; Weryszko-Chmielewska et al., l. c.). No obstante, conviene señalar que, independientemente del modelo elegido para la delimitación del PPP, durante los PPP y PRE definidos para los tipos de polen anteriormente citados, en diversos años, las correlaciones con la temperatura fueron de signo positivo, a excepción de Cupressaceae, que sólo las registró durante el PRE, posiblemente por poseer un PPP muy amplio. En el caso de Platanus, donde también se observó este comportamiento, estos resultados no se corresponden con lo observado en Santiago de Compostela (Jato et al., 2001b), donde si hubo una correlación positiva entre la temperatura y los niveles de polen, pues en esta especie ornamental hemos de tener presente otro factor extrínseco, el de la gestión antrópica de los núcleos urbanos, comentado en el apartado 6.1. 
La insolación, un factor meteorológico que favorece la liberación de los granos de polen (Galán et al., 1995), relacionado con la temperatura, también mostró una correlación positiva con los niveles polínicos de los tipos analizados, salvo en Alnus, Fraxinus, Populus y Ulmus, posiblemente por los mismos motivos expuestos para la temperatura. El efecto positivo de la insolación sobre las concentraciones polínicas se ha expuesto de forma clara para diversos tipos de polen en diferentes trabajos (Jato et al., 2001a; Valencia-Barrera et al., 2001; Rodríguez-Rajo et al., 2005b).

\begin{tabular}{|c|c|c|c|c|c|c|c|c|c|c|}
\hline & Temp & Insol & Precip & Hrel & VelMed & FrecCalm & VIC & $\mathrm{V} 2 \mathrm{C}$ & $\mathrm{V} 3 \mathrm{C}$ & V4C \\
\hline Acer & + & + & - & - & & $(-)$ & $(-)$ & $(-)$ & & + \\
\hline Ailanthus & + & + & $(-)$ & - & & $(-)$ & & & & + \\
\hline Alnus' & - & & & + & & & $(-)$ & & & \\
\hline Artemisia & + & + & $(-)$ & - & $(-)$ & $1+1$ & + & $1+1$ & $(-)$ & \\
\hline Castanea & + & + & - & - & & $1+1$ & & $(-)$ & & + \\
\hline Chenopodiaceae & + & + & - & - & - & & + & & - & + \\
\hline Compositae & + & + & - & - & & & & & & + \\
\hline Cupressaceae' & - & & & & & & $(-)$ & & + & \\
\hline Cyperaceae & + & + & - & - & & & & - & & + \\
\hline Echium & + & + & $(-)$ & - & $(-)$ & $(-)$ & $(-)$ & & + & + \\
\hline Fraxinus & - & & & + & & $(-)$ & $(-)$ & & + & $(-)$ \\
\hline Ligustrum & + & + & $(-)$ & - & & & $(-)$ & & & + \\
\hline Mercurialis & + & + & & - & & & & & & + \\
\hline Olea & + & + & - & - & & $(-)$ & $(-)$ & & + & + \\
\hline Papaver & $1+1$ & $1+1$ & $1+1$ & - & & & $(-)$ & & + & + \\
\hline Pinus & + & + & & - & & - & & $(-)$ & & + \\
\hline Plantago & + & + & - & - & & & & & & + \\
\hline Platanus' & $(-)$ & & $(-)$ & - & & $(-)$ & & $(-)$ & $(-)$ & \\
\hline Poaceae & + & + & - & - & $(-)$ & $(-)$ & & & $1+1$ & + \\
\hline Populus' & $(-)$ & $(-)$ & $1+1$ & & & $(-)$ & & & & $(-)$ \\
\hline Ouercus & + & + & $(-)$ & - & $1+1$ & - & $(-)$ & $(-)$ & + & + \\
\hline Robinia & + & + & $(-)$ & - & $1+1$ & $(-)$ & $(-)$ & - & + & + \\
\hline Rosaceae & + & + & & - & $1+1$ & $(-)$ & $(-)$ & & + & $1+1$ \\
\hline Rumex & + & + & $(-)$ & - & & & $(-)$ & $(-)$ & + & + \\
\hline Ulmus' & - & - & & & & & & & & - \\
\hline Urticaceae & + & + & - & - & - & & - & & $(+)$ & + \\
\hline Vitis & + & + & $(-)$ & - & & & & & & + \\
\hline
\end{tabular}

Tabla 6.4. Tipo de correlaciones (signo) entre las variables climatológicas - Temp (temperatura media, máxima y mínima), Insol (insolación), Precip (precipitación), Hrel (humedad relativa), VelMed (velocidad media), FrecCalm (frecuencia de calmas), V1C, V2C, V3C, V4C (vientos procedentes del I, II, III y IV cuadrante) - y los tipos de polen analizados. ${ }^{1}$ Correlaciones de diferente signo durante el PPP y PRE en diferentes parámetros meteorológicos y durante diversas anualidades. Entre paréntesis, correlaciones con valores bajos (inferiores a $0,1)$.

La precipitación tuvo una incidencia negativa sobre los niveles polínicos de los tipos analizados, algo que ha sido comprobado por varios autores en diferentes tipos (Subiza, 1980; Green et al., 2004; Ribeiro et al., 2006), con el fenómeno llamado como lavado atmosférico. A la hora de estudiar este parámetro hemos de tener en cuenta la distribución de la precipitación, ya que las lluvias prolongadas y constantes ejercen un efecto más negativo sobre las concentraciones de polen que las lluvias de corta duración e intensas 
(Iglesias et al., 1993). Así pues, las precipitaciones cortas e intensas propias de finales de primavera e inicios de verano en la ciudad de Salamanca (Rodríguez et al., 2008), revelaron correlaciones negativas de bajo valor en algunos tipos que florecen en esta época del año, como Ailanthus, Echium, Ligustrum, Quercus, Robinia, Rumex o Vitis, así como correlaciones positivas, también de escasa representación numérica, en Papaver o Populus, motivado también por la coincidencia de su floración con períodos lluviosos de corta duración y alta intensidad.

La humedad relativa es el parámetro meteorológico más relacionado con el anterior, pues una mayor precipitación incide en una mayor humedad relativa, que si sobrepasa un determinado umbral, posee un efecto negativo sobre los niveles de polen (Emberlin, 1994), algo que también ocurrió en gran parte de los tipos analizados en la ciudad de Salamanca, y que se corresponde con otros ejemplos estudiados (Herrero \& Fraile, 1997; Puc \& Puc, 2004; Silva et al., 2007). No obstante, en los géneros Alnus y Fraxinus, la humedad relativa tuvo una incidencia positiva, y que pudo estar relacionado con la influencia de la humedad en la producción polínica de estos géneros, como se ha puesto de manifiesto en Fraxinus (Candau et al., 1994), si bien en los PPP y PRE de algunas anualidades, la incidencia fue negativa, como se refleja en otras referencias (Weryszko-Chmielewska et al., l. c.).

Con respecto al viento, hemos de analizar por separado sus dos componentes principales, la velocidad y la dirección. En el primer caso, la velocidad, con su conocido efecto negativo sobre los niveles de polen tanto si es escasa como elevada (Bricchi et al., 1992), presentó correlaciones de diferente signo y, por lo general, de bajo valor numérico y/o poca significación. Esta influencia puede ser muy variable, no sólo entre los diferentes tipos de polen, sino también dentro del mismo tipo, dependiendo del año, tal y como se ha reflejado para Plantago en Extremadura (Tormo et al., 2001; Silva et al., l. c.). En relación a la dirección, debemos indicar que los vientos procedentes del III y IV cuadrante fueron los que tuvieron mayor influencia positiva sobre el incremento de las concentraciones de polen en gran parte de los tipos de polen estudiados, pues en esas zonas se encuentran las formaciones vegetales más importantes de la provincia (Batuecas-Sierra de Francia y Arribes de Duero, fundamentalmente). Así pues, la procedencia de los vientos dominantes se corresponde con las poblaciones más importantes productores de diferentes tipos de polen, como Compositae, Echium, Fraxinus, Olea, Papaver, Plantago, Poaceae, Quercus, Rumex, Urticaceae o Vitis, e incluso Chenopodiaceae, pero con vientos procedentes del I cuadrante, similar a lo acontecido en Tesalónica para Olea, Poaceae y Quercus (Damialis et al., l. c.), o en otros puntos de la Península Ibérica, como en Extremadura con Chenopodiaceae (Muñoz et al., 2000) o en Granada con Olea (Alba et al., 2000). Sin embargo, en algunos tipos de polen el efecto positivo de la dirección no se corresponde con la localización de las formaciones 
vegetales más abundantes y productoras de dichos tipos, como ocurre con Castanea y Pinus, algo similar a lo registrado en otras zonas de España con otros tipos (Rodríguez-Rajo et al., 2003; Muñoz et al., 2007), posiblemente por las adaptaciones de sus granos de polen a la dispersión a través del viento (Hesse, 1978; Schwendemann et al., 2007), y que pudieron facilitar su resupensión en la atmósfera (Mandrioli et al., 1998), y, en cierto modo, tergiversar estas correlaciones. Asimismo, el efecto de la dirección del viento sobre el contenido polínico de ciertos tipos de polen procedentes de especies eminentemente ornamentales como Acer, Ailanthus, Cupressaceae, Robinia o Ligustrum, debe de contemplarse con cierta cautela y remitirse a estudios posteriores, a realizar en zonas periurbanas.

\subsection{Valoración de los métodos utilizados para calcular el PPP}

En el transcurso de las últimas décadas, especialmente a partir de los años noventa, el uso de los datos de polen atmosférico suele englobar el período del año en el que se localiza la mayor parte del polen registrado en dicho año, utilizándose varios términos para definir este período (Mäkinen, 1977; González et al., 1998; Giorato et al., 2000), como estación polínica principal, período principal de polinización, período de máxima producción polínica, estación polínica efectiva o estación polínica atmosférica, de entre las cuales, como viene siendo utilizada a lo largo de esta Memoria, hemos elegido el término período principal de polinización (PPP). Asimismo, se han empleado numerosos métodos para su cálculo (Jäger et al., 1996; Feher \& Jàrai-Komlódi, 1997; Sánchez et al., 2003), de entre los cuales hemos escogido, los conocidos métodos del 90\% (Nilsson \& Persson, 1981), 95\% (Andersen, 1991) y 98\% (Galán et al., 1995) sobre el total anual registrado en cada uno de los tipos de polen estudiados.

En nuestro caso, el empleo de los diferentes métodos dio como resultado mayores PPP con el método del 98\% así como fechas de inicio más tempranas y de fin más tardías, y menores con el del 90\%, junto a fechas de inicio más tardías y de finalización más tempranas. Los tipos de polen (Tabla 6.5.), que mostraron mayores diferencias en la duración del PPP en función del método empleado, fueron Poaceae, Urticaceae, con un número similar al obtenido en Ponferrada (Vega-Maray et al., 2003), Rumex y Pinus, mientras que los que menos reflejaron fueron Castanea, Platanus y Populus, tal y como se indica para varias ciudades europeas, con Poaceae y Platanus (Jato et al., 2007), posiblemente por las diferencias fenológicas (períodos de floración de mayor o menor longitud), y por el número de especies incluidas en cada tipo de polen. Tras analizar la influencia de los parámetros meteorológicos en las diferentes anualidades y los distintos PPP y PRE definidos a través de los métodos empleados, mediante el coeficiente de correlación de Spearman en los 
principales tipos de polen, hemos observado pocas diferencias entre los mismos, si bien existen leves variaciones numéricas y en el grado de significación en función del método utilizado (Tabla 6.5.).

Pese a las escasas diferencias encontradas entre los métodos empleados, hemos de reseñar que los métodos que incluyen el 90\% y el 98\% del contenido polínico anual, reflejaron mejores resultados para diez de los doce tipos de polen utilizados para este análisis, cinco en cada uno de ellos, mientras que el método del 95\% sólo lo mostró con tres tipos, y uno de ellos, Poaceae, tuvo coeficientes muy similares a los obtenidos con el método del 90\%. En este mismo punto, también se alcanzaron valores numéricos más elevados en los coeficientes de correlación y mayor grado de significación durante el PRE en cinco de los tipos analizados, y el PPP, en cuatro, mostrando resultados similares en ambos períodos también para cuatro tipos. Con todo ello, resulta complicado establecer un patrón acorde con los tipos de polen incluidos en aquellos métodos para definir el PPP, a través de los cuales se ha permitido la obtención de coeficientes de correlación más elevados, así como en la distinción del propio PPP y el PRE en cada uno de los métodos. Este hecho puede deberse a la multitud de factores que influyen en la presencia de polen en el aire, y de entre las cuales podemos citar la adaptación de los diferentes granos de polen al transporte a través de la atmósfera, las condiciones climatológicas o el número de especies incluidas en cada tipo de polen (Jato et al., l. c.).

\begin{tabular}{|c|c|c|c|c|}
\hline & Días & $90 \%$ & $95 \%$ & $98 \%$ \\
\hline Castanea & 12 & & & PRE \\
\hline Cupressaceae & 34 & & & PRE \\
\hline Fraxinus & 24 & & PPP / PRE & \\
\hline Olea & 24 & & & PRE \\
\hline Pinus & 39 & PPP & & \\
\hline Plantago & 32 & PRE & & \\
\hline Platanus & 18 & & & PPP \\
\hline Poaceae & 88 & PPP / PRE & PPP / PRE & \\
\hline Populus & 19 & PPP & & \\
\hline Quercus & 29 & PPP / PRE & & \\
\hline Rumex & 48 & & PRE & \\
\hline Urticaceae & 72 & & & PPP \\
\hline
\end{tabular}

Tabla 6.5. Días de diferencia promedio entre la duración de diferentes períodos principales de polinización (PPP) obtenidos con los distintos métodos empleados. Coeficientes de correlación de Spearman más elevados entre los principales tipos de polen y los parámetros meteorológicos, en función del método empleado (destacado en sombreado gris) para definir el PPP y el consiguiente período prepico (PRE).

Por último, señalar que para algunos tipos de polen se han observado resultados similares, con coeficientes de correlación ligeramente superiores y/o significativos en función del método utilizado para calcular el PPP, al emplear estos mismos métodos, en varias ciudades europeas con el caso de Poaceae y la temperatura (Jato et al., l. c.), o en Ponferrada 
con Urticaceae (Vega-Maray et al., l. c.), si bien en el caso de Olea para la ciudad de Sevilla (González et al., 1999), se obtuvieron mejores resultados a través de los métodos de 90 y $95 \%$, con la temperatura previa a la fecha de inicio y las concentraciones polínicas.

\subsection{Variación intradiaria}

Las posibles diferencias en las concentraciones polínicas de cualquier tipo de polen a lo largo de las 24 horas del día pueden deberse a varios factores, fundamentalmente a las condiciones climatológicas (Berggren et al., 1995), a la topografía y a la distancia de la fuente de emisión polínica respecto al punto de muestreo (Spieksma \& den Tonkelaar, 1986). En la atmósfera de la ciudad de Salamanca, tras estudiar la distribución horaria en los últimos tres años analizados, de todos los tipos de polen con una representación igual o superior al o,5\% en, al menos, uno de los ocho años analizados (salvo para los tipos Juglans, Papaver y Sambucus, excluidos por una distribución tremendamente irregular), se han establecido tres franjas horarias de ocho horas cada una (desde las o horas hasta las 8, desde las 8 hasta las 16, y desde las 16 hasta las 24 horas), obteniéndose diferencias en la distribución de los distintos tipos de polen. La franja horaria correspondiente a lo que podríamos denominar como "horas centrales del día", entre las 8 y las 16 horas, es la que englobó a un mayor número de tipos con porcentajes de representación horarios más elevados con respecto a las concentraciones promedio diarias (Fig. 6.4.), pues en una buena parte de las especies productoras de polen tiene lugar la dehiscencia de las anteras y la consiguiente liberación de los granos de polen (Norris-Hill \& Emberlin, 1991; Latalowa et al., 2005; Nitiu et al., 2006). Dentro de estos tipos, se han reflejado distribuciones similares en Extremadura para Chenopodiaceae (Muñoz et al., 2000), Cyperaceae (Muñoz et al., 2007), y Plantago (Tormo et al., 2001; Paulino et al., 2006), y en Oporto para Cupressaceae y Plantago (Ribeiro et al., 2008).

Un comportamiento similar pudo observarse en una buena parte de los tipos de polen, distribuidos entre las 8 horas y la medianoche, si bien esta distribución más irregular, con porcentajes más o menos elevados a lo largo de 16 horas diarias pudo deberse a la presencia de diferentes especies productoras de un determinado tipo de polen (Spieksma et al., 1995), como pudo ser el caso de Pinus, al igual que ocurrió en Oporto (Ribeiro et al., l. c.), Poaceae, con diferencias horarias de hasta 13 horas en la hora de liberación de granos de polen entre el gran número de especies de esta familia (Reddi et al., 1988), y Quercus, con un comportamiento similar en el noroeste (Rodríguez-Rajo et al., 2005b), y el sur peninsular (Recio et al., 1999). En todo caso, esta amplia franja horaria también incluye a tipos de polen producidos por pocas especies, o incluso por una única especie, como en el tipo Olea, donde se han reflejado fenómenos de resuspensión (Alba et al., 2000), que con la ayuda de cambios 
en la dirección de los vientos dominantes, pudieron explicar su particular distribución, similar a la presentada en Vigo (Rodríguez-Rajo et al., 2004), o en el tipo Echium, que en Extremadura (Muñoz et al., 2005), se localizó fundamentalmente entre las 10 y las 12 horas, más restringida que en el caso de Salamanca, posiblemente por los ya mencionados fenómenos de resuspensión favorecidos por el pequeño tamaño de los granos de polen de este género.

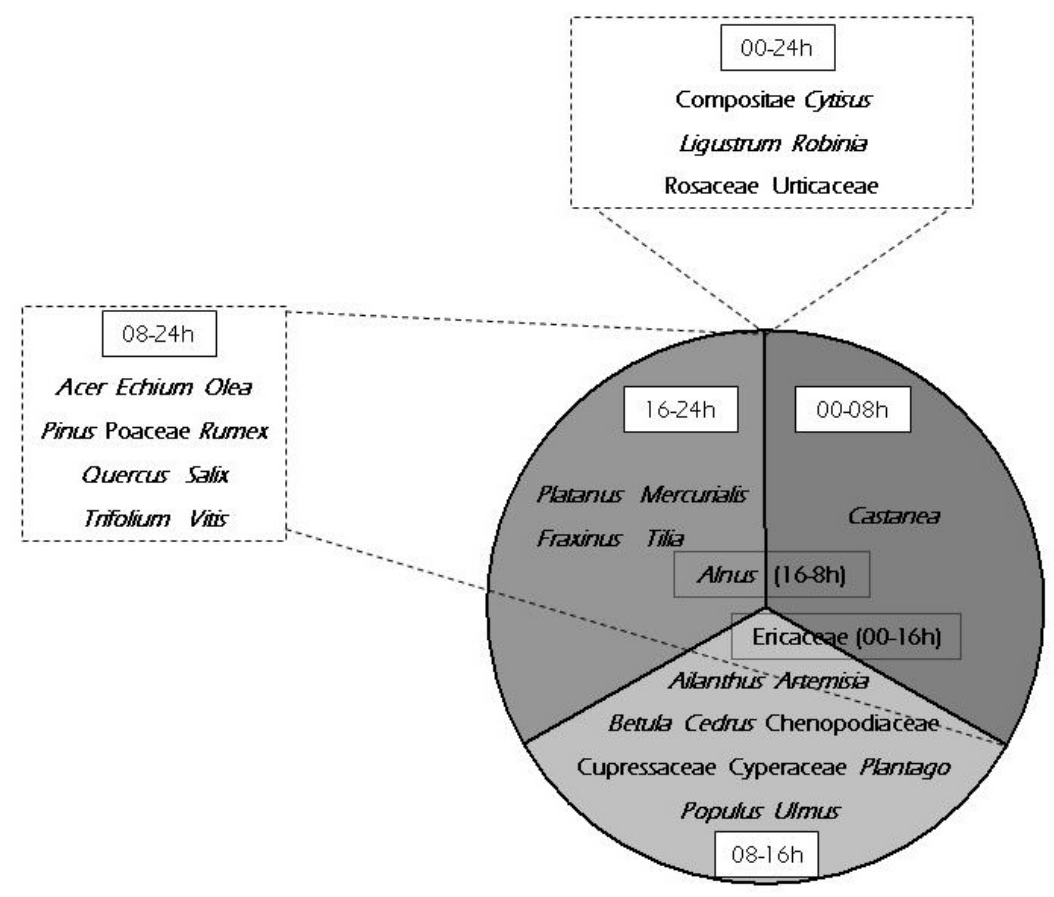

Fig. 6.4. Distribución horaria de los principales tipos de polen a lo largo de tres franjas horarias (oo-o8 horas; o8-16 horas; 16-24 horas), durante el período 2005-2007.

En las horas vespertinas del día se localizaron principalmente los granos de polen procedentes de los tipos Fraxinus, Mercurialis, Platanus, y Tilia, que en el caso del género Platanus, tuvo una distribución diferente a la registrada en Santiago de Compostela (Jato et al., 2001b), con mayores concentraciones horarias en las horas centrales, pero similar a la presentada en Valladolid (Sánchez et al., 2008), en la segunda mitad del día. Resulta complejo establecer una razón para esta peculiar distribución, pues admitiendo que una mayor representación en las horas centrales del día se corresponde con tipos cuyas especies productoras se encuentran en zonas próximas al captador (Trigo et al., 1997), dicha distribución no se correspondería con lo esperado para, al menos, los tres géneros arbóreos, salvo que la humedad relativa, que aumenta a lo largo de la tarde (Reddi \& Reddi, 1985), influyera en la liberación de los granos de polen de Fraxinus, cuyas concentraciones están correlacionadas de forma positiva con la humedad relativa. 
El género Castanea presentó sus mayores concentraciones diarias durante las primeras horas de la madrugada, semejante a lo registrado en Galicia (Jato et al., 2001a), distribuidas entre las $4 \mathrm{y}$ las 13 horas, y que pudo deberse a un transporte a media-larga distancia, propuesto ya para los granos de polen de este tipo (Peeters \& Zooler, 1988), procedentes de los castañares del sur de la provincia. La distribución horaria de los tipos Alnus y Ericaceae, fue particular, pues fueron los únicos tipos localizados entre las 16 y las 8 horas, y las o y las 16 horas, respectivamente, tal y como se reflejo en Oporto para Alnus (Ribeiro et al., l. c.), y en Valladolid (Sánchez et al., 2007), Vigo (Rodríguez-Rajo et al., 2005a) para Ericaceae, y que pudo estar condicionada por dos hechos que ya hemos comentado, como son la influencia positiva de la humedad relativa, en el caso de Alnus, o el transporte a media distancia de las características tétradas producidas por poblaciones de la familia Ericaceae, más abundantes en el sur de la provincia.

En último lugar, los tipos Compositae, Cytisus, Ligustrum, Robinia, Rosaceae y Urticaceae, presentaron concentraciones similares a lo largo del día, sin mostrar un patrón, más o menos claro, en su distribución intrahoraria, como ocurrió con Urticaceae en Oporto (Ribeiro et al., l. c.), y que puede deberse al elevado número de especies, con diferentes comportamientos a la hora de liberar granos de polen a la atmósfera, que abarca cada uno de estos tipos, a excepción de Ligustrum, que, en el caso de Compositae, incluye además a varios tipos polínicos. La elevada ornamentación reticulada y el grosor de la exina no favorecen el transporte de los granos de polen de Ligustrum, algo que pudo motivar la ausencia de un patrón en su distribución intrahoraria, como podría ocurrir también en algunos de los tipos que acabamos de mencionar.

\subsection{Diferencias cuantitativas y cualitativas entre los dos captadores}

El análisis de las posibles diferencias cuantitativas y cualitativas en los granos de polen recogidos en captadores emplazados en zonas próximas, bien en la misma ciudad o en localidades más o menos cercanas ha sido estudiada en las últimas décadas (Larsson et al., 1984; Frenz et al., 1997; Trigo et al., 2000; Moreno et al., 2006), así como la influencia de la altura sobre el nivel del suelo en la que estén situados los captadores a la hora de inferir variaciones en el contenido de polen y esporas de cada uno de ellos (Lyon et al., 1984; Bergamini et al., 2004). Con respecto al emplazamiento del captador, se admite que hay mayores diferencias entre los captadores cuanto más separados estén (Frenz, 2000), aunque existen otra serie de factores que pueden condicionar la existencia de divergencias, más o menos severas, en el contenido polínico registrado en dichos captadores separados, como la proximidad a las fuentes de emisión (Cariñanos et al., 2002a) o la influencia del transporte a media o larga distancia de granos de polen (Frenz, l. c.). 
En la ciudad de Salamanca, las diferencias observadas en el número total de granos de polen contabilizados en ambos captadores (Tabla 5.3.1., pág. 242), se debieron a los tipos de polen más abundantes, como Cupressaceae, Pinus, Platanus, Plantago, Poaceae y Quercus, en los que hubo diferencias significativas en el número total de granos de polen, sobretodo en el caso de Quercus y Poaceae, cercanas a los 1000 granos, algo que también se puso de manifiesto en Génova con dos captadores separados por 3 kilómetros (Arroba et al., 2000), ya que admiten que las divergencias más acentuadas entre ambos se registran con los tipos más abundantes. Esta variación en el contenido polínico de ambos captadores, reflejada en menor medida en los valores máximos diarios, pudo deberse al efecto de las barreras arquitectónicas y de la acumulación de partículas contaminantes en zonas céntricas (D’Amato, 2002), con la presencia de calles más estrechas que impiden la renovación de aire y favorecen la acumulación de partículas contaminantes, en las que estuvo situado el primero de los captadores, y que, como se señala para el caso de Córdoba (Cariñanos et al., 2002b), tiene gran influencia en una mayor representación de granos de polen procedentes de especies extralocales. También es posible hacer extensivo este hecho a Cupressaceae y Platanus, pues aunque se encuentren bien representados en la flora ornamental local, parte de sus granos de polen pudieron proceder de otras localidades más o menos próximas al núcleo urbano capitalino.

Los mayores valores diarios registrados en el captador emplazado en el Campus Unamuno para los tipos Fraxinus, Populus y Umbelliferae, indicaron la importancia de la situación del captador con respecto a las fuentes de emisión, puesto que las especies emisoras de estos tipos de polen son más abundantes en zonas próximas al río Tormes, muy cercano, a su vez, a dicho captador, tal y como se ha comprobado en Badajoz (Gozalo-Garijo et al., 2006), Córdoba (Cariñanos et al., l. c.; Alcázar et al., 2004), y Trentino (Gottardini \& Cristofolini, 1997). Asimismo, en la Tabla 6.6., se muestran aquellos tipos de polen con concentraciones máximas más tempranas en uno de los dos captadores, lo cual mostró que la incidencia de los granos de polen en cada uno de los captadores se desplaza en el tiempo durante algunos días en función de la proximidad de las fuentes, como ocurrió en Córdoba (Alcázar et al., l. c.).

El efecto que tiene la altura sobre el nivel del suelo en la que esté situado el captador volumétrico sobre el contenido en polen y esporas que registra es bien conocido, pues varios estudios han reflejado que, generalmente, las mayores concentraciones se obtienen en captadores situados a mayor altura (Alcázar \& Comtois, 2000; Armentia et al., 2004), aunque esta dinámica puede variar en función del tipo de polen (Fiorina et al., 1999). No obstante, también se ha demostrado que a mayor altura, las concentraciones máximas de polen atmosférico sufren un retraso con respecto a otros puntos de muestreo situados en alturas inferiores (Hart et al., 1994), algo diferente a lo registrado en Salamanca, y que, unido 
a la ausencia de divergencias en el contenido de dos captadores volumétricos fijos emplazados a diferentes alturas y separados por una distancia similar a la existente en nuestro caso en la ciudad de Perugia (Fornaciari et al., 1996), nos hace pensar que la incidencia de la altura no promovió diferencias significativas en los niveles de polen de ambos puntos de muestreo.

\begin{tabular}{ccc}
\hline Tipo / Fecha valor máximo & Captador Centro Histórico & Captador Campus Unamuno \\
\hline Ailanthus & 28-junio & 26-junio \\
Betula & 9-mayo & 14-abril \\
Corylus & 25-enero & 22-enero \\
Cupressaceae & 4-marzo & 10 -marzo \\
Chenopodiaceae & 18-agosto & 3-agosto \\
Echium & 9-junio & 13 -junio \\
Fraxinus & 16-febrero & 12-febrero \\
Helianthus & 21-julio & 3-agosto \\
Liguliflorae & 24-junio & 7-junio \\
Mercurialis & 26-julio & 1-septiembre \\
Plantago & 13 -julio & 10-mayo \\
Platanus & 16-abril & 19-abril \\
Populus & 19-marzo & 13-marzo \\
Quercus & 6-junio & 13-mayo \\
Tilia & 24-junio & 14-junio \\
Umbelliferae & 13-mayo & 8-mayo \\
Urticaceae & 23-junio & 29-abril \\
\hline
\end{tabular}

Tabla 6.6. Fecha en las que se registró el valor máximo en el período de comparación entre ambos captadores para ciertos tipos de polen seleccionados según la diferencia cronológica.

El efecto que tiene la altura sobre el nivel del suelo en la que esté situado el captador volumétrico sobre el contenido en polen y esporas que registra es bien conocido, pues varios estudios han reflejado que, generalmente, las mayores concentraciones se obtienen en captadores situados a mayor altura (Alcázar \& Comtois, l. c.; Armentia et al., l. c.), aunque esta dinámica puede variar en función del tipo de polen (Fiorina et al., l. c.). No obstante, también se ha demostrado que a mayor altura, las concentraciones máximas de polen atmosférico sufren un retraso con respecto a otros puntos de muestreo situados en alturas inferiores (Hart et al., l. c.), algo diferente a lo registrado en Salamanca, donde un buen número de tipos mostraron los mayores niveles en el captador del Campus Unamuno emplazado a una mayor altura sobre el nivel del suelo, y que, unido a la ausencia de grandes divergencias en el contenido de dos captadores volumétricos fijos localizados a diferentes alturas y separados por una distancia similar a la existente en nuestro caso en la ciudad de Perugia (Fornaciari et al., l. c.), nos hace pensar que la incidencia de la altura no promovió diferencias significativas en los niveles de polen de ambos puntos de muestreo. 
Con todo ello, tras poner de manifiesto las escasas diferencias existentes (Tabla 5.3.1., pág. 242), en el contenido polínico obtenido en los dos captadores, separados entre sí por 2 kilómetros de distancia, creemos que un único punto de muestreo es suficiente para reflejar correctamente el contenido polínico atmosférico de una determinada zona, tal y como han afirmado otros autores (Eversmeyer \& Kramer, 1987; El-Ghazaly et al., 1993), siempre que esté situado a más de 12,2 metros de altura (Hirst, 1994), y que el punto de muestreo no se encuentre en un área muy heterogénea desde el punto de vista de la vegetación existente (Fornaciari et al., l. c.). Sin embargo, no debemos obviar que estas escasas diferencias, que conllevan en divergencias puntuales en las concentraciones diarias de determinados tipos de polen, pueden tener una especial incidencia en personas sensibilizadas a dichos tipos (Cariñanos et al., l.c. ; Asensio et al., 2003; Alcázar et al., l. c.).

\subsection{Evolución anual, estacional y horaria de las esporas de pteridófitos}

La presencia de esporas de Pteridium en Salamanca durante el período 1998-2007, se circunscribe fundamentalmente entre los meses de agosto y octubre, algo similar a lo descrito en el Reino Unido (Lacey \& McCartney, 1994; Caulton et al., 2000), aunque en menor número que esas zonas rurales y en la ciudad de Edimburgo debido a su proximidad a poblaciones de este helecho, e incluso a varias zonas de Polonia para otras esporas de pteridófitos, como las de Equisetum y Lycopodium (Kasprzyk, 2004). En el estudio realizado en una granja experimental escocesa, rodeada de formaciones monoespecíficas de Pteridium (Lacey \& McCartney, l. c.), se propuso un transporte a baja escala, como el mecanismo más probable para dispersar las esporas, algo que no pudo darse en la ciudad de Salamanca, ya que las poblaciones más cercanas a la ciudad se encuentran a unos 70 kilómetros al sur del núcleo urbano. Por ello, las esporas pudieron llegar al captador gracias a fenómenos de transporte a media-larga distancia, según lo propuesto por Rantio-Lehtimäki en 1994, con ayuda de vientos procedentes del II cuadrante, como explica la correlación positiva con los niveles esporales durante el PPE y PRE (Tabla 5.4.2., pág. 254), pues la presencia de importantes barreras topográficas, como son distintas formaciones montañosas pertenecientes al Sistema Central, y el gran tamaño y ornamentación de este tipo de esporas, hacen que sean necesarias grandes masas de aire para que estas esporas lleguen a la ciudad de Salamanca. Este tipo de transporte se ha propuesto para otras esporas de pteridófitos, como las de Lycopodium (Di-Giovanni et al., 1995), gracias a sus propiedades de deposición, semejantes a las que presentan algunos granos de polen anemófilos.

La distribución horaria a lo largo de un día promedio (Fig. 5.4.3.) indicó mayores porcentajes en las primeras horas del día, diferente a la que presentaron en Escocia (Lacey \& McCartney, l. c.), con mayor presencia en las horas centrales del día, pues, tal y como hemos 
señalado para los granos de polen, el captador se encontraba muy próximo a grandes formaciones de este helecho. Consiguientemente, el efecto positivo de los vientos procedentes del II cuadrante durante el PPE y PRE, pudo ser importante (Fig. 6.5.), ya que las mayores concentraciones horarias se registraron cuando los vientos llegaron a la ciudad de Salamanca desde el sur-sureste.
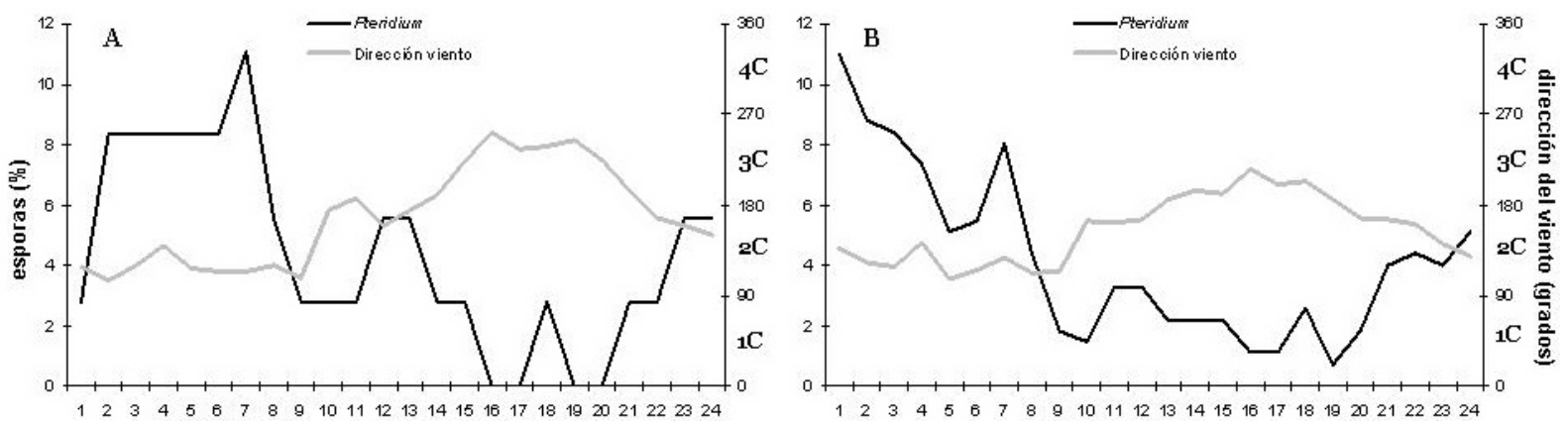

Fig. 6.5. Efectos de la dirección horaria del viento en la distribución horaria de esporas durante el PPE(A), Olea y PRE (C). 1C: Vientos procedentes del I cuadrante, 2C: II cuadrante, 3C: III cuadrante, y 4C: IV cuadrante.

La ausencia de correlaciones negativas entre las concentraciones esporales y las precipitaciones pudo estar relacionada con las tormentas típicas de finales de verano, y que como hemos señalado anteriormente, son menos efectivas en el llamado fenómeno de lavado atmosférico que las lluvias prolongadas (Iglesias et al., 1993). En el desarrollo de los esporocitos tienen una gran importancia las condiciones climatológicas existentes en los tres meses anteriores a la liberación de las esporas (Conway, 1957), por lo que tomando los datos de temperatura media para los meses de mayo, junio y julio de la estación meteorológica de Herguijuela de la Sierra, localidad al sur de la provincia y cercana a poblaciones de Pteridium, quisimos evaluar la influencia de la temperatura en dicho desarrollo. Los menores valores totales anuales de este tipo de espora se registraron en los años 2002 y 2007, años en los que la temperatura media de los tres meses precedentes a la liberación de esporas fue inferior a $18^{\circ} \mathrm{C}$ (Fig. 6.6.). Además, en el año 2000, el tercero con un menor valor total anual, la temperatura media fue de $18,1^{\circ} \mathrm{C}$, por lo que los efectos de la temperatura en los tres meses precedentes a la difusión de esporas, pudieron estar relacionados con un valor umbral de $18^{\circ} \mathrm{C}$, que con valores inferiores influyera en un menor desarrollo de los esporocitos y una consiguiente reducción en la producción de esporas. 


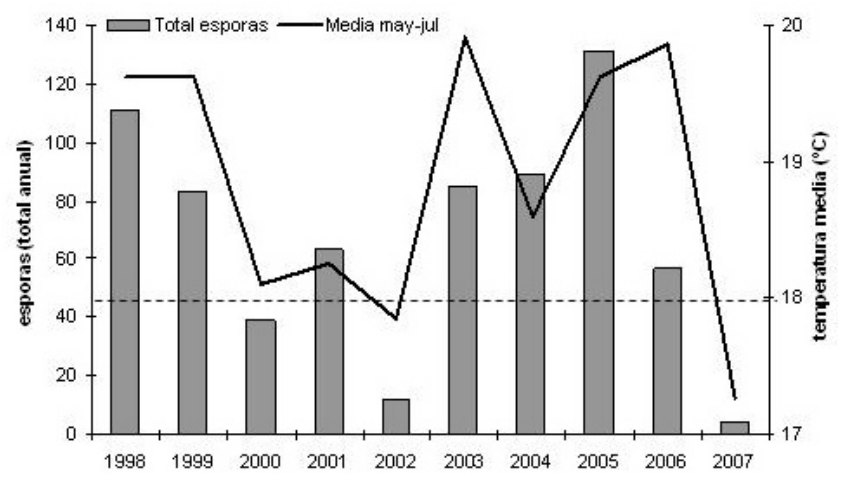

Fig. 6.6. Temperaturas medias de mayo a julio registradas en la estación meteorológica de Herguijuela de la Sierra, y los valores totales anuales obtenidos en la ciudad de Salamanca durante el período de estudio.

Los efectos de las máximas temperaturas sobre las concentraciones esporales no fueron significativos en Edimburgo (Caulton et al., l. c.), posiblemente por las diferencias climáticas existentes entre Escocia y el centro de la Península Ibérica. Sin embargo, la correlación positiva entre los niveles de esporas y la temperatura durante todo el período analizado, pudo indicar la influencia de este factor meteorológico en el mencionado desarrollo de los esporocitos. En esta línea, se ha visto que, mediante modelos predictivos, la biomasa de Pteridium podría incrementarse en algunas zonas del Reino Unido debido al conocido fenómeno del cambio climático (Pakeman \& Marrs, 1996), por lo que también podría aumentar la producción de esporas y un consiguiente mayor riesgo para la salud, debido a la carcinogenicidad de sus esporas (Freitas et al. 2001).

\subsection{Análisis del estudio clínico sobre una muestra poblacional de Salamanca}

En relación a la sintomatología de los 68 pacientes analizados, un 55,9\% presentaron rinitis o rinoconjuntivitis, un 1,5\% asma, y un 42,6\% rinitis/rinoconjuntivitis y asma, porcentajes diferentes a los pacientes infantiles analizados en otros estudios llevados a cabo en la unidad de alergia infantil del Hospital Clínico Universitario de Salamanca. Así pues, en la ciudad de Salamanca se estudiaron 288 casos infantiles con resultados positivos a pruebas intraepidérmicas a alérgenos procedentes de árboles a lo largo de todo el año 1986, y se estimó que el 84,82\% presentó rinitis/rinoconjuntivitis, y el 60\% asma (Fuentes, 1987), al igual que en 444 pacientes infantiles durante la primavera de los años 1994 y 1995 (Calvo, 1996), con un $81,5 \%$ de rinitis/rinoconjuntivitis y el $58 \%$ asma. Esta variación puede ser debida a la diferente valoración a la hora de determinar la sintomatología, como se pone de manifiesto al sumar los porcentajes obtenidos en nuestro estudio entre los pacientes con rinitis/rinoconjuntivitis y asma, y a los que sólo se les diagnosticó asma (44,1\%), y compararlos con los porcentajes de pacientes que sólo presentaron asma en los estudios de 
décadas anteriores. Todo ello viene refrendado por los resultados presentados en un estudio realizado en la Península Ibérica durante el año 2005 (Muñoz et al., 2008), donde el 47,11\% de los pacientes sensibilizados presentaron rinitis/rinoconjuntivitis, y un 52,88\% rinitis/rinconjuntivitis más asma, porcentajes similares a los obtenidos en nuestro caso.

A la hora de evaluar la prevalencia de positivos en nuestro estudio, debemos tener en cuenta los resultados obtenidos en otros trabajos realizados en la ciudad de Salamanca mediante pruebas intraepidérmicas con pacientes infantiles, como ya se ha reflejado, ya que muestran un elevado grado de hipersensibilidad a gramíneas (98,64\% positivos), en los años 1994 y 1995 (Calvo, l. c.), próximo al 79,41\% de positivos a la mezcla de alérgenos de gramíneas en los meses anteriores al comienzo de la estación polínica de 2007. Otro estudio realizado en la ciudad de Salamanca (Fuentes, l. c.), señala que el 65\% de pacientes sensibilizados lo fueron a alérgenos procedentes de granos de polen de árboles, y que dentro de los mismos, el 64,3\% presentaron positivos a alérgenos del olivo, 34,84\% a abedul y $32,6 \%$ a plátano de sombra, todos ellos superiores a los obtenidos en nuestro estudio, con un $42,65 \%, 3,03 \%$, y 16,18\%, respectivamente. Estas diferencias pudieron originarse por la aparición de falsos positivos o negativos debidas a la comprobada reactividad cruzada entre alérgenos (Weber, 2003), bien sea por tipos de polen producidos por especies o grupos de especies relacionadas filogenéticamente o por la presencia de proteínas preservadas a lo largo de la evolución, como ocurre, por ejemplo, con las profilinas. Asimismo no debemos olvidar la influencia que pudieron tener en estos falsos positivos, otros aspectos como la calidad de los extractos, la técnica o el propio paciente, junto a la comprobada mayor reactividad de esta técnica al efectuarse esta técnica en la estación polínica y justo después de ella (Oppenheimer \& Nelson, 1993; Eriksson \& Holmen, 1996), algo que ocurrió en los estudios realizados en años anteriores para la ciudad de Salamanca.

En otras doce ciudades españolas (Badajoz, Bilbao, Ciudad Real, Elche, Jaén, La Coruña, Logroño, Madrid, Málaga, Sevilla, Toledo, Zaragoza) se presentaron los datos de prevalencia de pruebas intraepidérmicas positivas a diferentes alérgenos procedentes de granos de polen en el trienio 1995-1997 (Subiza et al., 1998), resumidos en la Tabla 6.6. Cabe reseñar que el porcentaje de prevalencia de positivos promedio para las ciudades a alérgenos procedentes de la familia Poaceae, es casi idéntico al presentado en la ciudad de Salamanca en nuestro estudio (79\%), mientras que este mismo porcentaje promedio fue superior en el resto de tipos de polen analizados (Chenopodiaceae, Olea y Urticaceae), con respecto al obtenido en Salamanca, salvo en el caso de Cupressaceae, donde fue ligeramente superior en la ciudad castellana. Como consecuencia de los datos aportados por este trabajo, podemos ver que los porcentajes de prevalencia de positivos coincidieron con los presentados en las ciudades del centro peninsular (Ciudad Real, Toledo) para Cupressaceae y Poaceae, o del oeste (Badajoz, Sevilla), para Urticaceae y Chenopodiaceae, mientras que en el caso de Olea 
lo hizo con los resultados de Elche, probablemente por la mayor incidencia en los cuadros clínicos de alergia a los alérgenos procedentes de los granos de polen del tipo polínico Olea europaea en la mitad sur peninsular (Subiza et al., 1995; González \& Candau, 1997; Florido et al., 1999), menor en zonas del sureste peninsular, como en Cartagena con un $29,7 \%$ en la prevalencia de positivos (Elvira et al., 2008).

En otro estudio realizado a nivel peninsular con 3384 pacientes (Pereira et al., 2006), la prevalencia de pruebas intraepidérmicas positivas a diferentes alérgenos utilizados en Salamanca y en el centro peninsular (Artemisia, Cupressaceae, Gramíneas, Olea, Parietaria, Platanus y Plantago), fueron superiores en todos los casos (29\% y 17,65\%, 45\% y 16,18\%, $62 \%$ y $79,41 \%, 59 \%$ y $42,65 \%, 19 \%$ y $6 \%, 35 \%$ y $16,18 \%$, $48 \%$ y $35,29 \%$, respectivamente), salvo en la mezcla de gramíneas, posiblemente por la diferencia de pacientes utilizados, notablemente superior en el estudio realizado en España y Portugal.

\begin{tabular}{ccccc}
\hline & Media 12 ciudades & Máximo & Mínimo & Salamanca \\
\hline Chenopodiaceae & $46 \%$ & $92 \%$ Toledo & $14 \%$ Badajoz & $16,18 \%$ \\
\hline Cupressaceae & $12 \%$ & $23 \%$ Madrid & $0 \%$ Sevilla & $16,18 \%$ \\
\hline Olea & $62 \%$ & $97 \%$ Jaén & $4 \%$ Bilbao & $42,65 \%$ \\
\hline Poaceae & $79 \%$ & $97 \%$ Bilbao & $48 \%$ Elche & $79,41 \%$ \\
\hline Urticaceae & $12 \%$ & $30 \%$ Málaga & $14 \%$ Badajoz & $7,35 \%$ \\
\hline
\end{tabular}

Tabla 6.6. Prevalencia media de pruebas intraepidérmicas positivas a alérgenos procedentes de diferentes tipos de polen en pacientes con polinosis a lo largo de 12 ciudades españolas (extraído de Subiza et al., 1998), valor máximo, mínimo y prevalencia en la ciudad de Salamanca los tres meses anteriores al comienzo de la estación polínica.

El número de días en que las concentraciones de polen de Poaceae superaron los umbrales establecidos como susceptibles de desencadenar síntomas en aquellas personas que estén sensibilizadas, fue de 31 y 50 días en la ciudad de Salamanca durante los años 2006 y 2007, semejantes al que presentaron en otros trabajos referidos para años diferentes en la ciudad de Salamanca, como fueron los 32, 27 y 38 días en los años 1994, 1995, y 1996, respectivamente (Calvo, l. c.; Suárez et al., 2003; Sánchez et al., 2006), localizados como en el año 2007, entre los meses de mayo y julio, e incluso en otras ciudades como Lugo (Rodríguez-Rajo et al., 2003c), con 31 días.

Los valores umbrales para Cupressaceae, superados durante 11 y 22 días en Salamanca, fueron también semejantes a los presentados en otras ciudades españolas (Belmonte et al., 1999b), como media del período 1994-1998, y que oscilaron entre los 20 días en varias localidades catalanas, los 15 días de municipios situados en la mitad sur peninsular, y los 2 días de núcleos urbanos del noroeste peninsular. En el caso de Olea, los valores umbrales se superaron durante 2 y 4 días en la ciudad de Salamanca, similar a lo 
acontecido en los años 1994 y 1995 (Calvo, l. c.; Suárez et al., l. c.), con 1 y 4 días respectivamente, en el mes de junio, no superando el valor umbral durante el año 1996 (Sánchez et al., l. c.). Este número de días es semejante al obtenido como media del período 1995-2002 en la ciudad de Vigo (Rodríguez-Rajo et al., 2004), con 4 días, y sensiblemente inferior al presentado en Madrid (Gutiérrez \& Sáenz, 2000), con 12 días de media entre los años 1994 y 1997. Estas diferencias pudieron estar relacionadas con las cantidades totales de polen, con valores totales anuales similares entre Vigo y Salamanca (666 como valor anual medio y 678 durante el año 2007, respectivamente), más bajos que los obtenidos en la ciudad de Madrid (2122 como valor anual medio), aunque no debemos obviar las diferencias interanuales.

Un hecho semejante ocurre en el caso de las concentraciones umbrales de Urticaceae, que son sólo superadas durante un único día en Salamanca para los años 2006 y 2007, ninguno en el año 1996 (Sánchez et al., l. c.), y que coinciden con ciudades relativamente próximas como León y Madrid (Belmonte et al., 1999a), donde no se superó este umbral en el período 1994-1998, y que tuvieron valores totales anuales similares a los obtenidos en Salamanca, e inferiores a ciudades catalanas, con un consiguiente mayor número de días que sobrepasaron el umbral, que oscila entre los 84 de Gerona y los 49 de Barcelona como media del mencionado período. La ausencia de días superando el umbral establecido para las concentraciones diarias de Betula, es compartida en el caso de León (Jato et al., 1999), y difiere del número de días presentado en varias ciudades gallegas, entre los 12 de Santiago de Compostela y los 6 días de Vigo.

A lo largo de las pasadas décadas se han publicado una serie de trabajos que versaban sobre la posible relación entre los recuentos de granos de polen presentes en la atmósfera y la sintomatología que desencadenó en pacientes sensibilizados (Holberg et al., 1987; Dopazo et al., 2002), y que pusieron de manifiesto la existencia de una mayor presencia de síntomas cuando se presentaban mayores niveles de polen en la atmósfera. Siguiendo en esta línea, también se han desarrollado estudios sobre la posible relación entre la presencia de granos de polen en la atmósfera y la prevalencia de positivos tras el uso de pruebas intraepidérmicas (Kadocsa \& Juhász, 2002), así como otros que trataban de estimarla a través de la cantidad de IgE específica presente en el suero de pacientes sensibilizados (Malaczynska et al., 1995). En nuestro caso, hemos analizado la relación existente entre el polen atmosférico y los resultados obtenidos a través de la evaluación de la cantidad de IgE específica y la prevalencia de positivos tras aplicar las pruebas intraepidérmicas en pacientes sensibilizados, lográndose mayor relación entre la cantidad de IgE específica para cada alérgeno tomado en cuenta (se excluyeron los panalérgenos), y el valor anual total para el año 2007 de los tipos de polen en los que se encuentra dicho alérgeno (sumando los totales de Olea y Fraxinus para Ole e 1), que entre la prevalencia de positivos tras las pruebas 
intraepidérmicas y el porcentaje de cada tipo de polen sobre el total. Este hecho coincide con otros trabajos que muestran una ausencia de correlación entre el polen presente en la atmósfera y la prevalencia de positivos tras la aplicación de pruebas intraepidérmicas, como se puso de manifiesto en un estudio realizado en Ankara (Berna et al., 2008), con una elevada cantidad de positivos a alérgenos de gramíneas y una presencia atmosférica más reducida con respecto a otros tipos de polen, o en Ohio (White et al., 2005), con escasa correlación entre los recuentos de polen de árboles y la prevalencia de positivos a PIE.

Junto a ello, también se ha refrendado de forma estadística la correlación entre la presencia de alérgenos procedentes de granos de polen y la cantidad de polen en la atmósfera, como ocurrió en Cartagena (Moreno-Grau et al., 2006), para los valores totales de Olea y Urticaceae con los alérgenos Ole e 1, Par j 1 y Par j 2, aunque debemos señalar que en Gdansk, Polonia (Malaczynska et al., l. c.), la relación entre la concentración de polen aerovagante y la cantidad de IgE específica para cada alérgeno, no mostró relación alguna, como pone de manifiesto la mayor cantidad de IgE específica para alérgenos de gramíneas dentro de los alérgenos estudiados y la tercer lugar que ocupó de polen de esta familia en lo referente a totales anuales. Esta ausencia de relación pudo deberse a que este trabajo se realizó con un captador gravimétrico tipo Durham, cuyos datos sobre el polen atmosférico difieren de los obtenidos a través de un captador volumétrico (O’Rourke, 1990; Latorre et al., 2008), con el que se realizó nuestro estudio, y además, no debemos olvidar otra serie de factores como la limitación de nuestro propio estudio, realizado en un único año, la presencia de alérgenos fuera de la estación polínica (Fernández-Caldas et al., 1989), o la influencia de ciertos factores ambientales como las tormentas en el aumento del contenido de alérgenos en la atmósfera (D’Amato et al., 2007). 
Conclusiones 

Toda vez que ya han sido expuestos y discutidos los resultados del presente trabajo de investigación, y habida cuenta de los objetivos propuestos, hemos extraído las siguientes conclusiones:

Primera. En el período de estudio (2000-2007), se han contabilizado un total de 135330 granos de polen, pertenecientes a 72 tipos de polen, con un aumento en los valores totales anuales de 11296 granos de polen del año 2000 a los 31103 en el año 2007 (16916 como media del total anual en los ocho años), siendo 2002 el año que presentó un total anual menor (7901). Del mismo modo, el mayor contenido polínico en la atmósfera se concentró en los meses de mayo (un 35\% del total promedio), junio (27\%) y, en menor medida, marzo y abril (10\%), mientras que los últimos cuatro meses del año tuvieron los menores niveles a lo largo de un año promedio (2,5\%).

Segunda. La composición del espectro polínico varió de los 43 tipos de polen identificados en el año 2000 a los 66 tipos de 2004, existiendo un gran incremento cualitativo entre los tres primeros años y el resto. Los tipos de polen más representativos en el período analizado, fueron, por orden de abundancia, Quercus (23\%), Poaceae (22\%), Cupressaceae (11\%), Olea (5\%), Pinus (4\%), Plantago (4\%), Populus (4\%), Platanus (3\%), Urticaceae (3\%), y Castanea (2\%), quedando otros 23 tipos de polen con una representación anecdótica.

Tercera. La mayor parte de tipos de polen identificados experimentaron un incremento en sus valores totales anuales a lo largo de los años estudiados, con el refrendo estadístico de la regresión lineal, salvo los tipos Ailanthus y Sambucus, posiblemente por la eliminación de muchos ejemplares, Tilia, por la afectación de plagas, y Juncaceae, por la modificación de los ambientes riparios próximos a la ciudad de Salamanca.

Cuarta. El análisis conjunto de los valores totales anuales y de la distribución estacional de los principales tipos de polen identificados, permitió inferir diferencias tanto en el número anual como en la fecha de inicio del período principal de polinización (PPP) entre la ciudad de Salamanca y ciudades situadas al sur del Sistema Central, así como mayores semejanzas con localidades emplazadas al norte del mismo. Por ello, consideramos que esta cadena montañosa resulta fundamental para delimitar variaciones en los valores totales anuales y el comportamiento estacional de diversos tipos de polen, sin obviar la diversidad bioclimática existente en las dos mitades peninsulares, que condiciona diferente vegetación y, a su vez, diferente composición del espectro polínico desde el punto cuantitativo y cualitativo. 
Quinta. La duración de los PPP de los diferentes tipos analizados no mostró grandes diferencias, salvo en el caso de los tipos Fraxinus, Olea y Poaceae, que experimentaron un incremento, debido al retraso en la fecha de finalización de los dos primeros, y un adelantamiento de dicho período en el caso del tercero, mientras que los tipos Cupressaceae, Platanus y Quercus, tuvieron un comportamiento opuesto, pues su PPP indicó una tendencia a la reducción, debido a un retraso en la fecha de inicio del mismo.

Sexta. Los parámetros meteorológicos que incidieron de forma positiva en el contenido polínico de los tipos analizados, fueron la temperatura y la insolación, excepto en tipos de polen procedentes de táxones de floración temprana como Alnus, Cupressaceae, Fraxinus, Platanus, Populus o Ulmus, mientras que la precipitación y la humedad relativa tuvieron, de forma general, una influencia negativa en los mismos. El resto de parámetros meteorológicos analizados, englobados en la velocidad y dirección del viento, ejercieron un efecto diferente en función del tipo analizado, si bien podemos resaltar una influencia positiva en una buena parte de tipos de los vientos procedentes del tercer y cuarto cuadrante. Además, el método empleado para el cálculo del PPP no influyó a la hora de valorar la influencia de estos parámetros.

Séptima. La variación horaria de los diferentes tipos de polen estudiados, para el trienio 2005-2007, se localizó fundamentalmente entre las 8 y las 16 horas ("horas centrales"), si bien algunos tipos mostraron centraron su distribución en otras franjas horarias, debido a la mayor distancia de las poblaciones productoras con respecto al punto de muestreo, o se contabilizaron de forma más irregular a lo largo del día por la influencia de diversos factores, como el elevado número de especies incluidas en un determinado tipo.

Octava. Los dos captadores emplazados en zonas diferentes de la ciudad de Salamanca durante 371 días, no mostraron diferencias cualitativas y cuantitativas relevantes, aunque el captador situado en el centro histórico registró un mayor contenido polínico total y en gran parte de los tipos identificados, y el captador situado en el Campus Unamuno indicó una mayor proximidad a las especies productoras de un buen número de tipos de polen, como consecuencia de un adelantamiento en la fecha de mayor concentración polínica del período analizado.

Novena. En el período 1998-2007 se contabilizó un bajo número de esporas de Pteridium en la ciudad de Salamanca, en relación a los granos de polen, con variaciones anuales debidas probablemente a la influencia de la temperatura media en el desarrollo de los esporocitos durante los tres meses anteriores a la liberación de las esporas, que se localizaron 
principalmente entre los meses de agosto y octubre, así como en las primeras y últimas horas del día, gracias a la influencia positiva que ejercieron los vientos procedentes del segundo cuadrante, durante el período prepico (PRE) de los diez años estudiados.

Décima. Se encontró una relación estadísticamente significativa entre los valores de IgE específica frente a un determinado alérgeno recombinante, y el recuento total anal del tipo de polen correspondiente. Esta relación fue menos notoria en el caso de las pruebas intrapidérmicas, probablemente debido a un problema de reactividad cruzada. Los tipos de polen que durante los años 2006 y 2007 superaron en un mayor número de días los umbrales desencadenantes de síntomas en pacientes sensibilizados fueron los de las familias Poaceae y Cupressaceae. 

Bibliografía 

Adinoff, A. D., Rosloniec, D. M., McCall, L. L. \& Nelson, H. S. (1990). Inmediate skin test reactivity to Food and Drug Administration - approved standardized extracts. J Allergy Clin Immunol, 86: 766-774.

Adkinson, N. F., Busse, W. W., Bochner, B. S. \& Holgate, S. T. (2003). Middlenton's Allergy Principles \& Practice. $6^{\text {th }}$ edition. Simons F. E. R., Philadelphia.

Agashe, S. N. \& Alfadil, A. G. (1989). Atmospheric biopollutant monitoring in relation to meteorological parameters. Grana, 28: 97-104.

Aira, M. J., Jato, V. \& Iglesias, I. (1998). Alnus and Betula pollen content in the atmosphere of Santiago de Compostela, north-western Spain (1993-1995). Aerobiologia, 14: 135-140.

Aira, M. J., Jato, V., Stchigel, A. M., Rodríguez-Rajo, F. J. \& Piontellid, E. (2007). Aeromycological study in the Cathedral of Santiago de Compostela (Spain). Int Biodet Biodegrad, 60(4): 231-237.

Aira, M. J., La-Serna, I. \& Dopazo, A. (2003). Identification of fungal spores in the atmosphere of Santiago de Compostela (NW Spain) in the winter period. Polen, 12: 65-76.

Alba, F., Díaz de la Guardia, C. \& Comtois, P. (2000). The effect of meteorological parameters on diurnal patterns of airborne olive pollen concentration. Grana, 39: 200-208.

Alba, F., Nieto-Lugilde, D., Comtois, P., Díaz de la Guardia, C., De Linares, C. \& Ruiz, L. (2006). Airborne-pollen maps for Olea europaea L. in eastern Andalusia (Spain) using GIS: Estimation models. Aerobiologia, 22: 109-118.

Alcázar, P., Cariñanos, P., De Castro, C., Guerra, F., Moreno, C., Domínguez-Vilches, E. \& Galán, C. (2004). Airborne plane-tree (Platanus hispanica) pollen distribution in the city of Córdoba, South-western Spain, and possible implications on pollen allergy. J Invest Allergol Clin Immunol, 14(3): 238-243.

Alcázar, P. \& Comtois, P. (2000). The influence of sampler height and orientation on airborne Ambrosia pollen counts in Montreal. Grana, 39: 303-307.

Andersen, T. B. (1991). A model to predict the beginning of the pollen season. Grana, 30: 269275 .

Andrew, R. (1984). A practical pollen guide to the British flora. Quaternary Research Association Technical Guide, 1, Cambrigde.

Antepara, I., Fernández, J. C., Gamboa, P., Jáuregui, I. \& Miguel, F. (1995). Pollen allergy in the Bilbao area (European Atlantic seaboard climate): pollination forecasting methods. Clin Exp Allergy, 25: 133-140.

Arobba, D., Guido, M. A., Minale, P., Montanari, C., Placereani, S., Pracilio, S., Troise, C., Voltolini, S. \& Negrini, A. C. (2000). Airborne pollen in Genoa (NW-Italy): a comparison between two pollen-sampling stations. Aerobiologia, 16: 233-243.

Arobba, D., Imperiale, G. \& Negrini, A. C. (1992). The main pollen season of Parietaria in Genoa (Italy): forecast possibilities. Grana, 31: 237-240. 
Armentia, A., Asensio, T., Subiza, J., Arranz, M. L., Martín Gil, F. J. \& Callejo, A. (2004). Living in towers as risk factor of pollen allergy. Allergy, 59: 302-305.

Asensio, T., Armentia, A., Arranz, M. L., Callejo, A., Rebollo, S. \& Sedano, E. (2003). ¿̇Influye la altura de la vivienda en la sensibilización a pólenes?. Alergol Inmunol Clin, 18: 13-16.

Atkinson, H. \& Larsson, K. A. (1990). A 10-year record of the arboreal airborne pollen in Stockholm, Sweden. Grana, 29: 229-237.

Bagnouls, F. \& Gaussen, H. (1954). Saisson séche et indice xérothermique. Doc pour les cartes de prod veg, séries généralités, III, 1: 1-48.

Bartková-Ščevková, J. (2003). The influence of temperature, relative humidity and rainfall on the occurrence of pollen allergens (Betula, Poaceae, Ambrosia artemisiifolia) in the atmosphere of Bratislava (Slovakia). Int J Biometeorol, 48: 1-5.

Bhattacharya, K. \& Datta, B. K. (1992). Anthesis and pollen release of some pollen plants of West Bengal, India. Grana, 31: 67-71.

Behrendt, H., Becker, W. M., Fritzsche, C., Sliwa-Tomczok, W., Tomczok, J., Friedrichs, K. H. \& Ring, J. (1997). Air pollution and allergy: Experimental studies on modulation of allergen release from pollen by air pollutants. Int Arch Allergy Immunol, 113: 69-74.

Bellot Rodríguez, F., Casaseca Mena, B. \& Fernández Rodríguez, M. L. (1966). Mapa de la vegetación de Salamanca. Publicaciones I. O. A. T. O., Salamanca.

Belmonte, J. \& Roure, J. M. (1985). Contenido polínico de la atmósfera de Cataluña. Resultados año 1983. Ann Asoc Palinol Leng Esp, 2: 319-328.

Belmonte, J., Canela, M., Guàrdia, R., Guàrdia, R. A., Sbai, L., Vendrell, M., Alba, F., Alcázar, P., Cabezudo, B., Gutiérrez, M., Méndez, J. \& Valencia, R. (1999a). Aerobiological dynamics of the Urticaceae pollen in Spain, 1992-98. Polen, 10: 79-91.

Belmonte, J., Canela, M., Guàrdia, R. A., Sbai, L., Vendrell, M., Cariñanos, P., Díaz de la Guardia, C., Dopazo, A., Fernández, D., Gutiérrez, M. \& Trigo, M. M. (1999b). Aerobiological dynamics of the Cupressaceae pollen in Spain, 1992-98. Polen, 10: 27-38.

Bergamini, B. M., Grillenzoni, S., Andreoni, A. D., Natali, P., Ranzi, A. \& Bertolani, M. F. (2004). Alternaria spores at different heights from the ground. Allergy, 59: 746-752.

Berggren, B., Nilsson, S. \& Boëthius, G. (1995). Diurnal variation of airborne birch pollen at some sites in Sweden. Grana, 34: 251-259.

Berna Dursun, A., Çelik, C. E., Alan, S., Münevver Pinar, N., Mungan, D. \& Misirligil, Z. (2008). Regional pollen load: Effect on sensitisation and clinical presentation of seasonal allergic rhinitis in patients living in Ankara, Turkey. Allergol et Immunopathol, 36(6): 371378.

Bernadovičová, S. \& Ivanová, H. (2008). Leaf spot disease on Tilia cordata caused by the fungus Cercospora microsora. Biologia, 63(1): 44-49. 
Boi, M., Capó Martí, M. \& Servera, G. (2008). Aportación de la palinología forense en equinos. XVI Internacional A.P.L.E. Symposium of Palynology, Palma de Mallorca.

Bortenschlager, S. (1990). Aspects of pollen morphology in the Cupressaceae. Grana, 29: 129137.

Boyer, W. D. (1973). Air temperature, heat sums, and pollen shedding phenology of longleaf pine. Ecology, 54: 421-425.

Brandao, R., Caeiro, E., Lopes, M. L., Morais de Almeida, M., Nunes, C., Gaspar, A., Oliveira, J. F., Todo-Bom, A. \& Leitão, M. T. (2008). Airborne Pollen Monitoring in Portugal (20022007). XVI Internacional A.P.L.E. Symposium of Palynology, Palma de Mallorca.

Bricchi, E., Fornaciari, M., Giannoni, C., Greco, F., Fascini, G. Frenguelli, G., Mincigrucci, G. \& Romano, B. (1992). Fluctuations of grass pollen content in the atmosphere of East Perugia and meteorological correlations (year 1989). Aerobiologia, 8: 401-406.

Bryant, V. M. \& Jones, G.D. (2006). Forensic palynology: Current status of a rarely used technique in the United States of America. Forensic Scien Int, 163: 183-197.

Burt, P., Rutter, J. \& Ramírez, F. (1998). Airborne spores loads and mesoscale dispersal of the fungal pathogens causing Sigatoka diseases in banana and plantain. Aerobiologia, 14: 209214.

Calvo Bullón, A. P. (1996). Incidencia de la sensibilización alérgica en nuestro medio. Concentraciones de pólenes de gramíneas, oleáceas y Quercus durante las primaveras de 1994 y 1995. Tesis de Licenciatura, Universidad de Salamanca.

Candau, P. (1987a). Moraceae. In: Valdés, B., Díez, M. J. \& Fernández, I. (eds.). Atlas polínico de Andalucía Occidental. pp. 92. Instituto de Desarrollo Regional, Universidad de Sevilla, Sevilla.

Candau, P. (1987b). Myrtaceae. In: Valdés, B., Díez, M. J. \& Fernández, I. (eds.). Atlas polínico de Andalucía Occidental. pp. 204. Instituto de Desarrollo Regional, Universidad de Sevilla, Sevilla.

Candau, P. (1987c). Oleaceae. In: Valdés, B., Díez, M. J. \& Fernández, I. (eds.). Atlas polínico de Andalucía Occidental. pp. 294-296. Instituto de Desarrollo Regional, Universidad de Sevilla, Sevilla.

Candau, P. (1987d). Papaveraceae. In: Valdés, B., Díez, M. J. \& Fernández, I. (eds.). Atlas polínico de Andalucía Occidental. pp. 84-86. Instituto de Desarrollo Regional, Universidad de Sevilla, Sevilla.

Candau, P. (1987e). Plantaginaceae. In: Valdés, B., Díez, M. J. \& Fernández, I. (eds.). Atlas polínico de Andalucía Occidental. pp. 84-86. Instituto de Desarrollo Regional, Universidad de Sevilla, Sevilla. 
Candau, P. (1987f). Polygonaceae. In: Valdés, B., Díez, M. J. \& Fernández, I. (eds.). Atlas polínico de Andalucía Occidental. pp. 118-123. Instituto de Desarrollo Regional, Universidad de Sevilla, Sevilla.

Candau, P. (1987g). Simaroubaceae. In: Valdés, B., Díez, M. J. \& Fernández, I. (eds.). Atlas polínico de Andalucía Occidental. pp. 231-232. Instituto de Desarrollo Regional, Universidad de Sevilla, Sevilla.

Candau, P. (1987h). Thymelaeaceae. In: Valdés, B., Díez, M. J. \& Fernández, I. (eds.). Atlas polínico de Andalucía Occidental. pp. 203. Instituto de Desarrollo Regional, Universidad de Sevilla, Sevilla.

Candau, P., González Minero, F. \& Romero, F. (1994). Aeropalynology of Fraxinus (Ash) in an urban area of southwestern Spain. Aerobiologia, 10: 47-51

Capel Molina, J. J. (1981). Los climas de España. Ed. Oikos-tau S.A., Barcelona.

Caramiello, R. Siniscalco, C., Mercalli, L. \& Potenza, A. (1994). The relationship between airborne pollen grains and unusual weather conditions in Turin (Italy) in 1989, 1990 and 1991. Grana, 33: 327-332.

Cariñanos, P., Alcázar, P., Galán, C. \& Domínguez, E. (2002a). Privet pollen (Ligustrum sp.) as a potencial cause of pollinosis in the city of Córdoba, south-west Spain. Allergy, 57: 92-97.

Cariñanos, P., Sánchez-Mesa, J. A., Prieto-Baena, J. C., López, A., Guerra, F., Moreno, C., Domínguez, E. \& Galán, C. (2002b). Pollen allergy related to the area of residence in the city of Córdoba, south-west Spain. J Environ Monit, 4: 734-738.

Cariñanos, P., Galán, C., Alcázar, P. \& Domínguez, E. (1998). Spectrophotometric analysis as a complementary technique to aerobiology in the study of solid particles in the air. Aerobiologia, 14: 147-153.

Cariñanos, P., Galán, C., Alcázar, P. \& Domínguez, E. (1999). Diurnal variation of biological and non-biological particles in the atmosphere of Córdoba, Spain. Aerobiologia, 15: 177182.

Cariñanos, P., Galán, C., Alcázar, P. \& Domínguez, E. (2004). Airborne pollen records reponse to climatic conditions in arid areas of the Iberian Peninsula. Environ Exp Bot, 52: 11-22.

Carreño, V. \& Castillo. I. (2001). Principios de Biología Molecular. Springer-Verlag Ibérica, Barcelona.

Caulton, E. Keddie, S., Carmichael, R., Sales, J. (2000). A ten year study of the incidence of spores of bracken, (Pteridium aquilinum (L.) Kuhn.) in an urban rooftop airstream in south east Scotland. Aerobiologia, 16: 29-33.

Cecchi, L., Torrigiani Malaspina, T., Albertini, R., Zanca, M., Ridolo, E., Usberti, I., Morabito, M., Dall' Aglio, P. \& Orlandini, S. (2007). The contribution of long-distance transport to the presence of Ambrosia pollen in central northern Italy. Aerobiologia, 23: 145-151. 
Chapman, M. D. (1998). Allergens. In: Roitt, I. M. \& Delves, P. J. (eds.). Encyclopedia of Immunology. $2^{\mathrm{a}}$ ed. pp. 1-6. Academic Press, London.

Chehregani, A., Majde, A., Moin, M. Gholami, M., Shariatzadeh, M. A. \& Nassiri, H. (2004). Increasing allergy potency of Zimia pollen grains in polluted areas. Ecotoxicology and Enviromental Safety, 58: 267-272.

Christensen, P. B. \& Blackmore, S. (1988). Tiliaceae. Rev Palebot Palynol, 57: 33-43.

Chuine, I. (2000). A Unified Model for Budburst of Trees. J theor Biol, 207: 337-347.

Chuine, I., Cour, P. \& Rousseau, D.D. (1999). Selecting models to predict the timing of flowering of temperate trees: implications for tree phenology modelling. Plant, Cell \& Environ, 22: 1-13.

Connell, J. (1969). Quantitative intranasal pollen challenges: the priming effect in allergic rhinitis. J Allergy, 43: 33-44.

Conway, E. (1957). Spore production in bracken (Pteridium aquilinum (L.) Kuhn.). J Ecol, 45: 273-284.

Cookson, W. (1999). The alliance of genes and environment in asthma and allergy. Nature, 402: $\mathrm{B}_{5}-11$

Costa, Á., Bermúdez, F. \& Martínez, E. (1985). Salamanca verde. Parques y jardines de la ciudad de Salamanca. Servicio de Publicaciones del Ayuntamiento de Salamanca, Salamanca.

Cour, P. (1974). Nouvelles techniques de détection des flux et des retombées polliniques: étude de la sedimentation des pollens et des spores á la surface du sol. Pollen et spores, 16: 103141.

Cour, P. \& Van Campo, M. (1980). Prevision de rècoletes à partir de l'analyse du continue pollinique de l'atmosphere. Comptes Rendus de l'Academie des Sciences de Paris, 290: $1043-1046$.

Cristofolini, F. \& Gottardini, E. (2000). Concentration of airborne pollen of Vitis vinifera L. and yield forecast: a case study at S. Michele all'Adige, Trento, Italy. Aerobiologia, 16: 125129.

Cruden, R. W. (2000). Pollen grains: Why so many? Plant Syst Evol, 222: 143-165.

Culley, T. M., Weller, S. G., Sakai, A. K. (2002). The evolution of wind pollination in angiosperms. Ecology \&Evolution, 17(8): 361-369.

Cunha, M., Abreu, I., Pinto, P. \& de Castro, R. (2003). Airborne Pollen Samples for EarlySeason Estimates of Wine Production in a Mediterranean Climate Area of Northern Portugal. AmJ Enol Vitic, 54(3): 189-194.

D’Amato, G. (2000). Urban air pollution and plant-derived respiratory allergy. Clin Exp Allergy, 30: 628-636. 
D’Amato, G. (2001). Allergenic Pollen. In: D’Amato, G., Bonini, S., Bousquet, J., Durham, S. R. \& Platts-Mills, T. A. E. (eds.). Pollenosis 2000. Global Approach. pp. 69-76. JGC Editions, Naples.

D’Amato, G. (2002). Environmental urban factors (air pollution and allergens) and the rising trends in allergic respiratory diseases. Allergy, 57 (Suppl. 72): 30-33.

D’Amato, G., Liccardi, G. \& Frenguelli, G. (2007). Thunderstorm-asthma and pollen allergy. Allergy, 62: 11-16.

Damialis, A., Gioulekas, D., Lazopoulou, C., Balafoutis, C. \& Vokou, D. (2005). Transport of airborne pollen into the city of Thessaloniki: the effects of wind direction, speed and persistence. Int J Biometeorol, 49: 139-145.

Daub, M. E. \& Ehrenshaft, M. (2000). The photoactivated Cercospora toxin cercosporin: Contributions to plant disease and fundamental biology. Ann Rev Phytopathol, 38: 461490.

Davis, O. K. (2008). Quaternary Palynology and Plant Macrofossils. http://geo.arizona.edu/palynology/geos $581 /$

Davies, R. R. (1971). Air sampling for fungi, pollens and bacteria. Ed. Academic Press, London.

Dávila, I., Mullol, J., Ferrer, M., Bartra, J., del Cuvillo, A., Montoso, J., Jáuregui, I., Sastre, J. \& Valero, A. (2009). Genetic Aspects of Allergic Rhinitis. J Investig Allergol Clin Immunol, 19 (Suppl.1): 25-31.

De Weerd, N. A., Bhalla, P. L. \& Singh, M. B. (2002). Aeroallergens and pollinosis: Molecular characteristics of cloned pollen allergens. Aerobiologia, 18(2): 87-106.

Del Pino, J. A. \& Díez, M. J. (1990). Aportación a la palinología de plantas ornamentales de la ciudad de Sevilla. II. Lagascalia, 16(2): 291-309.

Denk, T. \& Tekleva, M. V. (2006). Comparative pollen morphology and ultrastructure of Platanus: Implications for phylogeny and evaluation of the fossil record. Grana, 45: 195221.

Di-Giovanni, F., Kevan, P. G. \& Nasr, M. E. (1995). The variability in settling velocities of some pollen and spores. Grana, 34: 39-44.

Díaz, M. R., Iglesias, I. \& Jato, M. V. (1997). Airborne concentration of Botrytis, Uncinula and Plasmopara spores in Leiro-Ourense (NW Spain). Aerobiologia, 13: 31-35.

Díaz de la Guardia, C., Alba, F., Trigo, M. M., Galán, C., Ruiz, L. \& Sabariego, S. (2003). Aerobiological analysis of Olea europaea L. pollen in different localities of southern Spain. Forecasting models. Grana, 42: 234-243.

Díaz de la Guardia, C., Galán, C., Domínguez, E., Alba, F., Ruiz, L., Sabariego, S., Recio Criado, M., Fernández-González, D., Méndez, J., Vendrell, M. \& Gutiérrez Bustillo, M. (1999). 
Variations in the main pollen season of Olea europaea L. at selected sites in the Iberian Peninsula. Polen, 10: 103-113.

Díaz de la Guardia, C., Sabariego, S., Alba, F., Ruiz, L., García Mozo, H., Toro, F. J., Valencia, R., Rodríguez Rajo, F. J., Guàrdia, A. \& Cervigón, P. (1999). Aeropalynological study of the genus Platanus L. in the Iberian Peninsula. Polen, 10: 93-101.

Díaz-Sánchez, D., Tsien, A., Fleming, J. \& Saxon, A. (1997). Combined diesel exhaust particulate and ragweed allergen challenge markedly enhances human in vivo nasal ragweed-specific IgE and skews cytokine production to a $\mathrm{T}$ helper cell 2-type pattern. $\mathrm{J}$ Immunol, 158: 2406-2413.

Díez, M. J. (1987a). Asteraceae (Compositae). In: Valdés, B., Díez, M. J. \& Fernández, I. (eds.). Atlas polínico de Andalucía Occidental. pp. 332-357. Instituto de Desarrollo Regional, Universidad de Sevilla, Sevilla.

Díez, M. J. (1987b). Betulaceae. In: Valdés, B., Díez, M. J. \& Fernández, I. (eds.). Atlas polínico de Andalucía Occidental. pp. 96-98. Instituto de Desarrollo Regional, Universidad de Sevilla, Sevilla.

Díez, M. J. (1987c). Boraginaceae. In: Valdés, B., Díez, M. J. \& Fernández, I. (eds.). Atlas polínico de Andalucía Occidental. pp. 265-281. Instituto de Desarrollo Regional, Universidad de Sevilla, Sevilla.

Díez, M. J. (1987d). Caprifoliaceae. In: Valdés, B., Díez, M. J. \& Fernández, I. (eds.). Atlas polínico de Andalucía Occidental. pp. 322-324. Instituto de Desarrollo Regional, Universidad de Sevilla, Sevilla.

Díez, M. J. (1987e). Cupressaceae. In: Valdés, B., Díez, M. J. \& Fernández, I. (eds.). Atlas polínico de Andalucía Occidental. pp. 67-68. Instituto de Desarrollo Regional, Universidad de Sevilla, Sevilla.

Díez, M. J. (1987f). Juglandaceae. In: Valdés, B., Díez, M. J. \& Fernández, I. (eds.). Atlas polínico de Andalucía Occidental. pp. 67-68. Instituto de Desarrollo Regional, Universidad de Sevilla, Sevilla.

Díez, M. J. (1987g). Salicaceae. In: Valdés, B., Díez, M. J. \& Fernández, I. (eds.). Atlas polínico de Andalucía Occidental. pp. 149-152. Instituto de Desarrollo Regional, Universidad de Sevilla, Sevilla.

Díez, M. J. (1987h). Ulmaceae. In: Valdés, B., Díez, M. J. \& Fernández, I. (eds.). Atlas polínico de Andalucía Occidental. pp. 90-91. Instituto de Desarrollo Regional, Universidad de Sevilla, Sevilla.

Díez, M. J. \& Suárez, R. (1987). Fagaceae. In: Valdés, B., Díez, M. J. \& Fernández, I. (eds.). Atlas polínico de Andalucía Occidental. pp. 94-96. Instituto de Desarrollo Regional, Universidad de Sevilla, Sevilla. 
Dolen, W. K. (2001). Skin testing and immunoassays for allergen-specific IgE. Clin Rev Allergy Immunol, 21: 229-239.

Domínguez, E., Galán, C., Villamandos, F. \& Infante, F. (1991). Manejo y evaluación de los datos obtenidos en los muestreos aerobiológicos. Sistema Hirst. REA, 1: 4-7.

Dopazo, A., Aira, M. J., Armisén, M. \& Vidal, C. (2002). Relationship of clinical and aerobiological pollen data in the north-west of Spain. Allergol et Immunopathol, 30(2): 7478.

Dorronsoro Fernández, C. F. (1992). Suelos. In: Gómez Gutiérrez, J. M. El libro delas dehesas salmantinas. Junta de Castilla y León, Consejería de Medio Ambiente y Ordenación del Territorio.

Durham, O. C. (1946). The volumetric incidence of atmospheric allergens, IV. A proposed standard method of gravity sampling counting and volumetric interpolation of results. J Allergy, 17: 79-86.

El-Ghazaly, G., El-Ghazaly, P. K., Larsson, K. A. \& Nilsson, S. (1993). Comparison of airborne pollen grains in Huddinge and Stockholm, Sweden. Aerobiologia, 9: 53-67.

Elvira Rendueles, B., Vergara Juárez, N., Moreno, J. M., García Sánchez, A. \& Moreno-Grau, S. (2008). Niveles umbrales de Olea en la atmósfera de Cartagena: estudio y análisis de su periodo principal de polinización. XVI Internacional A.P.L.E. Symposium of Palynology, Palma de Mallorca.

Emberlin, J. (1994). The effects of patterns in climate and pollen abundante on allergy. Allergy, 49: 15-20.

Emberlin, J. (1997). Polluted thoughts. Community Pharmacy, 5: 167-181.

Emberlin, J., Detandt, M., Gehrig, R., Jaeger, S., Nolard, N., Rantio-Lehtimäki, A. (2002). Responses in the start of Betula (birch) pollen seasons to recent changes in spring temperatures across Europe. IntJ Biometeorol, 46: 159-170.

Emberlin, J. \& Norris-Hill, J. (1991). Annual, daily and diurnal variation of Urticaceae pollen in North-central London. Aerobiologia, 7: 49-57.

Emberlin, J., Savage, M. \& Jones, S. (1993). Annual variations in grass pollen seasons in London 1961-1990: trends and forecast models. Clin Exp Allergy, 23: 911-918.

Emberlin, J., Smith, M., Close, R. \& Adams-Groom, B. (2007). Changes in the pollen seasons of the early flowering trees Alnus spp. and Corylus spp. in Worcester, United Kingdom, 1996-2005. Int J Biometeorol, 51: 181-191.

Erdtman, G. (1952). Pollen morphology and plant taxonomy. Angiosperms. Ed. Almqvist \& Wiksell, Stockholm.

Erdtman, G. (1960). The acetolysis method. A revised description. Svensk Bot Tidskr, 54: 561564. 
Erdtman, G. (1966). Pollen Morphology and Plant Taxonomy. Ed. Hafner Publishing, New York.

Erdtman, G. (1969). Handbook of Palynology. Ed. Munksgaard, Copenhagen.

Eriksson, N. E. \& Holmen, A. (1996). Skin prick tests with standardized extracts of inhalant allergens in 7099 adult patitents with asthma or rhinitis: cross-sensitizations and relationships to age, sex, month of birth and year of testing. J Investig Allergol Clin Immunol, 6: 36-46.

Estrella, N., Menzel, A., Krämer, U. \& Behrendt, H. (2006). Integration of flowering dates in phenology and pollen counts in aerobiology: analysis of their spatial and temporal coherence in Germany (1992-1999). IntJ Biometeorol, 51: 49-59.

Eversmeyer, M. G. \& Kramer, C. L. (1987). Single versus multiple sampler comparisons. Grana, 26: 109-112.

Faegri, K. (1956). Recent trends in palynology. Bot Rev, 22: 639-644.

Faegri, K. \& Iversen, J. (1975). Textbook of pollen analysis. Ed. Munksgaard, Copenhagen.

Faegri, K. \& Iversen, J. (1989). Textbook of pollen analysis. $4^{\text {a }}$ ed. Faegri, K., Kaland, P. E. \& Krzywinski (eds.). John Wiley \& Sons, New York.

Faegri, K. \& van der Pijl, L. (1979). The principles of pollination ecology. $3^{\text {rd }}$ ed. Pergamon Press, Oxford.

Feher, Z. \& Jàrai-Komlódi, M. (1997). An examination of the main characteristics of the pollen seasons in Budapest, Hungary (1991-1996). Grana, 36: 246-251.

Feo Brito, F., Galindo Bonilla, P. A., García Rodríguez, R., Gómez Torrijos, E., Fernández Martínez, F., Fernández-Pacheco, R., Delicado Gallego, A. (1998). Pólenes alergénicos en Ciudad Real: Aerobiología e incidencia clínica. Rev Esp Alergol Inmunol Clin, 13: 79-85.

Fernández, I. (1987a). Fabaceae (Papilionaceae). In: Valdés, B., Díez, M. J. \& Fernández, I. (eds.). Atlas polínico de Andalucía Occidental. pp. 185-200. Instituto de Desarrollo Regional, Universidad de Sevilla, Sevilla.

Fernández, I. (1987b). Poaceae (Gramineae). In: Valdés, B., Díez, M. J. \& Fernández, I. (eds.). Atlas polínico de Andalucía Occidental. pp. 373-376. Instituto de Desarrollo Regional, Universidad de Sevilla, Sevilla.

Fernández, I. (1987c). Vitaceae. In: Valdés, B., Díez, M. J. \& Fernández, I. (eds.). Atlas polínico de Andalucía Occidental. pp. 220-221. Instituto de Desarrollo Regional, Universidad de Sevilla, Sevilla.

Fernández-Caldas, E., Swanson, M. C., Pravda, J., Welsh, P., Yunginger, J. W. \& Reed, C. E. (1989). Immunochemical demonstration of red oak pollen aeroallergens outside the oak pollination season. Grana, 28: 205-209.

Fernández-González, D., González Parrado, Z., Fuertes Rodríguez, C. R., Sánchez Reyes, E., Rodríguez de la Cruz, D., Vega Maray, A. M., Sánchez Sánchez, J., de Castro Alfageme, S. \& 
Valencia-Barrera, R. M. (2008). Contenido palinológico durante el año 2007 en la atmósfera de la Comunidad de Castilla y León. XVI Internacional A.P.L.E. Symposium of Palynology, Palma de Mallorca.

Fernández-González, D., Valencia-Barrera, R. M., Vega, A. M. \& Gozalo-Requés, F. (1998). Aerobiología en Castilla y León: Estación de León (1997). Rea, 4: 61-64.

Fernández-González, D., Valencia-Barrera, R. M., Vega, A., Díaz de la Guardia, C., Trigo, M. M., Cariñanos, P., Guàrdia, A., Pertiñez, C. \& Rodríguez Rajo, F. J. (1999). Analysis of grass pollen concentrations in the atmosphere of several Spanish sites. Polen, 10: 127-136.

Fineschi, S., Taurchini, D., Villani, F. \& Vendramin, G. G. (2000). Chloroplast DNA polymorphism reveals little geographical structure in Castanea sativa Mill. (Fagaceae) throughout southern European countries. Mol Ecol, 9: 1495-1503.

Fiorina, A., Mincarini, M., Sivori, M., Brichetto, L., Scordamaglia, A., Canonica, G. W. (1999). Aeropollinic sampling at three different heights by personal volumetric collector (Partrap FA 52). Allergy, 54: 1309-1315.

Fischer, S., Grote, M., Fahlbusch, B., Muller, W. D., Kraft, D. \& Valenta, R. (1996). Characterization of $\mathrm{Phl} \mathrm{p} \mathrm{4,} \mathrm{a} \mathrm{major} \mathrm{timothy} \mathrm{grass} \mathrm{(Phleum} \mathrm{pratense)} \mathrm{pollen} \mathrm{allergen.} \mathrm{J}$ Allergy Clin Immunol, 98: 189-198.

Florido, J. F., González, P., Sáenz de San Pedro, B., Quiralte, J., Arias de Saavedra, J. M., Peralta, V. \& Ruiz, L. (1999). High levels of Olea europaea pollen and relation with clinical findings. Int Arch Allergy Immunol, 119: 133-137.

Font Quer, P. (1993). Diccionario de Botánica. Ed. Labor, Barcelona.

Fornaciari, M., Bricchi, E., Frenguelli, G. \& Romano, B. (1996). The results of 2-year pollen monitoring of an urban network in Perugia, Central Italy. Aerobiologia, 12: 219:227.

Fornaciari, M., Pieroni, L., Ciuchi, P. \& Romano, B. (1997). A statistical model for correlation airbone pollen grains Olea europaea L. (Oleaceae) with some meteorological parameters. Agric Mediterr, 127: 134-137.

Fornaciari, M. Pieroni, L., Orlandi, F. \& Romano, B. (2002). A new approach to consider the pollen variable in forecasting yield models. Economic Botany, 56 (1): 66-72.

Fountain, D. W. (2002). Pollen and inhalant allergy. Biologist, 49: 5-9.

Freitas, R. N., O'Connor, P. J., Prakash, A.S., Shahin, M. \& Povey, A. C. (2001). Bracken (Pteridium aquilinum)-Induced DNA Adducts in Mouse Tissues Are Different from the Adduct Induced by the Activated Form of Bracken Carcinogen Ptaquiloside. Biochem Biophys Res Commun, 281: 589-594.

Frenz, D. A. (2000). Interpreting atmospheric pollen counts for use in clinical allergy: spatial variability. Ann Allergy Asthma Immunol, 84: 481-491.

Frenz, D. A., Melcher, S. E., Murray, L. W., Sand, R. E. (1997). A comparison of total pollen counts obtained $5.6 \mathrm{~km}$ apart. Aerobiologia, 13: 205-208. 
Fuentes de Frutos, A. L. (1987). Importancia de la sensibilización a pólenes de árboles en la alergia infantil de nuestro medio. Tesis de Licenciatura, Universidad de Salamanca.

Fuertes-Rodríguez, C. R., González-Parrado, Z., Vega-Maray, A. M., Valencia-Barrera, R. M. \& Fernández-González, D. (2007). Effect of air temperature on forecasting the start of Cupressaceae pollen type in Ponferrada (León, Spain). Ann Agric Environ Med, 14: 237242.

Galán, C., Alcázar, P., Gómez, M. \& León, E. (2006). Contenido polínico de la familia Pinaceae en la atmósfera de Córdoba, España. Polen, 16: 60-61.

Galán, C., Cariñanos, P., Alcázar, P. \& Domínguez, E. (2007). Manual de Calidad y Gestión de la Red Española de Aerobiología. Servicio de publicaciones de la Universidad de Córdoba, Córdoba.

Galán, C., Cuevas, J., Infante, F. \& Domínguez, E. (1989). Seasonal and diurnal variation of pollen from Gramineae in the atmosphere of Córdoba (Spain). Allergol et Immunopathol, 17(5): 245-249.

Galán, C., Emberlin, J., Domínguez, E., Bryant, R. H. \& Villamandos, F. (1995). A comparative analysis of daily variations in the Graminae pollen counts at Córdoba, Spain and London, UK. Grana, 34: 189-198.

Galán, C., García-Mozo, H., Vázquez, L., Ruiz, L., Díaz de la Guardia, C. \& Trigo, M. M. (2005). Heat requirement for the onset of the Olea europaea L. pollen season in several sites in Andalusia and the effect of the expected future climate change. Int J Biometeorol, 49: 184188.

Galán, C., Tormo, R., Cuevas, J., Infante, F. \& Domínguez, E. (1991). Theoretical daily variation patterns of airborne pollen in the South-West of Spain. Grana, 30: 201-209.

Gall, G. A. E., Kreith, M. \& Staton, M. (1992). Global Climate Change. Agric Ecosystems Environ, 42: 93-100.

García González, M. (1999). Polinosis, una enfermedad en aumento. Rea, 5: 13-16.

García-Mozo, H., Chuine, I., Aira, M. J., Belmonte, J., Bermejo, D., Díaz de la Guardia, C., Elvira, B., Gutiérrez, M., Rodríguez-Rajo, J., Ruiz, L., Trigo, M. M., Tormo, R., Valencia, R. \& Galán, C. (2008). Regional phenological models for forecasting the start and peak of the Quercus pollen season in Spain. Agric Forest Meteorol, 148 (3): 372-380.

García-Mozo, H., Galán, C., Aira, M. J., Belmonte, J., Díaz de la Guardia, C., Fernández, D., Gutiérrez, A. M., Rodríguez, F. J., Trigo, M. M. \& Domínguez-Vilches, E. (2002). Modelling start of oak pollen season in different climatic zones in Spain. Agric Forest Meteorol, 110: 247-257.

García-Mozo, H., Galán, C., Belmonte, J., Bermejo, D., Candau, P., Díaz de la Guardia, C., Elvira, B., Gutiérrez, M., Jato, V., Silva, I., Trigo, M. M., Valencia, R. \& Chuine, I. (2009). 
Predicting the Start and peak dates of the Poaceae pollen season in Spain using processbased models. Agric Forest Meteorol, 149: 256-262.

García-Mozo, H., Galán, C., Cariñanos, P., Alcázar, P., Méndez, J., Vendrell, M., Alba, F., Sáenz, C., Fernández, D., Cabezudo, B. \& Domínguez, E. (1999). Variations in the Quercus sp. pollen season at selected sites in Spain. Polen, 10: 59-69.

García-Mozo, H., Galán, C., Gómez-Casero, M. T. \& Domínguez-Vilches, E. (2000). A comparative study of different temperature accumulation methods for predicting the start of the Quercus pollen season in Córdoba (South West Spain). Grana, 39: 194-199.

García-Mozo, H., Galán, C., Jato, V., Belmonte, J., Díaz de la Guardía, C., Fernández, D., Gutiérrez, M., Aira, M. J., Roure, J.M., Ruiz, L., Trigo, M. M., Domínguez-Vilches, E. (2006). Quercus pollen season dynamics in the Iberan Peninsula: Reponse to meteorological parameters and posible consequences of Climate Change. Ann Agric Environ Med, 13: 209-224.

Giorato, M., Lorenzoni, F., Bordin, A., De Biasi, G., Gemignani, C., Schiappoli, M. \& Marcer, G. (2000). Airborne allergenic pollens in Padua: 1991-1996. Aerobiologia, 16: 453-454.

González, J. \& Candau, P. (1995). Análisis del contenido polínico de la atmósfera de Huelva (1989-1992). Acta Bot Malacitana, 20: 71-81.

González, F. J., Iglesias, I., Jato, V., Aira, M. J., Candau, M. P., Morales, J. \& Tomás, C. (1998). Study of the pollen emissions of Urticaceae, Plantaginaceae and Poaceae at five sites in western Spain. Aerobiologia, 14: 117-129.

González-Minero, F. J., Candau, P., Morales, J. \& Tomás, C. (1998). Forecasting olive crop production based on ten consecutive years of monitoring airborne pollen in Andalucía (southern Spain). Agric Ecosystems Environ, 69: 201-215.

González Minero, F. J. \& Candau, P. (1997). Olea europaea airborne pollen in southern Spain. Ann Allergy Asthma Immunol, 78: 278-284.

González Minero, F. J., Morales, J., Tomás, C. \& Candau, P. (1999). Relationship between air temperature and the start of pollen emisión in some arboreal taxa in Southwestern Spain. Grana, 38: 306-310.

González-Parrado, Z., Fuertes-Rodríguez, C. R., Vega-Maray, A. M., Valencia-Barrera, R. M., Rodríguez-Rajo, F. J. \& Fernández-González (2006). Chilling and heat requirements for the prediction of the beginning of the pollen season of Alnus glutinosa (L.) Gaertner in Ponferrada (León, Spain). Aerobiologia, 22: 47-53.

Gottardini, E. \& Cristofolini, F. (1997). Spring airborne pollen data in two sites in Trentino (Northern Italy): a comparison with meteorological data. Aerobiologia, 13: 199-204.

Gozalo-Garijo, M. A., Tormo-Molina, R., Muñoz-Rodríguez, A. F. \& Silva-Palacios, I. (2006). Differences in the spatial distribution of airborne pollen concentrations at different urban locations within a city. J Investig Allergol Clin Immunol, 16(1): 37-43. 
Grant Smith, E. (2000). Sampling and identifying allergenic pollens and molds. An Illustrated Identification Manual for Air Samplers. Blewstone Press, San Antonio.

Green, B. J., Dettmann, M., Yli-Panula, E., Rutherford, S. \& Simpson, R. (2004). Atmospheric Poaceae pollen frequencies and associations with meteorological parameters in Brisbane, Australia: a 5-year record, 1994-1999. IntJ Biometeorol, 48: 172-178.

Gregory, P. H. (1973). The microbiology of the Atmosphere. Ed. Leonard Hill. Plymouth, London.

Gutiérrez, A. M., Sáenz, C., Cervigón, P., Alcázar, P., Dopazo, A., Ruiz, L., Trigo, M. M., Valencia, R. \& Vendrell, M. (1999). Comparative study of the presence of aeropollen from Plantago sp. at several locations in Spain. Polen, 10: 115-125 (1999).

Gutiérrez Bustillo, M., Cervigón Morales, P. \& Pertiñez Izquierdo, C. (2002). Aerobiología en Madrid: Estación de Ciudad Universitario (2000-2001). Rea, 7: 225-230.

Gutiérrez Bustillo, M. \& Sáenz Laín, C. (2000). Polen atmosférico de Olea europaea L. en Madrid (Ciudad Universitaria) y Aranjuez durante los años 1994-1997. Anales Jard Bot Madrid, 57 (2): 357-363.

Hart, M. L., Wentworth, J. E. \& Bailey, J. P. (1994). The effects of trap height and weather variables on recorded pollen concentration at Leicester. Grana, 33: 100-103.

Heath, G. L. A. (1984). Hippocastanaceae. In: Punt, W. \& Clarke, G. C. S. (eds.). The Northwest European Pollen Flora IV. pp. 111-119. Elsevier Science Publishers B. V., Amsterdam, The Netherlands.

Hemmer, W., Focke, M., Wantke, F., Götz, M., Jarisch, R. \& Jäger, S. \& Götz, M. (2000). Ash (Fraxinus excelsior)-pollen allergy in central Europe: specific role of pollen panallergens and the major allergen of ash pollen, Fra e 1. Allergy, 55(10): 923-930.

Hernández Prieto, M., Lorente Toledano, F., Romo Cortina, A., Dávila González, I., Laffond Yges, E. \& Calvo Bullón, A. (1998). Pollen calendar of the city of Salamanca (Spain). Aeropalynological analysis for 1981-1982 and 1991-1992. Allergol et Immunopathol, 26 (5): 209-222.

Herrero, B. \& Fraile, C. (1997). Annual variation of airborne pollen in the city of Palencia, Spain, 1990-92. Grana, 36(6): 358-365.

Hersey, K. G. (2004). Is it all in our genes? The "mite-y" truth. J Allergy Clin Immunol, 113: 392-394.

Hesse, M. (1978). Entwicklungsgeschichte und Ultrastruktur von Pollenkitt und Exine bei nahe verwandten entomophilen und anemophilen Sippen: Ranunculaceae, Hammamelidaceae, Platanaceae und Fagaceae. Plant Syst Evol, 130: 13-42.

Hidalgo, P. J., Galán, C. \& Domínguez, E. (2003). Male phenology of three species of Cupressus: correlation with airborne pollen. Trees, 17: 336-344.

Hirst, J. M. (1952). An automatic volumetric spore trap. Ann Apl Biol, 39(2): 257-265. 
Hirst, J. M. (1994). Aerobiology at Rothamsted. Grana, 33: 66-70.

Holberg, C. J., O’Rourke, M. K. \& Lebowitz, M. D. (1987). Multivariate analysis of ambient environmental factors and respiratory effects. Int J Epidemiol, 16: 399-410.

Hopkins, A. \& Davies, R. R. (1994). Changing grassland utilization in the United Kingdom and its implications for pollen production and hay fever. Grana, 33: 71-75.

Huttunen, K., Rintala, H., Hirvonen M. R., Vepsälïainen, A., Hyvärinen, A., Meklin, T., Toivola, M. \& Nevalainen, A. (2008). Indoor air particles and bioaerosols before and after renovation of moisture-damaged buildings: The effect on biological activity and microbial flora. Environ Res, 107(3): 291-298.

Hyde, H. A. (1952). Studies in atmospheric pollen. V. A daily census of pollen at Cardiff for six years 1943-1948. New Phytol, 51: 193-281.

Iglesias, I., Jato, M. V., Álvarez, E., Aira, M. J. \& Segura, A. (1993). Variaciones anuales y diarias de la concentración de polen de la atmósfera de la ciudad de Ourense. An Asoc Palinol Leng Esp, 6: 103-112.

Iglesias, I., Rodríguez-Rajo, F. J. \& Méndez, J. (2007). Behaviour of Platanus hispanica pollen, an important spring aeroallergen in Northwestern Spain. J Investig Allergol Clin Immunol, 17 (3), 145-156.

Isard, S. \& Ariatti, A. (2006). Application of the Integral Aerobiology Modelling System to Forecasting Soybean Rust Spread in North America. Abstracts The $8^{\text {th }}$ International Congress on Aerobiology, 1: 168.

Isard, S. \& Gage, S. H. (2001). Flow of Life in the Atmosphere. Ed. Michigan State University Press, Michigan.

Jäeger, S. (2002). Long term trends of pollen seasons in Europe: Changes in start, duration and intensity. $7^{\text {th }}$ International Congress on Aerobiology, Montebello, Canadá.

Jäeger, S., Nilsson, S., Berggren, B., Pessi, A. M., Helander, M. \& Ramfjord, H. (1996). Trends of some airborne tree pollen in the Nordic countries and Austria, 1980-1993. A comparison between Stockholm, Trondheim, Turku and Viena. Grana, 35: 171-178.

Jarosz, N., Loubet, B. \& Huber, L. (2004). Modelling airborne concentration and deposition rate of maize pollen. Atmos Environ, 38: 5555-5556.

Jato, V., Aira, M. J., Iglesias, M. I., Alcázar, P., Cervigón, P., Fernández, D., Recio, M., Ruiz, L. \& Sbai, L. (1999). Aeropalynology of birch (Betula sp.) in Spain. Polen, 10: 39-49.

Jato, V., Aira, M. J., Dopazo, A., Iglesias, M. I., Méndez, J. \& Rodríguez-Rajo, F. J. (2001a). Aerobiology of Castanea pollen in Galicia. Aerobiologia, 17: 233-240.

Jato, V., Dopazo, A. \& Aira, M. J. (2001b). Airborne pollen data of Platanaceae in Santiago de Compostela (Iberian Peninsula). Aerobiologia, 17: 143-149.

Jato, V., Dopazo, A. \& Aira, M. J. (2002). Influence of precipitation and temperature on airborne pollen concentration in Santiago de Compostela (Spain). Grana, 41: 232-241. 
Jato, M. V., Rodríguez, F. J. \& Seijo, M. C. (2000). Pinus pollen in the atmosphere of Vigo and its relationship to meteorological factors. Int J Biometeorol, 43: 147-153.

Jato, V., Rodríguez-Rajo, F. J. \& Aira, M. J. (2007). Use of phenological and pollen-production data for interpreting atmospheric birch pollen curves. Ann Agric Environ Med, 14: 271280.

Jato, V., Rodríguez-Rajo, F. J. \& Aira, M. J. (2008). El polen de Poaceae en Galicia: caracterización y tendencias recientes de su estación polínica atmosférica. XVI Internacional A.P.L.E. Symposium of Palynology, Palma de Mallorca.

Jato,V., Rodríguez-Rajo, F. J., Alcázar, P., De Nuntiis P., Galán, C. \& Mandrioli, P. (2006). May the definition of pollen season influence aerobiological results?. Aerobiologia, 22: 1325 .

Jato,V., Rodríguez-Rajo, F. J., Dacosta, N. \& Aira, M. J. (2004). Heat and chill requirements of Fraxinus flowering in Galicia (NW Spain). Grana, 43: 217-223.

Jiménez Díaz, C. (1932). El asma y otras enfermedades alérgicas. Ed. España, Madrid.

Jones, A. M. \& Harrison, R. M. (2004). The effects of meteorological factors on atmospheric bioaerosol concentrations - A review. Sci Total Envirom, 36: 151-180.

Kadocsa, E. \& Juhász, M. (2002). Study of airborne pollen composition and allergen spectrum of hay fever patients in South Hungary (1990-1999). Aerobiologia, 18:203-209.

Käpylä, M. (1981). Diurnal variation of non-arboreal pollen in the air in Finland. Grana, 20: 55-59.

Käpylä, M. (1984). Diurnal variation of tree pollen in the air in Finland. Grana, 23: 167-176.

Kasprzyk, I. (2004). Airborne pollen of entomophilous plants and spores of pteridophytes in Rzeszów and its environs (SE Poland). Aerobiologia, 20: 217-222.

Kasprzyk, I. (2008). Non-native Ambrosia pollen in the atmosphere of Rzeszów (Poland); evaluation of the effect of weather conditions on daily pollen concentrations and starting dates of the pollen season. Int J Biometeorol, 52: 341-351.

Kinet, J. P. (2002). Allergy and hypersensitivity. Editorial overview. Curr Opin Immunol, 14: 685-687.

Kjellman, N-IM., Johansson, S. G. O. \& Roth, A. (1976). Serum IgE levels in healthy children by a sandwich technique (PRISTTM). Clin Allergy, 6: 51-59.

Knox, R. B. (1984). The pollen grain. En: Johri, B. M. (ed.). Embryology of Angiosperms. pp. 197-217. Springer, Berlín.

Kramer, K. (1994). Selecting a model to predict the onset of growth of Fagus sylvatica. J Appl Ecol, 17: 367-377-

La Serna Ramos, I. E. \& Domínguez Santana, M. D. (2003). Pólenes y esporas aerovagantes en Canarias: incidencia en alergias. Servicio de Publicaciones, Universidad de La Laguna, La Laguna. 
Lacey, J., Crook, B. \& Janaku Bai, A. (1996). The detection of airborne allergens implicated in occupational asthma. In M. L. Muillenberg \& H. A. Burge. Aerobiology. Ed. Boca Raton CRC Press, New York.

Lacey, M. E. \& McCartney, H. A. (1994). Measurement of airborne concentrations of bracken (Pteridium aquilinum). Grana, 33: 91-93.

Lai, A.C.K. (2002). Particle deposition indoors: a review. Indoor air, 12(4): 211-214.

Larsson, K. A., El-Ghazaly, G., El-Ghazaly, P., Nilsson, S. \& Wiktorin, T. (1984). Pollen incidente in Eskilstuna, 1976-1982. Nordic Aerobiology, 74-84.

Latalowa, M., Uruska, A., Pedziszewska, A., Góra, M. \& Dawidowska, A. (2005). Diurnal patterns of airborne pollen concentration of the selected tree and herb taxa in Gdansk (northern Poland). Grana, 44: 192-201.

Latorre, F. (1999). Differences between airborne pollen and flowering phenology of urban trees with reference to production, dispersal and interannual climate variability. Aerobiologia, 15: 131-141.

Latorre, F., Romero, E. J. \& Manzini, M. V. (2008). Comparative study of different methods for capturing airborne pollen, and effects of vegetation and meteorological variables. Aerobiologia, 24: 107-120.

Lebowitz, M. D. \& O'Rourke, M. K. (1991). The significance of air pollution in aerobiology. Grana, 30:31-43.

Leuschner, R. M. \& Boehm, G. (1981). Pollen and inorganic particles in the air of climatically very different places in Switzerland. Grana, 20: 161-167.

Leuschner, R. M., Christen, H., Jordan, P. \& Vonthein, P. (2000). 30 years of studies of grass pollen in Basel (Switzerland). Aerobiologia, 16: 381-391.

Lieth, H. (1974). Phenology and seasonality modelling. Vol. 8. Berlin-Heideberg, New York.

López, C. \& Díez, M. J. (1987). Euphorbiaceae. In: Valdés, B., Díez, M. J. \& Fernández, I. (eds.). Atlas polínico de Andalucía Occidental. pp. 212-218. Instituto de Desarrollo Regional, Universidad de Sevilla, Sevilla.

Lyon, F. L., Kramer, C. L. \& Eversmeyer, M. G. (1984). Vertical variation of airspora concentrations in the atmosphere. Grana, 23: 123-125.

Llorente Maldonado, A. (1980). Las Comarcas Históricas y actuales de la provincia de Salamanca. CSIC, Salamanca.

Mäkinen, T. (1977). Correlation of atmospheric spore frequencies with meteorological data. Grana, 16: 149-153.

Makra, L., Juhász, M., Borsos, E. \& Béczi, R. (2004). Meteorological variables connected with airborne ragweed pollen in Southern Hungary. Int J Biometeorol, 49: 37-47.

Malaczynska, T., Szurogajlo, A., Szybinska, D. \& Rapiejko, P. (1995). The correlation between allergen-specific IgE concentration (RAST/CAP) in 411 allergic patients and pollen count. 
In: Spiewak, R. (ed.). Pollens and Pollinosis: Current Problems. pp. 53-54. Institute of Agricultural Medicine, Lublin.

Mandrioli, P., Caneva, G. \& Sabbioni, C. (2003). Cultural heritage and Aerobiology. Ed. Kluwer Academic Publisher, London.

Mandrioli, P., Comtois, P. \& Levizzani, V. (1998). Methods in Aerobiology. Ed. Pitagora Editrice Bologna, Bologna.

Mandrioli, P., Grazia Negrini, M., Scarani, C., Tampieri, F. \& Trombetti, F. (1980). Mesoscale transport of Corylus pollen grains in winter atmosphere. Grana, 19: 227-233.

Margni, R. A. (1996). Inmunología e Inmunoquímica. Fundamentos. $5^{\text {a }}$ ed. Ed. Médica Panamericana, Buenos Aires.

Márquez, J., Seoane-Camba, J. A. \& Suárez-Cervera, M. (1997). Allergenic and antigenic proteins release in the apertural sporoderm during the activation process in grass pollen grains. Sex Plant Reprod, 10: 269-278.

McKinney, M. (2006). Urbanization as a major cause of biotic homogenization. Biol Conserv, 127 (3): 247-260.

Moreno, A., Muñoz, A. F., Tormo, R. \& Silva, I. (1999). Aerobiología en Extremadura: Estación de Mérida (1998). Rea, 5: 111-114.

Moreno Corchero, A., Silva Palacios, I., Muñoz Rodríguez, A. F. \& Tormo Molina, R. (2006). Semejanzas y diferencias entre dos estaciones aerobiológicas. Polen, 16: 68-69.

Moreno-Grau, S., Angosto, J. M., Elvira-Rendueles, B., Bayo, J., Moreno, J. \& Moreno-Clavel, J. (2000). Effects of meteorological parameters and plant distribution on ChenopodiaceaeAmaranthaceae, Quercus and Olea airborne pollen concentrations in the atmosphere of Cartagena (Spain). Aerobiologia, 16: 17-20.

Moreno-Grau, S., Elvira-Rendueles, B., Moreno, J., García-Sánchez, A., Vergara, N., Asturias, J. A., Arilla, M. C., Ibarrola, I., Seoane-Camba, J. A. \& Suárez-Cervera, M. (2006). Correlation between Olea europaea and Parietaria judaica pollen counts and quantification of their major allergens Ole e 1 and Par j 1-Par j 2. Ann Allergy Asthma Immunol, 96: 858-864.

Muñoz Cano, R. M., Bartra Tomás, J. \& Valero Santiago, A. L. (2008). Prevalencia de la sensibilización a pólenes. In: Valero Santiago, A. L. \& Cadahía García, A. (eds.). Polinosis III. Polen y alergia. pp. 69-79. mra ediciones, S. L., Laboratorios Menarini, S. A., Barcelona.

Muñoz-Garmendia, F. (1986). Hypolepidaceae. In: Castroviejo, S. (ed.). Flora iberica. I. pp. 78-80. Servicio de Publicaciones del C.S.I.C., Madrid.

Muñoz Rodríguez, A. F., Silva Palacios, I. \& Tormo Molina, R. (2007). Cyperaceae and Juncaceae pollination measured in the air at two sites in SW Spain. Aerobiologia, 23: 259270. 
Muñoz Rodríguez, A. F., Silva Palacios, I., Tormo Molina, R., Moreno Corchero, A. \& Tavira Muñoz, J. (2000). Dispersal of Amaranthaceae and Chenopodiaceae pollen in the atmosphere of Extremadura (SW Spain). Grana, 39: 56-62.

Muñoz Rodríguez, A. F., Tormo Molina, R., Silva Palacios, I., Moreno Corchero, A. \& Tavira Muñoz, J. (2005). Airborne behaviour of Echium pollen. Aerobiologia, 21: 125-130.

Nesterina, E., Gradusova, O., Alieva, R. \& Kuropatina, N. (2008). The application of pollen analysis in forensic soil examination when a scene of crime being the urbanized territory. $4^{\text {th }}$ European Symposium on Aerobiology, Turku.

Niklas, K. J. (1985). The aerodynamics of wind pollination. Bot Rev, 51: 328-386.

Nilsson, S. \& Persson, S. (1981). Tree pollen spectra in the Stockholm region (Sweden) 19731980. Grana, 20: 179-182.

Nitiu, D. (2006). Aeropalynological analysis of La Plata City (Argentina) during 3-year period. Aerobiologia, 22: 79-97.

Norris-Hill, J. \& Emberlin, J. (1991). Diurnal variation in pollen concentration in the air of North-central London. Grana, 30: 229-241.

O’Rourke, M. K. (1990). Comparative pollen calendars from Tucson, Arizona: Durham vs. Burkard samplers. Aerobiologia, 6: 136-140.

Obispo, T. M., Melero, J. A., Carpizo, J. A., Carreira, J. \& Lombardero, M. (1993). The main allergen of Olea europaea (Ole e 1) is also present in other species of the Oleaceae family. Clin Exp Allergy, 23: 311-316.

Ogden, E. C. \& Raynor, G. S. (1967). A new sampler for airborne pollen emission in Ambrosia, Phleum, Zea and Ricinus. Amer J Bot, 56(1): 16-21.

Ogden, E. C., Raynor, G. S., Hayes, J. V., Lewis, D. M. \& Haines, J. H. (1974). Manual for sampling airborne pollen. Ed. Hapner Press, New York.

Oppenheimer, J. J. \& Nelson, H. S. (1993). Seasonal variation in immediate skin test reactions. Ann Allergy, 71: 227-229.

Orlandi, F., Vazquez, L. M., Ruga, L., Bonofiglio, T., Fornaciari, M., García-Mozo, H., Domínguez, E., Romano, B. \& Galán, C. (2005). Bioclimatic requirements for olive flowering in two mediterranean regions located at the same latitude (Andalucía, Spain, and Sicily, Italy). Ann Agric Environ Med, 12: 47-52.

Osborne, C. P., Chuine, I., Viner, D. \& Woodward, F. I. (2000). Olive phenology as a sensitive indicator of future climatic warming in the Mediterranean. Plant, Cell \& Environ, 23: 701710 .

Ownby, D. R. (1990). Environmental factors versus genetic determinants of childhood inhalant allergies. J Allergy Clin Immunol, 86: 279-287.

Pakeman, R. J. \& Marrs, R. H. (1996). Modelling the effects of climate change on the growth of bracken (Pteridium aquilinum) in Britain. J Appl Ecol, 33: 561-575. 
Pardo, C., Tahiri, H., Cubas, P. \& El Alaoui-Faris, F. E. (2000). Pollen morphology in Cytisus (Papilionoideae, Leguminosae) from Morocco and the Iberian Peninsula. Grana, 39: 159168.

Pathirane, L. (1975). Aerobiological literature in scientific periodicals. Grana, 15: 145-147.

Paulino, R., Tormo, R., Silva, I. \& Muñoz, A. F. (2002). Aerobiología en Extremadura: Estación de Cáceres (2000-2001). Rea, 7: 177-182.

Paulino Rubio, R., Tormo Molina, R., Silva Palacios, I. \& Muñoz Rodríguez, A. F. (2006). Relación entre la variación horaria de la concentración de polen de Plantago y la meteorología. Polen, 16: 66-67.

Peeters, A. G. \& Zooler, H. (1988). Long range transport of Castanea sativa pollen. Grana, 27: 203-207.

Pepys, J. (1975). Skin testing. Br J Hosp Med, 1: 412-417.

Pereira, C., Valero, A., Loureiro, C., Dávila, I., Martínez-Córcera, C., Murio, C., Rico, P. \& Palomino, R. (2006). Iberian study of aeroallergens sensitisation in allergic rhinitis. Eur Ann Allergy Clin Immunol, 38 (6): 186-194.

Perkins, W. A. (1957). The rotorod sampler. Second Semiannual Report. CLM 186. Standford Univ, California.

Peternel, R., Čulig, J., Hrga, I. \& Hercog, P. (2006). Airborne ragweed (Artemisia artemisiifolia L.) pollen concentrations in Croatia, 2002-2004. Aerobiologia, 22: 161-168.

Petersen, A. B., Gudmann, P., Milvang-Groenager, P., Moerkeberg, R., Boegestrand, S., Linneberg, A. \& Johansen, N. (2004). Perfomance evaluation of a specific IgE assay developed for the Advia Centaur immunoassay system. Clin Biochem, 37: 882-892.

Petushkova, A. \& Kanddyba, P. (1999). Aeromicrobiological studies in the Moscow cathedrals. Aerobiologia, 15(3): 193-201.

Pla Dalmau, J. M. (1958). Aeropalinología gerundense. An Inst Est Gerundenses, 12: 63-88.

Pola, J. (2003). Alergia a pólenes de Quenopodiáceas. Rev Esp Alergol Inmunol Clin, 18: 3944.

Polo, J. M. (1987). Juncaceae. In: Valdés, B., Díez, M. J. \& Fernández, I. (eds.). Atlas polínico de Andalucía Occidental. pp. 367-368. Instituto de Desarrollo Regional, Universidad de Sevilla, Sevilla.

Polo, J. M. \& Díez, M. J. (1987). Convolvulaceae. In: Valdés, B., Díez, M. J. \& Fernández, I. (eds.). Atlas polínico de Andalucía Occidental. pp. 261-264. Instituto de Desarrollo Regional, Universidad de Sevilla, Sevilla.

Prentice, I. C. (1985). Pollen representation, source area and basis size: toward a unified theory of pollen analysis. Quaternary Res, 23(1): 76-86.

Puc, M. \& Wolski, T. (2002). Betula and Populus pollen counts and meteorological conditions in Szczecin, Poland. Ann Agric Environ Med, 9: 65-69. 
Puc, M. \& Puc, M. I. (2004). Allergenic airborne grass pollen in Szczecin, Poland. Ann Agric Environ Med, 11: 237-244.

Punt, W., Bos, J. A. A. \& Hoen, P.P. (1991). Oleaceae. In: Punt, W. \& Blackmore, S. (eds.). The Northwest European Pollen Flora VI. pp. 23-47. Elsevier Science Publishers B. V., Amsterdam, The Netherlands.

Ranta, H., Kubin, E., Siljamo, P., Sofiev, M., Linkosalo, T., Oksanen, A. \& Bondestam, K. (2006). Long distance pollen transport cause problems for determining the timing of birch pollen season in Fennoscandia by using phenological observations. Grana, 45: 297-304.

Ranta, H., Sokol, C., Hicks, S., Heino, S. \& Kubin, E. (2008). How do airborne and deposition pollen samplers reflect the atmospheric dispersal of different pollen types? An example from northern Finland. Grana, 47: 285-296.

Rantio-Lehtimäki, A. (1994). Short, medium and long range transported airborne particles in viability and antigenicity analyses. Aerobiologia, 10: 175-181.

Rapiejko, P., Stanlaewicz, W., Szczygielski, K. \& Jurkiewicz, D. (2007). Threshold pollen count necessary to evoke allergenic symptoms. Otolaryngol Pol, 61(4): 591-594.

Rasmussen, A. (2002). The effects of climate change on the birch pollen season in Denmark. Aerobiologia, 18: 253-265.

Recio, M., Cabezudo, B., Trigo, M. M. \& Tormo, R. (1997). Accumulative air temperature as a predicting parameter for daily airborne olive pollen (Olea europaea L.) during the pre-peak period in Málaga (Western Mediterranean area). Grana, 36: 44-48.

Recio, M., Trigo, M. M., Toro, F. J. \& Cabezudo, B. (1999). Incidencia del polen de Quercus en la atmósfera de Málaga y su relación con los parámetros meteorológicos. Acta Bot Malacitana, 24: 77-88.

Reddi, C. S. (1988). Circadian isolation in pollen release as a reproductive isolating mechanism in Poaceae. Ind J Bot, 11: 40-43.

Reddi, C. B. \& Reddi, N. S. (1985). Relation of pollen release to pollen concentration in air. Grana, 24: 109-113.

Renault-Miskovsky, J. \& Petzold, M. (1989). Spores et pollen. La Duraulié, Cabriés.

Ribeiro, H., Cunha, M. \& Abreu I. (2005). Airborne pollen of Olea in five regions of Portugal. Ann Agric Environ Med, 12: 317-320.

Ribeiro, H., Oliveira, M. \& Abreu, I. (2008). Intradiurnal variation of allergenic pollen in the city of Porto (Portugal). Aerobiologia, 24: 173-177.

Ribeiro, H., Santos, L., Abreu, I. \& Cunha, M. (2006). Influence of meteorological parameters on Olea flowering date and airborne pollen concentration in four regions of Portugal. Grana, 45: 115-121. 
Ricci, G., Capelli, M., Miniero, R., Menna, G., Zannarini, L., Dillon, P. \& Masi, M. (2003). A comparison of different allergometric tests, skin prick test, Pharmacia UniCAP $₫$ and ADVIA Centaur $囚$, for diagnosis of allergic diseases in children. Allergy, 58(1): 38-45.

Rico Hernández, E. (1992). Flora vascular de la dehesa salmantina. In: Gómez Gutiérrez, J. M. (ed.). El libro de las dehesas salmantinas. pp. 181-208. Junta de Castilla y León, Consejería de Medio Ambiente y Ordenación del Territorio.

Rivas-Martínez, S. (1987). Memoria del mapa de series de vegetación de España. I. C. O. N. A., Madrid.

Rivas-Martínez, S., Díaz, T. E., Fernández-González, F., Izco, J., Loidi, J., Lousa, M. \& Penas, Á. (2002). Vascular plant communities of Spain and Portugal. Addenda to the syntaxonomical checklist of 2001. Part I. Itinera Geobotanica, 15 (I): 5-432.

Rivas-Martínez, S., Penas, Á. \& Díaz, T. E. (2004). Global bioclimatics. http://www.globalclimatics.org

Rizzi-Longo, L., Pizzulin-Sauli, M. \& Ganis, P. (2005). Aerobiology of Fagaceae pollen in Trieste (NE Italy). Aerobiologia, 21: 217-231.

Rodríguez, F. J., Díaz, M. R. \& Jato, V. (1998). Aerobiología en Galicia: Estación de Vigo. Rea, 4: 115-118.

Rodríguez de la Cruz, D. (2003). Estudio aeropalinológico de la ciudad de Salamanca durante el año 2000. Tesis de Licenciatura, Universidad de Salamanca.

Rodríguez de la Cruz, D., Sánchez Reyes, E. \& Sánchez Sánchez, J. (2007). Análisis aerobiológico del polen de algunos taxa entomófilos en la ciudad de Salamanca. Stud bot, 26: 67-76.

Rodríguez de la Cruz, D., Sánchez Reyes, E. \& Sánchez Sánchez, J. (2008). Aerobiological study of Fagaceae pollen in the middle-west of Spain. Aerobiologia, 24: 67-76.

Rodríguez-Rajo, F. J., Dacosta, N. \& Jato, V. (2004). Airborne olive pollen in Vigo (Northwestern Spain): a survey to forecast the onset and daily concentrations of the pollen season. Grana, 43: 101-110.

Rodríguez-Rajo, F. J., Frenguelli, G. \& Jato, M. V. (2003a). Effect of air temperature on forecasting the start of Betula pollen season at two contrasting sites in the south of Europe (1995-2001). IntJ Biometeorol, 47: 117-125.

Rodríguez-Rajo, F. J., Frenguelli, G. \& Jato, M. V. (2003b). The influence of air temperature on the starting date of Quercus pollination in the South of Europe. Grana, 42: 145-152.

Rodríguez-Rajo, F. J., Jato, V. \& Aira, M. J. (2003c). Pollen content in the atmosphere of Lugo (NW Spain) with reference to meteorological factors. Aerobiologia, 19: 213-225.

Rodríguez-Rajo, F. J., Méndez, J. \& Jato, V. (2005a). Airborne Ericaceae Pollen Grains in the Atmosphere of Vigo (Northwest Spain) and Its Relationship with Meteorological Factors. J Integr Plant Biol, 47(7): 792-80o. 
Rodríguez-Rajo, F. J., Méndez, J. \& Jato, V. (2005b). Factors affecting pollination ecology of Quercus anemophilous species in north-west Spain. Bot J Linn Soc, 149: 283-297.

Romero, T. \& Velasco, J. M. (1997). Árboles y bosques de Salamanca. Ed. Mediterráneo. Salamanca.

Sabariego, S., Díaz de la Guardia, C. \& Alba Sánchez, F. (1999). Contribución al estudio aeromicológico de la ciudad de Granada (S. España): variaciones estacionales e intradiarias. Rev Iberoam Micol, 16: 230-234.

Sabariego, S., Gutiérrez, M. \& Cervigón, P. (2008). Incidence of the Platanus pollen in the atmosphere of Madrid region (Spain). Bot Complutensis, 32: 205-211.

Saénz, C. (1978). Polen y esporas. Ed. H. Blume, Madrid.

Sáenz Laín, C. (2004). Glosario de términos palinológicos. Lazaroa, 25: 93-112.

Salvador de Luna, J. V. \& Sánchez Sánchez, J. (1990). Polen de plantas entomófilas en la atmósfera de Valladolid.. In: Blanca, G., Díaz, C., Fernández, M. C., Garrido, M., Rodríguez, M. I. \& Romero, A. T.(eds.). Polen, esporas y sus aplicaciones. VII Simposio de Palinología. pp. 363-368. Universidad de Granada, Granada.

Sánchez-Barbudo Ruiz-Tapiador, M. C. (1991). Guía de plantas con flores de La Armuña (Salamanca). Ediciones Diputación de Salamanca, Salamanca.

Sánchez Mesa, J. A., Smith, M., Emberlin, J., Allitt, U., Caulton, E. \& Galán, C. (2003). Characteristics of grass pollen seasons in areas of southern Spain and the United Kingdom. Aerobiologia, 19: 243-250.

Sánchez Reyes, E., Rodríguez de la Cruz, D. \& Sánchez Sánchez, J. (2006). Estudio aeropalinológico de la ciudad de Salamanca durante el año 1996. Stud bot, 25: 103-112.

Sánchez Reyes, E., Rodríguez de la Cruz, D., Sanchís Merino, M. E. \& Sánchez Sánchez, J. (2007). Comportamiento aerobiológico de la familia Ericaceae en la atmósfera de Valladolid. Stud bot, 26: 77-87.

Sánchez Reyes, E., Rodríguez de la Cruz, D., Sanchís Merino, M. E. \& Sánchez Sánchez, J. (2008). Efecto de la acción antrópica en las concentraciones atmosféricas de Platanus hispanica Mill. ex Münchh. en Salamanca y Valladolid (España). XVI Internacional A.P.L.E. Symposium of Palynology, Palma de Mallorca.

Schoene, K., Franz, J. T. \& Masuch, G. (2004). The effect of ozone on pollen development in Lolium perenne L. Envirom Pollut, 131: 347- 354.

Schwendemann, A. B., Wang, G., Mertz, M.L., McWilliams, R.T., Thatcher, S.L. \& Osborn, J. M. (2007). Aerodynamics of saccate pollen and its implications for wind pollination. Am J Bot, 94(8): 1371-1381.

Seaton, A., MacNee, W., Donaldson, K. \& Godden, D. (1995). Particulate air pollution and acute health effects. Lancet, 345: 176-178. 
Sibbald, B., Horn, M. E. C. \& Gregg, I. (1980). A family study of the genetic basis of asthma and wheezy bronchitis. Arch Dis Child, 55: 354-357.

Silva Palacios, I., Tormo Molina, R. \& Muñoz Rodríguez, A. F. (2007). The importance of interactions between meteorological conditions when interpreting their effect on the dispersal of pollen from homogeneously distributed sources. Aerobiologia, 23: 17-26.

Sin, B. A., Inceoglu, O., Mungan, D., Celik, G., Kaplan, A. \& Misirligil, Z. (2001). Is it important to perform pollen skin prick tests in the season?. Ann Allergy Asthma Immunol, 86(4): 382-386.

Solomon, A. E. (1970). Drawings of selected pollen grains used in a class of palynology. http://geo.arizona.edu/palynology/solomon/solmuofa.html

Spieksma, F. Th. M. (1991). Regional European Pollen Calendars. In: D’Amato, G., Spieksma, F. Th. M. \& Bonini, S. (eds.). Allergenic pollen and pollinosis in Europe. pp. 49-65. Blackwell Scientific Publications, Oxford.

Spieksma, F. Th. M. (1992). Allergological aerobiology. Aerobiologia, 8(1): 5-8.

Spieksma, F. Th. M., Corden, J. M., Detandt, M., Millington, W. M., Nikkels, H., Nolard, N., Schoenmakers, C. H. H., Wachter, R., de Weger, L. A., Willems, R. \& Emberlin, J. (2003). Quantitative trends in annual totals of five common airborne pollen types (Betula, Quercus, Poaceae, Urtica, and Artemisia), at five pollen-monitoring stations in western Europe. Aerobiologia, 19: 171-184.

Spieksma, F. Th. M. \& den Tonkelaar, J. F. (1986). Four-hourly fluctuations in grass-pollen concentrations in relation to wet versus dry weather, and to short versus long over-land advection. Int J Biometeorol, 30: 351-358.

Spieksma, F. Th. M. \& Nikkels, A.H. (1998). Airborne grass pollen in Leiden, the Netherlands: annual variations and trends in quantities and season starts over 26 years. Aerobiologia, 14: 347-358.

Spieksma, F. Th., Nikkels, A.H. \& Dijkman, J. H. (1995). Seasonal appearance of grass pollen allergen in natural, pauci-micronic aerosol of various size fractions; Relationship with airborne grass pollen concentration. Clin Exp Allergy, 25: 234-239.

Spieksma, F. Th. M., van den Assem, A. \& Collette, B. J. A. (1985). Airborne Pollen Concentration in Leiden, The Netherlands, 1977-1981. Grana, 24: 99-108.

Stach, A., Smith, M., Skjøth, C.A. \& Brandt, J. (2007). Examining Ambrosia pollen episodes at Poznań (Poland) using back-trajectory analysis. Int J Biometeorol, 51: 275-286.

Strachan, D. P. (1989). Hay fever, hygiene, and household size. BMJ , 299: 1259-1260.

Suárez Cervera M. \& Seoane Camba, J. A. (1983). Estudio del contenido polínico de la atmósfera de Barcelona según un nuevo método de filtración. Collectanea Bot, 14: 587-615.

Suárez Cervera M. \& Seoane Camba, J. A. (1985). Sobre el sistema de filtración automática en Aerobiología. An Asoc Palinol Leng Esp, 2: 307-317. 
Suárez González, R., Rodríguez de la Cruz, D., Pérez Gorjón, S. \& Sánchez Sánchez, J. (2003). Estudio aerobiológico de la ciudad de Salamanca durante el año 1995. Stud bot, 22: 27-35.

Subba Reddi, C. \& Reddi, N. S. (1985). Relation of pollen release to pollen concentrations in air. Grana, 24: 109-113.

Subiza, E. (1980). Incidencia de granos de pólenes en la atmósfera de Madrid. Método volumétrico. Allergol et Inmunopatol, Suplementum VII.

Subiza, J., Feo Brito, F., Pola, J., Moral, A., Fernández, J., Jerez, M. \& Ferreiro, M. (1998). Pólenes alergénicos y polinosis en 12 ciudades españolas. Rev Esp Alergol Inmunol Clín, 13(2): 45-58.

Subiza, J., Jerez, M., Jiménez, J. A., Narganes, M. J., Cabrera, M., Varela, S. \& Subiza, E. (1995). Allergenic pollen and pollinosis in Madrid. J Invest Allergol Clin Immunol, 96(1): $15-23$.

Subiza Garrido-Lestache, F. J., Pola Pola, J., Feo Brito, F. \& Moral de Gregorio, A. J. (2007). Pólenes de interés en alergología en nuestro medio. In: Pélaez Hernández, A. \& Dávila González, I. J. (eds.). Tratado de Alergología. Tomo I. pp. 425-447. Ergon, Madrid.

Sukopp, H., Numata, M. \& Huber, A. (1995). Urban ecology as the basis for urban planning. SPB Academic, The Hague.

Tauber, H. (1967). Investigations of the mode of pollen transfer in forested areas. Rev Palaeobot Palynol, 3: 277-286.

Tavira Muñoz, J., Tormo Molina, R., Muñoz Rodríguez, A. F., Silva Palacios, I. \& González Garijo, M. A. (1998). Calendario polínico de la ciudad de Cáceres. Rev Esp Alergol Inmunol Clín, 13(5): 288-293.

Tedeschini, E., Rodríguez-Rajo, F. J., Caramiello, R., Jato, V. \& Frenguelli, G. (2006). The influence of climate changes in Platanus spp. pollination in Spain and Italy. Grana, 45: 222-229.

Tormo Molina, R., Muñoz Rodríguez, A., Silva Palacios, I. \& Gallardo López, F. (1996). Pollen production in anemophilous trees. Grana, 35:38-46.

Tormo Molina, R., Silva Palacios, I., Muñoz Rodríguez, A. F., Tavira Muñoz, J. \& Moreno Corchero, A. (2001). Environmental Factors Affecting Airborne Pollen Concentration in Anemophilous Species of Plantago. Annals of Botany, 87: 1-8.

Toro, F. J., Recio, M., Trigo, M. M. \& Cabezudo, B. (1996). Contenido polínico de la atmósfera de Málaga: Año 1995. Acta Bot Malacitana, 21: 57-63.

Trigo, M. M., Jato, V., Fernández, D. \& Galán, C. (coord.). (2008a). Atlas aeropalinológico de España. Secretariado de Publicaciones de la Universidad de León, León.

Trigo, M. M., Recio, M., Docampo, S., García-Sánchez, J., Melgar, M., Aguilera, F., Alba, F., Candau, P., Díaz de la Guardia, C., Galán, C., González-Minero, F., Ogalla, V. \& Cabezudo, 
B. (2008b). Incidencia del polen de olivo en la atmósfera de Andalucía. XVI Internacional A.P.L.E. Symposium of Palynology, Palma de Mallorca.

Trigo, M. M., Recio, M., Toro, F. J. \& Cabezudo, B. (1997). Intradiurnal fluctuations in airborne pollen in Málaga (S. Spain): A quantitative method. Grana, 36: 39-43.

Trigo, M. M., Toro, F. J., Recio, M. \& Cabezudo, B. (2000). A statistical approach to comparing the results from different aerobiological stations. Grana, 39: 252-258.

Tyron, R.M. \& Lugardon, B. (1991). Spores of the Pteridophyta. Surface, wall, structure and diversity based on electrón microscope studies. Springer, New York.

Valdés, B., Díez, M. J. \& Fernández, I. (1987). Atlas polínico de Andalucía Occidental. Instituto de Desarrollo Regional, Universidad de Sevilla, Sevilla.

Valencia-Barrera, R. M., Comtois, P. \& Fernández-González, D. (2001). Biogeography and bioclimatology in pollen forecasting. An example of grass in León (Spain) and Montréal (Canada). Grana, 40(4-5): 223-229.

Valencia-Barrera, R. M., Comtois, P. \& Fernández-González, D. (2002). Bioclimatic indices as a tool in pollen forecasting. Int J Biometeorol, 46: 171-175.

Valencia-Barrera, R. M., Vega, A., Fernández-González, D., Díaz, C. \& Mencía, J. (1999). Aerobiología en Castilla y León: Estación de Ponferrada (1998). Rea, 5: 75-78.

Valle, C. J. \& García-Baquero, G. (1996). Sobre la vegetación del curso medio del río Tormes y sus afluentes (Salamanca, España). Stud bot, 15: 25-45.

Vázquez, L. M., Galán, C. \& Domínguez-Vilches, E. (2003). Influence of meteorological parameters on Olea pollen concentrations in Córdoba (South-western Spain). Int J Biometeorol, 48: 83-90.

Vega Maray, A. M., Fernández-González, D., Valencia-Barrera, R. M., Fernández Salegui, A. B., Santos, F. \& Latasa, M. (2002). Aerobiología en Castilla y León: Estación de León (20002001). Rea, 7: 119-124.

Vega-Maray, A. M., Valencia-Barrera, R. M., Fernández-González, D. \& Fraile, R. (2003). Urticaceae pollen concentration in the atmosphere of North Western Spain. Ann Agric Environ Med, 10: 249-255.

Vinckier, S., Cadot, P. \& Smets, E. (2005). The manifold characters of orbicules: structural diversity, systematic significance, and vector for allergens. Grana, 44: 300-307.

Vrtala, S., Fischer, S., Grote, M., Vangelista, L., Pastore, A., Sperr, W. R., Valent, P., Reichelt, R., Kraft, D. \& Valenta, R. (1999). Molecular, immunological, and structural characterization of $\mathrm{Phl} \mathrm{p} \mathrm{6,} \mathrm{a} \mathrm{major} \mathrm{allergen} \mathrm{and} \mathrm{P-particle-associated} \mathrm{protein} \mathrm{from}$ Timothy grass (Phleum pratense) pollen. J Immunol, 163: 5489-5496.

Waisel, Y., Mienis, Z., Kosman, E. \& Geller-Bernstein, C. (2004). The partial contribution of specific airborne pollen to pollen induced allergy. Aerobiologia, 20: 197-198. 
Weber, R. W. (2003). Patterns of pollen cross-allergenicity. J Allergy Clin Immunol 112: 229239.

Werner, M., Topp, R., Wimmer, K., Richter, K., Bischof, W., Wjst, M. \& Heinrich, J. (2003). TLR4 gene variants modify endotoxin effects on asthma. J Allergy Clin Immunol, 112: 323330.

Weryszko-Chmielewska, E., Puc, M. \& Piotrowska, K. (2006). Effect of meteorological factors on Betula, Fraxinus and Quercus pollen concentrations in the atmosphere of Lublin and Szczecin, Poland. Ann Agric Environ Med, 13: 243-249.

White, J. F., Levin, L., Villareal, M., Murphy, K., Biagini, R., Wellinghoff, L., St Clair, H. G. \& Bernstein, D. I. (2005). Lack of correlation between regional pollen counts and percutaneous reactivity to tree pollen extracts in patients with seasonal allergic rhinitis. Ann Allergy Asthma Immunol, 94(2): 240-246.

Wielgolaski, F. E. (1999). Starting dates and basic temperatures in phenological observations of plants. Int J Biometeorol, 42: 158-168.

Wilson, D., Donaldson, L. J. \& Sepai, O. (1998). Should be frightened by bracken? A review of the evidence. J Epidemiol Community Health, 52: 812-817. 
Anexo:

Láminas de polen y esporas 



\section{Lámina I \\ Microfotografías de diferentes tipos de polen}

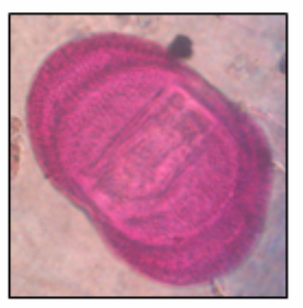

Abies

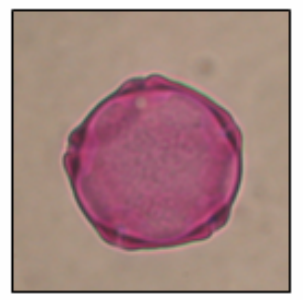

Ahus

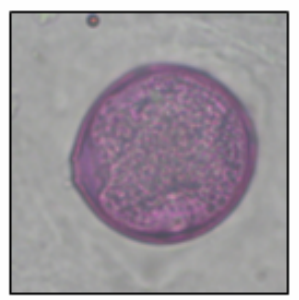

Campanula

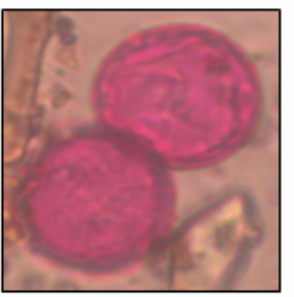

Celtis

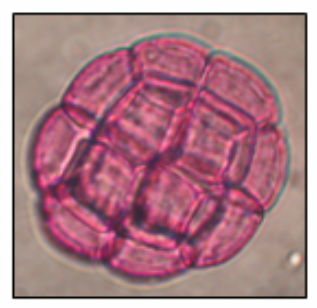

Acacia

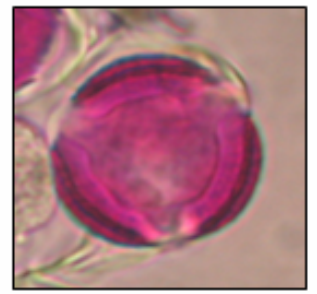

Artemisia

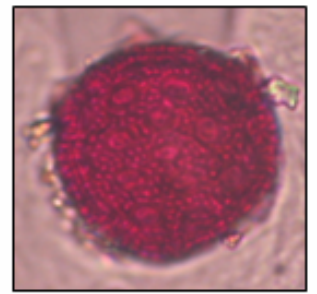

Caryophyllaceae

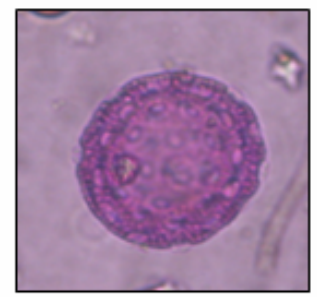

Chenopodiaceae

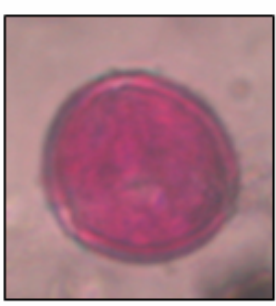

Acer

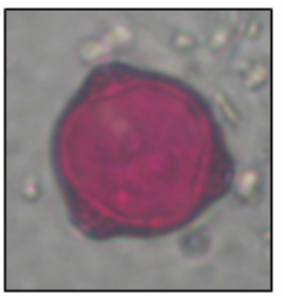

Betula

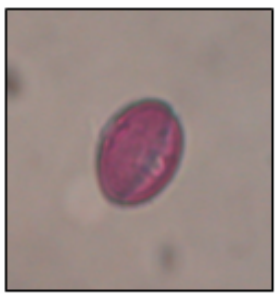

Castanea

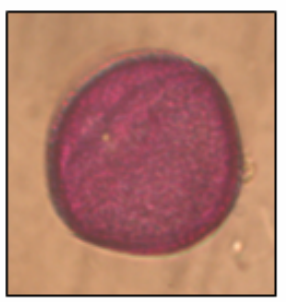

Cistaceae

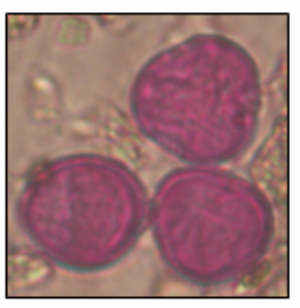

Aesculus

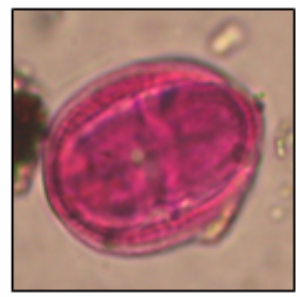

Boraginaceae $^{*}$

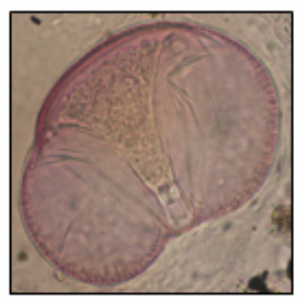

Cedrus

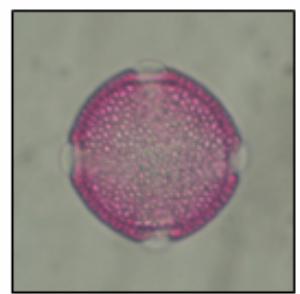

Citrus

Microfotografías tomadas con microscopio Nikon Optiphot II á través de la cámara fotográfica digital -Nikon Coolpix 5000- a 400 aumentos.

* Excluido Echium L. 


\section{Lámina II \\ Microfotografias de diferentes tipos de polen}

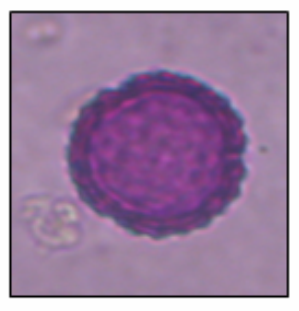

Compositae $^{1}$

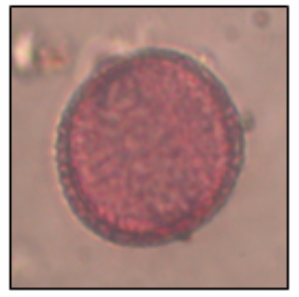

Cruciferae

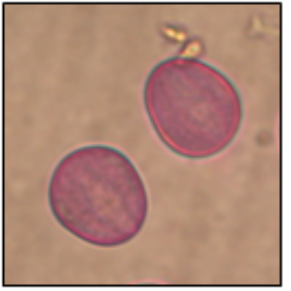

Echium

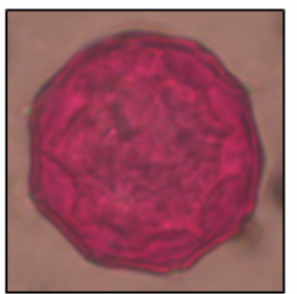

Juglans
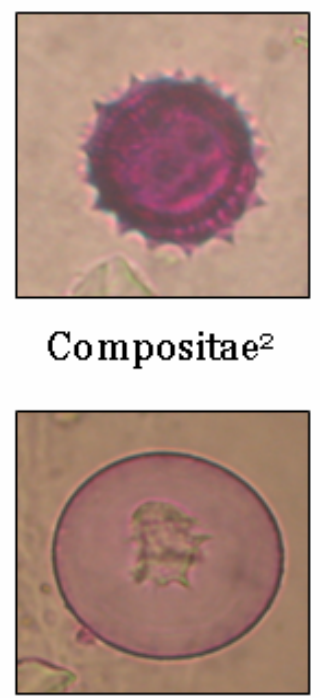

Cupressaceae

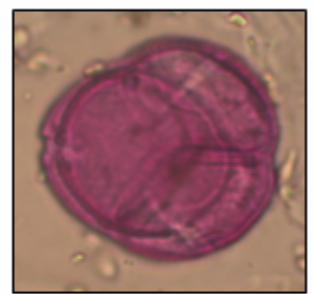

Ericaceae

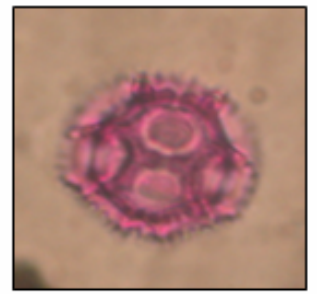

Liguliflorae

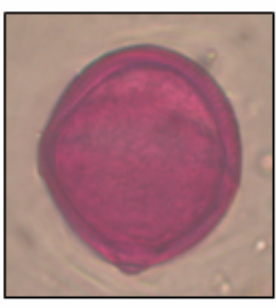

Convoluuhs

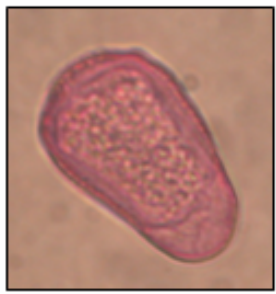

Cyperaceae

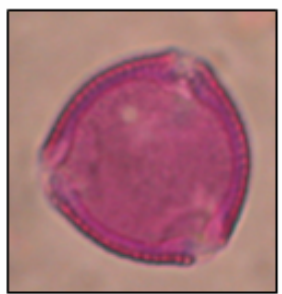

Fraximus

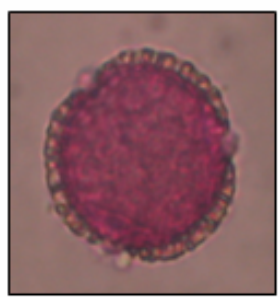

Ligustrum

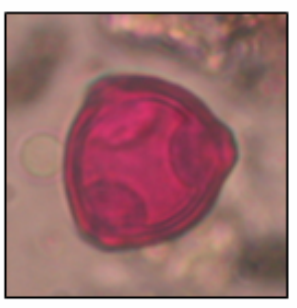

Coryhus

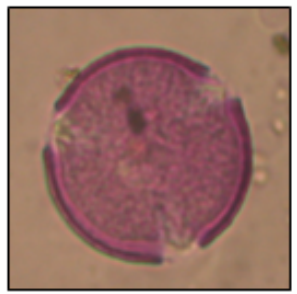

Cytisus

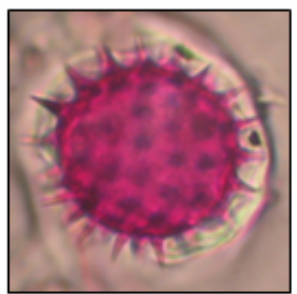

Helianthus

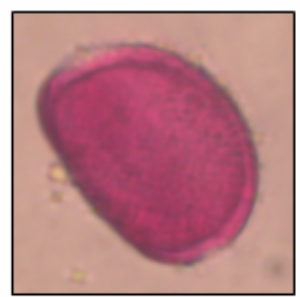

Liliaceae

Microfotografías tomadas con microscopio Nikon Optiphot II á través de la cámara fotográfica digital Nikon Coolpix 5000 a 400 aumentos.

${ }^{1}$ Compositae tipo Centaurea L. / ${ }^{2}$ Compositae tipo Senecio L. 


\section{Lámina III \\ Microfotografías de diferentes tipos de polen}

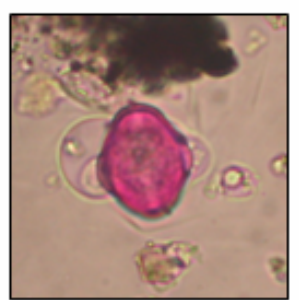

Lotus

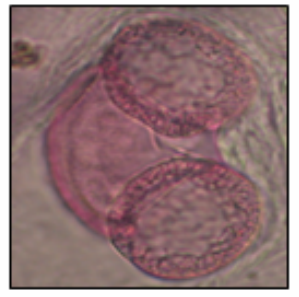

Pirus

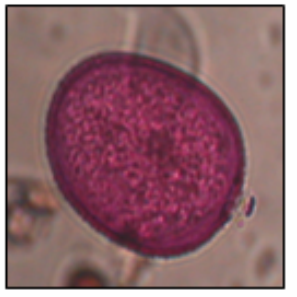

Poaceae

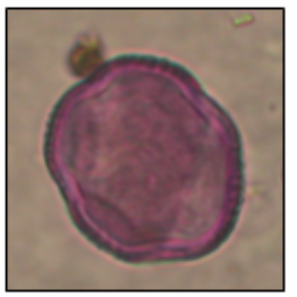

Rubiaceae

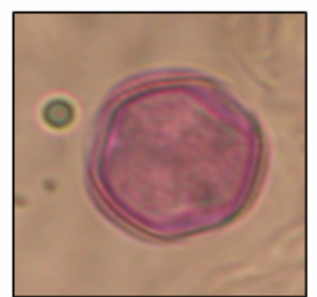

Mercurialis

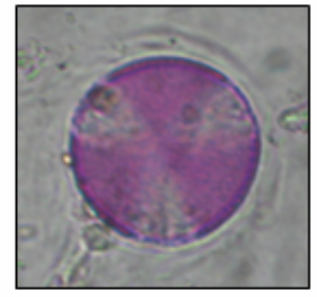

Pittosporzm

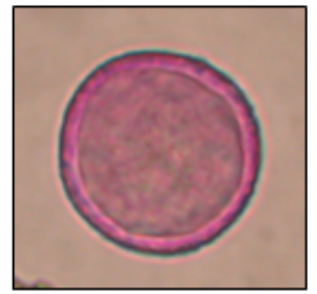

Populus

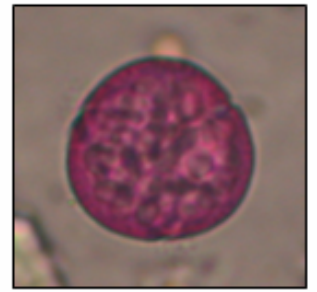

Rumex

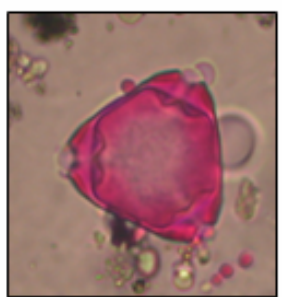

Myrtaceae

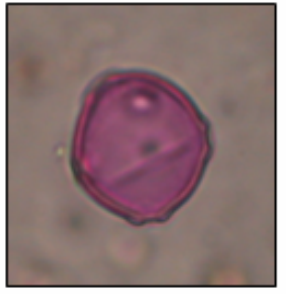

Plantago

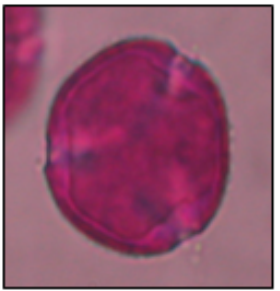

Quercus

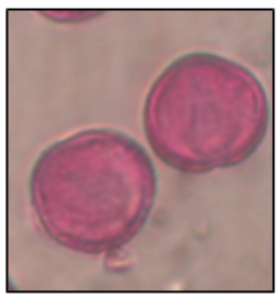

Salix

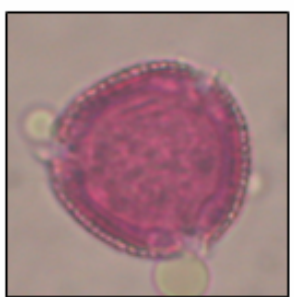

Olea

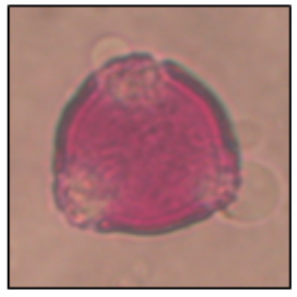

Platanus

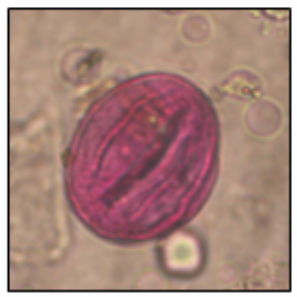

Rosaceae

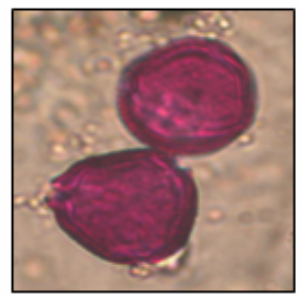

Sambucus

Microfotografías tomadas con microscopio Nikon Optiphot II á través de la cámara fotográfica digital Nikon Coolpix 5000 a 400 aumentos. 


\section{Lámina IV \\ Microfotografias de diferentes tipos de polen}

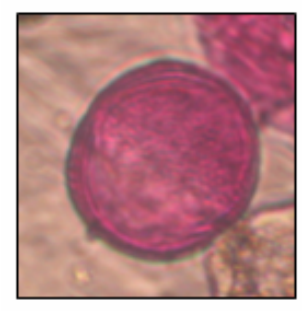

Scrophulariaceae

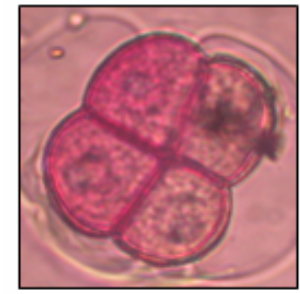

Typha

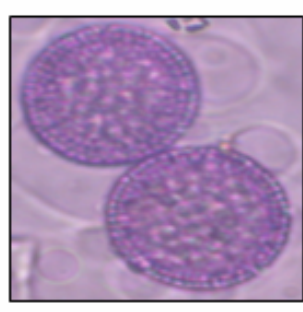

Thymelaeaceae

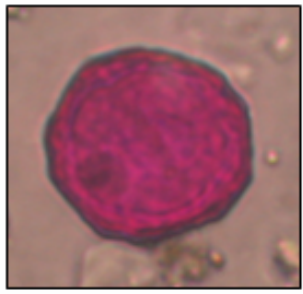

Utmus

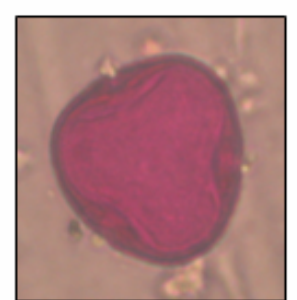

Tilia

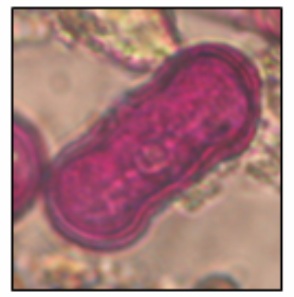

Umbelliferae

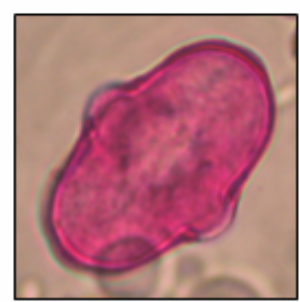

Trifolium

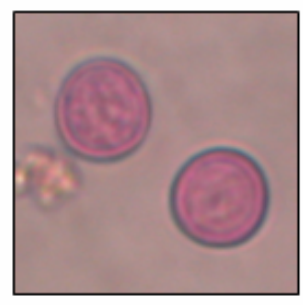

Urticaceae

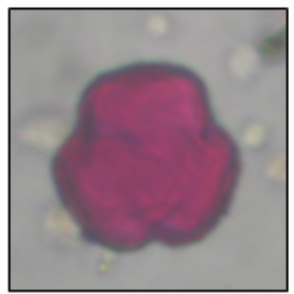

Vitis

Microfotografía de espora de Pteridium aquilinum L. (Kuhn.)

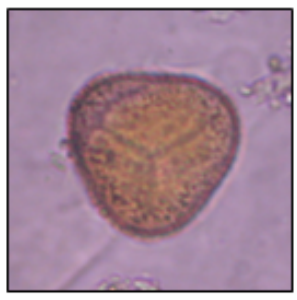

Pteridium

Microfotografías tomadas con microscopio Nikon Optiphot II á través de la cámara fotográfica digital Nikon Coolpix 5000 a 400 aumentos. 